\author{
UNIVERSIDADE DE SÃO PAULO \\ ESCOLA DE ENGENHARIA DE SÃO CARLOS \\ DEPARTAMENTO DE HIDRÁULICA E SANEAMENTO
}

GUSTAVO SILVA DO PRADO

CONCEPÇÃO E ESTUDO DE UMA UNIDADE COMPACTA PARA TRATAMENTO PRELIMINAR DE ESGOTO SANITÁRIO COMPOSTA POR SEPARADOR HIDRODINÂMICO POR VÓRTICE E GRADE FINA DE FLUXO TANGENCIAL 


\section{CONCEPÇÃO E ESTUDO DE UMA UNIDADE COMPACTA PARA TRATAMENTO PRELIMINAR DE ESGOTO SANITÁRIO COMPOSTA POR SEPARADOR HIDRODINÂMICO POR VÓRTICE E GRADE FINA DE FLUXO TANGENCIAL}

Tese apresentada à Escola de
Engenharia de São Carlos da
Universidade de São Paulo, como parte
dos requisitos para obtenção do título
de Doutor em Hidráulica e
Saneamento.

ORIENTADOR: Prof. Tit. José Roberto Campos

São Carlos

2006 


\section{FOLHA DE JULGAMENTO}

\section{Candidato: Engenheiro GUSTAVO SILVA DO PRADO}

Tese defendida e julgada em 15-09-2006 perante a Comissão Julgadora:
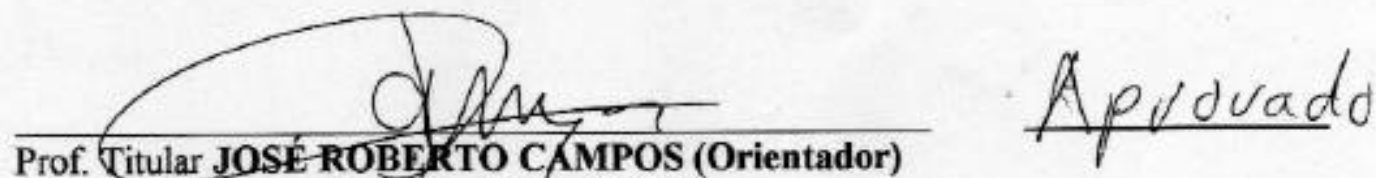

(Escola de Engenharia de São Carlos/USP)
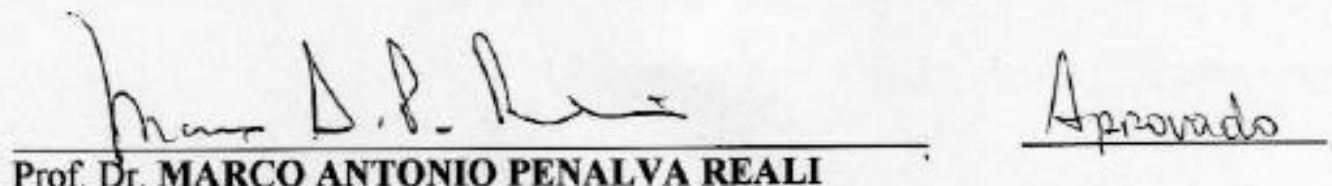

(Escola de Engenharia de São Carlos/USP)

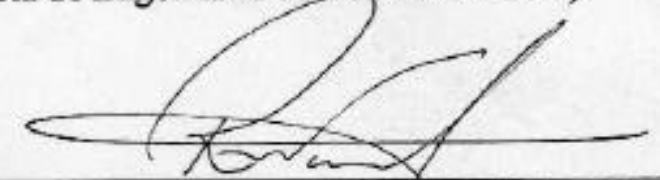

Prof. Associado RODRIGO DE MELO PORTO

(Escola de Engenharia de São Carlos/USP)
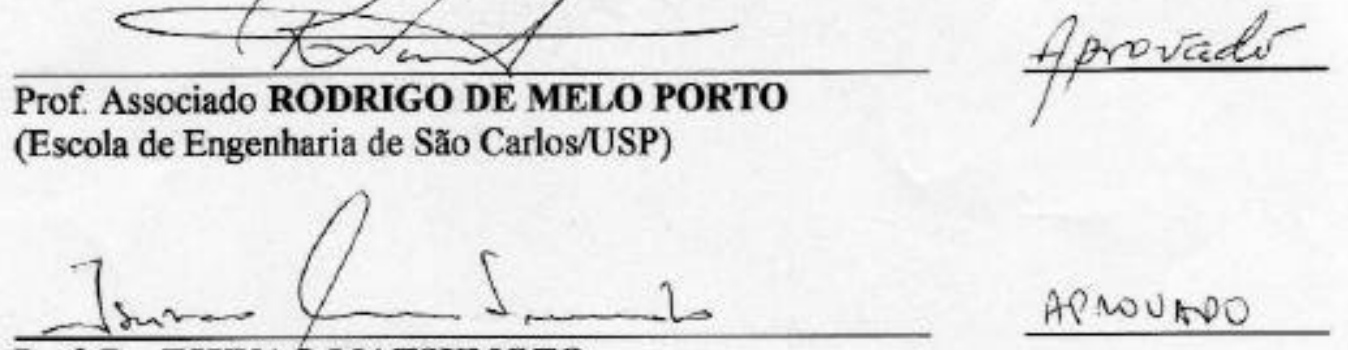

Prof. Dr. TSUNAO MATSUMOTO

(Universidade Estadual Paulista "Júlio de Mesquita Filho"/UNESP - Campus de Ilha Solteira)

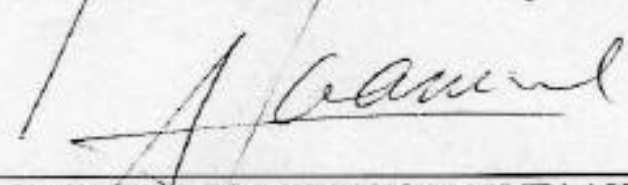

Prof. Dr. ADRIANUS CORNELIUS VAN HAANDEL

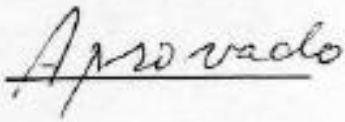

(Universidade Federal de Campina Grande/UFCG)

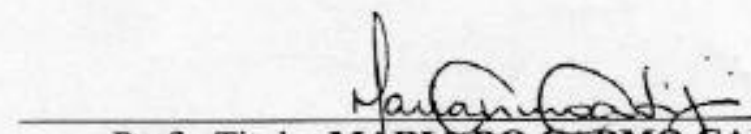

Profa. Titular MARIA DO CARMO CALIJURI

Coordenadora do Programa de Pós-Graduação em

Engenharia (Hidráulica e Saneamento) e

Presidente da Comissão de Pós-Graduação 


\section{DEDICATÓRIA}

Dedico esta tese à minha querida mãe, Edna Maria da Silva Oliveira, que faleceu precocemente de câncer aos 55 anos, no dia 18 de março de 2000. 


\section{AGRADECIMENTOS}

Ao Prof. Tit. José Roberto Campos - o profissional mais genial com quem já trabalhei pelos valiosos ensinamentos, pela confiança depositada em mim, pelo apoio, incentivos, e amizade constantes, toda a minha gratidão.

Ao doutorando Eudes José Arantes, ao Prof. Dr. Harry Edmar Schulz e ao Prof. Dr. Rodrigo de Melo Porto pela imensa ajuda com as simulações computacionais.

À Prof ${ }^{\underline{a}} \operatorname{Dr}^{\underline{a}}$.Ruth de Gouvêa Duarte pela amizade inestimável, e por ter despertado em mim o gosto e o amor pela leitura.

À PROMINAS por acreditar na nossa proposta e financiar boa parte da pesquisa.

Ao departamento de engenharia da PROMINAS e ao pessoal da Assistência Técnica, pela grande ajuda em todas as fases da pesquisa.

Ao Prof. Dr. Marco Reali e ao Prof. Dr. Rodrigo de Melo Porto pelas contribuições no exame de qualificação.

Ao Departamento de Água e Esgoto de Rio Claro por permitir a realização de parte da pesquisa na estação de tratamento de esgoto Jardim das Flores.

Aos funcionários da estação de tratamento de esgoto Jardim das Flores.

Aos técnicos do LATAR, Wagner e Glauce, pela presteza com que me ajudaram sempre que precisei.

Aos funcionários no Departamento de Hidráulica e Saneamento pela amigável convivência.

Aos amigos maravilhosos que fiz aqui em São Carlos: Rodrigo Moruzzi, Marcelo de Júlio, André Oliveira, Hélio dos Santos e Adelena, Carlos Magno (Cacá) e Janete, Neyson Mendonça, Arnaldo Sarti, Anderson, Sérgião, Sergio Brasil, Renato, Cristiano, Leonardo, Gabriel, Glauce, Mércia, Tininha, Katt, Madelana e a todos os outros cujos nomes posso ter esquecido.

Ao pessoal do basquete do CAASO pela amizade.

À Juliane Fregolente meu amor, minha fonte de inspiração. Gatinha valeu pela paciência!!!!

Aos meus pais Pedro do Prado Oliveira e Edna Maria Oliveira, pela educação que me proporcionaram e por sempre estarem presentes em todas as fases da minha vida... Eu adoro vocês!!! Mãe eu consegui!!!!!

À CAPES pela bolsa concedida. 


\section{EPÍGRAFE}

"Perfect as the wing of a bird may be, it will never enable the bird to fly if unsupported by the air. Facts are the air of science. Without them a man of science can never rise."

Ivan Pavlov — Fisiologista russo (1849 - 1936)

"The great tragedy of science - the slaying of a beautiful hypothesis by an ugly fact."

Thomas H. Huxley — Biólogo inglês (1825 - 1895) 


\section{RESUMO}

PRADO, G. S. (2006). Concepção e estudo de uma unidade compacta para tratamento preliminar de esgoto sanitário composta por separador hidrodinâmico por vórtice e grade fina de fluxo tangencial. 240p. Tese (Doutorado) - Escola de Engenharia de São Carlos, Universidade de São Paulo, São Carlos, 2006.

Atualmente, existe uma tendência entre os projetistas brasileiros de valorizar a etapa de tratamento preliminar em projetos de novas estações de tratamento de esgoto (ETE). Neste ensejo foi concebido, construído e estudado um protótipo, em escala plena, de uma unidade composta de separador hidrodinâmico por vórtice (SHV) - empregado como desarenador - e grade fina cilíndrica de fluxo tangencial. Estudos acerca da hidrodinâmica da unidade, fundamentados em ensaios de estímulo-resposta com traçador (sal de cozinha) e simulações computacionais do padrão de escoamento em software de dinâmica dos fluidos computacional, demonstrou que ao se operar a unidade com taxas de aplicação superficial (TAS) de $764 \mathrm{~m}^{3} / \mathrm{m}^{2} \mathrm{~d} ; 1.146 \mathrm{~m}^{3} / \mathrm{m}^{2} \mathrm{~d}$ e $1.528 \mathrm{~m}^{3} / \mathrm{m}^{2} / \mathrm{d}$ o regime de macro-mistura do padrão de escoamento que se desenvolve no SHV aproximou-se do plug-flow, porém com certo grau de mistura que diminuiu com o aumento da TAS. Nesta pesquisa, foram desenvolvidos dois métodos um para determinação da concentração de areia no esgoto sanitário e outro para determinação da distribuição granulométrica dos grãos dessa areia. Ambos foram empregados na avaliação de desempenho da unidade de tratamento preliminar desenvolvida, que foi realizada na estação elevatória de ETE Jardim das Flores do município de Rio Claro, SP. Durante esta fase da pesquisa, o SHV demonstrou enorme potencialidade na remoção de areia para as TAS de $764 \mathrm{~m}^{3} / \mathrm{m}^{2} / \mathrm{d} ; 1.146 \mathrm{~m}^{3} / \mathrm{m}^{2} / \mathrm{d}$ e $1.528 \mathrm{~m}^{3} / \mathrm{m}^{2} / \mathrm{d}$, porquanto, além de não remover significativamente matéria orgânica particulada (medida em termos de concentração de sólidos suspensos voláteis) presentes no esgoto sanitário, a unidade atingiu eficiências de remoção de grãos de areia de tamanho maior ou igual a $200 \mu \mathrm{m}$ entre $85 \%$ e 95\%. Entretanto, a grade fina cilíndrica de fluxo tangencial (auto-limpante) revelou-se inviável.

Palavras Chaves: Esgoto sanitário - Tratamento preliminar; Desarenadores; Gradeamento fino de esgoto sanitário; Separador hidrodinâmico por vórtice (SHV); Areia no esgoto sanitário; Determinação de tamanho de partículas; Distribuição granulométrica de areia presente no esgoto sanitário. 


\begin{abstract}
PRADO, G. S. (2006). Designing and study of a compact unit for sewage preliminary treatment made up of a hydrodynamic vortex separator and a tangential flux fine screen. 240p. Ph.D. Thesis - Engineering School of São Carlos, University of São Paulo, São Carlos, 2006.
\end{abstract}

Currently, there is a trend among the Brazilian designers of valorizing the preliminary treatment in recently designed wastewater treatment plants (WWTP). In this context, a full scale prototype of a unit made up of a hydrodynamic vortex separator (HVS) applied as a degritter - and a tangential flux fine screening was designed, built and evaluated. Research about the hydrodynamic of the prototype, based on stimulusresponse essays with a salt tracer (sodium chloride) and computational simulations of the flow pattern using the Computational Fluid Dynamic (CFD) software, showed that the macro mixture regime of the flow was similar to a plug-flow when the unit was operated with superficial loading rates (SLR) of $746 \mathrm{~m}^{3} / \mathrm{m}^{2} \mathrm{~d} ; 1.146 \mathrm{~m}^{3} / \mathrm{m}^{2} \mathrm{~d}$ and 1.528 $\mathrm{m}^{3} / \mathrm{m}^{2} \mathrm{~d}$, however, the flow presented a certain mixture degree that reduced with the SLR increase. In this research, two methods were developed: one for the determination of grit concentration in sewage and another one for the assessment of grit grading. Both methods were used on the evaluation of the HVS prototype efficiency, which was carried out at Jardim das Flores WWT, in the city of Rio Claro, SP. During this phase of the research, the HVS presented a great potential for grit removal when the SLR of 746 $\mathrm{m}^{3} / \mathrm{m}^{2} \mathrm{~d} ; 1.146 \mathrm{~m}^{3} / \mathrm{m}^{2} \mathrm{~d}$ and $1.528 \mathrm{~m}^{3} / \mathrm{m}^{2} \mathrm{~d}$ were applied; for the reason that, besides not significantly removing the particulate organic matter present in sewage (measured as volatile suspended solids), the unit achieved grit removal efficiencies in the range of $85 \%$ to $95 \%$ for grit equal to or large than $200 \mu \mathrm{m}$. However, the tangential flux cylindrical fine screening (self cleaning) did not reveal feasibility.

Keywords: Sewage - preliminary treatment; Degritters; Sewage fine screening; Hydrodynamic Vortex Separator (HVS); Grit in sewage; Particle size determination; sewage grit grading. 


\section{LISTA DE ILUSTRAÇÕES}

Figura 2.1 - Esquema de uma Grade grossa de limpeza manual

Figura 2.2 - Exemplo de uma grade grossa de limpeza mecânica: Link-Belt Catenary Bar screen.

Figura 2.3 - Exemplo de peneiras finas: em (a) tem-se um esquema de peneira estática parabólica, em (b) vê-se uma foto de uma peneira estática parabólica e em (c) pode ser observado um sistema de peneiramento fino constituído por duas peneiras estáticas parabólicas.

Figura 2.4 - Exemplo de peneiras de tambor rotativo: em (a) tem-se uma foto de uma peneira de tambor rotativo de alimentação externa, em (b) vê-se uma foto de um sistema de peneiramento constituído por duas peneiras de tambor rotativo de alimentação externa, em (c) pode-se observar um esquema de uma peneira de tambor rotativo de alimentação interna e em (d) vê-se uma foto da instalação de uma peneira de tambor rotativo de alimentação interna em uma ETE..

Figura 2.5 - Esboço de um conjunto com barras de seção transversal trapezoidal......

Figura 2.6 - Volumes máximo e médio de peneirado por volume de esgoto bruto em função do espaçamento entre barras. Dados obtidos de levantamento realizado em 133 ETEs dos Estados Unidos.

Figura 2.7 - Fotos de peneirados de grade grossa e peneira fina. Em (a) e (b) têm-se fotos do peneirado retido em grade com espaçamento entre barras de $20,0 \mathrm{~mm}$. Em (c) vê-se uma foto de amostra de peneirado, coletada de peneira com aberturas de $2,0 \mathrm{~mm}$. Em (d) pode ser observado o material retido em peneira fina de aberturas iguais a 2,0mm (Obs.: Fotos tiradas na ETE Jd. das Flores do Município de Rio Claro SP)...

Figura 2.8 - Padrão de escoamento espiralar de um desarenador aerado. .23

Figura 2.9 - Separadores vorticosos: (a) Mectan ${ }^{\circledR}$ da John Meunier Inc. (vórtice gerado por turbina); (b) Teacup ${ }^{\circledR}$ da Eutek (vórtice gerado por jato).

Figura 2.10 - Exemplos de SHVs: (a) seção transversal de um Fluidsep; (b) ilustração de Storm King Overflow com sistema de peneiramento do tipo self-cleansing...

Figura 2.11 - Esquema do padrão de escoamento desenvolvido dentro dos SHVs.

Figura 2.12 - Esquema ilustrativo do funcionamento de um SHV (Grit King Dynamic Separator da Hydro International).

Figura 2.13 - Esboço da superfície livre em um vórtice combinado de Rankine, e o perfil de velocidade tangencial esperado.

Figura 2.14 - Esquema ilustrativo para o cálculo da velocidade radial "líquida" de um SHV......

Figura 2.15 - Esquema mostrando uma seção transversal do SHV desenvolvido na presente pesquisa, no qual podem ser observadas algumas regiões com escoamento secundário.

Figura 2.16 - Desenho do primeiro separador hidrodinâmico por vórtice idealizado para a presente pesquisa.

Figura 2.17 - Desenho do segundo separador hidrodinâmico por vórtice idealizado para a presente pesquisa. 
Figura 2.18 - Desenho da última configuração do separador hidrodinâmico por vórtice idealizado para a presente pesquisa. .52

Figura 2.20 - Foto que mostra o SHV e a câmara do vertedor de controle de nível instalados na bancada de testes da PROMINAS para execução dos ensaios realizados para estudar a hidrodinâmica da unidade.

Figura 2.21 - Foto mostrando detalhe da escova fixada na parte interior do raspador do sistema de limpeza mecanizado da peneira localizada no topo do vertedor tubular de saída do SHV. .55

Figura 2.22 - Desenho do separador hidrodinâmico por vórtice com sistema mecanizado de limpeza da peneira e detalhes do sistema mecanizado de limpeza da peneira (cotas em milímetro) .56

Figura 3.1 - Fluxograma esquemático mostrando como foi organizado o estudo da hidrodinâmica do SHV .62

Figura 3.2 - Fotos do SHV instalado na bancada de teste da PROMINAS e detalhes do medidor de vazão e das válvulas de sangria: (a) foto do SHV mostrando a parte da tubulação de recalque na qual o medidor de vazão está instalado; (d) foto do medidor de vazão utilizado e (c) foto mostrando detalhe das válvulas de sangria empregadas para controlar a vazão de alimentação do SHV...... .63

Figura 3.3 - Esquema do aparato experimental utilizado para a realização dos ensaios de estímulo-resposta. 63

Figura 3.3 - Foto do SHV instalado na bancada de testes da PROMINAS, na qual pode-se observar o ponto de injeção do traçador (solução de $\mathrm{NaCl}$ ) usado nos ensaios de estímuloresposta. .64

Figura 3.5 - Tubo Pitot projetado e construído para realização das medições de pressão total no interior do SHV. (a) Foto do conjunto completo: corpo cilíndrico, haste de alumínio, ponteira do Pitot, transdutor de pressão e conversor de sinais com display digital. (b) Desenho esquemático do tubo Pitot. (c) Foto da ponteira do Pitot conectada a uma as pontas da haste de alumínio. (d) Foto do transdutor de pressão. (e) Foto do conversor de sinais com display digital.

Figura 3.6 - Foto do separador hidrodinâmico por vórtice instalado na bancada de testes da PROMINAS durante a execução das medições de pressão total. .68

Figura 3.7 - Fotos do medidor de pressão do tipo Pitot. (a) Foto da ponteira do Pitot dentro do corpo cilíndrico de nylon. (b) Foto da ponteira o Pitot totalmente "escondida" dentro do corpo cilíndrico de nylon. (c) Foto do corpo cilíndrico de nylon rosqueado em uma das válvulas instaladas na parede externa do SHV. (d) Foto do medidor de pressão conectado a uma válvula, com parte da haste de alumínio no interior o SHV e com o transdutor de pressão conectado no final da haste.

Figura 3.8 - Desenho do protótipo do SHV no qual foram realizadas as medições de pressão total (cotas em milímetro).

Figura 3.9 - Foto do tubo Pitot mostrando a haste de alumínio já graduada com espaçamento de um centímetro. .71

Figura 3.10 - Desenho mostrando metade da seção transversal do SHV com os pontos de leitura de pressão total (cotas em milímetro)... .72

Figura 3.11 - Foto do tubo Pitot com o transdutor de pressão conectado na extremidade da haste de alumínio. . .73

Figura 3.12 - Modelo tridimensional desenhado no software 3DEdge utilizado nas simulações computacionais. . .74 
Figura 3.13 - Malha gerada pelo software CAD2 Mesh, utilizada nas simulações. (a) Vista geral da malha. (b) Detalhe mostrando a malha prismática junto à parede da tubulação de entrada. (c) Detalhe da malha prismática junto à parede do cilindro interno do SHV. 76

Figura 3.14 - Curvas de distribuição de idade de saída: (a) Curvas de distribuição de idade de saída E(t) para cada uma das vazões estudadas (10 1/s; 15 1/s e 20 l/s); (b) Curvas de distribuição de idade de saída padronizada $\mathrm{E}(\theta)$ para cada uma das vazões estudadas $(10 \mathrm{l} / \mathrm{s} ; 15 \mathrm{l} / \mathrm{s}$ e 20

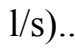

Figura 3.15 - Curva de distribuição de idade de saída $\mathrm{E}(\mathrm{t})$ para a vazão de alimentação do SHV de 10 l/s e curvas M(t) dos modelos ADM e TISM ajustadas. (a) Curva da distribuição da idade de saída $\mathrm{E}(\mathrm{t})$, assim como, as curvas $\mathrm{M}(\mathrm{t})$ dos dois modelos, ADM e TISM; (b) curva de regressão mostrando a qualidade do ajuste do modelo ADM; (c) curva de regressão mostrando a qualidade do ajuste do modelo TISM.

Figura 3.16 - Curva de distribuição de idade de saída E(t) para a vazão de alimentação do SHV de 15 l/s e curvas M(t) dos modelos ADM e TISM ajustadas. (a) Curva da distribuição da idade de saída $\mathrm{E}(\mathrm{t})$, assim como, as curvas $\mathrm{M}(\mathrm{t})$ dos dois modelos, ADM e TISM; (b) curva de regressão mostrando a qualidade do ajuste do modelo ADM; (c) curva de regressão mostrando a qualidade do ajuste do modelo TISM...

Figura 3.17 - Curva de distribuição de idade de saída $E(t)$ para a vazão de alimentação do SHV de 20 l/s e curvas M(t) dos modelos ADM e TISM ajustadas. (a) Curva da distribuição da idade de saída $\mathrm{E}(\mathrm{t})$, assim como, as curvas M(t) dos dois modelos, ADM e TISM; (b) curva de regressão mostrando a qualidade do ajuste do modelo ADM; (c) curva de regressão mostrando a qualidade do ajuste do modelo TISM.

Figura 3.18 - Gráficos da variação da razão TDHp/TDHt e do número de dispersão (D/uL) com a vazão de alimentação do SHV. 87

Figura 3.19 - Esquema que mostra as linhas radiais (linhas azuis) de onde foram obtidos os valores de pressão total calculados durante simulações, os quais foram plotados juntamente com os valores de pressão total medidos no protótipo do SHV para a realização da validação dos resultados das simulações computacionais.

Figura 3.20 - Gráficos de pressão total com valores experimentais e simulados para a vazão de 10 1/s. (a) Pressão total para a linha de válvulas V1j. (b) Pressão total para a linha de válvulas V2j. (c) Pressão total para a linha de válvulas V3j.. 89

Figura 3.21 - Gráficos de pressão total com valores experimentais e simulados para a vazão de 15 1/s. (a) Pressão total para a linha de válvulas V1j. (b) Pressão total para a linha de válvulas V2j. (c) Pressão total para a linha de válvulas V3j.

Figura 3.22 - Gráficos de pressão total com valores experimentais e simulados para a vazão de 20 1/s. (a) Pressão total para a linha de válvulas V1j. (b) Pressão total para a linha de válvulas V2j. (c) Pressão total para a linha de válvulas V3j.

Figura 3.23 - Vista superior do SHV mostrando os planos utilizados para a apresentação dos resultados das simulações computacionais.

Figura 3.24 - Linhas de correntes obtidas nas simulações computacionais para as três vazões. A cor azul indica movimento descendente do fluido e a cor vermelha movimento ascendente. (a) Linhas de corrente para a vazão de 10 1/s. (b) Linhas de corrente para a vazão de 15 1/s. (c) Linhas de corrente para a vazão de 20 1/s.

Figura 3.25 - Planos transversais contendo vetores velocidade para a vazão de 10 1/s. Vetores azuis indicam movimento descendente do fluido e vetores vermelhos indicam movimento ascendente....... 
Figura 3.26 - Planos transversais contendo vetores velocidade para a vazão de 15 1/s. Vetores azuis indicam movimento descendente do fluido e vetores vermelhos indicam movimento ascendente.

Figura 3.27 - Planos transversais contendo vetores velocidade para a vazão de 20 1/s. Vetores azuis indicam movimento descendente do fluido e vetores vermelhos indicam movimento ascendente.

Figura 3.28 - Campos de velocidades obtidos nas simulações computacionais para as três vazões estudadas. (a) Campo de velocidades para a vazão de 10 1/s. (b) Campo de velocidades para a vazão de 15 l/s. (c) Campo de velocidades para a vazão de 20 1/s... .98

Figura 3.29 - Planos transversais contendo vetores velocidade para a vazão de 10 1/s. .99

Figura 3.30 - Planos transversais contendo vetores velocidade para a vazão de 15 1/s............100

Figura 3.31 - Planos transversais contendo vetores velocidade para a vazão de 20 1/s............101

Figura 3.32 - Gráficos de velocidade radial do fluido para vazões de 10 1/s, 15 1/s e 20 1/s. (a) Gráfico das velocidades radiais para vazões de 10 1/s, 15 1/s e $201 / \mathrm{s}$ na linha radial correspondente à válvula V11. (b) Gráfico das velocidades radiais para vazões de 10 1/s, 15 1/s e 20 1/s na linha radial correspondente à válvula V12. (c) Gráfico das velocidades radias para vazões de 10 l/s, 15 l/s e 20 l/s na linha radial correspondente à válvula V13. (d) Gráfico das velocidades radias para vazões de $10 \mathrm{l} / \mathrm{s}, 15 \mathrm{l} / \mathrm{s}$ e $20 \mathrm{l} / \mathrm{s}$ na linha radial correspondente à válvula V14. Obs.: velocidade radial positiva significa movimento do fluido no sentido do centro do SHV. 104

Figura 3.33 - Figura esquemática que mostra um corte transversal do SHV com as quatro regiões no interior da unidade que apresentam padrão de escoamento com características distintas. 107

Figura 4.1 - Fluxograma das técnicas de determinação da distribuição de tamanho de partícula classificadas como: técnicas com fracionamento da amostra e técnicas sem fracionamento da amostra. 126

Figura 4.2 - Fluxograma esquemático da caracterização da areia presente no esgoto sanitário, com a apresentação das etapas dos dois métodos desenvolvidos nessa tese: determinação da concentração de areia presente no esgoto sanitário e determinação da granulometria da areia presente no esgoto sanitário. .128

Figura 4.3 - Esquema em planta da chegada do esgoto bruto na estação elevatória próximo a ETE Jardim das Flores e detalhe em corte do posicionamento da bomba submersível utilizada para coleta das amostras de esgoto bruto. 133

Figura 4.4 - Fotos do ponto de amostragem de esgoto bruto localizado na entrada do separador hidrodinâmico por vórtice (SHV): (a) vista geral do SHV e do ponto de amostragem; (b) detalhe do ponto de amostragem. .134

Figura 4.5 - Fotos de alguns materiais necessários para realização do ensaio de determinação da concentração de areia presente no esgoto bruto: (a) fotos dos materiais utilizados durante os ensaios; (b) detalhe da adaptação feita nos Cones Imhoff para propiciar coletas de fundo (mangueira de látex e pinça de Hoffman). 135

Figura 4.6 - Foto dos cones Imhoff, já cheios com a amostra de esgoto, colocados em seu suporte e dos Bequeres de $100 \mathrm{ml}$ posicionados sob cada um dos cones. 137

Figura 4.7 - Fotos dos sólidos concentrados no fundo de um cone Imhoff e da coleta desses sólidos: (a) foto dos sólidos concentrados no fundo de um cone Imhoff após $30 \mathrm{~min}$ de sedimentação; (b) foto dos sólidos concentrados já coletados em um béquer de $100 \mathrm{ml}$...... 138

Figura 4.8 - (a) Foto dos tubos Falcon depois da centrifugação e descarte do sobrenadante; (b) Foto da aplicação do peróxido de hidrogênio em um tubo Falcon; (c) Foto de um tubo Falcon sendo agitado no agitador elétrico; (e) Foto de um tubo Falcon logo após a agitação; (e) Foto 
de um tubo Falcon depois de alguns segundos, pode-se notar areia concentrada no fundo do tubo e uma camada de escuma na parte superior.

Figura 4.9 - Fluxograma esquemático que mostra as etapas envolvidas na determinação da distribuição de tamanho de partículas por análise de imagem. 146

Figura 4.10 - Foto do Microscópio com uma câmera CCD acoplada. Equipamento do SCPAM - LATAR - SHS - EESC - USP utilizado na aquisição das imagens digitais..

Figura 4.11 - Foto de uma amostra de areia seca sendo espalhada sobre a placa plana de vidro, posicionada sobre um fundo branco para garantir contraste necessário para a visualização dos grãos de areia. 148

Figura 4.12 - Desenho esquemático do padrão de movimentação adotado ao se tirar fotos de uma lâmina, para evitar que uma mesma partícula fosse fotografada mais de uma vez.. 149

Figura 4.13 - Conversão das imagens coloridas originais, com 16.777.216 níveis de brilho, em imagens em escala de cinzas, com 256 níveis de brilho. (a) imagem colorida original; (b) imagem em escala de cinzas...

Figura 4.14 - Binarização as imagens em escala de cinzas. (a) imagem em escala de cinzas (8 bits - 256 níveis de brilho); (b) imagem binarizada (1 bit -2 níveis de brilho).

Figura 4.15 - Utilização da operação morfológica fill holes (preencher buracos). (a) imagem anterior a utilização do fill holes apresentando "buracos"; (b) imagem posterior a utilização do fill holes com os "buracos"preenchidos. 153

Figura 4.16 - Utilização da operação morfológica watershed (divisor de águas) para separar aglomerados de partículas. (a) imagem anterior à utilização do watershed com a presença de aglomerados de partículas; (b) imagem posterior à utilização do watershed com as partículas dos aglomerados já separadas. 154

Figura 4.17 - Foto mostrando uma imagem de calibração com o fio de platina de diâmetro igual a $100 \mu \mathrm{m}$. 155

Figura 4.18 - Histograma de freqüências relativas, obtido a partir de 34 amostras de esgoto sanitário, coletadas junto à estação elevatória localizada nas proximidades da ETE Jardim das Flores da cidade de Rio Claro, SP, entre 17/08/2005 e 21/11/2005, das 09h30min até $17 \mathrm{~h} 30 \mathrm{~min}$. 159

Figura 4.19 - Gráfico de distribuição de freqüências relativas acumuladas, obtido a partir de 34 amostras de esgoto sanitário, coletadas junto à estação elevatória localizada nas proximidades da ETE Jardim das Flores da cidade de Rio Claro, SP, entre 17/08/2005 e 21/11/2005, das 09h30min até $17 \mathrm{~h} 30 \mathrm{~min}$.

Figura 4.20 - Gráfico tipo box-plot e curva de distribuição das concentrações de areia obtidas a partir de 34 amostras de esgoto sanitário, coletadas junto à estação elevatória localizada nas proximidades da ETE Jardim das Flores da cidade de Rio Claro, SP, entre 17/08/2005 e 21/11/2005, das 09 h30min até $17 \mathrm{~h} 30 \mathrm{~min}$. (-) Média aritmética dos dados...... 161

Figura 4.21 - Histograma de concentrações de areia construído a partir de 10 amostras de esgoto sanitário, coletadas junto à estação elevatória localizada nas proximidades da ETE Jardim das Flores da cidade de Rio Claro, SP, entre 17/08/2005 e 06/09/2005, das 09h30min até $15 \mathrm{~h} 00 \mathrm{~min}$ 165

Figura 4.22 - Histograma de concentrações de areia construído a partir de 24 amostras de esgoto sanitário, coletadas junto à estação elevatória localizada nas proximidades da ETE Jardim das Flores da cidade de Rio Claro, SP, entre 06/09/2005 e 21/11/2005, das 10h30min até $17 \mathrm{~h} 30 \mathrm{~min}$.

Figura 4.23 - Histograma de concentrações médias (geométrica e aritmética) de areia construído a partir de 24 amostras de esgoto sanitário, coletadas junto à estação elevatória 
localizada nas proximidades da ETE Jardim das Flores da cidade de Rio Claro, SP, entre 06/09/2005 e 21/11/2005, das 10h30min até 17h30min... 166

Figura 4.24 - Gráfico tipo box-plot das distribuições de concentração de areia para os dois períodos estudados, construído a partir de 32 amostras de esgoto sanitário, coletadas junto à estação elevatória localizada nas proximidades da ETE Jardim das Flores da cidade de Rio Claro, SP, entre 06/08/2005 e 21/11/2005, das 09h30min até 17h30min.(ロ a) Médias aritméticas dos dados.

167

Figura 4.25 - Box-plot das distribuições de concentração de areia para as três vazões de alimentação do $\operatorname{SHV}(10 \mathrm{l} / \mathrm{s}, 15 \mathrm{l} / \mathrm{s}$ e $20 \mathrm{l} / \mathrm{s})$, construído a partir de 32 amostras de esgoto sanitário, coletadas junto à estação elevatória localizada nas proximidades da ETE Jardim das Flores da cidade de Rio Claro, SP, entre 06/08/2005 e 21/11/2005, das 09h30min até 17h30min. (- - Médias aritméticas dos dados 169

Figura 4.28 - Histograma das distribuições de freqüências relativas numéricas e volumétricas obtidas a partir de 22.531 partículas observadas no conjunto de dados composto pelas 15 amostras estudadas.

Figura 4.29 - Gráfico das distribuições de freqüências relativas acumuladas numéricas e volumétricas obtidas a partir de 22.531 partículas observadas no conjunto de dados composto pelas 15 amostras estudadas.

.177

Figura 4.30 - Histograma das distribuições de freqüências relativas numéricas e volumétricas obtidas a partir das 745 partículas observadas na amostra coletada aos 06/11/2005, às $13 \mathrm{~h} 30 \mathrm{~min}$. Concentração de areia na amostra de $8,5 \mathrm{mg} / 1$

Figura 4.31 - Histograma das distribuições de freqüências relativas numéricas e volumétricas obtidas a partir das 2.237 partículas observadas na amostra coletada aos 09/11/2005, às $11 \mathrm{~h} 30 \mathrm{~min}$. Concentração de areia na amostra de $178,7 \mathrm{mg} / 1$.

Figura 4.32 - Gráfico das distribuições de freqüências relativas acumuladas numéricas e volumétricas de duas amostras. Amostra coletada aos 06/10/2005, às $13 \mathrm{~h} 30 \mathrm{~min}$, com 745 partículas e concentração de areia de $8,51 \mathrm{mg} / \mathrm{l}$; e amostra coletada aos 09/11/2005, às 11h30min, com 2.237 partículas e concentração de areia de $178,7 \mathrm{mg} / 1$

Figura 5.1 - Esquema da instalação experimental montada na estação elevatória da ETE Jardim das Flores do município de Rio Claro, SP, utilizada na avaliação do desempenho do SHV...... 187

Figura 5.2 - Foto da instalação experimental montada na estação elevatória da ETE Jardim das Flores do município de Rio Claro, SP, utilizada para avaliar o desempenho do SHV como desarenador e sistema de gradeamento fino. 188

Figura 5.3 - Foto mostrando panorama lateral da instalação experimental montada na estação elevatória da ETE Jardim das Flores do município de Rio Claro, SP, utilizada para avaliar o desempenho do SHV como desarenador e sistema de gradeamento fino. 188

Figura 5.4 - Primeira configuração da grade fina de fluxo tangencial instalada no topo do vertedor tubular de saída do SHV, a qual possuía diâmetro de $320 \mathrm{~mm}$ e espaçamento entre barras de 3,0 $\mathrm{mm}$. (a) Foto da grade fina instalada no topo do vertedor tubular de saída do SHV. (b) Foto da grade fina instalada no topo do vertedor tubular de saída do SHV durante o período de pré-operação com água.

Figura 5.5 - Segunda configuração da grade fina de fluxo tangencial instalada no topo do vertedor tubular de saída do SHV, com diâmetro de $600 \mathrm{~mm}$, espaçamento entre barras de 4,0 $\mathrm{mm}$, e com sistema mecanizado de limpeza.

Figura 5.6 - Foto que mostra o sistema de limpeza mecanizado da segunda configuração da grade fina de fluxo tangencial, instalado no topo do SHV. .191

Figura 5.7 - Padrão de linhas de corrente de um "vórtice de ralo" ou vórtice livre. 198 
Figura 5.8 - Foto que mostra a superfície livre que se forma no topo do SHV nas adjacências da grade cilíndrica. 198

Figura 5.9 - Foto que mostra o acúmulo de pedaços de poliestireno junto à grade cilíndrica posicionada no topo do vertedor tubular de saída do SHV. 199

Figura 5.10 - Foto que mostra a grade cilíndrica posicionada no topo do vertedor tubular de saída do SHV obstruída por sólidos grosseiros após 5 minutos de operação com vazão de alimentação de $20 \mathrm{l} / \mathrm{s}$ (TAS de $1.528 \mathrm{~m}^{3} / \mathrm{m}^{2} \mathrm{~d}$ ). 200

Figura 5.11 - Foto que mostra em detalhe os sólidos grosseiros que obstruíram a grade cilíndrica posicionada no topo do vertedor tubular de saída do SHV, após 5 minutos de operação com vazão de alimentação de $201 / \mathrm{s}$ (TAS de $1.528 \mathrm{~m}^{3} / \mathrm{m}^{2} \mathrm{~d}$ )...... 200

Figura 5.12 - Foto que mostra: a grade cilíndrica de $600 \mathrm{~mm}$ de diâmetro e com espaçamento entre barras de 4,0 mm, instalada no topo do vertedor tubular de saída do SHV; e o sistema mecanizado de limpeza da mesma em operação. 201

Figura 5.13 - Foto que mostra: detalhe da face interna da grade cilíndrica de $600 \mathrm{~mm}$ de diâmetro e com espaçamento entre barras de $4,0 \mathrm{~mm}$, instalada no topo do vertedor tubular de saída do SHV; e as cerdas da escova do raspador do sistema mecanizado de limpeza da mesma em operação. .201

Figura 5.14 - Gráfico de distribuição numérica de tamanho de grãos de areia presentes na amostra coletada aos 06/10/2005 às $13 \mathrm{~h} 30 \mathrm{~min}$. TAS de $764 \mathrm{~m}^{3} / \mathrm{m}^{2} \mathrm{~d}$. .211

Figura 5.15 - Gráfico de distribuição numérica de tamanho de grãos de areia presentes na amostra coletada aos 11/10/2005 às $14 \mathrm{~h} 30 \mathrm{~min}$. TAS de $764 \mathrm{~m}^{3} / \mathrm{m}^{2} \mathrm{~d}$. .212

Figura 5.16 - Gráfico de distribuição numérica de tamanho de grãos de areia presentes na amostra coletada aos 11/10/2005 às $15 \mathrm{~h} 30 \mathrm{~min}$. TAS de $764 \mathrm{~m}^{3} / \mathrm{m}^{2} \mathrm{~d}$.

Figura 5.17 - Gráfico de distribuição numérica de tamanho de grãos de areia presentes na amostra coletada aos 11/10/2005 às $16 \mathrm{~h} 30 \mathrm{~min}$. TAS de $764 \mathrm{~m}^{3} / \mathrm{m}^{2} \mathrm{~d}$. 213

Figura 5.18 - Gráfico de distribuição numérica de tamanho de grãos de areia presentes na amostra coletada aos 04/11/2005 às $10 \mathrm{~h} 30 \mathrm{~min}$. TAS de $1.146 \mathrm{~m}^{3} / \mathrm{m}^{2} \mathrm{~d}$. .213

Figura 5.19 - Gráfico de distribuição numérica de tamanho de grãos de areia presentes na amostra coletada aos $04 / 11 / 2005$ às $13 \mathrm{~h} 30 \mathrm{~min}$. TAS de $1.146 \mathrm{~m}^{3} / \mathrm{m}^{2} \mathrm{~d}$. .214

Figura 5.20 - Gráfico de distribuição numérica de tamanho de grãos de areia presentes na amostra coletada aos $17 / 11 / 2005$ às $16 \mathrm{~h} 30 \mathrm{~min}$. TAS de $1.146 \mathrm{~m}^{3} / \mathrm{m}^{2} \mathrm{~d}$.

Figura 5.21 - Gráfico de distribuição numérica de tamanho de grãos de areia presentes na amostra coletada aos $17 / 11 / 2005$ às $17 \mathrm{~h} 30 \mathrm{~min}$. TAS de $1.146 \mathrm{~m}^{3} / \mathrm{m}^{2} \mathrm{~d}$. .215

Figura 5.22 - Gráfico de distribuição numérica de tamanho de grãos de areia presentes na amostra coletada aos 09/11/2005 às $11 \mathrm{~h} 30 \mathrm{~min}$. TAS de $1.528 \mathrm{~m}^{3} / \mathrm{m}^{2} \mathrm{~d}$. .215

Figura 5.23 - Gráfico de distribuição numérica de tamanho de grãos de areia presentes na amostra coletada aos 09/11/2005 às $12 \mathrm{~h} 30 \mathrm{~min}$. TAS de $1.528 \mathrm{~m}^{3} / \mathrm{m}^{2} \mathrm{~d}$. .216

Figura 5.24 - Gráfico de distribuição numérica de tamanho de grãos de areia presentes na amostra coletada aos $21 / 11 / 2005$ às $14 \mathrm{~h} 30 \mathrm{~min}$. TAS de $1.528 \mathrm{~m}^{3} / \mathrm{m}^{2} \mathrm{~d}$.

Figura 5.25 - Gráfico de distribuição numérica de tamanho de grãos de areia presentes na amostra coletada aos $21 / 11 / 2005$ às $17 \mathrm{~h} 30 \mathrm{~min}$. TAS de $1.528 \mathrm{~m}^{3} / \mathrm{m}^{2} \mathrm{~d}$. .217 


\section{LISTA DE TABELAS}

Tabela 2.1 - Algumas características do peneirado retido por grades grossas.

.18

Tabela 2.2 - Algumas características do peneirado retido por peneiras finas. Valores médios e valores obtidos de peneiras com aberturas de $0,8 \mathrm{~mm}$ a $3,0 \mathrm{~mm}$.

Tabela 2.3 - Vantagens e desvantagens do emprego de desarenadores retangulares de escoamento horizontal.

Tabela 2.4 - Vantagens e desvantagens do emprego de desarenadores quadrados de escoamento horizontal.

Tabela 2.5 - Vantagens e desvantagens do emprego de desarenadores aerados. .24

Tabela 2.6 - Vantagens e desvantagens do emprego de desarenadores de remoção por vórtice ou separadores por vórtice.

.25

Tabela 2.7 - Quantidade de areia, obtida de levantamento feito em vinte duas ETEs dos Estados Unidos, que recebem esgoto de sistemas de coleta do tipo separador absoluto...... .27

Tabela 3.1 - Características gerais do domínio (malha), dos fluidos, da simulação, das condições de contorno iniciais e do critério de parada adotado para as simulações computacionais

Tabela 3.2 - Valores dos tempos de detenção hidráulica teóricos, médios (calculados pelo método dos momentos) e modais (correspondente ao pico das curvas de distribuição de idade de saída $\mathrm{E}(\mathrm{t})$ ), das razões entre tempo de detenção hidráulica médio e tempo de detenção hidráulica teórico, que indica a relação entre volume ativo e o volume útil do SHV, assim como das razões entre tempo de detenção hidráulica modal e tempo de detenção hidráulica teórico, que indica a relação entre volume com escoamento pistonado e o volume útil do SHV. .80

Tabela 3.3 - Valores de variância padronizada e número de dispersão para as três vazões utilizadas para alimentar o SHV (10 1/s; 15 l/s e 20 l/s)....

Tabela 4.1 - Distribuições de freqüências, freqüências relativas e freqüências relativas acumuladas das 34 amostras, coletadas junto à estação elevatória localizada nas proximidades da ETE Jardim das Flores da cidade de Rio Claro, SP, entre 17/08/2005 e 21/11/2005, das $09 \mathrm{~h} 30 \mathrm{~min}$ até $17 \mathrm{~h} 30 \mathrm{~min}$.

Tabela 4.2 - Intervalos de confiança baseados nas médias aritmética e geométrica com níveis de significância de $95 \%$, e parâmetros estatísticos da distribuição de concentrações de areia. 156

Tabela 4.3 - Parâmetros estatísticos usados para a realização do teste de hipótese da média populacional de concentrações de areia dos dois períodos estudados, considerando amostras independentes com variâncias desconhecidas e diferentes.

Tabela 4.4 - Parâmetros estatísticos usados para a realização do teste de hipótese da média populacional de concentrações de areia para as vazões de alimentação do SHV, 10 1/s e 15 l/s, considerando amostras independentes com variâncias desconhecidas e diferentes, com nível de significância de 0,05 .

Tabela 4.5 - Parâmetros estatísticos usados para a realização do teste de hipótese da média populacional de concentrações de areia para as vazões de alimentação do SHV, 10 l/s e 20 l/s, considerando amostras independentes com variâncias desconhecidas e diferentes, com nível de significância de 0,05 .

164

Tabela 4.6 - Parâmetros estatísticos usados para a realização do teste de hipótese da média populacional de concentrações de areia para as vazões de alimentação do SHV, 15 1/s e 20 1/s, considerando amostras independentes com variâncias desconhecidas e diferentes. .165 
Tabela 4.8 - Distribuições freqüências relativas e relativas acumuladas das distribuições numérica e volumétrica, obtidas a partir da soma das 15 amostras analisadas. O conjunto de dados resultante possui 22.531 partículas. 170

Tabela 4.9 - Diâmetros estatísticos obtidos a partir as 22.531 partículas observadas no conjunto composto pelas 15 amostras estudadas. 172

Tabela 4.10 - Resultados da análise estatística dos 22.531 valores de circularidade obtidos pela análise imagens. Intervalo de confiança com $98 \%$ de significância para a média populacional calculado assumindo amostras aleatórias distribuídas normalmente ao redor da média...... 174

Tabela 4.11 - Diâmetros estatísticos obtidos a partir das 745 partículas observadas na amostra coletada aos 06/10/2005, às $13 \mathrm{~h} 30 \mathrm{~min}$. Concentração de areia de $8,5 \mathrm{mg} / 1$. 176

Tabela 4.12 - Diâmetros estatísticos obtidos a partir das 2.237 partículas observadas na amostra coletada aos 09/11/2005, às 11h30min. Concentração de Areia de 178,7 mg/l..........176

Tabela 4.13 - Resultados da análise estatística dos 745 valores de circularidade obtidos pela análise imagens para a amostra de esgoto de 06/10/2005, coletada às $13 \mathrm{~h} 30 \mathrm{~min}$. Intervalo de confiança com $98 \%$ de significância para a média populacional calculado assumindo amostras aleatórias distribuídas normalmente ao redor da média. 178

Tabela 4.14 - Resultados da análise estatística dos 2.237 valores de circularidade obtidos pela análise imagens para a amostra de esgoto de 09/11/2005, coletada às $11 \mathrm{~h} 30 \mathrm{~min}$. Intervalo de confiança com $98 \%$ de significância para a média populacional calculado assumindo amostras aleatórias distribuídas normalmente ao redor da média. 178

Tabela 5.1 - Data, período, número de amostras coletadas e vazão de alimentação do SHV no momento das coletas realizadas para a avaliação do desempenho do SHV na remoção de areia do esgoto sanitário. .195

Tabela 5.2 - Concentrações de sólidos suspensos voláteis do esgoto sanitário afluente e efluente do SHV, respectivos valores de eficiência de remoção e as eficiências médias de remoção e seus desvios padrões para as TAS de $764 \mathrm{~m}^{3} / \mathrm{m}^{2} \mathrm{~d} ; 1.146 \mathrm{~m}^{3} / \mathrm{m}^{2} \mathrm{~d}$ e $1.528 \mathrm{~m}^{3} / \mathrm{m}^{2} \mathrm{~d}$. 204

Tabela 5.3 - Parâmetros estatísticos usados para a realização dos testes de hipóteses para a eficiência de remoção de sólidos suspensos voláteis. 206

Tabela 5.4 - Valores de concentração de areia presente em cada uma das amostras de esgoto sanitário afluente e efluente do SHV, valores de eficiência de remoção de areia calculados com a Equação 5.3, assim como as médias geométricas e os desvios padrões de todos esses valores. Condições operacionais: TAS de764 $\mathrm{m}^{3} / \mathrm{m}^{2} \mathrm{~d}(10 \mathrm{l} / \mathrm{s})$. 207

Tabela 5.5 - Valores de concentração de areia presente em cada uma das amostras de esgoto sanitário afluente e efluente do SHV, valores de eficiência de remoção de areia calculados com a Equação 5.3, assim como as médias geométricas e os desvios padrões de todos esses valores. Condições operacionais: TAS de $1146 \mathrm{~m}^{3} / \mathrm{m}^{2} \mathrm{~d}(15 \mathrm{l} / \mathrm{s})$...... 208

Tabela 5.6 - Valores de concentração de areia presente em cada uma das amostras de esgoto sanitário afluente e efluente do SHV, valores de eficiência de remoção de areia calculados com a Equação 5.3, assim como as médias geométricas e os desvios padrões de todos esses valores. Condições operacionais: TAS de $1528 \mathrm{~m}^{3} / \mathrm{m}^{2} \mathrm{~d}(20 \mathrm{l} / \mathrm{s})$...... 208

Tabela 5.7 - Intervalos de confiança (ICs) com nível de significância de 95\% das médias populacionais das concentrações de areia das amostras de esgoto sanitário afluente e efluente do SHV, e das eficiências de remoção de areia observadas para as TAS de $764 \mathrm{~m}^{3} / \mathrm{m}^{2} \mathrm{~d} ; 1146$ $\mathrm{m}^{3} / \mathrm{m}^{2} \mathrm{~d}$ e $1528 \mathrm{~m}^{3} / \mathrm{m}^{2} \mathrm{~d}$.

Tabela 5.8 - Valores de percentual mássico de grãos de areia de tamanho maior ou igual a 200 $\mu \mathrm{m}$ encontrados nas amostras de esgoto sanitário afluente do SHV, valores de eficiência de remoção parcial de areia, assim como, as médias geométricas e os desvios padrões de todos esses valores. TAS de $764 \mathrm{~m}^{3} / \mathrm{m}^{2} \mathrm{~d}(10 \mathrm{l} / \mathrm{s})$... 
Tabela 5.9 - Valores de percentual mássico de grãos de areia de tamanho maior ou igual a 200 $\mu \mathrm{m}$ encontrados nas amostras de esgoto sanitário afluente do SHV, valores de eficiência de remoção parcial de areia, assim como, as médias geométricas e os desvios padrões de todos esses valores. TAS de $1.146 \mathrm{~m}^{3} / \mathrm{m}^{2} \mathrm{~d}(15 \mathrm{l} / \mathrm{s})$

Tabela 5.10 - Valores de percentual mássico de grãos de areia de tamanho maior ou igual a 200 $\mu \mathrm{m}$ encontrados nas amostras de esgoto sanitário afluente do SHV, valores de eficiência de remoção parcial de areia, assim como, as médias geométricas e os desvios padrões de todos esses valores. TAS de $1.528 \mathrm{~m}^{3} / \mathrm{m}^{2} \mathrm{~d}(201 / \mathrm{s})$...... .219

Tabela 5.11 - Intervalos de confiança (ICs) com nível de significância de 95\% das médias populacionais das eficiências de remoção parcial de areia observadas para as TAS de 764 $\mathrm{m}^{3} / \mathrm{m}^{2} \mathrm{~d} ; 1146 \mathrm{~m}^{3} / \mathrm{m}^{2} \mathrm{~d}$ e $1528 \mathrm{~m}^{3} / \mathrm{m}^{2} \mathrm{~d}$... 


\section{SUMÁRIO}

Capítulo 1 - Introdução........................................................................................1

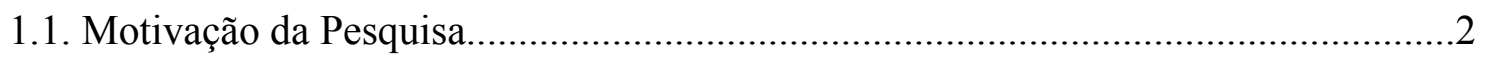

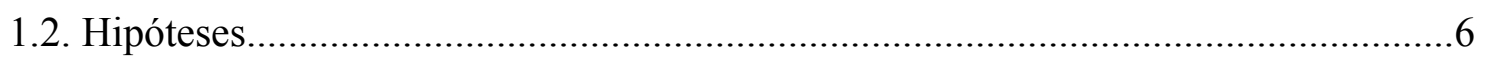

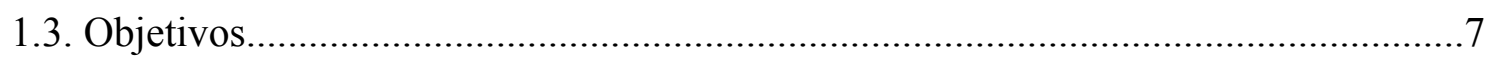

Capítulo 2 - O Tratamento Preliminar de Esgoto Sanitário e os Separados Hidrodinâmicos por Vórtice: Conceitos e Aplicações...........8

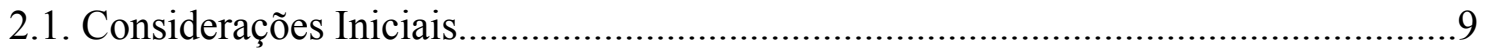

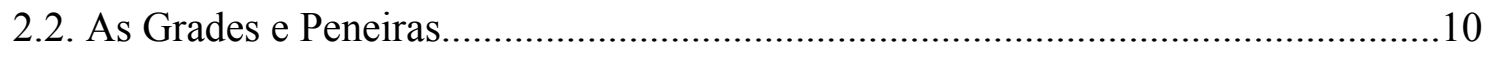

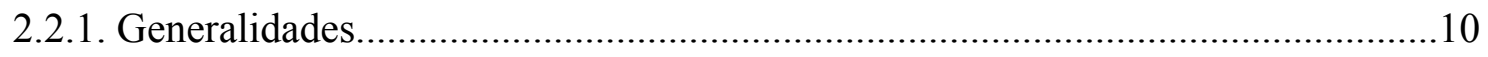

2.2.2. Quantidade e característica do material retido em grades e peneiras....................16

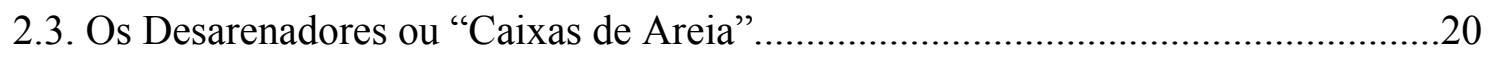

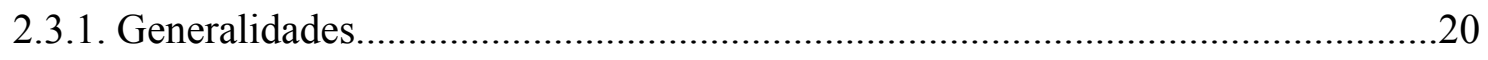

2.3.2. Tipo de desarenadores ou "caixas de areia"....................................................21

2.3.3. Quantidade e característica do material retido nos desarenadores.......................26

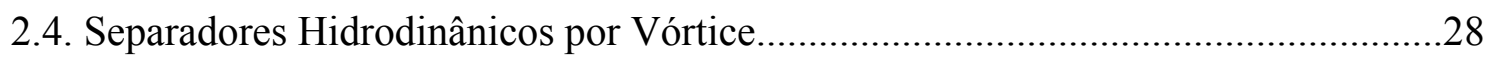

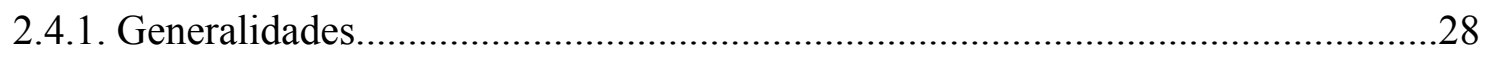

2.4.2. Histórico dos separadores hidrodinâmicos por vórtice........................................28

2.4.3. Conceitos básicos sobre os separadores hidrodinâmicos por vórtice.....................30

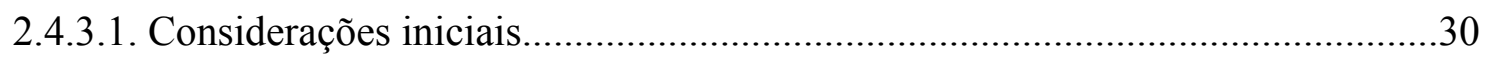

2.4.3.2. A velocidade tangencial do líquido em separadores hidrodinâmicos por

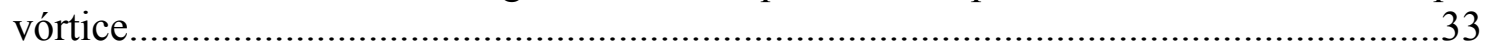

2.4.3.3. Velocidade radial do líquido em separadores hidrodinâmicos por vórtice..........37

2.4.3.4. A velocidade vertical do líquido em separadores hidrodinâmicos por

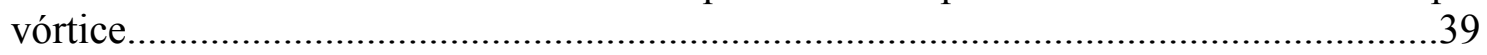

2.4.3.5. Escoamentos secundários em separadores hidrodinâmicos por vórtice..............39

2.4.3.6. Interações sólido-líquido em separadores hidrodinâmicos por vórtice...............41

2.4.4. Aplicabilidade dos separadores hidrodinâmicos por vórtice................................45

2.4.5. Histórico do desenvolvimento do protótipo do separador hidrodinâmico por

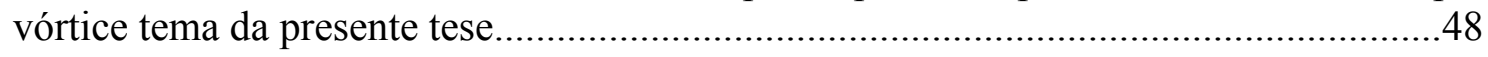

Capítulo 3 - Estudo da Hidrodinâmica do Separador Hidrodinâmico por Vórtice...................................................................................................................57

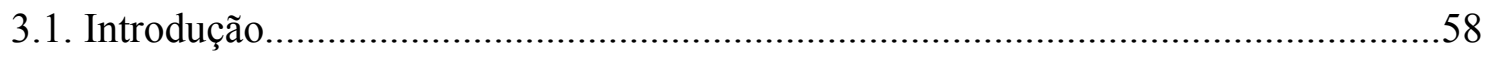




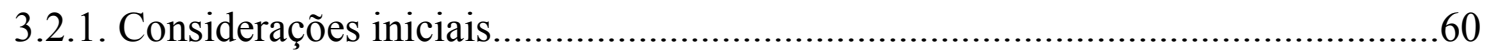

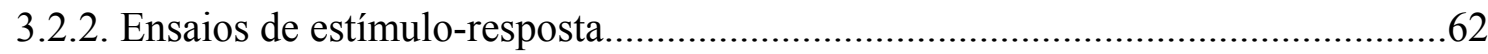

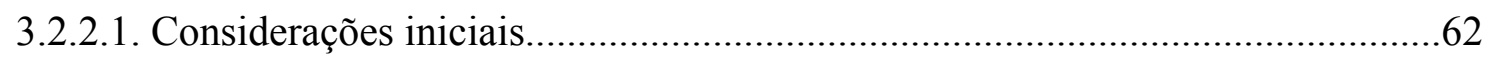

3.2.2.2. Materiais e equipamentos necessários à realização dos ensaios de estímuloresposta.

3.2.2.3. Procedimentos adotados na execução dos ensaios de estímulo-resposta.

3.2.3. Levantamento das pressões totais em pontos no interior do separador

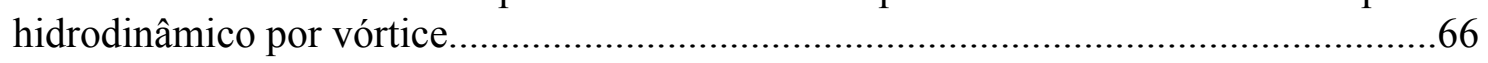

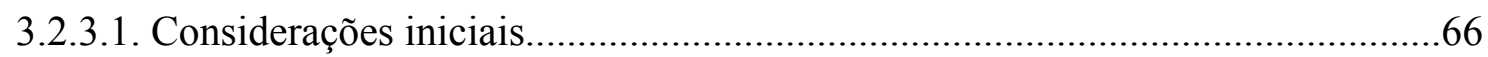

3.2.3.2. Materiais e equipamentos necessários para realização das medições de pressão

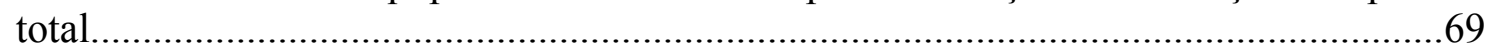

3.2.3.3. Procedimentos adotados nas medições de pressão total.................................... 71

3.2.4. Simulações computacionais do padrão de escoamento do separador

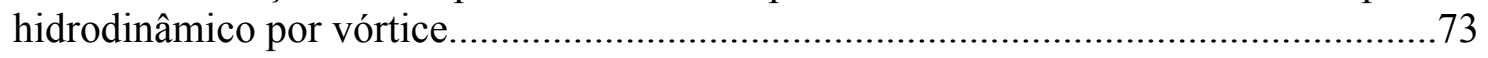

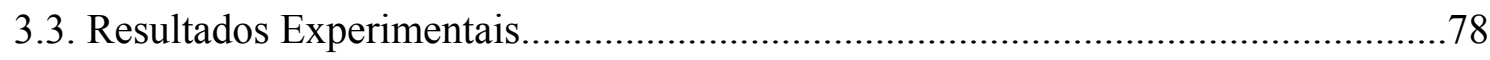

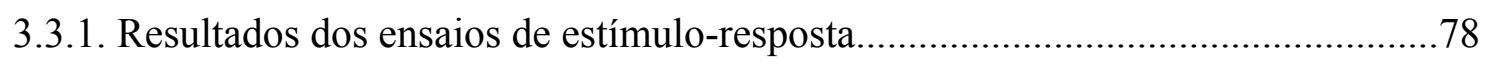

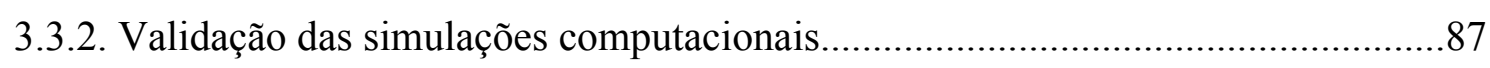

3.3.3. Resultados das simulações computacionais..................................................... 92

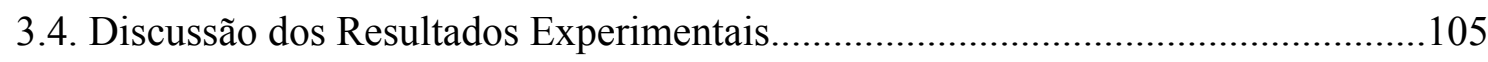

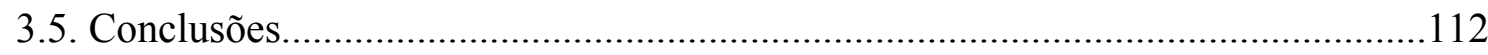

Capítulo 4 - A Problemática da Determinação da Quantidade de Areia no Esgoto Sanitário.......................................................................115

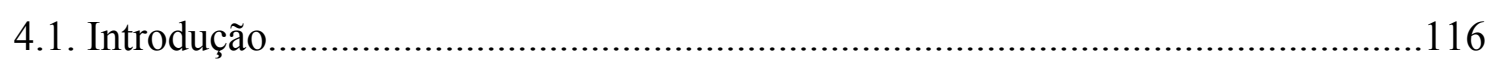

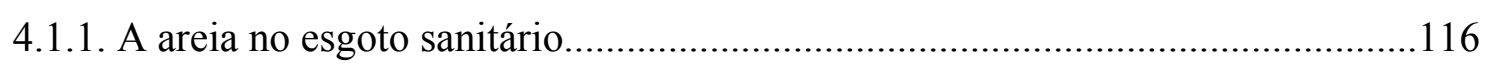

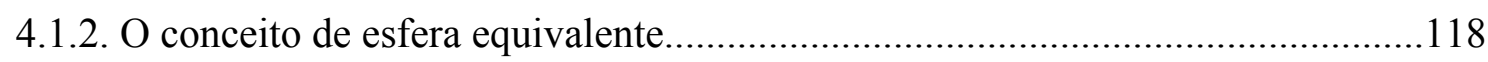

4.1.3. A interferência da forma das partículas na determinação de seus diâmetros

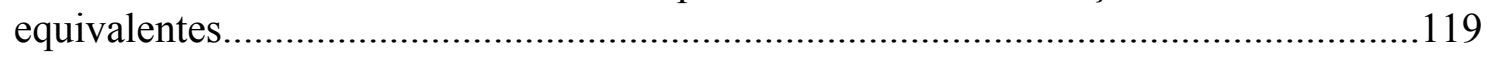

4.1.4. A escolha da técnica de determinação da distribuição de tamanho de

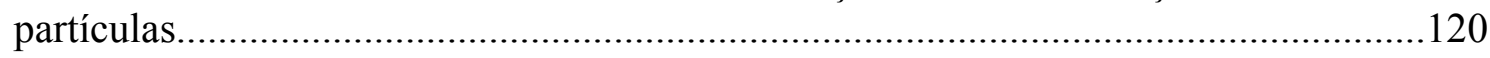

4.1.5. As técnicas de determinação da distribuição de tamanho de partículas..............121

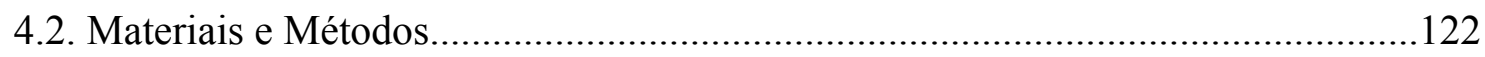

4.2.1. Considerações iniciais acerca dos métodos desenvolvidos................................122

4.2.2. Determinação da concentração de areia no esgoto bruto.....................................124

4.2.2.1. Os problemas encontrados durante o desenvolvimento do método e as soluções adotadas. 
4.2.2.2. Amostragem e conservação das amostras 125

4.2.2.3. Materiais e equipamentos necessários para determinação da concentração de areia no esgoto sanitário..

4.2.2.4. Procedimentos Adotados para Realização dos Ensaios Determinação da Concentração de Areia no Esgoto Sanitário.

4.2.3. Determinação da distribuição granulométrica da areia presente no esgoto bruto 136

4.2.3.1. Considerações sobre a escolha da técnica de determinação da distribuição de tamanho de partícula. 136

4.2.3.2. A análise de imagens como técnica de determinação da distribuição de tamanho de partículas.

4.2.3.3. Materiais e equipamentos necessários para a determinação da distribuição granulométrica da areia presente no esgoto sanitário.. 140

4.2.3.4. Amostragem dos grãos de areia e aquisição das imagens digitais 141

4.2.3.5. Tratamento e processamento das imagens e determinação da distribuição de tamanho de partículas das amostras 144

4.2.3.5.1. Detecção das feições de interesse ou detecção as bordas e segmentação dos objetos. 145

4.2.3.5.2. Processamento das imagens binárias 146

4.2.3.5.3. Calibração do programa 149

4.2.3.5.4. Análise e medições. 150

4.2.3.5.5. Tratamento dos Dados e Apresentação dos Resultados..... 151

4.3. Resultados e Discussões. 151

4.3.1. Considerações iniciais 151

4.3.2. Concentração de areia no esgoto sanitário. 152

4.3.3. Distribuição granulométrica da areia no esgoto sanitário. 166

4.4. Conclusões. 179

\section{Capítulo 5 - Análise do Desempenho do Separador Hidrodinâmico por Vórtice e da Grade Fina de Fluxo Tangencial.

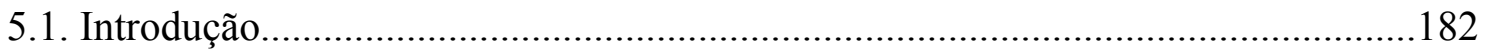

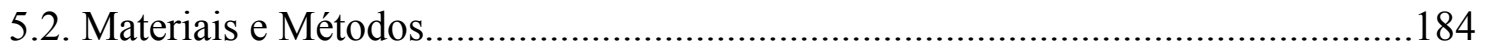

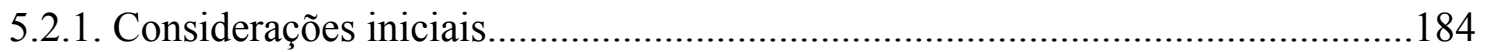

5.2.2. Materiais e equipamentos necessários para a montagem da instalação

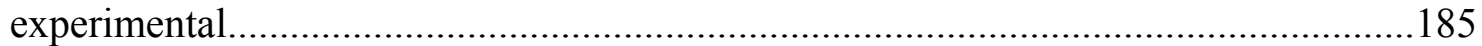

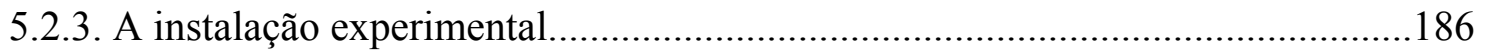

5.2.4. Metodologia empregada na avaliação do desempenho da grade fina de fluxo tangencial. 
5.2.5. Metodologia empregada na avaliação do desempenho do separador hidrodinâmico por vórtice como unidade de desarenação.

5.2.5.1. Considerações iniciais.

192

5.2.5.2. Amostragem e conservação das amostras. 194

5.2.5.3. Determinação da concentração de sólidos suspensos voláteis e da concentração e distribuição granulométrica da areia presente nas amostras de esgoto sanitário afluente e efluente do separador hidrodinâmico por vórtice 195

5.3. Resultados e Discussão. 197

5.3.1. Avaliação do desempenho do sistema de gradeamento fino de fluxo tangencial do separador hidrodinâmico por vórtice

5.3.2. Avaliação do desempenho do separador hidrodinâmico por vórtice como unidade de desarenação. 203

5.4. Conclusões 220

Capítulo 6 - Considerações Finais e Conclusões da Tese. 222

6.1. Considerações Finais. .223

6.2. Conclusões da Tese. .227

6.3. Sugestões para Futuras Pesquisas

Referências Bibliográficas. 233

APÊNDICE A - Gráficos de Distribuição Volumétrica de Tamanho dos Grãos de Areia Presentes no Esgoto Sanitário Afluente e Efluente do Separador Hidrodinâmico por Vórtice. 240 


\section{Capítulo 1 - Introdução}

Este capítulo apresenta a contextualização do tema proposto nesta pesquisa, enfatizando a necessidade de pesquisarem-se as unidades que compõem o tratamento preliminar de estações de tratamento de esgoto, com o intuito de aprimorar as unidades já existentes como, também, de desenvolver outras que atendam às demandas atuais, isto é, compacidade, eficiência e baixo custo de implantação e operação. Sugere-se, neste capítulo, que uma unidade que associasse um separador hidrodinâmico por vórtice a uma grade fina cilíndrica de fluxo tangencial atenderia a tais demandas, pois tal unidade somaria, em um mesmo local, a eficiência já comprovada dos separadores hidrodinâmicos por vórtice na remoção de sólidos sedimentáveis à praticidade de um sistema de gradeamento “auto-limpante”. Posteriormente, neste capítulo, são apresentados os objetivos e as hipóteses que nortearam esta tese. 


\subsection{Motivação da Pesquisa}

As estações de tratamento de esgoto podem ser definidas como conjunto seqüencial de unidades de tratamento, nas quais, a primeira unidade deve ser projetada de forma que seus efluentes sejam adequados ao processo ou operação de tratamento pelo qual serão submetidos a seguir e, assim, sucessivamente, até que se produzam efluentes que atendam aos padrões de lançamento e possam ser apropriadamente descartados. Dessa forma, é possível reunir as unidades de processo e de operações unitárias que compõem uma estação de tratamento de esgoto em quatro grupos, de acordo com o "nível” (grau) de tratamento que elas podem alcançar; são eles:

- Tratamento Preliminar - composto por equipamentos e unidades de operações unitárias, responsáveis pela remoção de areia, sólidos grosseiros, óleos e graxas, presentes no esgoto sanitário como, também, pela atenuação de odores, controle da vazão de esgoto e da carga orgânica que adentra uma estação de tratamento de esgoto.

- Tratamento Primário - composto, principalmente, por unidades de operações unitárias, que são responsáveis pela remoção de sólidos sedimentáveis e com eles parte da matéria orgânica presente no esgoto sanitário;

- Tratamento Secundário - composto por unidades de processo e de operação unitária, as quais são responsáveis pela remoção de matéria orgânica e, eventualmente, de nutrientes (fósforo e nitrogênio) encontrados no esgoto sanitário;

- $\quad$ Tratamento Terciário - composto por unidades de processo e operações unitárias, responsáveis pela remoção de contaminantes específicos (e.g. compostos tóxicos, patógenos) ou ainda, por complementar a remoção de matéria orgânica e nutrientes, não suficientemente removidos pelas unidades do tratamento secundário.

Entre esses quatro grupos de unidades, o tratamento preliminar é o que menos desperta o interesse da comunidade científica. Tal fato é corroborado pela escassez de publicações acerca do tema e pela ausência de linhas de pesquisa voltadas ao 
desenvolvimento e aperfeiçoamento das unidades e dos equipamentos que compõem o tratamento preliminar. Consoante Wilson (1985), esse desinteresse ocorre porque o tratamento preliminar sempre foi considerado a menos "nobre” das etapas de tratamento que compõem uma estação de tratamento de esgoto. No entanto, o mesmo autor assevera que considerar o tratamento preliminar menos "nobre” pode custar muito caro, pois, somente os desarenadores (unidades responsáveis pela remoção de areia) podem responder por até um terço do custo operacional de uma estação de tratamento de esgoto; e mais, o custo associado à operação e manutenção de equipamentos de bombeamento, transporte e manuseio de lodo, que contenha material abrasivo, é no mínimo cinco vezes maior do que o seria, caso este tipo de material não estivesse presente.

Atualmente, algumas linhas de pesquisa desenvolvidas no Departamento de Hidráulica e Saneamento da Escola de Engenharia de São Carlos da Universidade de São Paulo e em outros centros de pesquisa defendem o abandono da etapa de tratamento primário no projeto de novas estações de tratamento de esgoto, em favor do emprego de fluxogramas mais modernos, como por exemplo: reator UASB (Upfllow Anareobic Sludge Blanket) seguido de sistema de lodos ativados sem decantador primário, reator UASB seguido de flotação por ar dissolvido ou de decantação de alta taxa, entre outros. Tais configurações, praticamente eliminam o problema do lodo não-digerido que se acumula nos decantadores primários.

Todavia, a ausência do decantador primário que, anteriormente, se destinava a remover àquela parcela de sólidos grosseiros, os quais muitas vezes escapam do tratamento preliminar, pode acarretar sérios problemas operacionais às estações de tratamento de esgoto, como: acúmulo de sólidos inertes e não degradáveis nas unidades de tratamento secundário, entupimento das tubulações e dos sistemas de distribuição de esgoto nos reatores, acúmulo de pedaços de tecido e materiais fibrosos nas pás de aeradores superficiais, entre outros. Para se evitar tais percalços, o tratamento preliminar que, outrora, mesmo quando mal projetado ou mal operado acabava não causando tanto impacto no desempenho das unidades subseqüentes, agora precisa ser olhado cuidadosamente.

Recentes pesquisas têm demonstrado a potencialidade da utilização de separadores hidrodinâmicos por vórtice combinados a sistemas de peneiramento ou 
gradeamento na remoção de sólidos abrasivos (grãos de areia) e sólidos flutuantes (trapos, pedaços de plástico etc.), os principais responsáveis pelos problemas ainda pouco mencionados (ANDOH, 1998; ANDOH e SAUL, 2003). Os separadores hidrodinâmicos por vórtice são unidades cilíndricas com base cônica ou abaulada, nas quais o esgoto sanitário é introduzido por meio de um bocal, tangencialmente posicionado na parede externa dessas unidades.

A geometria dos separadores hidrodinâmicos por vórtice compele o esgoto sanitário afluente dessas unidades a percorrer trajetórias helicoidais e descendentes junto a suas paredes externas, e trajetórias helicoidais e ascendentes junto aos seus eixos centrais (ANDOH e SMISSON, 1993; ANDOH, 1998). Tais trajetórias helicoidais são muito mais longas do que a distância entre a entrada e a saída de um separador hidrodinâmico por vórtice, o que aumenta o tempo no qual o campo de aceleração gravitacional e o campo de aceleração “centrífuga”, resultante do movimento circulatório do fluido, atuam sobre partículas em suspensão no afluente da unidade, fazendo com que os separadores hidrodinâmicos por vórtice ao serem empregados como unidades de desarenação sejam capazes de: i) separar a areia da matéria orgânica presente no esgoto sanitário; ii) concentrar a areia em uma região de acúmulo no fundo da unidade para posteriormente ser descartada; e iii) permitir que matéria orgânica passe pela unidade sem ser removida (SULLIVAN, 1974; ANDOH, 1998).

Até 2003, existiam mais de mil e quinhentos separadores hidrodinâmicos por vórtice instalados mundo a fora, operando com eficiências de remoção de sólidos suspensos (SS) que variam de 30\% a 70\%, a depender das características locais dos sólidos presentes em seus afluentes brutos (ANDOH, 1998, ANDOH e SAUL, 2003). Tal fato comprova a eficiência dos separadores hidrodinâmicos por vórtice na remoção de sólidos sedimentáveis; no entanto, nenhuma dessas unidades encontra-se em território brasileiro. Provavelmente, isso ocorra devido à falta de informações acerca dos separadores hidrodinâmicos por vórtice, à resistência natural às novas tecnologias e aos valores incorridos na importação dessas unidades.

No ensejo do cenário apresentado, isto é, o abandono das unidades de tratamento primário e a conseqüente necessidade de se aprimorar as unidades de tratamento preliminar, somado à escassez de pesquisa acerca deste tema e à potencialidade dos separadores hidrodinâmicos por vórtice, buscou-se uma parceria com uma empresa 
local, a PROMINAS do Brasil, para o financiamento de uma pesquisa sobre o uso combinado de um separador hidrodinâmicos por vórtice com uma grade fina cilíndrica de fluxo tangencial, a qual tiraria proveito do padrão circulatório de escoamento do líquido ao redor da grade para promover a “auto-limpeza” de sua superfície. Feita tal parceria, o resultado foi o projeto e a construção de uma unidade compacta para tratamento preliminar de esgoto sanitário, a qual reúne um separador hidrodinâmico por vórtice a uma grade fina cilíndrica de fluxo tangencial. Esta unidade é o tema central da presente pesquisa e, atualmente, encontra-se em processo de aprimoramento para que, em breve, seja patenteada.

A seguir, no Capítulo 2 (O Tratamento Preliminar de Esgoto Sanitário e os Separadores Hidrodinâmicos por Vórtice: Conceitos e Aplicações) desta tese são apresentados: algumas generalidades sobre o tratamento preliminar de esgoto sanitário, um breve histórico dos separadores hidrodinâmicos por vórtice, assim como alguns conceitos acerca do funcionamento dessas unidades e suas principais aplicações na indústria da água. Ainda neste mesmo capítulo, é descrito todo o processo de desenvolvimento da unidade de tratamento preliminar tema central desta tese. No Capítulo 3 (Estudo da Hidrodinâmica do Separador Hidrodinâmico por Vórtice) é apresentado um estudo acerca da hidrodinâmica do separador hidrodinâmico por vórtice, que se fundamenta em resultados de ensaios de estímulo-resposta, medições de pressão total e simulações computacionais do padrão de escoamento da unidade em software de dinâmica dos fluidos computacional. No Capítulo 4 (A Problemática da Determinação da Quantidade de Areia no Esgoto Sanitário) são descritos os dois métodos desenvolvidos nesta pesquisa, um para a determinação da concentração de areia no esgoto sanitário e outro para determinação da distribuição granulométrica dos grãos dessa areia, os quais foram utilizados na avaliação de desempenho da unidade. No Capítulo 5 (Análise do Desempenho do Separador Hidrodinâmico por Vórtice e da Grade Fina de Fluxo Tangencial) são apresentados os resultados da avaliação de desempenho do separador hidrodinâmico por vórtice na remoção de areia do esgoto sanitário, e da avaliação do desempenho da grade fina de fluxo tangencial na retenção de sólidos grosseiros presentes no esgoto sanitário. Finalmente, no Capítulo 6 (Considerações Finais da Tese) são apresentadas as conclusões finais da tese, assim como, algumas sugestões para trabalhos futuros. 


\subsection{Hipóteses}

Durante o desenvolvimento do presente trabalho de Doutorado foram admitidas as seguintes hipóteses:

- A geometria do separador hidrodinâmico por vórtice (SHV) e de seus componentes internos propicia condições para o desenvolvimento de padrão circulatório de escoamento, caracterizado pelo movimento helicoidal e descendente do fluido junto à parede externa da unidade e pelo movimento helicoidal e ascendente do fluido próximo ao eixo central da unidade;

- $\quad$ O movimento helicoidal e descendente do fluido junto à parede externa da unidade faz com que partículas em suspensão no afluente do separador hidrodinâmico por vórtice experimentem a ação de um campo de aceleração “centrífuga” (efeito da inércia das partículas), a qual suplementa a ação do campo de aceleração gravitacional na separação de partículas discretas, como grãos de areia;

- $\quad$ O padrão circulatório de escoamento ao redor de uma grade fina cilíndrica de fluxo tangencial impede que os sólidos grosseiros, presentes no esgoto sanitário afluente da unidade, acumulem-se na superfície da grade, mantendo-a limpa ou, pelo menos, minimizando a freqüência de limpezas. 


\subsection{Objetivos}

A presente pesquisa tem com objetivo principal a concepção, desenvolvimento e avaliação do desempenho de uma unidade de tratamento preliminar em escala plena, a qual é constituída de um separador hidrodinâmico por vórtice e uma grade fina cilíndrica de fluxo tangencial, cujas funções são, respectivamente, a remoção de areia e a retenção de sólidos grosseiros presentes no esgoto sanitário. Para atingir este propósito, foi necessário o cumprimento de objetivos específicos, destacando-se:

- $\quad$ Estudo da hidrodinâmica do separador hidrodinâmico por vórtice mediante ensaios de estímulo-resposta, medições de pressão total e simulações computacionais do padrão de escoamento da unidade em software de dinâmica dos fluidos computacional (CFD - Computational fluid dynamics);

- $\quad$ Desenvolvimento de dois métodos, um para determinação da concentração de areia presente no esgoto sanitário e outro para determinação da distribuição granulométrica dos grãos dessa areia;

- Operação da unidade desenvolvida e avaliação do desempenho da grade fina cilíndrica de fluxo tangencial na retenção de sólidos grosseiros presentes no esgoto sanitário, verificando se o padrão de escoamento ao redor da mesma não permite a aderência de sólidos à sua superfície;

- Operação da unidade desenvolvida e avaliação do desempenho do separador hidrodinâmico por vórtice na remoção de areia presente no esgoto sanitário. 


\section{Capítulo 2 - O Tratamento Preliminar de Esgoto Sanitário e os Separados Hidrodinâmicos por Vórtice: Conceitos e Aplicações}

Este capítulo apresenta alguns conceitos sobre o tratamento preliminar de esgotos sanitários, com maior enfoque nas unidades de gradeamento, peneiramento e desarenação. Os tipos de grades e peneiras mais comuns, mormente, empregados em estações de tratamento de esgoto são apresentados e discutidos; logo após, são expostos os principais tipos de unidades de desarenação, assim como aplicação, vantagens e desvantagens de cada qual. Os separadores hidrodinâmicos por vórtice (SHVs) são pormenorizados, com a apresentação: de um breve histórico dessas unidades, de alguns conceitos básicos dos escoamentos vorticosos, dos mecanismos de separação sólidolíquido que governam o funcionamento dos SHVs e de alguns exemplos de aplicação. Por fim, é apresentado um breve histórico do desenvolvimento do protótipo do separador hidrodinâmico por vórtice, tema central dessa tese. 


\subsection{Considerações Iniciais}

A primeira "barreira" que, usualmente, as águas residuárias encontram ao chegar às estações de tratamento de esgoto (ETEs) é um conjunto de equipamentos e unidades de operação denominado tratamento preliminar, o qual pode ser constituído de: grades; peneiras; trituradores; desarenadores (“caixas de areia”); medidores de vazão; tanques de equalização (vazão e carga orgânica); removedores de gordura, óleos e graxas ("caixas de gordura"); e removedores de odor. Consoante a Water Environment Federation (1998), tais equipamentos e unidades de operação devem ser capazes de cumprir três funções básicas: i) remover materiais sólidos (sólidos grosseiros) que não podem ser tratados por ETEs (i.e. trapos, materiais fibrosos como estopa e fios de tecido, pedaços de plástico e madeira, pontas de cigarro, preservativos masculinos, areia, entre outros); ii) proteger equipamentos e tubulações, localizados à jusante, contra entupimentos, obstruções, esforços excessivos de motores de raspadores, aeradores etc.; e iii) melhorar o desempenho das unidades de processo atenuando picos de vazão, carga orgânica ou ambos. Além destas três funções básicas citadas por Water Environment Federation (1998), pode-se acrescentar outras duas funções para as unidades e equipamentos constituintes do tratamento preliminar de ETEs; são elas: melhorar o aspecto estético das unidades subseqüentes e reduzir laboriosas atividades dos operadores.

Não obstante serem responsáveis "apenas" pela remoção dos sólidos grosseiros, óleos e graxas presentes no esgoto bruto, as unidades e os equipamentos que formam o tratamento preliminar de ETEs são tão importantes quanto as demais unidades de tratamento que as sucedem; pois seu mau funcionamento pode afetar todo o sistema de tratamento. As grades e peneiras impedem que trapos, pedaços de plástico e outros materiais presentes nas águas residuárias obstruam tubulações, bombas, digestores, espessadores etc.. Os desarenadores ou "caixas de areia" ajudam a reduzir o desgaste provocado pelo contato direto de materiais abrasivos (i.e. grãos de areia, pequenos pedregulhos, entre outros) com as tubulações e os equipamentos de bombeamento e transporte de esgoto e lodo como, também, diminuem o acúmulo desses materiais inertes nas unidades de processo subseqüentes. À medida que se diminui o tempo de detenção hidráulica (TDH) adotado para unidades de tratamento biológico, o emprego de "caixas de gordura" torna-se importante, posto que, estas unidades são responsáveis 
pela remoção de óleos e graxas, que são compostos recalcitrantes. Os tanques de equalização e os medidores de vazão ajudam a melhorar a estabilidade operacional e o controle das unidades de processo à jusante, pois o primeiro atenua prováveis picos de vazão e carga orgânica e o segundo fornece ao operador o valor da vazão e do volume de esgoto que adentra a ETE. Por sua vez, o controle de odores melhora as condições de trabalho na estação e também auxilia no relacionamento do público, principalmente o circunvizinho, com a ETE; outra importante função do controle de odores é a proteção de equipamentos e das próprias instalações da estação contra os gases corrosivos liberados pelo esgoto durante seu processo de tratamento (METCALF \& EDDY, 2003; WATER ENVIRONMENT FEDERATION, 1998).

A seguir, somente três (grades, peneiras e desarenadores) das várias unidades de operação e equipamentos constituintes do tratamento preliminar de esgoto serão discutidas individualmente, por se tratarem do foco central deste trabalho de pesquisa.

\subsection{As Grades e Peneiras}

\subsubsection{Generalidades}

Os sistemas de gradeamento e de peneiramento são dois dos mais antigos equipamentos utilizados na remoção de sólidos grosseiros de efluentes líquidos, os quais, mesmo depois do desenvolvimento de processos químicos e bioquímicos de tratamento, ainda exercem papel fundamental ao protegerem as unidades e os equipamentos subseqüentes de avarias e mau funcionamento, provocados por sólidos grosseiros que chegam à ETE com o esgoto bruto (WATER ENVIRONMENT FEDERATION, 1994).

As grades podem ser descritas como conjunto de barras paralelas espaçadas uniformemente entre si, instalado verticalmente ou inclinado ao longo da largura do canal em que escoa o esgoto. As peneiras são "superfícies metálicas" com pequenas aberturas, geralmente, circulares ou retangulares ou podem ser malhas de fios metálicos ou poliméricos. 
As grades e peneiras podem ser classificadas de acordo com o espaçamento entre suas barras ou o tamanho de suas aberturas, como: grades e peneiras grossas (espaçamentos ou aberturas maiores que 6,0 $\mathrm{mm}$ ) e grades e peneiras finas (espaçamentos ou aberturas entre 1,5 $\mathrm{mm}$ e 6,0 $\mathrm{mm}$ ). Vale ressaltar que o emprego de peneiras grossas não é corriqueiro e que espaçamento entre barras superior a 50,0 mm, geralmente, é utilizado onde o sistema de coleta de esgotos não é do tipo separador absoluto (WATER ENVIRONMENT FEDERATION, 1998).

Outra forma de se classificar as grades e peneiras tem base nos procedimentos de limpeza adotados, são eles: grades e peneiras de limpeza manual e grades e peneiras de limpeza mecânica. As grades grossas de limpeza manual devem ser instaladas com inclinação entre $45^{\circ}$ e $60^{\circ}$ em relação ao fundo do canal e seu comprimento não deve exceder os 3,0 m, para que seja possível ao operador, com a ajuda de um ancinho, remover o material nelas retido. Via de regra, é utilizado espaçamento entre barras superior a $25,0 \mathrm{~mm}$, porquanto aberturas menores poderiam provocar aumento na freqüência de limpezas. Em decorrência destas limitações, o emprego de grades grossas de limpeza manual deve restringir-se às pequenas instalações e aos canais de by-pass (METCALF \& EDDY, 2003; WATER ENVIRONMENT FEDERATION, 1994). Na Figura 2.1, pode ser visto um esquema de grade grossa de limpeza manual, comumente empregada no tratamento preliminar de ETEs de pequeno e médio porte.

As grades de limpeza mecânica não apresentam certas limitações impostas às grades de limpeza manual, como: tamanho de aberturas, inclinação e comprimento. Elas são instaladas com inclinações que variam de $0^{\circ}$ a $60^{\circ} \mathrm{em}$ relação ao fundo do canal, e com espaçamento entre barras de 6,0 $\mathrm{mm}$ a 40,0 $\mathrm{mm}$. Segundo a Water Environment Federation (1998), essas unidades, quando comparadas àquelas de limpeza manual, reduzem a mão-de-obra com manutenção e melhoram as condições de escoamento no canal de chegada de esgoto, o que aumenta a captura de sólidos no sistema de gradeamento. Porém, a aquisição de grades de limpeza mecanizada é mais onerosa do que a aquisição daquelas de limpeza manual, além disso, as partes móveis que constituem seus mecanismos de limpeza podem se tornar uma fonte de problemas, caso as operações de manutenção não sejam devidamente executadas. A Figura 2.2 mostra um exemplo de grade grossa de limpeza mecânica conhecida como grade catenária, do inglês catenary bar screen. 


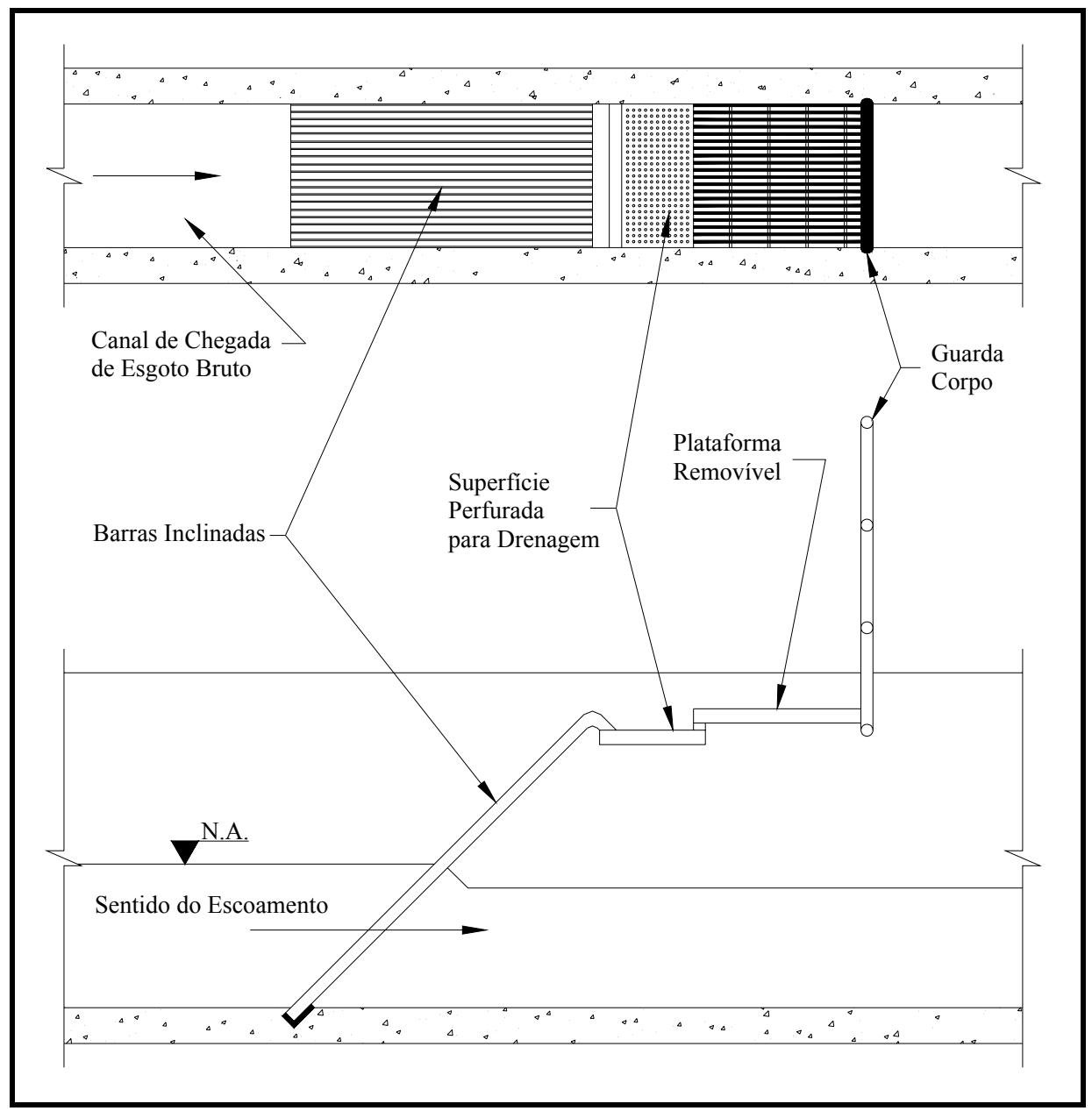

Figura 2.1 - Esquema de uma Grade grossa de limpeza manual. Fonte: Adaptado de Water Environment Federation (1994).

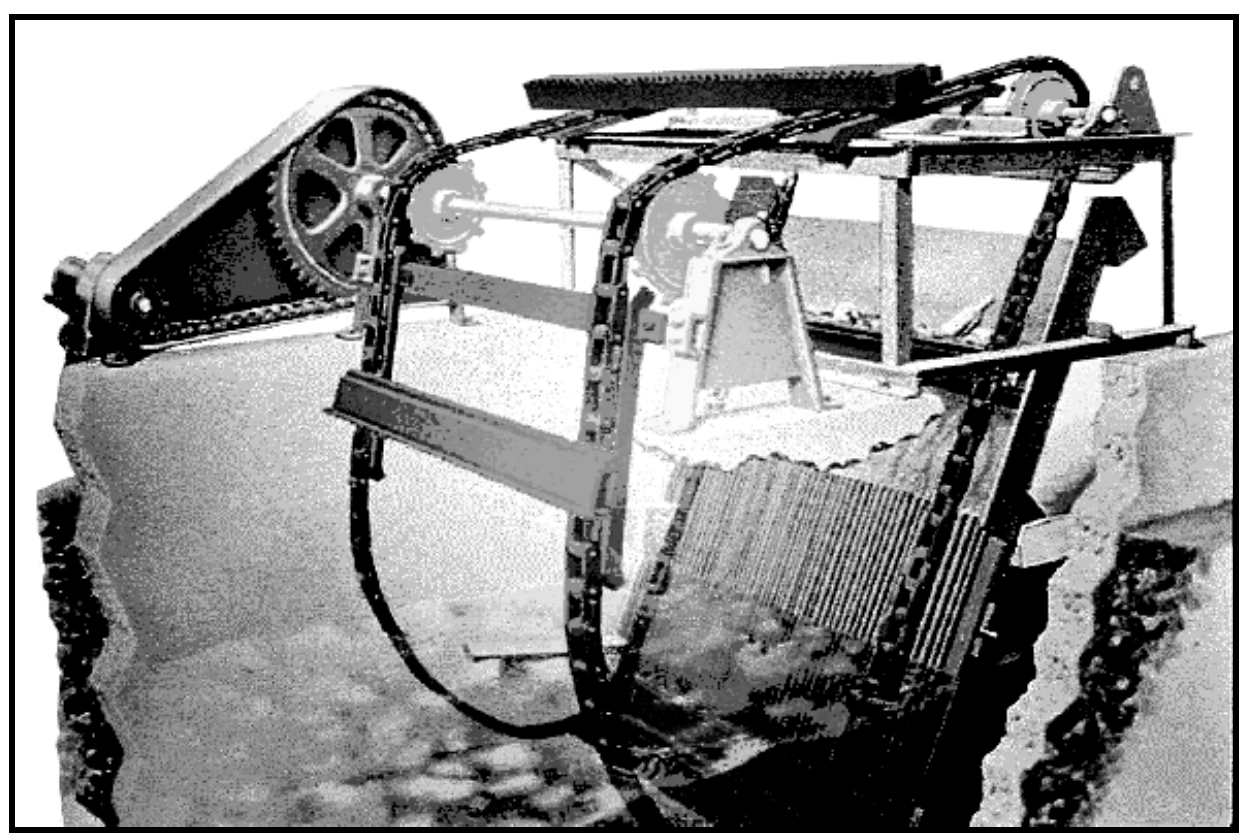

Figura 2.2 - Exemplo de uma grade grossa de limpeza mecânica: Link-Belt Catenary Bar Screen.

Fonte: USFilter (2003) 
As grades e peneiras finas podem ser classificadas, de acordo com Water Environment Federation (1994), como: in-channel, quando são alocadas no próprio canal por onde escoa o esgoto; ou freestanding, quando requerem instalações próprias à parte do canal. Os modelos de peneira fina, mormente encontrados em ETEs, são: a peneira estática parabólica, que é do tipo freestanding; e as peneiras de tambor ou disco rotativos, as quais são do tipo in-channel. Segundo a Water Environment Federation (1998), peneiras finas com aberturas entre $1,0 \mathrm{~mm}$ e $6,0 \mathrm{~mm}$ podem alcançar eficiências de remoção da ordem de $15 \%$ a $30 \%$ para os sólidos suspensos (SS), $15 \%$ a $25 \%$ para a DBO e $10 \%$ a $20 \%$ para bactérias presentes no esgoto bruto.

Nas Figuras 2.3 e 2.4 são apresentados os tipos mais comuns de peneiras finas utilizadas no tratamento preliminar de esgoto: a peneira estática parabólica, a peneira de tambor rotativo de alimentação externa e a peneira de tambor rotativo de alimentação interna.

As grades grossas e finas não são equipamentos difíceis de serem projetados, contudo, por serem amplamente comercializadas, geralmente projetistas de ETEs as especificam, de forma adequá-las às condições locais. Algumas recomendações devem ser observadas para que se garanta a escolha do sistema de gradeamento ou peneiramento apropriado, (METCALF \& EDDY, 2003; ASSOCIAÇÃO BRASILEIRA DE NORMAS TÉCNICAS - NBR 12209, 1992; WATER ENVIRONMENT FEDERATION, 1998):

- O espaçamento entre barras deve ser escolhido com base na menor dimensão do sólido que poderia causar dano às unidades e aos equipamentos subseqüentes. De acordo com a Water Environment Federation (1998), geralmente, grades grossas com espaçamento entre barras inferior a $20,0 \mathrm{~mm}$ oferecem proteção suficiente às demais unidades de uma ETE; porém, é importante lembrar que à medida que se diminui o espaçamento entre as barras, aumenta a quantidade de peneirado retido nas grades grossas;

- As grades grossas devem ser alocadas antes de quaisquer outras unidades, pois seu objetivo é protegê-las; além disso, o aumento do nível de água à montante das grades, ocasionado pelo acúmulo de sólidos nas barras, pode prejudicar o funcionamento de unidades instaladas no local; 
- O esgoto deve ser uniformemente distribuído por toda a seção transversal da grade para evitar acúmulo de material sólido em regiões específicas da grade;

- A velocidade de escoamento do esgoto pelo canal de aproximação deve ser superior a $0,45 \mathrm{~m} / \mathrm{s}$, para evitar o depósito de areia e de outros materiais à montante das peneiras;

- A velocidade de escoamento por entre as barras não deve exceder $1,0 \mathrm{~m} / \mathrm{s}$, porquanto velocidades maiores poderiam provocar o carreamento de sólidos previamente retidos principalmente, durante as operações de limpeza;

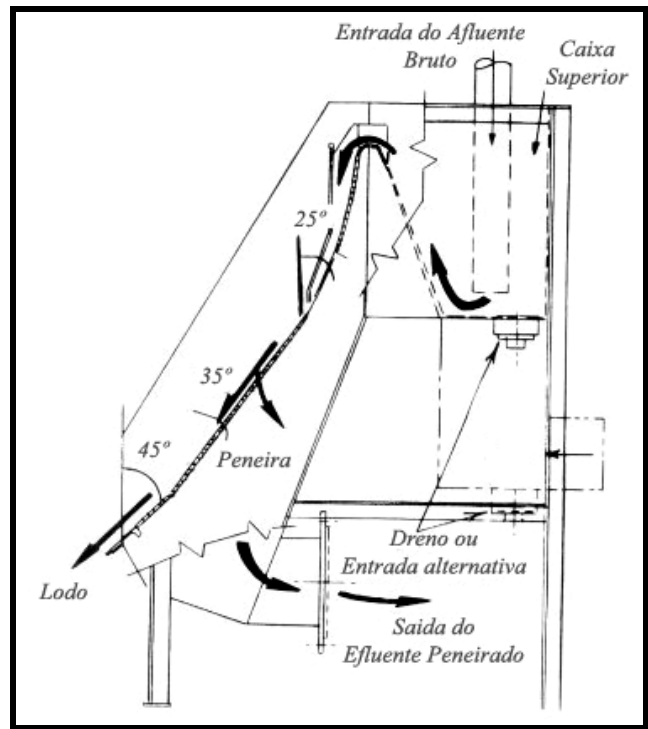

(a)

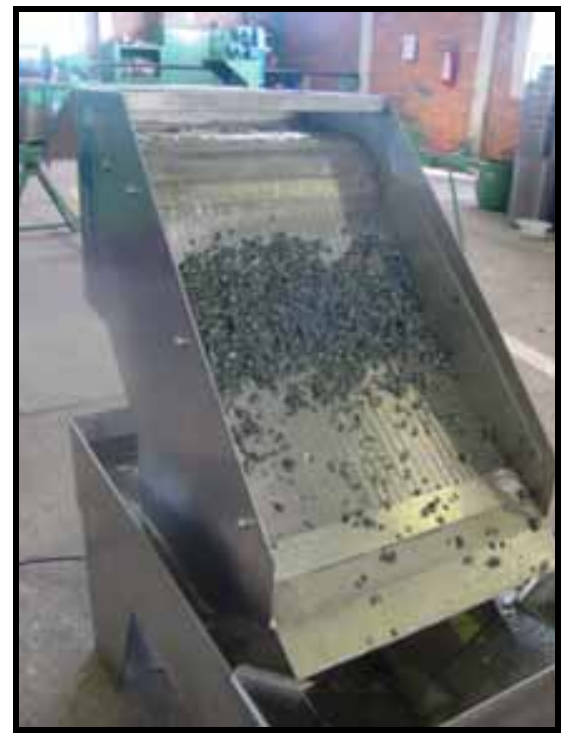

(b)

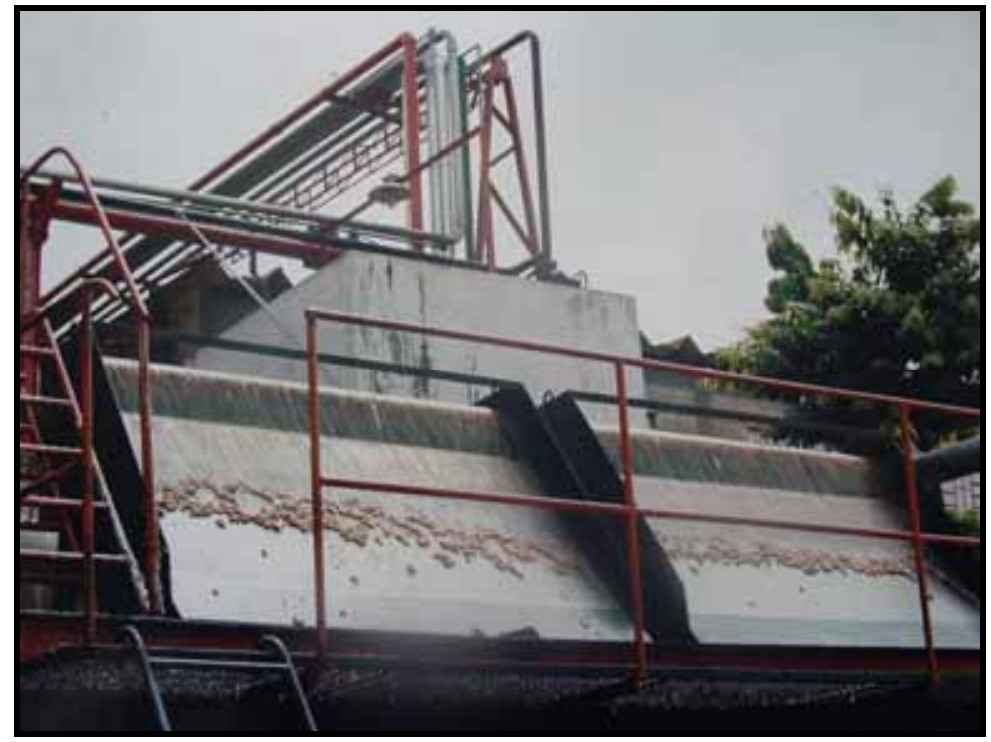

(c)

Figura 2.3 - Exemplo de peneiras finas: em (a) tem-se um esquema de peneira estática parabólica, em (b) vê-se uma foto de uma peneira estática parabólica e em (c) pode ser observado um sistema de peneiramento fino constituído por duas peneiras estáticas parabólicas.

Fonte: Fotos cedidas pela PROMINAS do Brasil. 


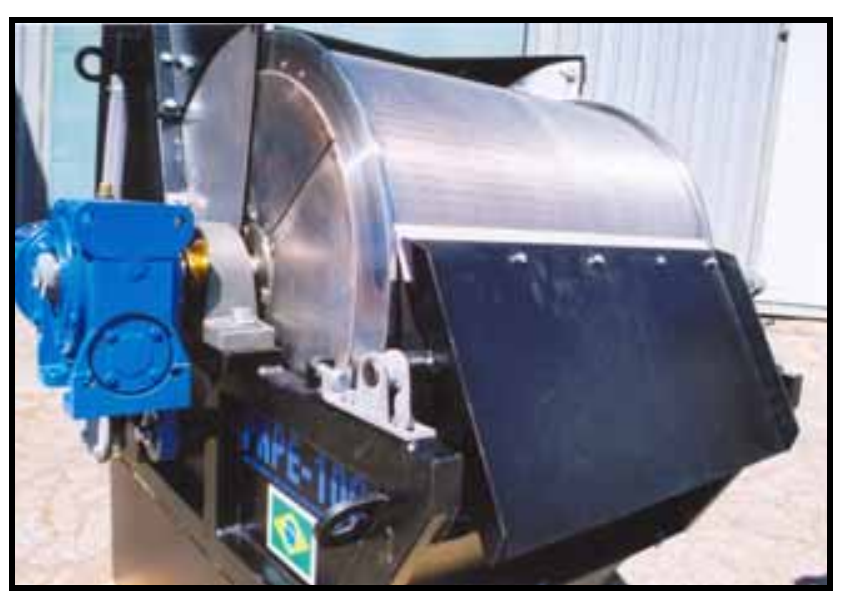

(a)

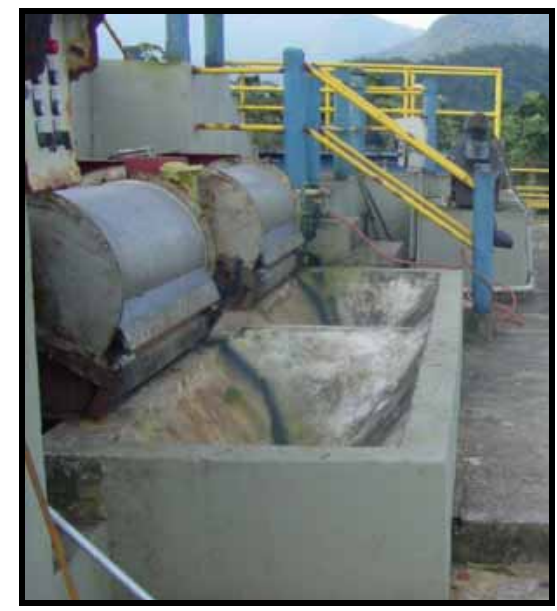

(b)

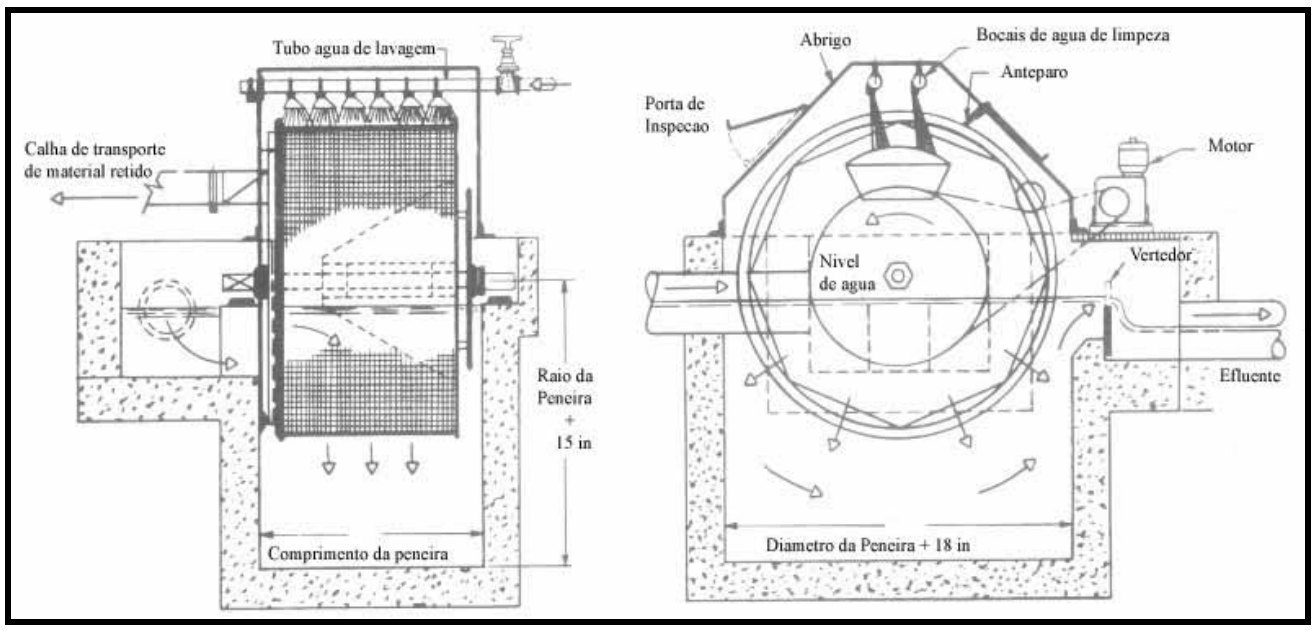

(c)

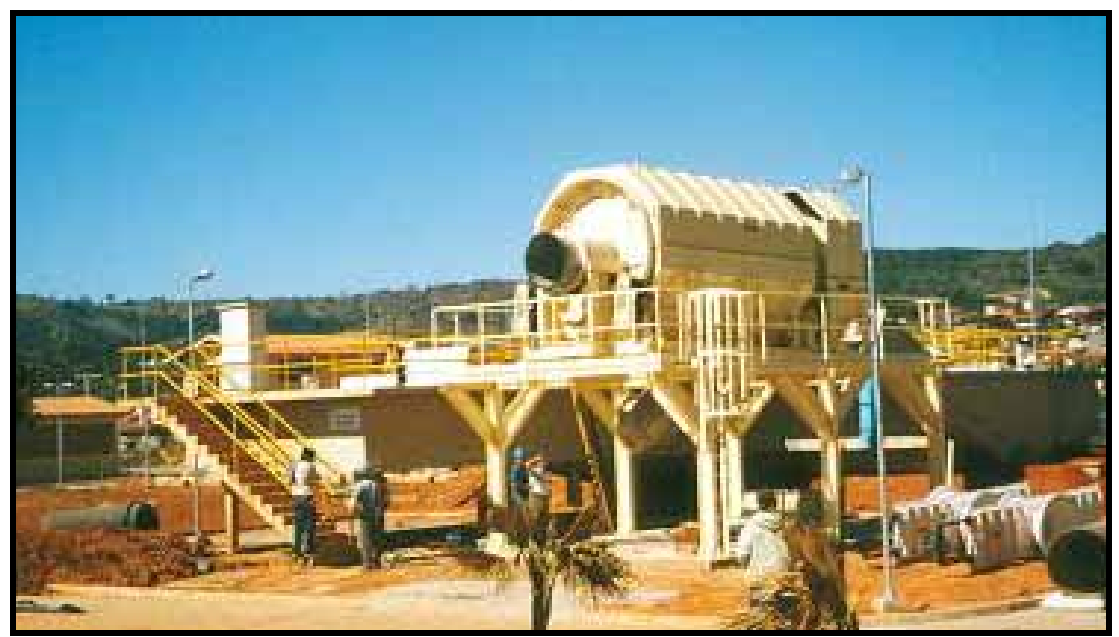

(d)

Figura 2.4 - Exemplo de peneiras de tambor rotativo: em (a) tem-se uma foto de uma peneira de tambor rotativo de alimentação externa, em (b) vê-se uma foto de um sistema de peneiramento constituído por duas peneiras de tambor rotativo de alimentação externa, em (c) pode-se observar um esquema de uma peneira de tambor rotativo de alimentação interna e em (d) vê-se uma foto da instalação de uma peneira de tambor rotativo de alimentação interna em uma ETE. Fonte: Fotos cedidas pela PROMINAS do Brasil. 
- O formato da seção transversal das barras que compõem as grades também deve ser cuidadosamente escolhido. A adoção de barras com seção transversal trapezoidal ou em forma de cunha tem ganhado espaço entre os projetistas, posto que este formato evita que sólidos se prendam entre as barras, desde que suas faces planas mais largas fiquem voltadas contra o sentido do escoamento de esgoto. A Figura 2.5 mostra um exemplo de conjunto de barras com seção transversal trapezoidal de uma peneira ou grade.

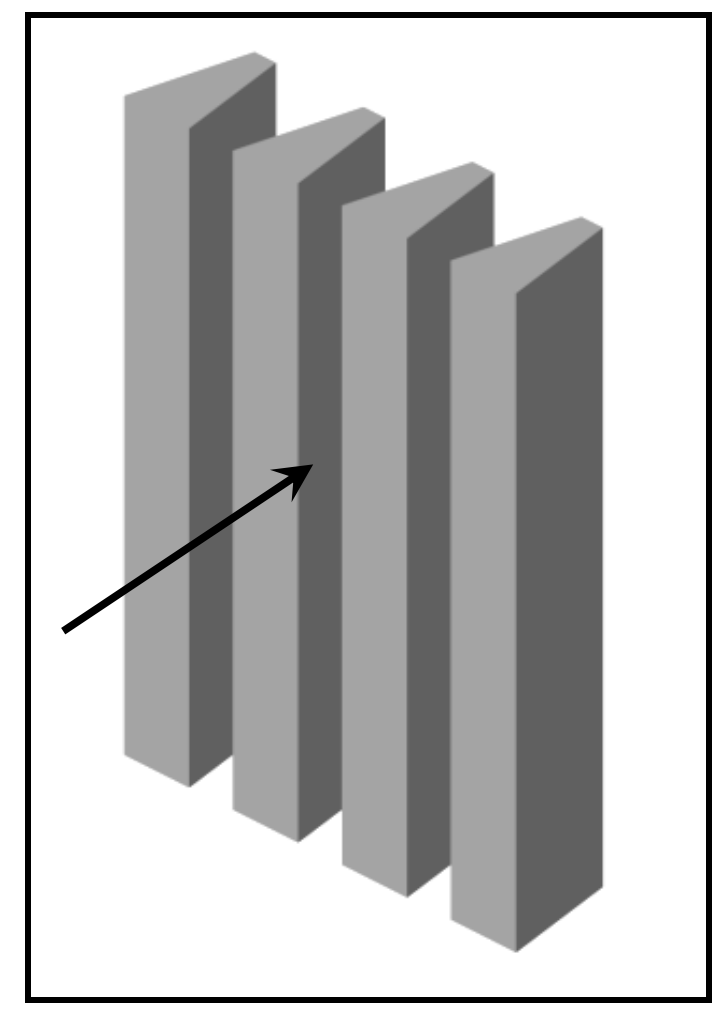

Figura 2.5 - Esboço de um conjunto com barras de seção transversal trapezoidal.

\subsubsection{Quantidade e característica do material retido em grades e peneiras}

O material retido em grades e peneiras, o qual será designado neste texto como "peneirado", é constituído basicamente por: trapos; pequenos pedaços de pedra, plástico, madeira, papel, ossos e comida; preservativos masculinos; tampas de garrafas; fios de cabelo e outros materiais fibrosos como estopa etc.. Sua composição e quantificação dependem das características da bacia de coleta de esgoto atendida pela 
ETE e do tipo de sistema de gradeamento ou peneiramento empregado no tratamento preliminar.

A quantidade e composição do peneirado retido por grades e peneiras grossas são pouco afetadas pelas características da bacia coletora, cabendo o papel de maior importância ao tamanho das aberturas das peneiras ou ao espaçamento entre barras das grades (WATER ENVIRONMENT FEDERATION, 1998). Na Figura 2.6, pode ser observado que ao se diminuir o espaçamento entre as barras de grades grossas, as quantidades máxima e média de peneirado removidas aumentam exponencialmente. Outro fator importante é o procedimento de limpeza utilizado; as peneiras ou grades de limpeza mecânica retêm maior quantidade de peneirado, se comparadas àquelas de limpeza manual (WATER ENVIRONMENT FEDERATION, 1998).

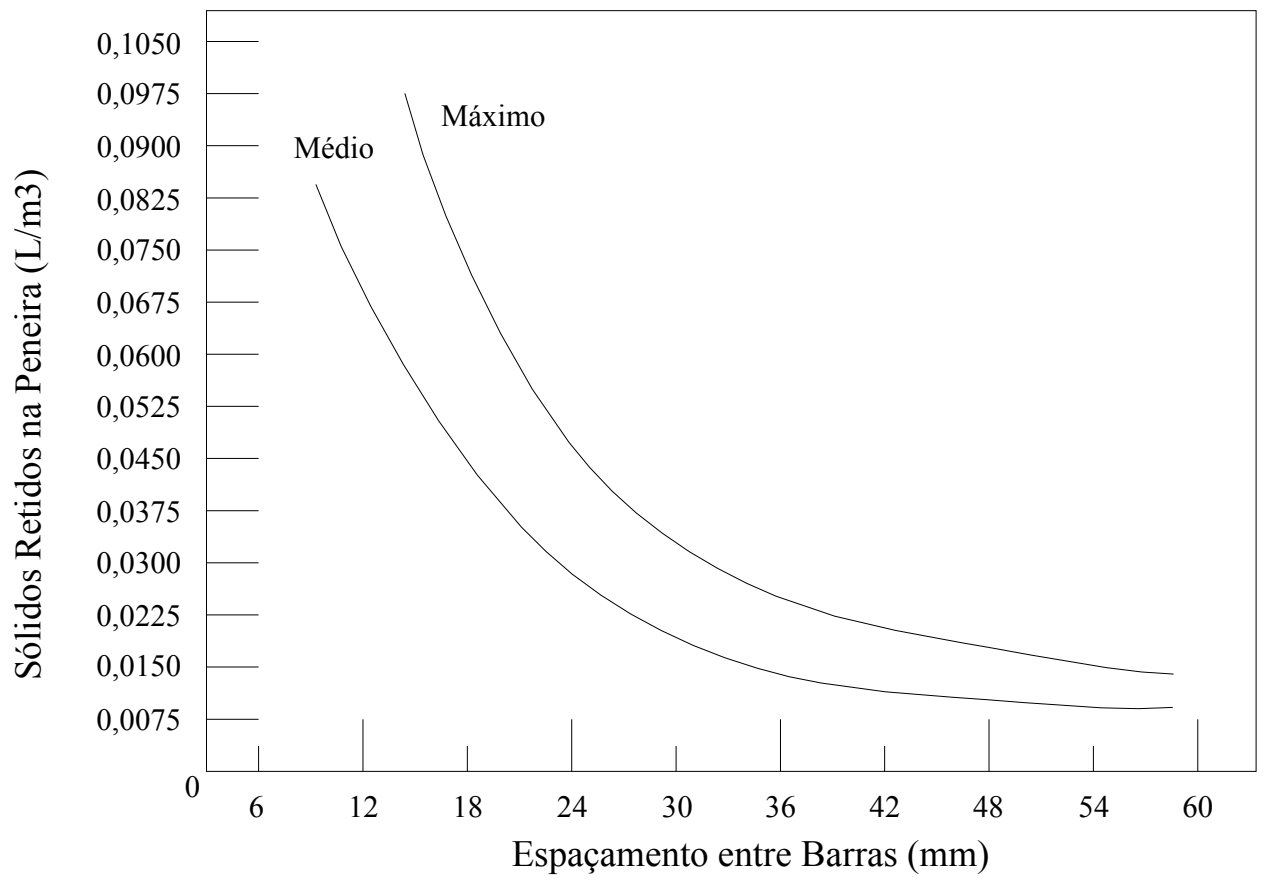

Figura 2.6 - Volumes máximo e médio de peneirado por volume de esgoto bruto em função do espaçamento entre barras. Dados obtidos de levantamento realizado em 133 ETEs dos Estados Unidos.

Fonte: Water Environment Federation (1998).

As características da bacia coletora têm maior influência na quantificação e composição do peneirado retido por grades e peneiras finas. Entre essas características, as que merecem maior destaque são (WATER ENVIRONMENT FEDERATION, 1994; WATER ENVIRONMENT FEDERATION, 1998): 
- O tamanho e tipo de ocupação da bacia, devido à correlação dessas características com a vazão e o tipo de material que chega à ETE;

- O tamanho do sistema de coleta de esgoto, pois em sistemas "longos" a degradação ocorrida ao longo das tubulações tende a diminuir a quantidade de material retido no gradeamento;

- A presença de estações elevatórias também diminui a quantidade de peneirado que adentra a ETE; pois parte dos sólidos é removida antes do bombeamento e a parcela que é bombeada junto com o esgoto tende a ter seus tamanhos reduzidos pela elevada turbulência provocada pelas bombas;

- O nível sócio-cultural e a educação sanitária da população atendida, porquanto, boa parte do material removido pelo gradeamento não deveria, nem sequer, ter entrado no sistema de coleta de esgotos. O brilhante professor José Martiniano de Azevedo Netto dizia em suas aulas: “... pode-se avaliar o nível cultural de uma comunidade, na grade e na peneira da estação de tratamento de esgoto local...".

O peneirado, tanto o de grades grossas como o de peneiras finas basicamente é composto por duas frações distintas: uma "orgânica", formada por material fecal, pedaços de comida, papel etc.; e outra predominantemente "não orgânica", na qual podem ser encontrados pedaços de plástico, pontas de cigarro, pequenos pedregulhos, entre outros. Na Tabela 2.1, são apresentadas algumas propriedades do peneirado retido por grades grossas, enquanto na Tabela 2.2, são mostrados valores médios e valores obtidos de sistemas de peneiramento com aberturas de $0,8 \mathrm{~mm}$ a $3,0 \mathrm{~mm}$ para as propriedades do peneirado retido em peneiras finas.

Tabela 2.1 - Algumas características do peneirado retido por grades grossas.

\begin{tabular}{lc}
\hline \multicolumn{1}{c}{ Itens } & Valores médios \\
\hline$\%$ de Sólidos Secos & $10 \%$ a $20 \%$ \\
Densidade aparente $\left(\rho_{\text {aparente }}\right)$ & $640 \mathrm{~kg} / \mathrm{m}^{3}$ a $1.100 \mathrm{~kg} / \mathrm{m}^{3}$ \\
$\%$ de Sólidos Voláteis & $70 \%$ a $95 \%$ \\
Valor Combustível & $12.600 \mathrm{~kJ} / \mathrm{kg}$ \\
\hline
\end{tabular}

Fonte: Water Environment Federation (1998). 
Tabela 2.2 - Algumas características do peneirado retido por peneiras finas. Valores médios e valores obtidos de peneiras com aberturas de $0,8 \mathrm{~mm}$ a $3,0 \mathrm{~mm}$.

\begin{tabular}{lcc}
\hline \multicolumn{1}{c}{ Itens } & $\begin{array}{c}\text { Valores } \\
\text { médios }\end{array}$ & $\begin{array}{c}\text { Peneiras finas } \\
\text { (aberturas de 0,8 mm a } \\
\mathbf{3 , 0} \mathbf{~ m m} \text { ) }\end{array}$ \\
\hline \% de Sólidos Secos & $10 \%$ a $20 \%$ & $8 \%$ a $23 \%$ \\
Densidade aparente $\left(\rho_{\text {aparente }}\right)$ & $640 \mathrm{~kg} / \mathrm{m}^{3}$ a $960 \mathrm{~kg} / \mathrm{m}^{3}$. & $850 \mathrm{~kg} / \mathrm{m}^{3}$ a $1.070 \mathrm{~kg} / \mathrm{m}^{3}$ \\
$\%$ de Sólidos Voláteis & $80 \%$ a $90 \%$ & $68 \%$ a $94 \%$ \\
Valor Combustível & $7.820 \mathrm{~kJ} / \mathrm{kg}$ & - \\
\hline
\end{tabular}

Fonte: Water Environment Federation (1998).

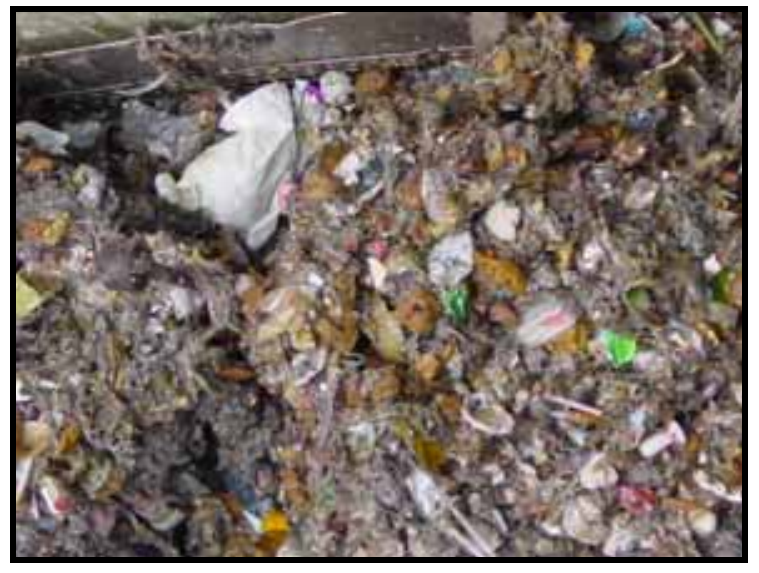

(a)

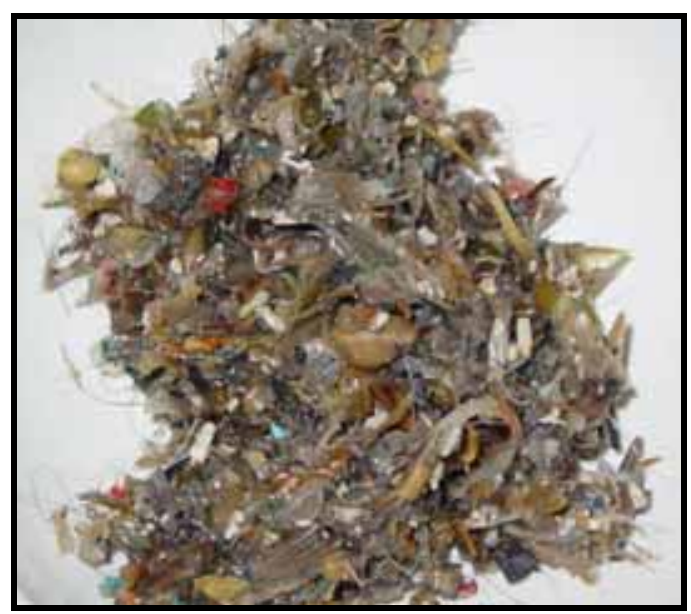

(c)

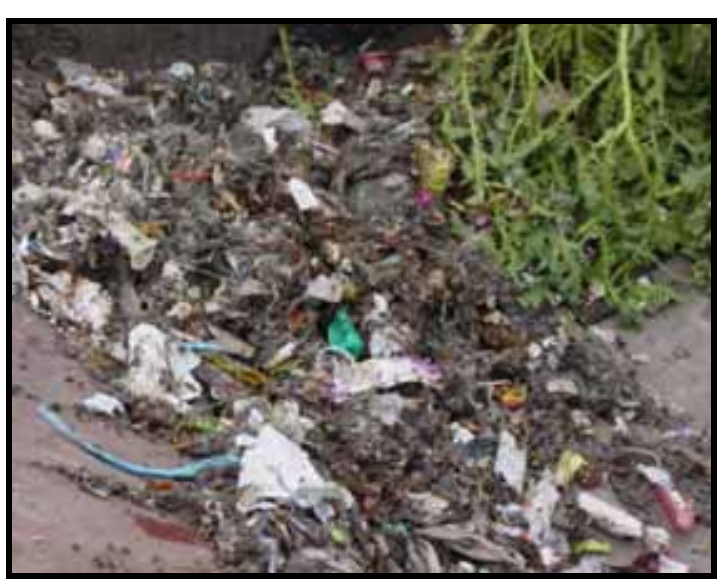

(b)

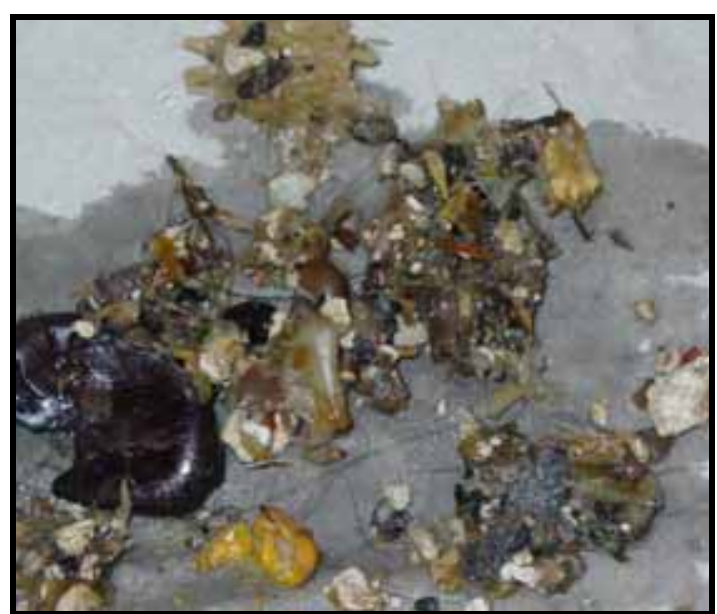

(d)

Figura 2.7 - Fotos de peneirados de grade grossa e peneira fina. Em (a) e (b) têm-se fotos do peneirado retido em grade com espaçamento entre barras de 20,0 mm. Em (c) vê-se uma foto de amostra de peneirado, coletada de peneira com aberturas de 2,0mm.

Em (d) pode ser observado o material retido em peneira fina de aberturas iguais a 2,0mm (Obs.: Fotos tiradas na ETE Jd. das Flores do Município de Rio Claro - SP). 
Apesar de aparentemente semelhantes, como pode ser observado pelas Tabelas 2.1 e 2.2 , o peneirado de grades grossas e o de peneiras finas são bastante distintos. O primeiro geralmente possui concentrações de compostos orgânicos inferiores àquelas encontradas no segundo, além do fato que os sólidos que o compõe são de dimensões até muitas vezes maiores. A Figura 2.7 demonstra claramente as diferenças visuais entre os dois tipos de peneirado. Nas duas primeiras fotos (a) e (b), pode-se observar a aparência dos sólidos removidos por uma grade grossa com espaçamento entre barras de $20,0 \mathrm{~mm}$, os quais são maiores e de natureza mais diversificada do que os retidos em uma peneira fina de abertura igual a 2,0 mm, mostrados pelas fotos (c) e (d).

O peneirado libera odores ofensivos, está contaminado pelos patógenos presentes no esgoto bruto e pode atrair insetos e roedores, caso não seja cuidadosamente manejado antes de sua disposição final. O destino final desses sólidos, freqüentemente, é o aterro sanitário (ou, indevidamente, o "lixão") mais próximo; porém, a legislação local vigente sempre deve ser consultada, pois a composição e volume do peneirado podem afetar ou até mesmo restringir sua disposição em aterros sanitários (WATER ENVIRONMENT FEDERATION, 1998).

\subsection{Os Desarenadores ou "Caixas de Areia”}

\subsubsection{Generalidades}

As "caixas de areia" ou desarenadores são sedimentadores que priorizam a remoção de sólidos abrasivos e não-putrescíveis, os quais chegam às estações de tratamento juntamente com o esgoto. De acordo com Metcalf \& Eddy (2003), as três principais funções dessas unidades são: i) prevenir o desgaste excessivo de equipamentos, provocado pela abrasão com o material particulado; ii) reduzir o acúmulo de detritos em tubulações e canais; e iii) diminuir a freqüência de limpeza de digestores anaeróbios e tanques de aeração, ocasionadas pela deposição de sólidos inertes em seus interiores. Para tanto, os desarenadores devem ser capazes de remover partículas densas $\left(\rho_{\mathrm{s}} \cong 2400 \mathrm{~kg} / \mathrm{m}^{3}\right.$ a $2600 \mathrm{~kg} / \mathrm{m}^{3}$ ) maiores que $0,15 \mathrm{~mm}$ ou pelo menos aquelas com tamanho superior a 0,20 mm (METCALF \& EDDY, 2003; HORVÁTH, 1994; WATER ENVIRONMENT FEDERATION, 1998). 


\subsubsection{Tipo de desarenadores ou "caixas de areia”}

Existe grande variedade de tipos de desarenadores, entre os quais, destacam-se quatro, por serem os mais utilizados; são eles: os desarenadores retangulares de escoamento horizontal; os desarenadores quadrados de escoamento horizontal; os desarenadores aerados e os desarenadores de remoção por vórtice ou separadores vorticosos.

Os desarenadores retangulares de escoamento horizontal são os mais antigos removedores de areia utilizados. Este tipo de unidade deve ser projetado de tal forma que velocidade média de escoamento horizontal do líquido no seu interior seja mantida praticamente constante e o mais próxima possível de $0,3 \mathrm{~m} / \mathrm{s}$. Consoante a Water Environment Federation (1998), a experiência operacional tem mostrado que tal velocidade mantém a matéria orgânica particulada menos densa, em suspensão e ressuspende aquela parcela que sedimentou, enquanto permite que partículas densas como grãos de areia sedimentem.

Tabela 2.3 - Vantagens e desvantagens do emprego de desarenadores retangulares de escoamento horizontal.

\section{Vantagens Desvantagens}

Possibilidade de se alterar o desempenho da unidade pelo ajuste do controle de escoamento na saída;

Unidade de fácil construção;

Quando operadas eficientemente, a areia removida não necessita ser lavada antes de sua disposição final.
Dificuldade de manter constante a velocidade horizontal de 0,3 m/s, quando há grande variação de vazão de entrada;

Desgaste excessivo dos mecanismos de limpeza que ficam submersos;

Se não for possível manter a velocidade horizontal de $0,3 \mathrm{~m} / \mathrm{s}$, significantes quantidades de matéria orgânica são removidas com a areia, que deverá ser lavada antes de ser disposta;

Os dispositivos de controle de escoamento, normalmente, requerem descarga livre, o que aumenta a perda de carga na unidade;

Os vertedores proporcionais podem provocar aumento da velocidade de escoamento no fundo do canal o que pode acarretar o carreamento de sedimentos já removidos. 
Como a vazão de esgoto de uma ETE varia não somente ao longo do dia como também ao longo do ano, os desarenadores retangulares de escoamento horizontal necessitam de algum sistema de controle de nível, para que o valor de sua velocidade média de escoamento horizontal possa ser mantido constante. Para tal função, comumente, são utilizados vertedores proporcionais (vertedor Sutro) ou calhas Parshall, o que justifica a designação de desarenadores de velocidade controlada, conferida a essas unidades com freqüência (METCALF \& EDDY, 2003; WATER ENVIRONMENT FEDERATION, 1998). Na Tabela 2.3 são listadas algumas vantagens e desvantagens da utilização dos desarenadores retangulares de escoamento horizontal no tratamento preliminar de esgotos.

Os desarenadores quadrados de escoamento horizontal são sedimentadores de nível constante, operados com tempos de detenção hidráulica inferiores a um minuto. Como essas unidades não são providas de dispositivo de controle de velocidade do escoamento, parte da matéria orgânica sedimenta durante os períodos de vazão baixa (valores próximos à vazão mínima da ETE); conseqüentemente, faz-se necessária a utilização de equipamentos para lavagem com posterior classificação da areia junto a essas unidades (WATER ENVIRONMENT FEDERATION, 1998). Na Tabela 2.4, são apresentadas vantagens e desvantagens do emprego desse tipo de desarenador.

Tabela 2.4 - Vantagens e desvantagens do emprego de desarenadores quadrados de escoamento horizontal.

\begin{tabular}{|c|c|}
\hline Vantagens & Desvantagens \\
\hline $\begin{array}{c}\text { Não há necessidade de controlar o } \\
\text { escoamento; }\end{array}$ & $\begin{array}{c}\text { Os anteparos de entrada não podem ser ajustados } \\
\text { para conseguir distribuição uniforme do escoamento } \\
\text { quando a vazão varia ao longo do dia. }\end{array}$ \\
\hline $\begin{array}{l}\text { Equipamentos de limpeza ficam } \\
\text { acima do nível d'água; }\end{array}$ & $\begin{array}{l}\text { Remoção de grande quantidade de material } \\
\text { orgânico junto com a areia quando as vazões } \\
\text { mínimas são atingidas, o que torna necessária a } \\
\text { lavagem da areia antes de sua disposição final. }\end{array}$ \\
\hline $\begin{array}{c}\text { A perda de carga ao longo da } \\
\text { unidade é mínima. }\end{array}$ & $\begin{array}{c}\text { Em unidades rasas, o raspador de fundo pode } \\
\text { causar perda de sólidos, devido à agitação } \\
\text { provocada por seu movimento. }\end{array}$ \\
\hline
\end{tabular}

Fonte: Water Environment Federation (1998). 
Os desarenadores aerados são sedimentadores, nos quais é introduzido ar difuso ao longo de uma de suas paredes laterais, próximo ao fundo da unidade. Esta aeração provoca um padrão helicoidal de escoamento, em forma de espiral, perpendicular ao eixo longitudinal de escoamento no desarenador, por conseqüência partículas densas, como os grãos de areia, são "lançadas" ao fundo da unidade, enquanto a matéria orgânica particulada é mantida em suspensão (METCALF \& EDDY, 2003; WATER ENVIRONMENT FEDERATION, 1998). A Figura 2.8 ilustra o padrão helicoidal de escoamento (em forma de espiral) desejável para desarenador aerado.

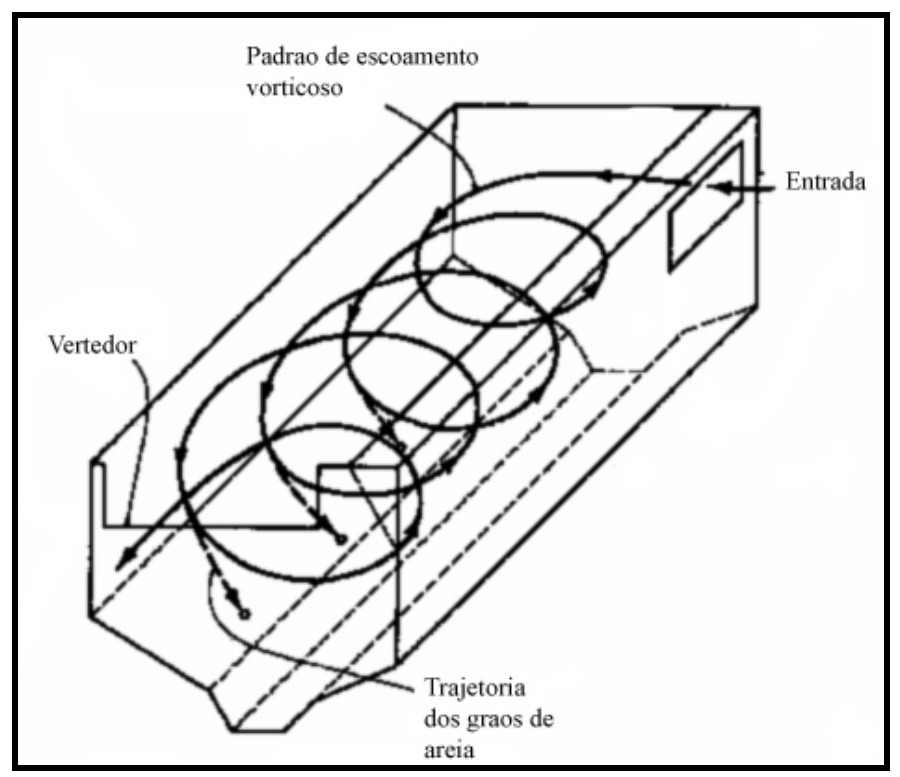

Figura 2.8 - Padrão de escoamento espiralar de um desarenador aerado. Fonte: Metcalf \& Eddy (1991)

Segundo Metcalf \& Eddy (2003) "o controle da velocidade do escoamento em forma de espiral 'governa' o tamanho da partícula (de determinada massa específica) que será removida pela unidade"; assim, a quantidade de ar utilizada deve ser devidamente ajustada para que não haja carreamento dos grãos de areia, nem remoção de matéria orgânica particulada. Outro fator importante a ser considerado no projeto dos desarenadores aerados é a presença, no esgoto bruto, de compostos orgânicos voláteis danosos à saúde humana. Estas substâncias podem ser liberadas via turbulência gerada por bolhas de ar emitidas pelos difusores. Nestes casos, os desarenadores aerados devem ser cobertos ou, preferencialmente, somente devem ser empregados se houver motivo específico que demande tal alternativa (WATER ENVIRONMENT FEDERATION, 1998). A Tabela 2.5 apresenta vantagens e desvantagens da utilização dessas unidades. 
Tabela 2.5 - Vantagens e desvantagens do emprego de desarenadores aerados.

\begin{tabular}{|c|c|}
\hline Vantagens & Desvantagens \\
\hline $\begin{array}{c}\text { Pode ser mantida a mesma eficiência } \\
\text { de remoção para ampla faixa de } \\
\text { vazões; }\end{array}$ & $\begin{array}{c}\text { Consumo de energia mais alto que o dos outros } \\
\text { tipos de caixa de areia; }\end{array}$ \\
\hline $\begin{array}{c}\text { A perda de carga ao longo da unidade } \\
\text { é mínima; }\end{array}$ & $\begin{array}{l}\text { Aumento do serviço de manutenção, devido à } \\
\text { presença do sistema de aeração; }\end{array}$ \\
\hline $\begin{array}{l}\text { O controle da vazão de ar empregada } \\
\text { pode permitir remoção areia com baixa } \\
\text { quantidade de material putrescível; }\end{array}$ & $\begin{array}{l}\text { Existe confusão quanto aos critérios de projeto } \\
\text { necessários para se conseguir um bom padrão } \\
\text { de escoamento em forma de espiral; }\end{array}$ \\
\hline $\begin{array}{c}\text { A pré-aeração pode aliviar as } \\
\text { condições sépticas do esgoto que chega } \\
\text { a ETE; }\end{array}$ & $\begin{array}{c}\text { Pode ocorrer liberação de compostos orgânicos } \\
\text { voláteis e odores ofensivos, potencialmente } \\
\text { perigosos. }\end{array}$ \\
\hline $\begin{array}{l}\text { Os desarenadores aerados podem } \\
\text { servir como: reatores de mistura para } \\
\text { adição de produtos químicos, pré- } \\
\text { aeradores e floculadores anteriores ao } \\
\text { tratamento primário. }\end{array}$ & \\
\hline
\end{tabular}

Fonte: Water Environment Federation (1998).

Os desarenadores de remoção por vórtice ou separadores vorticosos são unidades cilíndricas, nas quais o esgoto é introduzido tangencialmente, criando um padrão de escoamento helicoidal (espirálico) na direção do fundo da unidade. A separação sólido-líquido ocorre pela ação combinada de dois campos de aceleração: o gravitacional e o "centrífugo" (efeito da inércia das partículas).

Segundo Metcalf \& Eddy (2003), partículas de natureza orgânica com velocidades de sedimentação iguais as de grãos de areia, geralmente são 4 a 8 vezes maiores, o que corresponde a forças de arrasto 16 a 64 vezes maiores. Como resultado, partículas densas, como grãos de areia, são "lançadas" em direção às paredes externas da unidade devido à aceleração "centrífuga”, enquanto partículas de natureza orgânica, de menor densidade, permanecem suspensas no interior do escoamento e são transportadas para fora da unidade juntamente com o efluente.

Existem dois tipos básicos de unidades de separação por vórtice. Em um deles o escoamento vorticoso é gerado por turbina com hélices, como exemplificado na Figura 2.9(a); no outro, o jato provocado pela introdução do afluente através de um bocal 
posicionado tangencialmente ao corpo cilíndrico da unidade é responsável pela manutenção do padrão helicoidal de escoamento, como mostra a Figura 2.9(b).

Na Tabela 2.6, estão listadas algumas vantagens e desvantagens do emprego de separadores por vórtice como unidades de desarenação de esgotos.

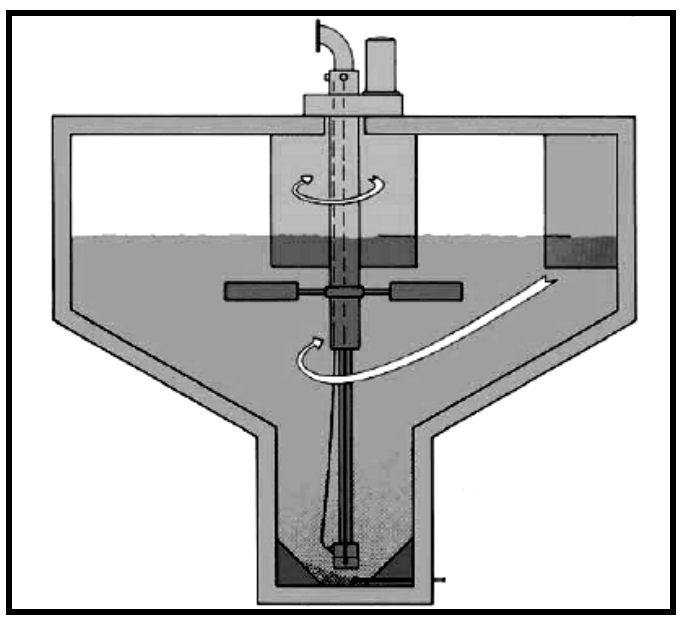

(a)

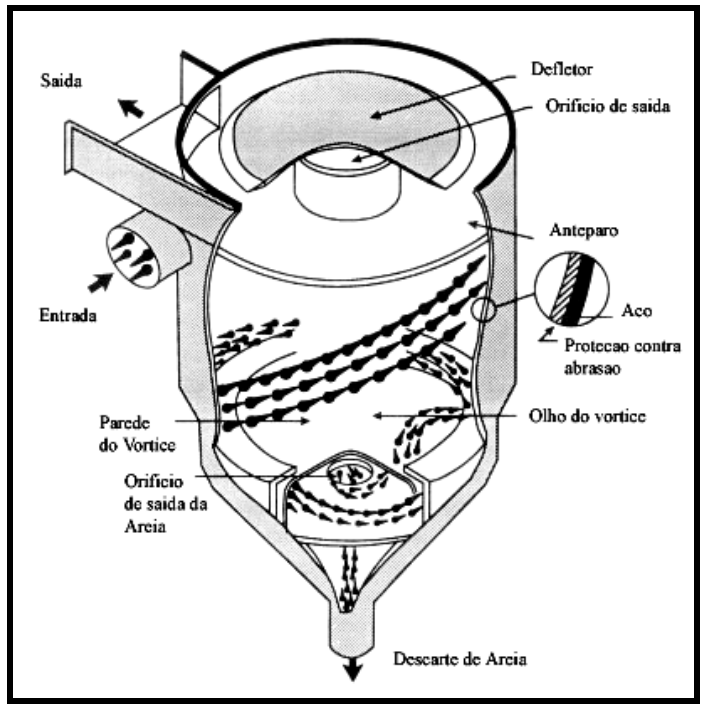

(b)

Figura 2.9 - Separadores vorticosos: (a) Mectan ${ }^{\circledR}$ da John Meunier Inc. (vórtice gerado por turbina); (b) Teacup ${ }^{\circledR}$ da Eutek (vórtice gerado por jato). Fonte: Metcalf \& Eddy (2003).

Tabela 2.6 - Vantagens e desvantagens do emprego de desarenadores de remoção por vórtice ou separadores por vórtice.

\begin{tabular}{|c|c|}
\hline Vantagens & Desvantagens \\
\hline $\begin{array}{c}\text { Eficiente, mesmo com grande } \\
\text { variação da vazão; }\end{array}$ & $\begin{array}{c}\text { O projeto da unidade é realizado pela empresa que } \\
\text { a comercia; }\end{array}$ \\
\hline $\begin{array}{l}\text { Nenhuma parte mecânica submersa } \\
\text { necessita manutenção; }\end{array}$ & $\begin{array}{c}\text { Alguns tipos de unidade possuem agitadores, o que } \\
\text { pode ocasionar acúmulo de trapos em suas } \\
\text { hélices; }\end{array}$ \\
\hline $\begin{array}{l}\text { Requer espaço mínimo, quando } \\
\text { comparado aos demais tipos de } \\
\text { desarenadores; }\end{array}$ & $\begin{array}{c}\text { A areia retida na região de acúmulo pode } \\
\text { compactar-se, sendo necessário a utilização de } \\
\text { equipamentos de alta pressão para ressuspendê-la } \\
\text { e, posteriormente, removê-la. }\end{array}$ \\
\hline \multicolumn{2}{|l|}{ Baixa perda de carga; } \\
\hline $\begin{array}{l}\text { Possibilidade de se remover sólidos } \\
\text { mais finos, da ordem de } 0,11 \mathrm{~mm} \text {, } \\
\text { com relativa eficiência. }\end{array}$ & \\
\hline
\end{tabular}

Fonte: Water Environment Federation (1998). 


\subsubsection{Quantidade e característica do material retido nos desarenadores}

Metcalf \& Eddy (2003) asseveram que a quantidade (concentração) de areia presente nas águas residuárias depende: (i) do tipo de sistema de coleta e transporte de esgotos (sistema combinado, água pluvial e esgoto sanitário; ou sistema de separação absoluta, somente esgoto sanitário); (ii) do tipo de ocupação da bacia coletora de esgoto atendida pelo sistema de coleta (residencial, industrial, comercial, etc.); (iii) das condições de conservação do sistema de coleta e transporte de esgotos; e (iv) do tipo de solo da bacia coletora de esgotos (presença de solos arenosos).

O tipo do sistema de coleta de esgoto é o fator que mais influencia a concentração de areia presente nas águas residuárias pois, em sistemas combinados, o escoamento superficial (runoff) carreia grandes quantidades de areia para dentro dos coletores e, mais, as elevadas vazões coletadas durante os períodos chuvosos ressuspendem as partículas que haviam sedimentado ao longo das tubulações durante os períodos de estiagem. Outro fator importante, que também merece destaque, é a condição de conservação do sistema coletor. Sistemas mal conservados permitem que grãos de areia adentrem suas tubulações pela infiltração. No Brasil, como a maioria dos sistemas de coleta de esgoto existentes é do tipo separador absoluto, os fatores que mais influenciam a concentração de areia presente no esgoto sanitário são: o estado de conservação dos sistemas de coleta de esgoto e a ocorrência de ligações clandestinas de coletores residenciais de águas pluviais aos coletores de esgoto sanitário.

Existem, ainda, poucos dados acerca da quantidade de areia removida nas unidades de desarenação; os poucos existentes correspondem a levantamentos realizados em vinte duas ETEs dos Estados Unidos, como os dados apresentados na Tabela 2.7 .

Caso não seja possível determinar a quantidade de areia presente no esgoto bruto do local, a Water Environment Federation (1998) recomenda o uso de valores entre $0,0041 / \mathrm{m}^{3}$. e $0,0371 / \mathrm{m}^{3}$. como estimativas, enquanto Metcalf \& Eddy (2003) apresentam $0,015 \mathrm{l} / \mathrm{m}^{3}$. como o valor, tipicamente, empregado por projetistas, o qual é muito próximo a $0,0141 / \mathrm{m}^{3}$ - média ponderada extraída dos dados da Tabela 2.7 . 
O material arenoso removido pelos desarenadores, geralmente, possui entre $35 \%$ a $80 \%$ de sólidos na fase seca, e de $1 \%$ a $55 \%$ de sólidos voláteis, dependendo do tipo de desarenador utilizado (METCALF \& EDDY, 2003; WATER ENVIRONMENT FEDERATION, 1998). Por permanecer imerso no esgoto, esse material está contaminado por organismos patogênicos, libera odores ofensivos, além de atrair insetos e roedores. A areia acumulada nos desarenadores deve ser lavada — caso contenha matéria orgânica particulada que fora juntamente removida — depois desaguada e, por fim, disposta em aterro sanitário.

Tabela 2.7 - Quantidade de areia, obtida de levantamento feito em vinte duas ETEs dos Estados Unidos, que recebem esgoto de sistemas de coleta do tipo separador absoluto.

\begin{tabular}{|c|c|c|c|}
\hline ETEs dos EUA & $\begin{array}{l}\text { Vazão } \\
\text { m³/dia }^{3}\end{array}$ & $\begin{array}{c}\text { Areia } \\
\mathbf{L} / \mathbf{m}^{3}\end{array}$ & $\begin{array}{l}\text { Areia } \\
\text { L/dia }\end{array}$ \\
\hline Norwalk & 44.474 & 0,0250 & 1.112 \\
\hline Portsmouth & 36.715 & 0,0030 & 110 \\
\hline East Hartford & 15.140 & 0,0180 & 273 \\
\hline Oklahoma City & 94.625 & 0,0150 & 1.419 \\
\hline Waterbury & 56.775 & 0,0300 & 1.703 \\
\hline Duluth & 45.420 & 0,0060 & 273 \\
\hline East Bay & 484.480 & 0,0095 & 4.578 \\
\hline Chicago & 3.440 .000 & 0,0031 & 10.578 \\
\hline New York (Jamaica) & 378.500 & 0,0168 & 6.359 \\
\hline New York (Port Richmond) & 227.100 & 0,0038 & 852 \\
\hline New York (North River) & 832.700 & 0,0113 & 9.368 \\
\hline Boston & 423.920 & 0,0051 & 2.162 \\
\hline St. Louis & 632.095 & 0,0202 & 12.753 \\
\hline $\begin{array}{c}\text { Passaic Valley Treatment } \\
\text { Plant }\end{array}$ & 851.625 & 0,0287 & 24.399 \\
\hline Allegheny County & 757.000 & 0,0249 & 18.849 \\
\hline Forth Worth & 170.325 & 0,0097 & 1.648 \\
\hline County of Milwaukee & 454.200 & 0,0036 & 1.635 \\
\hline Twin City Metro & 825.130 & 0,0362 & 29.828 \\
\hline San Jose & 541.255 & 0,0188 & 10.149 \\
\hline Los Angeles (Hyperion) & 1.589 .700 & 0,0150 & 23.846 \\
\hline Santa Rosa & 45.420 & 0,0375 & 1.703 \\
\hline Livermore & 23.656 & 0,0075 & 177 \\
\hline
\end{tabular}

Fonte: Water Environment Federation (1998). 


\subsection{Separadores Hidrodinânicos por Vórtice}

\subsubsection{Generalidades}

Devido ao fato de um separador hidrodinâmico por vórtice (SHV) ser o tema central dessa tese, faz-se necessário que esse tipo de unidade seja apresentado de forma mais aprofundada, de modo que os leitores possam compreender os princípios que regem seu funcionamento. Nas seções seguintes serão expostos: um breve histórico dos SHVs; alguns conceitos acerca do escoamento que se desenvolve no interior dessas unidades e dos mecanismos de separação sólido-líquido envolvidos; a aplicabilidade dos SHVs na área de tratamento de águas residuárias e, finalmente, o protótipo do SHV desenvolvido para este trabalho de pesquisa.

\subsubsection{Histórico dos separadores hidrodinâmicos por vórtice}

Os separadores hidrodinâmicos por vórtice (SHVs), i.e. unidades cujo princípio de separação baseia-se no movimento circular de um fluído dentro de um recipiente, são empregados como unidades de separação sólido-líquido ou líquido-líquido há mais de 114 anos. Consoante Svarovsky (1984), a primeira patente de hidrociclone, que é um tipo de SHV, foi registrada nos Estados Unidos em 1891, por Bretney (U.S.Patent $\mathrm{n}^{\mathrm{o}}$ 453.105); contudo, foi apenas após o término da II Guerra Mundial, que esse tipo de unidade começou a ser utilizado pela indústria. Segundo o mesmo autor, a indústria da mineração foi a primeira a empregar SHVs, seguida pelas indústrias petroquímica, de geração de energia, têxtil e de acabamento de metais.

Os SHVs ganharam notoriedade na indústria da água depois da publicação do trabalho de Gierger (1942), que usou este tipo de unidade para a remoção de partículas sólidas presentes em afluentes de estações de tratamento de esgoto (ETEs). Na década seguinte, Bernard Smisson iniciou suas pesquisas com modelos reduzidos de SHVs, que culminaram na instalação de uma unidade em escala plena na cidade de Bristol, Reino Unido (UK), no início da década de 1960. Essa unidade tinha como objetivo remover sólidos de sistemas de coleta de esgoto do tipo coletor unitário (água de drenagem urbana mais esgoto sanitário), bem como atenuar picos de vazão dentro desses sistemas 
de coleta, de forma a evitar extravasamentos e inundações subseqüentes (SMISSON, 1967).

De acordo com Andoh (1998), Smisson continuou suas pesquisas sobre SHVs durante a década de 1970, como consultor da American Public Works Association (APWA). Desse trabalho, resultou o desenvolvimento da segunda geração de unidades de separação por vórtice, projetadas para diminuir os curtos-circuitos hidráulicos observados nas unidades de primeira geração. Tal evolução aumentou a eficiência de remoção de sólidos sedimentáveis dos SHVs, e rendeu à Environmental Protection Agency (EPA) americana a patente de duas unidades, o USEPA Swirl Concentrator e o USEPA Swirl Degritter.

De volta ao Reino Unido no início de 1980, Smisson ajudou a desenvolver a atual geração de SHVs, e.g.: Storm King Overflow, Grit King Separator e Swirl-Flow Separator. Essas unidades de terceira geração passaram a ter elementos internos, como anteparos e defletores, os quais auxiliam a estabilização do padrão de escoamento desenvolvido em seus interiores, aumentando a eficiência na remoção de sólidos, e diminuindo a perda de carga nos SHVs (Figura 2.10) (ANDOH e SMISSON, 1993; ANDOH, 1998).

O desenvolvimento de SHVs não se restringiu aos Estados Unidos e Reino Unido. Em meados de 1980, tiveram início, na Alemanha, estudos sobre os SHVs, que visavam à diminuição da turbulência que se desenvolvia dentro dessas unidades, principalmente, quando eram operadas com vazões altas. O resultado dessas pesquisas foi a proposição de uma nova unidade de separação por vórtice, patenteada com o nome de Fluidsep (Figura 2.10(a)) (BROMBACH ${ }^{1} .1992$ apud ANDOH e SAUL, 2003).

Com a introdução da Urban Wastewater Treatment Directive (Norma para Tratamento de Águas Residuárias Urbanas) na Europa, no início de 1990, foram impostas severas restrições ao lançamento de águas residuárias urbanas em corpos receptores. Uma delas refere-se à presença de sólidos flutuantes (sólidos flotáveis), como: trapos, materiais fibrosos, pedaços de plástico, preservativos masculinos etc., nos

1 BROMBACH, H. (1992). Solids removal from combined sewer overflows with vortex separators. Proceedings of NOVATECH '92 - International Conference on Innovative Technologies in the Domain of Urban Water Drainage. 15p., 8-13 September, Portland, Oregon, USA. 
efluentes líquidos a serem descartados. Apesar de tais sólidos, geralmente, não exercerem demandas de oxigênio nos corpos receptores, provocam prejuízo à estética, a "poluição" visual. Em resposta a essa imposição legal, no Reino Unido, foram desenvolvidos SHVs de quarta geração, aos quais acoplaram-se sistemas de peneiramento (aberturas de 4,0 $\mathrm{mm}$ a $6,0 \mathrm{~mm}$ ), que tiram proveito do padrão de escoamento desenvolvido nos SHVs para promover a limpeza das peneiras (selfcleansing system) (Figura 2.10(b)) (ANDOH, 1998; ANDOH e SAUL, 2003).

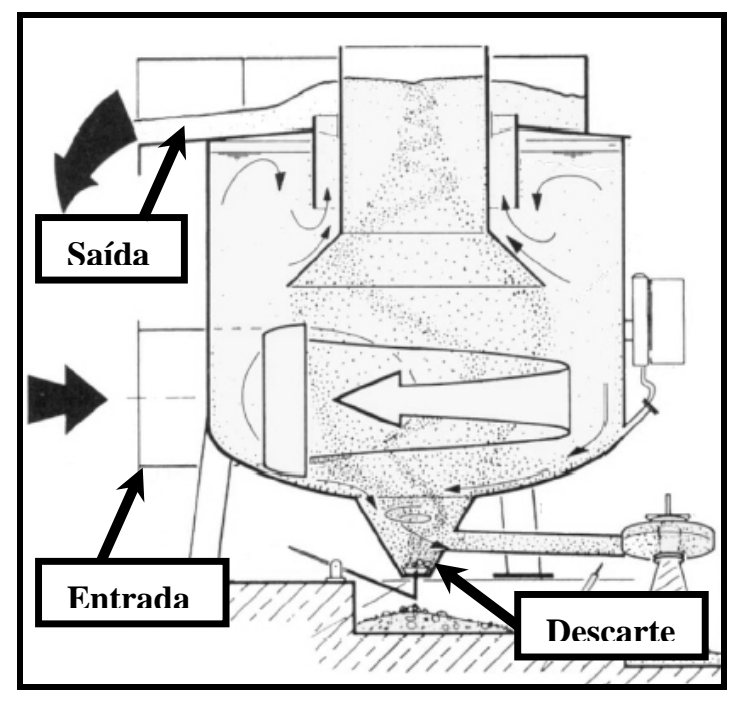

(a)

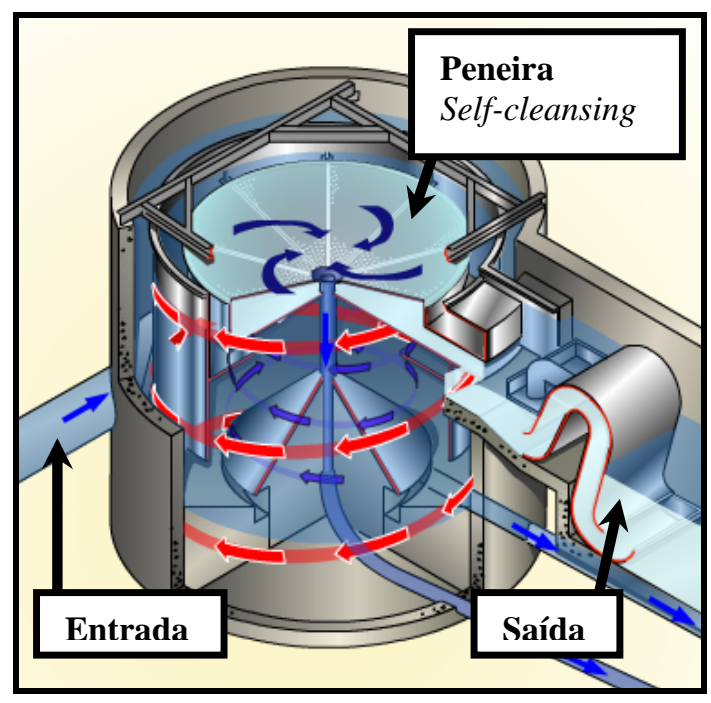

(b)

Figura 2.10 - Exemplos de SHVs: (a) seção transversal de um Fluidsep; (b) ilustração de Storm King Overflow com sistema de peneiramento do tipo self-cleansing. Fonte: John Meunier, Inc. (sem data) e Hydro International (sem data).

\subsubsection{Conceitos básicos sobre os separadores hidrodinâmicos por vórtice}

\subsubsection{Considerações iniciais}

Os separadores hidrodinâmicos por vórtice (SHVs) são unidades de separação por vórtice, assim como as centrífugas e os separadores por vórtice induzido por turbinas (Figura 2.9a)). Todavia, diferentemente das últimas unidades citadas, a energia necessária para gerar o padrão circular de escoamento dentro dos SHVs provém, unicamente, da própria energia cinética do escoamento, i.e. a tubulação de entrada é 
disposta tangencialmente em um corpo cilíndrico, fazendo com que o líquido que entra na unidade descreva trajetórias helicoidais para baixo, que mudam de direção no fundo da unidade, dirigindo-se em trajetórias também helicoidais, porém com sentido oposto, isto é, para cima, como mostra a Figura 2.11 (SVAROVSKY, 1984).

O movimento helicoidal do líquido dentro dos SHVs, de certa forma, suplementa a força da gravidade que age sobre as partículas suspensas no meio líquido e mais importante do que isso, esse movimento "obriga" o fluído a percorrer trajetórias muito mais longas do que a distância entre a entrada e a saída das unidades, aumentando o tempo em que as forças de campo (força peso e força centrífuga) atuam sobre as partículas (SMISSON, 1967; SVAROVSKY, 1984; ANDOH e SMISSON, 1993; ANDOH, 1998).

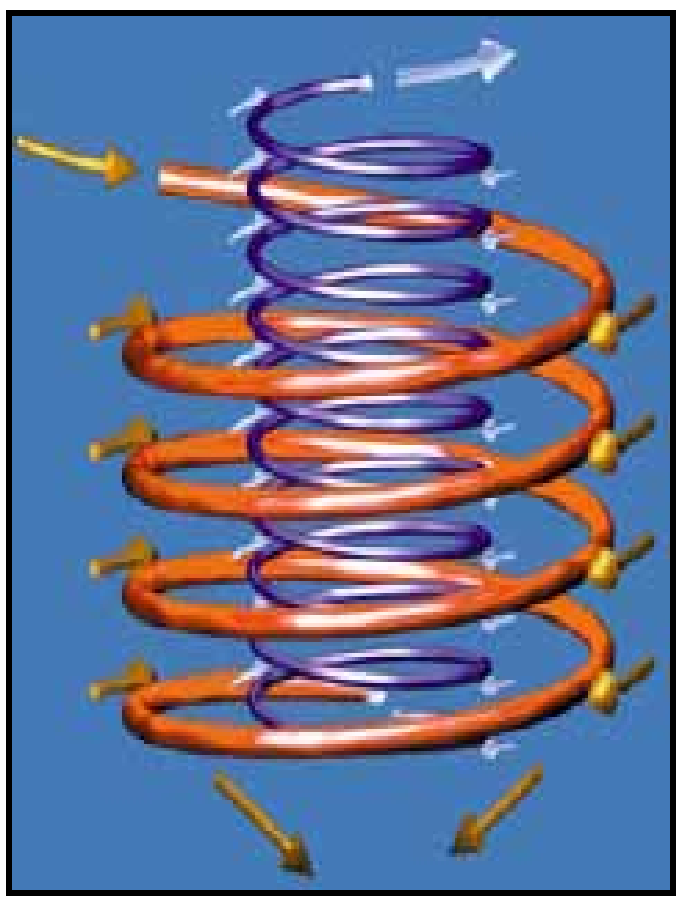

Figura 2.11 - Esquema do padrão de escoamento desenvolvido dentro dos SHVs. Fonte: HYNDS Environmental (sem data)

O princípio de separação sólido-líquido dos SHVs baseia-se no movimento helicoidal do meio fluído e nas diferenças de densidade: entre os sólidos e o líquido e entre as próprias partículas sólidas suspensas no meio líquido, pois os SHVs, além de serem separadores sólido-líquido, são capazes de classificar partículas por diferença de densidade, ou seja, separar de forma seletiva as partículas mais densas como os grãos de areia, daquelas de menor densidade como as partículas orgânicas. 
Partículas densas (i.e. com massa específica muito maior que a da água), quando suspensas em um líquido (e.g. água residuária) que se movimenta helicoidalmente, experimentam a ação de um campo de aceleração "centrífuga" (efeito da inércia das partículas), além do gravitacional. O campo de aceleração "centrífuga" faz com que essas partículas concentrem-se próximo à parede externa (cilindro externo) dos SHVs, onde o líquido movimenta-se helicoidalmente para baixo. Nessa região, a ação do campo de aceleração gravitacional somado ao próprio movimento do meio líquido, conduzem as partículas densas para o fundo dos SHVs, onde o escoamento secundário (recirculação no fundo da unidade), provocado por efeitos de camada limite, faz com que essas partículas sejam impelidas para uma zona de acúmulo de sólidos, de onde, posteriormente, são descartadas. (Figura 2.12) (SMISSON, 1967; ANDOH e SMISSON, 1993).

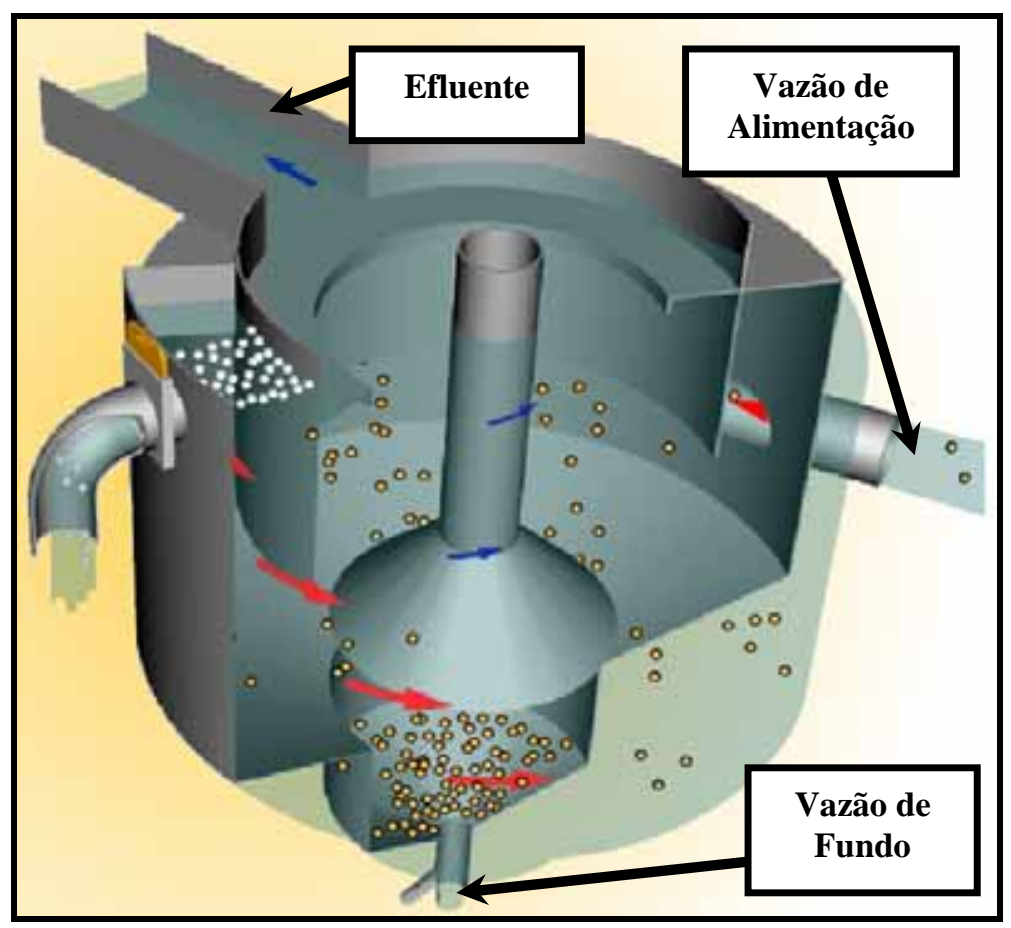

Figura 2.12 - Esquema ilustrativo do funcionamento de um SHV (Grit King Dynamic Separator da Hydro International).

Fonte: Hydro International (sem data)

Partículas de menor densidade (i.e. com massa específica próxima à da água), como por exemplo, sólidos orgânicos, sofrem a ação do campo de aceleração “centrífuga” em escala muito pequena, pois não possuem massa específica suficiente para vencer a força de arrasto exercida pelo meio líquido. Uma partícula orgânica com massa específica igual a $1.100 \mathrm{~kg} / \mathrm{m}^{3}$, que tenha a mesma velocidade terminal de 
sedimentação de um grão de areia de massa específica igual a $2.600 \mathrm{~kg} / \mathrm{m}^{3}$. será aproximadamente 15 vezes maior, portanto, sofrerá a ação de uma força de arraste 225 vezes maior.

Em recente pesquisa, Veerapen et al. (2005) comprovaram, por meio de simulações computacionais e ensaios com um SHV em escala piloto, aquilo que Andoh e Smisson (1993) já haviam conjecturado, isto é, que a separação sólido-líquido que ocorre nos SHVs utilizados em estações de tratamento de água (ETAs) e em estações de tratamento de esgoto (ETEs), preponderantemente, é resultado da ação do campo de aceleração gravitacional sobre as partículas suspensas no afluente da unidade, e que cabe ao campo de aceleração "centrífuga" (efeito da inércia das partículas) um papel secundário. Essa característica difere os SHVs empregados em ETEs e ETAs dos hidrociclones, pois nestas unidades a separação sólido-líquido resulta, unicamente, da ação do campo de aceleração "centrífuga" (efeito da inércia das partículas). Por essa razão, Veerapen et al. (2005) assevera que se deve evitar o emprego de conceitos utilizados para o projeto hidrociclones no projeto SHVs destinados à indústria da água.

\subsubsection{A velocidade tangencial do líquido em separadores hidrodinâmicos por vórtice}

Segundo Rushton et al. (1996), no campo de velocidade, a velocidade tangencial é a componente que tem maior influência no processo de separação ocorrido em SHVs, posto ser a responsável pelo campo de aceleração "centrífuga" (efeito da inércia das partículas) experimentado pelas partículas suspensas nos afluentes dessas unidades.

Svarovsky (1984) apresenta a Equação 2.1 como possível representação da velocidade tangencial do líquido em determinado círculo (mesmo raio) dentro de um SHV. O expoente " $n$ " da Equação 2.1 pode variar entre 0,5 e 0,9 para hidrociclones, entretanto, quando estas unidades são operadas com cargas hidráulicas (i.e. perda de carga na unidade) da ordem de $3,06 \mathrm{~m}$; as quais são consideradas bem baixas para o padrão normalmente empregado em hidrociclones, que é da ordem de algumas dezenas de metros (ANDOH e SAUL, 2003), o expoente " $n$ " varia de 0,2 a 0,4. Vale lembrar, que nada consta na literatura sobre o expoente "n", para SHVs operados com cargas 
hidráulicas ainda menores, da ordem de um metro de coluna d'água ou menos, as quais são bastante comuns quando essas unidades são empregadas como desarenadores.

$$
\mathrm{v}_{\mathrm{t}} \cdot \mathrm{r}^{\mathrm{n}}=\text { const. }
$$

Em que:

$\mathrm{V}_{\mathrm{t}}$ : velocidade tangencial $\left({\mathrm{L} . \mathrm{T}^{-1}}^{-1}\right)$;

r: raio do hidrociclone $(\mathrm{L})$;

n: expoente determinado empiricamente.

Svarovsky (1984) também salienta que ao se fazer o expoente " $n$ " da Equação 2.1 igual a 1, obtém-se a equação da velocidade tangencial para vórtices livres; e ao se fazer o expoente " $n$ " igual a -1, o resultado é a equação da velocidade tangencial para vórtices forçados. Muitos autores discutem o escoamento nos SHVs em termos desses padrões de escoamento idealizados (fluídos não-viscosos) (SMISSON, 1967; SVAROVSKY, 1984; PAUL et al., 1989). Smisson (1967) observou, em seus primeiros experimentos com modelos reduzidos de SHVs, superfícies livres com perfis parabólicos, compatíveis com aqueles formados em vórtices forçados, os quais tem início junto à parede externa da unidade, e se estendiam até a região central, onde a superfície livre tornava-se elíptica, compatível com aquelas formadas em vórtices livres. Não obstante, Svarovsky (1984) e Paul et al. (1989), encontraram o oposto do observado por Smisson (1967). Ambos atestam a formação de vórtices livres na parte externa de seus SHVs e vórtices forçados na região central.

Consoante Casamassa Neto (1991), esta combinação observada por Svarovsky (1984) e Paul et al. (1989), i.e. vórtice livre na parte externa da unidade e vórtice forçado na interna; já foi bastante estudada, e recebeu o nome de vórtice combinado de Rankine. Casamassa Neto (1991), também afirma que as velocidades tangenciais na região central de "vórtices livres" são altas e, como resultado disso, o atrito viscoso nesta região, também é elevado. Tal atrito viscoso traduz-se em: perda de carga, gradientes de velocidade e rebaixamento da superfície livre na região central do vórtice. Outra conseqüência desse elevado atrito viscoso é a rotação do núcleo do vórtice ao 
redor de seu próprio eixo, como se fosse um corpo rígido. Este movimento circular dos elementos de fluído similar a corpos rígidos rotacionando é chamado vórtice forçado. A Figura 2.13 mostra o esquema da superfície livre de vórtices combinados de Rankine, assim como o perfil de velocidade tangencial esperado.

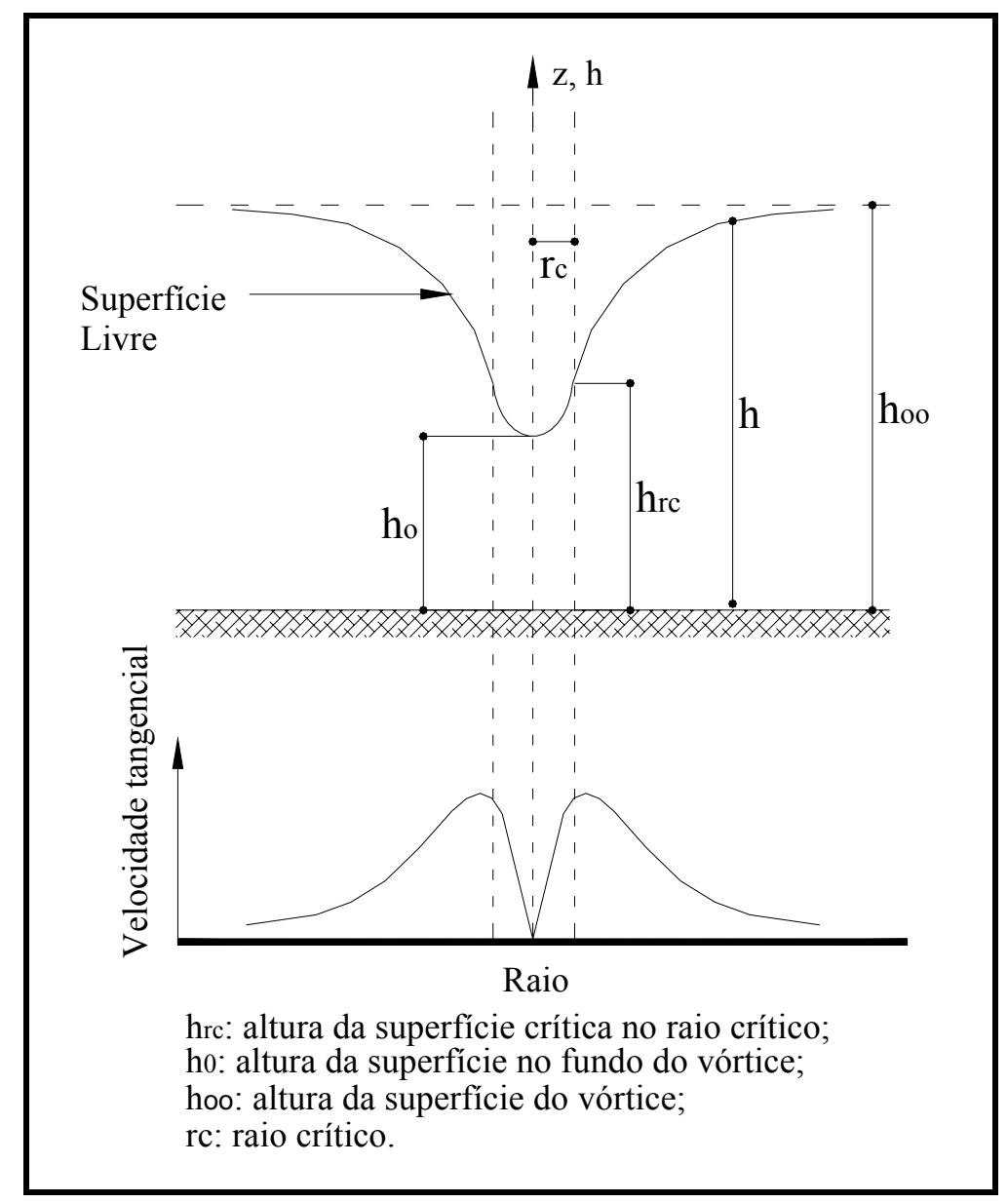

Figura 2.13 - Esboço da superfície livre em um vórtice combinado de Rankine, e o perfil de velocidade tangencial esperado.

Fonte: Casamassa Neto (1991)

Cruzando as afirmações de Casamassa Neto (1991) com o resultado das observações de Smisson (1967), Svarovsky (1984) e Paul et al. (1989) há de se supor mais coerente o constatado pelos dois últimos trabalhos, porquanto, como já foi dito, os vórtices forçados ocorrem quando velocidades tangenciais nos vórtices são suficientemente elevadas, de forma que o atrito viscoso faça com que a massa líquida rotacione como um corpo rígido; porém, para serem mantidos valores de velocidade tangencial elevados na parte externa de SHVs, seria necessário cargas hidráulicas elevadíssimas em sua entrada, fato, normalmente, raro nas condições operacionais experimentadas por esse tipo de unidade (menos de 1,0 m) (ANDOH e SAUL, 2003). 
Assumindo que o padrão de escoamento nos SHVs assemelha-se ao vórtice combinado de Rankine, a velocidade tangencial em dado raio (r) da unidade, pode ser estimada pelas equações apresentadas logo abaixo (KNAUSS, 1987).

$$
\begin{aligned}
& \mathrm{v}_{\mathrm{t}}=\mathrm{r} . \omega \quad \text { para } \quad \mathrm{r}<\mathrm{r}_{\mathrm{c}} \text { (vórtice forçado) } \\
& \mathrm{v}_{\mathrm{t}}=\frac{\mathrm{C}}{\mathrm{r}} \quad \text { para } \quad \mathrm{r}>\mathrm{r}_{\mathrm{c}} \text { (vórtice livre) } \\
& \mathrm{C}=\frac{\Gamma}{2 \cdot \pi} \\
& \Gamma=2 . \pi \cdot \mathrm{r}_{\mathrm{t}}
\end{aligned}
$$

Em que:

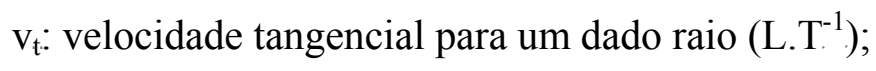

r: raio qualquer do vórtice $(\mathrm{L})$;

$\omega:$ rotação do vórtice $\left(\operatorname{rad} . \mathrm{T}^{-1}\right)$;

$\mathrm{C}$ : constante que mede a intensidade do vórtice livre $\left(\mathrm{L}^{2} \cdot \mathrm{T}^{-1}\right)$;

$\Gamma$ : circulação no núcleo do vórtice $\left(\mathrm{L}^{2} \cdot \mathrm{T}^{-1}\right)$

O raio no qual a velocidade tangencial é máxima $\left(\mathrm{r}_{\mathrm{c}}\right.$ ) (Figura 2.13) pode ser determinado igualando-se as Equações 2.2 e 2.3 (CASAMASSA NETO, 1991).

$$
r_{c}=\sqrt{\left(\frac{C}{\omega}\right)}
$$

A altura do vórtice forçado $\left(\mathrm{h}_{\mathrm{rc}}-\mathrm{h}_{\mathrm{o}}\right)$ pode ser estimada pela Equação 2.7 (CASAMASSA NETO, 1991). 


$$
\mathrm{h}_{\mathrm{rc}}-\mathrm{h}_{\mathrm{o}}=\frac{\mathrm{v}_{\mathrm{c}}^{2}}{2 \cdot \mathrm{g}}=\frac{\mathrm{r}_{\mathrm{c}}^{2} \cdot \omega^{2}}{2 \cdot \mathrm{g}}
$$

Em que:

$\mathrm{h}_{\mathrm{rc}}$ : altura do ponto de transição entre vórtice forçado e livre (Figura 2.13) (L);

$\mathrm{h}_{\mathrm{o}}$ : altura do fundo do vórtice forçado (Figura 2.13) (L);

$\mathrm{V}_{\mathrm{c}}$ : velocidade tangencial no ponto de transição $\left(\mathrm{L} . \mathrm{T}^{-1}\right)$;

g: aceleração da gravidade;

A altura do vórtice livre pode ser estimada pela Equação 2.8 (CASAMASSA NETO, 1991).

$$
\mathrm{h}_{\infty}-\mathrm{h}_{\mathrm{rc}}=\frac{\mathrm{C}^{2}}{2 \cdot \mathrm{g}} \cdot\left(\frac{1}{\mathrm{r}_{\mathrm{c}}^{2}}-\frac{1}{\mathrm{R}^{2}}\right)
$$

Em que:

R: diâmetro do vórtice livre(L);

$\mathrm{h}_{\infty}$ : altura em que $\mathrm{r}$ é igual ao raio do vórtice $(\mathrm{L})$;

\subsubsection{Velocidade radial do líquido em separadores hidrodinâmicos por vórtice}

Rushton et al. (1996) reportam que a velocidade radial do líquido ( $\mathrm{v}_{\mathrm{r}}$ ) difere, substancialmente, da velocidade radial das partículas suspensas no meio líquido, prova disso é a diferença de concentração de sólidos entre o afluente e o efluente de SHVs. Enquanto o líquido movimenta-se no sentido do centro da unidade, parte dos sólidos move-se no sentido oposto. Esta afirmação, pode ser considerada verdadeira para uma análise global da distribuição de velocidades radiais dentro de SHVs pois, pela lei da 
continuidade, todo fluído que entra nessas unidades, através de bocais de entrada, fixados tangencialmente em suas paredes externas, será obrigado a dirigir-se ao centro das mesmas, pois é lá que se localizam suas saídas. Porém, em uma análise local da distribuição de velocidades radiais de SHVs, Svarovsky (1984) constatou que, apesar de pequena, esta componente do campo de velocidade apresenta flutuações tanto em sua intensidade, como em seu sentido.

Casamassa Neto (1991) assevera ser possível estimar velocidades radiais médias $\left(\mathrm{v}_{\mathrm{rm}}\right)$ para diferentes raios $(\mathrm{r})$ dentro de um vórtice. Para tanto, divide-se a vazão que passa através do vórtice pela área lateral de um cilindro de raio (r) e altura (h) igual à profundidade do vórtice. Este conceito pode ser extrapolado para os SHVs na forma da Equação 2.9, fazendo de (Q) a vazão de alimentação da unidade, de (r) um raio qualquer da unidade e de (h) a distância entre o fim do cilindro interno e o fundo da unidade, como mostra a Figura 2.14.

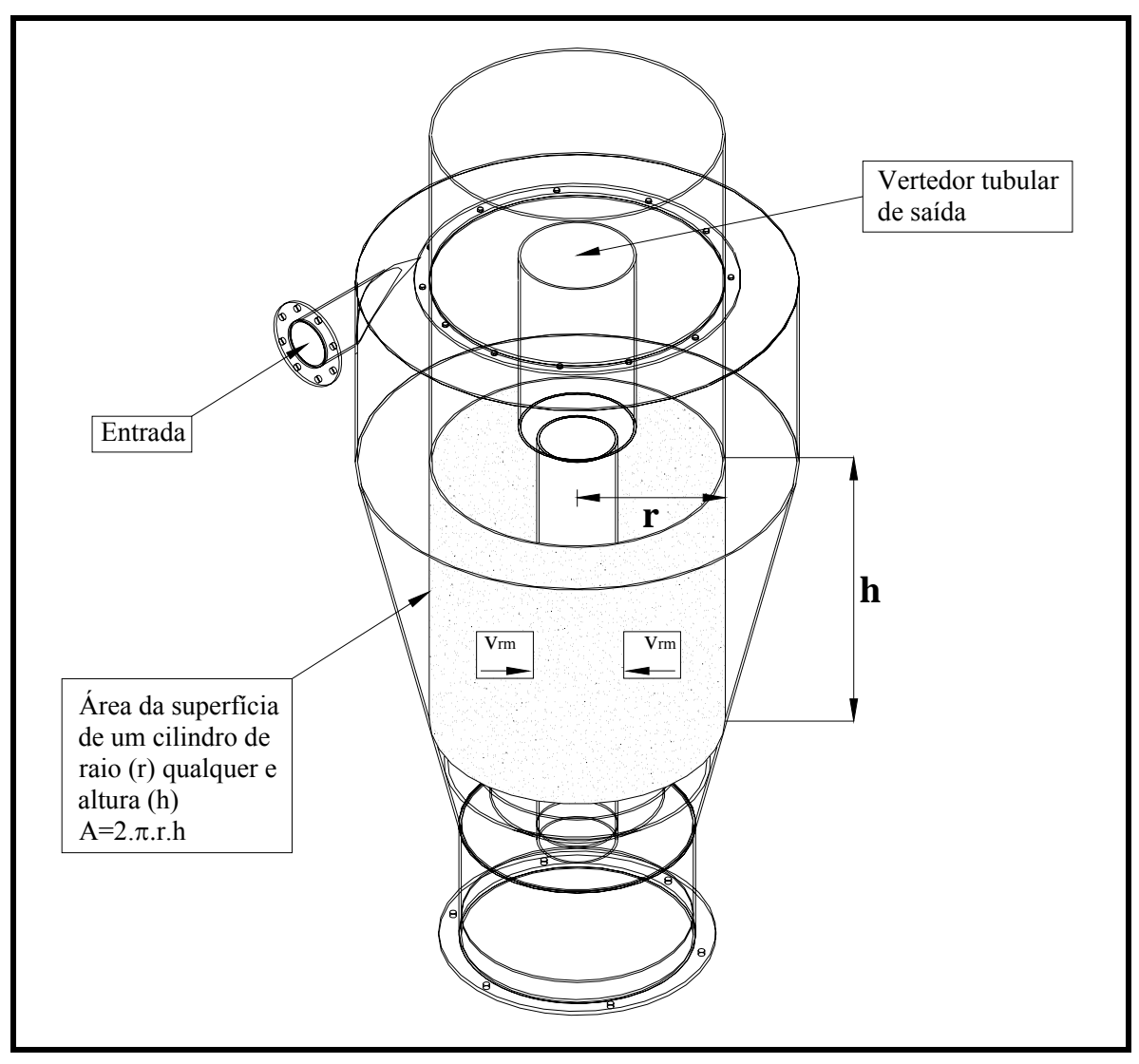

Figura 2.14 - Esquema ilustrativo para o cálculo da velocidade radial "líquida" de um SHV.

$$
\mathrm{v}_{\mathrm{rg}}=\frac{\mathrm{Q}}{2 \cdot \pi \cdot \mathrm{r} \cdot \mathrm{h}}
$$


Em que:

$\mathrm{V}_{\mathrm{rg}}$ : velocidade radial "global" $\left({\left.\mathrm{L} . \mathrm{T}^{-1}\right)}^{-1}\right.$;

Q: vazão de alimentação do $\operatorname{SHV}\left(\mathrm{L}^{3} \cdot \mathrm{T}^{-1}\right)$;

r: raio qualquer dentro da unidade $(\mathrm{L})$;

h: profundidade do vórtice

\subsubsection{A velocidade vertical do líquido em separadores hidrodinâmicos por vórtice}

Andoh e Smisson (1993) atestam que o padrão médio de escoamento dos SHVs é uma espiral descendente na parte externa da unidade, e uma espiral ascendente na região central (Figura 2.11). Esta afirmação implica na existência de duas regiões de velocidades verticais médias $\left(\mathrm{v}_{\mathrm{zm}}\right)$ com sentidos opostos, i.e. na parte externa dos SHVs, a velocidade vertical média orienta-se para baixo, assim como o padrão médio de escoamento dessa região, e na região central dos SHVs, a velocidade vertical média orienta-se para cima, mantendo o mesmo sentido do padrão médio de escoamento da região. Uma conseqüência imediata, da existência dessas duas regiões de velocidades verticais médias com sentidos opostos, é a formação de um plano de cisalhamento com velocidade vertical zero. Este plano foi chamado Locus of Zero Vertical Velocity (LZVV) - local de velocidade vertical zero - o qual é uma superfície tri-dimensional que acompanha a geometria dos SHVs, estendendo-se do topo ao fundo das unidades (SVAROVSKY, 1984; RUSHTON et al.,1996).

\subsubsection{Escoamentos secundários em separadores hidrodinâmicos por vórtice}

Quando fluídos viscosos escoam em regime turbulento, através de seções não circulares, como é o caso da seção transversal do SHV mostrado na Figura 2.15, as tensões de cisalhamento praticamente são constantes junto às paredes da unidade e caem, drasticamente, a zero em suas arestas. Tal fato deve-se ao fenômeno chamado 
escoamento secundário, o qual implica em componentes radiais e verticais do campo de velocidade não nulas (WHITE, 1999).

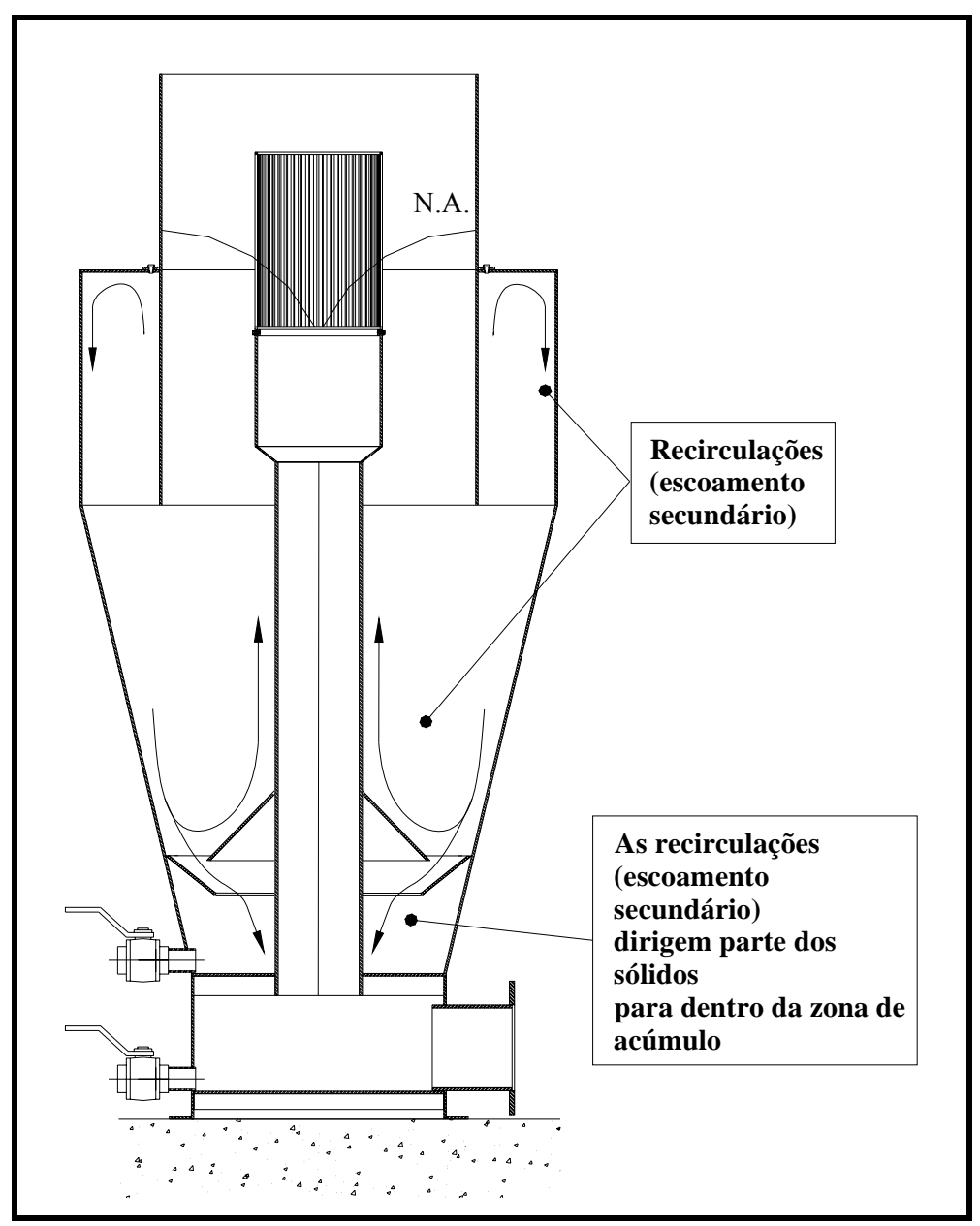

Figura 2.15 - Esquema mostrando uma seção transversal do SHV desenvolvido na presente pesquisa, no qual podem ser observadas algumas regiões com escoamento secundário.

O escoamento secundário é um fenômeno comum em muitos escoamentos naturais; em curvas de rios, ele é responsável pelo acúmulo de material na parte interna e pelo carreamento de material da parte externa das curvas (SIMM, 1983). Ao se agitar uma suspensão de areia e água dentro de um béquer é possível observar os efeitos do escoamento secundário em escoamentos circulares em recipientes cilíndricos. Logo após cessar-se a agitação, quando a massa líquida ainda conserva boa parte da energia a ela fornecida, nota-se que os grãos de areia concentram-se na região central do fundo do béquer na forma de um toróide e, depois de alguns minutos, quando toda a energia do escoamento já foi dissipada, os grãos de areia acumulam-se no centro do fundo do béquer (ANDOH, 1998). 
Segundo Paul et al. (1989) o escoamento secundário em SHVs desenvolve-se como resultado: da desaceleração das camadas mais externas de líquido (efeito de camada limite), ocasionada pelo "atrito" entre as paredes das unidades e o fluído; e da existência de escoamento cruzado nos SHVs.

De forma global, o escoamento secundário traduz-se como recirculações dentro dos SHVs, i.e. o desenvolvimento de um padrão de escoamento dentro de um padrão de escoamento principal (PAUL et al., 1989; ANDOH e SMISSON, 1993). Consoante Paul et al. (1989), o escoamento secundário no fundo da unidade faz com que parte dos sólidos seja impelida para dentro da zona de acúmulo (Figura 2.15). Entretanto, Svarovsky (1984) relata que na região central, logo acima do fundo dos SHVs, partículas sólidas que não entraram na zona de acúmulo ou que dela saíram e são muito grandes ou muito densas para serem arrastadas para fora das unidades, permanecem suspensas em uma espécie de "leito fluidizado" rotativo. A presença deste "leito fluidizado" rotativo é um forte indício da ressuspensão de sólidos causada por correntes ascensionais (Figura 2.15) decorrentes de escoamentos secundários no fundo dos SHVs.

Segundo Andoh (1998), flutuações excessivas do campo de velocidade, i.e. turbulência intensa, assim como perturbação no escoamento, ocasionadas por escoamentos secundários sempre que possível devem ser evitadas, ou pelo menos controladas, para que seja satisfatória a eficiência de remoção de sólidos dos SHVs, porquanto, tais fenômenos são os principais responsáveis: por curtos-circuitos hidráulicos, que diminuem o tempo de detenção hidráulica dessas unidades; e pela ressuspensão de sólidos e subseqüentes arrastes de partículas junto ao efluente de SHVs.

\subsubsection{Interações sólido-líquido em separadores hidrodinâmicos por vórtice}

A operação de separação sólido-líquido por vórtice pode ser encarada como uma espécie de "sedimentação" em escoamento circular, para o qual o campo de aceleração "centrífuga", decorrente do movimento do líquido, suplementa o campo de aceleração gravitacional na composição da força resultante responsável pela remoção (sedimentação) de sólidos sedimentáveis (ANDOH, 1998). Field e O’Connor (1996) corroboram as afirmações de Andoh (1998), e as complementam ao afirmar que a 
diferença de inércia entre partículas sedimentáveis e meio líquido provoca um fenômeno que os autores chamaram de separação tangencial (spinoff).

Andoh e Smisson (1993) afirmam que uma partícula sólida, de massa "m", dentro de um sistema que rotaciona, experimenta outras forças, além da gravitacional, incluindo: i) forças decorrentes de desvios do movimento em relação a uma linha reta; ii) força decorrente da rotação do sistema; iii) força devida à aceleração de Coriollis; e iv) forças resultantes de mudanças na velocidade de rotação do sistema. Logo, a trajetória descrita por partículas que se encontram dentro de sistemas que rotacionam, dependerá da força resultante da combinação de todas as forças citadas.

Todavia, a maioria dos modelos e equações utilizadas para o dimensionamento de SHVs assume como válidas algumas simplificações, e.g. não há diferença entre as velocidades verticais e tangenciais do líquido e das partículas; o escoamento é permanente; as partículas atingem suas velocidades radiais terminais de sedimentação $\left(\mathrm{v}_{\mathrm{sr}}\right)$ instantaneamente; as velocidades radiais terminais de sedimentação $\left(\mathrm{v}_{\mathrm{sr}}\right)$ das partículas ocorrem quando a força "centrífuga", devido ao movimento circular do sistema, iguala-se à força de arraste exercida nas partículas pelo líquido etc. (SVAROVSKY, 1984).

Assumindo como válidas tais simplificações, o balanço de forças que atuam em uma partícula de diâmetro equivalente igual a $d_{e}$ e massa "m", que rotaciona com o líquido em um SHV, pode ser escrito como:

$$
\mathrm{F}_{\mathrm{c}}-\mathrm{F}_{\mathrm{D}}=0
$$

Para:

$$
\begin{aligned}
& \mathrm{F}_{\mathrm{c}}=\mathrm{m} \cdot \frac{\mathrm{v}_{\mathrm{t}}^{2}}{\mathrm{r}} \\
& \mathrm{F}_{\mathrm{c}}=\frac{\pi}{6} \cdot \mathrm{d}_{\mathrm{e}}^{3} \cdot \rho_{\mathrm{s}} \cdot \frac{\mathrm{v}_{\mathrm{t}}^{2}}{\mathrm{r}}
\end{aligned}
$$

Em que:

$\mathrm{F}_{\mathrm{c}}$ : força centrífuga (M.L.T ${ }^{-1}$ ); 
$\mathrm{F}_{\mathrm{D}}$ : força de arrasto $\left(\right.$ M.L.T $\left.{ }^{-1}\right)$;

m: massa da partícula (M);

$\mathrm{V}_{\mathrm{t}}$ : velocidade tangencial do líquido $\left(\mathrm{L} . \mathrm{T}^{-1}\right)$;

r: raio qualquer da unidade $(\mathrm{L})$;

$\mathrm{d}_{\mathrm{e}}$ : diâmetro equivalente da partícula (L);

$\rho_{\mathrm{s}}$ : massa específica da partícula (M.L $\left.{ }^{-3}\right)$;

A força de arrasto $\left(\mathrm{F}_{\mathrm{D}}\right)$, que atua em partículas que se movimentam em meio fluido, depende do número de Reynolds da partícula, o qual pode ser calculado pela Equação 2.12.

$$
\operatorname{Re}=\frac{\rho \cdot u \cdot d_{e}}{\mu}
$$

Em que:

Re: número de Reynolds da partícula;

$\rho:$ massa específica do meio fluido $\left({\left.\mathrm{M} . \mathrm{L}^{-3}\right)}^{3}\right.$;

u: diferença entre a velocidade radial terminal de sedimentação ( $\left.\mathrm{v}_{\mathrm{sr}}\right)$ da partícula e a velocidade radial do líquido $\left({\mathrm{L} . \mathrm{T}^{-1}}^{-1}\right)$;

$\mu$ : viscosidade absoluta da partícula $\left(\mathrm{M} \cdot \mathrm{T}^{-1} \cdot \mathrm{L}^{-1}\right)$.

Como os SHVs são unidades projetadas para remover sólidos densos, que sedimentam com altas velocidades terminais de sedimentação (FIELD e O'CONNOR, 1996), i.e. Reynolds da partícula maior que a unidade, a força de arrasto exercida pelo líquido nas partículas suspensas que se movimentam dentro dessas unidades pode ser calculada pela lei da resistência quadrática de Newton, escrita na forma: 


$$
\begin{aligned}
& F_{D}=C_{D} \cdot \rho \cdot A_{p} \cdot \frac{u^{2}}{2} \\
& F_{D}=\frac{\pi}{8} \cdot C_{D} \cdot \rho \cdot d_{e}^{2} \cdot u^{2}
\end{aligned}
$$

Em que:

$\mathrm{C}_{\mathrm{D}}$ : coeficiente de arrasto;

$\rho$ : massa específica do líquido (M.L $\left.{ }^{-3}\right)$;

$\mathrm{A}_{\mathrm{p}}$ : área projetada da partícula na direção do movimento $\left(\mathrm{L}^{2}\right)$;

Combinando as Equações 2.10, 2.11, e 213, tem-se:

$$
u=1,155 \cdot v_{t} \cdot \sqrt{\frac{\rho_{s} \cdot d_{e}}{\rho \cdot r \cdot C_{D}}}
$$

Como a velocidade radial média do líquido pode ser estimada pela Equação 2.9, "u", que é a diferença entre a velocidade radial terminal de sedimentação da partícula $\left(\mathrm{v}_{\text {sr }}\right)$ e a velocidade radial do líquido, pode ser reescrito e substituído na Equação 2.14, obtendo-se:

$$
\mathrm{v}_{\mathrm{rs}}=1,155 \cdot \mathrm{v}_{\mathrm{t}} \cdot \sqrt{\frac{\rho_{\mathrm{s}} \cdot \mathrm{d}_{\mathrm{e}}}{\rho \cdot \mathrm{r} \cdot \mathrm{C}_{\mathrm{D}}}}+\frac{\mathrm{Q}}{2 \cdot \pi \cdot \mathrm{r} \cdot \mathrm{h}}
$$

Em que:

Q: vazão de alimentação da unidade $\left(\mathrm{L}^{3} . \mathrm{T}^{-1}\right)$;

h: profundidade do vórtice para um determinado raio (r) da unidade (L).

A Equação 2.15 não tem aplicação prática; ela não passa de mero exercício de raciocínio, pois não se pode chegar a qualquer resultado numérico por ela, posto que o coeficiente de arrasto $\left(\mathrm{C}_{\mathrm{D}}\right)$ é função do número de Reynolds da partícula, que por sua vez depende da diferença entre a velocidade radial do líquido e a velocidade radial de 
sedimentação ( $\mathrm{v}_{\mathrm{rs}}$ ) das partículas, ou seja, um dos termos da equação depende da resposta que se pretende obter ao usá-la. Outro problema é a velocidade tangencial do líquido que não é constante, é uma função dependente do raio do SHV onde se encontra a partícula, e da vazão de alimentação da unidade.

Devido a essas e a outras dificuldades de se equacionar tanto o escoamento como as interações fluido-partículas que ocorrem dentro dos SHVs, mesmo quando são assumidas diversas simplificações grosseiras como mostrado nessa seção, a grande maioria dos pesquisadores que trabalham com essas unidades recorrem a modelos semiempíricos, baseados em resultados experimentais obtidos em ensaios com modelos reduzidos e na experiência prática acumulada ao longo dos anos (ANDOH e SMISSON, 1993; VEERAPEN et al., 2005). Na última década, porém, com o advento de computadores cada vez mais poderosos, o uso de simulações computacionais, via softwares de dinâmica dos fluidos computacional (CFD - Computational Fluid Dynamics), tem ganhado espaço como uma importante ferramenta para se estudar e projetar SHVs (FARAM e ANDOH, 2000; FARAM e HARWOOD, 2000, 2002, 2003, OKAMOTO et al.,2002; EGARR et al., 2004).

\subsubsection{Aplicabilidade dos separadores hidrodinâmicos por vórtice}

Os separadores hidrodinâmicos por vórtice são unidades, mormente, empregadas para controlar a qualidade e a quantidade das águas residuárias provenientes de sistemas de coleta do tipo coletor universal. Para esta aplicação, geralmente, os SHVs são operados com três vazões diferentes: a vazão de alimentação da unidade, que pode sofrer enormes variações durante eventos de chuva; o overflow, o qual é o efluente "limpo" dos SHVs, e, finalmente, o underflow ou vazão de fundo, que geralmente varia entre $10 \%$ e $30 \%$ da vazão de entrada (Figura 2.12). Todavia, estas unidades também têm sido utilizadas como desarenadores, como decantadores primários ou, ainda como unidades de coagulação e floculação em estações de tratamento de esgoto (ETEs); nestes casos, geralmente, os SHVs são operados sem vazão de fundo (SMISSON, 1967; ANDOH e SMISSON, 1993; ANDOH, 1998, ANDOH et al., 2002; FARAM et al., 2004). 
Segundo Andoh (1998), os SHVs são unidades adequadas para remoção de sólidos sedimentáveis ou "flotáveis", mais efetivos na remoção de partículas discretas e densas, como grãos de areia. Refere o mesmo autor, que o desempenho dos SHVs é governado pelos seguintes fatores: i) sedimentabilidade dos sólidos presentes no esgoto bruto; ii) taxa de aplicação superficial (TAS); e iii) o tempo de detenção hidráulica (TDH) da unidade. Conseqüentemente, pode-se empregar SHVs com altas TAS e baixos TDH, quando os sólidos presentes nos afluentes dessas unidades apresentar boas características de sedimentabilidade, e quando os sólidos apresentarem baixa sedimentabilidade, deve-se utilizar SHVs com baixas TAS e altos TDH.

O uso de coagulantes é uma forma de melhorar a sedimentabilidade dos sólidos de pequenas dimensões presentes em águas residuárias; todavia, Svarovsky (1984) afirma que a utilização de coagulantes nos afluentes de hidrociclones é um desperdício de dinheiro pois, os elevados gradientes médios de velocidade dentro das unidades restringem a formação de flocos. Esta afirmação de Svarovsky (1984) é válida apenas para hidrociclones, porquanto, os SHVs empregados na remoção de sólidos de águas residuárias, apesar de pertencerem à mesma família de separadores, da qual os hidrociclones fazem parte, diferem dessas unidades por serem operados com "baixa energia", ou seja, cargas hidráulicas (perda de carga) inferiores a 1,0 m (ANDOH e SAUL, 2003). Nestas condições operacionais, a utilização de coagulantes, como o cloreto férrico e o sulfato de alumínio, tem se mostrado promissora.

Menezes et al. (1996) estudaram o uso de coagulantes e auxiliares de floculação para melhorar a sedimentabilidade dos sólidos presentes em afluentes de SHVs. Para tanto, os autores utilizaram: um SHV de $30 \mathrm{~cm}$ de diâmetro e $38 \mathrm{~cm}$ de altura, uma mistura de sílica $\left(500 \mathrm{mg} / \mathrm{l}\right.$ e diâmetro de Saulter. ${ }^{1}$ de $\left.19,7 \mu \mathrm{m}\right)$ e argila $(50 \mathrm{mg} / \mathrm{l}$ e diâmetro de Saulter de 6,6 $\mu \mathrm{m}$ ) para simular partículas suspensas no esgoto sanitário, cloreto férrico como coagulante e polímero aniônico (Nalco A-625) como auxiliar de floculação. Menezes et al. (1996) obtiveram 99\% de remoção de sólidos totais,

\footnotetext{
1. O diâmetro de Saulter é um diâmetro estatístico do tipo $\mathrm{D}[3,2]$, isto é, relação entre o volume e a superfície das partículas. Esse diâmetro é usado para caracterizar a faixa de tamanho na qual se concentra o maior volume ou massa de partículas presentes em uma amostra. Maiores informações acerca de tamanho de partículas e diâmetros estatístico, encontra-se do capítulo 4 desta tese.
} 
operando o SHV com TAS entre $204 \mathrm{~m}^{3} / \mathrm{m}^{2} \mathrm{~d}$ e $244 \mathrm{~m}^{3} / \mathrm{m}^{2} \mathrm{~d}$, e aplicando $70 \mathrm{ppm}$ de cloreto férrico $\left(\mathrm{FeCl}_{3}\right.$.) somado a 0,85 ppm do auxiliar de floculação (Nalco A-625).

O excelente e quase inacreditável resultado obtido por Menezes et al. (1996) deve ser interpretado com muito cuidado para evitar conclusões precipitadas e entusiásticas. Os SHVs são unidades muito sensíveis ao fator de escala adotado, pois o campo de aceleração "centrifuga" é inversamente proporcional ao raio da unidade, consequentemente, pode-se concluir que as dimensões da unidade empregada na pesquisa de Menezes et al. (1996) - apenas $30 \mathrm{~cm}$ de diâmetro e $38 \mathrm{~cm}$ de altura (aproximadamente, 27 litros) —, tiveram enorme influência nos resultados finais de remoção obtidos e mais, a escolha de uma mistura de sílica e argila para simular sólidos suspensos do esgoto sanitário é no mínimo questionável, por tratar-se de sólidos densos, que ao serem devidamente coagulados e floculados produzem flocos pesados e de fácil remoção. Vale lembrar que, muitas vezes, a sílica é empregada como auxiliar de floculação, usada para conferir "peso" a flocos formados a partir de sólidos pouco densos. Apesar de não serem factíveis, como já discutido nesse parágrafo, os resultados obtidos por Menezes et al. (1996) demonstram a aplicabilidade da coagulação seguida da floculação para melhorar a sedimentabilidade dos sólidos presentes em afluentes de SHVs.

Andoh et al. (2002) relatam que os SHVs, além de serem empregados como sedimentadores também podem ser utilizados como unidades de coagulação e floculação devido a algumas particularidades do regime de escoamento que se desenvolve dentro dessas unidades. Na região de entrada, a turbulência gerada pelo encontro do "jato" de fluido que adentra a unidade com o volume de fluido que rotaciona dentro dela provoca o aparecimento de altos gradientes de velocidade que proporcionam condições para uma efetiva mistura do coagulante com o meio líquido, enquanto que no volume restante do SHV (corpo da unidade) ocorre naturalmente a floculação com escalonamento de gradientes de velocidade (tapering flocculation), a qual é fomentada pela diminuição dos gradientes de velocidades ao longo das trajetórias descritas pelo meio líquido dentro dos SHVs, isto é, gradientes de velocidades mais altos na parte externa das unidades, onde o líquido rotaciona com maior velocidade descrevendo trajetórias helicoidais no sentido do fundo das mesmas, e gradientes de velocidade menores na região interna das unidades, onde o líquido rotaciona com velocidades mais baixas descrevendo trajetórias helicoidais no sentido do topo. Segundo 
os mesmos autores, os SHVs são comumente operados com TAS de $380 \mathrm{~m}^{3} / \mathrm{m}^{2} \mathrm{~d}$ a 480 $\mathrm{m}^{3} / \mathrm{m}^{2} \mathrm{~d}$ quando utilizados como floculadores hidráulicos em ETEs.

Boner et al. (1995) propuseram uma combinação mais criativa - além de usarem a coagulação para melhorar a sedimentabilidade das partículas suspensas em águas residuárias provenientes de sistemas de coleta do tipo coletor unitário - os autores combinaram a flotação por ar dissolvido (DAF) a um SHV e comparam o desempenho desta nova unidade com aquele obtido para SHVs convencionais (sem DAF). Os resultados demonstraram que, para uma mesma TAS, os SHVs com a nova configuração atingiram eficiências de remoção de sólidos maiores que as atingidas pelas unidades convencionais.

Devido ao fato de o regime de escoamento dos SHVs aproximar-se do fluxo pistonado (plug-flow), alguns pesquisadores enxergam essas unidade como potenciais câmaras de contato para desinfecção. Um exemplo desse tipo de aplicação dos SHVs é o trabalho de Alkhaddar et al. (2000), que aproveitando as característica de o escoamento dessas unidades, usaram um SHV, com capacidade de 60 litros, como tanque de contato de uma unidade de desinfecção com cloro, cujo afluente era água de abastecimento inoculada com uma suspensão de Escherichia coli K12 (10, $\left.{ }^{8} \mathrm{cfu} / \mathrm{ml}\right)$. Os resultados obtidos variaram entre 39\% de inativação para vazão de $61 / \mathrm{mim}$ e $48 \%$ de inativação para vazão de $30 \mathrm{l} / \mathrm{min}$. Como pode ser visto, os resultados do trabalho de Alkhaddar et al. (2000) não foram animadores, porém também não foram conclusivos, o que indica a necessidade de mais pesquisas acerca do assunto, para que SHVs possam ser empregados como tanques de contato de unidades de desinfecção de estações de tratamento de água ou esgoto.

\subsubsection{Histórico do desenvolvimento do protótipo do separador hidrodinâmico por vórtice tema da presente tese}

O desenvolvimento do separador hidrodinâmico por vórtice (SHV), tema desta pesquisa, teve início na primeira metade de 2002. Naquela época, pretendia-se projetar uma unidade de gradeamento fino que pudesse ser operada com fluxo tangencial, 
porquanto tal tipo de escoamento poderia evitar o acúmulo de sólidos na grade durante sua operação. Para tanto, pensou-se em uma unidade cilíndrica que recebesse seus afluentes por uma entrada tangencial e que fosse capaz de atender uma vazão de pico de 55 1/s (aproximadamente 15.000 habitantes).

A primeira unidade de separação idealizada era constituída por três cilindros concêntricos de diâmetros internos iguais a $300 \mathrm{~mm}, 512 \mathrm{~mm}$ e $725 \mathrm{~mm}$, sobre um fundo cônico, como mostra a Figura 2.16. O cilindro central era a câmara de coleta (saída da unidade); entre o cilindro central e o intermediário, formava-se uma segunda câmara e entre o cilindro externo e o intermediário formava-se a primeira câmara.

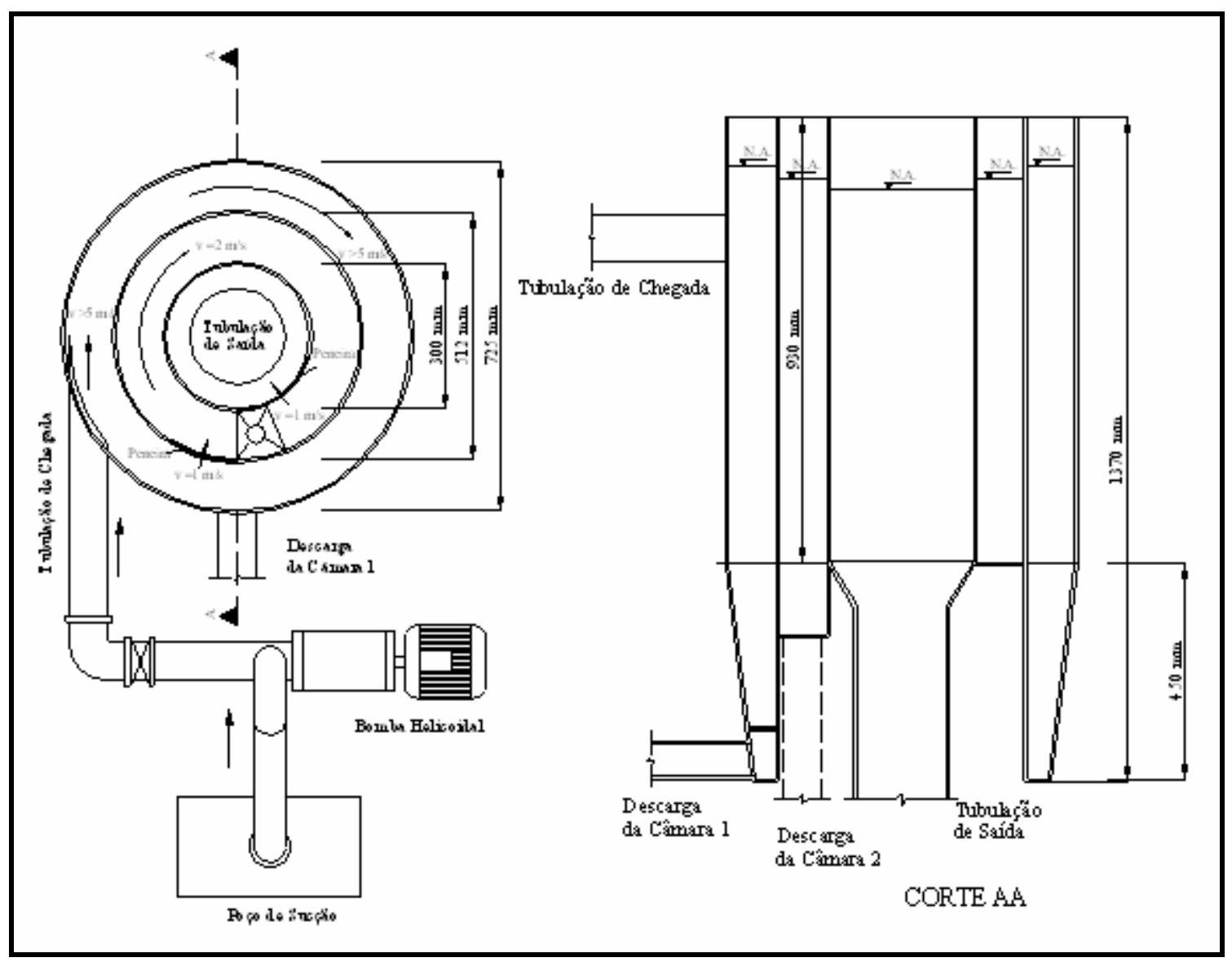

Figura 2.16 - Desenho do primeiro separador hidrodinâmico por vórtice idealizado para a presente pesquisa.

O esgoto sanitário seria bombeado por uma bomba helicoidal de baixa rotação para dentro da primeira câmara da unidade de separação, através de um bocal, tangencialmente posicionado na parede do cilindro externo. A primeira câmara funcionaria como zona de sedimentação "centrífuga", na qual o campo de aceleração 
“centrífuga", gerado pelo movimento circular do líquido, assistiria o campo gravitacional na remoção de partículas densas ("pesadas"). As partículas que não sedimentassem na primeira câmara poderiam ser retidas em uma grade instalada na parede do cilindro intermediário. Ao adentrar a segunda câmara, o esgoto seria reacelerado por uma pequena turbina porém, desta vez não se pretendia criar condições para sedimentação "centrífuga" de partículas, mas promover movimento circular, no intuito de se evitar o acúmulo de sólidos na segunda grade, localizada na parede do cilindro central.

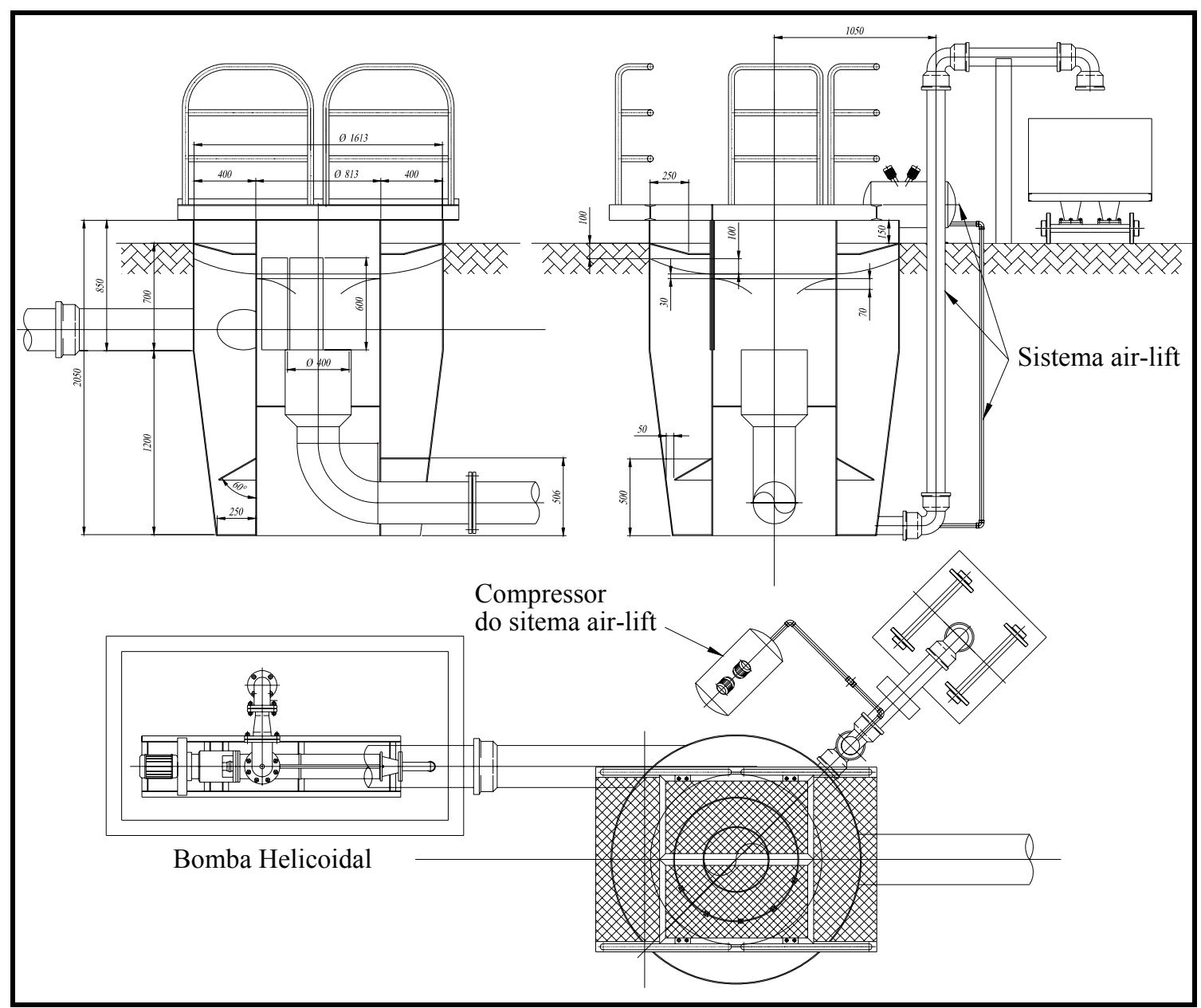

Figura 2.17 - Desenho do segundo separador hidrodinâmico por vórtice idealizado para a presente pesquisa.

No final de 2002, a geometria da unidade de separação pela primeira vez foi modificada. Abandonou-se a idéia das três câmaras, que foram reduzidas a apenas duas: uma câmara externa, que funcionaria como zona de sedimentação "centrífuga" e uma câmara interna, onde se localizava um vertedor tubular de saída, como mostra a Figura 2.17. Como no primeiro desenho, o esgoto continuaria a ser bombeado, por uma bomba PRADO, G. S. (2006) 
helicoidal de baixa rotação, para dentro da primeira câmara, através de um bocal, tangencialmente, posicionado na parede do cilindro externo. Os sólidos que sedimentassem na primeira câmara seriam coletados em uma região de acúmulo na base da unidade e de lá seriam bombeados, por um sistema de air-lift, para dentro de uma caçamba postada ao lado da unidade de separação, porquanto aqueles sólidos que não sedimentassem, poderiam ficar retidos em uma grade localizada na parede do cilindro interno.

Com o objetivo de se conseguir financiamento para a construção de um protótipo, o segundo desenho da unidade de separação foi apresentado à PROMINAS do Brasil, empresa local especializada na produção de sistemas de peneiramento e gradeamento para a indústria e para estações de tratamento de água e esgoto. O financiamento foi aprovado pelos diretores da empresa, porém, o segundo desenho da unidade ainda estava longe de ser o ideal, pois, até aquele instante, nenhum esforço havia sido empregado na otimização da zona de sedimentação da unidade.

Na tentativa de melhorar a eficiência da zona de sedimentação, o segundo desenho da unidade de separação foi radicalmente modificado. Com base nos conceitos discutidos neste capítulo, o corpo cônico da unidade foi alongado, enquanto o corpo cilíndrico teve sua altura reduzida. Foi abandonada, em definitivo, a idéia de câmaras separadas; para tanto, o cilindro interno que antes se estendia do topo à base da unidade, teve sua altura reduzida, passando a estender-se do topo ao final do corpo cilíndrico. $\mathrm{O}$ cilindro externo que antes possuía a mesma altura do cilindro interno, teve sua altura ainda mais reduzida e o canal que se formava entre os dois cilindros, que antes não era coberto, foi completamente tampado, exceto em uma pequena faixa, na qual se pretende capturar sólidos flutuantes. A grade, que se localizava na parede do cilindro interno, tornou-se cilíndrica com diâmetro de $320 \mathrm{~mm}$ e espaçamento entre barras de 3,0 $\mathrm{mm}$ e foi reposicionada no topo do vertedor tubular de saída da unidade (Figura 2.18 e 2.19).

O objetivo de todas essas modificações foi tentar aproximar o desenho da unidade de separação ao de um hidrociclone. O resultado final obtido foi um separador hidrodinâmico por vórtice (SHV), unidade que pertence à mesma família dos hidrociclones, diferindo destas por serem operadas com cargas hidráulicas bem mais baixas. A entrada tangencial do líquido somada à nova configuração dos cilindros externo e interno confina o escoamento da região de entrada da unidade, obrigando o 
líquido a seguir trajetórias helicoidais e descendentes. Os defletores, posicionados no fundo da unidade, ajudam a redirecionar o sentido do escoamento que na parte externa da unidade é descendente e na interna ascendente, além de criarem uma região livre de perturbações para acúmulo de sólidos capturados (Figura 2.18 e 2.19).

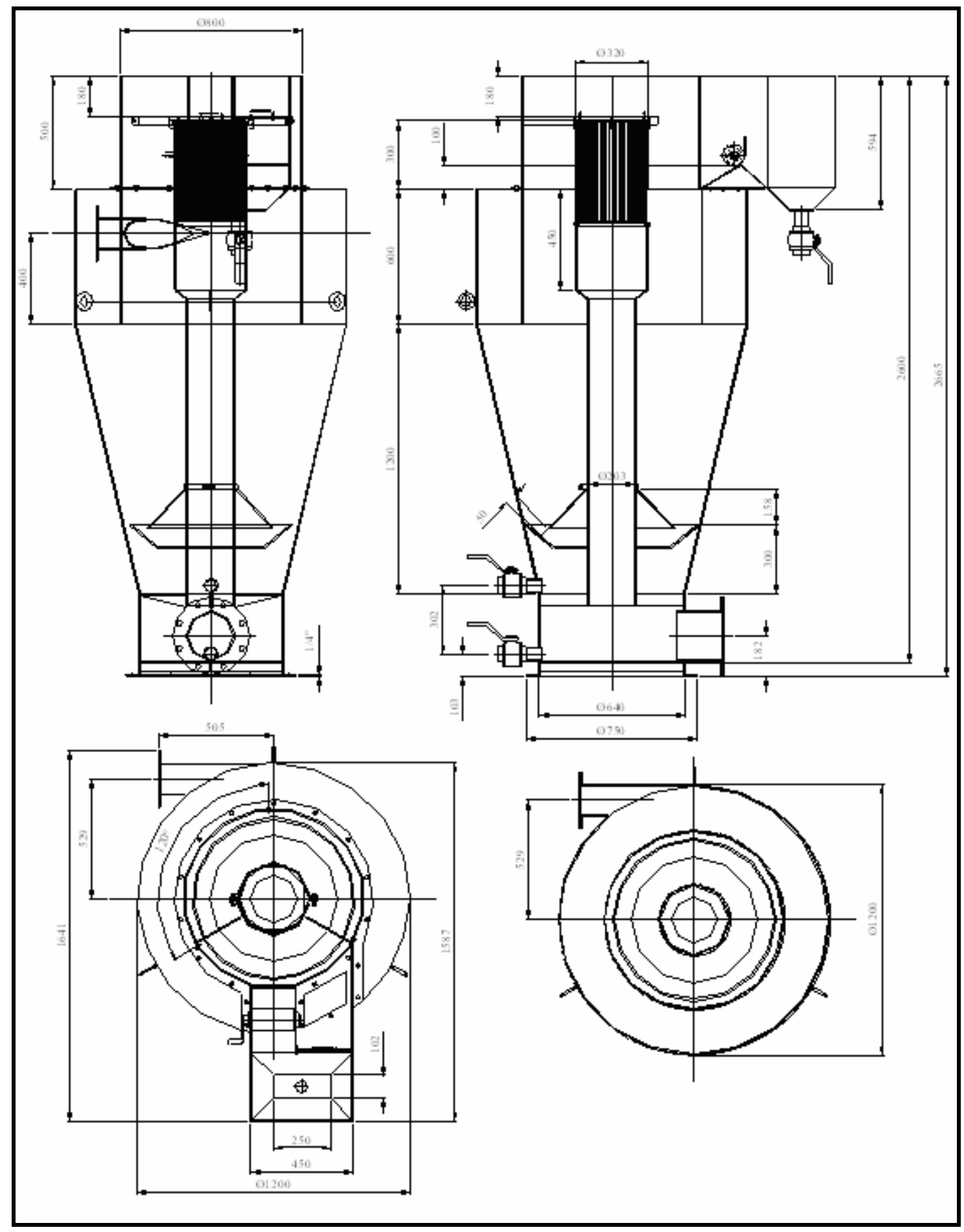

Figura 2.18 - Desenho da última configuração do separador hidrodinâmico por vórtice idealizado para a presente pesquisa. 


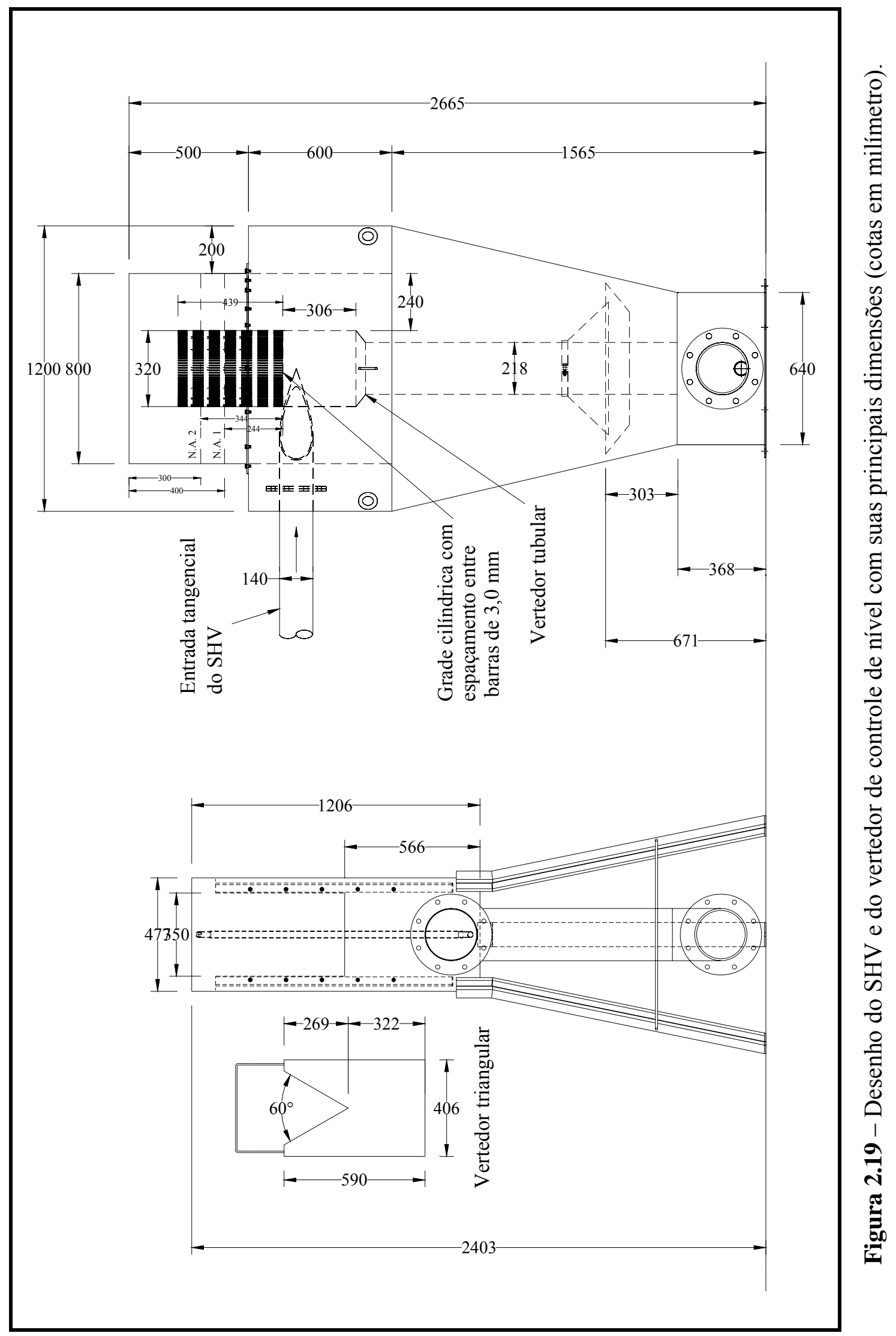


A Figura 2.20 mostra o protótipo do SHV que foi construído pela PROMINAS do Brasil para a realização da pesquisa apresentada nesta tese. Como se pode observar nas Figuras 2.18 e 2.19, a unidade construída mede 2,67 m de altura e 1,20 m de diâmetro; seu volume útil é de aproximadamente 1500 litros $\left(1,5 \mathrm{~m}^{3}\right)$. Além do SHV, foi construída também uma câmara com vertedor triangular, que acumula duas funções, a primeira é controlar o nível de água no interior da unidade e a segunda é servir como medidor de vazões. Vale ressaltar que a escolha do material utilizado na construção e impermeabilização do SHV e da câmara do vertedor de controle de nível ficou a cargo do Departamento de Engenharia da PROMINAS do Brasil.

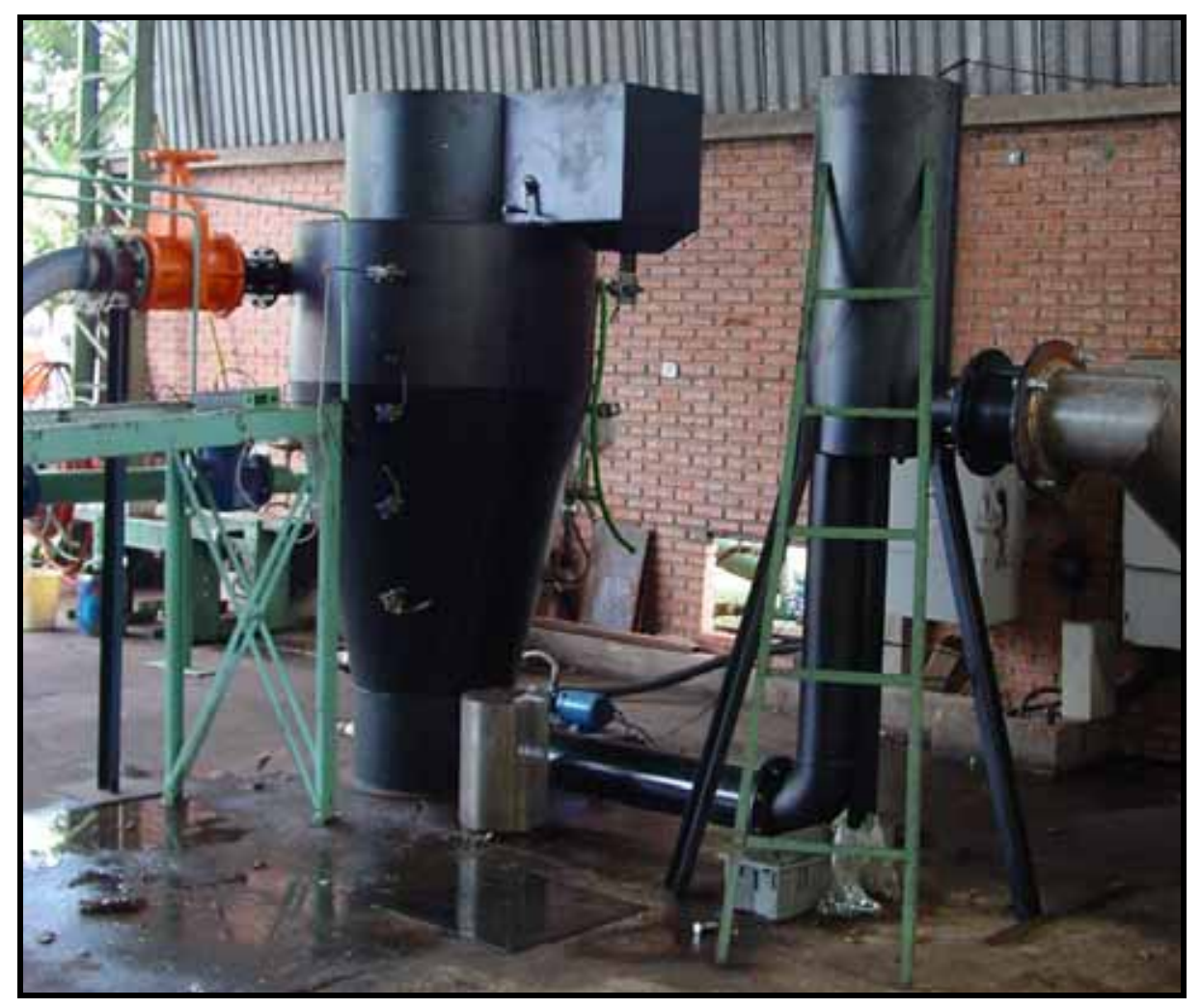

Figura 2.20 - Foto que mostra o SHV e a câmara do vertedor de controle de nível instalados na bancada de testes da PROMINAS para execução dos ensaios realizados para estudar a hidrodinâmica da unidade.

O SHV, mostrado nas Figuras 2.19 e 2.20, foi utilizado na primeira parte da pesquisa, realizada na bancada de teste da PROMINAS do Brasil de janeiro a maio de 2005. Nesta fase, o SHV foi alimentado apenas com água, para que fossem executados ensaios de estímulo-resposta e medições pressão total, cujos resultados são apresentados no Capítulo 3 (Estudo da Hidrodinâmica do Separador Hidrodinâmico por Vórtice) dessa tese. 
Problema algum foi identificado na unidade durante o estudo da hidrodinâmica da mesma, porém, no início de agosto de 2005, quando o SHV foi instalado na estação elevatória da ETE Jardim das Flores do município de Rio Claro, SP para que se pudesse avaliar o desempenho da unidade como desarenador e sistema de gradeamento fino: observou-se que a grade cilíndrica de fluxo tangencial (espaçamento entre barras de 3,0 $\mathrm{mm}$ ) posicionada no topo do vertedor tubular de saída do SHV não funcionava como havia sido idealizado. Para sanar tal problema, o qual será pormenorizado no Capítulo 5 (Análise do Desempenho do Separador Hidrodinâmico por Vórtice) dessa tese, foram realizadas algumas mudanças no SHV, mais precisamente na grade cilíndrica que deveria funcionar como grade de fluxo tangencial.

O diâmetro da grade cilíndrica foi aumentado de $320 \mathrm{~mm}$ para $600 \mathrm{~mm}$, e o espaçamento entre barras que antes era de 3,0 $\mathrm{mm}$ passou a ser de 4,0 $\mathrm{mm}$. No entanto a mudança mais radical foi a instalação de um sistema de limpeza mecanizado para remover sólidos grosseiros aderidos à grade. Como pode ser observado na Figura 2.22, o sistema de limpeza mecanizado é constituído por um conjunto moto-redutor que gira uma barra com dois raspadores, um em cada extremidade da barra. No lado interno dos raspadores foi fixada uma escoava para remover os sólidos presos à grade à medida que se gira a barra que sustenta os raspadores (Figura 2.21).

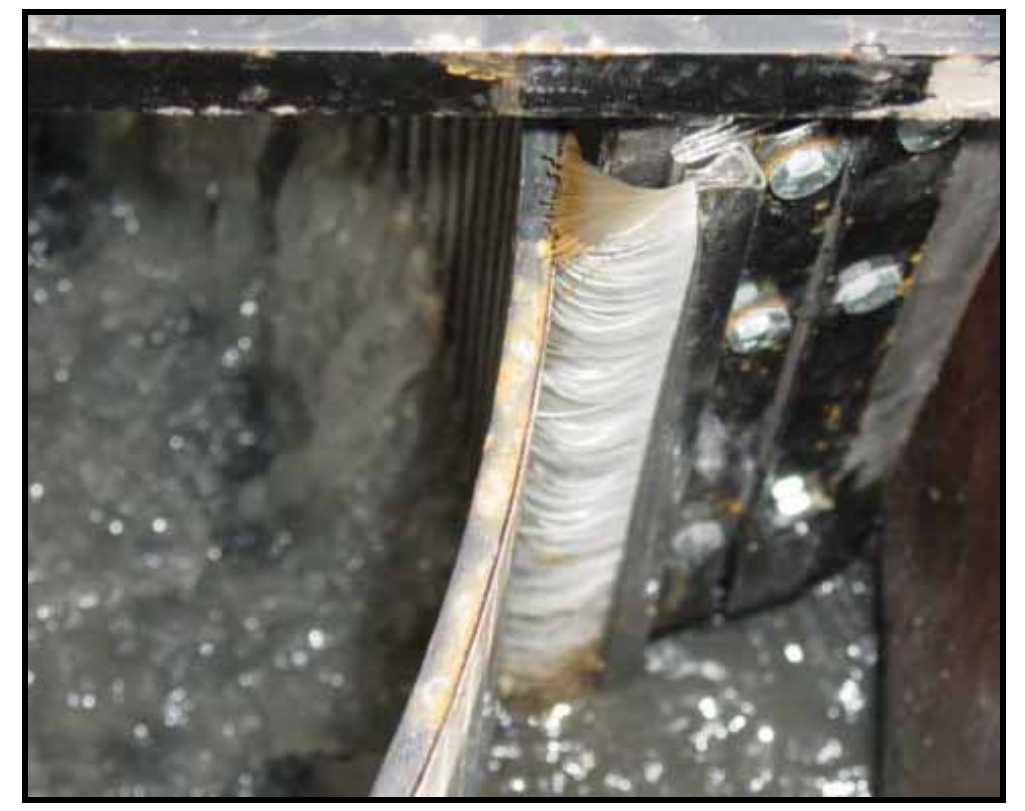

Figura 2.21 - Foto mostrando detalhe da escova fixada na parte interior do raspador do sistema de limpeza mecanizado da peneira localizada no topo do vertedor tubular de saída do SHV. 


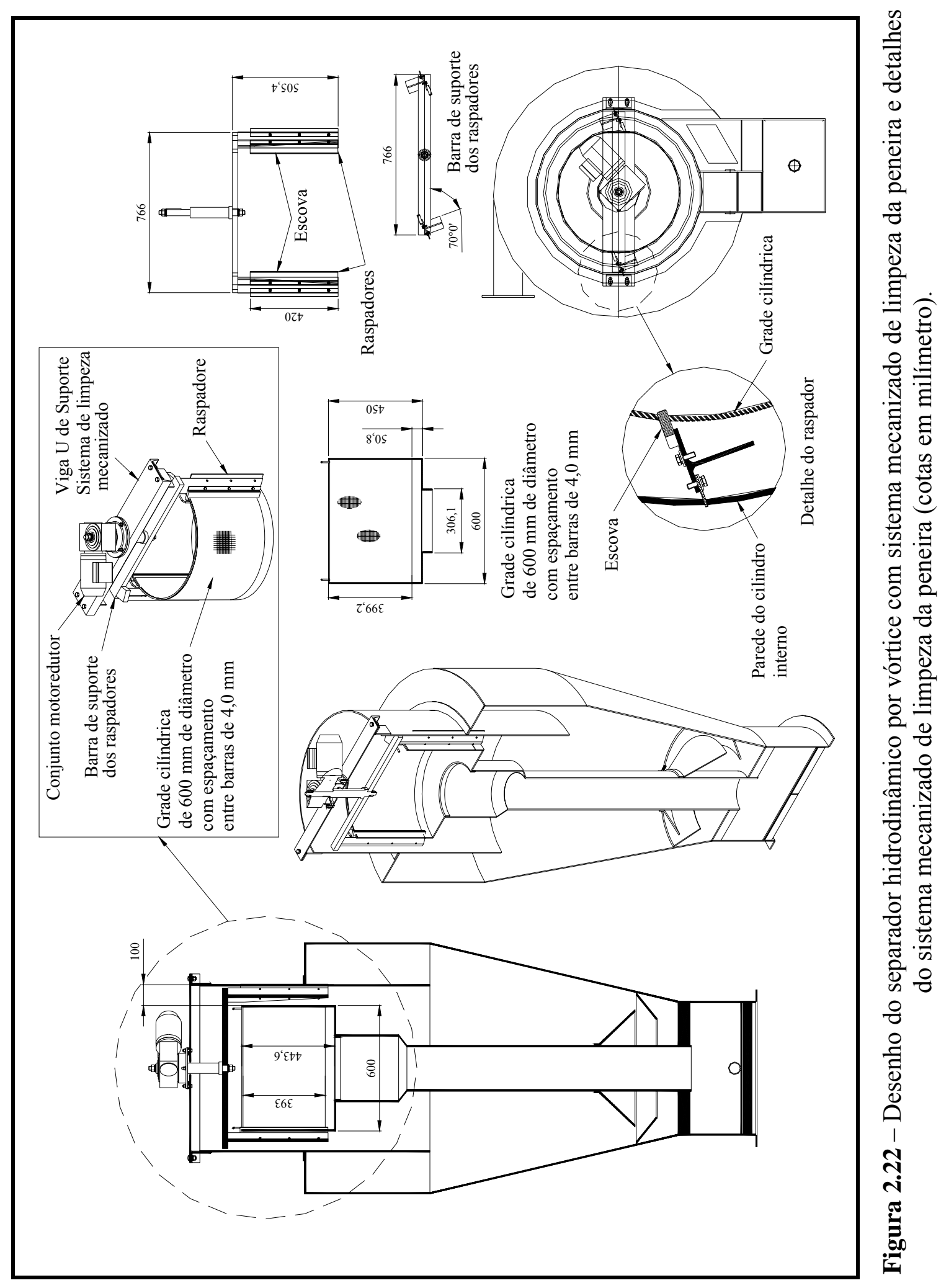




\section{Capítulo 3 - Estudo da Hidrodinâmica do Separador Hidrodinâmico por Vórtice}

Este capítulo apresenta um estudo acerca da hidrodinâmica do separador hidrodinâmico por vórtice (SHV) tema central da presente tese. Tal estudo fundamenta-se em resultados de ensaios de estímulo-resposta e resultados de simulações computacionais em software de dinâmica dos fluidos computacionais, chamado CFX 10.0. Os resultados dos ensaios de estímulo-resposta mostram que o regime de macro-mistura do escoamento do separador hidrodinâmico por vórtice aproxima-se do plug-flow, porém apresenta certo grau de mistura que diminui com o aumento da vazão de alimentação da unidade. Os resultados das simulações computacionais demonstram que junto à parede externa do separador hidrodinâmico por vórtice, as partículas de fluido descrevem trajetórias helicoidais e descendentes, enquanto próximo ao eixo central da unidade a trajetória helicoidal das partículas de fluido tornam-se ascendentes. Este comportamento do fluido é observado para as três vazões de alimentação estudada (10 1/s; 15 1/s e 20 1/s), principalmente no corpo cônico do separador hidrodinâmico por vórtice. 


\subsection{Introdução}

Os separadores hidrodinâmicos por vórtice (SHV) são unidades de operação unitária cujo mecanismo de separação sólido-líquido baseia-se unicamente no movimento vorticoso do fluido em seus interiores; consequentemente, para que seja possível avaliar o funcionamento e o desempenho de um SHV é imprescindível conhecer e entender seu complexo padrão de escoamento.

No Capítulo 2 dessa tese foram apresentados diversos conceitos e equações acerca do padrão de escoamento dos SHVs porém, devido a complexidade inerente dos escoamentos vorticosos, a maioria destes conceitos e equações não possui aplicação prática, pois baseiam-se em simplificações, muitas vezes, grosseiras do escoamento real.

Frente à impossibilidade de se estudar analiticamente o padrão de escoamento dos SHVs, resultados de experimentos com modelos físicos reduzidos e com unidades em escala plena ou piloto, como ensaios de estímulo-resposta e medições de pressão e velocidade no interior das unidades tem sido a base de boa parte dos trabalhos publicados sobre o padrão de escoamento dos SHVs, desde da publicação do primeiro artigo científico acerca desse tipo de unidade em 1942 até os dias atuais (GIEGER, 1942; SMISSON, 1967; SULLIVAN et al., 1974; ALKHADDAR et al., 2001a; VEERAPEN et al., 2005).

Segundo Levenspiel (2000), um dos experimentos mais utilizados para se estudar o padrão de escoamento de unidades tratamento em escala piloto ou plena são os ensaios de estímulo-resposta. Nestes ensaios injeta-se uma quantidade de traçador junto com o afluente da unidade, cujo padrão de escoamento pretende-se estudar e acompanha-se a concentração desse traçador no efluente da mesma. Tal procedimento possibilita a realização de análises da distribuição dos tempos de detenção hidráulica (TDH), isto é, análise da distribuição do tempo de permanência do líquido dentro da unidade. Por meio desse tipo de análise é possível caracterizar o regime de macromistura do escoamento da unidade estudada (entre plug-flow e mistura perfeita) e verificar a ocorrência de algumas "anomalias" em seu padrão de escoamento, como: curtos-circuitos hidráulicos e regiões de estagnação de fluido (“zonas mortas”). 
Consoante Metcalf \& Eddy (2003), unidades de separação sólido-líquido, como os sedimentadores e os desarenadores, devem ser projetadas de modo que o regime de macro-mistura do escoamento em seus interiores seja, na medida do possível, plug-flow (escoamento pistonado). Este regime de macro-mistura é caracterizado pela permanência de todos os elementos de fluido dentro da unidade por tempo igual ao tempo teórico de detenção hidráulica da mesma. No caso das unidades de sedimentação, isto possibilita que o campo de aceleração gravitacional atue por mais tempo sobre partículas que estejam em suspensão em seus afluentes líquidos, favorecendo, assim, a remoção de tais sólidos. Na prática, isso é alcançado projetando-se unidades com distribuição adequada do afluente líquido na região de entrada e com elevada razão comprimento-largura (ou comprimento-diâmetro no caso de unidades tubulares).

Os SHVs, não obstante possuírem geometria singular que acarreta o desenvolvimento de padrões de escoamento circulares, caracterizados por movimentos helicoidais do fluido (ora descendente, ora ascendente), são unidades de sedimentação e, como tal, seus padrões de escoamento devem apresentar regime de macro-mistura do tipo plug-flow, para que os campos de aceleração gravitacional e "centrifuga" atuem concomitantemente sobre partículas suspensas em seus afluentes pelo maior tempo possível (ANDOH e SMISSON, 1993). Ensaios de estímulo-resposta realizados por Sullivan et al. (1974) e por Alkhaddar et al. (2001a, 2001b) mostraram que o escoamento no interior dos SHVs apresenta regime de macro-mistura próximo ao plugflow.

Apesar de serem úteis e fornecerem informações importantes acerca do escoamento nos SHVs, os ensaios de estímulo-resposta não fornecem subsídios suficientes para que se possa compreender e até mesmo otimizar o intrincado padrão de escoamento desse tipo de unidade. Para tanto é necessário o emprego de métodos ou ferramentas que possibilitem a visualização do comportamento do fluido no interior dos SHVs.

Uma ferramenta que permite a visualização do comportamento do fluido no interior de vasos fechados e por isso tem ganhado espaço no estudo da hidrodinâmica de unidades de operação unitária são os softwares de dinâmica dos fluidos computacional (do inglês Computational Fluid Dynamics - CFD), principalmente a partir do final da década de 1990, devido ao desenvolvimento de computadores potentes e velozes. 
Atualmente, existem vários softwares multipropósito de dinâmica dos fluidos computacional, podendo-se destacar: o FLUENTE da FLUENTE Inc.; o CFX da ANSYS; o PHOENICS da CHAM; entre outros, os quais são amplamente utilizados por diversos segmentos industriais, como: o aeroespacial, automotivo, bioquímico, alimentício, esportivo, ambiental etc. (CFX, 2004).

$\mathrm{Na}$ indústria da água, o emprego de softwares de dinâmica dos fluidos computacional para simular numericamente o padrão de escoamento de unidades de operação unitário de estações de tratamento de água e de esgoto teve início no começo da década de 1990, com a publicação de trabalhos como os de Krebs (1991), Bretscher et al. (1992) e Brouckaert e Buckley (1999), os quais atestam a aplicabilidade do uso das simulações computacionais no estudo e na otimização dos padrões de escoamento de decantadores secundários de estações de tratamento de esgoto, e de decantadores de estações de tratamento de água.

Os separadores hidrodinâmicos por vórtice (SHVs) já foram também estudados utilizando-se simulações computacionais; muitos trabalhos publicados nos últimos 10 anos têm mostrado a potencialidade do uso de simulações numéricas na predição do padrão de escoamento e da eficiência de remoção de sólidos de SHVs (FARAM e ANDOH, 2000; OKAMOTO et al., 2002; FARAM e HARWOOD, 2003; EGARR et al., 2004; VEERAPEN et al.,2005). No entanto, Faram e Harwood (2003) lembram que as simulações computacionais devem ser utilizadas com critério pois seus resultados, não obstante apresentarem boa correlação com aqueles observados em unidade de escala plena, não representam o escoamento de forma totalmente realista. Segundo os autores, simulações computacionais do padrão escoamento desenvolvido em SHVs devem ser empregadas para avaliar tendências e comportamentos gerais do líquido dentro dessas unidades.

\subsection{Materiais e Métodos}

\subsubsection{Considerações iniciais}

O estudo da hidrodinâmica do separador hidrodinâmico por vórtice (SHV), apresentado e detalhado na seção 2.4.5 (Histórico do desenvolvimento do protótipo do 
separador hidrodinâmico por vórtice) do Capítulo 2 (O Tratamento Preliminar de Esgoto Sanitário e os Separadores Hidrodinâmicos por Vórtice: Conceitos e Aplicações) da presente tese, fundamentou-se em duas abordagens distintas, porém complementares: a experimentação, com um protótipo em escala plena e a simulação computacional do escoamento dessa unidade, via software de dinâmica dos fluidos computacional.

A experimentação, com o protótipo do SHV, consistiu da realização de dois tipos diferentes de ensaios: ensaios de estímulo-resposta com traçador não reativo e medições de pressão total com medidor de pressão do tipo Pitot em pontos prédeterminados, no interior da unidade. Os ensaios de estímulo-resposta foram realizados com o intuito de obter informações acerca do tempo de detenção hidráulica (TDH) e do regime de macro-mistura do $\mathrm{SHV}$, assim como, detectar a presença de regiões de estagnação de fluido ("zonas mortas"), para as três vazões de interesse (10 1/s; 15 1/s e 20 1/s). Por sua vez a execução das medições de pressão total teve como único objetivo a validação dos resultados das simulações computacionais.

As simulações computacionais foram efetuadas em um software de dinâmica dos fluidos computacional, chamado CFX 10.0, produzido pela ANSYS ${ }^{\circledR}$. Objetivou-se, com esta abordagem, a obtenção de panoramas mais completos dos padrões de escoamentos que se desenvolvem no SHV estudado, uma vez que os resultados fornecidos pelo software (CFX 10.0) permitem a visualização da distribuição dos vetores velocidade no interior da unidade possibilitando, assim, a identificação de "perturbações" como: recirculações internas, regiões de estagnação do fluido ("zonas mortas"), entre outras, as quais são as principais causas da diminuição da eficiência de remoção de sólidos dos SHVs.

A Figura 3.1 mostra um fluxograma que demonstra a interdependência das duas abordagens empregadas no estudo da hidrodinâmica do SHV. Como pode ser visto, a análise final dos resultados depende do cruzamento de dados obtidos em ensaios de estímulo-resposta com aqueles provenientes das simulações computacionais, os quais precisam ser validados. Para tanto, os valores de pressão total medidos durante o levantamento dos campos de pressão total do SHV (protótipo em escala plena) foram comparados com os valores de pressão total fornecidos pelas simulações computacionais, de forma que os desvios entre resultados experimentais e simulados pudessem ser visualizados graficamente. 


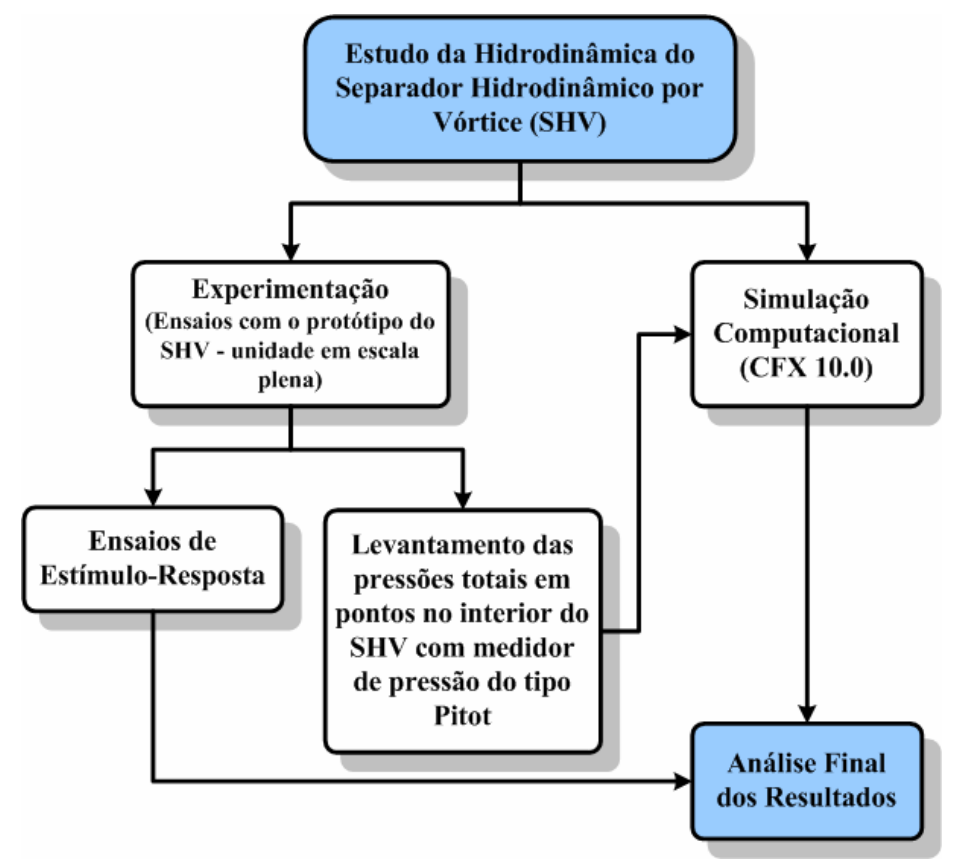

Figura 3.1 - Fluxograma esquemático mostrando como foi organizado o estudo da hidrodinâmica do SHV.

A seguir serão apresentados os procedimentos experimentais adotados na execução dos ensaios de estímulo-resposta e das medições de pressão total, assim como alguns detalhes importantes acerca das simulações computacionais.

\subsubsection{Ensaios de estímulo-resposta}

\subsubsection{Considerações iniciais}

A caracterização do regime de macro-mistura do separador hidrodinâmico por vórtice (SHV), tema desta pesquisa, foi realizada pela análise de resultados obtidos de ensaios de estímulo-resposta com traçador não reativo. Foram efetuados dois ensaios para cada vazão em estudo (10 l/s; 15 l/s e 20 l/s), todos eles executados na bancada de testes da PROMINAS - empresa patrocinadora da pesquisa.

O SHV foi instalado junto a um reservatório de $40 \mathrm{~m}^{3}$ de água limpa, do qual uma bomba centrífuga de $80 \mathrm{CV}$ bombeava água para dentro da unidade. A vazão que adentrava no SHV era controlada por intermédio de válvulas de sangria localizadas na tubulação de recalque da bomba (Figura 3.2(c)); as medições de vazão eram feitas em um medidor de vazão, instalado a jusante dessas sangrias (Figura 3.2(a, b)). 


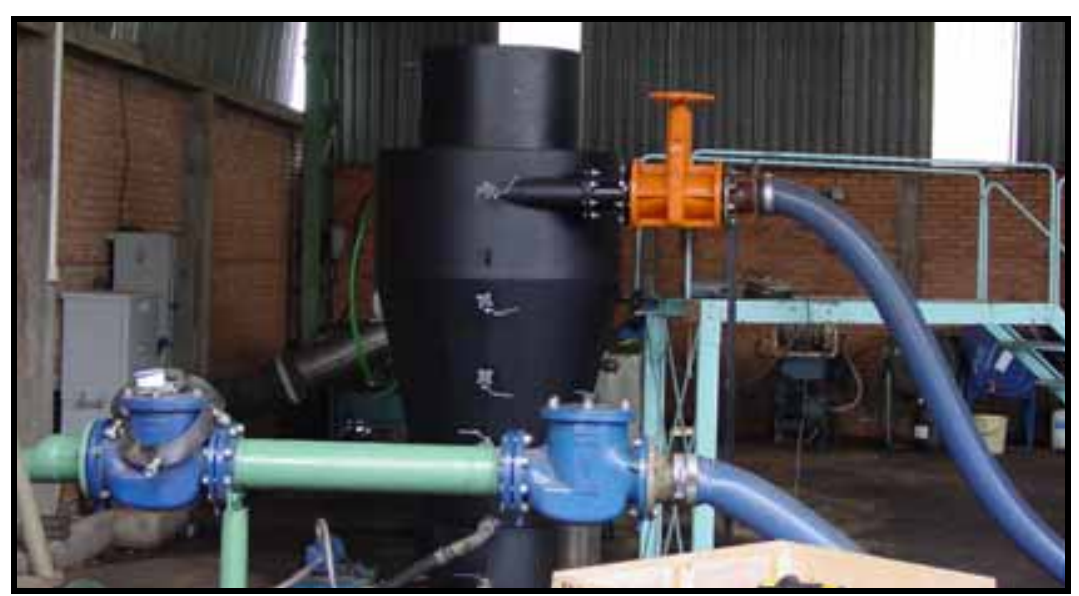

(a)

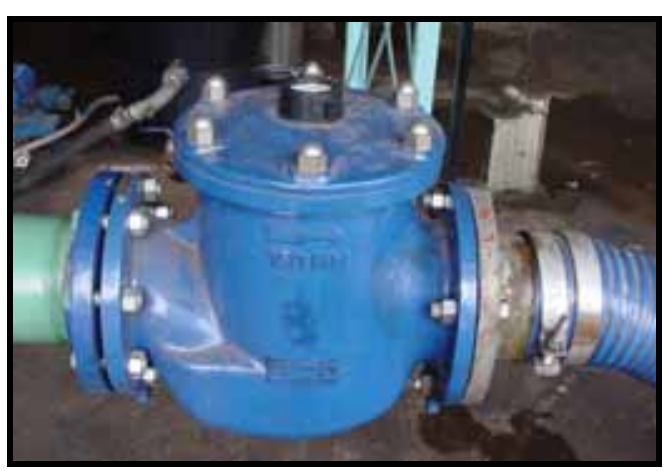

(b)

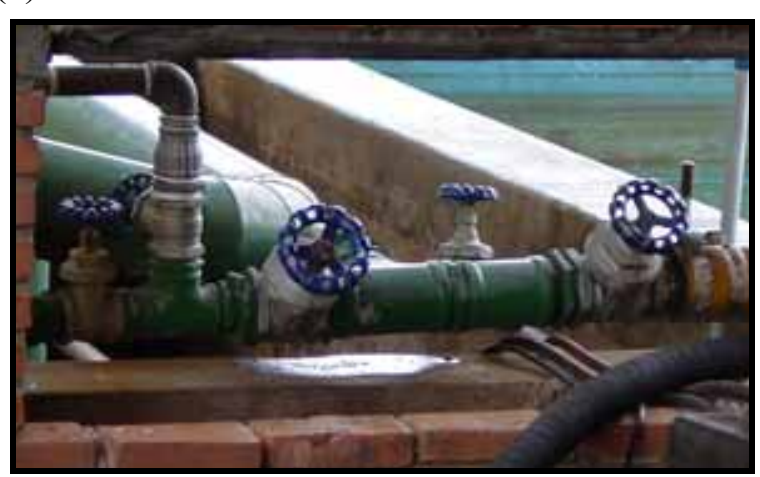

(c)

Figura 3.2 - Fotos do SHV instalado na bancada de teste da PROMINAS e detalhes do medidor de vazão e das válvulas de sangria: (a) foto do SHV mostrando a parte da tubulação de recalque na qual o medidor de vazão está instalado; (d) foto do medidor de vazão utilizado e (c) foto mostrando detalhe das válvulas de sangria empregadas para controlar a vazão de alimentação do SHV.

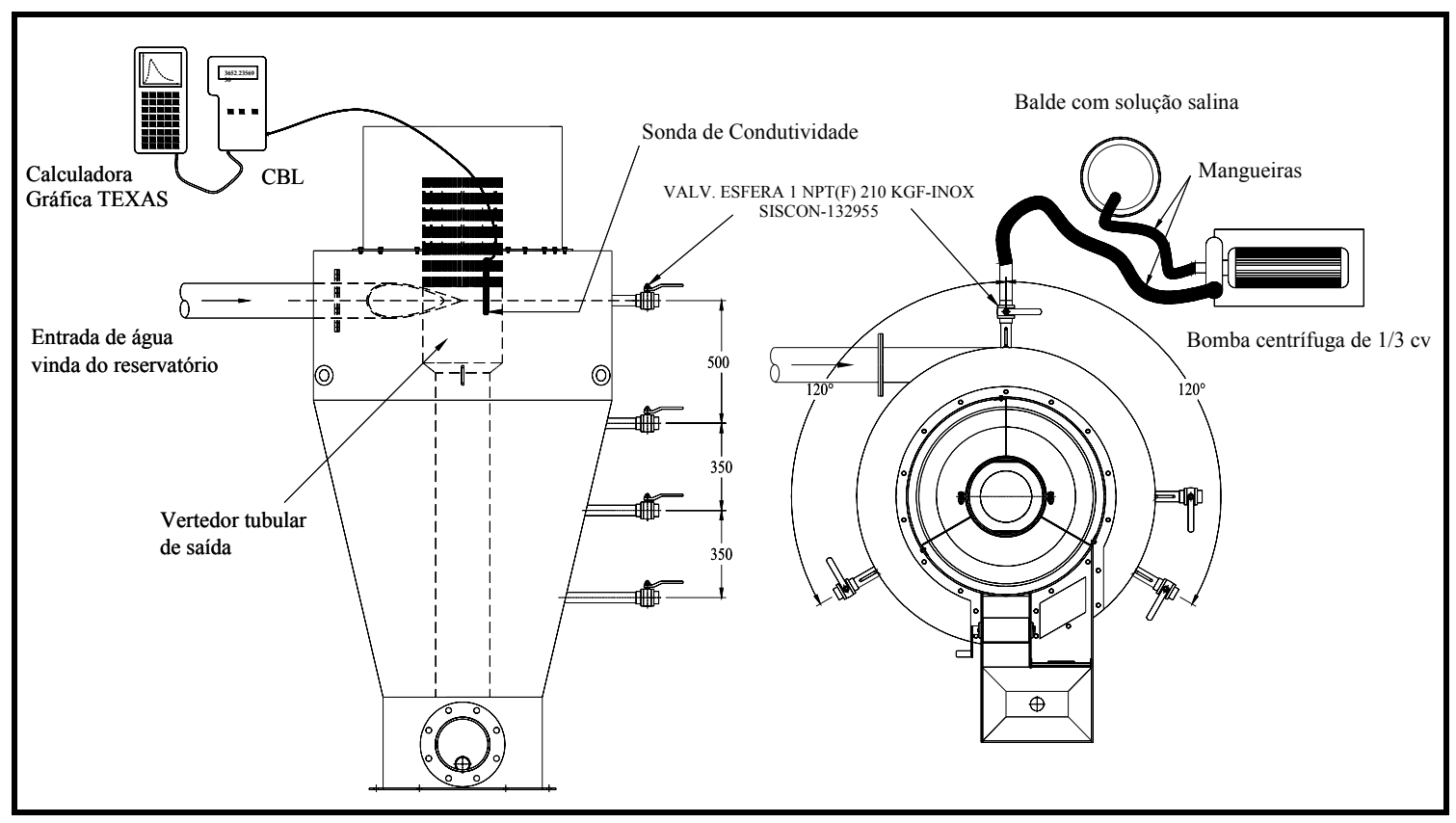

Figura 3.3 - Esquema do aparato experimental utilizado para a realização dos ensaios de estímulo-resposta. 
O traçador empregado em todos os ensaios foi uma solução de cloreto de sódio $(\mathrm{NaCl}$ - sal de cozinha). Esta solução era bombeada para dentro do SHV por intermédio de uma bomba centrífuga de $1 / 3 \mathrm{CV}$, enquanto uma sonda de condutividade (conectada a um CBL2 - Calculator-Based Laboratory - e a uma calculadora gráfica TI-89 Texas Instruments com software TI-Graph Link 89), posicionada dentro do vertedor tubular de saída da unidade, media a variação deste parâmetro, ao longo do tempo (Figura 3.3).

Em cada ensaio, aproximadamente, cinco litros da solução de cloreto de sódio eram introduzidos através de uma válvula localizada junto à entrada do SHV (Figuras 3.3 e 3.4). Este procedimento levava cerca de três segundos. Logo após o início da injeção da solução salina, iniciava-se a medição da variação da condutividade pela sonda, em intervalos $(\Delta \mathrm{t})$ de um segundo, durante 480 segundos ( $8 \mathrm{~min}): 3,2$ vezes o tempo de detenção hidráulica teórico $\left(\mathrm{TDH}_{\mathrm{t}}\right)$ do SHV para vazão de 10 1/s; 4,8 vezes o $\mathrm{TDH}_{\mathrm{t}}$ do SHV para vazão de 15 1/s e 6,4 vezes o $\mathrm{TDH}_{\mathrm{t}}$ do $\mathrm{SHV}$ para vazão de 20 1/s.

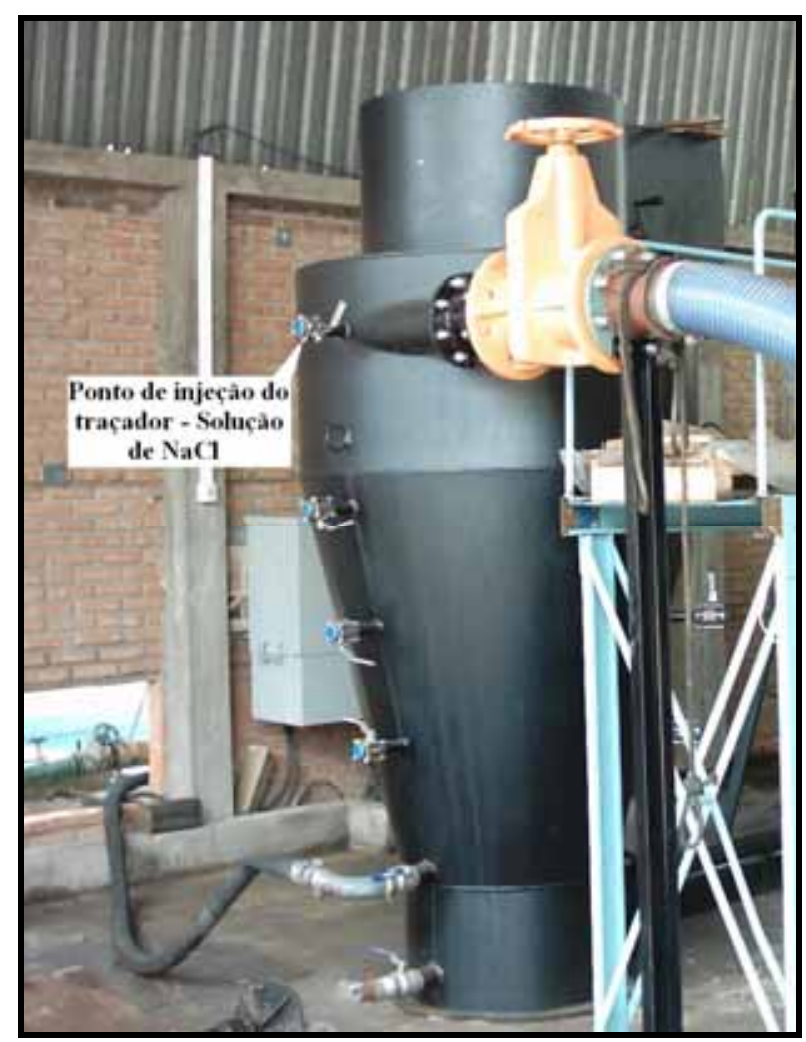

Figura 3.4 - Foto do SHV instalado na bancada de testes da PROMINAS, na qual pode-se observar o ponto de injeção do traçador (solução de $\mathrm{NaCl}$ ) usado nos ensaios de estímulo-resposta. 
Devido à diferença entre o tempo de injeção da solução de cloreto de sódio (3 s) e o tempo de duração dos ensaios (480 s), a injeção de traçador foi classificada como do tipo pulso. Um esquema do aparato experimental necessário para a execução dos ensaios de estímulo-resposta pode ser observado na Figura 3.3.

\subsubsection{Materiais e equipamentos necessários à realização dos ensaios de estímulo-resposta}

Para realização dos ensaios de estímulo-resposta no separador hidrodinâmico por vórtice (SHV) foram necessários:

- Solução de $\operatorname{NaCl}$ (5 a 7 g/l), preparada de acordo com a faixa de detecção da sonda de condutividade utilizada;

- $\quad$ Balde graduado (de 5 em 5 litros);

- $\quad$ Bomba centrífuga de $1 / 3 \mathrm{CV}$;

- Sonda de condutividade programável, que realiza amostragens em intervalos de tempo $(\Delta \mathrm{t})$ fixos;

- Mangueiras para ligar o balde à bomba e esta à unidade em estudo;

\subsubsection{Procedimentos adotados na execução dos ensaios de estímulo- resposta}

Os procedimentos adotados para a execução dos ensaios de estímulo-resposta no separador hidrodinâmico por vórtice (SHV) foram:

A. Preparar solução concentrada de $\mathrm{NaCl}$ (sal de cozinha - 5 a 7 g/l) de acordo com a faixa de detecção da sonda de condutividade;

B. Dispor volume conhecido desta solução em balde graduado (5 litros); 
C. Conectar a mangueira de sucção da bomba de $1 / 3 \mathrm{CV}$ ao balde, e a mangueira de recalque da mesma ao SHV;

D. Fixar a vazão de alimentação do SHV (10 1/s; 15 1/s ou 20 1/s);

E. Programar o tempo total do ensaio ( 3 a 4 vezes o $\mathrm{TDH}_{\mathrm{t}}$ da unidade) e os intervalos de tempo $(\Delta \mathrm{t})$ em que serão feitas as medições de condutividade;

F. Fixar a sonda de condutividade dentro do vertedor de saída da unidade;

G. Ligar a bomba e iniciar as medições de condutividade simultaneamente;

H. Esperar o volume conhecido de solução concentrada de $\mathrm{NaCl}$ ser bombeado e desligar a bomba;

I. Aguardar o fim da coleta de dados pela sonda.

\subsubsection{Levantamento das pressões totais em pontos no interior do separador hidrodinâmico por vórtice}

\subsubsection{Considerações iniciais}

Como já mencionado nesse texto, o objetivo da realização das medições de pressão total no interior do separador hidrodinâmico por vórtice (SHV) foi levantar dados para validação dos resultados obtidos nas simulações computacionais. Porém, uma questão ainda não foi respondida: por que a pressão total foi a grandeza escolhida se os resultados das simulações computacionais utilizados na análise da hidrodinâmica do SHV foram os campos de velocidade? Seria razoável considerar a velocidade a grandeza mais indicada para ser usada no processo de validação; todavia, diversas dificuldades técnicas e principalmente econômicas impossibilitaram a aquisição ou, ainda, o desenvolvimento de um medidor de velocidades que pudesse ser empregado na execução de tal tarefa.

As medições de pressão total foram realizadas com medidor de pressão do tipo Pitot, especialmente desenvolvido para esse propósito, o qual era constituído de corpo cilíndrico de nylon axialmente vazado, com rosca de uma polegada em uma de suas 
extremidades e por haste de alumínio de meia polegada de diâmetro que atravessava axialmente o cilindro de nylon (Figura 3.5(a, b)). Mantendo o cilindro de nylon fixo em uma posição, era possível deslocar a haste de alumínio de um lado para o outro através do corpo cilíndrico do medidor de pressão.

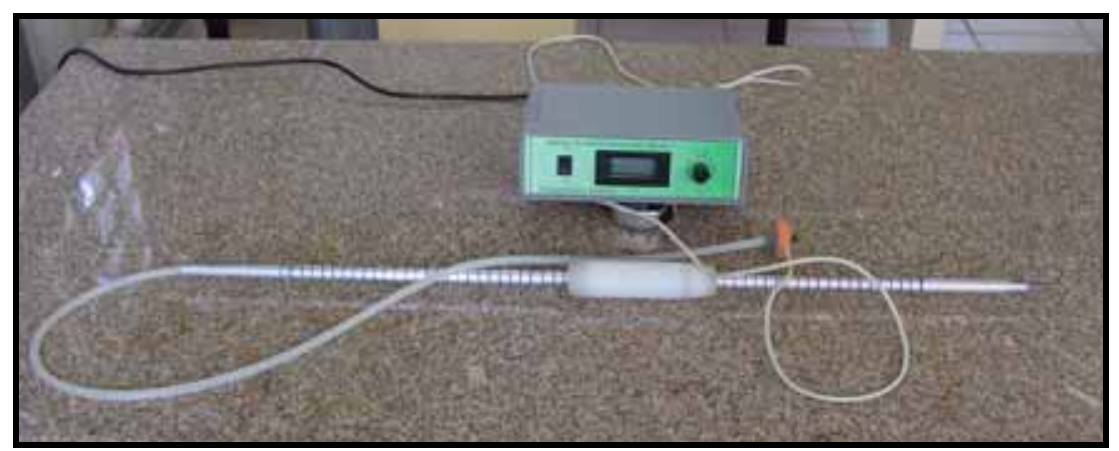

(a)

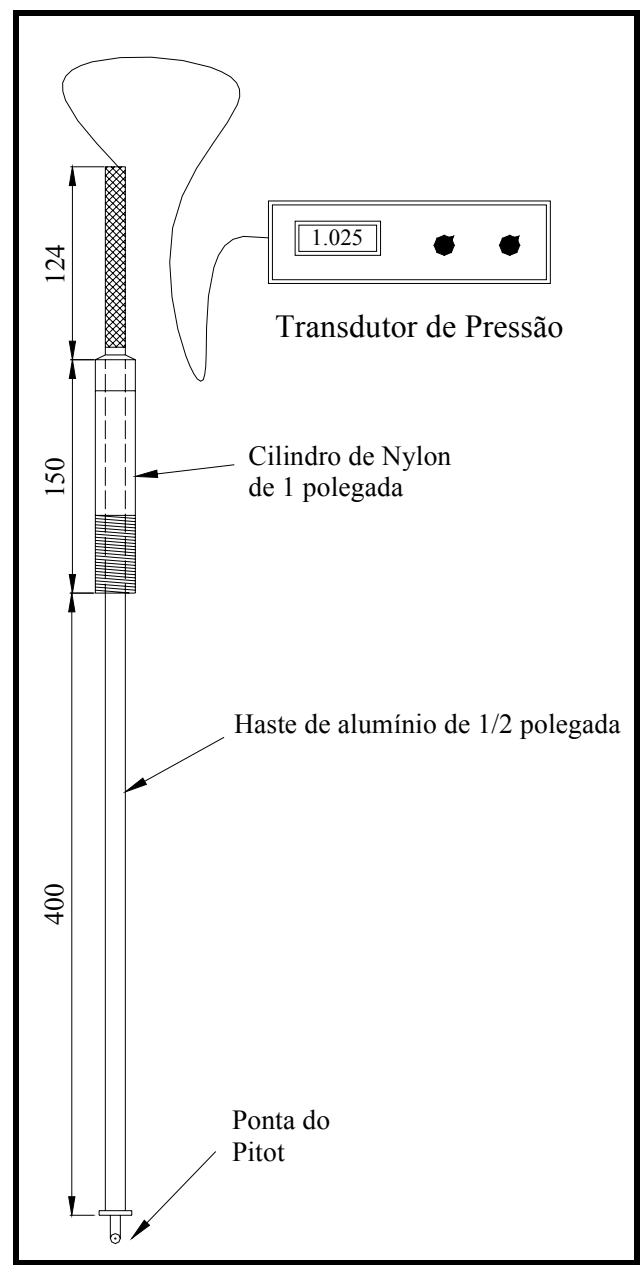

(b)

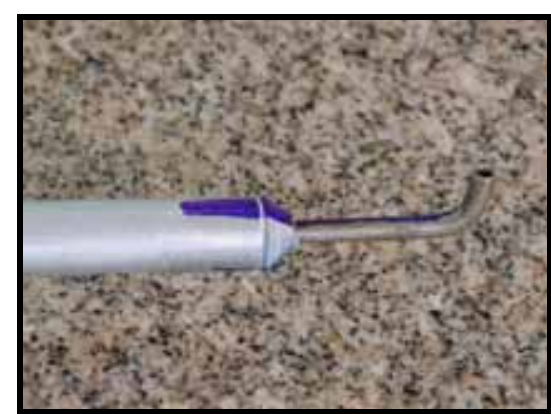

(c)

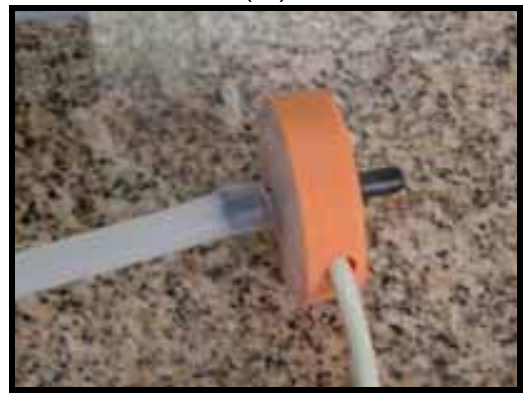

(d)

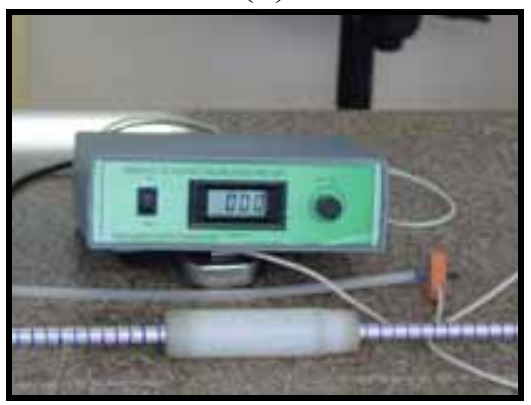

(e)

Figura 3.5 - Tubo Pitot projetado e construído para realização das medições de pressão total no interior do SHV. (a) Foto do conjunto completo: corpo cilíndrico, haste de alumínio, ponteira do Pitot, transdutor de pressão e conversor de sinais com display digital. (b) Desenho esquemático do tubo Pitot. (c) Foto da ponteira do Pitot conectada a uma as pontas da haste de alumínio. (d) Foto do transdutor de pressão. (e) Foto do conversor de sinais com display digital. 
Em uma das pontas da haste de alumínio fixava-se a ponteira do Pitot (Figura 3.5(c)), e na outra ponta conectava-se um transdutor de pressão (Figura 3.5(d)) a uma mangueira de silicone que estava ligada à ponteira do Pitot. $\mathrm{O}$ transdutor de pressão era interligado a um conversor de sinais que amplificava e convertia, em valores numéricos que podiam ser lidos em um display digital, os pequenos sinais elétricos emitidos pelo transdutor, quando este era submetido a variações de pressão (Figura 3.5(e)).

Para ser possível o acesso da ponteira do Pitot ao interior do SHV, foram instaladas doze válvulas (uma polegada) ao redor da parede externa da unidade. Essas válvulas foram dispostas em três linhas verticais espaçadas uma das outras $(\mathrm{V} 1 \mathrm{j}$; V2j e $\mathrm{V} 3 \mathrm{j}$ ). A primeira linha de válvulas (V1j) foi instalada de forma que a primeira válvula, de cima para baixo, (V11) ficasse junto ao final da tubulação de entrada da unidade (Figura 3.6). A partir da posição da primeira linha de válvulas foram posicionadas as duas outras linhas, de forma que cada uma delas ficasse a $120^{\circ}$ uma das outras, como mostra a Figura 3.8.

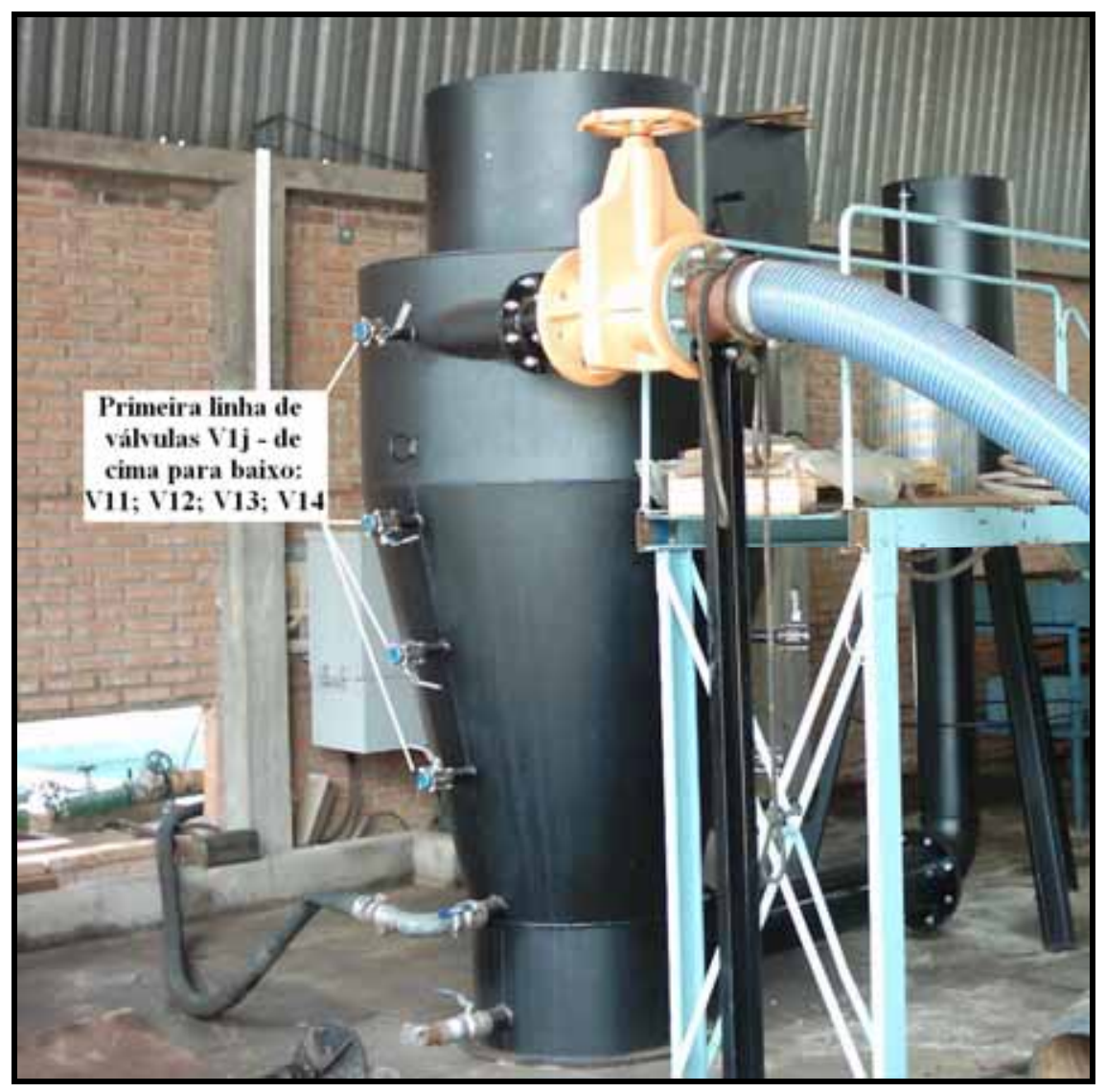

Figura 3.6 - Foto do separador hidrodinâmico por vórtice instalado na bancada de testes da PROMINAS durante a execução das medições de pressão total. 


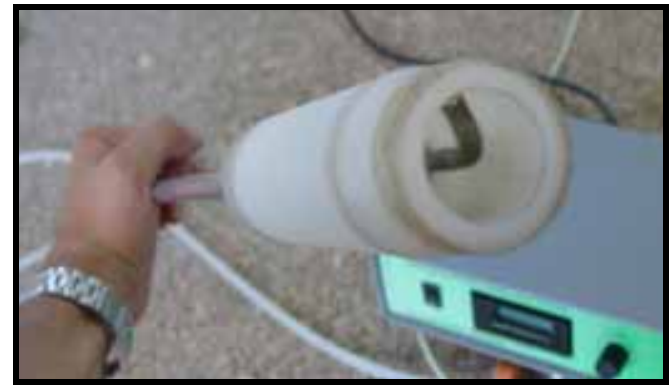

(a)

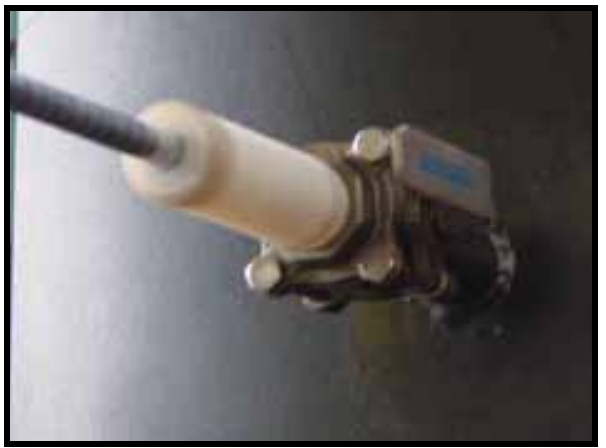

(c)

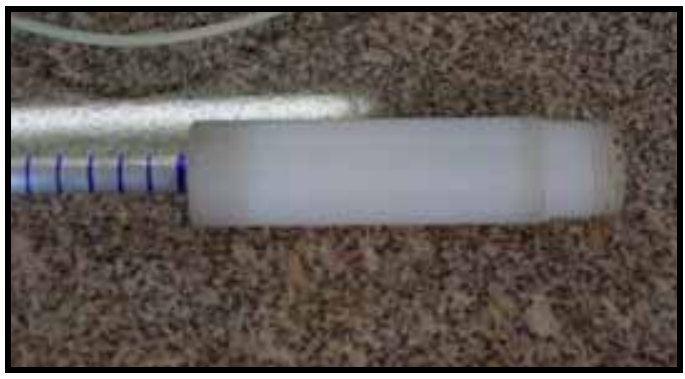

(b)

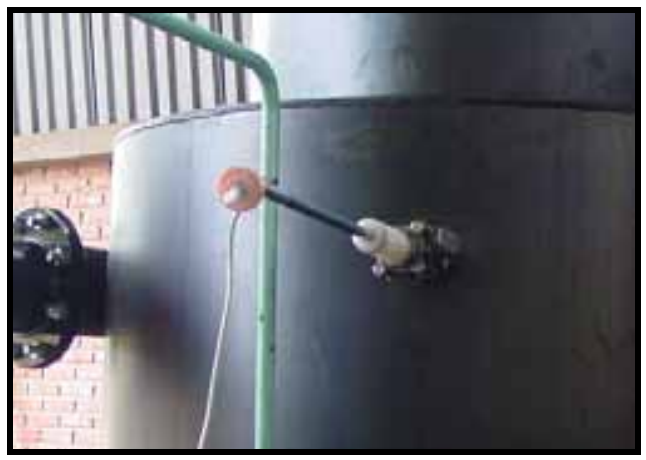

(d)

Figura 3.7 - Fotos do medidor de pressão do tipo Pitot. (a) Foto da ponteira do Pitot dentro do corpo cilíndrico de nylon. (b) Foto da ponteira o Pitot totalmente "escondida" dentro do corpo cilíndrico de nylon. (c) Foto do corpo cilíndrico de nylon rosqueado em uma das válvulas instaladas na parede externa do SHV. (d) Foto do medidor de pressão conectado a uma válvula, com parte da haste de alumínio no interior o SHV e com o transdutor de pressão conectado no final da haste.

Em umas das extremidades do corpo cilíndrico no medidor de pressão havia uma abertura na qual, ao se retrair ao máximo a haste de alumínio ao máximo, era possível "esconder" a ponteira do Pitot, como mostra a Figura 3.7(a, b). Para realizar as medições bastava: retrair a ponteira do Pitot para dentro do corpo cilíndrico do medidor de pressão, rosquear o corpo cilíndrico em uma das doze válvulas instaladas na parede externa do SHV, abrir a válvula e introduzir a haste com a ponteira do Pitot no interior da unidade (Figura 3.7(c, d)).

\subsubsection{Materiais e equipamentos necessários para realização das medições de pressão total}

Para a execução das medições de pressão total no interior do separador hidrodinâmico por vórtice (SHV), foram necessários: 


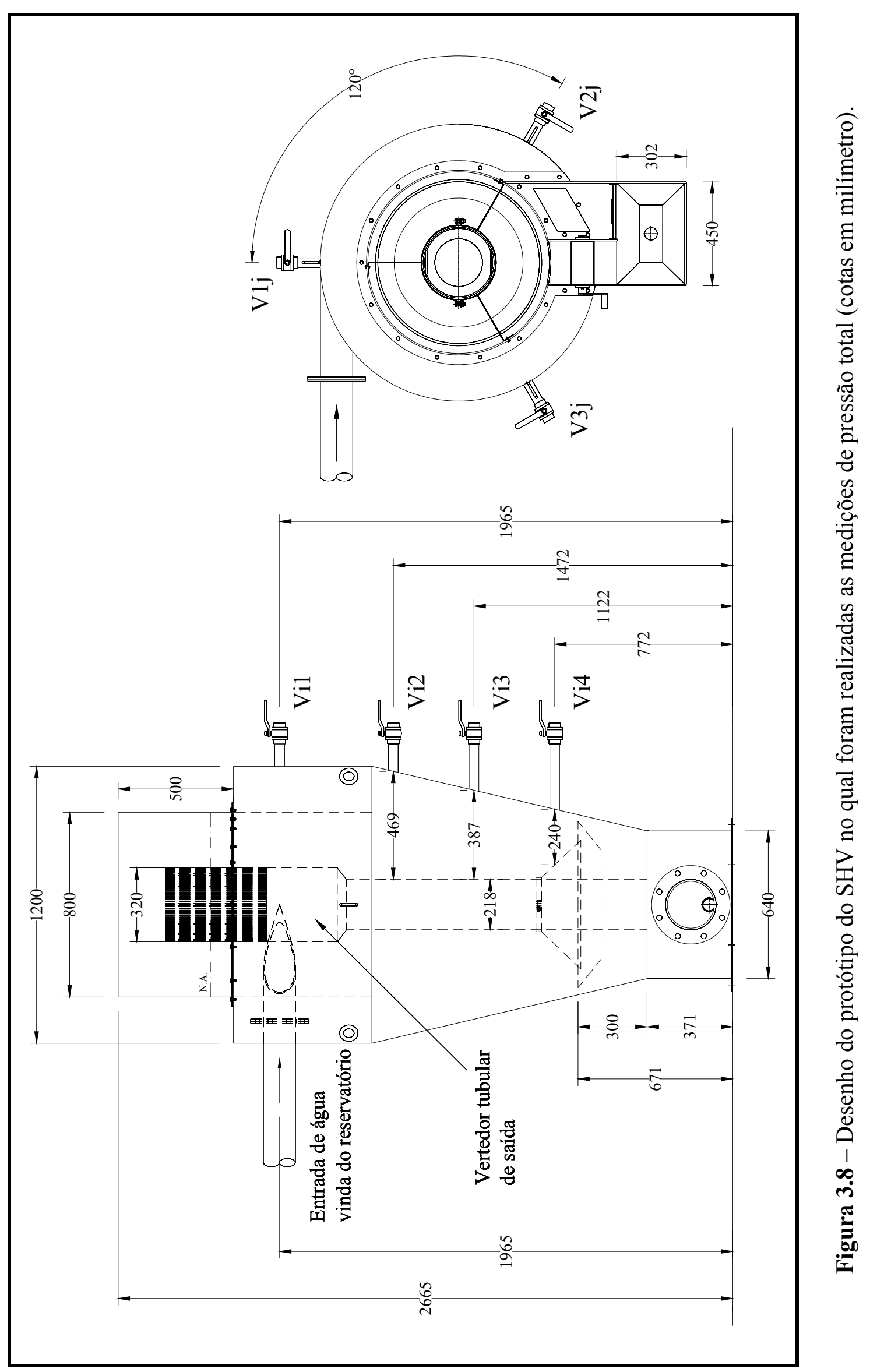


- Medidor de pressão do tipo Pitot especialmente desenvolvido para realização das medições de pressão total;

- $\quad$ Transdutor de pressão;

- $\quad$ Conversor de sinal com display digital;

- $\quad$ Cronômetro digital;

- $\quad$ Caneta de retroprojetor;

- $\quad$ Caneta e papel para anotação;

\subsubsection{Procedimentos adotados nas medições de pressão total}

Os procedimentos adotados para a execução de todas as medições de pressão total no interior do separador hidrodinâmico por vórtice (SHV) foram:

A. Com a caneta de retroprojetor graduar a haste de alumínio como uma régua, com espaçamentos de um centímetro (Figura 3.9);

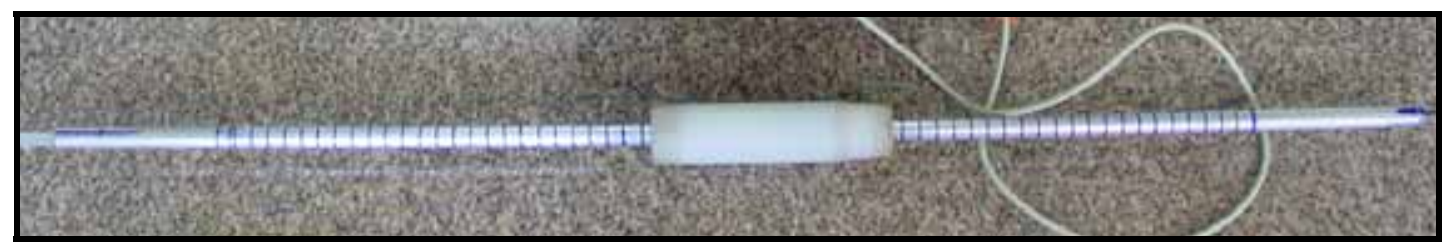

Figura 3.9 - Foto do tubo Pitot mostrando a haste de alumínio já graduada com espaçamento de um centímetro.

B. Escolher uma seqüência de válvulas para realização das medições - na presente pesquisa a seqüência escolhida foi: V11, V21, V31, V12, V22, V32, V13, V23, V33, V14, V24, V34, V44;

C. Fixar a vazão de alimentação do SHV (10 1/s; 15 1/s ou 20 1/s);

D. Desconectar o transdutor de pressão da mangueira que o liga à ponteira do Pitot; 
E. Retrair a haste de alumínio ao máximo de forma que a ponteira com Pitot fique totalmente dentro o corpo cilíndrico de nylon do medidor de pressão;

F. Rosquear o corpo cilíndrico do medidor de pressão em uma das doze válvulas localizadas na parede externa do SHV, conforme a seqüência escolhida para a execução das medições;

G. Abrir a válvula e introduzir a ponteira do Pitot no interior do SHV, deixando que seja purgado o ar preso na mangueira de silicone que liga a ponteira do Pitot ao transdutor de pressão;

H. Usar a graduação feita na haste de alumínio do medidor de pressão para fixar o ponto de leitura (a Figura 3.10 mostra a distribuição dos pontos onde foram feitas as leituras de pressão total);

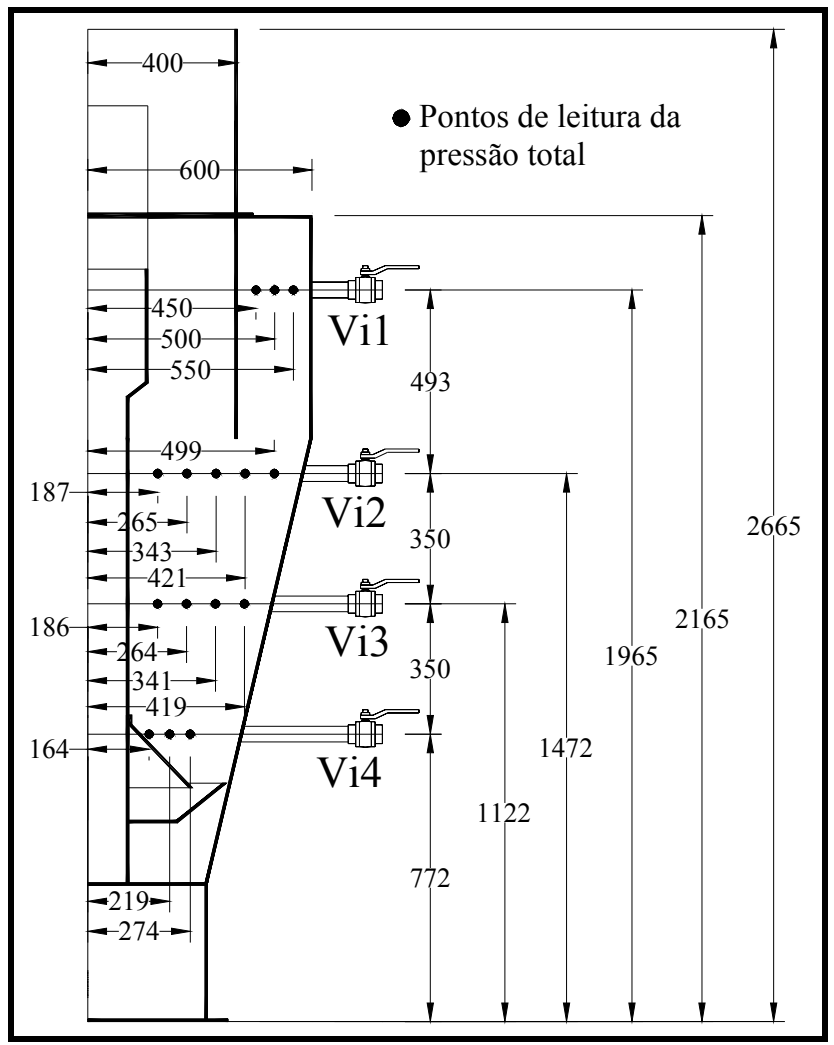

Figura 3.10 - Desenho mostrando metade da seção transversal do SHV com os pontos de leitura de pressão total (cotas em milímetro).

I. Zerar a leitura mostrada no display do conversor de sinais e conectar o transdutor de pressão à mangueira de silicone que o liga à ponteira do Pitot, como mostra a Figura 3.11; 


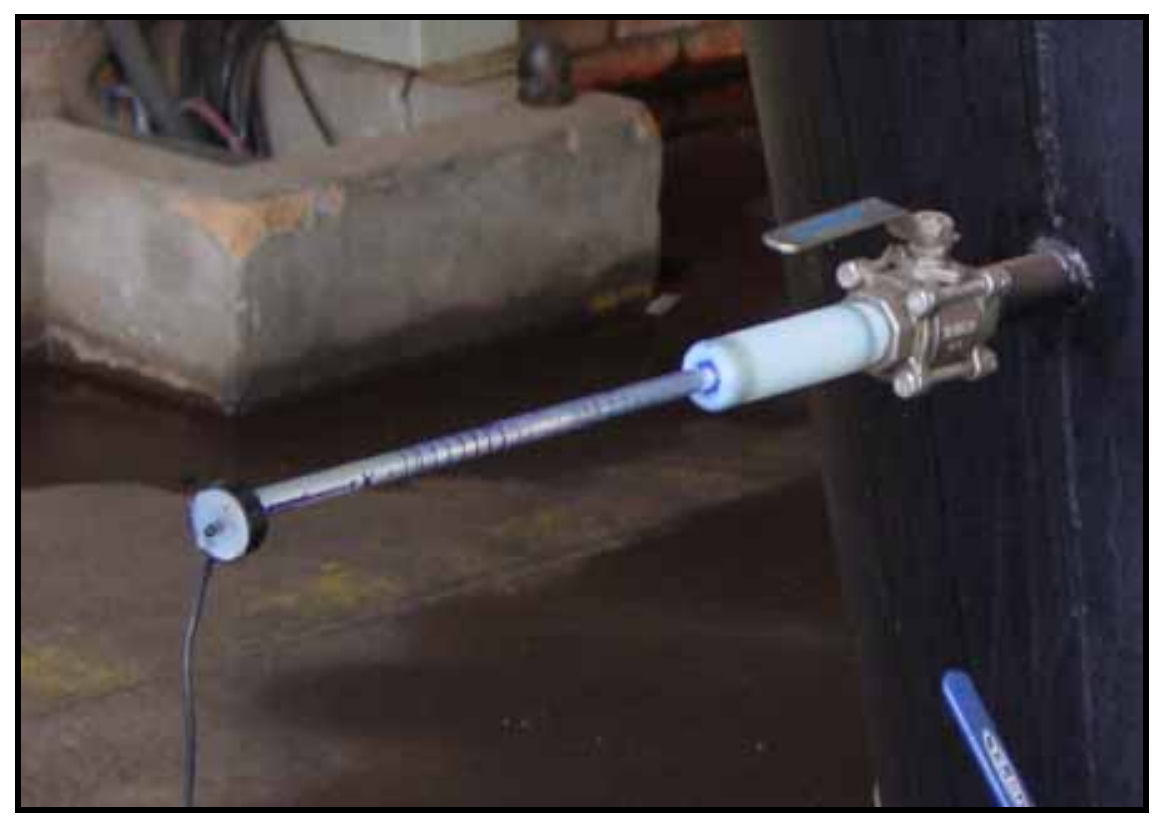

Figura 3.11 - Foto do tubo Pitot com o transdutor de pressão conectado na extremidade da haste de alumínio.

J. Depois de fixado o ponto no qual se pretende realizar a medição, disparar o cronômetro e, a cada dez segundos, anotar o valor de pressão total mostrado no display do conversor de sinais, na presente pesquisa foram anotados 20 valores de pressão para cada ponto de medição;

K. Repetir os procedimentos D, E, F, G, H, I e J para cada ponto de medição previamente escolhido;

\subsubsection{Simulações computacionais do padrão de escoamento do separador hidrodinâmico por vórtice}

Devido à potencialidade, demonstrada pela literatura, do emprego de simulações computacionais no estudo da hidrodinâmica de unidades de separação sólido-líquido, somada ao fato de um software multipropósito de dinâmica dos fluído computacional, amplamente utilizado pelo setor industrial, chamado CFX 10.0, produzido pela ANSYS $^{\circledR}$, encontrar-se disponível para uso no Departamento de Hidráulica e Saneamento da Escola de Engenharia de São Carlos (EESC), foram realizadas algumas simulações do padrão de escoamento do SHV, tema deste trabalho de pesquisa. O 
objetivo dessas simulações foi calcular os campos de pressão e velocidade que se desenvolvem no SHV para as três vazões estudadas 10L/s, 15L/s e 20L/s.

Um modelo tridimensional simplificado, não obstante, com as mesmas dimensões do SHV, que fora construído para a realização dessa pesquisa (Figura 3.12(a, b)), foi desenhado em um software denominado 3DEdge (3DEdge faz parte do pacote do CFX 10.0 da ANSYS $^{\circledR}$ ). O cesto de peneira, localizado no topo do vertedor tubular de saída da unidade, foi substituído por um cilindro e a perda de carga na peneira foi simulada adicionando-se um perfil hidrostático de pressão na face interna desse cilindro (Figura 3.12(a, b)).

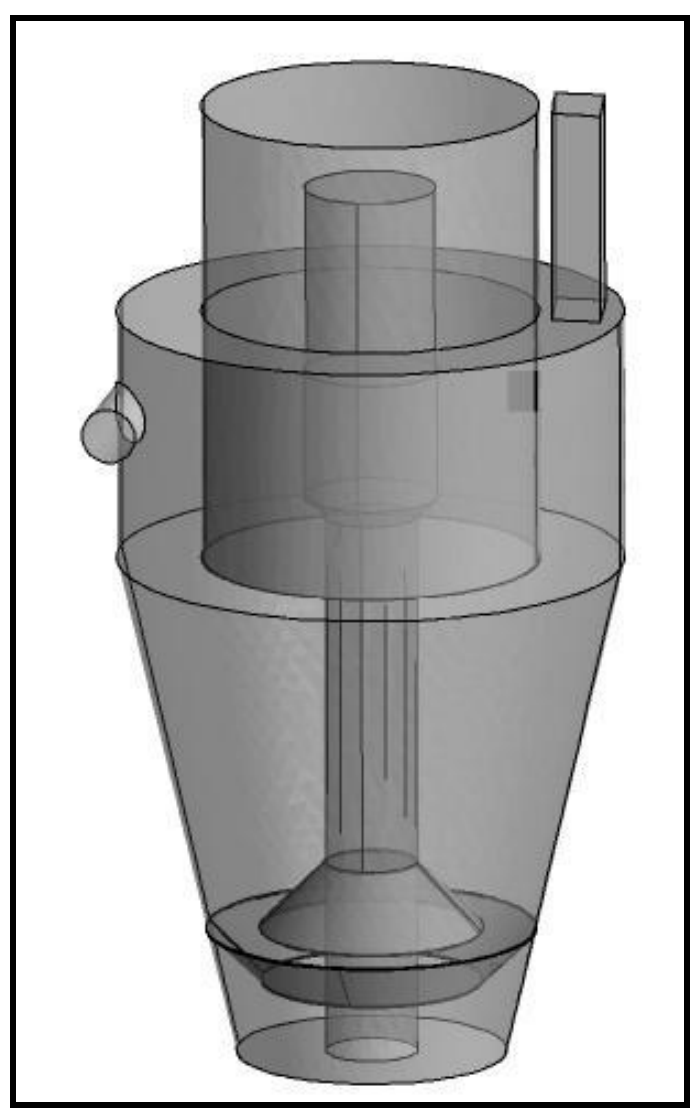

(a)

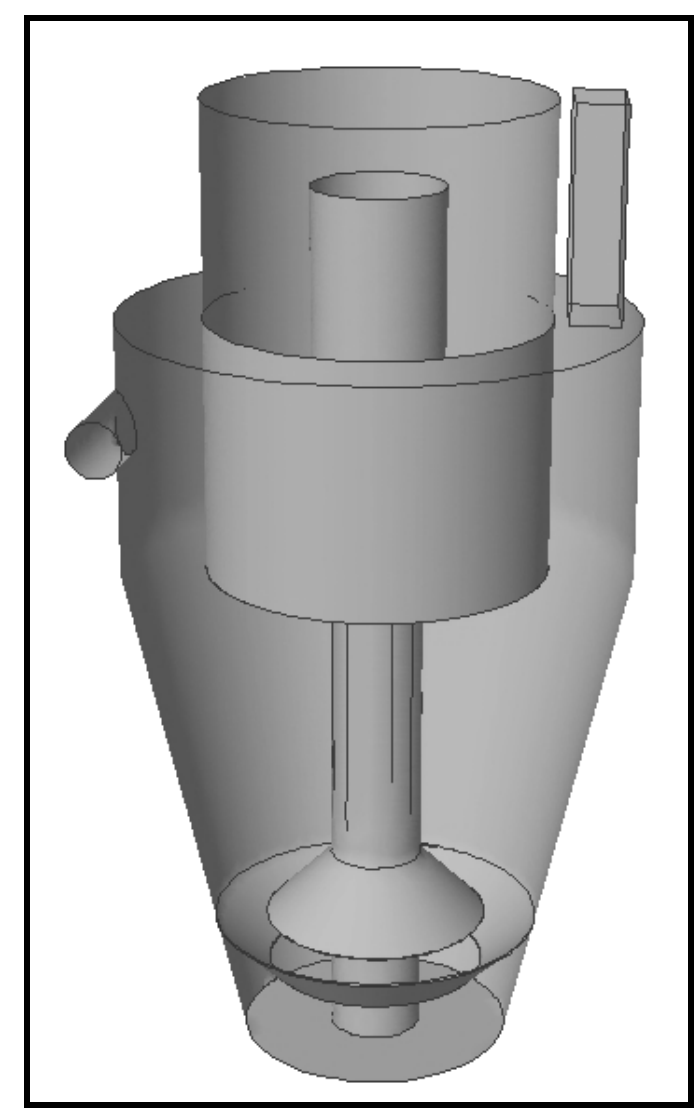

(b)

Figura 3.12 - Modelo tridimensional desenhado no software 3DEdge utilizado nas simulações computacionais.

Uma malha, com 913.924 células computacionais (ou elementos de malha) e 231.637 nós, foi automaticamente gerada em um software de nome CAD2 Mesh, também pertencente ao pacote do CFX 10.0 (Figura 3.13(a)). A malha gerada era composta por 720.128 elementos tetraédricos, 190.906 elementos prismáticos (forma de 
cunha) e 2.890 elementos piramidais. Vale ressaltar a importância da utilização dos elementos prismáticos junto às paredes do SHV (Figura 3.13(b, c)), pois são nesses elementos que os efeitos de camada limite são calculados. Em algumas simulações realizadas sem a presença desse tipo de malha, os campos de velocidade calculados durante as simulações apresentaram valores incoerentes, porquanto as velocidades no interior da unidade eram superiores (até duas vezes maiores) àquelas encontradas na tubulação de entrada do SHV.

O grande número de células computacionais é justificável, porquanto, consoante CFX (2004), quanto maior for o número de células computacionais, maior será a resolução da simulação, pois o CFX 10.0 obtém suas respostas, resolvendo iterativamente as equações de Navier-Stokes (equações médias de Reynolds) e da continuidade para cada um dos volumes de controle estabelecidos (células computacionais ou elementos de malha). Este método numérico utilizado pelo CFX 10.0 é conhecido como técnica dos volumes finitos; contudo, sua apresentação e discussão fogem do escopo desta pesquisa.

Todas as simulações foram realizadas considerando o escoamento no interior do SHV em regime permanente e, para computar os efeitos de escoamentos com altos números de Reynolds (escoamentos turbulentos), foi empregado nas simulações um modelo de turbulência conhecido como Tensões de Reynolds (Reynolds Stress Model). Não foi utilizado qualquer critério especial na escolha do modelo de turbulência. $\mathrm{O}$ modelo de Tensões de Reynolds foi o adotado por ser o mais simples em uma lista de modelos, disponíveis no software, os quais consideram a anisotropia da turbulência dentro do domínio de escoamento, além de ser o modelo adotado por diversos pesquisadores que trabalham com simulações computacionais do escoamento em SHVs (FARAM e HARWOOD, 2002, 2003; EGARR et al., 2004).

As simulações eram encerradas depois de duas condições serem satisfeitas: tempo simulado maior ou igual a $150 \mathrm{~s}$ (tempo de detenção hidráulica teórico para a vazão de 10 1/s) e erro residual das interações $(\Delta \mathrm{e})$ menor ou igual a $10^{-3}$. Este valor de erro residual pode ser considerado muito alto pela maioria dos matemáticos e fluidodinamicistas porém, segundo Okamoto et al. (2002) e Faram e Harwood (2003), ele é suficientemente adequado se o objetivo da execução das simulações for apenas a 
realização de análises qualitativas do padrão de escoamento de uma unidade de processo ou operação unitária.

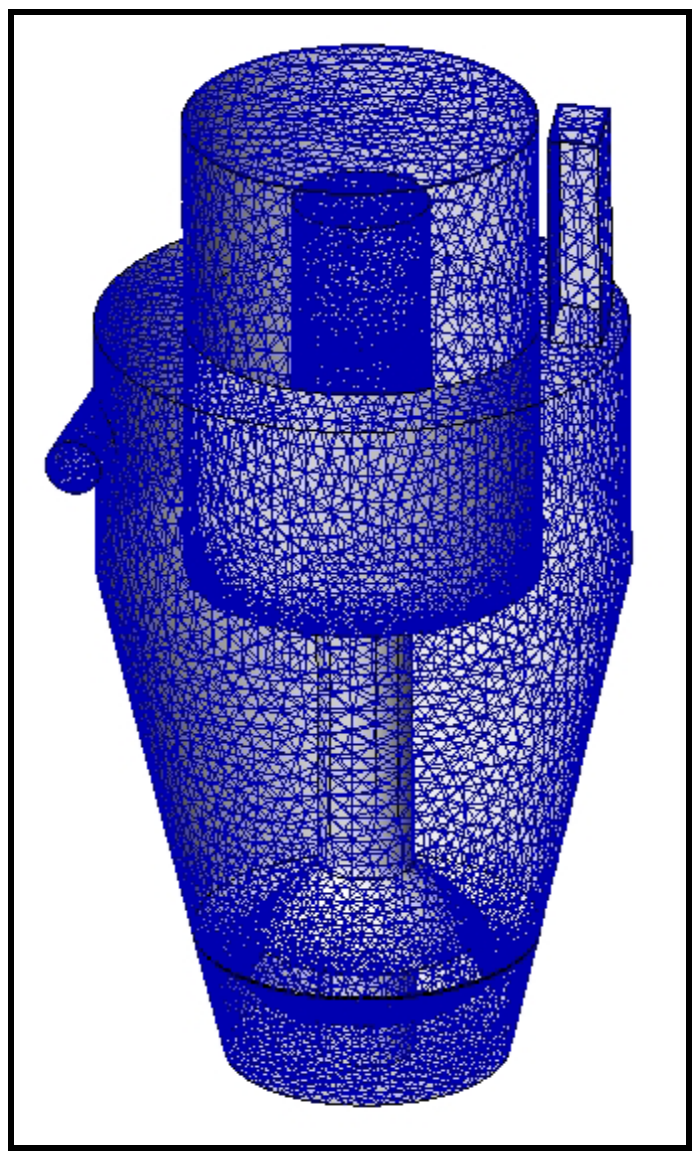

(a)

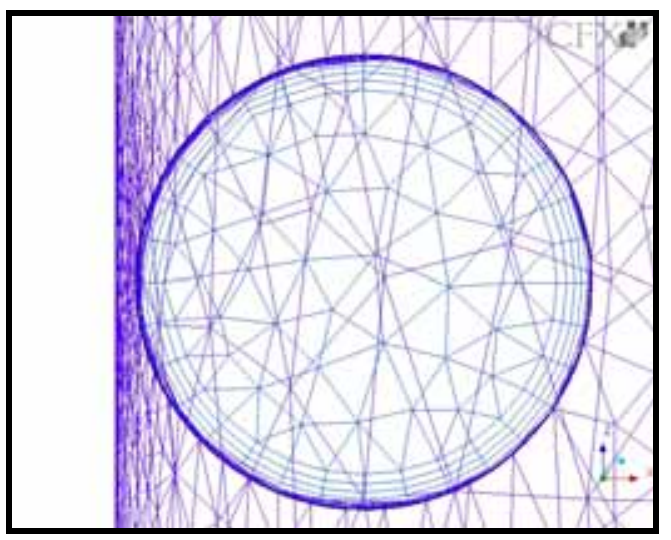

(b)

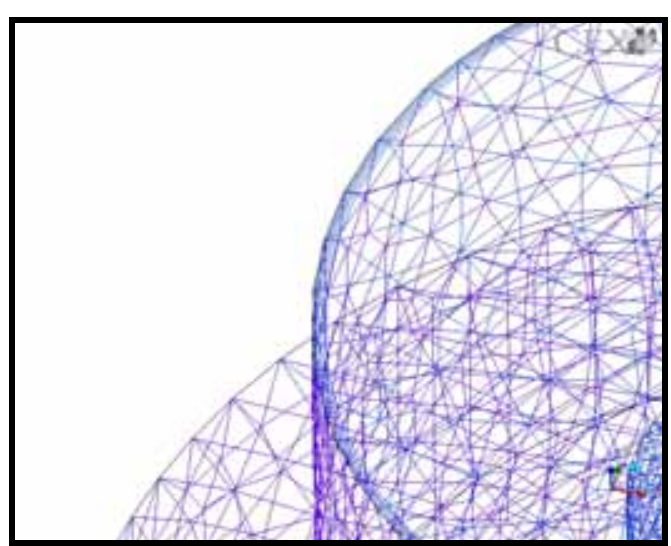

(c)

Figura 3.13 - Malha gerada pelo software CAD2 Mesh, utilizada nas simulações. (a)

Vista geral da malha. (b) Detalhe mostrando a malha prismática junto à parede da tubulação de entrada. (c) Detalhe da malha prismática junto à parede do cilindro interno do SHV.

A Tabela 3.1 traz as principais informações acerca das simulações, como: características gerais da malha, propriedades dos fluidos (água e ar), passo de tempo, 
tempo de processamento, tempo simulado, características do processador empregado, condições de contorno iniciais e critérios de parada adotados.

Tabela 3.1 - Características gerais do domínio (malha), dos fluidos, da simulação, das condições de contorno iniciais e do critério de parada adotado para as simulações computacionais.

\begin{tabular}{|c|c|c|c|}
\hline \multicolumn{4}{|c|}{ Domínio } \\
\hline \multicolumn{2}{|c|}{ Número de nós } & \multicolumn{2}{|c|}{231.637} \\
\hline \multicolumn{2}{|c|}{ Número de elementos } & \multicolumn{2}{|c|}{913.924} \\
\hline \multicolumn{2}{|c|}{ Elementos tetraédricos } & \multicolumn{2}{|c|}{720.128} \\
\hline \multicolumn{2}{|c|}{ Elementos piramidais } & \multicolumn{2}{|c|}{2.890} \\
\hline \multicolumn{2}{|c|}{ Elementos prismáticos } & \multicolumn{2}{|c|}{190.906} \\
\hline \multicolumn{4}{|c|}{ Fluido } \\
\hline \multicolumn{2}{|c|}{ Água } & \multicolumn{2}{|c|}{ Ar } \\
\hline Temperatura & $25^{\circ} \mathrm{C}$ & Temperatura & $25^{\circ} \mathrm{C}$ \\
\hline Viscosidade dinâmica & $8,899 \times 10^{-4} \mathrm{~kg} / \mathrm{m} . \mathrm{s}$ & Viscosidade dinâmica & $1,831 \times 10^{-5} \mathrm{~kg} / \mathrm{m} . \mathrm{s}$ \\
\hline Massa específica & $998 \mathrm{~kg} / \mathrm{m}^{3}$ & Massa específica & $1,185 \mathrm{~kg} / \mathrm{m}^{3}$ \\
\hline $\begin{array}{l}\text { Coef. de tensão } \\
\text { superficial }\end{array}$ & $0,0732 \mathrm{~N} / \mathrm{m}$ & & \\
\hline
\end{tabular}

\begin{tabular}{cc}
\hline & Simulação \\
\hline Regime de escoamento & Regime permanente (falso transiente) \\
Passo de tempo & $0,1 \mathrm{~s}$ \\
Tempo simulado & $\approx 150 \mathrm{~s}$ \\
Características do processador & AMD Opteron 64 Processor TM 844 Authentica \\
& MD \\
Tempo de processamento de dados pela CPU & $\approx 5,5 \times 10^{5} \mathrm{~s}$ \\
\hline
\end{tabular}

\section{Condições de Contorno Iniciais}

\begin{tabular}{|c|c|}
\hline Paredes & Paredes rugosas $($ rugosidade $=0.06 \mathrm{~mm})$ \\
\hline Topo & Aberto \\
\hline Entrada & $\begin{array}{l}\text { Velocidade normal ao plano de entrada: } \\
\qquad \quad \mathrm{Q}=10 \mathrm{l} / \mathrm{s}=>\mathrm{v}=0,787 \mathrm{~m} / \mathrm{s} \\
\bullet \quad \mathrm{Q}=15 \mathrm{l} / \mathrm{s}=>\mathrm{v}=1,181 \mathrm{~m} / \mathrm{s} \\
\bullet \quad \mathrm{Q}=20 \mathrm{l} / \mathrm{s}=>\mathrm{v}=1,567 \mathrm{~m} / \mathrm{s}\end{array}$ \\
\hline Saída & Pressão hidrostática \\
\hline \multicolumn{2}{|r|}{ Critério de Parada } \\
\hline \multicolumn{2}{|c|}{$\Delta \mathrm{e}<1,0 \times 10^{-3}$ e Tempo simulado $\geq 150 \mathrm{~s}$} \\
\hline
\end{tabular}




\subsection{Resultados Experimentais}

\subsubsection{Resultados dos ensaios de estímulo-resposta}

Os dados de variação de condutividade coletados e armazenados durante a execução dos ensaios de estímulo-resposta foram transformados, consoante Levenspiel (2000), em curvas de distribuição de idade de saída $\mathrm{E}(\mathrm{t})$ e curvas de distribuição de idade de saída padronizada $\mathrm{E}(\theta)$, as quais podem ser observadas na Figura 3.14(a, b). Vale lembrar que cada ensaio de estímulo-resposta foi executado em duplicata, logo, as curvas finais de $E(t)$ e $E(\theta)$ de cada vazão (10 l/s; 15 l/s e 20 l/s) são resultados médios de dois ensaios.

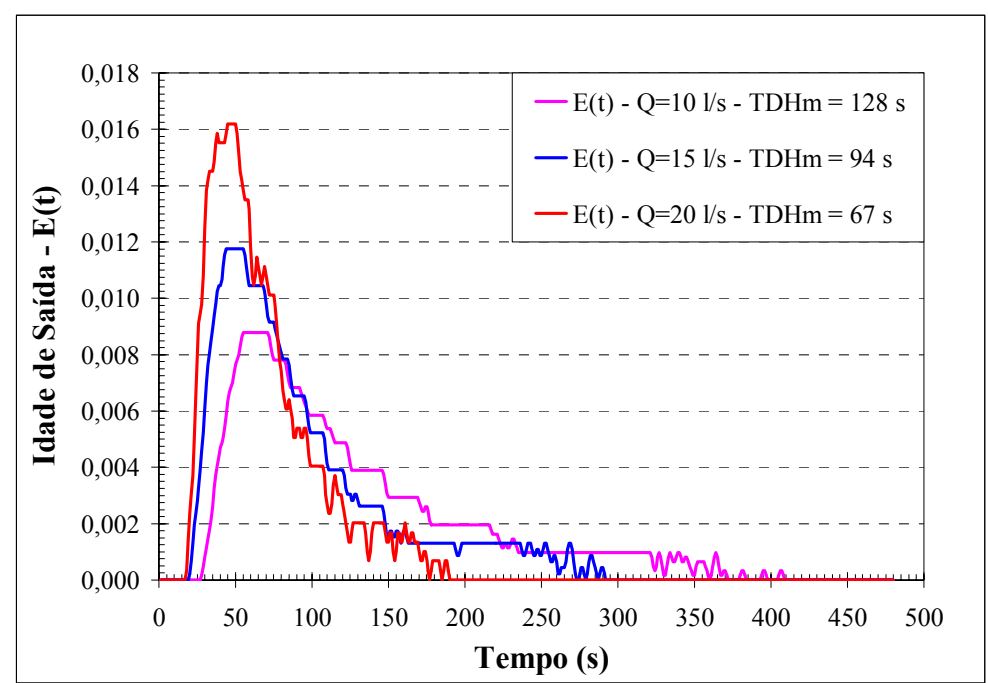

(a)

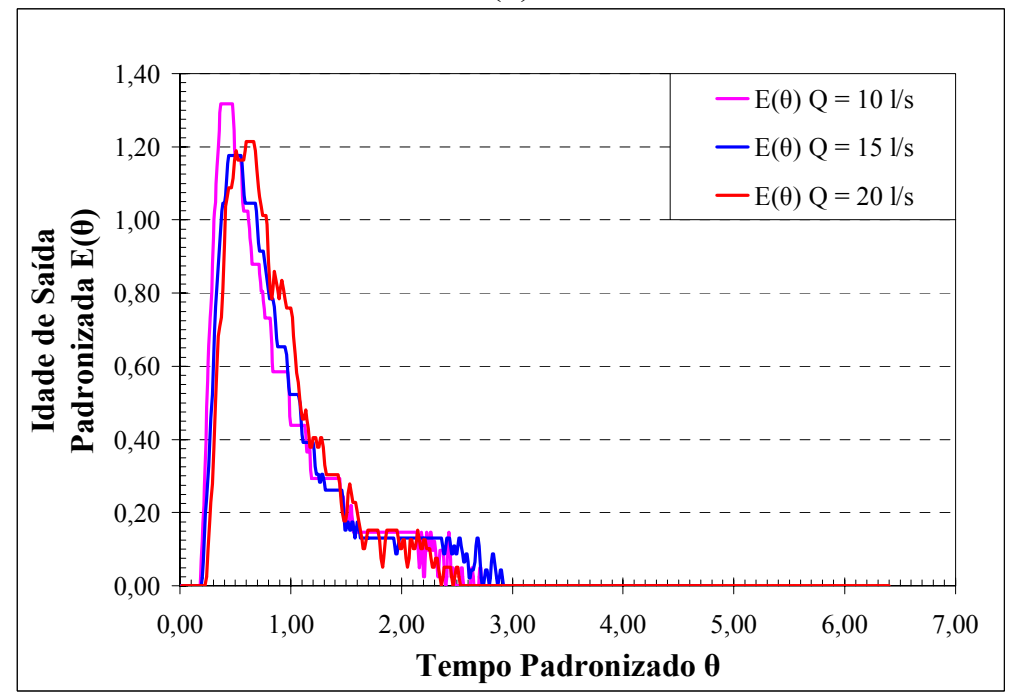

(b)

Figura 3.14 - Curvas de distribuição de idade de saída: (a) Curvas de distribuição de idade de saída $\mathrm{E}(\mathrm{t})$ para cada uma das vazões estudadas (10 l/s; 15 l/s e 20 1/s); (b) Curvas de distribuição de idade de saída padronizada $\mathrm{E}(\theta)$ para cada uma das vazões estudadas ( $10 \mathrm{l} / \mathrm{s} ; 15 \mathrm{l} / \mathrm{s}$ e $20 \mathrm{l} / \mathrm{s})$. 
As curvas de distribuição de idade de saída E(t) mostradas na Figura 3.14(a) apresentam picos pronunciados e "caudas" longas. Tal comportamento sugere que o regime de macro-mistura do escoamento que se desenvolve no separador hidrodinâmico por vórtice (SHV) estudado é do tipo plug-flow, porém, com algum grau de mistura (dispersão axial). Percebe-se que ao se aumentar a vazão de alimentação da unidade, o comprimento da cauda das curvas de $\mathrm{E}(\mathrm{t})$ diminui. Isto indica que quanto maior a vazão, mais pistonado é o escoamento dentro do SHV. O mesmo pode ser concluído pela análise das curvas de distribuição de idade de saída padronizada $E(\theta)$ da Figura 3.14(b), pois o aumento da vazão, faz com que o pico das curvas de $\mathrm{E}(\theta)$ aproxime-se do valor de $\theta$ igual a um sugerindo, também, que o aumento da vazão de alimentação do SHV, faz o escoamento na unidade ficar mais pistonado.

Como base no volume útil do SHV (aproximadamente 1.500 litros) e nas três vazões empregadas para alimentá-lo (10 1/s, 15 l/s e 20 1/s), foram calculados os tempos de detenção hidráulica teóricos $\left(\mathrm{TDH}_{\mathrm{t}}\right)$ da unidade; a partir das curvas de distribuição de idade de saída $\mathrm{E}(\mathrm{t})$ estimou-se, pelo método dos momentos (Equação 3.1), os tempos de detenção hidráulica médios $\left(\mathrm{TDH}_{\mathrm{m}}\right)$ para cada uma das vazões de alimentação do SHV. Destas curvas foram obtidos, também, os três tempos de detenção hidráulica modais $\left(\mathrm{TDH}_{\mathrm{p}}\right)$ - tempo para o qual se verifica o pico das curvas de $\mathrm{E}(\mathrm{t})$. Todos esses dados são apresentados na Tabela 3.2, juntamente com as razões: $\mathrm{TDH}_{\mathrm{m}}$ por $\mathrm{TDH}_{\mathrm{t}}$, que indica a relação entre o volume ativo e o volume útil do $\mathrm{SHV}$; e $\mathrm{TDH}_{\mathrm{p}}$ por $\mathrm{TDH}_{\mathrm{t}}$, que indica a relação entre o volume com escoamento pistonado e o volume útil do SHV (LEVENSPIEL, 2000; METCALF \& EDDY, 2003).

$$
\mathrm{TDH}_{\mathrm{m}}=\sum \mathrm{t}_{\mathrm{i}} \cdot \mathrm{E}\left(\mathrm{t}_{\mathrm{i}}\right) \cdot \Delta \mathrm{t}_{\mathrm{i}}
$$

Em que:

$\mathrm{TDH}_{\mathrm{m}}$ : Tempo de detenção hidráulica médio $(\mathrm{T})$;

$\mathrm{t}_{\mathrm{i}}$ : i-ésimo tempo $(\mathrm{T})$;

$\mathrm{E}\left(\mathrm{t}_{\mathrm{i}}\right)$ : Valor da idade de saída para o i-ésimo tempo $\left(\mathrm{T}^{-1}\right)$;

$\Delta \mathrm{t}_{\mathrm{i}}$ : i-ésimo intervalo de tempo $(\mathrm{T})$. 
Tabela 3.2 - Valores dos tempos de detenção hidráulica teóricos, médios (calculados pelo método dos momentos) e modais (correspondente ao pico das curvas de distribuição de idade de saída $\mathrm{E}(\mathrm{t})$ ), das razões entre tempo de detenção hidráulica médio e tempo de detenção hidráulica teórico, que indica a relação entre volume ativo e

o volume útil do SHV, assim como das razões entre tempo de detenção hidráulica modal e tempo de detenção hidráulica teórico, que indica a relação entre volume com escoamento pistonado e o volume útil do SHV.

\begin{tabular}{cccccc}
\hline $\begin{array}{c}\text { Vazão } \\
(1 / \mathrm{s})\end{array}$ & $\begin{array}{c}\mathrm{TDH}_{\mathrm{t}} \\
(\mathrm{s})\end{array}$ & $\begin{array}{c}\mathrm{TDH}_{\mathrm{m}} \\
(\mathrm{s})\end{array}$ & $\begin{array}{c}\mathrm{TDH}_{\mathrm{p}} \\
(\mathrm{s})\end{array}$ & $\frac{\mathrm{TDH}_{\mathrm{m}}}{\mathrm{TDH}_{\mathrm{t}}}$ & $\frac{\mathrm{TDH}_{\mathrm{p}}}{\mathrm{TDH}_{\mathrm{t}}}$ \\
\hline 10,0 & 150 & 128 & 62 & 0,85 & 0,41 \\
15,0 & 100 & 94 & 49 & 0,94 & 0,49 \\
20,0 & 75 & 67 & 47 & 0,89 & 0,63 \\
\hline
\end{tabular}

$\mathrm{TDH}_{\mathrm{t}}$ : Tempo de detenção hidráulica teórico; $\mathrm{TDH}_{\mathrm{m}}$ : Tempo de detenção hidráulica médio, calculado pelo método dos momentos; $\mathrm{TDH}_{\mathrm{p}}$ : Tempo de detenção hidráulica modal, que corresponde ao pico da curva de distribuição da idade de saída $\mathrm{E}(\mathrm{t})$.

Os valores da razão $\mathrm{TDH}_{\mathrm{p}}$ por $\mathrm{TDH}_{\mathrm{t}}$ apresentados na Tabela 3.2 atestam a hipótese de que o aumento da vazão de alimentação do SHV faz com que o escoamento no interior da unidade fique mais pistonado. Observa-se que ao se alimentar o SHV com vazão de 10 1/s apenas $41 \%$ do volume útil da unidade apresenta escoamento com regime de macro-mistura do tipo plug-flow, e que ao se aumentar a vazão de alimentação do SHV para 15 l/s e depois para 20 l/s, este percentual sobe para $49 \%$ e $63 \%$, respectivamente.

Dois modelos de escoamento propostos em Alkhaddar et al. (2001a) foram ajustados às curvas de distribuição da idade de saída $\mathrm{E}(\mathrm{t})$ mostradas na Figura 3.14(a). O primeiro deles é um modelo de dispersão axial (AMD - Axial Dispersion Model) que possui como parâmetros de ajuste: o tempo de detenção hidráulica médio $\left(\mathrm{TDH}_{\mathrm{m}}\right)$, obtido pelo método dos momentos, e a variância padronizada, que pode ser calculada pela Equações 3.3 e 3.4. O segundo modelo utilizado é um modelo de tanques em série (TISM - Tanks-in-Series Model), o qual tem com parâmetros de ajuste o tempo de detenção hidráulica médio $\left(\mathrm{TDH}_{\mathrm{m}}\right)$, obtido pelo método dos momentos, e o número de tanques em série com mistura perfeita $(\mathrm{N})$ que representam o escoamento no SHV. As Equações 3.2 e 3.5 descrevem o modelo de dispersão axial e o modelo de tanques em série empregados, respectivamente. 


$$
\begin{gathered}
M(t)=\sqrt{\frac{\mathrm{TDH}_{\mathrm{m}}}{2 \cdot \pi \cdot \pi_{\theta}^{2} \cdot \mathrm{t}^{3}} \cdot \exp \left[-\frac{\left(\mathrm{t}-\mathrm{TDH}_{\mathrm{m}}\right)^{2}}{2 \cdot \mathrm{TDH}_{\mathrm{m}} \cdot \sigma_{\theta}^{2}}\right]} \\
\sigma_{\theta}^{2}=\frac{\sigma^{2}}{\mathrm{TDH}_{\mathrm{m}}^{2}} \\
\sigma^{2}=\sum \mathrm{t}_{\mathrm{i}}^{2} \cdot \mathrm{E}\left(\mathrm{t}_{\mathrm{i}}\right) \cdot \Delta \mathrm{t}_{\mathrm{i}}-\mathrm{TDH}_{\mathrm{m}}^{2} \\
M(\mathrm{t})=\frac{\mathrm{N}^{\mathrm{N}} \cdot \mathrm{t}^{\mathrm{N}-1}}{\mathrm{TDH}_{\mathrm{m}}^{\mathrm{N}} \cdot(\mathrm{N}-1) !} \cdot \exp \left[-\frac{\mathrm{N} \cdot \mathrm{t}^{\mathrm{TDH}}}{\mathrm{m}}\right]
\end{gathered}
$$

Em que:

$\mathrm{M}(\mathrm{t})$ : Curva de idade de saída obtida pelos modelos $\left(\mathrm{T}^{-1}\right)$;

$\sigma_{\theta}^{2}:$ Variância padronizada;

$\sigma^{2}$ : Variância, obtida pelo método dos momentos (Equação 3.4) $\left(\mathrm{T}^{2}\right)$;

t: Tempo qualquer $(\mathrm{T})$;

N: Número de tanques em série, parâmetro do modelo TISM;

A Figura 3.15(a) mostra a curva de distribuição de idade de saída experimental $\mathrm{E}(\mathrm{t})$ e as curvas de distribuição de idade de saída $\mathrm{M}(\mathrm{t})$, obtidas a partir do ajuste dos modelos de dispersão axial (ADM) e de tanques em série (TISM) para a vazão de 10 1/s. Observa-se que o modelo de dispersão axial ajustou-se melhor aos dados experimentais. Tal fato pode ser comprovado analisando as curvas de regressão linear na Figura 3.15(b, c). Nota-se que a curva de regressão linear (linha cheia) do modelo de dispersão axial da Figura 3.15(b) além de apresentar coeficiente de determinação maior $\left(\mathrm{R}^{2}=0,950\right.$ - $\mathrm{ADM}$; $\mathrm{R}^{2}=0,836$ - TISM), praticamente, coincide com a linha pontilhada (linha a $45^{\circ}$ ), a qual indica o ajuste perfeito entre modelo e dados experimentais. 


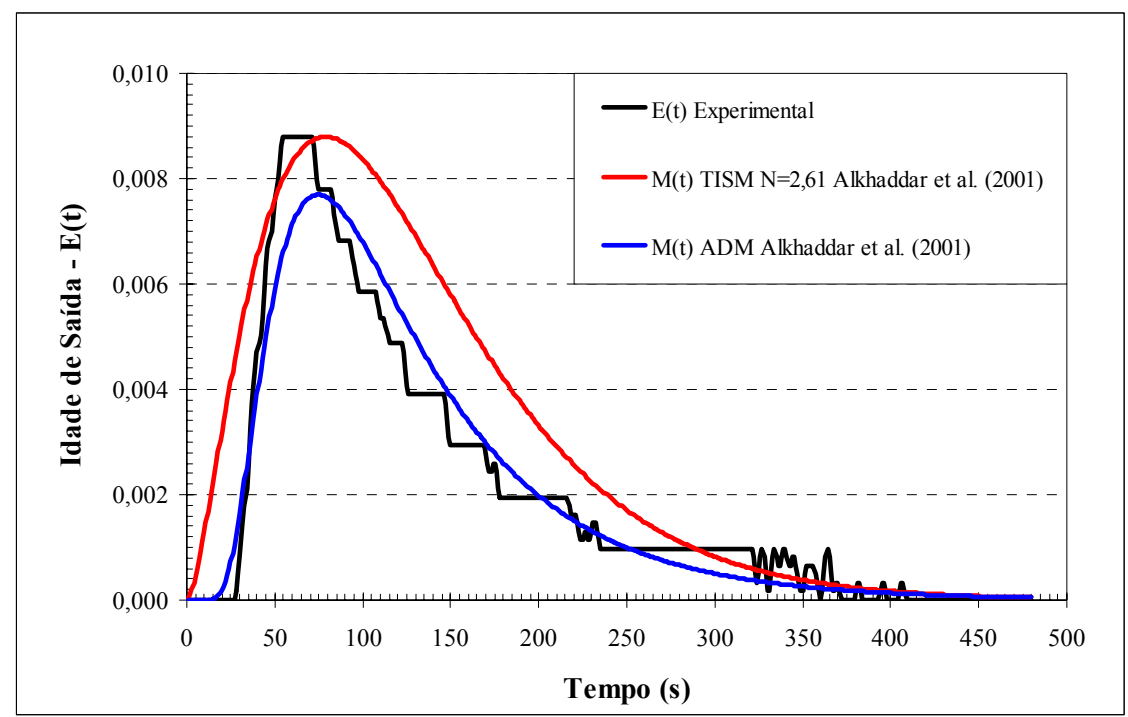

(a)

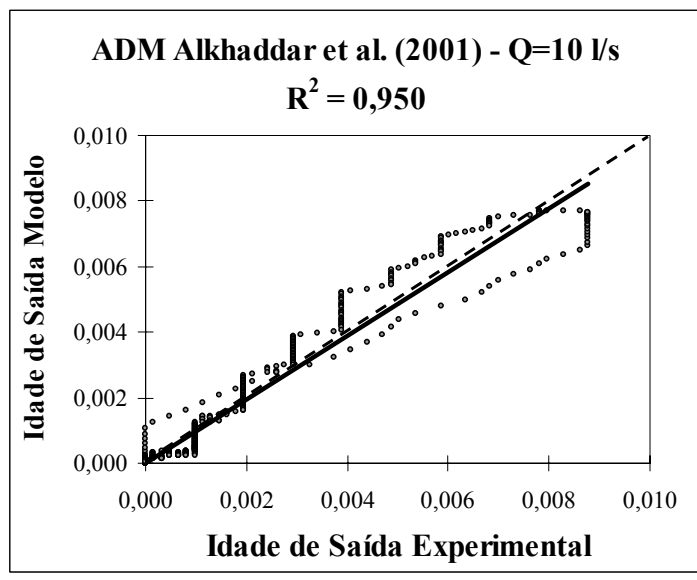

(b)

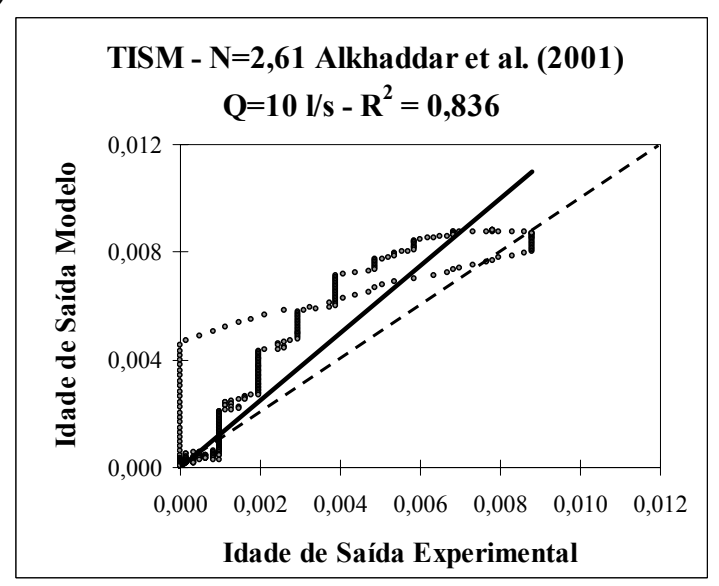

(c)

Figura 3.15 - Curva de distribuição de idade de saída E(t) para a vazão de alimentação do SHV de 10 1/s e curvas M(t) dos modelos ADM e TISM ajustadas. (a) Curva da distribuição da idade de saída $\mathrm{E}(\mathrm{t})$, assim como, as curvas $\mathrm{M}(\mathrm{t})$ dos dois modelos, ADM e TISM; (b) curva de regressão mostrando a qualidade do ajuste do modelo ADM; (c) curva de regressão mostrando a qualidade do ajuste do modelo TISM.

A Figura 3.16(a) mostra a curva de distribuição de idade de saída experimental $\mathrm{E}(\mathrm{t})$ e as curvas de distribuição de idade de saída $\mathrm{M}(\mathrm{t})$, obtidas a partir do ajuste dos modelos de dispersão axial (ADM) e de tanques em série (TISM) para a vazão de 15 1/s. Observa-se que, para esta vazão, mais uma vez o modelo de dispersão axial foi o que melhor ajustou-se aos dados experimentais. Tal fato pode ser comprovado analisando-se as curvas de regressão linear na Figura 3.16(b, c). Nota-se que a curva de regressão linear (linha cheia) do modelo de dispersão axial da Figura 3.16(b) além de possuir coeficiente de determinação maior $\left(\mathrm{R}^{2}=0,973\right.$ - $\mathrm{ADM} ; \mathrm{R}^{2}=0,884$ - TISM), praticamente, coincide com a linha pontilhada (linha a $45^{\circ}$ ), a qual indica o ajuste perfeito entre modelo e dados experimentais. 


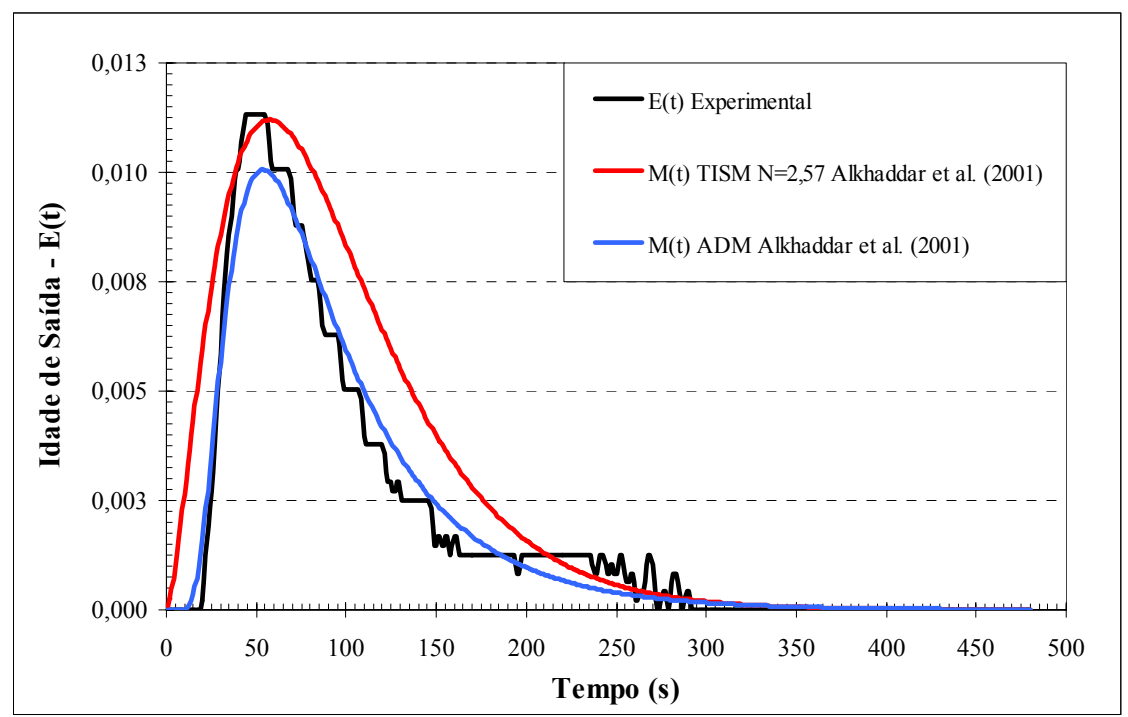

(a)

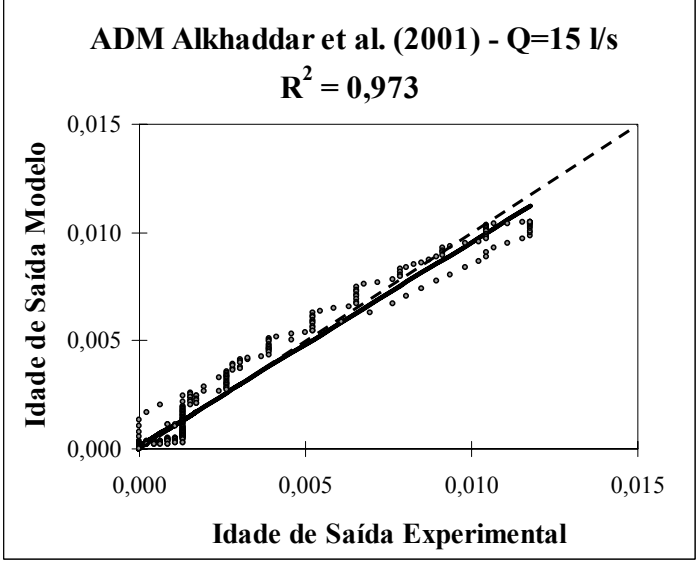

(b)

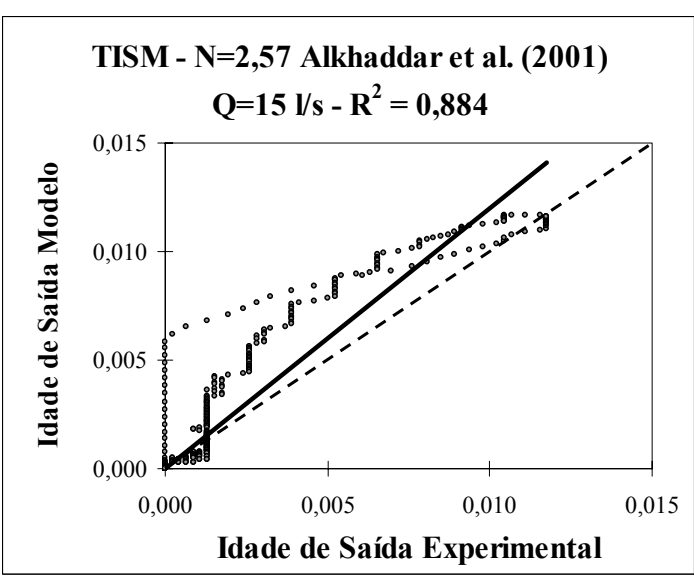

(c)

Figura 3.16 - Curva de distribuição de idade de saída $\mathrm{E}(\mathrm{t})$ para a vazão de alimentação do SHV de 15 l/s e curvas M(t) dos modelos ADM e TISM ajustadas. (a) Curva da distribuição da idade de saída $\mathrm{E}(\mathrm{t})$, assim como, as curvas $\mathrm{M}(\mathrm{t})$ dos dois modelos, ADM e TISM; (b) curva de regressão mostrando a qualidade do ajuste do modelo ADM; (c) curva de regressão mostrando a qualidade do ajuste do modelo TISM.

A Figura 3.17(a) mostra a curva de distribuição de idade de saída experimental $\mathrm{E}(\mathrm{t})$ e as curvas de distribuição de idade de saída $\mathrm{M}(\mathrm{t})$, obtidas a partir do ajuste dos modelos de dispersão axial (ADM) e de tanques em série (TISM) para a vazão de 20 1/s. Observa-se, mais uma vez, que o modelo de dispersão axial foi o que apresentou melhor ajuste aos dados experimentais, como mostra as curvas de regressão linear na Figura 3.17(b, c). Nota-se que a curva de regressão linear (linha cheia) do modelo de dispersão axial da Figura 3.17(b) possui coeficiente de determinação maior $\left(\mathrm{R}^{2}=0,984\right.$ - ADM; $\mathrm{R}^{2}=0,933$ - TISM), além disto, a curva de regressão literalmente coincide com a linha pontilhada (linha a $45^{\circ}$ ) a qual indica ajuste perfeito entre modelo e dados experimentais. 


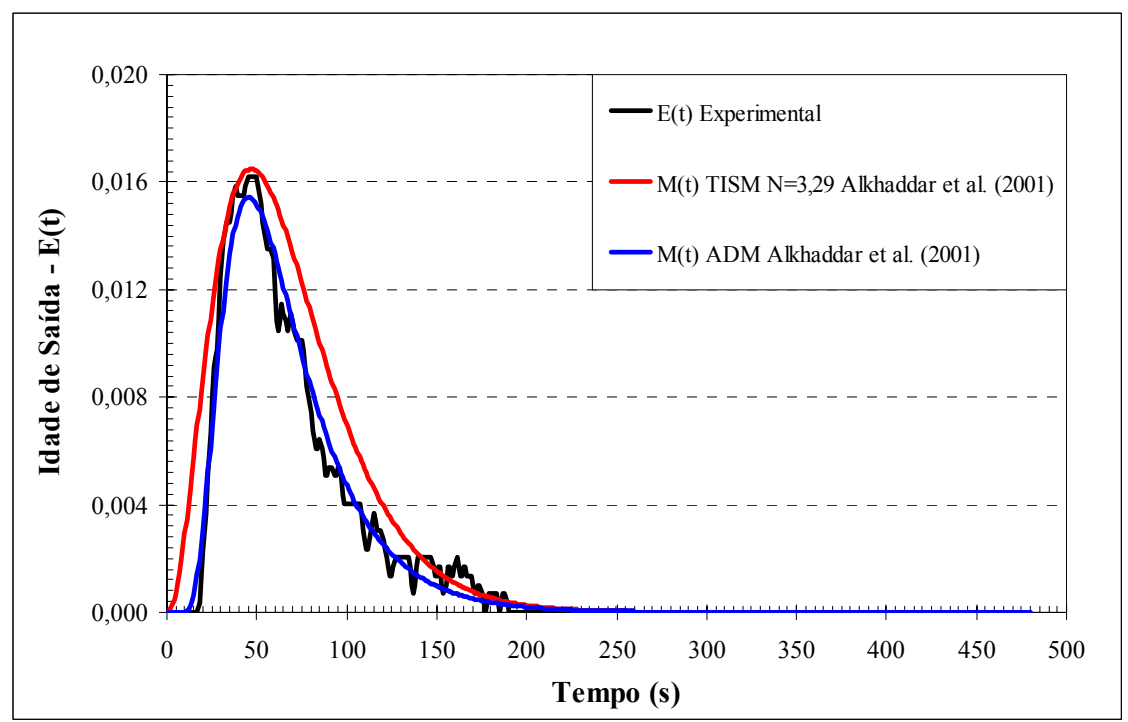

(a)

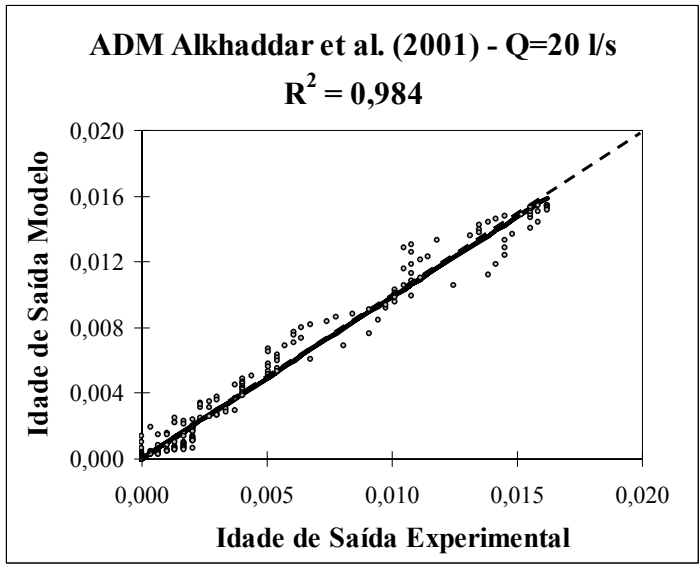

(b)

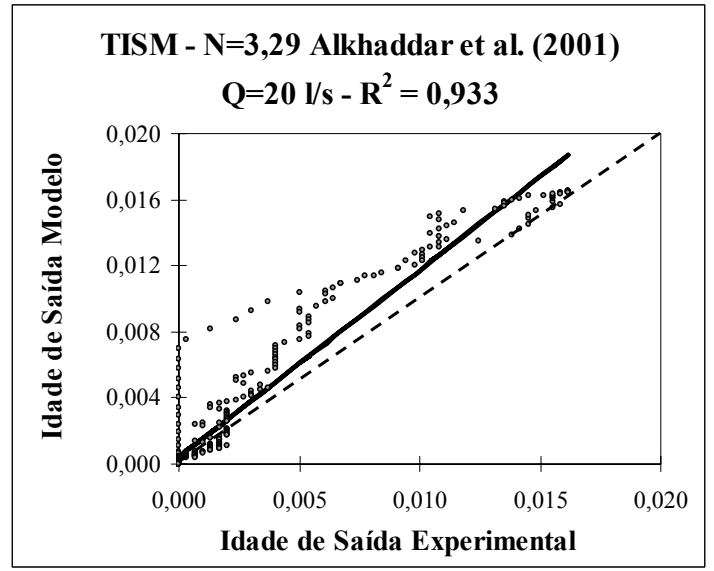

(c)

Figura 3.17 - Curva de distribuição de idade de saída $E(t)$ para a vazão de alimentação do SHV de 20 l/s e curvas M(t) dos modelos ADM e TISM ajustadas. (a) Curva da distribuição da idade de saída $\mathrm{E}(\mathrm{t})$, assim como, as curvas $\mathrm{M}(\mathrm{t})$ dos dois modelos, ADM e TISM; (b) curva de regressão mostrando a qualidade do ajuste do modelo ADM; (c) curva de regressão mostrando a qualidade do ajuste do modelo TISM.

As Figuras 3.15, 3.16 e 3.17 demonstram que os resultados experimentais apresentaram uma tendência clara: quanto maior a vazão de alimentação do SHV, melhor foi o ajuste dos modelos. Todavia, com os dados disponíveis não foi possível explicar tal fato, além de que o aprofundamento nesse tema extrapolaria o escopo desse capítulo.

Dentre os dois modelos utilizados, aquele que apresentou melhor ajuste aos dados experimentais para todas as vazões $(10 \mathrm{l} / \mathrm{s} ; 15 \mathrm{l} / \mathrm{s}$ e $20 \mathrm{l} / \mathrm{s})$ foi o modelo de dispersão axial (ADM) e por isso, um de seus parâmetros, a variância padronizada $\left(\sigma_{\theta}{ }^{2}\right)$, foi utilizado para caracterizar o grau de macro-mistura do escoamento no SHV. 
Segundo Alkhaddar et al. (2001a), a partir do valor da variância padronizada pode-se calcular pela Equação 3.6 um grupo adimensional designado pela literatura como número de dispersão $(\mathrm{D} / \mathrm{uL})$. Este número indica o grau de dispersão axial (mistura) do escoamento em uma unidade de processo ou operação unitária. Quanto menor o número de dispersão menor o grau de mistura e, consequentemente, mais pistonado o escoamento na unidade.

$$
\sigma_{\theta}^{2}=2 \cdot\left(\frac{\mathrm{D}}{\mathrm{uL}}\right)-2 \cdot\left(\frac{\mathrm{D}}{\mathrm{uL}}\right)^{2} \cdot\left(1-\exp \left[-\frac{1}{\left(\frac{\mathrm{D}}{\mathrm{uL}}\right)}\right]\right)
$$

Em que:

$\sigma_{\theta}^{2}:$ Variância padronizada;

$\left(\frac{\mathrm{D}}{\mathrm{uL}}\right)$ : Número de dispersão.

A Tabela 3.3 mostra os valores de variância padronizada e os números de dispersão calculados pela Equação 3.6, para as três vazões utilizadas na alimentação do $\operatorname{SHV}(10$ 1/s; 15 l/s e 20 l/s).

Tabela 3.3 - Valores de variância padronizada e número de dispersão para as três vazões utilizadas para alimentar o SHV (10 l/s; 15 l/s e 20 l/s).

\begin{tabular}{ccc}
\hline $\begin{array}{c}\text { Vazão } \\
(\mathbf{l} / \mathbf{s})\end{array}$ & $\sigma_{\theta}^{2}$ & $\left(\frac{\mathrm{D}}{\mathrm{uL}}\right)$ \\
\hline 10,0 & 0,376 & 0,248 \\
15,0 & 0,388 & 0,261 \\
20,0 & 0,267 & 0,158 \\
\hline
\end{tabular}

Metcalf \& Eddy (2003) propõem cinco limites para o valor do número de dispersão, de forma que o regime de macro-mistura do escoamento em unidades de processo ou operação unitária possa ser classificado, como: plug-flow ideal, com dispersão baixa, com dispersão moderada, com dispersão alta e mistura perfeita. 
- $\left(\frac{\mathrm{D}}{\mathrm{uL}}\right)=0 \quad \Rightarrow$ Nenhuma dispersão axial — Plug-flow ideal;

- $\left(\frac{\mathrm{D}}{\mathrm{uL}}\right) \leq 0,05 \quad \Rightarrow$ Dispersão axial baixa;

- $\quad 0,05<\left(\frac{\mathrm{D}}{\mathrm{uL}}\right)<0,25 \Rightarrow$ Dispersão axial moderada;

- $\left(\frac{\mathrm{D}}{\mathrm{uL}}\right) \geq 0,25 \quad \Rightarrow$ Dispersão axial alta;

- $\left(\frac{\mathrm{D}}{\mathrm{uL}}\right) \rightarrow \infty \quad \Rightarrow$ Mistura perfeita.

Comparando os números de dispersão apresentados na Tabela 3.3 com os limites propostos por Metcalf \& Eddy (2003), conclui-se que para a vazão de 10 1/s e 15 1/s o escoamento no SHV apresenta dispersão axial moderada tendendo a alta e que para a vazão de 20 1/s o escoamento no SHV apresenta dispersão axial moderada.

Percebe-se com essa análise uma ligeira discordância entre os valores do número de dispersão e a hipótese defendida nesta seção (o aumento da vazão de alimentação do SHV faz com que o regime de macro-mistura do escoamento na unidade aproxime-se do plug-flow), uma vez que, o número de dispersão calculado para a vazão de 15 1/s é praticamente igual àquele calculado para a vazão de 10 1/s. Na Figura 3.18 é possível visualizar tal fato pois, como pode ser visto, a curva da razão $\mathrm{TDH}_{\mathrm{p}}$ por $\mathrm{TDH}_{\mathrm{t}}$ pela vazão de alimentação é crescente, isto é, o aumento da vazão faz com que o percentual do volume útil do SHV, que apresenta escoamento com regime de macro-mistura do tipo plug-flow, cresça de $41 \%(\mathrm{Q}=10 \mathrm{l} / \mathrm{s})$ para $49 \%(\mathrm{Q}=15 \mathrm{l} / \mathrm{s})$ e depois para $63 \%(\mathrm{Q}=20$ $1 / \mathrm{s}$ ), enquanto o número de dispersão ao invés de sempre diminuir com o aumento da vazão, como esperado, fica praticamente constante na faixa de 0,25 a 0,26 para as vazões de 10 l/s e 15 l/s, e depois diminui para 0,16 para a vazão de 20 l/s.

Uma explicação para essa ligeira discordância entre os valores do número de dispersão e os valores da razão $\mathrm{TDH}_{\mathrm{p}}$ por $\mathrm{TDH}_{\mathrm{t}}$ pode ser encontrada com a análise da Figura 3.14(b). Observa-se que a "cauda" da curva de distribuição de idade de saída padronizada $\mathrm{E}(\theta)$ para a vazão de $15 \mathrm{l} / \mathrm{s}$ é a mais longa, indicando maior espalhamento 
dos dados experimentais. Como a variância é uma medida do espalhamento dos dados experimentais, quanto maior o comprimento da cauda da curva de distribuição de idade de saída padronizada, maior será o valor do número de dispersão. No entanto, o mesmo não ocorre com os valores da razão $\mathrm{TDH}_{\mathrm{p}}$ por $\mathrm{TDH}_{\mathrm{t}}$, pois eles dependem, exclusivamente, da posição do pico da curva de distribuição de idade de saída $E(t)$, uma vez que $\mathrm{TDH}_{\mathrm{t}}$ é calculado a partir de valores fixos: a vazão de alimentação e o volume útil do SHV.

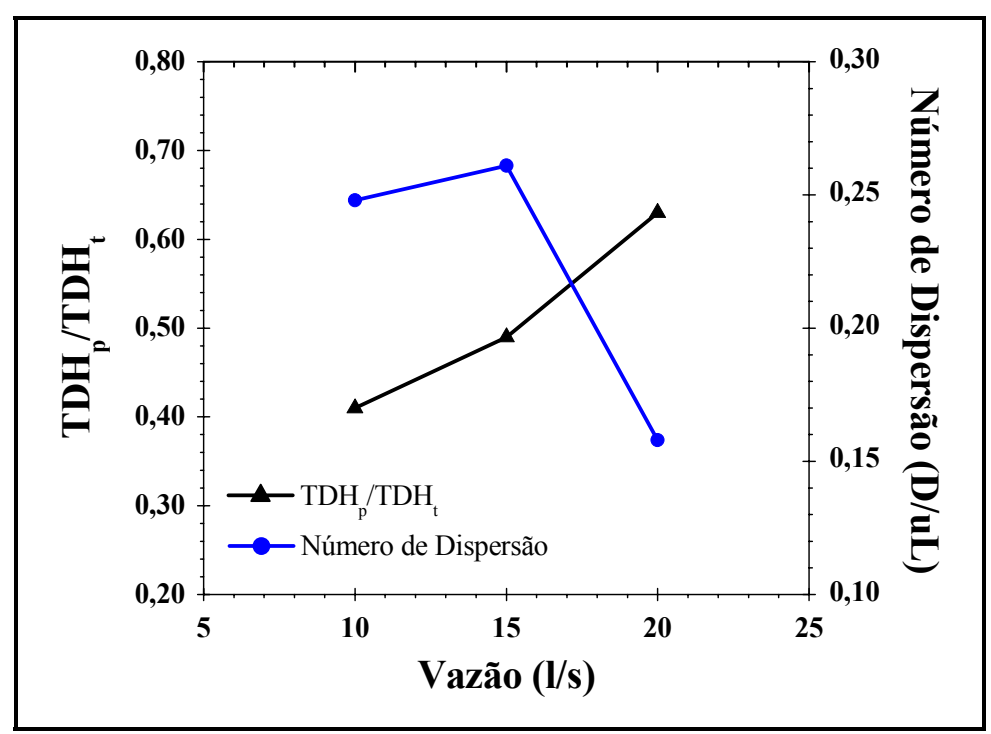

Figura 3.18 - Gráficos da variação da razão $\mathrm{TDH}_{\mathrm{p}} / \mathrm{TDH}_{\mathrm{t}} \mathrm{e}$ do número de dispersão (D/uL) com a vazão de alimentação do SHV.

Infelizmente, a simples análise dos resultados de ensaios de estímulo-resposta não fornece informações suficientes para esclarecer quais são as causas do maior espalhamento dos dados experimentais para a vazão de 15 1/s. Para tanto, é necessário o emprego de ferramentas de análise mais poderosas, que permitam a visualização do padrão de escoamento no interior do SHV. Uma dessas ferramentas são os softwares comerciais de dinâmica dos fluidos computacional.

\subsubsection{Validação das simulações computacionais}

Como anteriormente discutido, resultados de simulações computacionais devem sempre que possível ser validados, ou seja, é necessário verificar-se a concordância entre os valores calculados nas simulações e aqueles obtidos de medições em unidade 
de mesma escala do modelo simulado. Este procedimento deve ser feito por meio de análises estatísticas, como por exemplo: a análise de variâncias (ANOVA). Contudo, na presente pesquisa, não se pretende usar os resultados das simulações computacionais para realizar análises quantitativas dos padrões de escoamento do separador hidrodinâmico por vórtice (SHV); o que se deseja é poder visualizar os padrões de escoamento da unidade de forma geral, ou seja, realizar análises qualitativas acerca do escoamento no interior do SHV. Por conseguinte, julgou-se desnecessário o uso de análises estatísticas para a validação dos resultados das simulações computacionais e que a simples observação do distanciamento entre curvas de pressão total, experimentais e simuladas, seria suficiente.

Em face ao que foi discutido no parágrafo anterior, os valores de pressão total medidos no SHV, para as três vazões estudadas (10 1/s; 15 1/s e 20 1/s), juntamente com aqueles provenientes das simulações computacionais, foram plotados em gráficos (Figuras 3.20(a, b, c); 3.21(a, b, c) e 3.22(a, b, c)) que representam as linhas radiais na Figura 3.19.

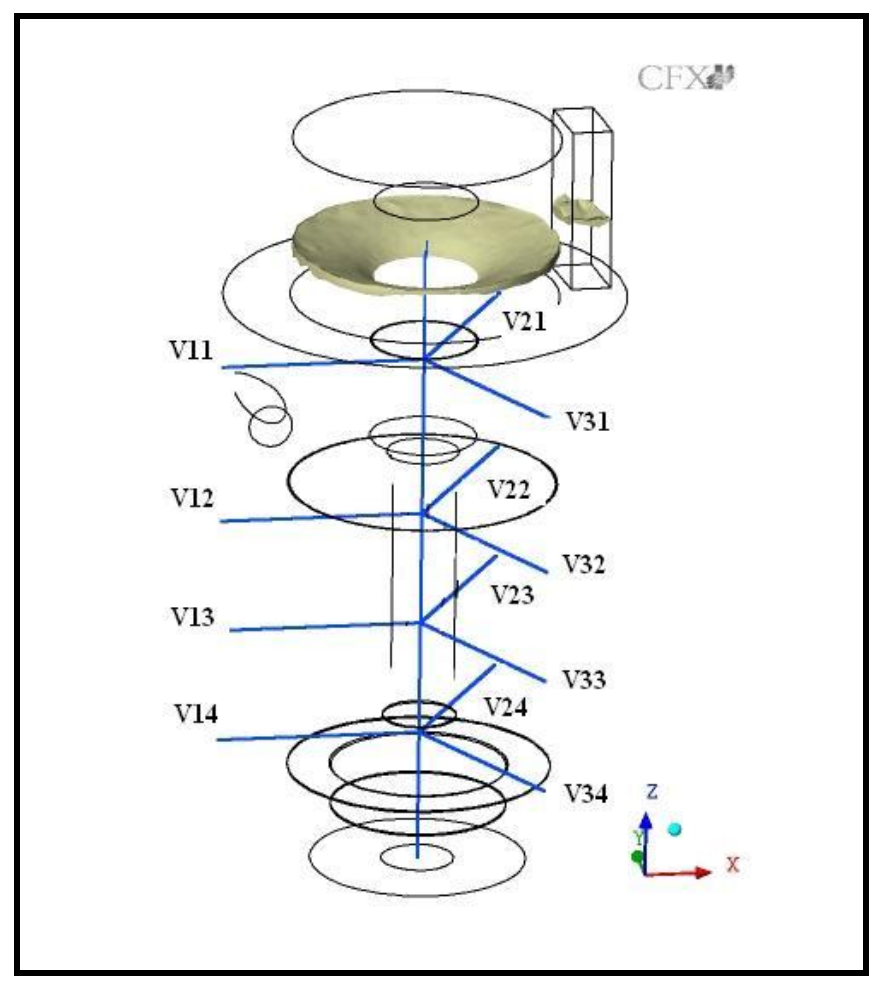

Figura 3.19 - Esquema que mostra as linhas radiais (linhas azuis) de onde foram obtidos os valores de pressão total calculados durante simulações, os quais foram plotados juntamente com os valores de pressão total medidos no protótipo do SHV para a realização da validação dos resultados das simulações computacionais. 


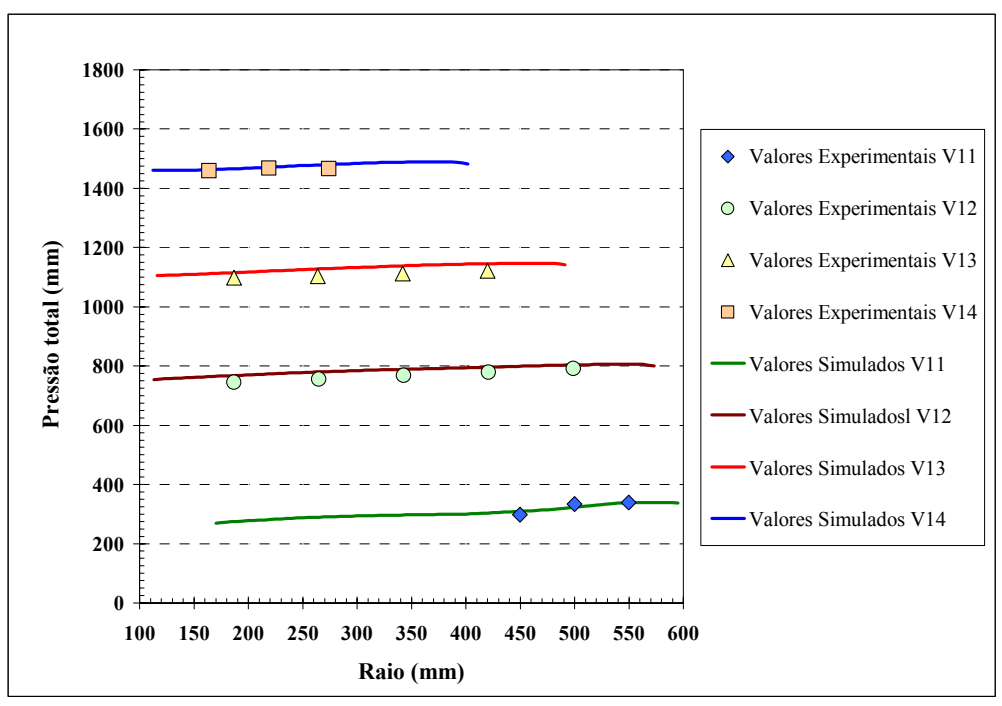

(a)

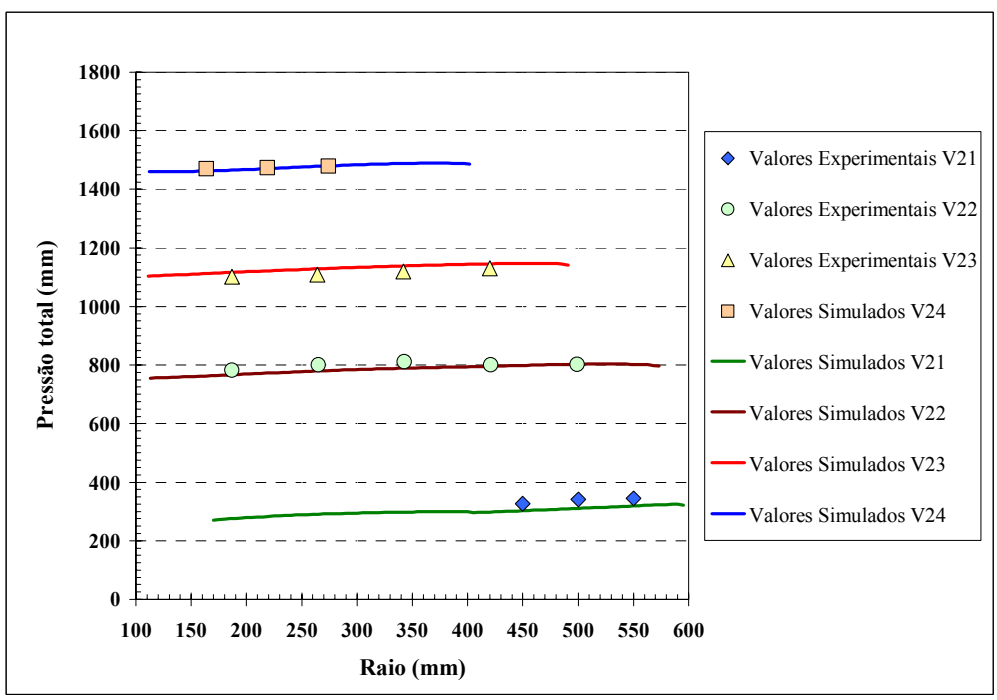

(b)

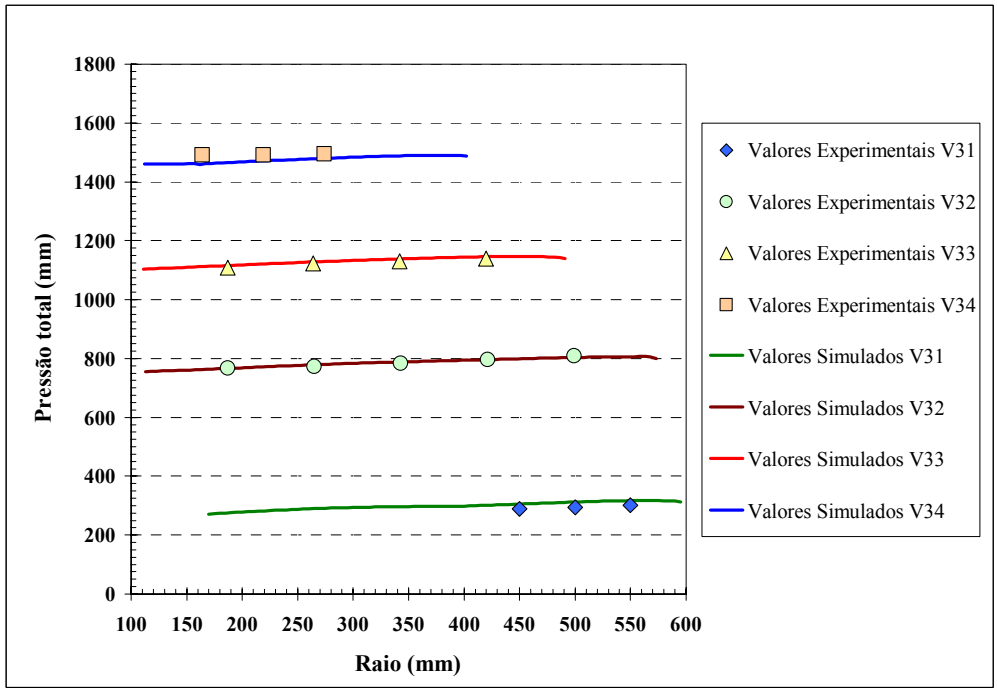

(c)

Figura 3.20 - Gráficos de pressão total com valores experimentais e simulados para a vazão de 10 l/s. (a) Pressão total para a linha de válvulas V1j. (b) Pressão total para a linha de válvulas V2j. (c) Pressão total para a linha de válvulas V3j. 


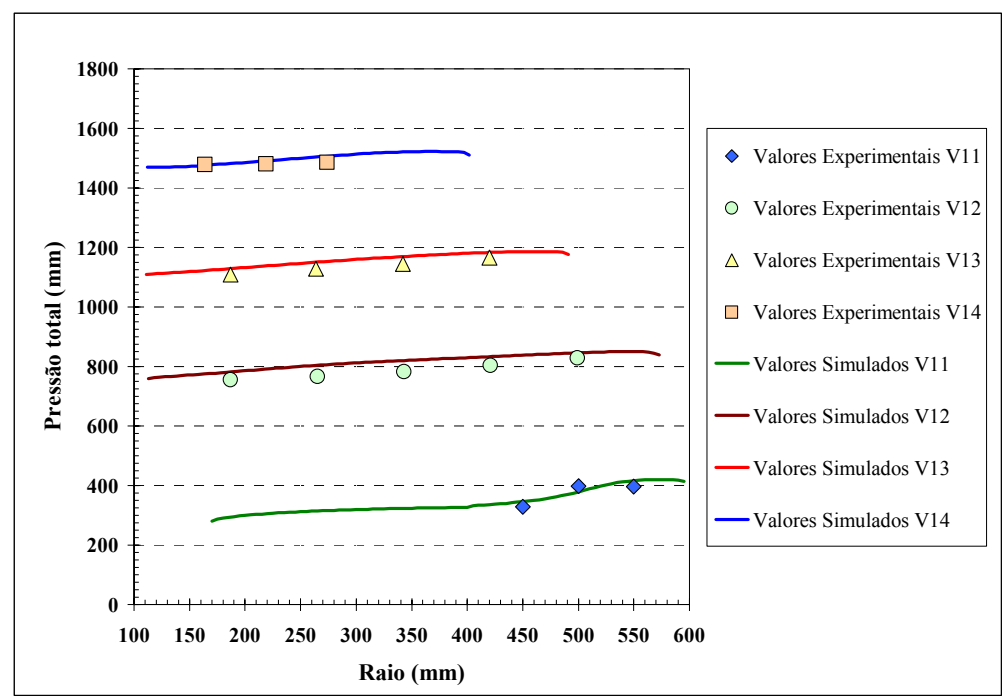

(a)

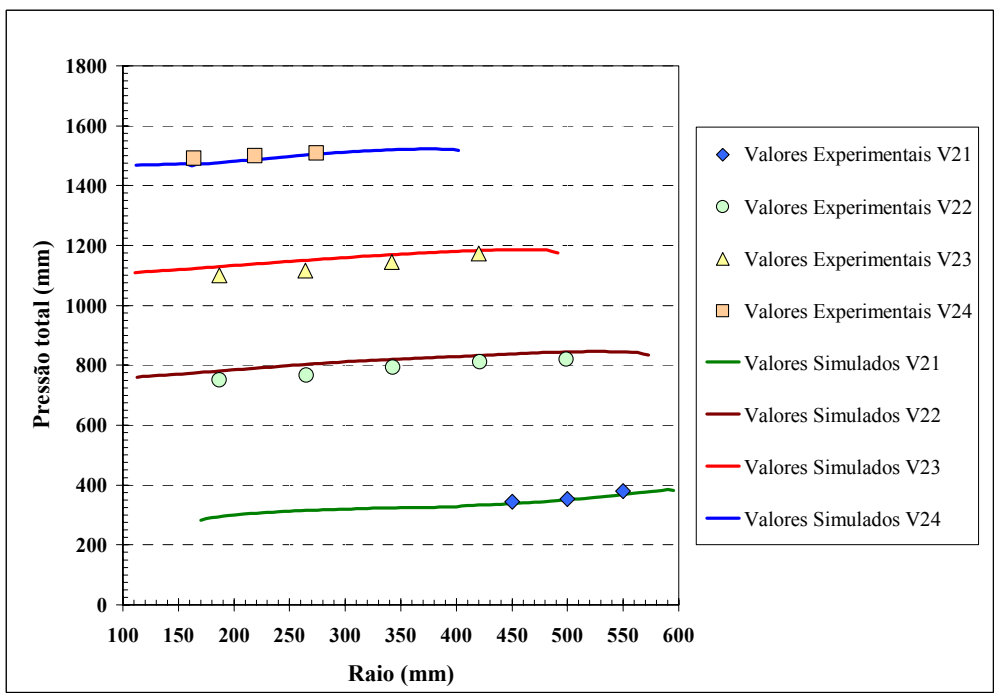

(b)

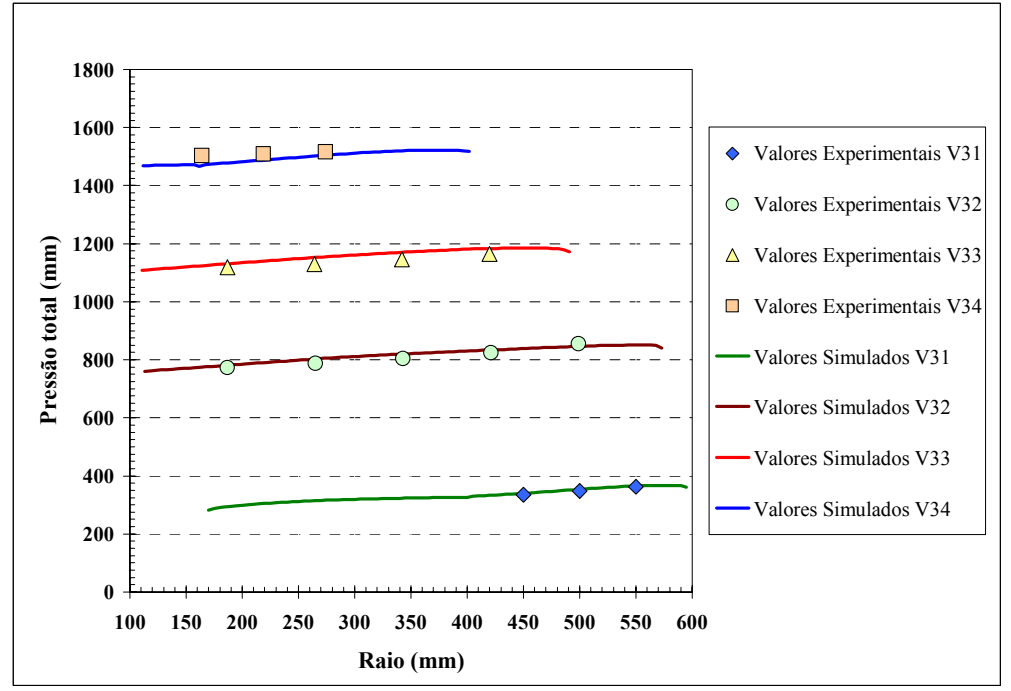

(c)

Figura 3.21 - Gráficos de pressão total com valores experimentais e simulados para a vazão de 15 l/s. (a) Pressão total para a linha de válvulas V1j. (b) Pressão total para a linha de válvulas V2j. (c) Pressão total para a linha de válvulas V3j. 


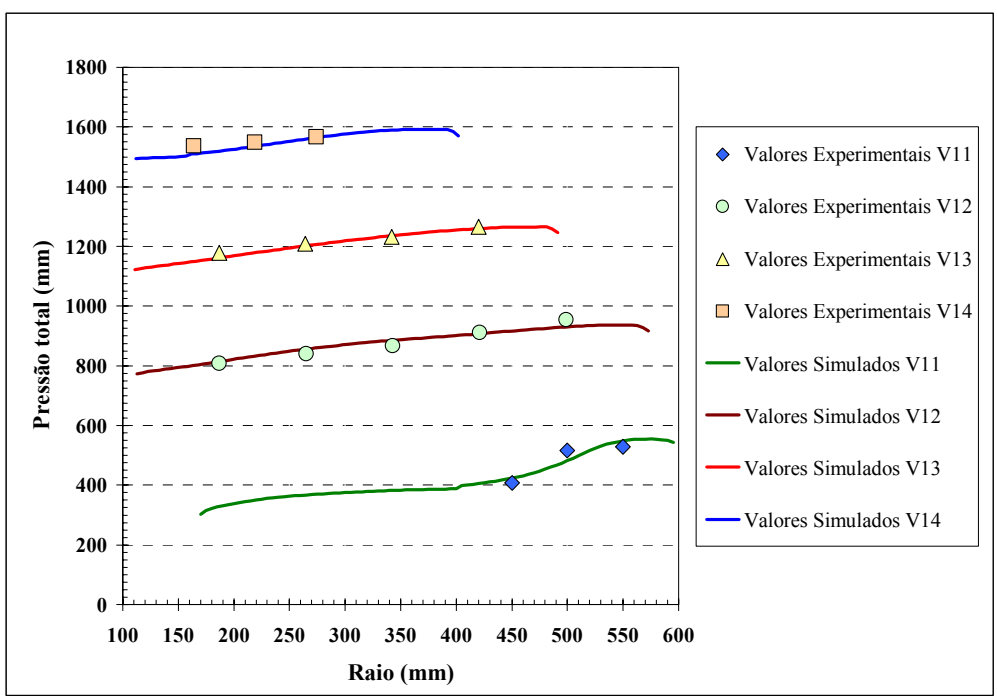

(a)

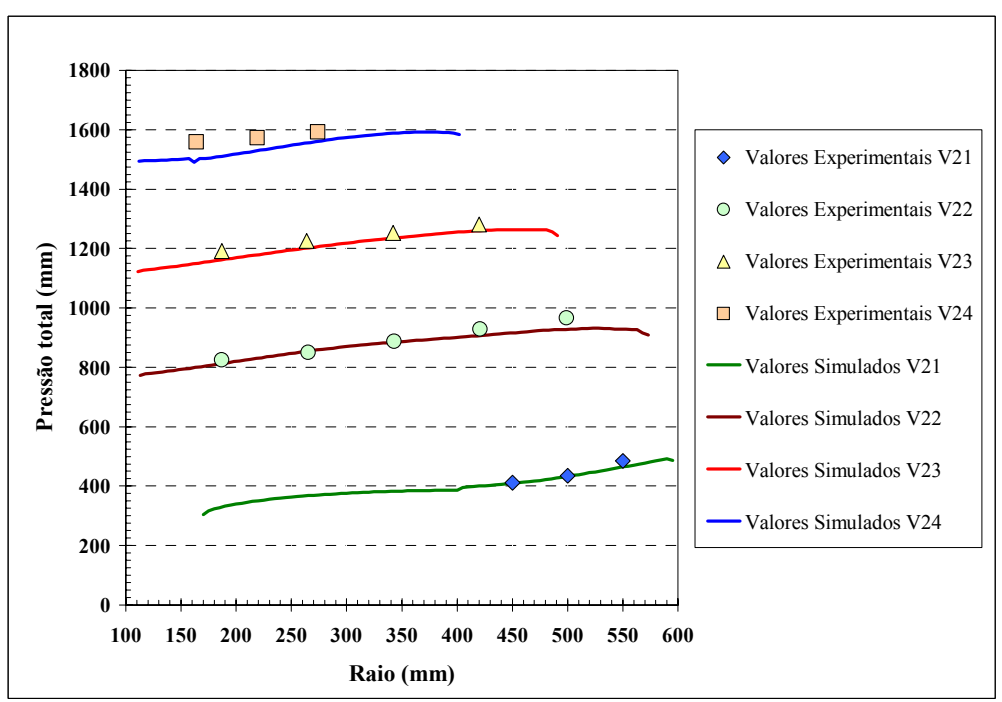

(b)

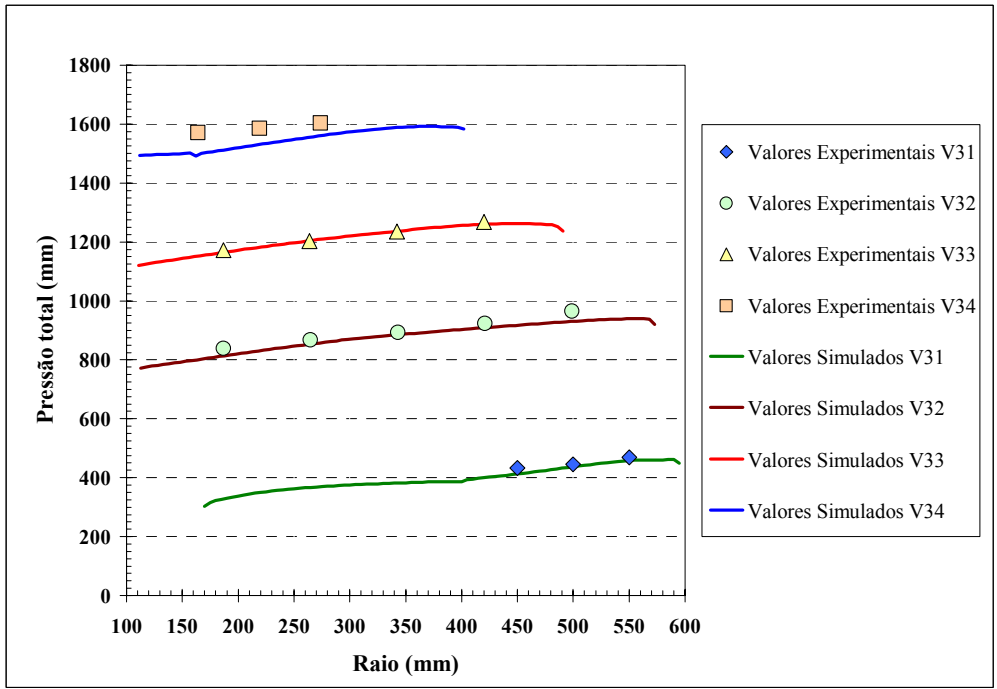

(c)

Figura 3.22 - Gráficos de pressão total com valores experimentais e simulados para a vazão de 20 1/s. (a) Pressão total para a linha de válvulas V1j. (b) Pressão total para a linha de válvulas V2j. (c) Pressão total para a linha de válvulas V3j. 
Nos gráficos das Figuras 3.20(a, b, c); 3.21(a, b, c) e 3.22(a, b, c) observa-se que os valores de pressão total calculados nas simulações computacionais, apesar de algumas vezes não coincidirem exatamente com os resultados experimentais, apresentam boa concordância com os valores de pressão total obtidos nas medições feitas no protótipo do SHV. Isto indica que os resultados das simulações computacionais são válidos, isto é, representam satisfatoriamente os padrões de escoamento do SHV para as vazões de 10 l/s, 15 l/s e 20 l/s.

\subsubsection{Resultados das simulações computacionais}

A maioria dos softwares comerciais de dinâmica dos fluidos computacional (CFD - Computational Fluid Dynamics), como por exemplo: o CFX 10.0 usado neste trabalho, oferece ao usuário diferentes formas de apresentação de resultados, as quais permitem a visualização do padrão de escoamento no interior de unidades de processo ou operação unitária. Tais recursos gráficos possibilitam a realização de análises qualitativas impossíveis de serem feitas pelos métodos tradicionalmente empregados em estudos sobre a hidrodinâmica de unidade de tratamento, como: ensaios de estímuloresposta, medições pontuais de pressão, velocidade etc.

A visualização dos campos de velocidade no interior do separador hidrodinâmico por vórtice (SHV) permite verificar se o padrão de escoamento do SHV desenvolvido na presente pesquisa apresenta algumas características prenunciadas pela literatura. Segundo Svarovsky (1984), Andoh e Smisson (1993), Field e O’Connor (1996) e Veerapen et al. (2005), junto à parede externa dos SHVs o movimento do fluído deve ser helicoidal e descendente, enquanto na região central das unidades, o movimento do fluido também deve ser helicoidal, porém ascendente. Observa-se pelas linhas de corrente mostradas na Figura 3.24(a, b, c) que para as três vazões estudadas (10 1/s; 15 1/s e 20 l/s), os padrões de escoamento do protótipo do SHV condizem com o padrão de escoamento prenunciado pela literatura, porquanto junto à parede externa da unidade as linhas de corrente descrevem trajetórias helicoidais e descendentes (linhas de corrente azuis indicam movimento descendente do fluido), enquanto na região central da mesma, as linhas de correntes são helicoidais e ascendentes (linhas de corrente vermelhas indicam movimento ascendente do fluido). 
Outro fato importante que pode ser observado na Figura 3.24 é que algumas linhas de corrente mudam de cor, do azul para o vermelho e vice-versa, indicando que em algumas regiões do SHV o movimento vertical do fluido troca de sentido, ou seja, ora é ascendente ora é descendente. Isto ocorre, principalmente, entre os cilindros externo e interno da unidade, sugerindo que, nesta região do SHV, ocorra intensa mistura (altos gradientes de velocidade). Todavia tal comportamento do fluido era esperado, pois nesta região localiza-se a entrada da unidade; consequentemente, as altas velocidades do jato de fluido que adentra a unidade através do bocal de entrada aumentam a turbulência na região. Percebe-se na Figura 3.24(b, c) — linhas de corrente para as vazões de 15 l/s e 20 l/s —, que a mudança de sentido das linhas de corrente não acontece somente entre os cilindros externo e interno do SHV. Logo abaixo do corpo cilíndrico do SHV, algumas linhas de corrente trocam de sentido e dirigem-se para o centro da unidade, o que prova a existência de curtos-circuitos hidráulicos nesta região.

Uma conseqüência da existência de duas regiões com velocidades verticais em sentidos opostos é a formação de um plano de cisalhamento onde a velocidade vertical do fluido é zero, o Locus of Zero Vertical Velocity (LZVV), ou local de velocidade vertical zero (SVAROVSKY, 1984; ANDOH e SMISSON, 1993). Para que se possa confirmar a existência desse plano de cisalhamento é necessário "enxergar" o escoamento dentro do SHV. Com este objetivo, os vetores velocidade para as três vazões estudadas $(10 \mathrm{l} / \mathrm{s} ; 15 \mathrm{l} / \mathrm{s}$ e $20 \mathrm{l} / \mathrm{s})$ foram plotados em três planos que cortam a unidade transversalmente. A posição destes planos pode ser vista na Figura 3.23.

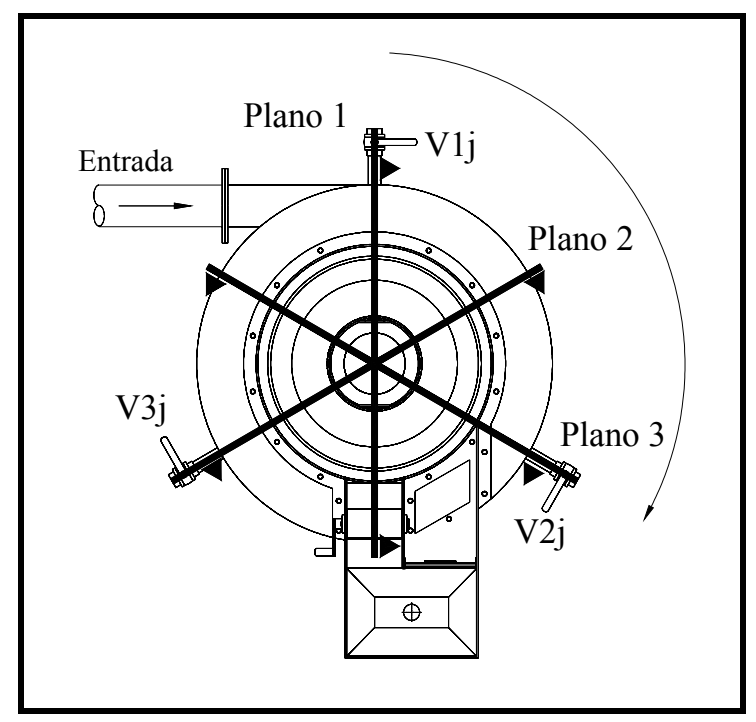

Figura 3.23 - Vista superior do SHV mostrando os planos utilizados para a apresentação dos resultados das simulações computacionais. 

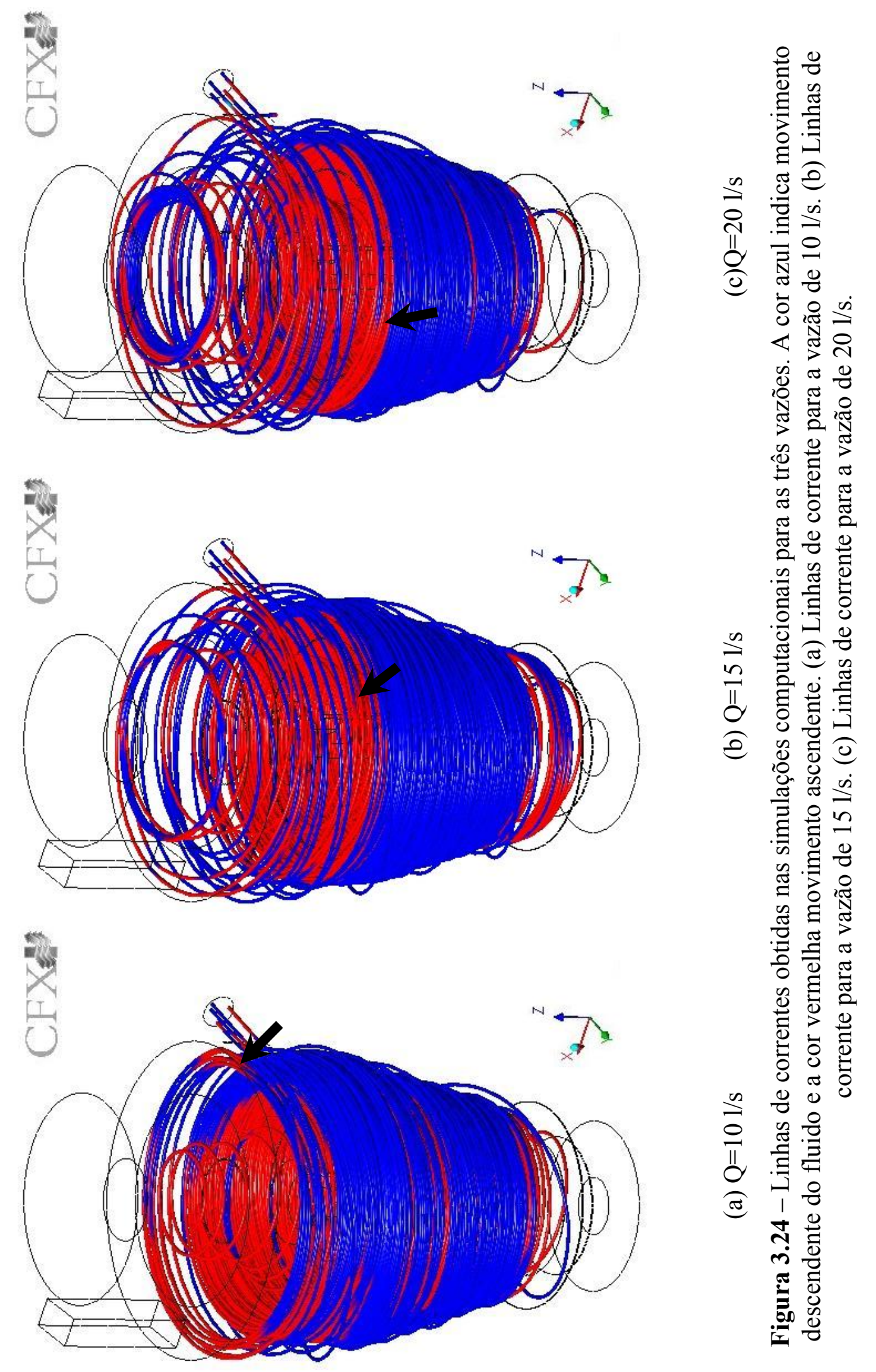

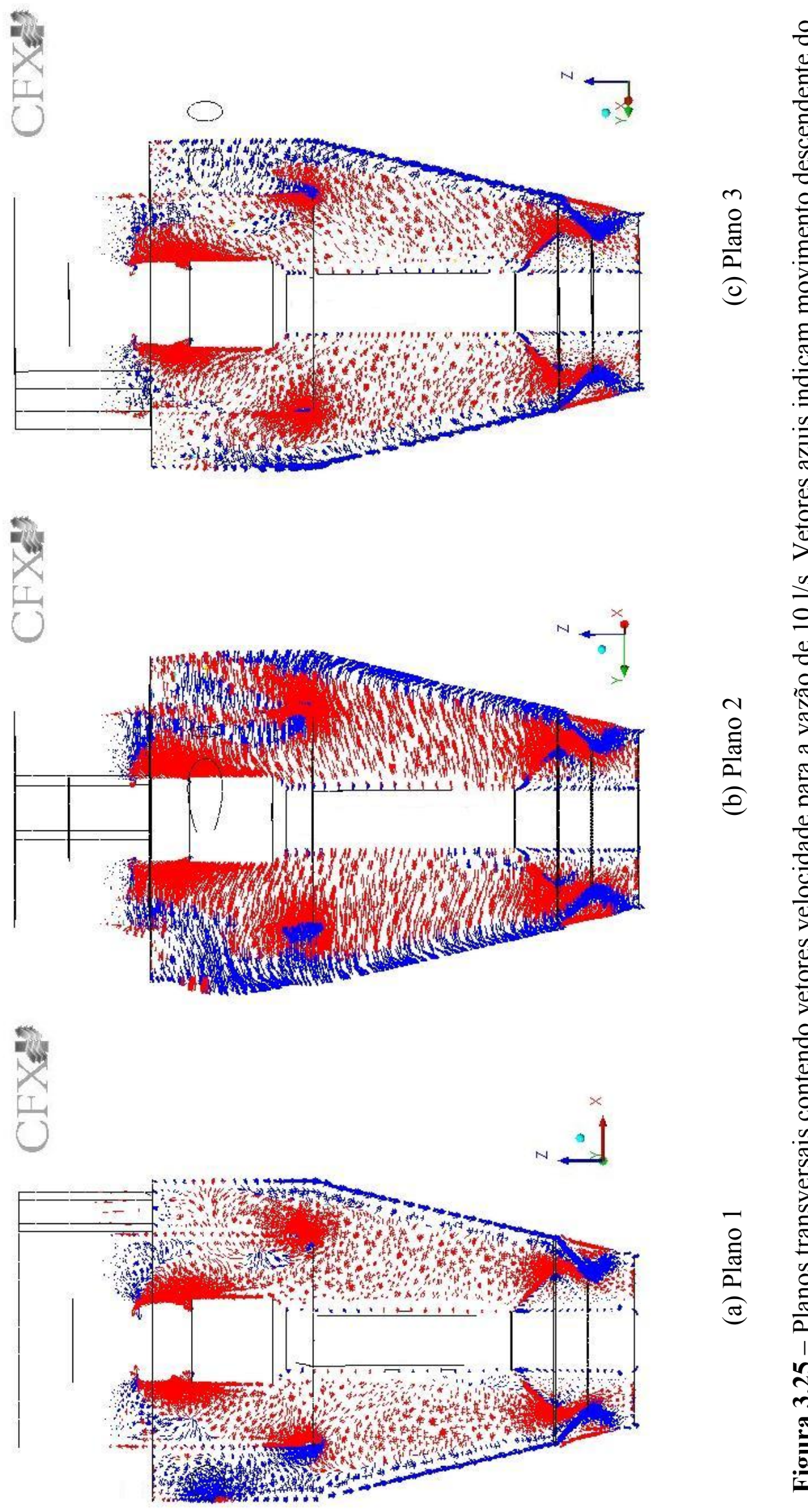

O 


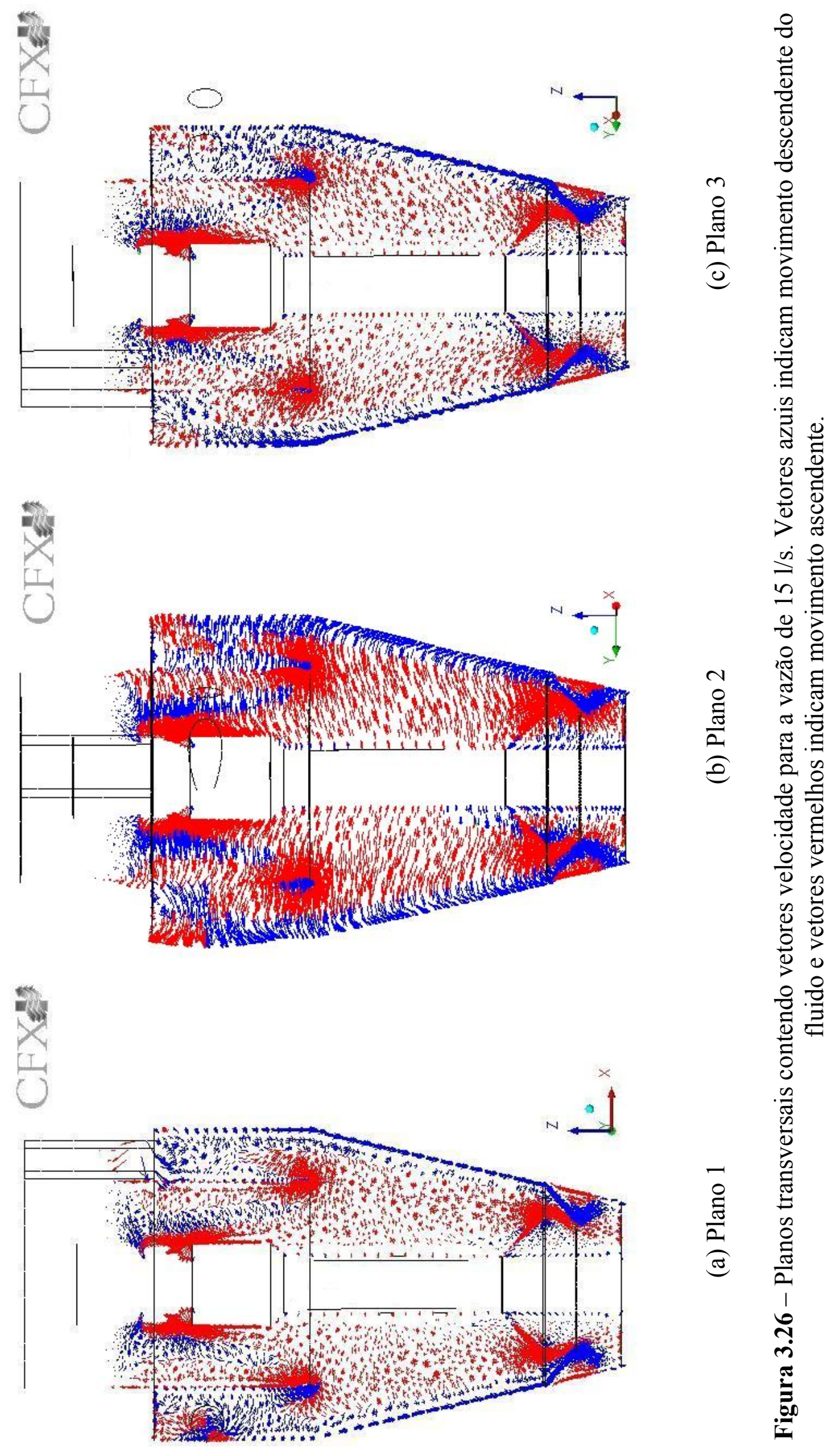



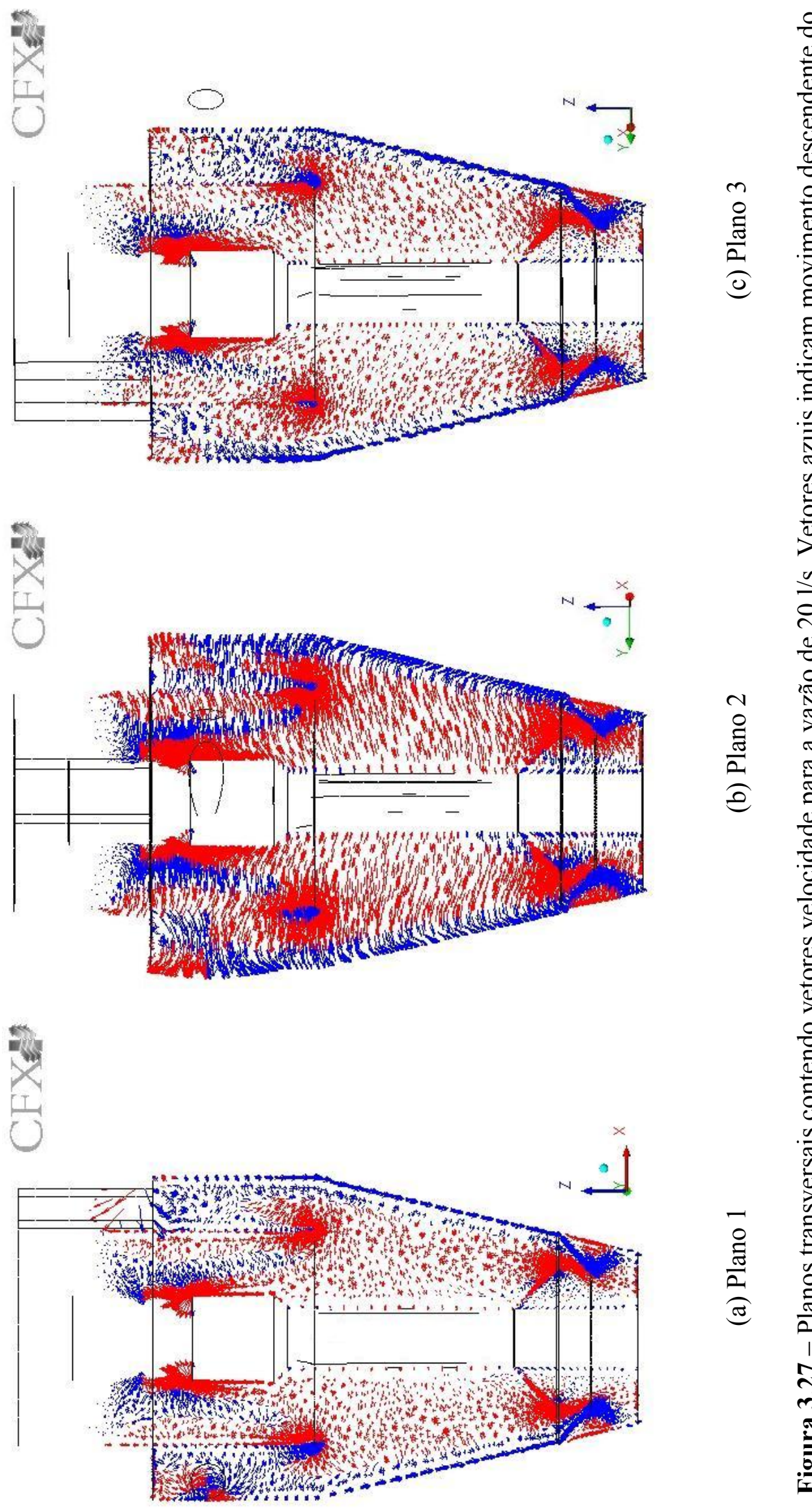

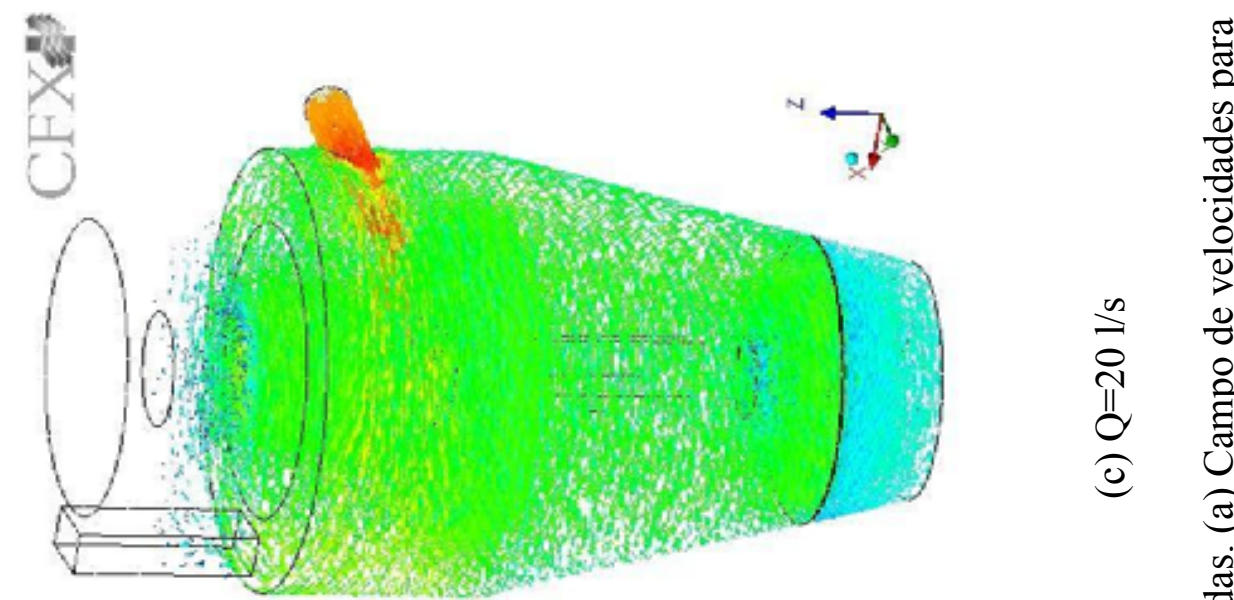

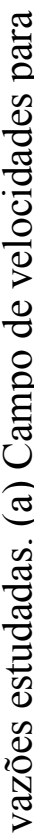
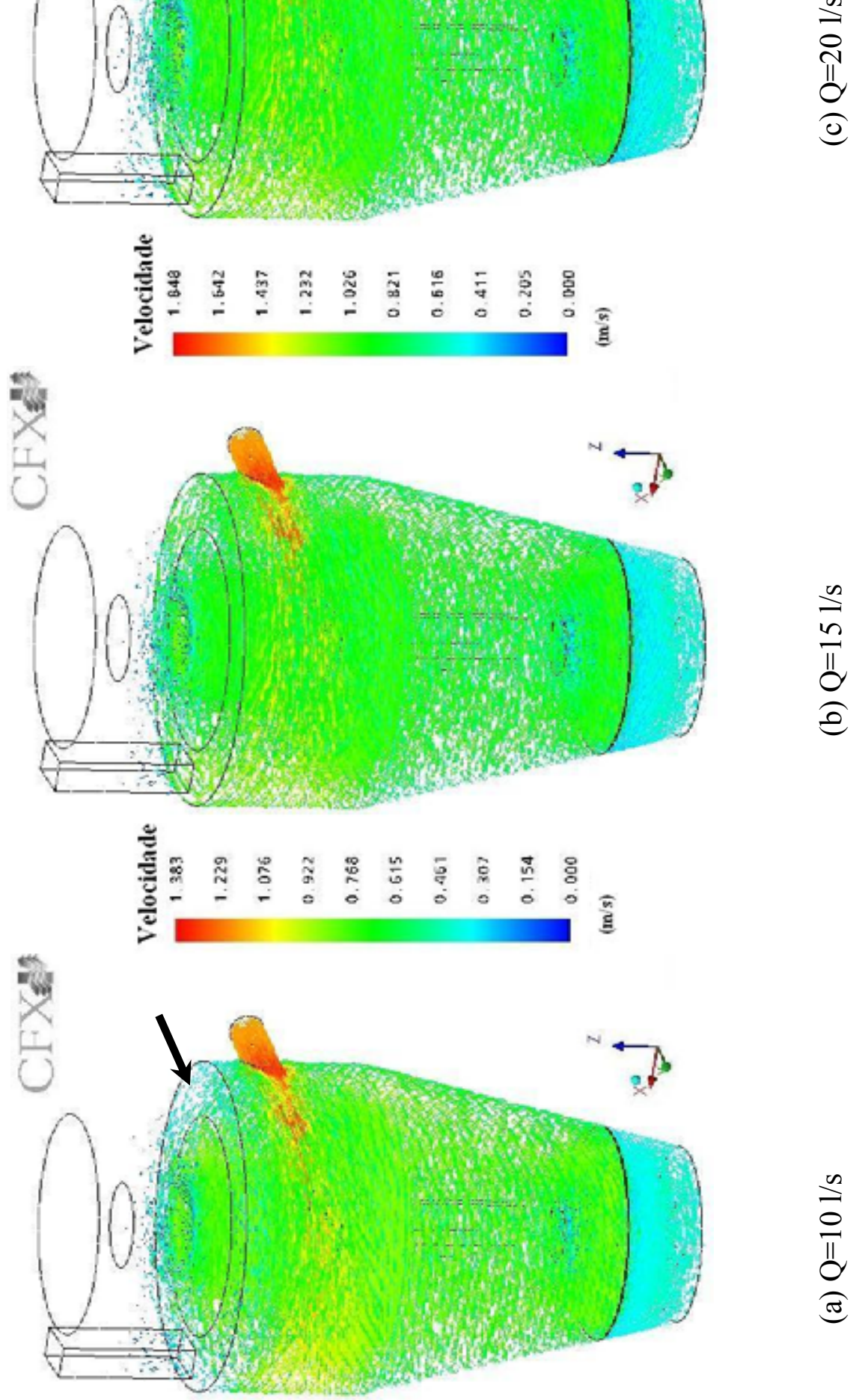

$\frac{n}{2} \frac{n}{2}$

ช

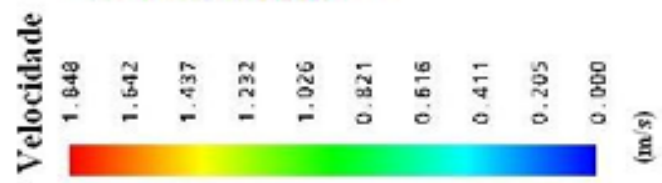

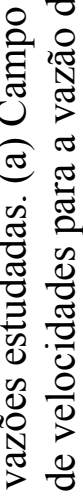

幽

ปี

苞

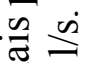

은

용

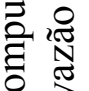

थै

莺

艺

का

‡ี

की 0

음

n

苂

อ

a $\quad \frac{0}{0}$

응

11) 0

త్

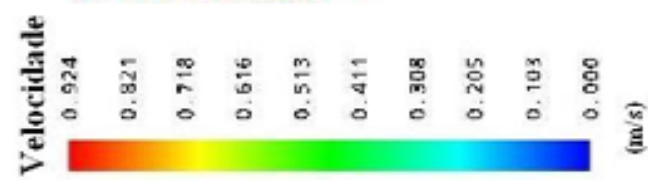

ஸे 

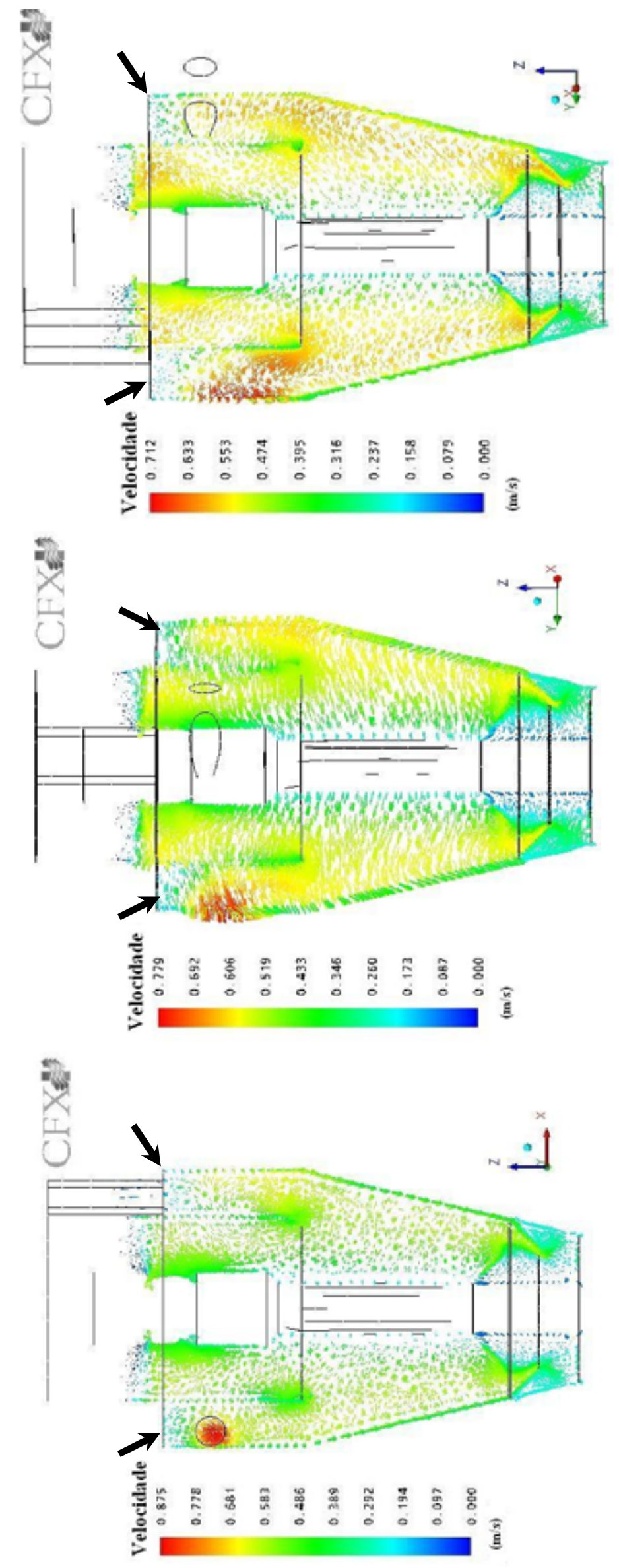

อ

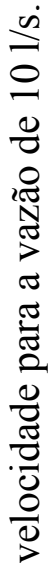

$\frac{2}{2}$

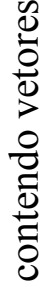

芯

量

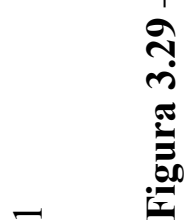

PRADO, G. S. (2006) 


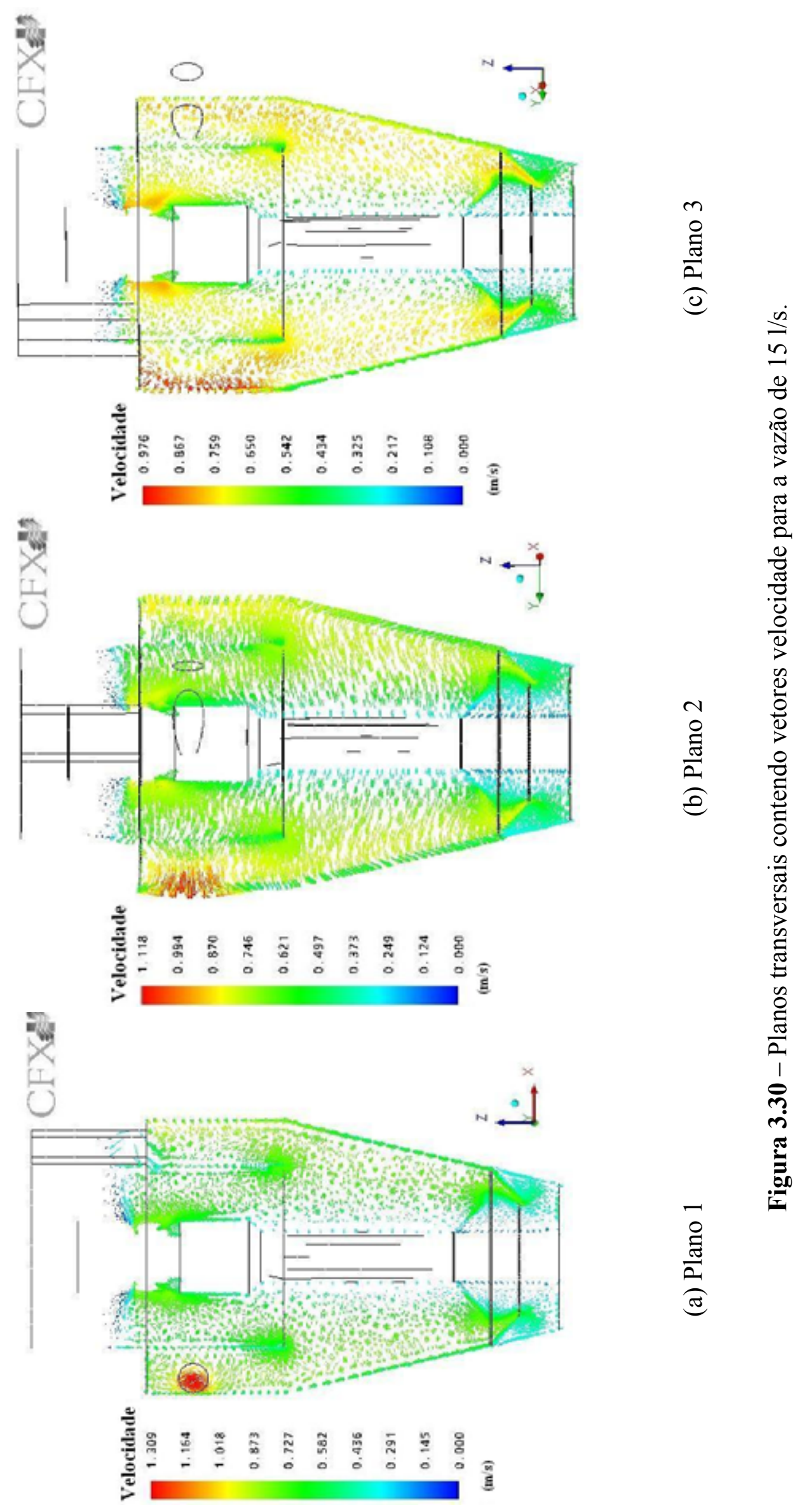




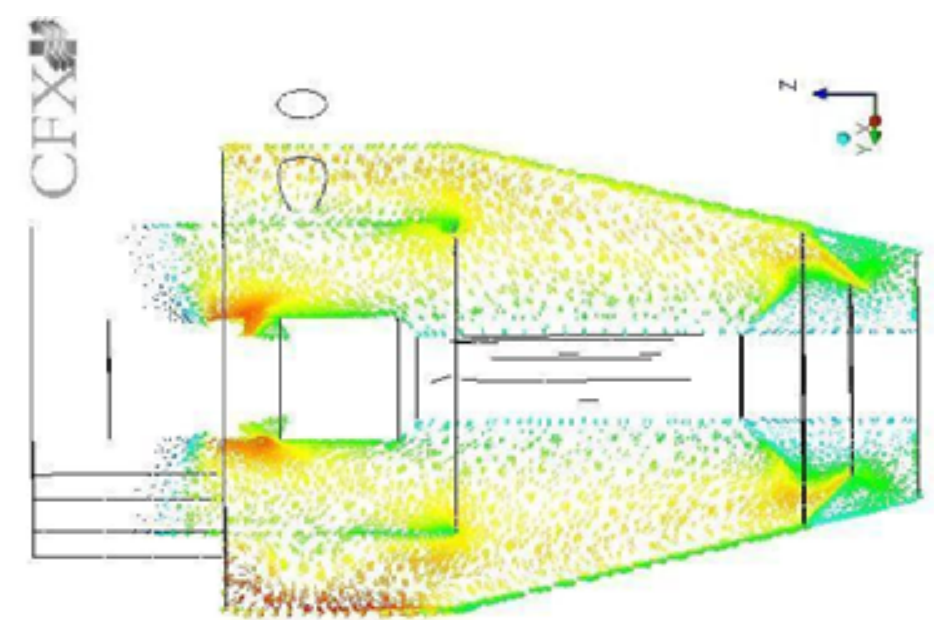

$\frac{n}{0}$
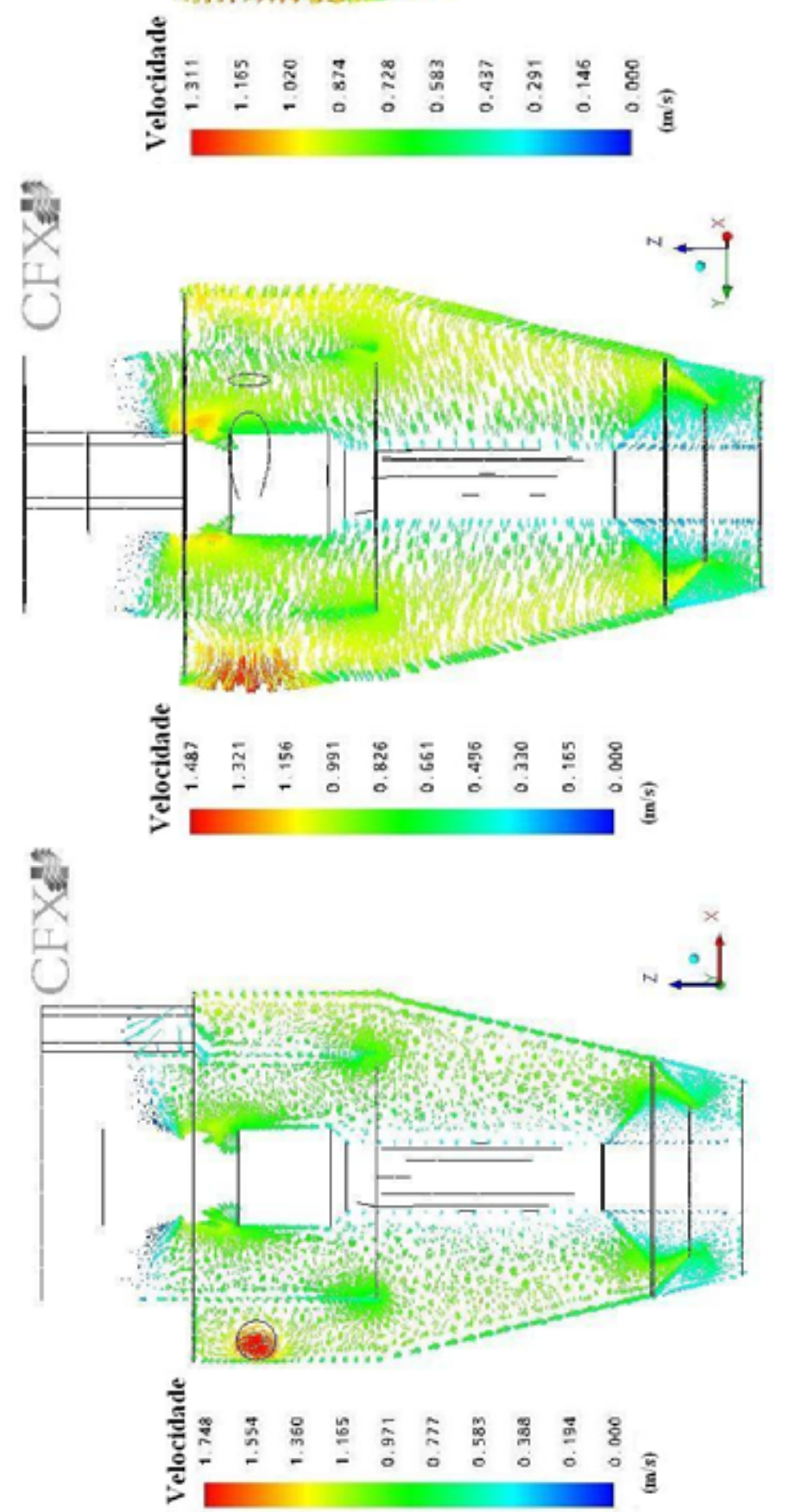

2
0
$\frac{1}{2}$
$\frac{1}{2}$ 
As Figuras 3.25, 3.26 e 3.27 mostram os vetores velocidade nos três planos (Plano 1; Plano 2 e Plano 3) para as três vazões estudadas (10 1/s; 15 1/s e 20 1/s). A distribuição das cores dos vetores velocidades obedece ao mesmo critério adotado para as linhas de corrente, isto é, vetores de cor azul indicam movimento descendente do fluido e vetores de cor vermelha indicam movimento ascendente do fluido. Nota-se que o movimento do fluido, em todos os planos e para as três vazões estudadas, é descendente junto à parede externa e ascendente na região central da unidade, principalmente no interior do corpo cônico do SHV, onde é nítida a formação do LZVV. Percebe-se, também, que entre os cilindros externo e interno do SHV o escoamento apresenta certo grau de "desordem", com presença de escoamentos secundários. Provavelmente, isto ocorra devido a dois fatores concorrentes: a diferença entre as velocidades do jato de fluido que entra no SHV através do bocal de entrada e o fluido que rotaciona dentro da unidade e a forma da seção transversal do SHV, pois, consoante White (1999), as arestas formadas entre as paredes dos cilindros, externo e interno, com a parede superior da unidade são precursoras de escoamento secundário. Outro fato importante que pode ser observado nas Figuras 3.25, 3.26 e 3.27 é a presença de curtoscircuitos hidráulicos na borda inferior do cilindro interno do SHV.

Até agora as figuras apresentadas nesta seção forneceram subsídios para que fossem discutidas somente questões relacionadas ao sentido do movimento vertical do fluído no interior do SHV. Tais figuras permitiram que fosse confirmada a existência de curtos-circuitos hidráulicos e de escoamentos secundários, porém nada pôde ser constatado acerca da existência de regiões de estagnação de fluido, conhecidas também como “zonas mortas”. Para que seja possível a visualização destas regiões é necessário conhecer os valores dos vetores velocidade no interior do protótipo do SHV. Com este objetivo foram plotadas as Figuras 3.28, 3.29, 3.30 e 3.31 .

A Figura 3.28(a, b, c) mostra os campos de velocidade do SHV para vazões de: $10 \mathrm{l} / \mathrm{s}, 15 \mathrm{l} / \mathrm{s}$ e $20 \mathrm{l} / \mathrm{s}$, respectivamente. Observa-se que para as três vazões as velocidades do fluido na região de acúmulo localizada no fundo do SHV são inferiores às velocidades do fluido encontradas junto à parede externa da unidade, porém os valores das velocidades do fluido na região de acúmulo não são tão baixos, aproximadamente: $0,2 \mathrm{~m} / \mathrm{s}$ para a vazão de $10 \mathrm{l} / \mathrm{s} ; 0,3 \mathrm{~m} / \mathrm{s}$ para a vazão de $15 \mathrm{l} / \mathrm{s}$ e 0,4 $\mathrm{m} / \mathrm{s}$ para a vazão de $20 \mathrm{l} / \mathrm{s}$. Considerando que grãos de areia de $200 \mu \mathrm{m}$ possuem velocidades terminais de sedimentação de $0,025 \mathrm{~m} / \mathrm{s}$ (CAMP, 1942) fica nítido que as PRADO, G. S. (2006) 
velocidades do fluido na região de acúmulo do SHV, mesmo para a menor vazão (10 1/s), são suficientemente altas para promover ressuspensão de partículas já capturadas.

A Figura 3.28(a) permite que se constate outro fato interessante; para a vazão de 10 1/s, as velocidades do fluido junto ao topo da região confinada entre os cilindros, externo e interno do SHV têm a mesma ordem de grandeza das velocidades observadas na região de acúmulo da unidade, indicando que esta é uma região de estagnação de fluido, ou "zona morta". O mesmo não é observado na Figura 3.28(b, c) para as vazões de 15 l/s e 20 l/s.

Para entender as causas da presença dessa região de estagnação de fluido entre os cilindros, externo e interno, do SHV para a vazão de 10 1/s e as causas da ausência dessa mesma região para as vazões de 15 1/s e 20 1/s é necessário, mais uma vez, visualizar o escoamento no interior da unidade. Com esse objetivo os vetores velocidade foram plotados em três planos (Plano 1; Plano 2 e Plano 3) que cortam transversalmente o SHV, como indicado na Figura 3.23.

Pela análise das Figuras 3.29, 3.30 e 3.31 pode se concluir que a presença da região de estagnação de fluido na parte superior do volume compreendido entre os cilindros, externo e interno, do SHV está relacionada ao espalhamento da frente de fluido que adentra a unidade através do bocal de entrada (vetores de cor vermelha). Nota-se que para a vazão de 10 1/s (Figura 3.29(a, b, c)) o espalhamento desta frente de fluido (vetores de cor vermelha) é menor que aquele observado para as vazões de $15 \mathrm{l} / \mathrm{s}$ e 20 1/s (Figuras 3.30(a, b, c) e 3.31(a, b, c)), ou seja, para a vazão de 10 1/s, apenas os dois terços inferiores do volume compreendido entre os cilindros, externo e interno, do SHV, são diretamente influenciados pelas altas velocidades do jato de fluido proveniente do bocal de entrada, enquanto que para as vazões de 15 1/s e 20 1/s todo o volume compreendido entre dois cilindros recebe tal influência, impossibilitando a formação de regiões de estagnação de fluido nesta região.

A análise da Figura 3.28 já havia permitido a constatação de que as velocidades no interior da região de acúmulo de sólidos do SHV poderiam causar ressuspensão de sólidos capturados, no entanto, tal cenário pode ser ainda mais grave, pois sobrepondo os planos das Figuras 3.29, 3.30 e 3.31 aos planos das Figuras 3.25, 3.26 e 3.27 pode-se observar a ocorrência de movimento ascensional do fluido na entrada da região de 
acúmulo de sólidos e mais, as velocidades do fluido com movimento ascendente são da mesma ordem de grandeza das velocidades do fluido com movimento descendente. Este fato indica a necessidade de mudar a posição dos anteparos que "protegem" a região de acúmulo de sólidos, de modo que se evite ou pelo menos atenue a ocorrência de movimentos ascensionais do fluido na região e; ainda, aumentar o volume da região de acúmulo de sólidos para que se diminuam as velocidades no seu interior.

Outra forma de apresentação dos resultados das simulações computacionais são os gráficos de velocidade. Neste trabalho de pesquisa, este tipo de apresentação dos resultados foi utilizado para estudar a ocorrência de curtos-circuitos hidráulicos no interior do SHV. Para tanto, foram plotados gráficos de velocidades radiais (Figura 3.32), as quais foram obtidas de linhas radiais correspondentes às válvulas V11, V12, V13 e V14. Estas linhas podem ser visualizadas na Figura 3.19 (linhas de cor azul).

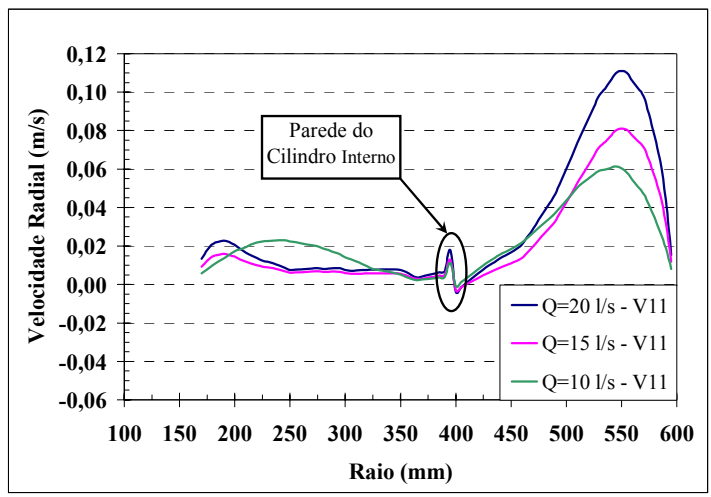

(a)

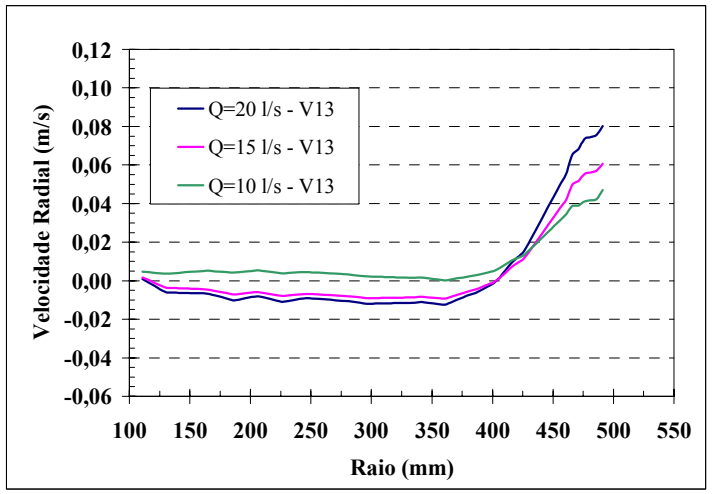

(c)

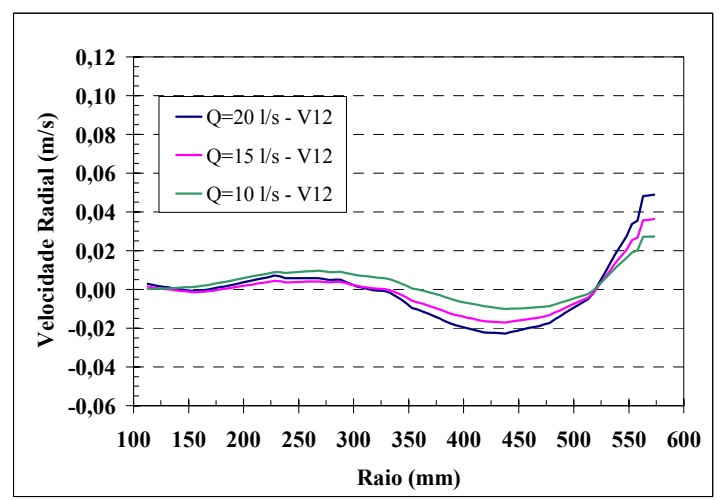

(b)

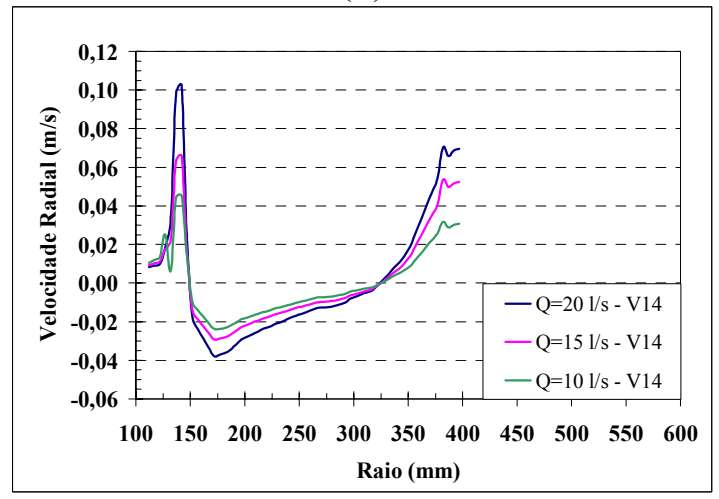

(d)

Figura 3.32 - Gráficos de velocidade radial do fluido para vazões de 10 1/s, 15 l/s e 20 1/s. (a) Gráfico das velocidades radiais para vazões de 10 l/s, 15 1/s e 20 1/s na linha radial correspondente à válvula V11. (b) Gráfico das velocidades radiais para vazões de 10 l/s, 15 l/s e 20 l/s na linha radial correspondente à válvula V12. (c) Gráfico das velocidades radias para vazões de $10 \mathrm{l} / \mathrm{s}, 15 \mathrm{l} / \mathrm{s}$ e $20 \mathrm{l} / \mathrm{s}$ na linha radial correspondente à válvula V13. (d) Gráfico das velocidades radias para vazões de 10 1/s, 15 1/s e 20 1/s na linha radial correspondente à válvula V14. Obs.: velocidade radial positiva significa movimento do fluido no sentido do centro do SHV. 
Como pode ser observado na Figura 3.32(a, b, c, d) a velocidade radial junto à parede externa do SHV é sempre positiva. Este comportamento já havia sido prenunciado pela literatura (SVAROVSKY, 1984), principalmente, para o corpo cônico do SHV, pois a inclinação da parede externa da unidade faz com que ela direcione o fluxo descendente para o centro da mesma porém, é interessante notar que na região central da unidade, onde o fluxo é ascendente, a velocidade radial é negativa. Isto indica a existência de um Locus of Zero Radial Velocity (LZRV), ou local de velocidade radial zero, o qual praticamente coincide com o LZVV. Esta inversão do sentido da velocidade radial não ocorre para a vazão de 10 1/s na linha radial correspondente à válvula V13 (Figura 3.32(c)). Para esta vazão, a velocidade radial na linha radial V13 é sempre positiva, o que pode ser interpretado como curto-circuito hidráulico.

\subsection{Discussão dos Resultados Experimentais}

O estudo acerca da hidrodinâmica do separador hidrodinâmico por vórtice (SHV), desenvolvido na presente pesquisa, fundamenta-se em resultados obtidos de ensaios de estímulo-resposta e de simulações computacionais do padrão de escoamento da unidade em um software de dinâmica dos fluidos computacional chamado CFX 10.0.

Os resultados dos ensaios de estímulo-resposta mostram que o regime de macromistura do escoamento que se desenvolve no SHV, para as vazões de 10 1/s, 15 1/s e 20 1/s, aproxima-se do plug-flow, porém com certo grau de mistura, o qual diminui com o aumento da vazão de alimentação da unidade, como mostra a razão $\mathrm{TDH}_{\mathrm{p}}$ por $\mathrm{TDH}_{\mathrm{t}}-$ percentagem do volume útil do SHV que apresenta escoamento com regime de macromistura do tipo plug-flow - (Tabela 3.2). Para a vazão de 10 1/s, 41\% do volume útil do SHV apresentam escoamento com regime de macro-mistura do tipo plug-flow; aumentando-se a vazão de alimentação da unidade para 15 1/s esse percentual sobe para $49 \%$, e alcança os $63 \%$ ao se elevar a vazão de alimentação do SHV para 20 1/s.

Os resultados das simulações computacionais demonstram que os padrões de escoamento do SHV, para as três vazões estudadas (10 1/s; 15 1/s e 20 1/s), apresentam características prenunciadas pela literatura, como: movimento helicoidal e descendente do fluido junto à parede externa da unidade e movimento helicoidal e ascendente do 
fluido junto ao centro da mesma; e existência de um plano de cisalhamento com velocidade vertical zero (LZVV). Estas características do padrão de escoamento do SHV são importantíssimas, pois indicam que o fluido descreve longas trajetórias helicoidais mais longas do que a distância entre a entrada e a saída da unidade, aumentando o tempo de detenção hidráulica (TDH) do SHV e, consequentemente, o tempo em que os campos de aceleração gravitacional e "centrífuga" atuam sobre partículas suspensas no meio fluido (ANDOH e SMISSON, 1993). Os resultados das simulações computacionais (Figuras 3.25; 3.26; 3.27; 3.29; 3.30 e 3.31) permitem, também, a identificação de quatro regiões no interior do SHV, cada qual com padrão de escoamento que apresenta características distintas (Figura 3.33), são elas:

- Região de entrada (RE) - corresponde ao volume compreendido entre os cilindros, externo e interno, do SHV, onde se localiza o bocal de entrada da unidade (região de cor vermelha na Figura 3.33). O escoamento nesta região apresenta forte influência do jato de fluido que entrava pelo bocal de entrada com altas velocidades, consequentemente, nesta região a turbulência do escoamento é alta, o que provoca o aparecimento de escoamentos secundários (recirculações internas). Pode-se deduzir que o regime de macro-mistura do escoamento na RE aproxima-se da mistura perfeita. O volume estimado da RE é de $0,4 \mathrm{~m}^{3}$ (400 litros);

- Região de acúmulo (RA) — corresponde ao volume útil do corpo cônico do SHV que é "protegido" por anteparos (região de cor verde na Figura 3.33). O escoamento nesta região apresenta velocidades mais baixas que aquelas encontradas no restante do SHV e, por isso, pode ser considerada como região de estagnação de fluido. O volume estimado da RA é de 0,1 $\mathrm{m}^{3}$ (100 litros)

- Região de separação (RSe) - corresponde ao volume útil do corpo cônico do SHV menos o volume da região de acúmulo (região de cor azul na Figura 3.33). É na região de separação que provavelmente ocorre a separação sólido-líquido. O escoamento na RSe é caracterizado pela presença de duas regiões com movimento vertical do fluido em sentidos opostos: junto à parede externa do SHV o movimento do fluido é helicoidal e descendente e na região central da unidade o movimento do 
fluido é helicoidal e ascendente. Esta característica do escoamento na região de separação acarreta a formação de um plano de cisalhamento com velocidade vertical zero o LZVV. Análises das velocidades radiais na RSe deram indícios da existência de um LZRV (plano de cisalhamento com velocidade radial zero) que, praticamente, coincide com o LZVV. Pode-se inferir que o regime de macro-mistura do escoamento na RSe aproxima-se do plug-flow. O volume estimado da RSe é de $0,7 \mathrm{~m}^{3}$ (700 litros);

- Região de saída (RS) - corresponde ao volume útil no interior do cilindro interno do SHV (região de cor laranja na Figura 3.33). Nesta região localiza-se o vertedor tubular de saída da unidade. Tal fato faz com que o escoamento nesta região apresente certo grau de "desordem”, ou seja, turbulência elevada e escoamentos secundários (recirculações internas). Pode-se deduzir que o regime de macro-mistura do escoamento na RS aproxima-se da mistura perfeita. O volume estimado da RS é de 0,3 $\mathrm{m}^{3}$ (300 litros).

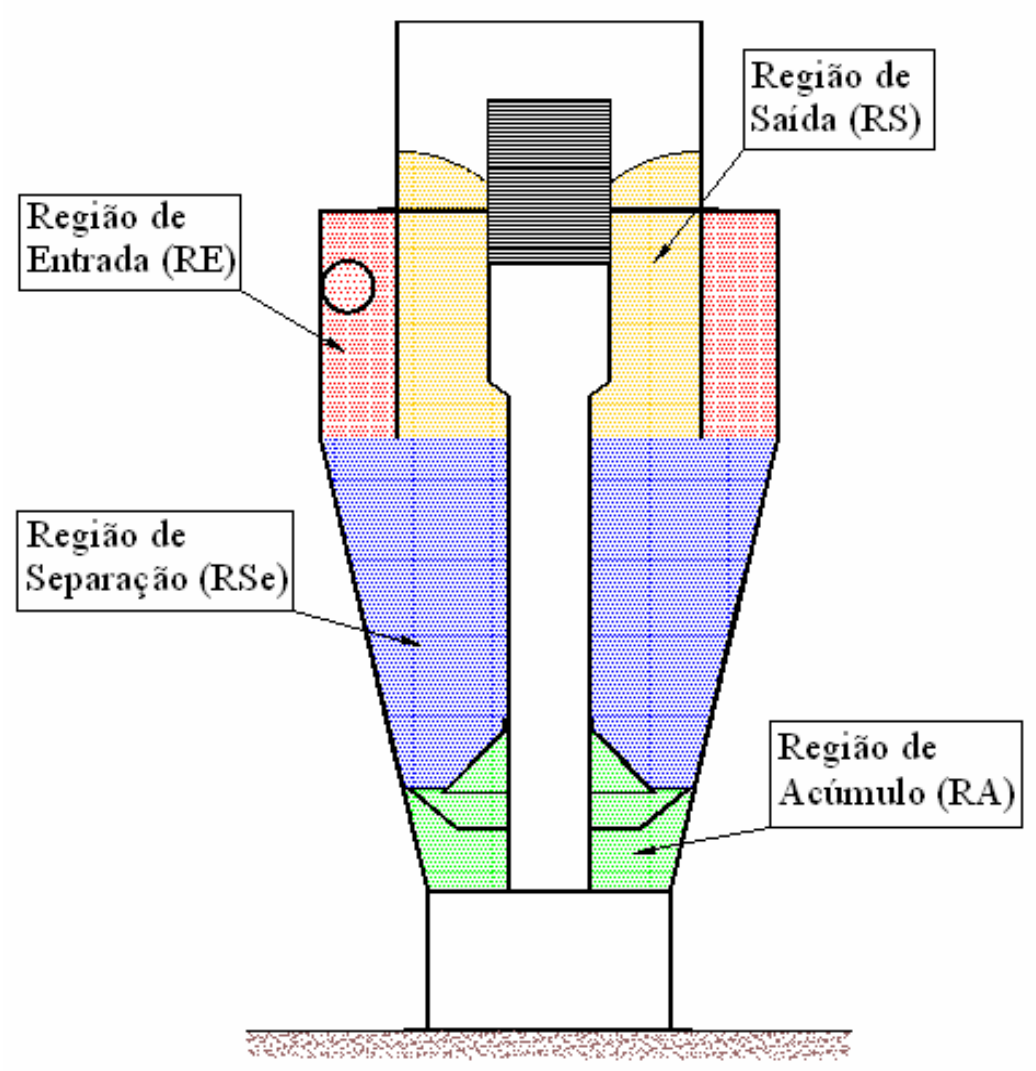

Figura 3.33 - Figura esquemática que mostra um corte transversal do SHV com as quatro regiões no interior da unidade que apresentam padrão de escoamento com características distintas. 
Apesar dos valores da razão $\mathrm{TDH}_{\mathrm{p}}$ por $\mathrm{TDH}_{\mathrm{t}}$ mostrados na Tabela 3.2 indicarem que quanto maior a vazão menor é o grau de mistura do escoamento na unidade, os valores dos números de dispersão $(\mathrm{D} / \mathrm{uL})$ apresentados na Tabela 3.3 não demonstram a mesma tendência, uma vez que: para a vazão de 10 1/s o valor do número dispersão é de 0,248 (dispersão de moderada a alta); para a vazão de 15 1/s o valor do número de dispersão, ao invés de diminuir como era de se esperar, aumenta para 0,261 (dispersão alta); e para a vazão de $20 \mathrm{l} / \mathrm{s}$ o valor do número de dispersão diminui para 0,158 (dispersão moderada). Sendo assim, quais valores podem ser considerados como os mais "confiáveis", os valores da razão $\mathrm{TDH}_{\mathrm{p}}$ por $\mathrm{TDH}_{\mathrm{t}}$ ou os valores dos números de dispersão?

Os resultados das simulações computacionais não fornecem subsídios suficientes para que essa questão seja respondida porém, dão fortes indícios de que aumentando a vazão de alimentação do SHV o regime de macro-mistura do escoamento que se desenvolve na unidade aproxima-se do plug-flow, dada a maior uniformidade da distribuição dos vetores velocidade nas Figuras 3.26 e 3.27 (vazões de 15 1/s e 20 1/s) em relação à Figura 3.25 (vetores velocidade para a vazão de $10 \mathrm{l} / \mathrm{s}$ ), principalmente nas regiões de entrada e saída (RE e RS). Além disso, na seção 3.3.1 (Resultados dos ensaios de estímulo-resposta) foi discutido que o aumento do número de dispersão para a vazão de 15 l/s é reflexo do maior espalhamento dos dados experimentais para esta vazão. Tal fato pode ser verificado na Figura 3.14(b), já que a cauda da curva de distribuição de idade de saída padronizada para a vazão 15 1/s é mais longa do que as demais. Portanto, pode-se supor que os valores da razão $\mathrm{TDH}_{\mathrm{p}}$ por $\mathrm{TDH}_{\mathrm{t}}$ sejam os mais "confiáveis" pois eles concordam com o que foi constatado pelos resultados das simulações computacionais, e mais, eles dependem, exclusivamente, da posição do pico da curva de distribuição de idade de saída $\mathrm{E}(\mathrm{t})$, a qual não é influenciada pelo espalhamento dos dados experimentais.

Além do número de dispersão, o valor de $\mathrm{TDH}_{\mathrm{m}}$ (tempo de detenção hidráulica médio), também, sofre influência direta do alongamento da cauda da curva de distribuição de idade de saída, por conseguinte, a razão $\mathrm{TDH}_{\mathrm{m}}$ por $\mathrm{TDH}_{\mathrm{t}}$ percentagem ativa do volume útil do SHV - apresenta valores inesperados, uma vez que, para a vazão de 15 1/s, 94\% do volume útil do SHV é ativo, isto é, $6 \%$ do volume útil da unidade é composto por regiões de estagnação de fluido, enquanto que para a vazão de 20 1/s, o percentual do volume útil constituído por regiões de estagnação de 
fluido, ao invés de diminuir ou continuar o mesmo, aumenta para $11 \%$. Como pode ser observado nas Figuras 3.26, 3.27, 3.28(b, c), 3.30 e 3.31 os padrões de escoamento obtidos nas simulações computacionais para as vazões de 15 1/s e 20 1/s não apresentam diferenças que possam esclarecer o alongamento da cauda da curva de distribuição de idade de saída padronizada para a vazão de 15 1/s em relação às demais (Figura 3.14(b)). Portanto, é provável que o percentual ativo do volume útil do SHV para a vazão de 15 1/s seja um pouco menor do que $94 \%$, e que o percentual ativo do volume útil do SHV para a vazão de 20 1/s seja um pouco maior do que $89 \%$.

Uma causa crível para o alongamento da cauda da curva de distribuição de idade de saída para a vazão de 15 1/s é a ocorrência de problemas relacionados às condições de contorno que foram assumidas na análise dos resultados dos ensaios de estímuloresposta, ou seja, vaso fechado, pois dentro do vertedor tubular de saída do SHV existia um quebra-vórtice, o qual provocava mistura intensa, exatamente, onde foi posicionada a sonda de condutividade usada na execução dos ensaios. Esta região de mistura na saída da unidade pode ter provocado recirculações do fluido, que por sua vez, podem ser a causa do maior espalhamento dos dados experimentais para a vazão de 15 1/s. Porém, por que as recirculações do fluido provocadas pelo quebra-vórtice posicionado no vertedor tubular de saída só teriam causado o alongamento da cauda da curva de distribuição de idade de saída padronizada para a vazão de 15 1/s?

Infelizmente, não é possível responder a esta pergunta com base nos dados coletados durante o estudo da hidrodinâmica do SHV; pode-se apenas inferir que o quebra-vórtice posicionado no vertedor tubular de saída da unidade não deve ter sido o único responsável pelo maior espalhamento dos dados experimentais para a vazão de 15 1/s, e que outros fatores não identificados durante a pesquisa devem ter contribuído para o fato.

Ao se observar o volume da região de acúmulo (RA) do SHV, a qual foi projetada para ser uma região de estagnação de fluido, nota-se que ele corresponde à aproximadamente $6 \%$ do volume útil da unidade. Isto sugere que para a vazão de $15 \mathrm{l} / \mathrm{s}$, ocorra a formação de apenas uma região de estagnação de fluido, exatamente onde deveria ocorrer, isto é, na região de acúmulo do SHV. Tal fato é corroborado pelo campo de velocidades mostrado na Figura 3.28(b) e pelos vetores velocidade mostrados na Figura 3.30(a, b, c), os quais mostram que os valores da velocidade na RA são duas e 
até três vezes menores do que aqueles observados nas demais regiões do SHV. O mesmo ocorre com a vazão de 20 1/s, porquanto as Figuras 3.28(c) e 3.31(a, b, c) indicam a existência de somente uma região de estagnação de fluido, a região de acúmulo.

Para a vazão de 10 1/s, os resultados dos ensaios de estímulo-resposta e das simulações computacionais, também apresentam excelente concordância em relação à presença de regiões de estagnação de fluido no interior do SHV. Para essa vazão, os resultados dos ensaios de estímulo-resposta indicam que as regiões de estagnação de fluido correspondem a $15 \%$ do volume útil da unidade, já os resultados das simulações computacionais (Figuras 3.28(a) e 3.29(a, b, c)) mostram que para a vazão de 10 1/s existem duas regiões de estagnação de fluido no interior do SHV, uma delas é a região de acúmulo (RA) da unidade, que responda por $6 \%$ do volume útil da mesma, e a outra, localiza-se na região de entrada (RE) da unidade, mais precisamente, no terço superior da mesma. Ao se calcular um terço do volume da RE, obtém-se 133 litros que correspondem a $8,9 \%$ do volume útil do SHV. Somando-se os 6\% correspondentes ao volume da RA aos 8,9\% correspondentes a um terço do volume da RE, obtém-se aproximadamente os $15 \%$ do volume útil do SHV que os ensaios de estímulo-resposta indicaram como regiões de estagnação de fluido.

As simulações computacionais demonstram, também, que não obstante as velocidades na região de acúmulo (RA) do SHV serem duas e até três vezes inferiores às velocidades observadas nas demais regiões da unidade, elas ainda são suficientemente altas para promover ressuspensão de grãos de areia anteriormente retidos, além disso, sobrepondo as Figuras 3.25, 3.26 e 3.27 às Figuras 3.29, 3.30 e 3.31, observa-se a existência de fluxo ascensional do fluido na entrada da RA com velocidades tão altas quanto àquelas do fluxo descendente no mesmo local. Com base nestas constatações verifica-se a necessidade de se alterar a geometria da região de acúmulo do SHV. Com o intuito de diminuir as velocidades no interior da RA e atenuar o fluxo ascensional do fluido na entrada da mesma pode-se aumentar o volume da região de acúmulo e alterar a posição dos anteparos que a "protegem”.

Durante o estudo da hidrodinâmica do SHV constatou-se a ocorrência de curtoscircuitos hidráulicos que, somados aos efeitos da diminuição do volume ativo da unidade decorrente da presença de regiões de estagnação de fluido, causam a 
antecipação do pico das curvas de distribuição de idade de saída, o qual pode ser observado na Figura 3.14(a) (LEVENSPIEL, 2000).

Assumindo que os valores de $\mathrm{TDH}_{\mathrm{m}}$ refletem os efeitos da diminuição do volume ativo do SHV, é possível exprimir numericamente os efeitos dos curtoscircuitos hidráulicos na antecipação do pico das curvas de distribuição de idade de saída subtraindo de $\mathrm{TDH}_{\mathrm{m}}$ o valor de $\mathrm{TDH}_{\mathrm{p}}$. Esta diferença entre $\mathrm{TDH}_{\mathrm{m}}$ e $\mathrm{TDH}_{\mathrm{p}}$ para a vazão de 10 l/s é de $66 \mathrm{~s}$; para vazão de 15 1/s é de $47 \mathrm{~s}$; e para a vazão de 20 1/s é de $20 \mathrm{~s}$. Com base nestes valores pode-se concluir que os curtos-circuitos hidráulicos diminuem com o aumento da vazão de alimentação do SHV.

Os resultados das simulações computacionais não permitem que se confirme a diminuição dos curtos-circuitos hidráulicos com o aumento da vazão de alimentação do SHV, todavia, eles indicam que logo abaixo da borda inferior do cilindro interno da unidade, provavelmente, ocorra curtos-circuitos hidráulicos, independentemente, da vazão de alimentação empregada (Figuras 3.25, 3.26 e 3.27). O único indício fornecido pelas simulações computacionais de que os curtos-circuitos hidráulicos são mais pronunciados para menores vazões de alimentação, pode ser visto nos gráficos de velocidade radial da Figura 3.32, uma vez que, as velocidades radiais para a vazão de 10 1/s na linha radial V13 é sempre positiva, ou seja, o fluido movimenta-se para o centro da unidade. Tal fato sugere que, para a vazão de 10 1/s, também, ocorram curtoscircuitos hidráulicos na região de separação do SHV.

Frente ao exposto neste capítulo, percebe-se que o SHV desenvolvido na presente pesquisa ainda necessita de pequenos ajustes, principalmente, no que concerne ao volume da região de acúmulo da unidade e à posição dos anteparos que a protegem. Contudo, de forma geral, o padrão de escoamento do SHV apresenta as características imprescindíveis para que ocorra a separação e a remoção de grãos de areia suspensos no esgoto sanitário, como por exemplo: movimento helicoidal de descendente o fluido junto à parede externa da unidade e movimento helicoidal e ascendente do fluido na região central da mesma; formação de um plano de cisalhamento com velocidade vertical igual a zero (LZVV); regime de macro-mistura próximo ao plug-flow; dentre outros (ANDOH e SMISSON, 1993; ANDOH, 1998; ANDOH e SAUL, 2003; VEERAPEN et al., 2005). 


\subsection{Conclusões}

Os resultados apresentados nesse capítulo permitem concluir que:

- O regime de macro-mistura do escoamento que se desenvolve no SHV, para as vazões de 10 l/s, 15 l/s e 20 l/s, aproxima-se do plug-flow porém, com certo grau de mistura, o qual diminui com o aumento da vazão de alimentação da unidade;

- Podem ser identificadas quatro regiões no interior do SHV as quais apresentam padrões de escoamento com características distintas, são elas: região de entrada (RE), região de saída $(\mathrm{RS})$, região de separação (RSe) e região de acúmulo (RA);

- $\quad$ Na região de entrada (RE) o escoamento apresenta forte influência do jato de fluido que entrada pelo bocal de entrada do SHV com altas velocidades; consequentemente, nesta região, a turbulência do escoamento é alta, o que provoca o aparecimento de escoamentos secundários. Pode-se deduzir que o regime de macro-mistura do escoamento na RE aproxima-se da mistura perfeita;

- $\quad \mathrm{Na}$ região de acúmulo (RA) o escoamento apresenta velocidades mais baixas que aquelas encontradas no restante do SHV e, por isso, pode ser considerada como região de estagnação de fluido;

- $\quad$ Na região de separação (RSe) é onde, provavelmente, ocorre a separação sólido-líquido. O escoamento na RSe é caracterizado pela presença de duas regiões com movimento vertical do fluido em sentidos opostos: junto à parede externa do SHV o movimento do fluido é helicoidal e descendente e na região central da unidade o movimento do fluido é helicoidal e ascendente. Esta característica do escoamento na região de separação acarreta a formação de um plano de cisalhamento com velocidade vertical zero o LZVV. Análises das velocidades radiais na RSe deram indícios da existência de um LZRV (plano de cisalhamento com velocidade radial zero) que, praticamente, coincide com o LZVV. Pode-se 
inferir que o regime de macro-mistura do escoamento na RSe aproxima-se do plug-flow;

- $\quad$ Na região de saída (RS) localiza-se o vertedor tubular de saída do SHV, o que faz com que o escoamento nesta região apresente certo grau de “desordem", ou seja, turbulência elevada e escoamentos secundários (recirculações internas). Pode-se deduzir que o regime de macro-mistura do escoamento na RS aproxima-se da mistura perfeita;

- Para vazão de alimentação de 10 1/s: 41\% do volume útil do SHV apresentam escoamento com regime de macro-mistura do tipo plug-flow; o volume das regiões de estagnação de fluido corresponde a $15 \%$ do volume útil do SHV, divididos em duas porções: uma delas é a região de acúmulo da unidade ( $6 \%$ do volume útil do SHV) e a outra é a parte superior da região de entrada da unidade ( $8,9 \%$ do volume útil do SHV);

- Para vazão de alimentação de 15 1/s: 49\% do volume útil do SHV apresentam escoamento com regime de macro-mistura do tipo plug-flow; para esta vazão existe somente uma região de estagnação de fluido, a região de acúmulo que corresponde a $6 \%$ do volume útil do SHV;

- Para vazão de alimentação de 20 1/s: 63\% do volume útil do SHV apresentam escoamento com regime de macro-mistura do tipo plug-flow; para esta vazão a região de estagnação de fluido corresponde a $11 \%$ do volume útil do SHV, a qual é pouco maior que a região de acúmulo da unidade;

- $\quad$ O escoamento no SHV apresenta curtos-circuitos hidráulicos logo abaixo da borda inferior do cilindro interno da unidade, independentemente da vazão de alimentação empregada;

- Para vazão de $10 \mathrm{l} / \mathrm{s}$ há indícios da ocorrência de curtos-circuitos hidráulicos na região de separação (RSe) do SHV; 
- Deve-se alterar a posição dos anteparos que "protegem" a região de acúmulo (RA) do SHV pois, para três vazões de alimentação estudas, verificaram-se movimentos ascensionais do fluido na entrada da mesma;

- Deve-se aumentar o volume da região de acúmulo (RA) do SHV, no intuito de diminuir as velocidades no seu interior, pois foram observadas velocidades altas o suficiente para promover ressuspensão de grãos de areia previamente retidos na $\mathrm{RA}$;

- A análise combinada de resultados de ensaios de estímulo resposta e de simulações computacionais permitiu não somente verificar a ocorrência de recirculações do fluido, regiões de estagnação ou "zonas mortas" e curtoscircuitos hidráulicos como, também, identificar a localização de tais fenômenos, fornecendo, assim, subsídios para verificar a necessidade de “ajustar" pontualmente a geometria do SHV, isto é, alterar apenas os componentes que apresentam problemas. 


\section{Capítulo 4 -A Problemática da Determinação da Quantidade de Areia no Esgoto Sanitário}

Este capítulo apresenta dois métodos de análise utilizados para avaliar a eficiência de remoção de areia do separador hidrodinâmico por vórtice, tema principal desta tese. Primeiramente, é apresentado e discutido o método de determinação da concentração de areia no esgoto, desenvolvido durante esta pesquisa. Este método é totalmente original e baseia-se em concentrar os sólidos de uma amostra de esgoto por sedimentação em cone Imhoff e centrifugação; separar a matéria orgânica da areia presente na amostra, usando oxidação com peróxido de hidrogênio $\left(\mathrm{H}_{2} \mathrm{O}_{2}\right)$ e enxágües sucessivos com água destilada; calcinar a areia separada para eliminar qualquer resíduo que possa ter permanecido e, finalmente, pesar a amostra de areia resultante. Depois, a técnica de determinação de tamanho de partículas chamada análise de imagens, a qual foi adaptada para que fosse possível utilizá-la para determinar a distribuição granulométrica dos grãos de areia presentes em amostras de areia seca, é apresentada e pormenorizada. Tal técnica consiste em coletar grãos de areia com fita adesiva transparente, colá-los em lamínulas de vidro, fotografá-los por meio de câmera CCD (Charge Coupled Device) acoplada a microscópio óptico, tratar as imagens adquiridas e proceder a contagem e determinação de tamanho de partículas em software de análise imagens. Finalmente, são apresentados e discutidos os resultados de concentração de areia e distribuição granulométrica dos grãos presentes no esgoto sanitário utilizado para alimentar o separador hidrodinâmico por vórtice, que foram obtidos pelas duas técnicas. 


\subsection{Introdução}

\subsubsection{A areia no esgoto sanitário}

O emprego dos desarenadores como uma das unidades de operação que compõem a etapa de tratamento preliminar de estações de tratamento de esgoto (ETEs) é prática comum entre projetistas há mais de um século (GEIGER, 1942). Todavia, estranhamente, ainda hoje muito pouco se sabe a respeito da eficiência dessas unidades. Mesmo textos consagrados, como Metcalf \& Eddy (2003), acrescentam pouco a respeito do tema, porquanto, segundo seus autores, é muito difícil interpretar dados de eficiência de remoção dos desarenadores pois, além da escassez desses dados, o próprio material que estas unidades removem é "pobremente" caracterizado e, por conseguinte, as eficiências de diferentes sistemas de desarenação não podem ser comparadas. Para realizar tal tarefa é necessário primeiro conhecer qualitativamente e quantitativamente os materiais que adentram os desarenadores e, também, aqueles materiais que são removidos.

No Brasil, os desarenadores são conhecidos também como "caixas de areia". Ambos os nomes podem levar a conclusões errôneas acerca do material que essas unidades removem, pois a palavra desarenador, etimologicamente, significa separador de areia ("des-" prefixo latino que designa separação + "arena" que em latim significa areia + "-dor" sufixo latino que designa o agente da ação). Essa imprecisão não se verifica, quando os nomes da unidade são usados em inglês, "grit chamber" (traduzido para o português como "caixa de areia") ou degritter (traduzido para o português como desarenador). Seguindo o mesmo raciocínio adotado para se entender o significado da palavra desarenador, degritter significa separador de grit. Porém qual seria a tradução desse termo? Infelizmente grit não possui uma tradução exata para o português, mas para resolver esse impasse pode-se usar a definição dada por Camp (1942); consoante o autor, uma miríade de materiais particulados encontrados no esgoto sanitário podem ser classificados como grit, por exemplo: areia, silte, pó de carvão, cinzas, pó de café, sementes de frutas, fragmentos de ossos e de cascas de ovos, entre outros.

No entanto, saber apenas a composição dos materiais removidos pelos desarenadores não é suficiente para se medir a eficiência dessas unidades; é necessário, também, saber em quais quantidade esses matérias são encontrados tanto nos afluentes 
(esgoto bruto peneirado), quanto nos efluentes dos desarenadores. Essa tarefa, diferentemente de apenas inventariar constituintes, não é fácil, dada à heterogeneidade e à variabilidade dos materiais que os desarenadores removem. Não obstante, segundo Camp (1942), "a experiência tem demonstrado que se um desarenador for capaz de remover todos os grãos de areia maiores ou iguais a $0,2 \mathrm{~mm}$, ele removerá a maior parte do material que causa problemas a uma ETE”. Essa citação é quase tão antiga quanto os próprios desarenadores e ,como conseqüência de sua aceitação ao longo dos anos, a tradição de seu uso acabou tacitamente convencionando a quantidade de areia como "parâmetro" de controle dessas unidades, e 0,2 mm (200 $\mu \mathrm{m})$, como tamanho das menores partículas que devem ser removidas pelos desarenadores.

Apesar de o "parâmetro" quantidade de areia e o tamanho limite de 0,2 mm serem mundialmente aceitos como forma de se avaliar a eficiência de remoção dos desarenadores, ainda não existe tal consenso acerca de qual técnica analítica deve ser usada para medi-los. Gardner e Deamer (1996) já acenavam para o fato que, até 1996, ainda não existiam métodos de análise padronizados nem para determinação da massa, nem para determinação da distribuição granulométrica da areia presente em uma amostra de esgoto, mas o que assombra é que, passados 10 anos, tais métodos ainda inexistem.

Gardner e Deamer (1996) alertam, também, sobre um sério problema decorrente da falta de métodos de análise padronizados para determinação da quantidade (massa ou concentração) e da distribuição granulométrica da areia presente nos esgoto sanitários. Segundo os autores, esta carência metodológica dificulta negociações entre clientes (municipalidades, companhias de saneamento e projetistas) e empresas, que projetam e fornecem desarenadores, pois nem os fornecedores podem comprovar a eficiência de suas unidades, nem os clientes podem verificar se as unidades fornecidas atendem as especificações de projeto.

No intuito de suplantar este déficit, buscou-se, com esse trabalho de pesquisa, a proposição de uma metodologia de análise para determinação da concentração de areia no esgoto, que fosse acima de tudo viável para a grande maioria dos laboratórios de análise de ETEs, de centros de pesquisa e de universidades. Para tanto, foram utilizados somente materiais e equipamentos comuns à maioria dos laboratórios, como: cones Imhoff, centrífuga, balança analítica, mufla, pissetas, pipetas, entre outros. 
Na presente pesquisa tentou-se, também, ir além da "simples" determinação das quantidades de areia presente nos esgotos, com a utilização de uma técnica de determinação da distribuição de tamanho de partículas (DTP), denominada análise de imagens. Por essa técnica é possível determinar a distribuição granulométrica dos grãos de areia presentes nos esgotos afluentes e efluentes de desarenadores possibilitando, assim, melhor compreensão do funcionamento dessas unidades. Essa abordagem vai ao encontro do que foi preconizado por Ives (1995), isto é, a necessidade de se estudar as unidades de tratamento não como se elas fossem "caixas pretas". Para isso é imperativa a adoção de "parâmetros" de controle que "digam" mais sobre os fenômenos que ocorrem dentro das unidades; logo a utilização da DTP parece ser perfeitamente adequada ao estudo dos desarenadores, pois, os fenômenos envolvidos no processo de separação dos grãos de areia são puramente físicos e, por conseguinte, saber o tamanho desses grãos é fundamental para se entender porque alguns deles são removidos enquanto outros não o são.

A seguir, serão apresentados alguns conceitos importantes acerca da determinação da distribuição de tamanho de partículas (DTP) que, por se tratar de assunto ainda pouco comum em meio aos profissionais que trabalham com tratamento de água e esgoto, precisam ser apresentados de forma mais detalhada, pois serão imprescindíveis para a correta compreensão e interpretação dos dados de DTP, apresentados e discutidos neste trabalho. Na seqüência, as duas técnicas desenvolvidas durante esta pesquisa, assim como os resultados por elas obtidos serão apresentados e discutidos.

\subsubsection{O conceito de esfera equivalente}

As partículas suspensas encontradas em afluentes e efluentes de sistemas de tratamento de água e esgoto são estruturas tridimensionais, polidispersas (de vários tamanhos) e com diferentes propriedades físico-químicas, todavia, os métodos disponíveis para determinação de seus tamanhos fornecem como resposta um único valor, normalmente designado como diâmetro derivado ou equivalente.

Existem algumas formas geométricas tridimensionais que podem ter seu tamanho expresso com um único valor, como o cubo, o tetraedro regular e a esfera. 
Todas elas podem ser usadas como representações gráficas de diâmetros equivalentes, contudo, a forma geométrica mormente empregada, é a esfera, o que deu origem ao nome esfera equivalente. $\mathrm{O}$ diâmetro de uma esfera equivalente, ou apenas diâmetro equivalente, é obtido medindo-se uma propriedade de uma dada partícula, que dependa de seu tamanho, como: comprimento máximo ou mínimo, área superficial ou projetada, volume, velocidade terminal de sedimentação, espalhamento de luz etc.; e, posteriormente, relacionando este valor a uma única dimensão linear, o diâmetro equivalente. Portanto, podem ser obtidos vários diâmetros equivalentes para uma mesma partícula, a depender de qual propriedade dessa partícula foi medida (ALLEN, 1997). Por exemplo: um cubo de arestas iguais a $1 \mu \mathrm{m}$ tem o mesmo volume de uma esfera de diâmetro equivalente igual a $1,24 \mu \mathrm{m}$, a mesma área superficial de uma esfera de diâmetro equivalente igual a 1,38 $\mu \mathrm{m}$ e a mesma área projetada que uma esfera de diâmetro equivalente igual a $1,13 \mu \mathrm{m}$ teria.

\subsubsection{A interferência da forma das partículas na determinação de seus diâmetros equivalentes}

Allen (1997) aponta a forma das partículas como importante fonte de interferência na determinação da distribuição do tamanho de partículas (DTP). Dependendo da propriedade analisada, partículas de formas distintas podem ser representadas por um mesmo valor de diâmetro (mesma esfera equivalente) ou por diâmetros diferentes (diferentes esferas equivalentes). Por exemplo: um cubo com arestas de $1 \mu \mathrm{m}$, uma esfera com diâmetro de $1 \mu \mathrm{m}$ e um cilindro com diâmetro de $1 \mu \mathrm{m}$ e altura igual a $3 \mu \mathrm{m}$ possuem o mesmo diâmetro equivalente de peneiramento $\left(\mathrm{d}_{\mathrm{p}}\right)$; não obstante, ao se aproximar cada uma destas partículas a uma esfera de igual volume, obtêm-se diâmetros equivalentes $\left(d_{V}\right)$ muito distintos: $d_{V}=1 \mu \mathrm{m}$, para a esfera; $d_{V}=$ $1,24 \mu \mathrm{m}$, para o cubo; e $\mathrm{d}_{\mathrm{V}}=1,65 \mu \mathrm{m}$, para o cilindro.

Os afluentes e efluentes de sistemas de tratamento de água e de esgoto carregam partículas dos mais variados tipos, formas e tamanhos, como partículas floculentas, minerais, microrganismos etc.. Em virtude dessa heterogeneidade de formas, alguns cuidados devem ser considerados para a escolha do mais adequado método a cada aplicação. 


\subsubsection{A escolha da técnica de determinação da distribuição de tamanho de partículas}

A determinação da distribuição de tamanho de partículas (DTP) é um tipo de caracterização física e, diferentemente das análises químicas, depende dos procedimentos analíticos empregados (ALLEN, 1997). Ou seja, ao se medir, por exemplo, a concentração de fósforo total ou nitrogênio total de uma amostra, os resultados obtidos não devem depender dos procedimentos adotados durante suas determinações, enquanto ao se determinar a DTP de uma amostra, os resultados variarão de acordo com a técnica de determinação utilizada. Em virtude disso, resultados obtidos de diferentes técnicas de determinação de DTP jamais poderão ser comparados indiscriminadamente uns aos outros.

Apesar de potencialmente promissora, a utilização da DTP como parâmetro de controle de processos e operações de tratamento de água e esgoto requer cuidados no que concerne à escolha da técnica de determinação a ser adotada. A escolha da técnica de determinação mais adequada depende de uma série de fatores, como: a natureza da amostra (seca, dissolvida ou em suspensão, solubilidade das partículas, tamanho das partículas etc.), a natureza do processo (uso do valor de diâmetro obtido), a resolução de cada técnica (precisão do método) e a tradição da utilização da técnica. A escolha de qual propriedade da partícula deve ser analisada, mormente, está ligada à utilidade desta informação. Por exemplo, ao se avaliar o desaguamento de lodo, segundo Lawler et al. (1986) e Feitz et al. (2001), o uso do diâmetro de esfera equivalente de mesma área superficial pode ser o mais adequado. Todavia, ao se estudar processos que envolvem interações entre partículas, como floculação, filtração, flotação etc., a razão área superficial por volume das partículas pode ser o fator de maior influência. Deste modo, a escolha da técnica de determinação de tamanho de partícula, sempre que possível, deve estar atrelada ao fenômeno que governa o processo ou a operação de tratamento investigada.

Em termos práticos, porém, outros fatores devem ser considerados na escolha da técnica, como: custo de aquisição, manutenção e operação do equipamento; disponibilidade de mão-de-obra especializada; tempo de resposta; facilidade de obtenção, tratamento e interpretação dos dados, necessidade ou não de fracionamento da amostra, entre outras.

PRADO, G. S. (2006) 


\subsubsection{As técnicas de determinação da distribuição de tamanho de partículas}

Santos et al. (2004) dividem as técnicas de determinação da distribuição do tamanho de partículas (DTP) em dois grupos: técnicas com e sem fracionamento de amostra. Nas técnicas com fracionamento de amostra (peneiramento, filtração em membranas, sedimentação etc.) as partículas são removidas da amostra por faixas (frações) de tamanho, de modo que a distribuição de tamanho de partículas é obtida depois de sucessivas etapas de separação. Em conseqüência, as diferentes faixas de tamanho podem ser individualmente analisadas. Nas técnicas sem fracionamento, por sua vez, não é aplicado mecanismo algum de separação, conseqüentemente as frações de tamanhos presentes na amostra são determinadas por uma única medição.

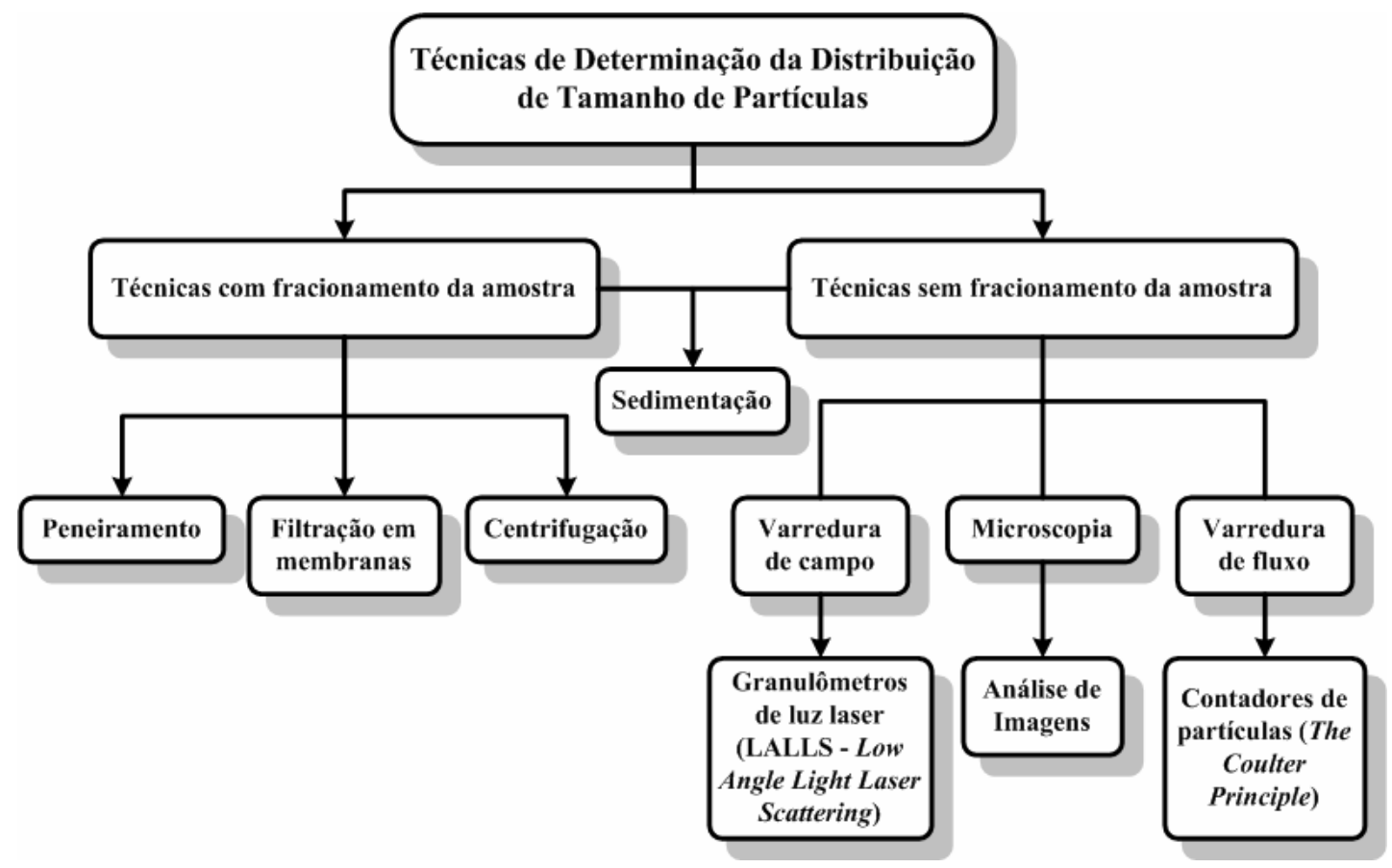

Figura 4.1 - Fluxograma das técnicas de determinação da distribuição de tamanho de partícula classificadas como: técnicas com fracionamento da amostra e técnicas sem fracionamento da amostra.

Fonte: Santos et al. (2004).

Na Figura 4.1, são apresentadas algumas técnicas de determinação de tamanho de partículas, divididas em dois grandes grupos como proposto por Santos et al. (2004). Maiores detalhes acerca de cada uma das técnicas citadas na Figura 4.1, assim como uma revisão bibliográfica mais profunda sobre distribuição de tamanho de partículas, podem ser encontrados em Allen (1997) e Santos et al. (2004). 


\subsection{Materiais e Métodos}

\subsubsection{Considerações iniciais acerca dos métodos desenvolvidos}

Nessa seção serão apresentadas as duas metodologias desenvolvidas, uma para a determinação da concentração da areia no esgoto sanitário e outra para determinação da distribuição granulométrica dessa areia, cada qual em uma seção própria. Antes, porém, vale a pena ressaltar que ambas as metodologias foram desenvolvidas com um único objetivo: fornecer subsídios para o estudo e desenvolvimento da unidade de desarenação tema desta tese. Em nenhum momento o autor dessa pesquisa teve a pretensão de propor a padronização do que foi desenvolvido.

As duas metodologias propostas nesta tese são originais porquanto, até hoje, não existem métodos amplamente utilizados para a determinação da concentração e distribuição granulométrica da areia presente no esgoto sanitário. No entanto, a originalidade dessas metodologias não está em qualquer dos procedimentos adotados para se chegar aos resultados almejados e sim no encadeamento lógico de procedimentos existentes e bem conhecidos pela comunidade científica.

O método de determinação da concentração de areia presente no esgoto sanitário originou-se de um método no qual a oxidação com peróxido de hidrogênio é utilizada para separar areia da matéria orgânica em amostras de lodo primário. O trabalho do autor desta tese foi, simplesmente, adaptar e incrementar os procedimentos deste método, de forma a ser possível sua utilização para separação de areia da matéria orgânica em amostras muito mais diluídas.

Por sua vez, a metodologia utilizada para determinação da distribuição granulométrica da areia no esgoto sanitário nada mais é que a aplicação de uma das mais conhecidas técnicas de determinação de tamanho de partículas, a análise de imagens. A originalidade nesse caso está na preparação das amostras de areia seca, as quais são resultado imediato dos procedimentos aplicados para determinação da concentração de areia. Pode-se, também, considerar como original a utilização da análise de imagem como ferramenta de estudo de desarenadores pois, nos poucos trabalhos existentes sobre o tema, a técnica, mormente, utilizada é o peneiramento. 


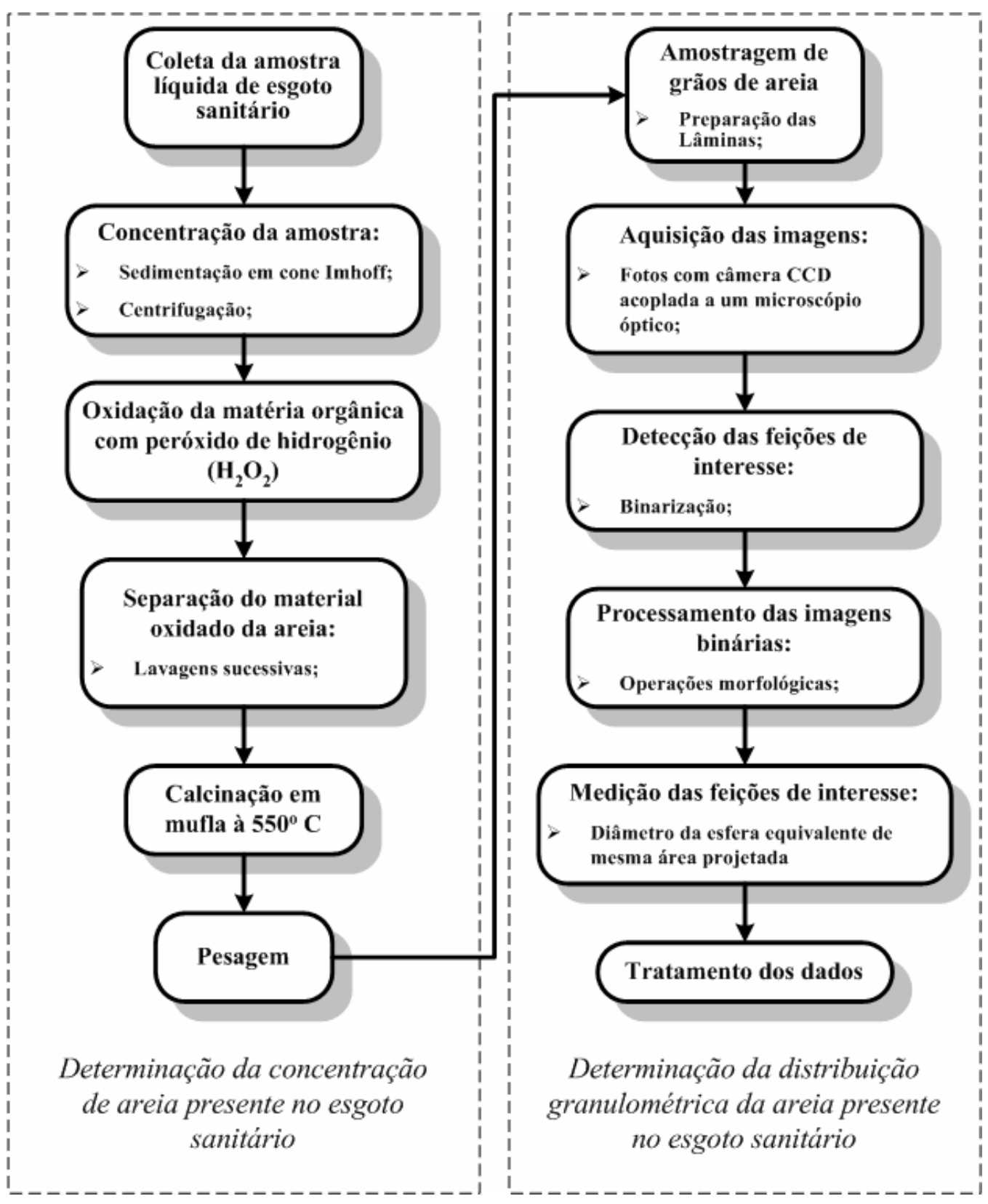

Figura 4.2 - Fluxograma esquemático da caracterização da areia presente no esgoto sanitário, com a apresentação das etapas dos dois métodos desenvolvidos nessa tese: determinação da concentração de areia presente no esgoto sanitário e determinação da granulometria da areia presente no esgoto sanitário.

Para que se possa ter uma idéia geral dos procedimentos constituintes das duas metodologias desenvolvidas, foi construído um fluxograma esquemático que é apresentado na Figura 4.2. Pode-se observar, as duas metodologias são complementares, isto é, ao final da determinação da concentração de areia é produzida uma amostra de areia seca, que por sua vez é usada na determinação da distribuição granulométrica. 


\subsubsection{Determinação da concentração de areia no esgoto bruto}

\subsubsection{Os problemas encontrados durante o desenvolvimento do método e as soluções adotadas}

Dos percalços encontrados para proposição de um método para a determinação da concentração de areia no esgoto sanitário, três merecem destaque especial: o primeiro deriva da baixa concentração de areia presente nos esgotos sanitários proveniente de sistemas de coleta do tipo separador absoluto; o segundo tem origem na presença de partículas orgânicas nas amostras; e o terceiro decorre da dificuldade de se conseguir amostras de esgoto bruto que sejam representativas e ao mesmo tempo viáveis.

Problemas referentes à determinação de compostos, contaminantes etc., que apresentam baixa concentração no esgoto sanitário são corriqueiros na rotina de qualquer laboratório de análises e podem ser atenuados com esmero do experimentador ao realizar cada procedimento descrito na metodologia, no entanto outras medidas podem ser adotadas, como por exemplo uso de volumes maiores de amostra. Nesta pesquisa foi utilizado um litro de amostra de esgoto bruto para cada determinação, pois essa era a capacidade dos cones Imhoff disponíveis e, também, devido a problemas de armazenamento e transporte de amostras maiores. $O$ volume adotado (1 litro) demonstrou ser suficiente para todas as determinações realizadas com o esgoto afluente da estação elevatória da ETE Jardim das Flores, do município de Rio Claro - SP. Entretanto, o esgoto de outras localidades pode apresentar concentrações de areia muito inferiores àquelas encontradas no esgoto utilizado nesta pesquisa; por conseguinte, pode ser necessária a utilização de amostras de volume maior. Sugere-se que um litro seja o volume mínimo de amostra a ser usada para cada determinação e que esse volume seja aumentado na medida em que seja necessário.

A presença de material orgânico, tanto aderido aos grãos de areia como suspenso no meio líquido, sem sombra de dúvidas, foi o maior obstáculo a ser transposto. Este problema, a princípio, aparenta ter solução trivial, pois se poderia calcinar a amostra de esgoto em uma mufla à $550^{\circ} \mathrm{C}$, como é feito nas determinações de sólidos voláteis (SV) e sólidos fixos (SF). Porém esse procedimento não elimina o material orgânico, apenas o "reduz em tamanho", isto é, os resíduos resultantes de sua queima não desaparecem, 
eles tornam-se partículas muito pequenas indistinguíveis em meio aos diminutos grãos de areia (GARDNER e DEAMER, 1996). A solução desse impasse foi obtida concentrando-se os sólidos das amostras, depois oxidando o material orgânico com peróxido de hidrogênio e por fim, dentro do possível, separando ou eliminando a matéria orgânica presente, com lavagens sucessivas da amostra com água destilada.

Foram empregados dois procedimentos para concentrar as amostras de esgoto. Primeiro as amostras eram deixadas por $30 \mathrm{~min}$. em cones Imhoff, especialmente adaptados (Figura 4.5(b)) para que fosse possível a coleta do material sedimentável que se concentrava no fundo de cada cone. Este material era disposto em tubos Falcon, os quais eram centrifugados por alguns segundos e, então, o sobrenadante de cada tubo era descartado, obtendo-se assim as amostras concentradas.

Para separar ou eliminar a matéria orgânica das amostras concentradas foram empregadas: oxidação com peróxido de hidrogênio e lavagens sucessivas da amostra com água destilada. O peróxido de hidrogênio foi escolhido por ser um oxidante poderoso que "mineraliza" a matéria orgânica, o que contribui para que o processo de lavagens sucessivas das amostras seja mais fácil de realizar e, ao mesmo tempo, seguro para o experimentador.

Os cuidados referentes ao processo de amostragem, por serem o "gargalo" da metodologia, serão abordados em seção própria (seção 4.2.2.2), assim como: lista completa dos materiais e equipamentos necessários para a realização das análises (seção 4.2.2.3) e procedimentos de análise empregados na determinação da concentração de areia no esgoto sanitário (seção 4.2.2.4).

\subsubsection{Amostragem e conservação das amostras}

Um dos grandes problemas encontrados na determinação da concentração de areia presente no esgoto sanitário reside na escolha do procedimento de amostragem adequado. Neste caso, deve-se entender como adequado aquele procedimento pelo qual seja possível coletar amostras representativas, mas que acima de tudo seja viável.

Os grãos de areia, geralmente, são as partículas mais densas entre aquelas usualmente encontradas no esgoto sanitário bruto e, por isso, tendem a concentrar-se 
próximas ao fundo de canais e tubulações por onde escoa o esgoto. Esta peculiaridade comportamental acarreta sérias dificuldades práticas ao processo de amostragem, pois a grande maioria das ETEs não possuem pontos, à montante das unidade de tratamento preliminar, nos quais seja viável a coleta de esgoto bruto junto ao fundo das tubulações ou canais que o transportam.

A depender do arranjo espacial da chegada do esgoto e da vazão recebida pela ETE, é possível sugerir algumas alternativas para a escolha do ponto e do processo de amostragem. Todavia, deve-se levar em consideração que as sugestões indicadas não resolvem todos os problemas encontrados no campo e que a escolha do processo adequado dependerá muito da criatividade do experimentador em improvisar soluções práticas que se adéqüem aos problemas de cada ETE.

i) Em ETEs de pequeno porte, onde o emissário de esgoto não se encontra afogado na entrada da estação, pode ser possível coletar todo o volume de esgoto que chega a ETE por alguns segundos ou até mesmo por alguns minutos; no entanto este procedimento raramente é viável, seja pela configuração espacial do emissário, seja pela vazão elevada de esgoto recebida ou, ainda, por ambos os problemas;

ii) Em ETEs de pequeno a médio porte, onde o esgoto ao chegar à estação é transportado por algum canal, pode-se coletar amostras por meio de amostradores com fundo plano, que possam ser introduzidos dentro da corrente líquida, de modo que a amostra seja extraída próxima ao fundo do canal por onde escoa o esgoto; todavia este procedimento depende muito de se achar ou criar um amostrador adequado a cada caso;

iii) Em ETEs, onde o emissário deságua em caixas de distribuição é possível coletar amostras por meio de bombeamento, com a sucção da bomba posicionada próxima ao fundo da caixa (as bombas submersíveis portáteis podem facilmente desempenhar essa função). Mesmo em ETEs, onde o esgoto é transportado por canais é possível o uso de bombas para a realização da coleta porém, nesses casos, deve-se observar se o nível de água no canal é suficiente para o uso de um bomba e segundo Gardner e Deamer (1996), é recomendável também que a rotação da bomba seja ajustada para 
que a velocidade do esgoto na tubulação de sucção seja igual ou pelo menos próxima à velocidade da corrente líquida no canal.

Até agora só foram discutidos, neste texto, de onde e como coletar as amostras, porém nada foi mencionado sobre qual o volume coletar e que tipo de amostragem deve ser feita. Para isso não existe uma regra clara, o que deve ser levado em consideração é que a concentração de areia no esgoto sanitário geralmente é baixa, por conseguinte, quanto maior o volume de amostra coletada, menor será o erro amostral do ensaio. Quanto ao tipo de amostragem a ser escolhida, isso dependerá do tipo de análise que se pretende fazer. Podem-se realizar perfis de monitoramento 24 horas com amostragens horárias, para acompanhar a variação da concentração de areia no esgoto, ou coletar amostras pontuais à montante e à jusante de desarenadores, para avaliar a eficiência de remoção dessas unidades ou, ainda, coletar amostras compostas, para ser determinada a concentração média diária de areia no esgoto bruto.

$\mathrm{Na}$ presente pesquisa, as amostras de esgoto bruto foram coletadas da estação elevatória da ETE Jardim das Flores localizada no município de Rio Claro, SP. Devido à configuração espacial da chegada do esgoto bruto, optou-se pelo uso de bomba submersível portátil de $5 \mathrm{CV}$, posicionada dentro do poço de sucção da elevatória, junto ao anteparo que o separa do canal de chegada de esgoto (Figura 4.3). A escolha deste local é justificável, pois o poço de chegada do emissário, a caixa de detritos e o canal que transporta o esgoto ao poço de sucção não possuíam profundidades suficientes para a operação de uma bomba; ademais, optou-se pelo arranjo experimental que menos interferisse na operação da estação elevatória e consequentemente da ETE. Merece destaque, também, o fato de a bomba não ter sido instalada junto ao fundo do poço de sucção da elevatória e sim junto à parede lateral do anteparo que o separa do canal de chegada do esgoto. Optou-se por essa configuração porque foi constatada presença de grande quantidade de detritos (areia e material orgânico particulado sedimentável) no fundo do poço de sucção, os quais, caso fossem sugados pela bomba, poderiam interferir na representatividade das amostras.

A bomba submersível foi utilizada para alimentar um separador hidrodinâmico por vórtice (SHV), tema central desta pesquisa. O esgoto bruto era bombeado do poço de sucção por uma mangueira siraflex de 4 polegadas, passava por uma derivação em "T", à qual foi conectada uma válvula de esfera de 4 polegadas que funcionava como 
"sangria" para controle da vazão de alimentação do SHV e seguia pela mangueira até a entrada da unidade, onde foi instalada uma válvula de esfera de 2 polegadas conectada a um pedaço de mangueira (Figura 4.4). Por esta válvula foram coletadas todas as amostras de esgoto bruto utilizadas nesta pesquisa.

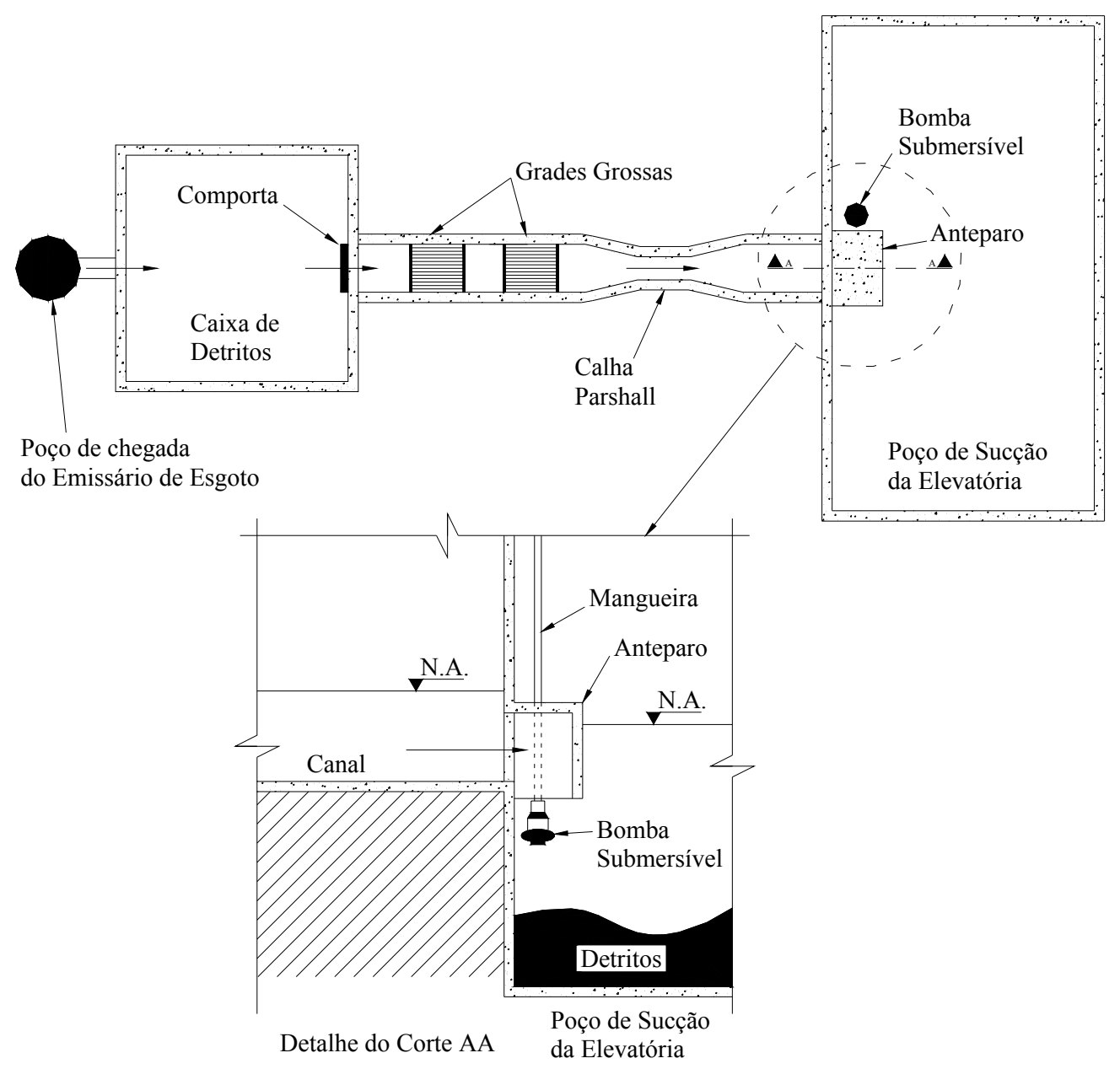

Figura 4.3 - Esquema em planta da chegada do esgoto bruto na estação elevatória próximo a ETE Jardim das Flores e detalhe em corte do posicionamento da bomba submersível utilizada para coleta das amostras de esgoto bruto.

As amostras foram coletadas em garrafas plásticas de um litro, de hora em hora, durante os períodos em que o SHV era operado; normalmente das 09h00min até às $13 \mathrm{~h} 30 \mathrm{~min}$ ou das $14 \mathrm{~h} 00 \mathrm{~min}$ até às $17 \mathrm{~h} 30 \mathrm{~min}$, sendo que a primeira amostragem de cada dia somente era realizada após 30 minutos de operação, isto é 09h30min ou 14h30min. Os procedimentos adotados em todas as coletas de amostras de esgoto bruto foram:

A. Abrir a válvula de esfera de 2 polegadas por 5 segundos para que o esgoto e a areia acumulados dentro dela sejam completamente descartados; 
B. Fechar a válvula e rapidamente posicionar a garrafa plástica de 1 litro na ponta do pedaço de mangueira conectado à válvula;

C. Abrir a válvula, mais uma vez, e quando o esgoto começar a transbordar pela boca da garrafa plástica fechá-la;

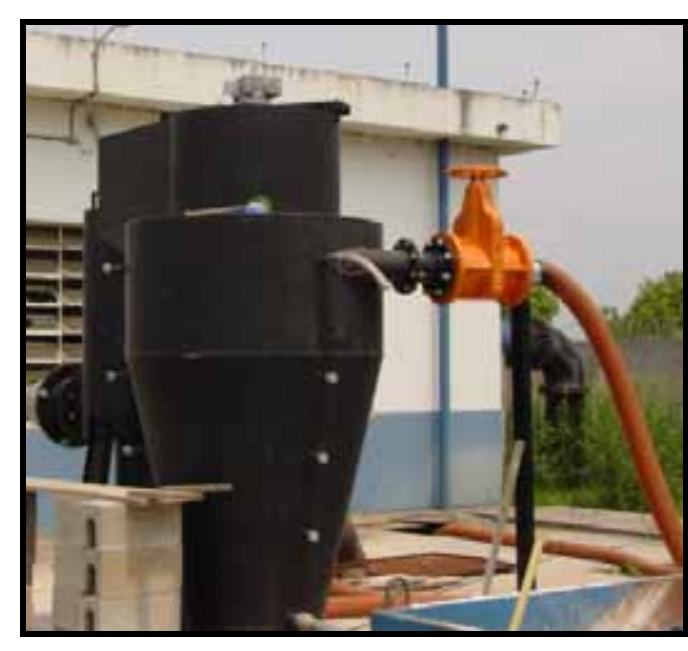

(a)

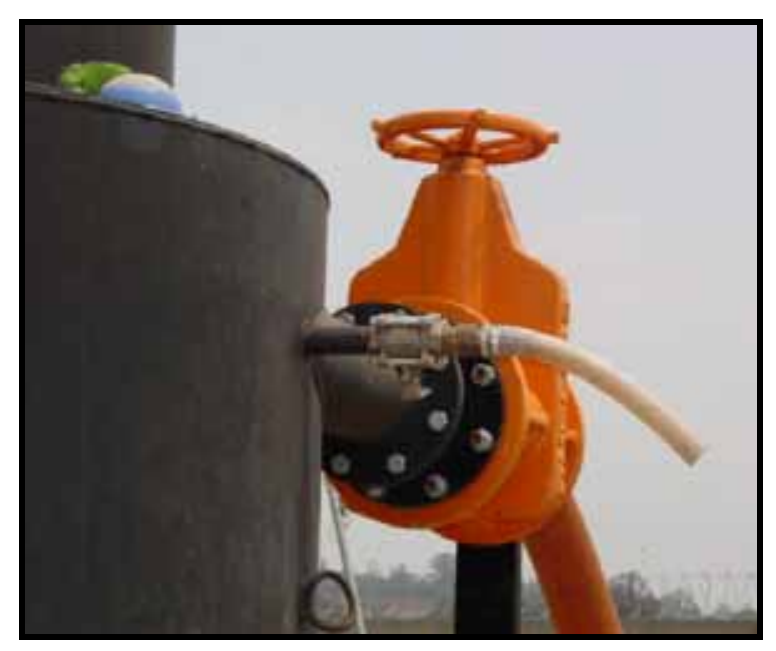

(b)

Figura 4.4 - Fotos do ponto de amostragem de esgoto bruto localizado na entrada do separador hidrodinâmico por vórtice (SHV): (a) vista geral do SHV e do ponto de amostragem; (b) detalhe do ponto de amostragem.

Depois de coletadas, as amostras eram conservadas em um refrigerador na ETE Jardim das Flores, e lá permaneciam até serem transportadas para o Laboratório de Tratamento Avançado e Reuso de Água (LATAR) da Escola de Engenharia de São Carlos (EESC) da Universidade de São Paulo (USP), onde foram conduzida as determinações de concentração de areia presente no esgoto bruto.

\subsubsection{Materiais e equipamentos necessários para determinação da concentração de areia no esgoto sanitário}

Os materiais e equipamentos necessários para execução dos ensaios de determinação da concentração (mg/l) de areia presente no esgoto sanitário foram:

- $\quad$ Cones Imhoff com adaptação para coleta de fundo (Figura 4.5(b));

- $\quad$ Suporte para Cones Imhoff; 


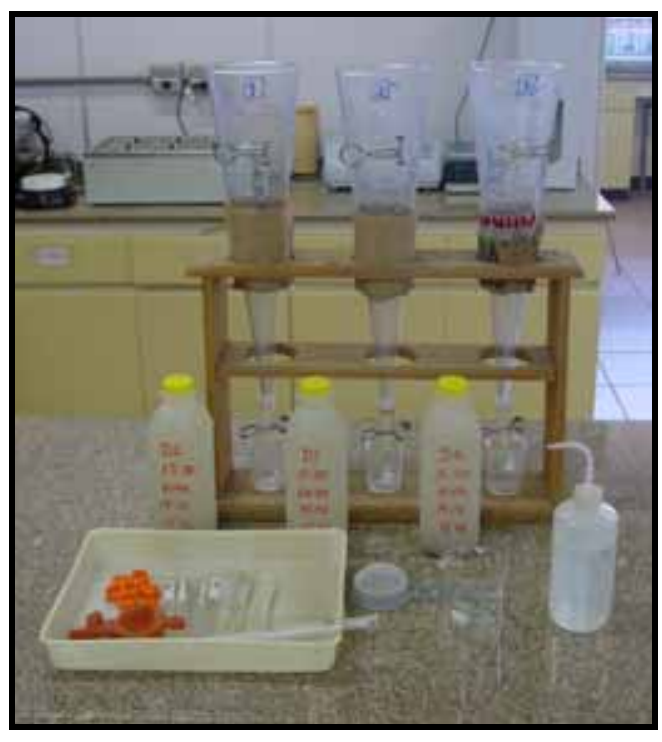

(a)

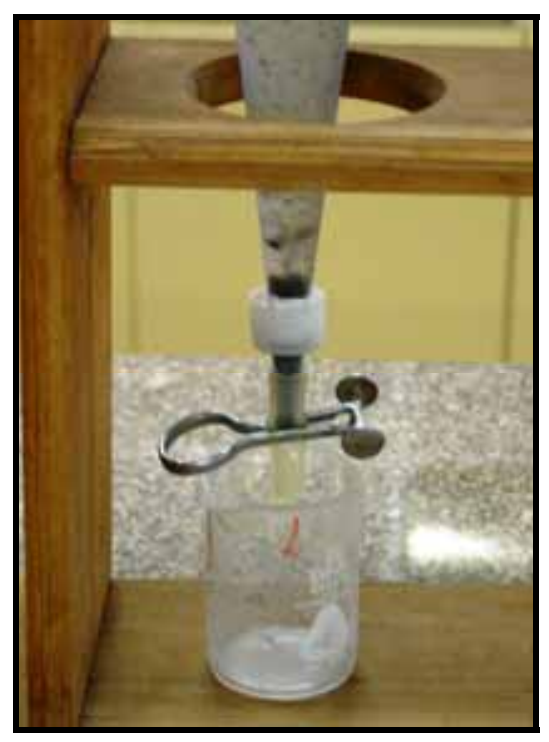

(b)

Figura 4.5 - Fotos de alguns materiais necessários para realização do ensaio de determinação da concentração de areia presente no esgoto bruto: (a) fotos dos materiais utilizados durante os ensaios; (b) detalhe da adaptação feita nos Cones Imhoff para propiciar coletas de fundo (mangueira de látex e pinça de Hoffman).

- $\quad$ Bastonete de vidro para promover agitação;

- $\quad$ Béqueres de $100 \mathrm{ml}$ para coleta;

- $\quad$ Béquer de $250 \mathrm{ml}$ ou $500 \mathrm{ml}$ para descarte;

- $\quad$ Pipetas de $20 \mathrm{ml}$ ou $10 \mathrm{ml}$;

- $\quad$ Tubos Falcon de $15 \mathrm{ml}$ ou mais;

- $\quad$ Pisseta com água destilada;

- $\quad$ Peneira de plástico;

- Garrafas de volume conhecido (1 litro) para coleta de amostras;

- $\quad$ Peróxido de Hidrogênio $\left(\mathrm{H}_{2} \mathrm{O}_{2}\right)$ (solução 35\%);

- Cronômetro digital;

- Cápsulas de porcelana de $50 \mathrm{ml}$; 
- $\quad$ Agitador elétrico de tubos de ensaio (opcional);

- Centrífuga;

- Balança analítica;

- $\quad$ Mufla que opere a $550^{\circ} \mathrm{C}$.

\subsubsection{Procedimentos Adotados para Realização dos Ensaios Determinação da Concentração de Areia no Esgoto Sanitário}

Os procedimentos adotados para execução dos ensaios de determinação da concentração de areia foram:

A. Colocar os cones Imhoff em seu suporte e posicionar um béquer de $100 \mathrm{ml}$ sob cada um dos cones (Figura 4.6);

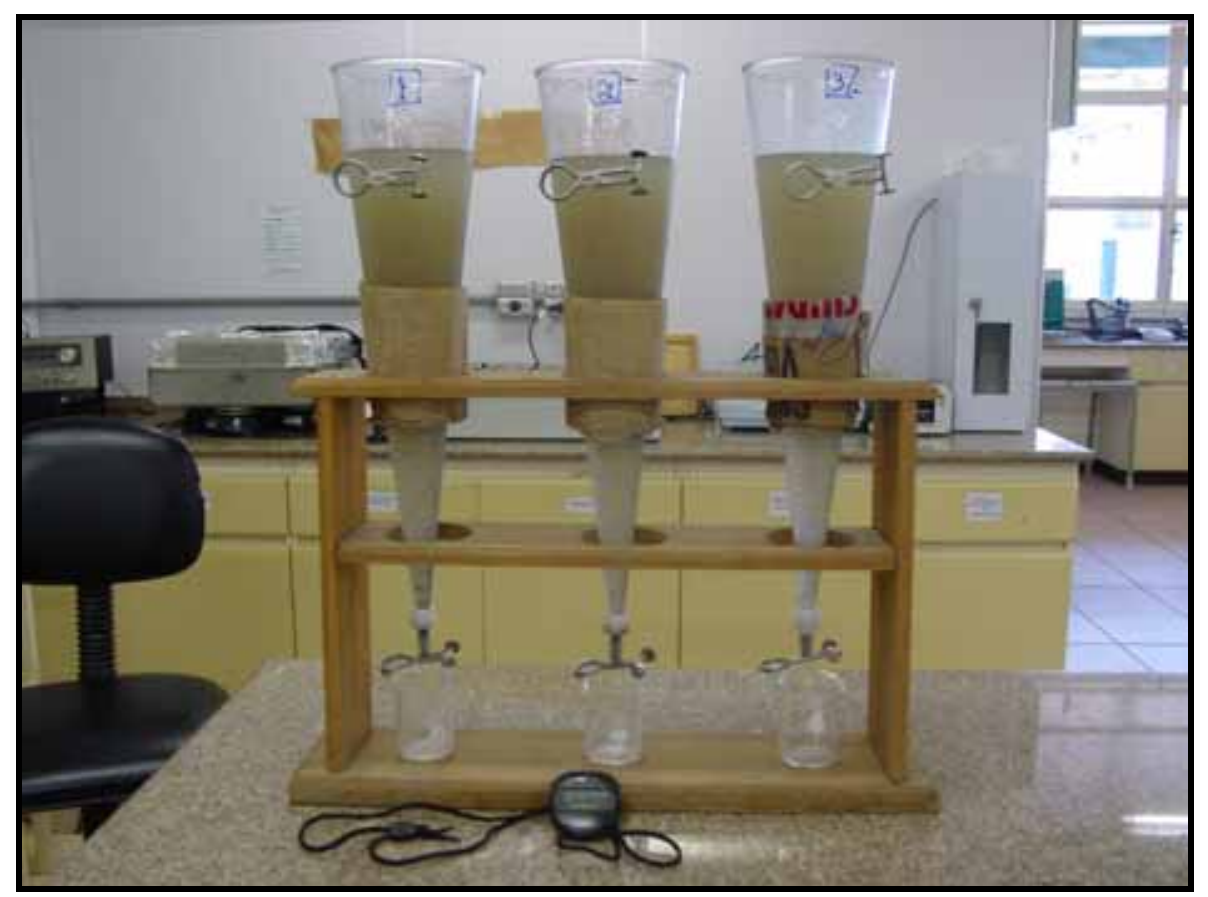

Figura 4.6 - Foto dos cones Imhoff, já cheios com a amostra de esgoto, colocados em seu suporte e dos Bequeres de $100 \mathrm{ml}$ posicionados sob cada um dos cones.

B. Verter o conteúdo das garrafas usadas na coleta para dentro dos cones Imhoff (uma garrafa por cone), usando a peneira de plástico para evitar que sólidos grosseiros presentes na amostra adentrem os cones; 
C. Com ajuda de uma pisseta, enxaguar as garrafas onde estavam as amostras de esgoto de modo que todas as partículas que eventualmente ainda permaneçam dentro delas sejam carreadas para dentro dos cones. Cuidado especial deve ser dispensado nesta etapa do ensaio, pois os grãos de areia tendem a permanecer no fundo das garrafas;

D. Disparar o cronômetro digital;

E. Após $20 \mathrm{~min}$, com ajuda de um bastonete de vidro, delicadamente ressuspender as partículas que permanecem junto às paredes dos cones Imhoff;

F. Após $30 \mathrm{~min}$, coletar apenas os sólidos que se concentraram no fundo dos cones Imhoff nos béqueres posicionados sob cada cone (Figura 4.7);

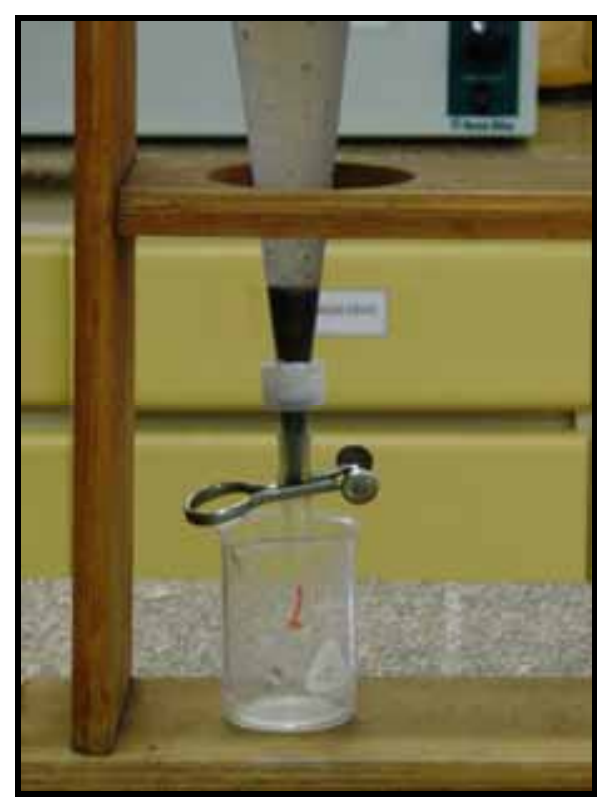

(a)

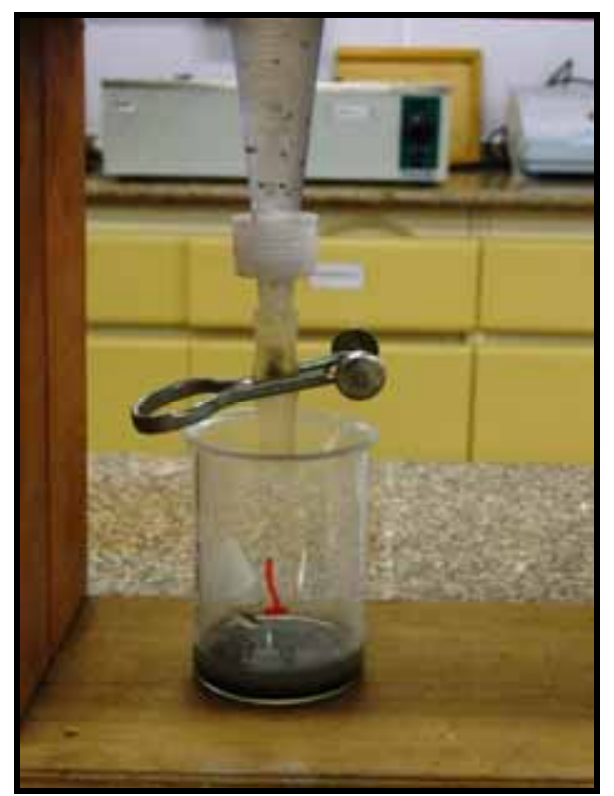

(b)

Figura 4.7 - Fotos dos sólidos concentrados no fundo de um cone Imhoff e da coleta desses sólidos: (a) foto dos sólidos concentrados no fundo de um cone Imhoff após 30 min de sedimentação; (b) foto dos sólidos concentrados já coletados em um béquer de $100 \mathrm{ml}$.

G. Verter o conteúdo de cada béquer de $100 \mathrm{ml}$ em um tubo Falcon de $15 \mathrm{ml}$; 
H. Com a ajuda de uma pisseta, enxaguar cada béquer de modo que partículas que eventualmente fiquem retidas em seus interiores sejam enxaguadas para dentro dos tubos Falcon;

I. Centrifugar os tubos Falcon por alguns segundos;

J. Descartar sobrenadante de cada tubo Falcon;

K. Com a ajuda de uma pipeta, colocar aproximadamente $10 \mathrm{ml}$ de peróxido de hidrogênio $\left(\mathrm{H}_{2} \mathrm{O}_{2}\right)$ em cada tudo Falcon (Figura 4.8(b));

L. Com o agitador elétrico agitar os tubos Falcon por alguns segundos para que os sólidos que se encontram no fundo dos tubos sejam misturados com o Peróxido de Hidrogênio (Figura 4.8(c));

M. Deixar os tubos Falcon em repouso por alguns segundos para que a areia mais densa sedimente e se concentre no fundo dos tubos, enquanto a matéria orgânica oxidada, juntamente com partículas muito pequenas flotem devido a grande quantidade de micro-bolhas formadas pela dissociação do peróxido de hidrogênio em $\mathrm{H}_{2} \mathrm{O}$ e $\mathrm{O}_{2}$ (Figura 4.8(e));

N. Descartar a camada de escuma formada no tubo Falcon em um béquer de $500 \mathrm{ml}$ (esse procedimento deve ser realizado tubo por tubo, isso é não se deve descartar o conteúdo de dois tubos em um mesmo béquer);

O. Com uma pipeta, cuidadosamente remover o líquido sobrenadante, tomando cuidado para não pipetar a areia que está no fundo do tubo Falcon;

P. Descartar o líquido sobrenadante que se encontra na pipeta no béquer de 500 $\mathrm{ml}$ no qual foi descartado a escuma;

Q. Com a pisseta completar o tubo Falcon com água destilada;

R. Repetir os procedimentos $\mathrm{O} ; \mathrm{P}$ e $\mathrm{Q}$ até que a água que se encontra dentro do tubo Falcon fique límpida ("visualmente clarificada"). Tal procedimento é muito importante, pois a areia acumulada no fundo do tubo deve ser lavada para que sejam eliminados quaisquer resquícios de matéria orgânica aderida aos grãos; 


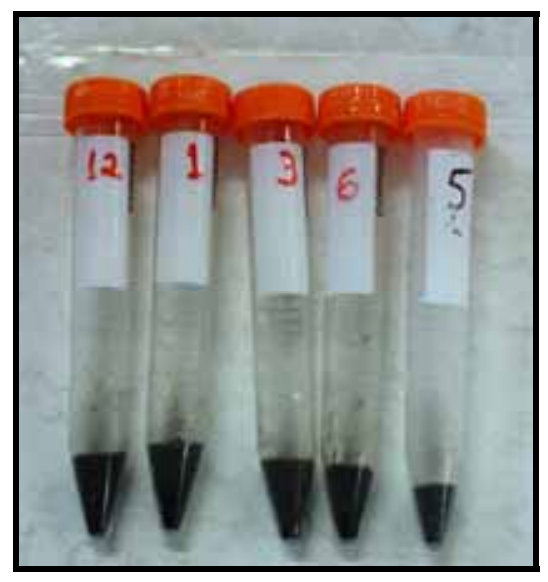

(a)

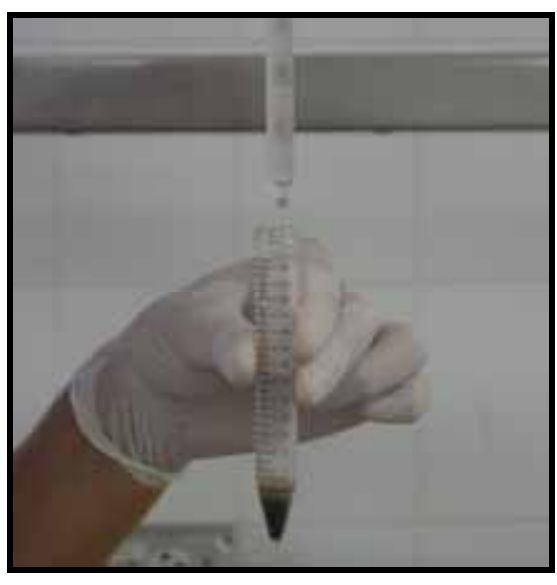

(b)

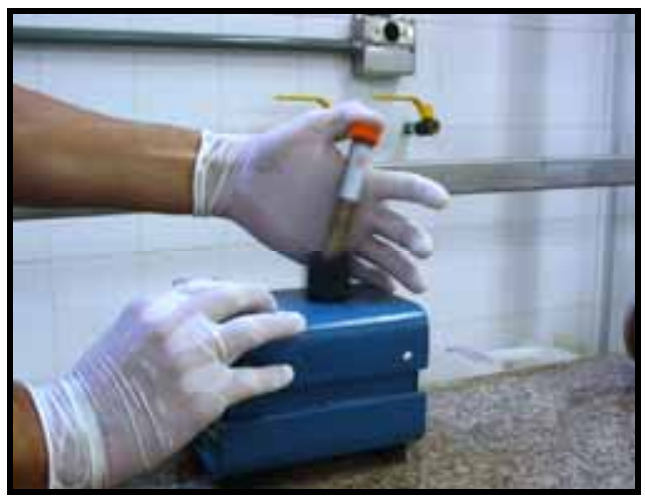

(c)

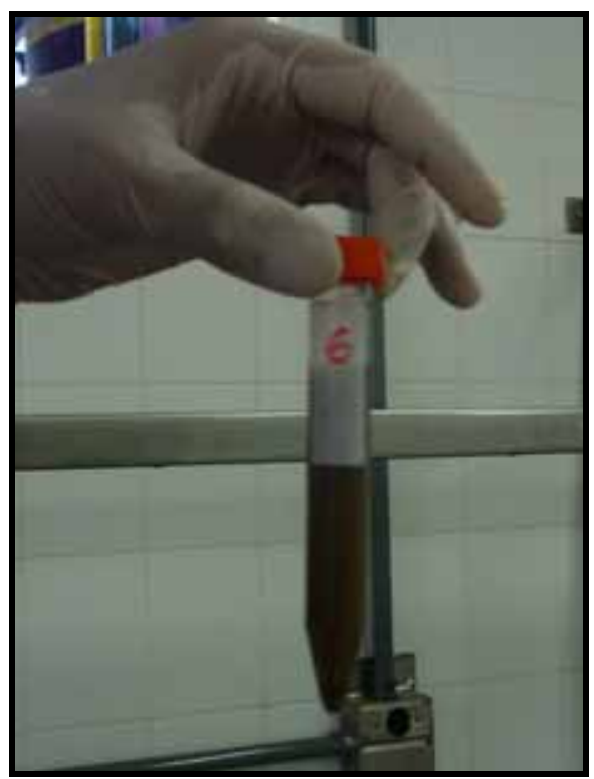

(d)

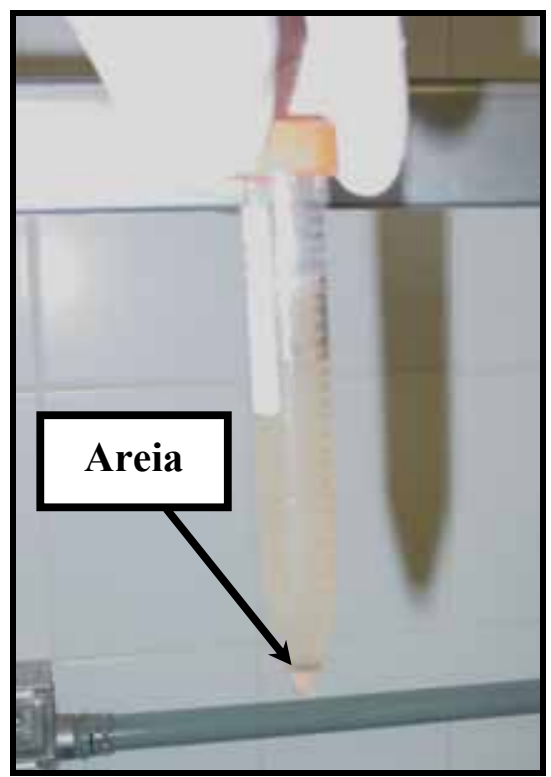

(e)

Figura 4.8 - (a) Foto dos tubos Falcon depois da centrifugação e descarte do sobrenadante; (b) Foto da aplicação do peróxido de hidrogênio em um tubo Falcon; (c) Foto de um tubo Falcon sendo agitado no agitador elétrico; (e) Foto de um tubo Falcon logo após a agitação; (e) Foto de um tubo Falcon depois de alguns segundos, pode-se notar areia concentrada no fundo do tubo e uma camada de escuma na parte superior. 
S. Devido ao fato de que parte das partículas (predominantemente as muito finas) que se encontram na amostra serem descartadas juntamente com a escuma no béquer de $500 \mathrm{ml}$, faz-se necessário promover a recuperação desse material. Para isso deve-se cuidadosamente verter o sobrenadante do béquer em um outro recipiente qualquer, tomando cuidado para não perder as pequenas partículas que se acumulam no seu fundo.

T. Com a pisseta, enxaguar o material que permanece no béquer;

U. Com uma pipeta, cuidadosamente remover o líquido sobrenadante, tomando cuidado para não pipetar as pequenas partículas que se encontram no fundo do béquer;

$\mathrm{V}$. Repetir os procedimentos $\mathrm{T}$ e $\mathrm{U}$ até que o líquido que se encontra dentro do béquer fique límpido;

W. Pipetar o líquido em excesso e retornar as partículas contidas no béquer para dentro do mesmo tubo Falcon de onde este material foi perdido;

$\mathrm{X}$. Com a ajuda de uma pisseta, enxaguar béquer de $500 \mathrm{ml}$, de modo que, partículas que eventualmente fiquem retidas na sua parede e fundo sejam enxaguadas para dentro do tubo Falcon;

Y. Verter o conteúdo de cada tubo Falcon em cápsulas de porcelana de $50 \mathrm{ml}$ previamente preparadas (calcinadas à $550^{\circ} \mathrm{C}$ em uma mufla) e pesadas $\left(\mathrm{P}_{0}\right)$;

Z. Calcinar as cápsulas de porcelana em uma mufla à $550^{\circ} \mathrm{C}$, para ser eliminado qualquer material volátil que ainda permaneça aderido aos grãos ou dissolvido na água que se encontrava dentro dos tubos Falcon;

AA. Remover as cápsulas da mufla e deixá-las esfriar em um dessecador, depois pesá-las para obter $\mathrm{P}_{1}$;

BB. Usar a Equação 4.1 para calcular a concentração de areia presente na amostra;

$$
\mathrm{C}_{\mathrm{AR}}=\frac{\left(\mathrm{P}_{1}-\mathrm{P}_{0}\right)}{\mathrm{V}_{\mathrm{am}}}
$$


Em que:

$\mathrm{C}_{\mathrm{AR}}$ : Concentração de areia na amostra $\left(\mathrm{M} . \mathrm{L}^{-3}\right)$;

$\mathrm{P}_{0}$ e $\mathrm{P}_{1}$ : Pesos provenientes das pesagens das cápsulas $(\mathrm{M}) ;$

$\mathrm{V}_{\mathrm{am}}$ : Volume de amostra utilizada no ensaio $\left(\mathrm{L}^{3}\right)$.

\subsubsection{Determinação da distribuição granulométrica da areia presente no esgoto bruto}

\subsubsection{Considerações sobre a escolha da técnica de determinação da distribuição de tamanho de partícula}

Nessa pesquisa, procurou-se, dentro do possível, usar as recomendações mencionadas na seção 4.1.4 (A Escolha da Técnica de Determinação da Distribuição de Tamanho de Partículas) desse capítulo para nortear a escolha da técnica de determinação de tamanho de partículas (DTP) a ser adotada nas determinações de distribuição granulométrica da areia presente no esgoto sanitário. Para isso, foram avaliados: a natureza da amostra (seca, dissolvida, ou em suspensão; solubilidade das partículas; tamanho as partículas, etc.); a tradição da utilização do método; custo de aquisição, manutenção e operação do equipamento; disponibilidade de mão-de-obra especializada; tempo de resposta; e a facilidade de obtenção, tratamento e interpretação dos dados.

Com relação à tradição da utilização do método, as técnicas de determinação da DTP mais utilizadas em pesquisas na área de tratamento de água e esgoto sanitário, atualmente, são: o peneiramento, os contadores de partículas (Contadores Coulter e Contadores ópticos - técnicas de varredura de fluxo) e os granulômetros a luz laser (LALLS - Low Angle Light Laser Sacattering — técnica de varredura de campo); todavia, nenhuma dessas técnicas pôde ser aplicada para a determinação da distribuição granulométrica das amostras de areia estudas nessa pesquisa.

Os contadores de partícula têm sua utilização limitada à contagem de partículas mais finas $(0,5 \mu \mathrm{m}$ a $500 \mu \mathrm{m})$, distribuídas em faixas de tamanho estreitas, pois foram 
desenvolvidos para a contagem de glóbulos brancos e vermelhos do sangue (ALLEN, 1997). Na área de tratamento de efluentes líquidos, esses equipamentos têm sido utilizados para estudo de unidades de tratamento de água, como filtros rápidos, flotadores etc., uma vez que, as faixas de tamanho de partícula, mormente observadas nos afluentes e efluentes dessas unidades permitem sua utilização (LEWIS et al., 1992; O'SHAUGHNESSY et al., 1997; GELDER et al., 1999). Todavia, os contadores de partícula não são indicados para determinação da distribuição granulométrica da areia presente nos esgotos, devido às faixas de tamanho dos grãos serem extensas e muito grossas $(0,5 \mu \mathrm{m}$ a mais de $1000 \mu \mathrm{m})$. Por essa razão, o uso desses equipamentos para determinação da distribuição granulométrica da areia encontrada nos esgotos sanitários foi descartado.

Recentemente, foi publicado artigo técnico que reporta a experiência bem sucedida do uso de um granulômetro a laser no estudo da DTP de sedimentos provenientes de sistemas de coleta de esgoto do tipo combinado. Nessa pesquisa, os autores usaram, com sucesso, um granulômetro a laser para estudos, em escala piloto, acerca: da DTP de sedimentos acumulados em sistemas combinados de coleta de esgoto das cidades de Loenen (Holanda), e Dundee (Inglaterra); e da interferência da DTP no fenômeno de erosão dos depósitos de sedimentos, quando estes eram submetidos a aumentos sucessivos das tensões de cisalhamento (BIGGS et al., 2005). Não obstante o sucesso alcançado por Biggs et al. (2005), a indisponibilidade e o alto custo de aquisição e manutenção desses equipamentos impossibilitaram o emprego dessa técnica para a determinação da distribuição granulométrica da areia presente nos esgotos.

O peneiramento, técnica tradicionalmente utilizada na determinação da DTP de amostras de areia, poderia ser utilizado, como mostra Moilleron et al. (2005). Nesse trabalho, os autores empregaram o peneiramento em peneiras sucessivas para fracionar, em diferentes faixas de tamanho de partículas, amostras de sedimentos de diversos desarenadores da cidade de Paris e estudaram, então, a distribuição de contaminantes, como: metais pesados, hidrocarbonetos e matéria orgânica, em cada uma dessas faixas de tamanho. Porém, desta vez, o tamanho das amostras (pequena massa de areia), somada a baixa concentração de areia encontrada no esgoto sanitário estudado não permitiram a utilização de tal técnica. 
Uma opção que se mostrou viável e bastante satisfatória foi o emprego da técnica de análise de imagens, porquanto, praticamente, não existem restrições a sua utilização para determinar a distribuição granulométrica de pequenas amostras de areia seca com largas faixas de tamanho. Ademais, a análise de imagem foi empregada com muito sucesso em uma pesquisa, recentemente, concluída no Departamento de Hidráulica e Saneamento da Escola de Engenharia de São Carlos da Universidade de São Paulo. O autor empregou a técnica de análise de imagens para determinar a DTP de micro-bolhas e de flocos na zona de reação de uma unidade piloto de flotação por ar dissolvido (FAD), conseguindo resultados expressivos e avanços significativos na compreensão dos fenômenos que envolvem as interações entre micro-bolhas e flocos em unidades de FAD (MORUZZI, 2005).

Frente ao exposto e somado ao fato de o Setor de Caracterização de Partículas e Análise com Micro-sensores do Laboratório de Tratamento Avançado de Reuso de Águas do Departamento de Hidráulica e Saneamento da Escola de Engenharia de São Carlos, da Universidade de São Paulo, (SCPAM / LATAR / SHS / EESC / USP) possuir os equipamentos necessários para a aquisição das imagens digitais, a análise de imagens foi a técnica escolhida para determinar a distribuição granulométrica da areia presente no esgoto sanitário.

A seguir serão apresentados alguns conceitos acerca da técnica de análise de imagens; depois, os materiais e equipamentos necessários para realização das determinações de DTP e os procedimentos adotados na amostragem dos grãos de areia, na aquisição das imagens, no processamento das imagens e na análise e medição dos tamanhos de partícula serão descritos e detalhados.

\subsubsection{A análise de imagens como técnica de determinação da distribuição de tamanho de partículas}

A pormenorização de todos os aspectos envolvidos na determinação de tamanho de partículas utilizando técnicas de análise de imagens foge do escopo desta tese, no entanto alguns conceitos importantes devem ser apresentados para que o leitor possa entender, de forma geral, todos os procedimentos que foram empregados na determinação da distribuição granulométrica da areia presente nas amostras de esgoto 
sanitário. Sugere-se, àqueles que desejarem mais informações sobre o tema, a leitura de textos especializados, como: Russ (1991), Gonzales e Woods (1993) e Russ (1994).

Segundo Allen (1997) a análise de imagens é um ramo da estereologia, isto é, avaliação quantitativa ou qualitativa de feições geométricas tridimensionais expostas em imagens bidimensionais. Essa citação remete o leitor ao conceito de diâmetro equivalente discutido na seção 4.2 desse capítulo, pois quando a análise de imagem é utilizada para a determinação do tamanho de uma partícula, alguma característica geométrica de sua feição bidimensional é relacionada a uma única dimensão linear, chamada diâmetro equivalente.

A feição de uma partícula exposta em uma imagem bidimensional, nada mais é do que sua área projetada; por conseguinte, as dimensões dessa área dependem da orientação da partícula no instante em que a imagem foi capturada. Ao se espalhar partículas discretas em uma superfície plana, elas tendem a se orientar de forma estável “escondendo" sua menor dimensão, logo, os diâmetros equivalentes obtidos por microscopia geralmente são maiores que os obtidos por outras técnicas de determinação de tamanho de partículas.

Existem, basicamente, duas formas de se usar a análise de imagens para contagem e determinação de tamanho de partículas: manualmente ou usando sistemas de análise de imagens. Contar ou determinar tamanho de partículas "manualmente" por meio de análise de imagens consiste em comparar as partículas, que se pretende analisar, com retículos previamente calibrados via microscópio. A análise de imagem "manual" é considerada como o método absoluto de determinação de tamanho de partículas, por ser a única técnica, pela qual partículas são observadas e medidas individualmente; no entanto esta característica dessa técnica torna sua utilização tediosa e extremamente lenta, logo seu emprego deve restringir-se a avaliações qualitativas e a análises preliminares de amostras (ALLEN, 1997). Para realizar determinações de distribuição de tamanho de partículas (DTP), recomenda-se a utilização de sistemas de análise de imagens, isto é, aquisição de imagens digitais por câmeras, fotográfica ou de vídeo, acopladas a computadores, seguida do processamento dessas imagens e da determinação da DTP utilizando algum software de análise de imagens. 


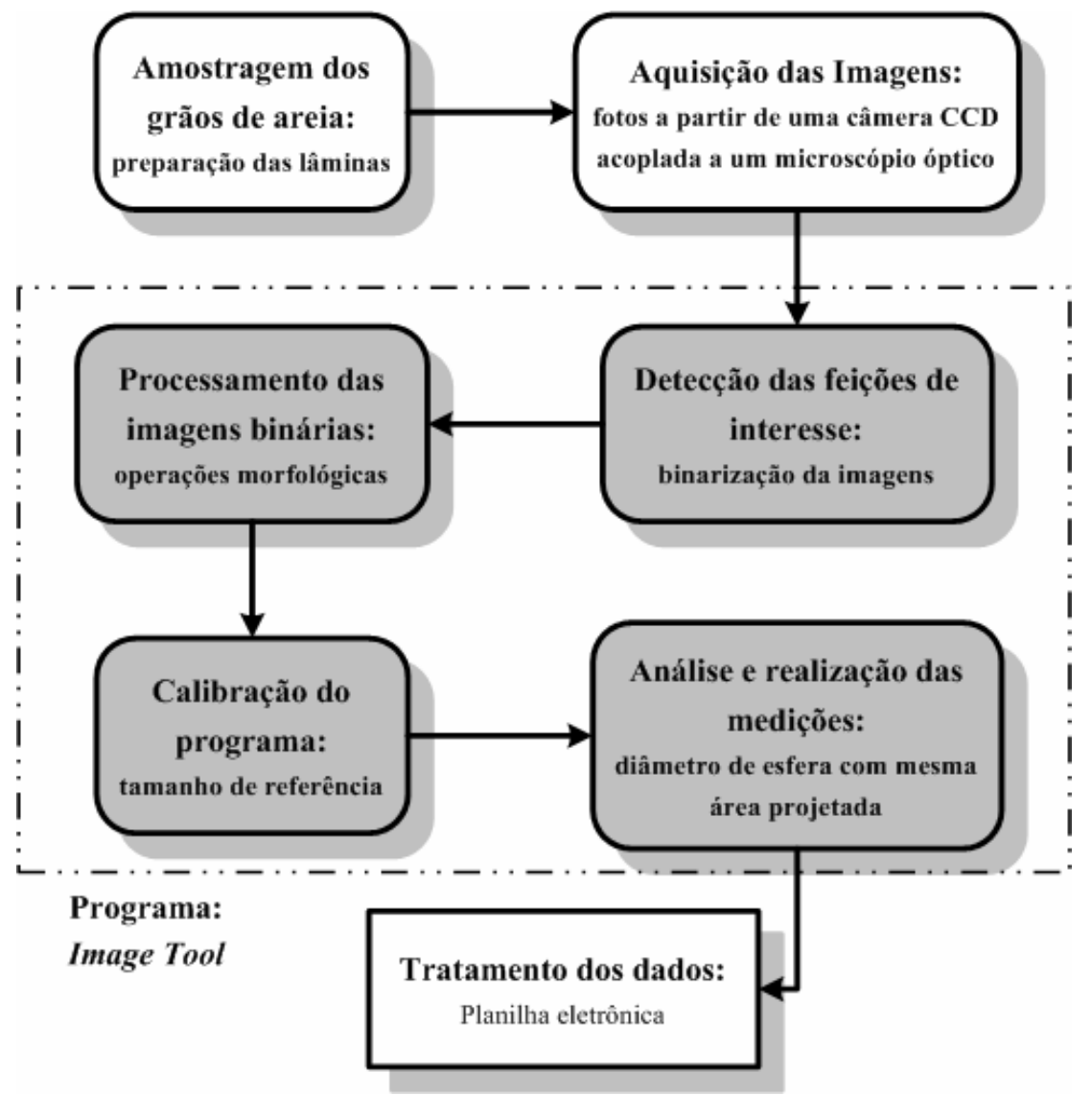

Figura 4.9 - Fluxograma esquemático que mostra as etapas envolvidas na determinação da distribuição de tamanho de partículas por análise de imagem.

A determinação da DTP por sistemas de análise de imagens geralmente é um processo de seis etapas: aquisição das imagens, detecção das feições de interesse, processamento das imagens binárias, calibração do equipamento, análise e realização das medidas e, por fim, tratamento dos dados e apresentação dos resultados. Um resumo esquemático de todo o processo é apresentado na Figura 4.9.

\subsubsection{Materiais e equipamentos necessários para a determinação da distribuição granulométrica da areia presente no esgoto sanitário}

Os equipamentos e materiais necessários para execução da análise de imagens para determinar da distribuição granulométrica dos grãos de areia encontrados no esgoto sanitário foram:

- $\quad$ Placa de vidro $(30 \times 25 \mathrm{~cm})$; 
- Lamínulas;

- $\quad$ Fita adesiva transparente;

- $\quad$ Microscópio óptico (Olympus BX41 - ampliações de 4; 10; 20; 40 e 100 vezes) com adaptação para acoplamento de câmera (Figura 4.10);

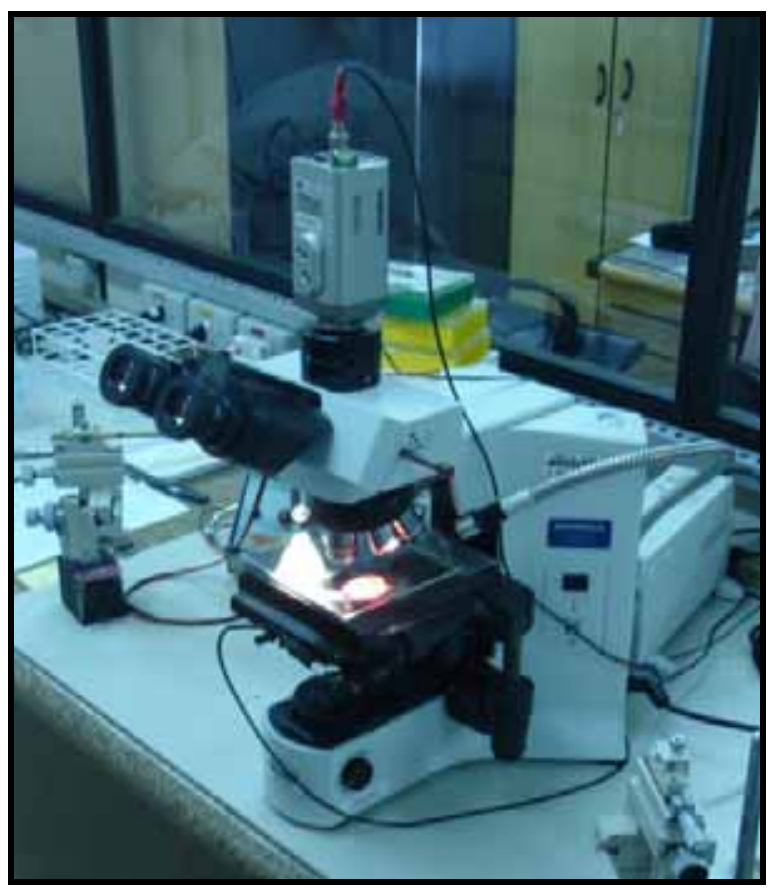

Figura 4.10 - Foto do Microscópio com uma câmera CCD acoplada. Equipamento do SCPAM - LATAR - SHS - EESC - USP utilizado na aquisição das imagens digitais.

- Câmera CCD (Coupled Charged Device) com dispositivo para acoplamento em microscópio e saída para computador (Samsung SDC 313) (Figura 4.10);

- $\quad$ Micro-computador;

- $\quad$ Fio de referência com diâmetro conhecido, para a calibração do software $(100 \mu \mathrm{m})$.

\subsubsection{Amostragem dos grãos de areia e aquisição das imagens digitais}

A amostragem e a aquisição das imagens, sem dúvida, são os pontos chaves da utilização da técnica de análise de imagens para a determinação da distribuição de 
tamanho de partículas (DTP). Deve-se garantir a contagem do maior número possível de partículas, pois uma das grandes críticas acerca da utilização da análise de imagens recai sobre a representatividade estatística de seus resultados. Segundo Allen (1997), no mínimo 625 partículas devem ser contadas para que o erro amostral não ultrapasse $2 \%$. Para garantir esse número mínimo de partículas, toda a massa de areia seca de cada amostra foi utilizada na amostragem dos grãos de areia e preparação das lamínulas que foram fotografadas.

Como já mencionado nesse texto, as amostras de areia seca foram obtidas como resultado da aplicação dos procedimentos utilizados na determinação da concentração de areia no esgoto. Depois de serem obtidas, as amostras eram uma a uma espalhadas em uma placa de vidro plana posicionada sobre um fundo branco, para garantir o contraste necessário, de forma que os grãos de areia pudessem ser observados (Figura 4.11). Após toda a amostra ser dispersa sobre a placa de vidro, ela era delicadamente agitada para que os grãos de areia se distanciassem, um pouco, uns dos outros.

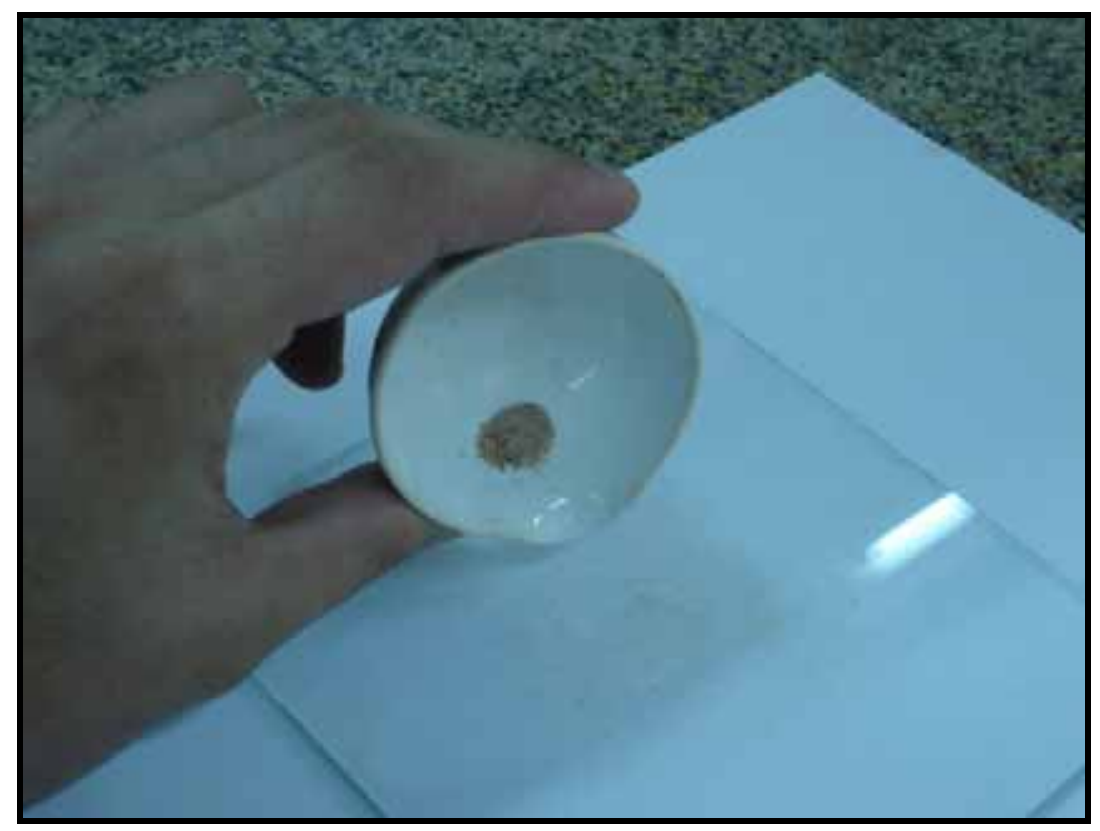

Figura 4.11 - Foto de uma amostra de areia seca sendo espalhada sobre a placa plana de vidro, posicionada sobre um fundo branco para garantir contraste necessário para a visualização dos grãos de areia.

Depois de espalhados, os grãos de areia foram amostrados utilizando-se, para isso, um pedaço de fita adesiva transparente, não maior que a largura das lamínulas de vidro disponíveis. A amostragem era feita com cuidado, para evitar a formação de 
aglomerados de grãos de areia também chamados clusters. Esses aglomerados dificultam a utilização de softwares de análise de imagens e impõem à necessidade da utilização de ferramentas de processamento e tratamento de imagem, as quais, em suma, alteram a imagem original causando perda de informação. Foram preparadas em média de 8 a 12 lamínulas para cada amostra de areia seca, dependendo da massa de cada amostra.

Para a aquisição das imagens foram adotados os seguintes procedimentos:

A. Posicionar a lamínula no microscópio, acertar a iluminação e o foco, observando a imagem na tela do computador que deve estar conectado à câmera CCD acoplada ao microscópio;

B. Posicionar o fio de referência sobre a lamínula (obs.: caso o foco não seja alterado, a utilização do fio de referência em todas as fotos não será necessária; porém a cada reajuste no foco o fio de referência de ser posicionado sobre a lamínula antes da foto seguinte ser capturada);

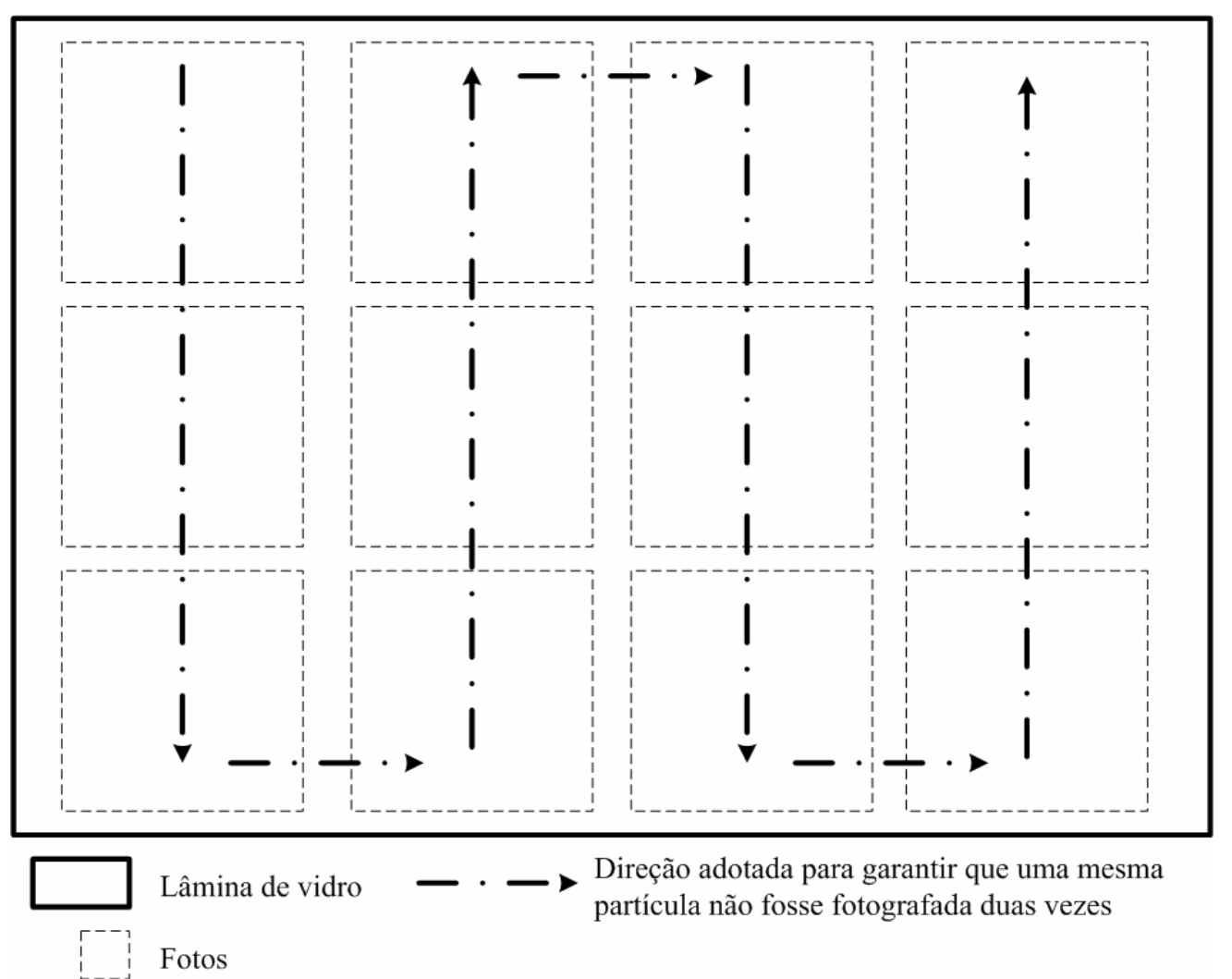

Figura 4.12 - Desenho esquemático do padrão de movimentação adotado ao se tirar fotos de uma lâmina, para evitar que uma mesma partícula fosse fotografada mais de uma vez. 
C. Seguir um padrão pré-determinado de movimentação da lamínula ao tirar as fotos, para evitar que uma mesma partícula seja fotografada mais de uma vez. O padrão de movimentação utilizado nessa pesquisa é mostrado na Figura 4.12;

D. Repetir os procedimentos A; B e C para todas as lamínulas preparadas.

Foram obtidas, aproximadamente, 18 fotos por lamínula; assumindo 10 lamínulas por amostra, têm-se como resultado um total de 180 fotos por amostra, como foram utilizadas 15 amostras, o número final de fotos capturadas é algo perto de 2.700 . Nestas 2.700 fotos, foram contados 22.531 grãos de areia, em média 8 grãos por foto. Evidentemente, este valor foi muito maior em algumas fotos e muito menor em outras.

\subsubsection{Tratamento e processamento das imagens e determinação da distribuição de tamanho de partículas das amostras}

Nesta seção serão detalhados os procedimentos que se encontram nas caixas de cor cinza dentro do quadro de linha segmentada na Figura 4.9, isto é, detecção das feições de interesse, tratamento das imagens binárias (aplicação de operações morfológicas), calibração do programa e, finalmente, análise e realização das medições. Todos estes procedimentos foram realizados em um software aberto chamado ImageTool na sua versão 3.0. Este programa de análise de imagens foi desenvolvido pelo Health Science Center da University of Texas de San Antonio, EUA, opera normalmente em plataforma Windows, e pode ser obtido do website: http://www.ddsdx.uthscsa.edu/dig/download.html.

A seguir, somente serão descritos os procedimentos que foram utilizados no processamento e análise das imagens, pois eles independem do software empregado. Detalhes de como realizar tais procedimentos usando o Image-Tool 3.0 podem ser obtidos no manual do usuário que acompanha o programa, ou ainda em Moruzzi (2005). 


\subsection{Detecção das feições de interesse ou detecção as bordas e segmentação dos objetos}

Toda imagem digital é formada por um número finito de elementos primários chamados pixels. Dependendo da profundidade do pixel, cada um destes elementos primários que compõem as imagens digitais pode assumir uma grande quantidade de intensidades (tonalidades - níveis de brilho), que variaram de 16 tons (imagens de 4 bits por pixel) até 16.777.216 tons (imagens de 24 bits por pixel).

As bordas de um objeto em uma imagem digital são regiões onde ocorrem mudanças de intensidade em um certo intervalo de espaço, em uma certa direção; portanto, quanto maior a diferença de intensidade entre um objeto e o plano de fundo (background) em uma imagem, mais nítidas serão as bordas desse objeto. Os procedimentos adotados na detecção das feições de interesse têm, como única finalidade, tornar eminente a diferença de intensidade entre os pixels que compõem o objeto e aqueles que compõem o plano de fundo evidenciando, assim, as bordas dos objetos que se pretende analisar.

O primeiro procedimento a ser realizado é a conversão das imagens coloridas originais em imagens em escala de cinzas. Com isso, as imagens originais que possuíam 16.777.216 níveis de brilho (24 bits) são transformadas em imagens com 256 níveis de brilho (8 bits) (Figura 4.13).

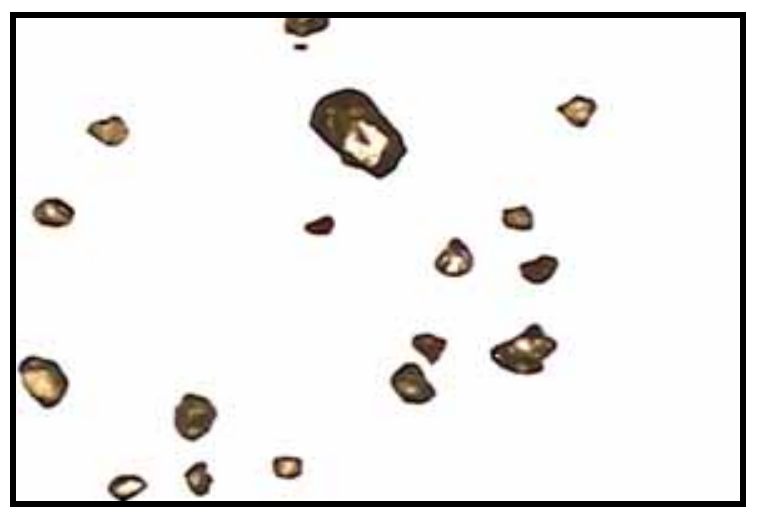

(a)

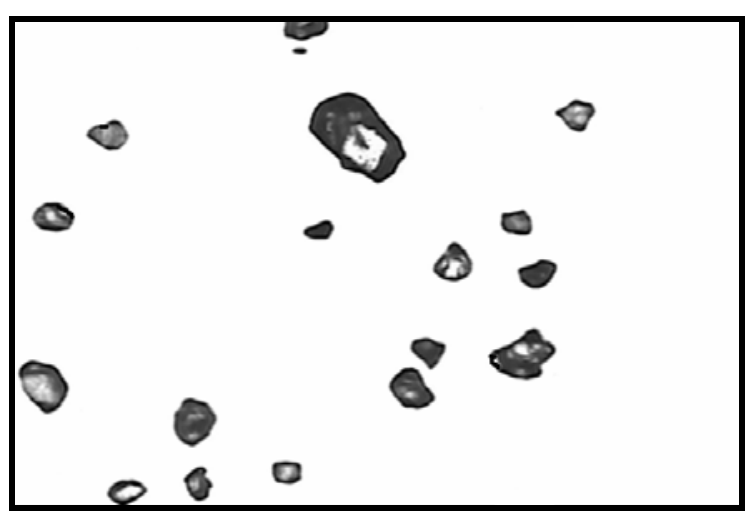

(b)

Figura 4.13 - Conversão das imagens coloridas originais, com 16.777.216 níveis de brilho, em imagens em escala de cinzas, com 256 níveis de brilho. (a) imagem colorida original; (b) imagem em escala de cinzas. 
A etapa seguinte, segmentação dos objetos de interesse, é a etapa mais delicada da análise de imagens, pois todas as medidas que se pretende realizar baseiam-se nas dimensões das regiões por ela identificadas. Com esta etapa, procura-se distinguir os objetos uns dos outros e do plano de fundo permitindo, assim, que o programa interprete pixels contíguos e os agrupem em regiões. O procedimento utilizado para a segmentação foi a limiarização, que é a utilização da intensidade dos pixels para distingui-los. Para isso, as imagens foram binarizadas, isto é, transformadas em imagens de 1 bit, com apenas duas intensidades diferentes, como mostra a Figura 4.14.

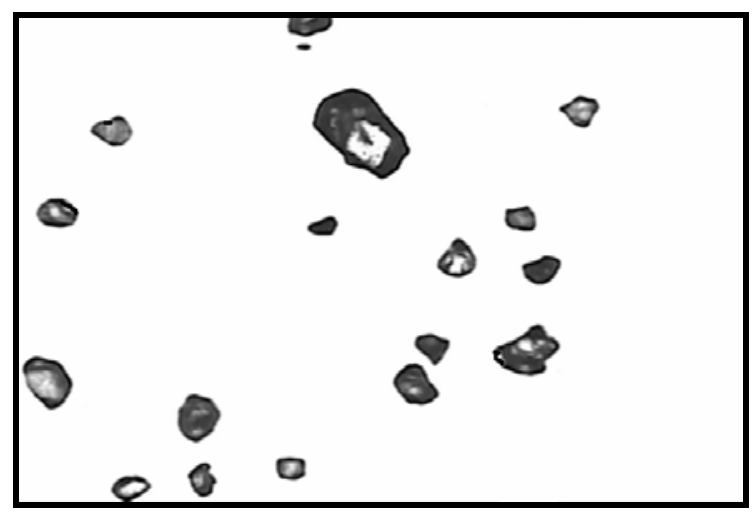

(a)

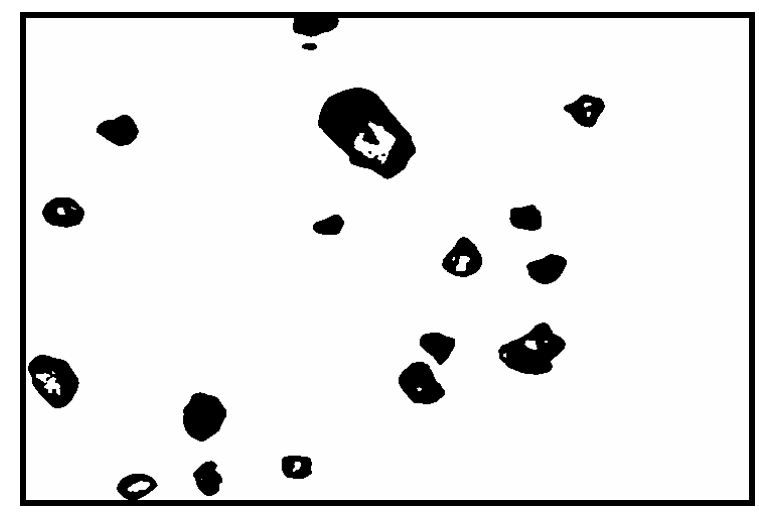

(b)

Figura 4.14 - Binarização as imagens em escala de cinzas. (a) imagem em escala de cinzas ( 8 bits - 256 níveis de brilho); (b) imagem binarizada (1 bit - 2 níveis de brilho).

\subsection{Processamento das imagens binárias}

Os grãos de areia geralmente são partículas translúcidas, o que faz com que suas imagens binarizadas, dependendo da posição da fonte de luz, apresentem "buracos", como mostra a Figura 4.14(b). Imagens como esta não são adequadas para a realização das medições, pois tais "buracos" devem ser preenchidos para que o programa interprete a região como um único objeto (Figura 4.15(b)). Outro problema muito comum é a presença de aglomerados de partículas nas fotos (clusters), como mostra a Figura 4.16(a). Estes aglomerados devem ter suas partículas separadas para que o programa não o reconheça como um único objeto. 
Essas e outras inadequações das imagens binarizadas devem ser contornadas antes das medições serem conduzidas. Isso é alcançado empregando ferramentas de processamento de imagens binárias chamadas operações morfológicas; entre elas podese destacar:

- Erosion (erosão) - a última camada de pixels do contorno dos objetos é removida, diminuindo suas áreas. Essa operação morfológica é utilizada para separar objetos que se tocam e para eliminar objetos muito pequenos;

- Dilation (dilatação) - adiciona-se uma camada de pixels ao contorno dos objetos, aumentando suas áreas. Essa operação morfológica é utilizada para preencher pequenos "buracos" e para fechar objetos côncavos;

- Fill holes (preenchimento de buracos) — são adicionados pixels a "buracos" localizados dentro de regiões fechadas. Essa operação morfológica é utilizada para preencher "buracos", e sua utilização é mostrada na Figura 4.15;

- Watershed (separação de águas) — por meio de operações matemáticas, denominadas transformadas de distâncias, objetos que se sobrepõe ou se tocam são separados. A utilização dessa operação morfológica é mostrada na Figura 4.16.

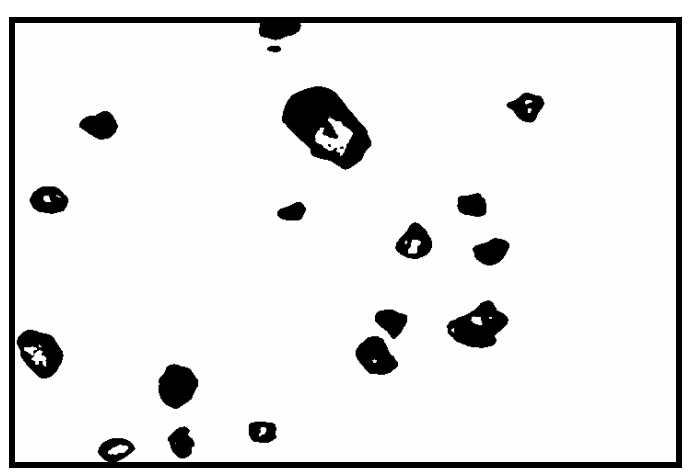

(a)

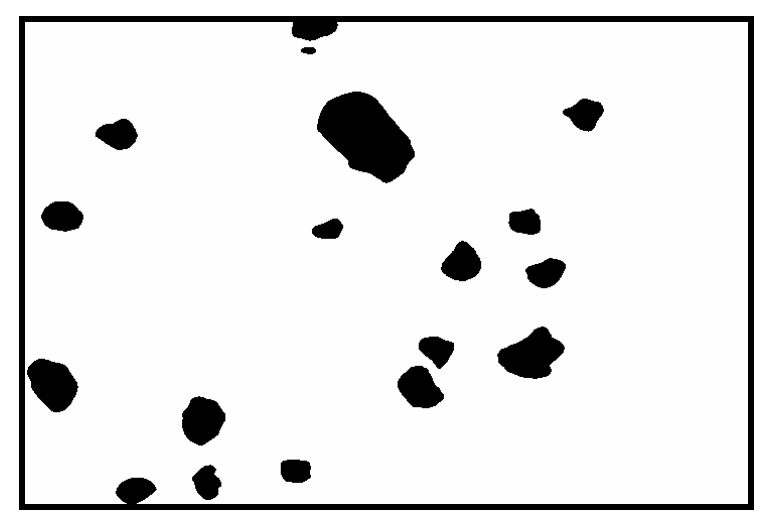

(b)

Figura 4.15 - Utilização da operação morfológica fill holes (preencher buracos). (a) imagem anterior a utilização do fill holes apresentando "buracos"; (b) imagem posterior a utilização do fill holes com os "buracos"preenchidos. 


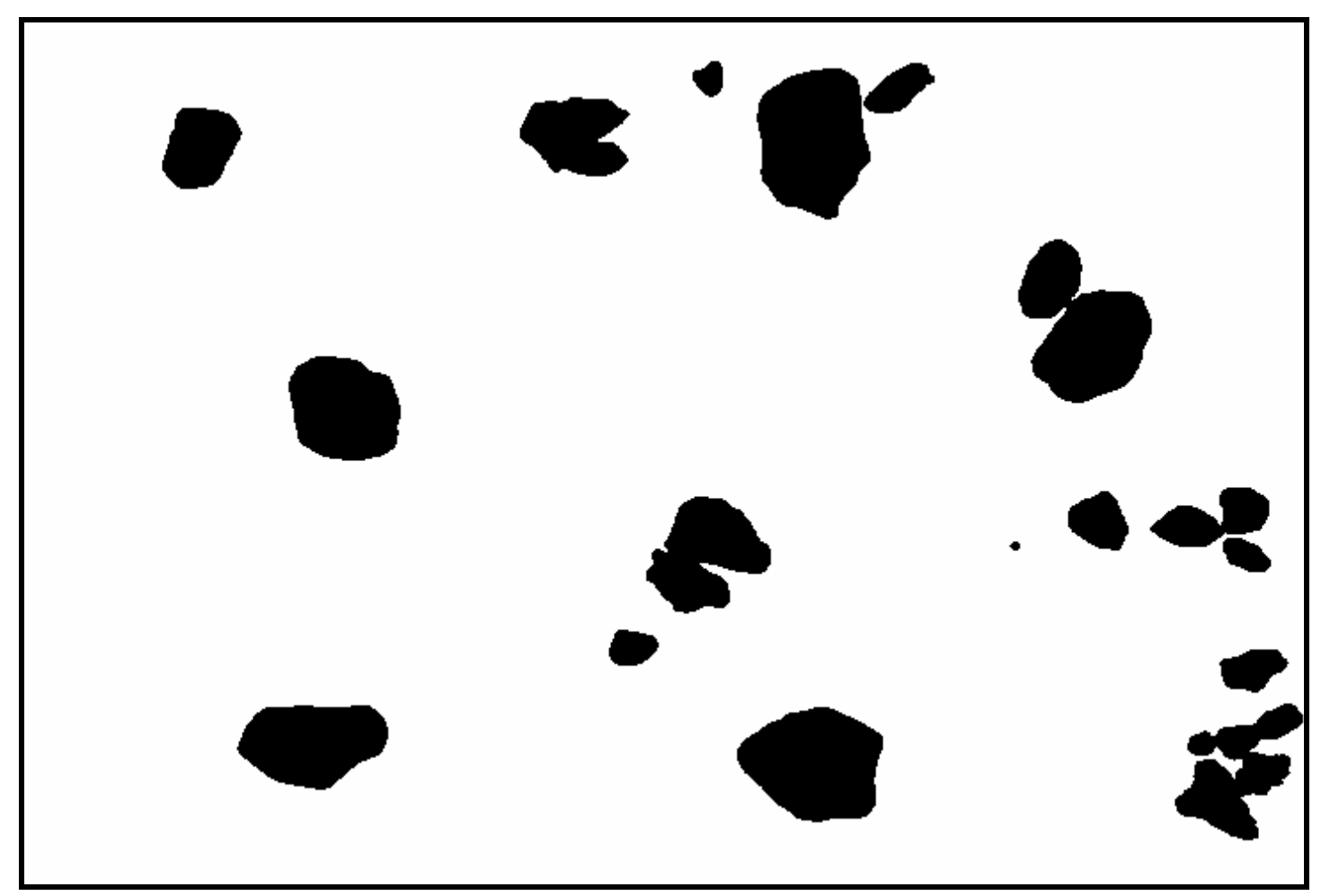

(a)

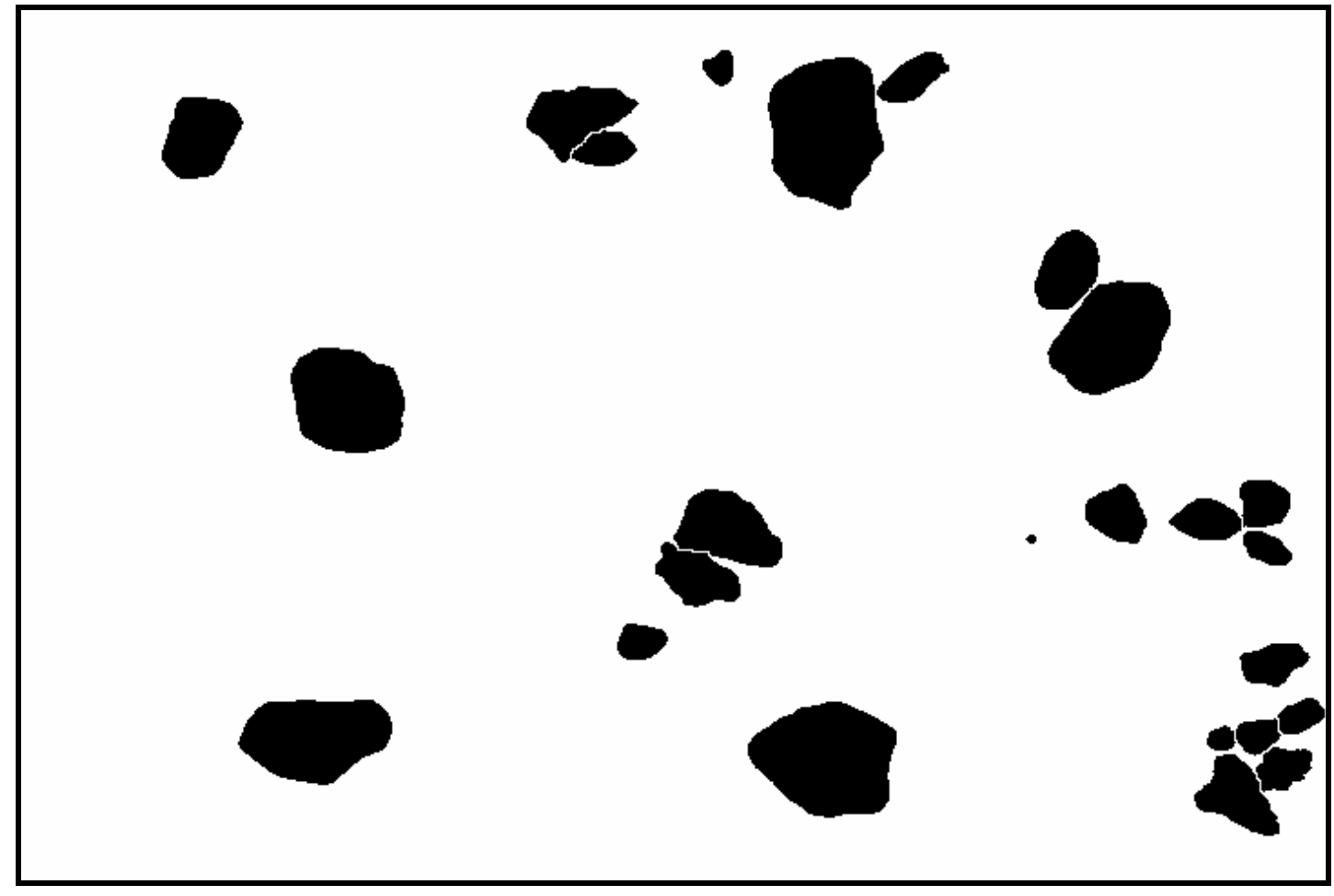

(b)

Figura 4.16 - Utilização da operação morfológica watershed (divisor de águas) para separar aglomerados de partículas. (a) imagem anterior à utilização do watershed com a presença de aglomerados de partículas; (b) imagem posterior à utilização do watershed com as partículas dos aglomerados já separadas. 
As duas primeiras operações, dentro do possível devem ser usadas de forma combinada, ou seja, ciclos de " $n$ " erosões seguidos de ciclos de "n" dilatações, ou viceversa.

Vale destacar que todas as operações morfológicas descritas de alguma forma alteram a imagem binária original, causando inevitável perda de informação; para corroborar tal afirmativa pode-se recorrer a uma perspicaz citação de Allen (1997); consoante o autor, "o objetivo de todo processamento e tratamento de imagens é melhorar a imagem original, no entanto a única coisa certa é o fato de que a imagem original é alterada". Portanto, as operações morfológicas devem ser usadas com critério, visto que elas podem provocar sérias distorções nos resultados finais de DTP obtidos pela análise de imagens, pois deformam a geometria dos objetos de interesse.

\subsection{Calibração do programa}

Todo programa de análise de imagens necessita de uma imagem de calibração para que possam ser conduzidas medidas de tamanho. Isso porque se deve "informar" ao computador qual é a escala da imagem, ou seja, atribuir a um pixel uma unidade de comprimento. Para isso, deve-se obter uma imagem de referência com algum objeto de tamanho previamente conhecido. Nesta pesquisa foi utilizado um fio de platina de diâmetro igual a $100 \mu \mathrm{m}$; este fio era posicionado sobre a lamínula e, então, fotografado; um exemplo de uma imagem de referência pode ser visto na Figura 4.17.

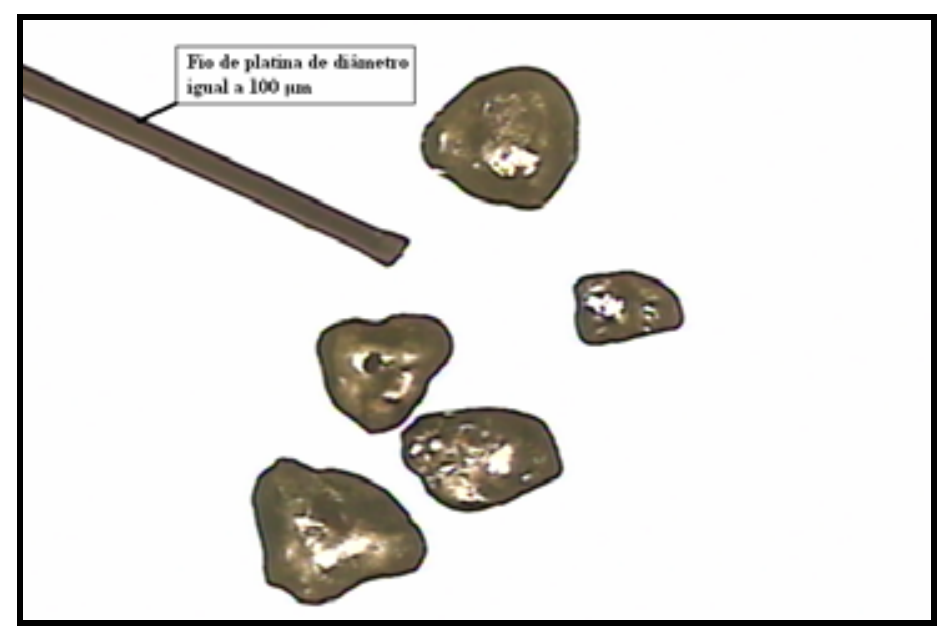

Figura 4.17 - Foto mostrando uma imagem de calibração com o fio de platina de diâmetro igual a $100 \mu \mathrm{m}$. 
Não é necessário usar o fio de referência em todas as fotos, pois a calibração pode ser salva e carregada para análise das demais fotos porém, sempre que o foco da imagem for reajustado, uma nova imagem de calibração deve ser obtida, pois o aumento ou diminuição da distância focal altera o tamanho dos objetos na imagem. Para a calibração do programa não é necessário processar as imagens de referência (binarização e tratamento das imagens binárias), se os contornos do objeto de tamanho conhecido estiverem nítidos; no entanto, nesta pesquisa, preferiu-se processar as imagens de referência antes de proceder a calibração, pois quaisquer distorções na geometria dos objetos de interesse, ocasionadas pela utilização de operações morfológicas, seriam automaticamente transmitidas para o objeto de referência, ocorrendo assim uma compensação de erros.

\subsection{Análise e medições}

Uma vez concluído o processo de segmentação e tratamento das imagens binárias, podem ser realizadas as medidas sobre a imagem. Estas medidas podem ser agrupadas em duas classes: medidas de campo, referentes ao campo visual como um todo, como: número de objetos, área total dos objetos, etc.; e medidas de região, referentes aos objetos individualmente, como: tamanho, fatores de forma, área, perímetro dos objetos, entre outras.

Essa etapa não requer interferência humana, pois é toda realizada pelo programa, ficando a cargo do experimentador somente a escolha de quais medidas devem ser feitas. Na presente pesquisa, foram medidos: o número, o tamanho e a circularidade (fator de forma) dos objetos. O tamanho do objeto nada mais é que seu diâmetro equivalente. Foi escolhido o diâmetro de esfera equivalente de área igual à área projetada do objeto, porquanto, consoante Allen (1997), esse medida de tamanho é preferível, pois leva em consideração as duas dimensões do objeto presentes na imagem. O fator de forma, circularidade, medido é definido pela Equação 4.2.

$$
\operatorname{cir}=\frac{\mathrm{P}^{2}}{4 \cdot \pi \cdot \mathrm{A}_{\mathrm{p}}}
$$


Em que:

cir: Circularidade;

P: Perímetro (L);

$\mathrm{A}_{\mathrm{p}}$ : Área Projetada $\left(\mathrm{L}^{2}\right)$.

\subsection{Tratamento dos Dados e Apresentação dos Resultados}

O tratamento dos dados e a apresentação dos resultados foram realizados usando planilhas eletrônicas, e como tal procedimento é bastante corriqueiro para a grande maioria da comunidade científica, não merece atenção especial, sendo assim o assunto não será abordado neste texto.

\subsection{Resultados e Discussões}

\subsubsection{Considerações iniciais}

Por razões meramente organizacionais os resultados experimentais foram reunidos em dois grandes grupos: no primeiro foram apresentados e discutidos os resultados obtidos nas determinações de concentração de areia e no segundo foram apresentados e discutidos os resultados das determinações de distribuição granulométrica da areia presente no esgoto sanitário. Vale lembrar que todas as amostras utilizadas para a análise apresentada nesse capítulo foram coletadas com o intuito de verificar a eficiência de remoção de areia do separador hidrodinâmico por vórtice (SHV), tema desta tese. Nessa seção serão apresentadas as características da areia (concentração e distribuição granulométrica) presente no esgoto sanitário que foi utilizado para alimentar o SHV, isto é, o esgoto sanitário afluente da ETE Jardim das Flores, do município de Rio Claro, SP. 


\subsubsection{Concentração de areia no esgoto sanitário}

A primeira pergunta que pode advir do leitor é: qual é a concentração média de areia no esgoto sanitário afluente da estação de tratamento de esgoto (ETE) Jardim das Flores da cidade de Rio Claro, SP? Para responder esta questão fez-se uso da análise estatística dos resultados obtidos de 34 amostras, as quais foram coletadas em 11 dias diferentes, entre 17/08/2005 e 21/11/2005, das 09h30min até 17h30min. Estes resultados foram organizados em tabelas e posteriormente plotados em gráficos que serão apresentados a seguir.

Tabela 4.1 - Distribuições de freqüências, freqüências relativas e freqüências relativas acumuladas das 34 amostras, coletadas junto à estação elevatória localizada nas proximidades da ETE Jardim das Flores da cidade de Rio Claro, SP, entre 17/08/2005 e 21/11/2005, das 09h30min até 17h30min.

\begin{tabular}{cccc}
\hline \multicolumn{3}{c}{ Concentração de Areia $(\mathbf{m g} / \mathbf{l})$} & \\
\hline Intervalo & Freqüência & $\begin{array}{c}\text { Freqüência } \\
\text { Relativa }\end{array}$ & $\begin{array}{c}\text { Freqüência } \\
\text { Relativa } \\
\text { Acumulada }\end{array}$ \\
\hline$<15$ & 5 & 0,1471 & 0,1471 \\
$15 \rightarrow 30$ & 6 & 0,1765 & 0,3235 \\
$30 \rightarrow 45$ & 8 & 0,2353 & 0,5588 \\
$45 \rightarrow 60$ & 1 & 0,0294 & 0,5882 \\
$60 \rightarrow 75$ & 3 & 0,0882 & 0,6765 \\
$75 \rightarrow 90$ & 3 & 0,0882 & 0,7647 \\
$90 \rightarrow 105$ & 0 & 0,0000 & 0,7647 \\
$105 \rightarrow 120$ & 1 & 0,0294 & 0,7941 \\
$120 \rightarrow 135$ & 1 & 0,0294 & 0,8235 \\
$135 \rightarrow 150$ & 0 & 0,0000 & 0,8235 \\
$150 \rightarrow 165$ & 1 & 0,0294 & 0,8529 \\
$165 \rightarrow 180$ & 1 & 0,0294 & 0,8824 \\
$180 \rightarrow 195$ & 0 & 0,0000 & 0,8824 \\
$195 \rightarrow 210$ & 1 & 0,0294 & 0,9118 \\
$210 \rightarrow 225$ & 2 & 0,0588 & 0,9706 \\
$225 \rightarrow 240$ & 0 & 0,0000 & 0,9706 \\
$240 \rightarrow 255$ & 0 & 0,0000 & 0,9706 \\
$255 \rightarrow 270$ & 1 & 0,0294 & 1,0000 \\
\hline Total & $\mathbf{3 4}$ & $\mathbf{1 , 0 0 0 0}$ & $\mathbf{1 , 0 0 0 0}$ \\
\hline
\end{tabular}


A Tabela 4.1 mostra as distribuições: de freqüências, de freqüências relativas e de freqüências relativas acumuladas. Por outro lado, nas Figuras 4.18 e 4.19 são apresentados o histograma de freqüências relativas e o gráfico de distribuição de freqüências relativas acumuladas, respectivamente. Pode-se observar, tanto pela Tabela 4.1 como pelo gráfico da Figura 4.18, que o intervalo com maior valor de freqüência (moda) vai de $30 \mathrm{mg} / \mathrm{l}$ a $45 \mathrm{mg} / \mathrm{l}$, e pelo gráfico da Figura 4.19 é possível constatar que a mediana da distribuição de freqüência das 34 amostras é aproximadamente $40 \mathrm{mg} / 1$. Por conseguinte, conclui-se da análise da Tabela 4.1 e dos gráficos das Figuras 4.18 e 4.19 que uma boa estimativa para a concentração média de areia encontrada nas 34 amostras de esgoto, coletadas junto à estação elevatória localizada nas proximidades da ETE Jardim das Flores da cidade de Rio Claro, SP, está entre 30 mg/l e 45 mg/l.

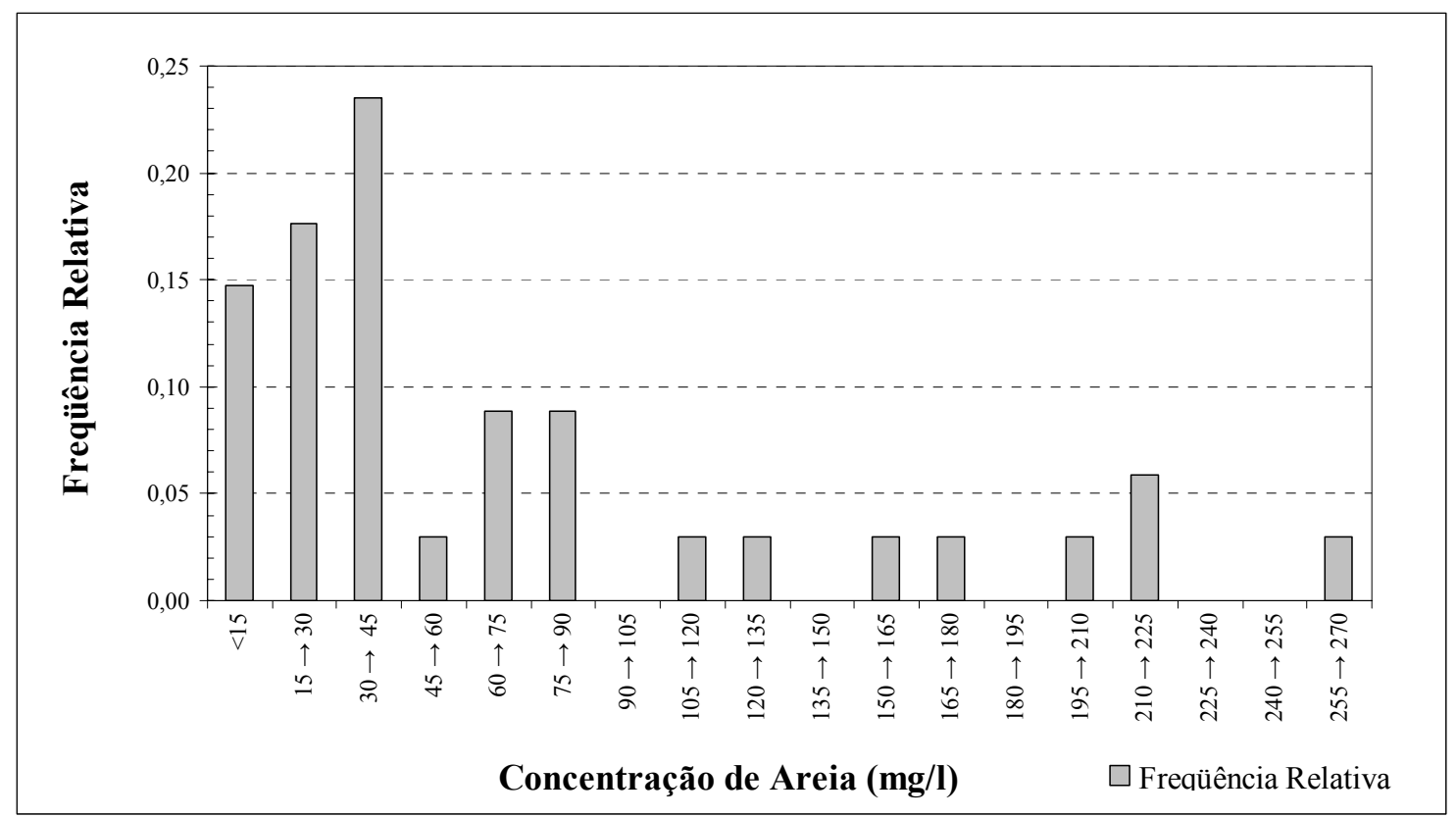

Figura 4.18 - Histograma de freqüências relativas, obtido a partir de 34 amostras de esgoto sanitário, coletadas junto à estação elevatória localizada nas proximidades da ETE Jardim das Flores da cidade de Rio Claro, SP, entre 17/08/2005 e 21/11/2005, das $09 \mathrm{~h} 30 \mathrm{~min}$ até $17 \mathrm{~h} 30 \mathrm{~min}$.

Todavia, a resposta para a questão levantada no primeiro parágrafo desta seção ainda não foi respondida pois, o que se pretende descobrir, a partir de uma análise estatística de um conjunto de dados amostrais são as características populacionais desse conjunto, nesse caso representadas pela a concentração média de areia de qualquer amostra coletada junto à estação elevatória localizada nas proximidades da ETE Jardim das Flores. Para aproximar-se da resposta desta questão é necessário aprofundar-se um 
pouco mais na análise estatística, observando as características da distribuição dos dados amostrais, ou seja, das concentrações de areia obtidas. Uma forma de representar a curva de distribuição de concentrações de areia obtidas a partir das 34 amostras analisadas é o gráfico da Figura 4.20. Nele pode ser observado o formato da curva de distribuição das concentrações de duas maneiras, uma pela própria distribuição dos dados e outra por um tipo de gráfico chamado box-plot.

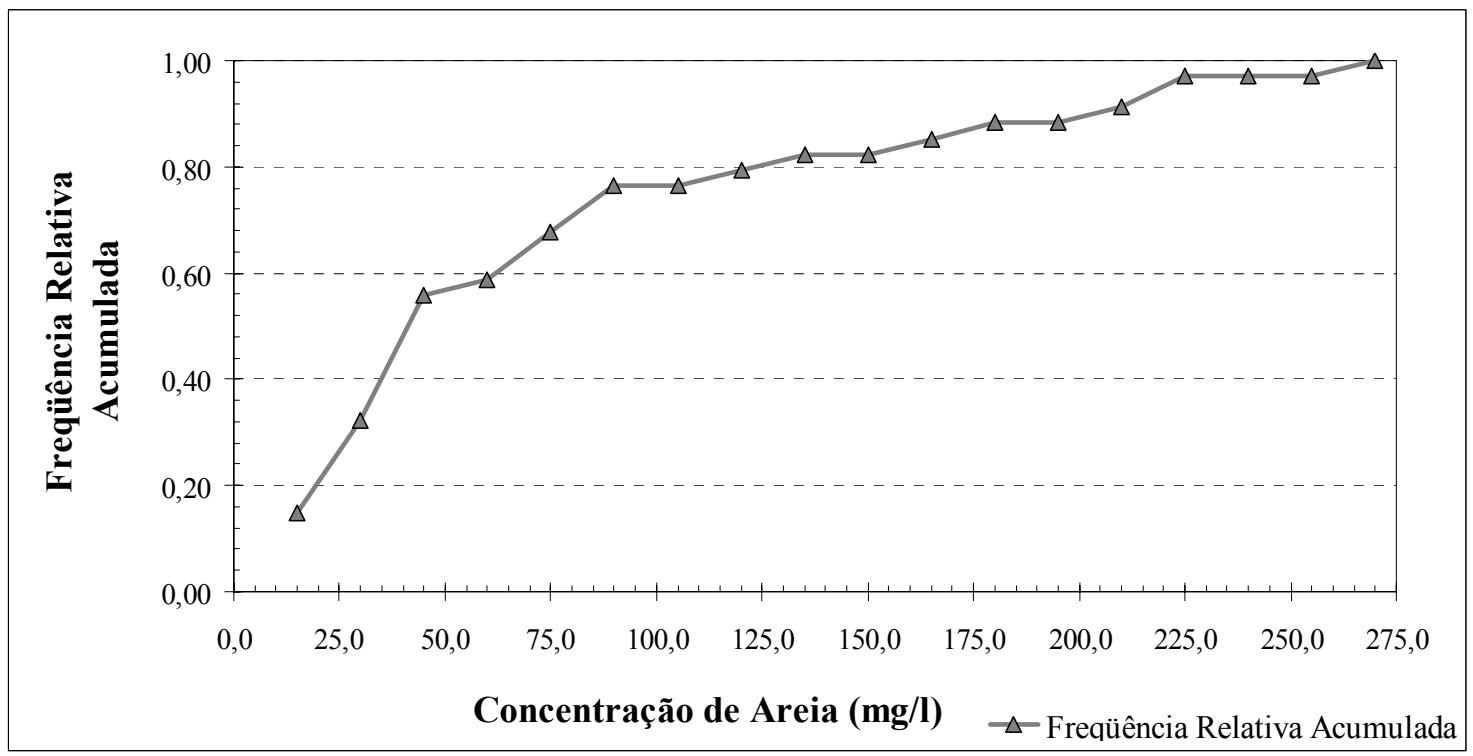

Figura 4.19 - Gráfico de distribuição de freqüências relativas acumuladas, obtido a partir de 34 amostras de esgoto sanitário, coletadas junto à estação elevatória localizada nas proximidades da ETE Jardim das Flores da cidade de Rio Claro, SP, entre $17 / 08 / 2005$ e $21 / 11 / 2005$, das $09 \mathrm{~h} 30 \mathrm{~min}$ até $17 \mathrm{~h} 30 \mathrm{~min}$.

Observa-se no gráfico da Figura 4.20 certa assimetria na distribuição das concentrações de areia. Este fato demonstra que os 34 dados amostrais analisados não se distribuem normalmente em torno de uma média. No entanto, segundo Barros Neto et al. (2002), em situações como essa, considerando que a concentração de areia no esgoto é uma variável aleatória, pode-se fazer uso de um dos teoremas fundamentais da Estatística o Teorema do Limite Central, o qual assevera que:

Se a flutuação total numa certa variável aleatória for o resultado da soma das flutuações de muitas variáveis independentes e de importância mais ou menos iguais, a sua distribuição tenderá para a normalidade, não importa qual seja a distribuição das variáveis individuais (BARROS NETO et al., 2002). 


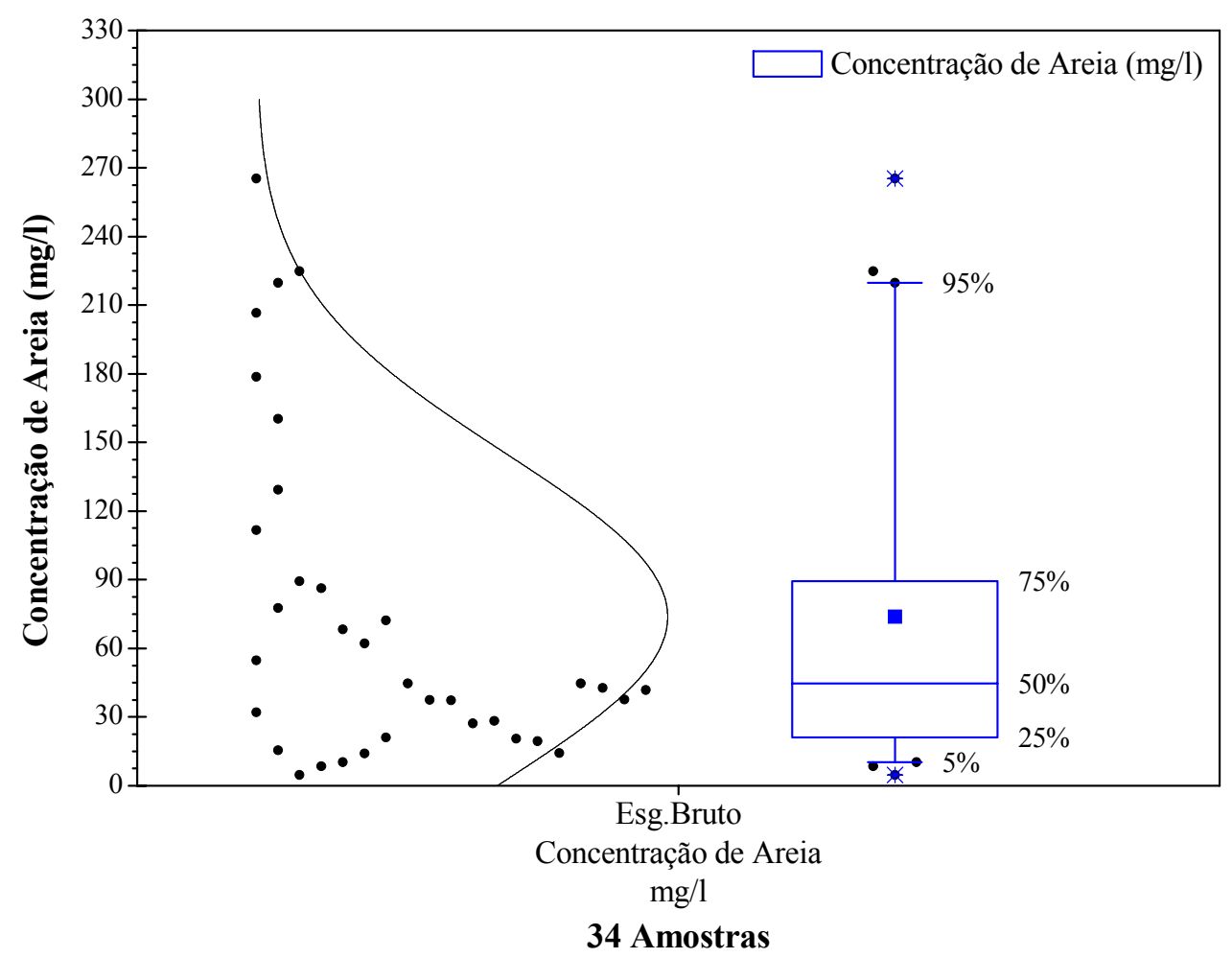

Figura 4.20 - Gráfico tipo box-plot e curva de distribuição das concentrações de areia obtidas a partir de 34 amostras de esgoto sanitário, coletadas junto à estação elevatória localizada nas proximidades da ETE Jardim das Flores da cidade de Rio Claro, SP, entre 17/08/2005 e 21/11/2005, das 09h30min até 17h30min. (ロ) Média aritmética dos dados.

Assumindo que a concentração de areia no esgoto sanitário é uma variável aleatória, e que o pelo Teorema do Limite Central a distribuição das concentrações médias de areia no esgoto para uma amostra grande o bastante se distribui normalmente, foram calculados dois intervalos de confiança, um baseado na média aritmética e outro baseado na média geométrica das concentrações de areia encontradas nas 34 amostras de esgoto sanitário. Os dois intervalos de confiança (IC) foram calculados usando a distribuição t-Student (variâncias populacionais desconhecidas) com nível de significância de 95\%, e são apresentados na Tabela 4.2, juntamente com outros parâmetros estatísticos do conjunto amostral, como: médias geométrica e aritmética, desvios padrões e variâncias para as médias geométricas e aritméticas, mediana da distribuição de concentrações de areia, número de amostras analisadas e as concentrações máxima e mínima encontradas.

Como se pode notar na Tabela 4.2, os valores das médias geométrica e aritmética são consideravelmente desiguais. Este resultado já era esperado, pois a média aritmética é bastante influenciada pelos valores extremos de um conjunto de dados, consequentemente, o IC calculado a partir dela apresenta valores maiores para a 
concentração média de areia encontrada no esgoto sanitário. Porém a amplitude dos dois ICs é praticamente a mesma, $53 \mathrm{mg} / 1$ para média geométrica e $50 \mathrm{mg} / 1$ para a média aritmética, pois os desvios padrões e o nível de significância são praticamente os mesmos para os dois casos.

Tabela 4.2 - Intervalos de confiança baseados nas médias aritmética e geométrica com níveis de significância de $95 \%$, e parâmetros estatísticos da distribuição de concentrações de areia.

\begin{tabular}{|c|c|}
\hline \multicolumn{2}{|c|}{ Concentração de Areia (mg/l) } \\
\hline Média Geométrica & 46,7 \\
\hline Desvio padrão & 76,51 \\
\hline Variância da amostra & 5853,16 \\
\hline \multicolumn{2}{|c|}{$\mathrm{IC}\left(\mu_{\mathrm{g}} ; 95 \%\right)=[19,977 \mathrm{mg} / \mathrm{l} ; 73,373 \mathrm{mg} / \mathrm{l}]$} \\
\hline Média Aritmética & 73,8 \\
\hline Desvio padrão & 71,38 \\
\hline Variância da amostra & 5095,53 \\
\hline \multicolumn{2}{|c|}{$\mathrm{IC}\left(\mu_{\mathrm{a}} ; 95 \%\right)=[48,882 \mathrm{mg} / \mathrm{l} ; 98,703 \mathrm{mg} / \mathrm{l}]$} \\
\hline Mediana & 43,7 \\
\hline Mínimo & 4,8 \\
\hline Máximo & 265,3 \\
\hline Número de Amostras & 34 \\
\hline
\end{tabular}

Outra conclusão que se pode obter ao analisar os valores de desvio padrão e a amplitude dos ICs, na Tabela 4.2, é que a concentração de areia no esgoto sanitário apresenta grande variabilidade. Este fato é corroborado pela enorme diferença (260 $\mathrm{mg} / \mathrm{l}$ ) entre o menor valor de concentração de areia encontrado, $5 \mathrm{mg} / \mathrm{l}$, e o maior, 265 $\mathrm{mg} / \mathrm{l}$.

Finalmente, depois de todas as análises e considerações expostas nesse texto, podem ser dadas duas repostas à pergunta proposta no início dessa seção, uma delas baseada na simples análise da distribuição dos valores de concentração encontrados nas 34 amostras e outra influenciada, também, por questões de engenharia.

A análise da distribuição dos valores de concentração mostra que o valor da média geométrica (47 mg/l), por ser menos influenciado pelos valores extremos, é mais próximo ao valor da mediana do conjunto de dados (44 mg/l); consequentemente, ele 
parece representar com mais fidelidade o valor médio da distribuição de concentrações de areia; por isso, o intervalo de confiança calculado a partir dele pode ser considerado como boa estimativa, isto é, a concentração média de areia no esgoto sanitário estudado tem $95 \%$ de chance de estar entre $20 \mathrm{mg} / \mathrm{l}$ e $73 \mathrm{mg} / \mathrm{l}$.

Entretanto, quando se leva em consideração o emprego desses valores médios de concentração para o projeto de sistemas de remoção, lavagem e disposição final da areia presente no esgoto sanitário, é prudente a utilização de valores mais conservadores. Nesse caso, aconselha-se a adoção de IC calculado a partir da média aritmética como representação da concentração média de areia no esgoto sanitário, a qual, para o esgoto afluente da ETE Jardim das Flores, com 95\% de significância, está entre 50 mg/l e 100 $\mathrm{mg} / \mathrm{l}$.

Infelizmente, a falta de dados acerca da quantidade de areia no esgoto sanitário impede a comparação dos resultados obtidos nessa pesquisa com valores encontrados em outras localidades. Contudo, valores de concentração de areia de até $265 \mathrm{mg} / 1$ (maior valor encontrado), demonstram que o projeto de sistemas de desarenação de grandes cidades deve ser realizado com muito cuidado, pois a quantidade de areia removida por esses sistemas pode ocasionar grande problema à operação dessas ETEs, por outro lado, caso tais quantidades de areia não sejam devidamente removidas por desarenadores, podem ocorrer problemas ainda maiores, como a diminuição da vida útil de equipamentos e unidade subseqüentes.

Para exemplificar o tamanho, ou melhor, a quantidade desse problema, vale a pena fazer um mero exercício de raciocínio com os dados dessa pesquisa. Assumindo que uma ETE atenda uma população de 100.000 habitantes, e adotando: 180 1/hab.dia, coeficiente de retorno de 0,8 e concentração média de areia no esgoto sanitário de 50 $\mathrm{mg} / \mathrm{l}$; obtém-se com isso um total de $721 \mathrm{~kg}$ de areia seca por dia; 5,05 t de areia seca por semana e 21,6 t de areia seca por mês. Ao se considerar o custo de transporte e disposição final dessa quantidade de areia removida nos desarenadores, o custo de operação e manutenção (O\&M) da ETE pode aumentar consideravelmente.

Como já mencionado nesse texto, os valores de desvio padrão, a amplitude dos ICs calculados e a enorme diferença entre as concentrações mínima e máxima encontradas demonstram um grande variabilidade do valor da concentração de areia do 
esgoto sanitário afluente da ETE Jardim das Flores. No entanto, tais dados não permitem que essa variabilidade seja visualizada. Para que isso fosse possível, os 34 resultados experimentais foram divididos em dois grupos diferentes: resultados preliminares, com 10 valores de concentração de areia obtidos de amostras coletadas entre 17/08/2005 e 06/09/2005, das 09h30min até 15h00min; e resultados finais, com 24 valores de concentração de areia obtidos de amostras coletadas entre 06/10/2005 e 21/11/2005, das 10h30min até 17h30min.

A Figura 4.21 traz o histograma dos valores de concentração encontrados nas 10 amostras agrupadas como resultados preliminares. Nela podem ser observados dois picos de concentração bem pronunciados: um às 13h40min $(265 \mathrm{mg} / \mathrm{l})$ e outro às 15h00min $(225 \mathrm{mg} / \mathrm{l})$. Outra característica do histograma da Figura 4.21 é o padrão ascendente dos valores de concentração entre 09h30min e 13h40min, que pode ser justificado pelo aumento de vazão, normalmente observado em ETEs durante esse período; todavia, tal fato não pode ser confirmado nessa pesquisa, pois o medidor de vazões da estação elevatória de onde foram coletadas as amostras era uma calha Parshall, que durante boa parte do dia permanecia afogada, não fornecendo, assim, valores de vazão que pudessem ser utilizados.

Sabe-se, porém, que uma única amostra não pode ser utilizada para se verificar padrões de comportamento, é necessário que mais amostras coletadas em mesmo horário sejam analisadas para que se possa concluir algo sobre a variação horária da areia no esgoto sanitário afluente da ETE Jardim das Flores. Tal procedimento foi realizado e os valores de concentração obtidos foram agrupados como resultados finais.

A Figura 4.22 mostra o histograma construído a partir desses valores; nela podese observar que o padrão ascendente encontrado na Figura 4.21 não se faz presente e que a variabilidade dos valores de concentração é verificada não somente ao longo do dia, mas para um mesmo horário também. Na Figura 4.23 foi plotado um histograma com os valores médios calculados para cada horário. Mais uma vez, observa-se uma diferença significativa entre os valores das médias aritméticas e geométricas, principalmente às $11 \mathrm{~h} 30 \mathrm{~min}$ e às $16 \mathrm{~h} 30 \mathrm{~min}$, quando é grande a diferença entre os menores e os maiores valores de concentração de areia. 


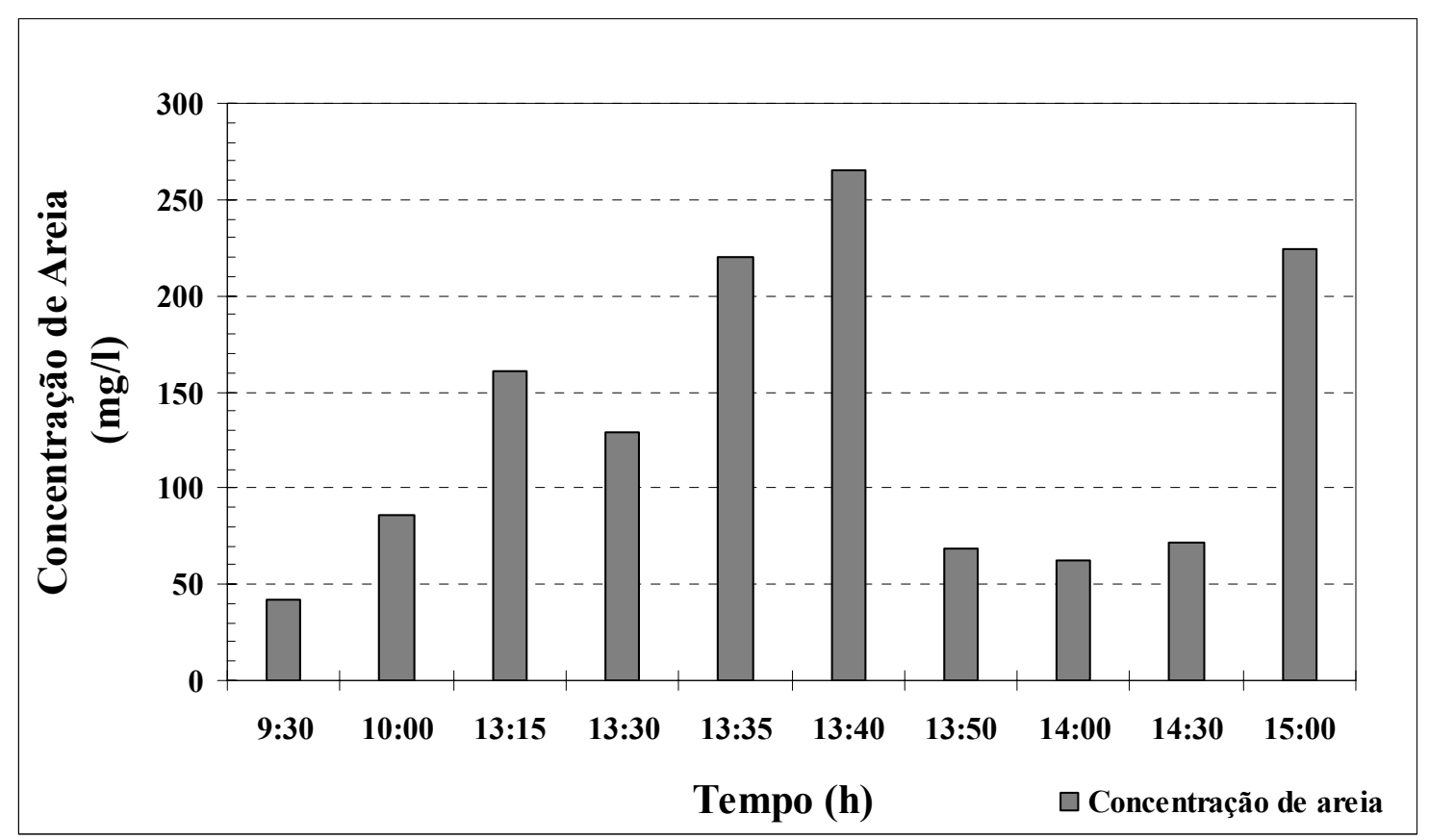

Figura 4.21 - Histograma de concentrações de areia construído a partir de 10 amostras de esgoto sanitário, coletadas junto à estação elevatória localizada nas proximidades da ETE Jardim das Flores da cidade de Rio Claro, SP, entre 17/08/2005 e 06/09/2005, das $09 \mathrm{~h} 30 \mathrm{~min}$ até $15 \mathrm{~h} 00 \mathrm{~min}$.

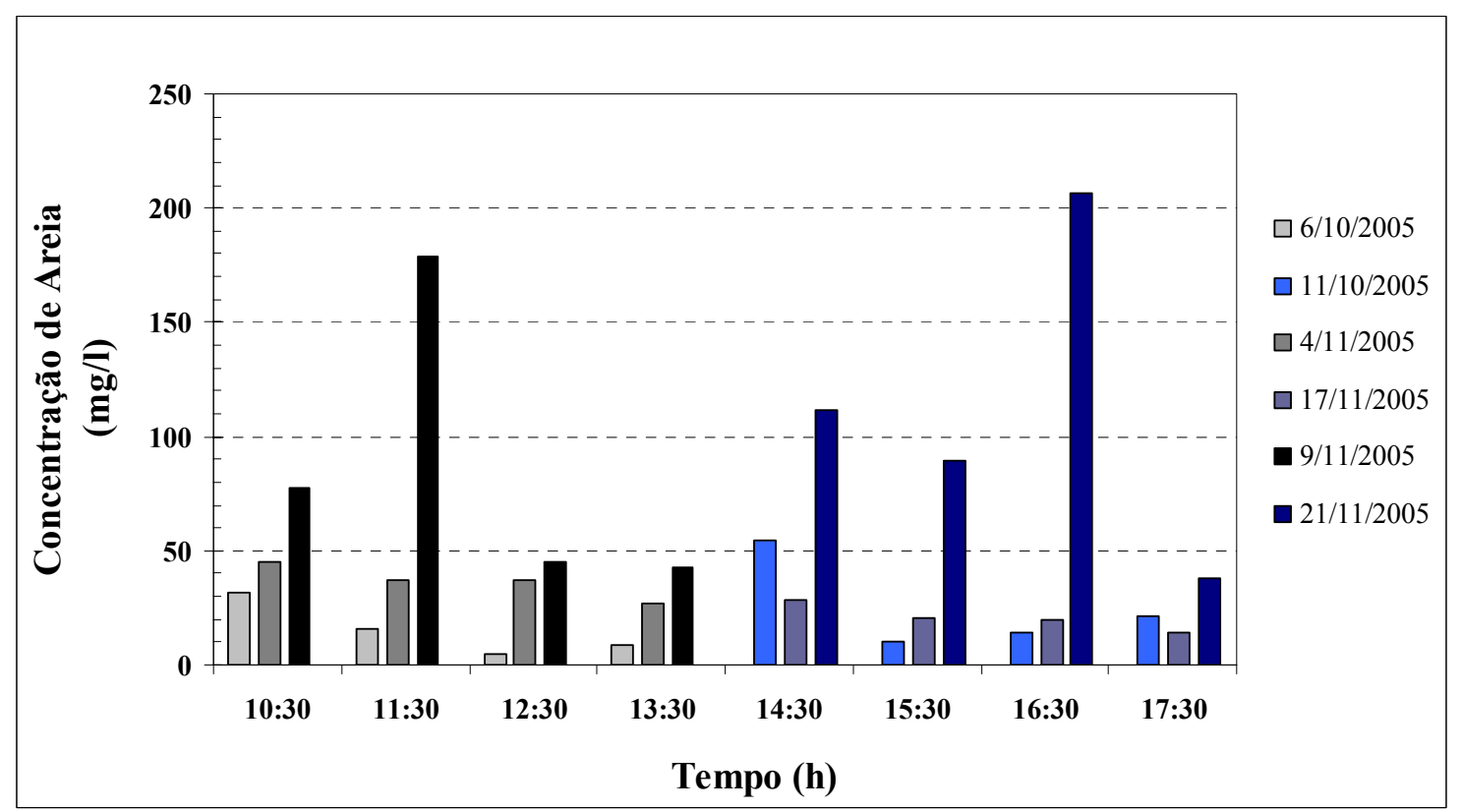

Figura 4.22 - Histograma de concentrações de areia construído a partir de 24 amostras de esgoto sanitário, coletadas junto à estação elevatória localizada nas proximidades da ETE Jardim das Flores da cidade de Rio Claro, SP, entre 06/09/2005 e 21/11/2005, das $10 \mathrm{~h} 30 \mathrm{~min}$ até $17 \mathrm{~h} 30 \mathrm{~min}$.

Em nenhuma das duas Figuras 4.22 e 4.23 nota-se algum tipo de padrão na variabilidade horária da concentração de areia presente no esgoto sanitário afluente da 
ETE Jardim das Flores; por isso nada pode ser concluído, além de a concentração de areia poder apresentar variações significativas tanto para um mesmo horário como ao longo do dia.

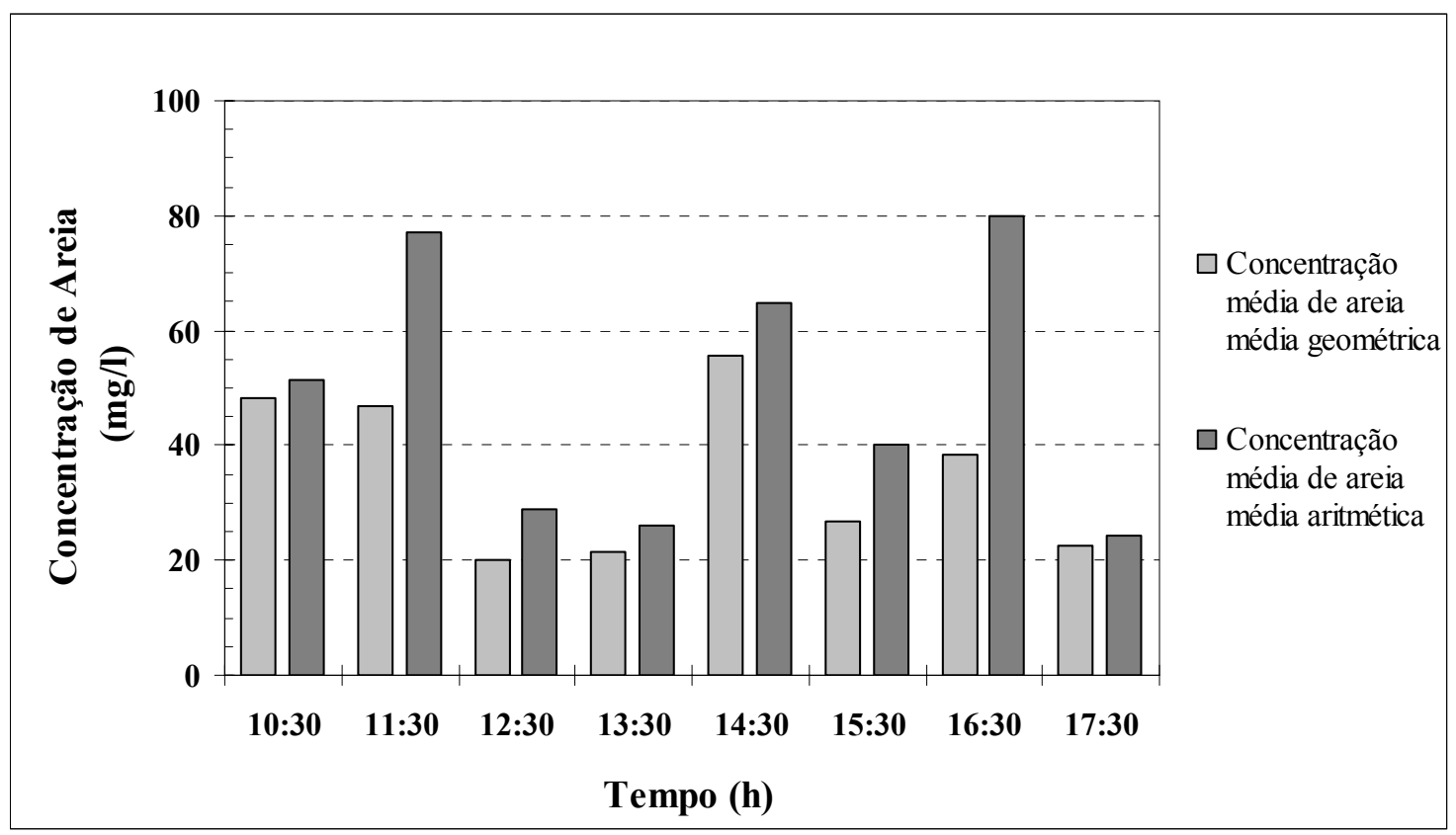

Figura 4.23 - Histograma de concentrações médias (geométrica e aritmética) de areia construído a partir de 24 amostras de esgoto sanitário, coletadas junto à estação elevatória localizada nas proximidades da ETE Jardim das Flores da cidade de Rio Claro, SP, entre 06/09/2005 e 21/11/2005, das 10h30min até 17h30min.

Ainda analisando a variação horária da concentração de areia no esgoto, decidiuse verificar a existência de alguma diferença entre as concentrações médias (populacionais) de areia em dois períodos diferentes, período 1 das 09h30min às 13h30min e período 2 das $13 \mathrm{~h} 30 \mathrm{~min}$ às $17 \mathrm{~h} 30 \mathrm{~min}$. Para isso, foram utilizadas 32 amostras de esgoto coletadas entre 06/10/2005 e 21/11/2005, das 09h30min às $17 \mathrm{~h} 30 \mathrm{~min}$.

A Figura 4.24 mostra um gráfico tipo box-plot com a distribuição de concentrações de areia dos dois períodos estudados. O gráfico permite que se observe uma pequena diferença entre as médias aritméticas amostrais dos dois períodos, porém será que tal diferença é significativa e se faz presente nas médias populacionais de concentração de areia? 


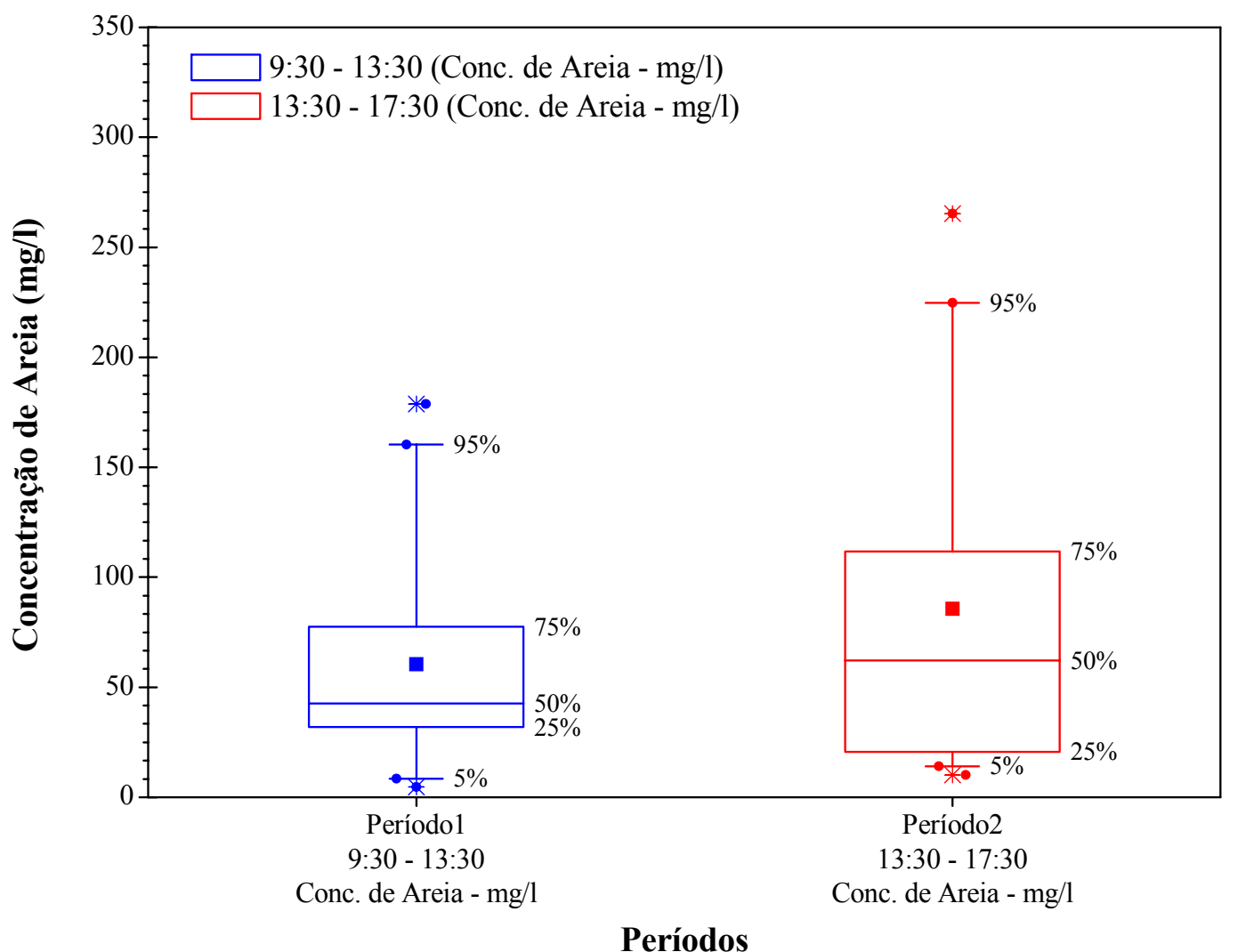

Figura 4.24 - Gráfico tipo box-plot das distribuições de concentração de areia para os dois períodos estudados, construído a partir de 32 amostras de esgoto sanitário, coletadas junto à estação elevatória localizada nas proximidades da ETE Jardim das Flores da cidade de Rio Claro, SP, entre 06/08/2005 e 21/11/2005, das 09h30min até 17h30min.( $\square$ ) Médias aritméticas dos dados.

Para responder a esta questão foi utilizado um teste de hipóteses (Teste-t) para as concentrações médias populacionais, assumindo que as amostras dos dois períodos eram aleatórias, independentes e com variâncias desconhecidas e diferentes. O teste de hipóteses foi realizado utilizando umas das ferramentas de análise de dados do Microsoft Excel, e seu resultado pode ser visto na Tabela 4.3. As Equações 4.3 e 4.4 mostram como o teste de hipóteses foi montado (MAGALHÃES e LIMA, 2002):

$$
\begin{aligned}
& \mathrm{H}_{0}: \mu_{\mathrm{A} 1}=\mu_{\mathrm{A} 2} \text { ou }\left(\mu_{\mathrm{A} 1}-\mu_{\mathrm{A} 2}\right)=0 \\
& \mathrm{H}_{\mathrm{a}}: \mu_{\mathrm{A} 1} \neq \mu_{\mathrm{A} 2} \text { ou }\left(\mu_{\mathrm{A} 1}-\mu_{\mathrm{A} 2}\right) \neq 0
\end{aligned}
$$

Em que:

$\mathrm{H}_{0}$ : hipótese nula;

$\mathrm{H}_{\mathrm{a}}$ : hipótese alternativa; 
$\mu_{\mathrm{A} 1}:$ média populacional para a amostra 1 ;

$\mu_{\mathrm{A} 2}$ : média populacional para a amostra 2 .

Para um nível de significância $\alpha$, a região crítica $(\mathrm{RC})$ pode ser escrita como:

$$
\mathrm{RC}=\left\{\mathrm{t} \in \mathfrak{R}: \mathrm{t}_{\text {obs }}<-\mathrm{t}_{\text {crítico }} \text { ou } \mathrm{t}_{\text {obs }}>\mathrm{t}_{\text {crítico }}\right\}
$$

Em que:

$\mathrm{t}_{\mathrm{obs}}$ : valor estatístico padronizado obtido a partir da diferença das médias amostrais que estão sendo testadas;

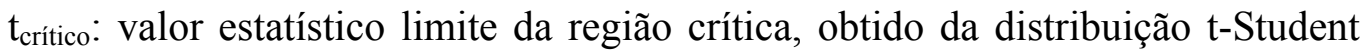
com $n$ graus de liberdade e nível de significância $\alpha$;

RC: região crítica de não aceitação da hipótese nula.

Como se pode observar na Tabela 4.3, apesar das médias amostrais das concentrações serem diferentes, o Teste-t não verificou existência de diferença significativa entre as médias populacionais dos dois períodos estudados, pois $\mathrm{t}_{\mathrm{obs}}$ está fora da região crítica de não aceitação da hipótese nula, ou seja, médias populacionais iguais. Logo, pode se concluir que a concentração média de areia do período 1 não difere significativamente da concentração média de areia do período 2 .

Para finalizar a análise dos resultados de concentração de areia presente no esgoto sanitário afluente da ETE Jardim das Flores é necessário verificar se a vazão utilizada para a amostragem interferiu nos resultados obtidos. Apesar de a vazão de sucção da bomba submersível, posicionada ao lado do anteparo que divide o poço de sucção da estação elevatória do canal de chegada do esgoto bruto (Figura 4.3), ter sido mantida constante (20 1/s), a vazão de alimentação do separador hidrodinâmico por vórtice (SHV) não o foi. Uma derivação na mangueira que ligava a bomba submersível e a unidade permitiu que a vazão de alimentação fosse alterada para 10 1/s, 15 1/s e 20 $1 / \mathrm{s}$. 
Tabela 4.3 - Parâmetros estatísticos usados para a realização do teste de hipótese da média populacional de concentrações de areia dos dois períodos estudados, considerando amostras independentes com variâncias desconhecidas e diferentes.

Teste-t: duas amostras presumindo variâncias diferentes e desconhecidas com nível de significância $\alpha=0,05$

\begin{tabular}{|c|c|c|}
\hline Parâmetros Estatísticos & $9: 30 \rightarrow 13: 30$ & $13: 30 \rightarrow 17: 30$ \\
\hline Média (mg/1) & 60,5 & 85,6 \\
\hline Variância & 2775,48 & 7130,34 \\
\hline Observações & 16 & 18 \\
\hline Hipótese da diferença de médias & \multicolumn{2}{|c|}{0} \\
\hline Graus de liberdade & \multicolumn{2}{|c|}{29} \\
\hline Stat $t\left(t_{\text {obs }}\right)$ & \multicolumn{2}{|c|}{$-1,0485$} \\
\hline $\mathrm{t}_{\text {crítico }}$ bi-caudal & \multicolumn{2}{|c|}{2,0452} \\
\hline \multicolumn{3}{|c|}{$\mathrm{RC}=\left\{\mathrm{t} \in \mathfrak{R}: \mathrm{t}_{\mathrm{obs}}<-2,0452\right.$ ou $\left.\mathrm{t}_{\mathrm{obs}}>2,0452\right\}$} \\
\hline
\end{tabular}

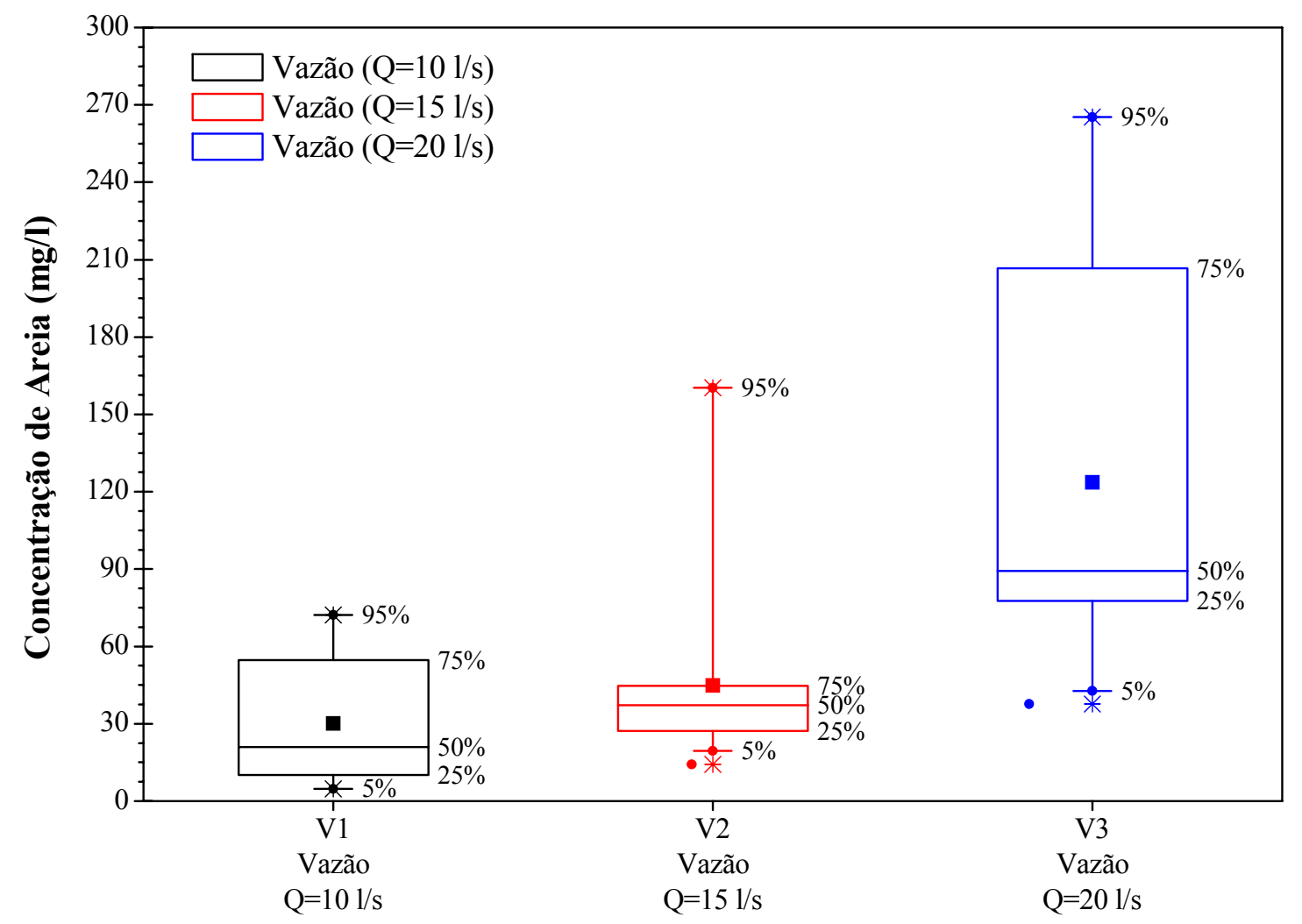

Vazões de Trabalho

Figura 4.25 - Box-plot das distribuições de concentração de areia para as três vazões de alimentação do SHV (10 l/s, 15 l/s e 20 l/s), construído a partir de 32 amostras de esgoto sanitário, coletadas junto à estação elevatória localizada nas proximidades da ETE Jardim das Flores da cidade de Rio Claro, SP, entre 06/08/2005 e 21/11/2005, das 09h30min até 17h30min. ( $\square$ ) Médias aritméticas dos dados. 
A Figura 4.25 mostra um gráfico tipo box-plot com distribuição de concentrações obtidas de amostras coletadas com as três vazões de alimentação do SHV. Pode-se observar que existe diferença nas distribuições dos resultados amostrais, todavia será que essas diferenças permanecem significativas ao se fazer uma análise populacional das concentrações médias de areia?

Tabela 4.4 - Parâmetros estatísticos usados para a realização do teste de hipótese da média populacional de concentrações de areia para as vazões de alimentação do SHV, 10 l/s e 15 l/s, considerando amostras independentes com variâncias desconhecidas e diferentes, com nível de significância de 0,05.

\begin{tabular}{|c|c|c|}
\hline \multicolumn{3}{|c|}{$\begin{array}{l}\text { Teste-t: duas amostras presumindo variâncias diferentes e } \\
\text { desconhecidas } \\
\text { com nível de significância } \alpha=0,05\end{array}$} \\
\hline Parâmetros Estatísticos & $10 \mathrm{l} / \mathrm{s}$ & $15 \mathrm{l} / \mathrm{s}$ \\
\hline Média (mg/l) & 30,1 & 44,9 \\
\hline Variância & 654,76 & 1651,75 \\
\hline Observações & 10 & 11 \\
\hline Hipótese da diferença de médias & \multicolumn{2}{|c|}{0} \\
\hline Graus de liberdade & \multicolumn{2}{|c|}{17} \\
\hline Stat $t\left(t_{o b s}\right)$ & \multicolumn{2}{|c|}{$-1,00462$} \\
\hline $\mathrm{t}_{\text {crítico }}$ bi-caudal & \multicolumn{2}{|c|}{2,10982} \\
\hline \multicolumn{3}{|c|}{$\mathrm{RC}=\left\{\mathrm{t} \in \mathfrak{R}: \mathrm{t}_{\mathrm{obs}}<-2,10982\right.$ ou $\left.\mathrm{t}_{\mathrm{obs}}>2,10982\right\}$} \\
\hline
\end{tabular}

Tabela 4.5 - Parâmetros estatísticos usados para a realização do teste de hipótese da média populacional de concentrações de areia para as vazões de alimentação do SHV, 10 l/s e 20 l/s, considerando amostras independentes com variâncias desconhecidas e diferentes, com nível de significância de 0,05 .

\begin{tabular}{|c|c|c|}
\hline \multicolumn{3}{|c|}{$\begin{array}{l}\text { Teste-t: duas amostras presumindo variâncias diferentes e } \\
\text { desconhecidas } \\
\text { com nível de significância } \alpha=0,05\end{array}$} \\
\hline Parâmetros Estatísticos & $10 \mathrm{l} / \mathrm{s}$ & $20 \mathrm{l} / \mathrm{s}$ \\
\hline Média (mg/l) & 30,1 & 123,7 \\
\hline Variância & 654,77 & 6424,11 \\
\hline Observações & 10 & 11 \\
\hline Hipótese da diferença de médias & \multicolumn{2}{|c|}{0} \\
\hline Graus de liberdade & \multicolumn{2}{|c|}{12} \\
\hline Stat $\mathrm{t}\left(\mathrm{t}_{\mathrm{obs}}\right)$ & \multicolumn{2}{|c|}{$-3,67080$} \\
\hline$t_{\text {crítico }}$ bi-caudal & \multicolumn{2}{|c|}{2,17881} \\
\hline \multicolumn{3}{|c|}{$\mathrm{RC}=\left\{\mathrm{t} \in \mathfrak{R}: \mathrm{t}_{\mathrm{obs}}<-2,17881\right.$ ou $\left.\mathrm{t}_{\mathrm{obs}}>2,17881\right\}$} \\
\hline
\end{tabular}


Tabela 4.6 - Parâmetros estatísticos usados para a realização do teste de hipótese da média populacional de concentrações de areia para as vazões de alimentação do SHV, 15 l/s e 20 l/s, considerando amostras independentes com variâncias desconhecidas e diferentes.

\begin{tabular}{lcc}
\hline \multicolumn{3}{c}{ Teste-t: duas amostras presumindo variâncias diferentes e } \\
cosconhecidas \\
com nível de significância $\boldsymbol{\alpha}=\mathbf{0 , 0 5}$ \\
\hline \multicolumn{1}{c}{ Parâmetros Estatísticos } & $\mathbf{1 5} \mathbf{l} \mathbf{s}$ & $\mathbf{2 0} \mathbf{~ / /}$ \\
\hline Média $(\mathrm{mg} / \mathrm{l})$ & 44,9 & 123,7 \\
Variância & 1651,75 & 6424,11 \\
Observações & 11 & 11 \\
\hline Hipótese da diferença de médias & 0 \\
Graus de liberdade & 15 \\
Stat $\mathrm{t}\left(\mathrm{t}_{\mathrm{obs}}\right)$ & $-2,90816$ \\
\hline $\mathrm{t}_{\text {crítico }}$ bi-caudal & 2,13145 \\
\multicolumn{2}{c}{$\mathrm{RC}=\left\{\mathrm{t} \in \mathfrak{R}: \mathrm{t}_{\mathrm{obs}}<-2,13145\right.$ ou $\left.\mathrm{t}_{\mathrm{obs}}>2,13145\right\}$} \\
\hline
\end{tabular}

Mas uma vez fez-se uso de testes de hipóteses (Teste-t) para responder tal questão. Foram comparadas entre si as concentrações médias populacionais das 3 vazões de alimentação do SHV utilizadas. Os três Testes-t realizados foram montados de acordo com as Equações 4.3 e 4.4. Os resultados dos 3 testes de hipóteses são mostrados nas Tabelas 4.4, 4.5 e 4.6.

Como pode ser constatado na Tabela 4.4, as concentrações de areia obtidas com as vazões de alimentação, 10 1/s e 15 1/s, não são significativamente diferentes; assim pode se concluir que para este caso o aumento de vazão de alimentação do SHV de 10 1/s para 15 l/s não causou interferência na determinação da concentração de areia presente no esgoto sanitário que alimentava a unidade. Contudo, ao se analisar os resultados das Tabelas 4.5 e 4.6, observa-se que a concentração média de areia para vazão de alimentação do SHV de 20 1/s apresentou diferenças significativas em relação às demais. No entanto não é possível atribuir estas diferenças a alguma interferência provocada pelo aumento da vazão de alimentação da unidade, pois não foi constatada diferença significativa entre as concentrações médias obtidas com vazões de alimentação de 10 1/s e 15 1/s. Conclui-se, então, que não existem evidências suficientes e significativas para assumir que a vazão utilizada para alimentar o SHV, de alguma 
forma, tenha interferido nas determinações de concentração de areia presente no esgoto sanitário afluente da ETE Jardim das Flores.

\subsubsection{Distribuição granulométrica da areia no esgoto sanitário}

Apesar de ser ferramenta poderosa e confiável, a técnica de determinação da distribuição de tamanho de partículas (DTP) por análise de imagens é extremamente laboriosa e demorada, por essa razão, não foram analisadas todas as 34 amostras de esgoto sanitário afluente da ETE Jardim das Flores, apenas um conjunto de 15 amostras, cinco para cada vazão (10 1/s; 15 1/s; 20 1/s) de alimentação do separador hidrodinâmico por vórtice (SHV) foram utilizadas. A Tabela 4.7 mostra algumas características de cada amostra, como: vazão de alimentação do SHV, dia e horário de coleta, número de partículas observado nas amostras e concentração de areia encontrada nas amostras.

Tabela 4.7 - Características das 15 amostras analisadas pela técnica de análise de imagens, como dia e horário de coleta, vazão de trabalho do SHV, número de partículas contadas e concentração de areia encontrada na amostra.

\begin{tabular}{|c|c|c|c|c|}
\hline $\begin{array}{c}\text { Vazão } \\
(\mathbf{l} / \mathbf{s})\end{array}$ & Data & $\begin{array}{l}\text { Horário } \\
\text { (h) }\end{array}$ & $\begin{array}{l}\text { Número de } \\
\text { Partículas }\end{array}$ & $\begin{array}{c}\text { Concentração de } \\
\text { Areia (mg/l) }\end{array}$ \\
\hline \multirow{5}{*}{10,0} & $6 / 9 / 2005$ & $14: 30$ & 773 & 73 \\
\hline & $6 / 10 / 2005$ & $13: 30$ & 745 & 8 \\
\hline & $11 / 10 / 2005$ & $14: 30$ & 1.108 & 55 \\
\hline & $11 / 10 / 2005$ & $15: 30$ & 744 & 10 \\
\hline & $11 / 10 / 2005$ & $16: 30$ & 1.816 & 14 \\
\hline \multirow{5}{*}{15,0} & $25 / 8 / 2005$ & $13: 15$ & $441^{*}$ & 160 \\
\hline & $4 / 11 / 2005$ & $10: 30$ & 1.484 & 45 \\
\hline & $4 / 11 / 2005$ & $13: 30$ & 2.882 & 27 \\
\hline & $17 / 11 / 2005$ & $16: 30$ & 2.582 & 20 \\
\hline & $17 / 11 / 2005$ & $17: 30$ & 2.535 & 14 \\
\hline \multirow{5}{*}{20,0} & $25 / 8 / 2005$ & $13: 35$ & $222^{*}$ & 220 \\
\hline & 9/11/2005 & $11: 30$ & 2.237 & 179 \\
\hline & $9 / 11 / 2005$ & $12: 30$ & 1.293 & 45 \\
\hline & $21 / 11 / 2005$ & $14: 30$ & 1.521 & 112 \\
\hline & $21 / 11 / 2005$ & $17: 30$ & 2.148 & 38 \\
\hline
\end{tabular}

* Amostras com menos de 625 partículas e por isso podem apresentar erros amostrais superiores a $2 \%$ (ALLEN, 1997). 
Os resultados obtidos pela técnica de análise de imagens são distribuições de número de partículas por faixas de tamanho, em outras palavras, são distribuições numéricas de partículas. No entanto, esses dados são difíceis de interpretar e de relacionar com a concentração de areia encontrada nas amostras. Por essa razão, foram obtidas, a partir dos dados das distribuições numéricas, distribuições volumétricas de tamanho de partículas que, em suma, correspondem a distribuições mássicas, quando apresentadas em termos de porcentagem. Vale ressaltar que, apesar das distribuições volumétricas serem aproximações feitas a partir de um conjunto de dados primários, elas constituem excelente ferramenta de análise de eficiência, pois podem ser relacionadas diretamente à massa de areia presente na amostra permitindo, assim, que a eficiência de remoção das unidades de desarenação possam ser analisadas em termos de massa e DTP ao mesmo tempo, pois ambos os parâmetros têm a mesma "unidade".

Na Figura 4.26 é apresentado um gráfico no qual foram plotadas as 15 distribuições numéricas de tamanho de partículas. Tal procedimento permite a visualização da variabilidade da distribuição granulométrica dos grãos de areia encontrados nas amostras de esgoto sanitário afluente da ETE Jardim das Flores. Na Figura 4.27, foram plotadas as 15 distribuições volumétricas de tamanho de partícula obtidas das 15 amostras analisadas. Nesta figura, pode-se observar que no máximo 4,5\% da massa de areia encontrada no esgoto sanitário estudado era composta por partículas menores ou iguais a $100 \mu \mathrm{m}$, e que no mínimo $6,5 \%$ e no máximo $31,5 \%$ da massa de areia era constituída por partículas menores ou iguais a $200 \mu \mathrm{m}$.

Para obter uma curva média de distribuição granulométrica da areia encontrada no esgoto sanitário estudado, as 15 amostras foram agrupadas em uma só, com 22.531 partículas. A Tabela 4.8 mostra as distribuições de freqüências relativas e relativas acumuladas em termos numéricos e volumétricos. A partir delas podem ser estudadas algumas características gerais da DTP da areia presente no esgoto sanitário afluente da ETE Jardim das Flores. 

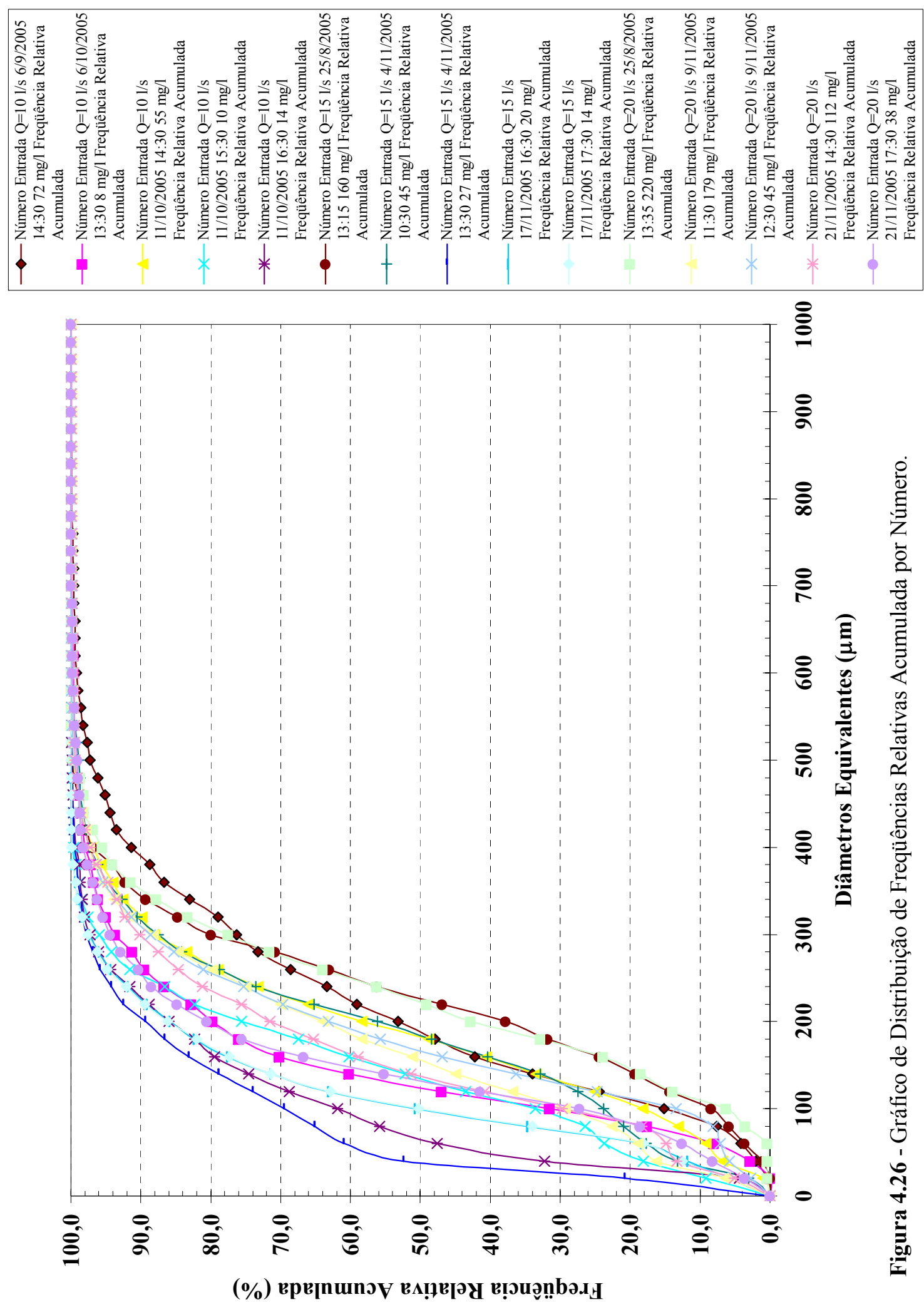

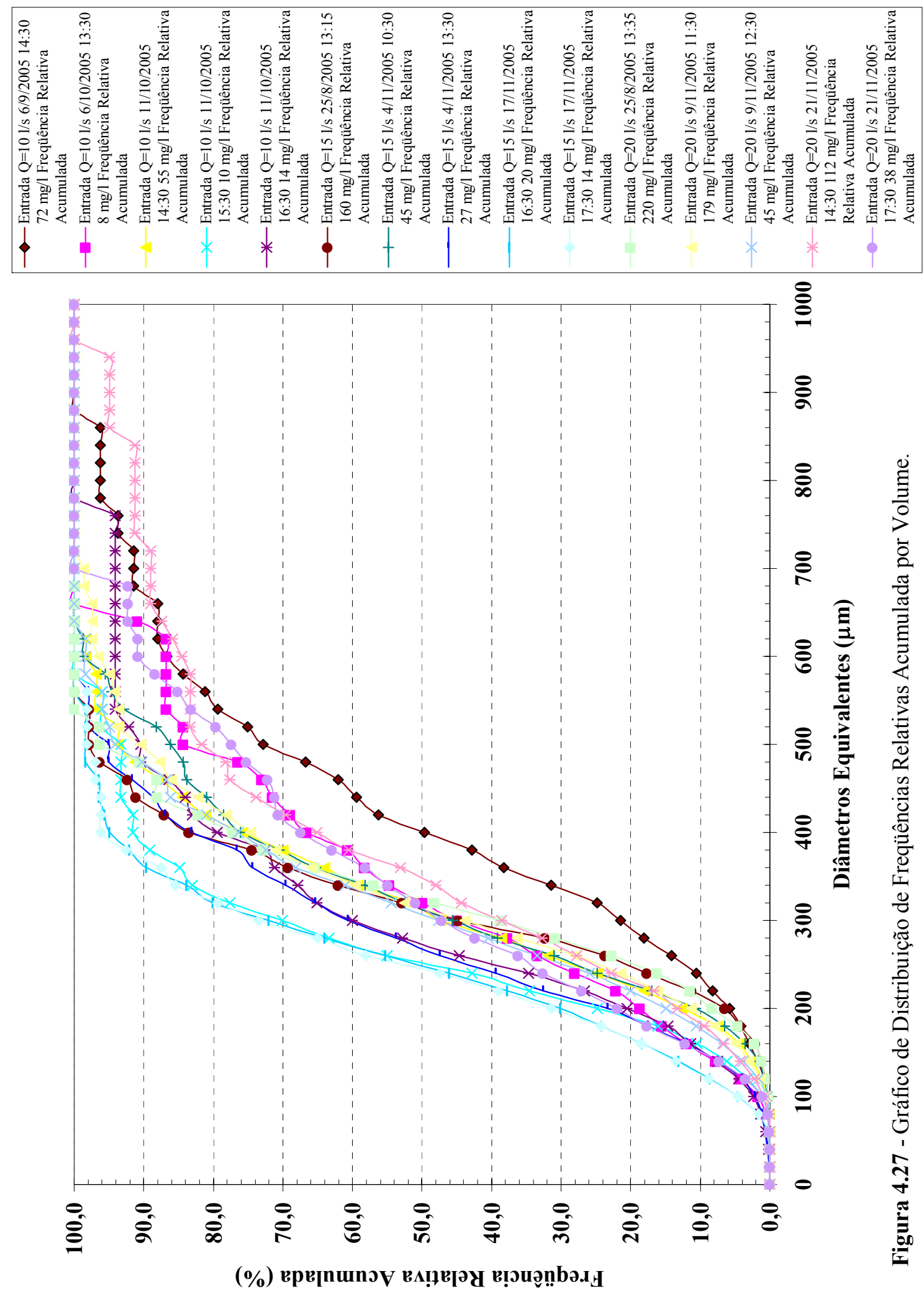
Tabela 4.8 - Distribuições freqüências relativas e relativas acumuladas das distribuições numérica e volumétrica, obtidas a partir da soma das 15 amostras analisadas. O conjunto de dados resultante possui 22.531 partículas.

\begin{tabular}{|c|c|c|c|c|c|}
\hline \multirow{2}{*}{\multicolumn{2}{|c|}{ Intervalos $(\mu \mathrm{m})$}} & \multicolumn{2}{|c|}{ Distribuição Numérica } & \multicolumn{2}{|c|}{ Distribuição Volumétrica } \\
\hline & & \multirow{2}{*}{$\begin{array}{c}\begin{array}{c}\text { Frequiência } \\
\text { Relativa (\%) }\end{array} \\
0,0000\end{array}$} & \multirow{2}{*}{$\begin{array}{c}\begin{array}{c}\text { Freqüência } \\
\text { Relativa } \\
\text { Acumulada (\%) }\end{array} \\
0,00\end{array}$} & \multirow{2}{*}{$\begin{array}{c}\begin{array}{c}\text { Freqüência } \\
\text { Relativa (\%) }\end{array} \\
0,0000\end{array}$} & \multirow{2}{*}{$\begin{array}{c}\begin{array}{c}\text { Freqüência } \\
\text { Relativa } \\
\text { Acumulada (\%) }\end{array} \\
0,0000\end{array}$} \\
\hline 0,00 & 0 & & & & \\
\hline 20,00 & $0-20$ & 6,4184 & 6,42 & 0,0062 & 0,0062 \\
\hline 40,00 & $20-40$ & 11,2655 & 17,68 & 0,0369 & 0,0431 \\
\hline 60,00 & $40-60$ & 5,4774 & 23,16 & 0,0830 & 0,1261 \\
\hline 80,00 & $60-80$ & 7,0664 & 30,23 & 0,2937 & 0,4198 \\
\hline 100,00 & $80-100$ & 8,7754 & 39,00 & 0,7753 & 1,1951 \\
\hline 120,00 & $100-120$ & 9,3835 & 48,39 & 1,5136 & 2,7087 \\
\hline 140,00 & $120-140$ & 8,4735 & 56,86 & 2,2561 & 4,9648 \\
\hline 160,00 & $140-160$ & 6,9999 & 63,86 & 2,8631 & 7,8279 \\
\hline 180,00 & $160-180$ & 6,0544 & 69,91 & 3,6049 & 11,4328 \\
\hline 200,00 & $180-200$ & 5,1445 & 75,06 & 4,2764 & 15,7092 \\
\hline 220,00 & $200-220$ & 4,7628 & 79,82 & 5,3455 & 21,0547 \\
\hline 240,00 & $220-240$ & 4,1946 & 84,02 & 6,1851 & 27,2397 \\
\hline 260,00 & $240-260$ & 3,4888 & 87,50 & 6,6065 & 33,8463 \\
\hline 280,00 & $260-280$ & 2,8807 & 90,39 & 6,8717 & 40,7180 \\
\hline 300,00 & $280-300$ & 2,3348 & 92,72 & 6,9010 & 47,6189 \\
\hline 320,00 & $300-320$ & 1,6823 & 94,40 & 6,0737 & 53,6927 \\
\hline 340,00 & $320-340$ & 1,3272 & 95,73 & 5,7802 & 59,4729 \\
\hline 360,00 & $340-360$ & 1,0387 & 96,77 & 5,3970 & 64,8698 \\
\hline 380,00 & $360-380$ & 0,7768 & 97,55 & 4,7684 & 69,6382 \\
\hline 400,00 & $380-400$ & 0,6969 & 98,24 & 5,0098 & 74,6481 \\
\hline 420,00 & $400-420$ & 0,4261 & 98,67 & 3,5592 & 78,2073 \\
\hline 440,00 & $420-440$ & 0,2930 & 98,96 & 2,8228 & 81,0301 \\
\hline 460,00 & $440-460$ & 0,1997 & 99,16 & 2,2059 & 83,2359 \\
\hline 480,00 & $460-480$ & 0,1909 & 99,35 & 2,4016 & 85,6375 \\
\hline 500,00 & $480-500$ & 0,1864 & 99,54 & 2,6581 & 88,2956 \\
\hline 520,00 & $500-520$ & 0,0977 & 99,64 & 1,5699 & 89,8654 \\
\hline 540,00 & $520-540$ & 0,0977 & 99,73 & 1,7619 & 91,6273 \\
\hline 560,00 & $540-560$ & 0,0399 & 99,77 & 0,8055 & 92,4328 \\
\hline 580,00 & $560-580$ & 0,0577 & 99,83 & 1,2951 & 93,7279 \\
\hline 600,00 & $580-600$ & 0,0488 & 99,88 & 1,2153 & 94,9432 \\
\hline 620,00 & $600-620$ & 0,0133 & 99,89 & 0,3663 & 95,3095 \\
\hline 640,00 & $620-640$ & 0,0266 & 99,92 & 0,8071 & 96,1165 \\
\hline 660,00 & $640-660$ & 0,0133 & 99,93 & 0,4432 & 96,5597 \\
\hline 680,00 & $660-680$ & 0,0133 & 99,95 & 0,4854 & 97,0451 \\
\hline 700,00 & $680-700$ & 0,0178 & 99,96 & 0,7069 & 97,7520 \\
\hline 720,00 & $700-720$ & 0,0044 & 99,97 & 0,1925 & 97,9445 \\
\hline 740,00 & $720-740$ & 0,0089 & 99,98 & 0,4185 & 98,3630 \\
\hline 760,00 & $740-760$ & 0,0000 & 99,98 & 0,0000 & 98,3630 \\
\hline 780,00 & $760-780$ & 0,0089 & 99,99 & 0,4912 & 98,8542 \\
\hline 800,00 & $780-800$ & 0,0000 & 99,99 & 0,0000 & 98,8542 \\
\hline 820,00 & $800-820$ & 0,0000 & 99,99 & 0,0000 & 98,8542 \\
\hline 840,00 & $820-840$ & 0,0000 & 99,99 & 0,0000 & 98,8542 \\
\hline 860,00 & $840-860$ & 0,0044 & 99,99 & 0,3304 & 99,1846 \\
\hline 880,00 & $860-880$ & 0,0044 & 100,00 & 0,3542 & 99,5388 \\
\hline 900,00 & 880 - 900 & 0,0000 & 100,00 & 0,0000 & 99,5388 \\
\hline 920,00 & $900-920$ & 0,0000 & 100,00 & 0,0000 & 99,5388 \\
\hline 940,00 & 920 - 940 & 0,0000 & 100,00 & 0,0000 & 99,5388 \\
\hline 960,00 & 940 - 960 & 0,0044 & 100,00 & 0,4612 & 100,0000 \\
\hline 980,00 & $960-980$ & 0,0000 & 100,00 & 0,0000 & 100,0000 \\
\hline 1000,00 & $980-1000$ & 0,0000 & 100,00 & 0,0000 & 100,0000 \\
\hline
\end{tabular}




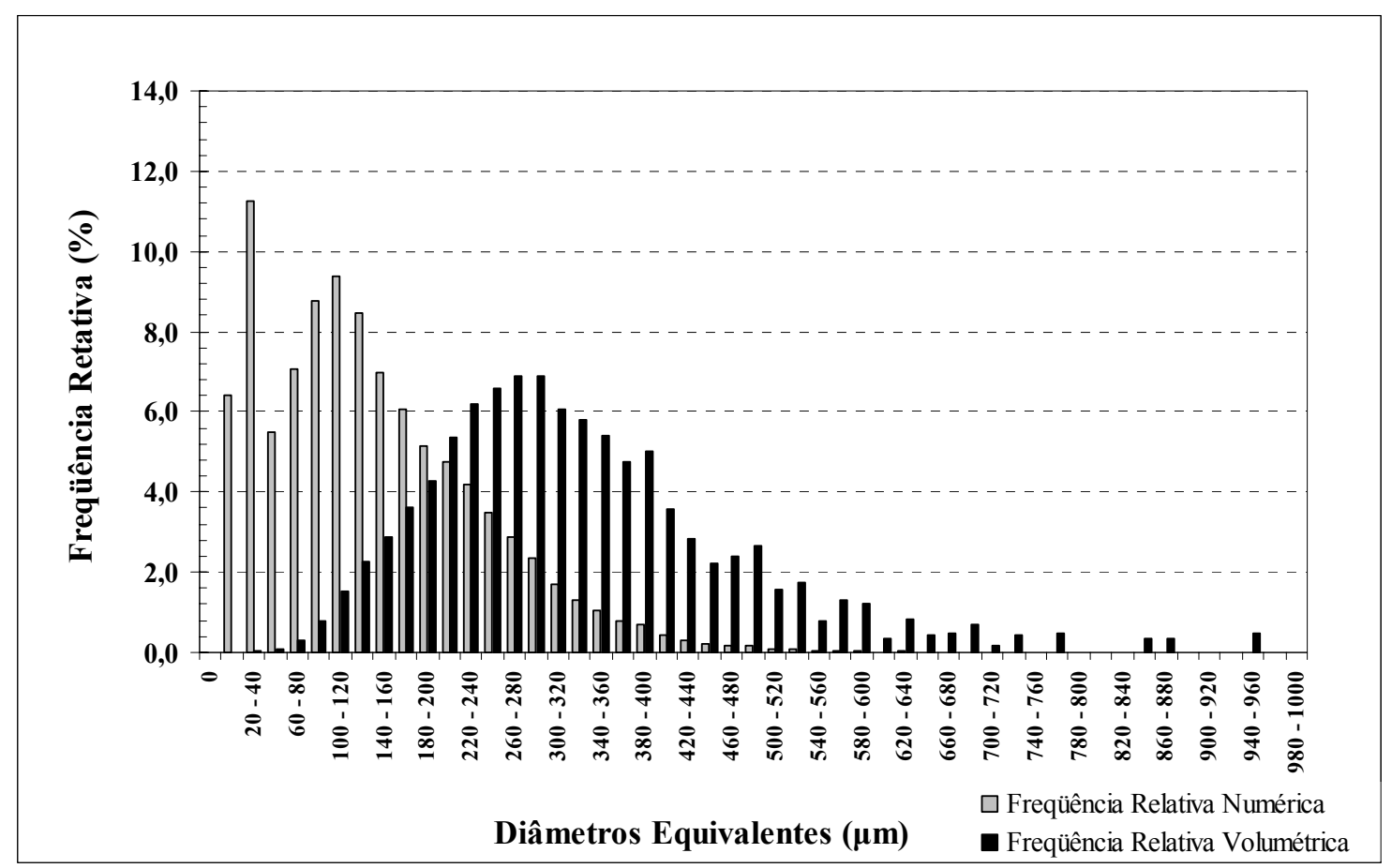

Figura 4.28 - Histograma das distribuições de freqüências relativas numéricas e volumétricas obtidas a partir de 22.531 partículas observadas no conjunto de dados composto pelas 15 amostras estudadas.

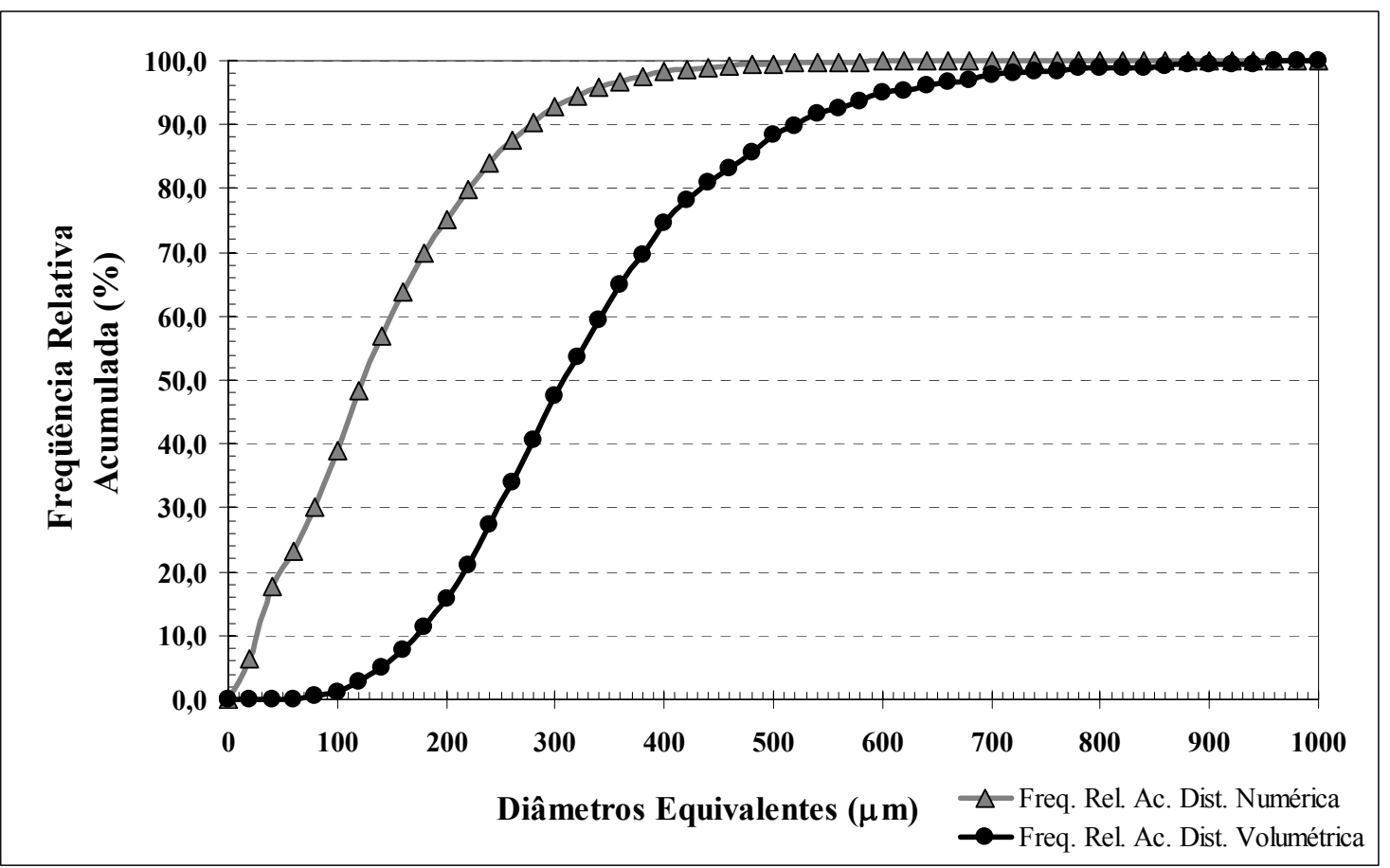

Figura 4.29 - Gráfico das distribuições de freqüências relativas acumuladas numéricas e volumétricas obtidas a partir de 22.531 partículas observadas no conjunto de dados composto pelas 15 amostras estudadas. 
Tabela 4.9 - Diâmetros estatísticos obtidos a partir as 22.531 partículas observadas no conjunto composto pelas 15 amostras estudadas.

\begin{tabular}{lr}
\hline \multicolumn{2}{c}{ Diâmetros Estatísticos } \\
\hline \multicolumn{2}{c}{ Diâmetro $(\boldsymbol{\mu m})$} \\
\hline Saulter [3,2] & 273,03 \\
Aritmético [1,N] & 141,71 \\
Mínimo & 4,5 \\
Máximo & 941,8 \\
\hline No de Partículas Contadas $^{\circ}$ & 22531 \\
\hline
\end{tabular}

$$
\begin{aligned}
& \text { Saulter }[3,2]=\frac{\sum \mathrm{d}_{\mathrm{Ap}}^{3}}{\sum \mathrm{d}_{\mathrm{Ap}}^{2}} \\
& \text { Aritmético }[1, \mathrm{~N}]=\frac{\sum \mathrm{d}_{\mathrm{Ap}}}{\mathrm{N}}
\end{aligned}
$$

Onde:

$\mathrm{d}_{\mathrm{Ap}}$ : diâmetro da esfera equivalente de mesma área projetada obtido da análise de imagens (L);

$\mathrm{N}$ : número de partículas contadas;

Saulter [3,2]: diâmetro estatístico que relaciona volume e área, indicado para estudos em que as partículas interagem com meios fluídos (L);

Aritmético $[1 ; \mathrm{N}]$ : média aritmética dos diâmetros obtidos pela análise de imagem (L).

O gráfico mostrado na Figura 4.28 apresenta dois histogramas, um das freqüências relativas numéricas e outro das freqüências relativas volumétricas. Pode-se observar que as duas curvas apresentam formatos diferentes, pois o histograma de freqüências relativas numéricas evidencia a região de maior concentração numérica de partículas, enquanto o histograma de freqüências relativas volumétricas evidencia a região com maior massa (ou volume) de partículas. Ambas as curvas são representações médias de todo o universo amostral (15 amostras, com um total de 22.531 partículas), e 
serão usadas para análise geral da presença de areia no esgoto sanitário utilizado para alimentar o SHV estudado nessa pesquisa.

Na Figura 4.28 os intervalos que apresentam maior quantidade de partículas são: de $20 \mu \mathrm{m}$ a $40 \mu \mathrm{m}$, com aproximadamente $11 \%$ do número total de partículas; e de 100 $\mu \mathrm{m}$ a $120 \mu \mathrm{m}$, com aproximadamente $9 \%$ do número total de partículas. Observa-se que o valor da média aritmética dos 22.531 diâmetros $\left(\mathrm{d}_{\mathrm{Ap}}\right)$ obtidos pela análise de imagens (Aritmético $[1, \mathrm{~N}]$, Tabela 4.8) está próximo ao valor do limite superior do segundo intervalo com maior freqüência de partículas; isso demonstra que a média aritmética é um bom indicador da faixa de tamanho em que existe maior concentração numérica de partículas.

Porém, ser a região de maior concentração numérica de partículas não significa, necessariamente, ser região em que se encontra a maior quantidade de massa de partículas. Isso pode ser comprovado ao observar-se o histograma de freqüências relativas volumétricas da Figura 4.28. Segundo este gráfico, a faixa de tamanho que mais contribui para massa total de grãos de areia está entre $260 \mu \mathrm{m}$ e $300 \mu \mathrm{m}$, com aproximadamente $14 \%$ da massa total de areia. Quando esta faixa de tamanho é confrontada com os valores de diâmetros estatísticos da Tabela 4.9, observa-se que o valor do diâmetro estatístico de Saulter pertence a essa faixa; com isso conclui-se ser ele um bom indicador da faixa de tamanho em que está presente a maior massa de partículas.

Na Figura 4.29, pode-se observar grande distanciamento entre a curva de distribuição de freqüências relativas acumuladas em termos numéricos e a curva de distribuição de freqüências relativas acumuladas em termos volumétricos. Observa-se também que, em média, menos de $2 \%$ da massa total de areia presente no esgoto sanitário é composta por partículas menores ou iguais a $100 \mu \mathrm{m}$; todavia, em termos numéricos estas partículas correspondem a 39\% do total. Já as partículas menores ou iguais a $200 \mu \mathrm{m}$, em média, respondem por $16 \%$ da massa de areia presente no esgoto sanitário; consequentemente, eficiências de remoção de areia superiores a $84 \%$ não devem ser esperadas se o esgoto afluente de uma unidade de desarenação possuir grãos de areia com distribuição granulométrica semelhante à apresentada na Figura 4.29. Em termos numéricos as partículas menores ou iguais a $200 \mu \mathrm{m}$ correspondem a $75 \%$ do total. 
Além de fornecer medidas de tamanho, a análise de imagens também pode ser utilizada para se determinar fatores de forma de um conjunto de partículas. Nessa pesquisa, a circularidade (cir) dos grãos de areia foi o fator de forma escolhido para análise. A circularidade é a relação entre o perímetro da área projetada de uma partícula, elevado ao quadrado, e a área projetada dessa partícula, multiplicada por $4 \pi$ (Equação 4.2). Um círculo possui circularidade igual a um; assim, quanto menor o valor da circularidade de uma partícula, menos a área projetada dessa partícula aproximar-se-á de um círculo.

Foram analisados estatisticamente os 22.531 valores de circularidade obtidos pela análise de imagens e os resultados de tal análise são apresentados na Tabela 4.10. Pelos dados da Tabela 4.10 pode-se concluir, em nível populacional, que a circularidade média dos grãos de areia é de aproximadamente 0,80 . Os dados analisados permitem uma conclusão bastante precisa a respeito da circularidade das partículas, pois o desvio padrão de apenas 0,0849 , somado ao fato de a amplitude do intervalo de confiança (IC) ser de apenas 0,002, demonstram que a variabilidade desse fator de forma é muito pequena para os grãos de areia presentes no esgoto afluente da ETE Jardim das Flores.

Tabela 4.10 - Resultados da análise estatística dos 22.531 valores de circularidade obtidos pela análise imagens. Intervalo de confiança com $98 \%$ de significância para a média populacional calculado assumindo amostras aleatórias distribuídas normalmente ao redor da média.

\begin{tabular}{lr}
\hline \multicolumn{2}{c}{ Circularidade } \\
\hline Média Aritmética & 0,795 \\
Erro padrão & 0,0006 \\
Mediana & 0,80 \\
Moda & 0,79 \\
Desvio padrão & 0,0849 \\
Variância da amostra & 0,0072 \\
Mínimo & 0,13 \\
Máximo & 1,00 \\
\hline \multicolumn{2}{c}{$\mathrm{N}^{\mathbf{o}}$ de partículas contadas } \\
\hline \multicolumn{2}{c}{ Intervalo de Confiança } \\
\multicolumn{2}{c}{ IC $\left(\boldsymbol{\mu}_{\mathbf{a}} ; \mathbf{9 8 \%}\right)=[\mathbf{0 , 7 9 4 ; ~ 0 , 7 9 6 ]}$} \\
\hline \multicolumn{2}{c}{}
\end{tabular}

Os resultados de duas outras amostras, as quais estão marcadas em negrito no Tabela 4.7, foram selecionados para serem apresentados nessa seção: a amostra coletada 
aos 06/10/2005, às 13h30min, por ser a que apresentou menor concentração de areia; e amostra coletada dia 09/11/2005, às $11 \mathrm{~h} 30 \mathrm{~min}$, por ser aquela que apresentou a maior concentração de areia, desconsiderando as duas amostras, cujos números de partículas contadas foram inferiores a 625 .

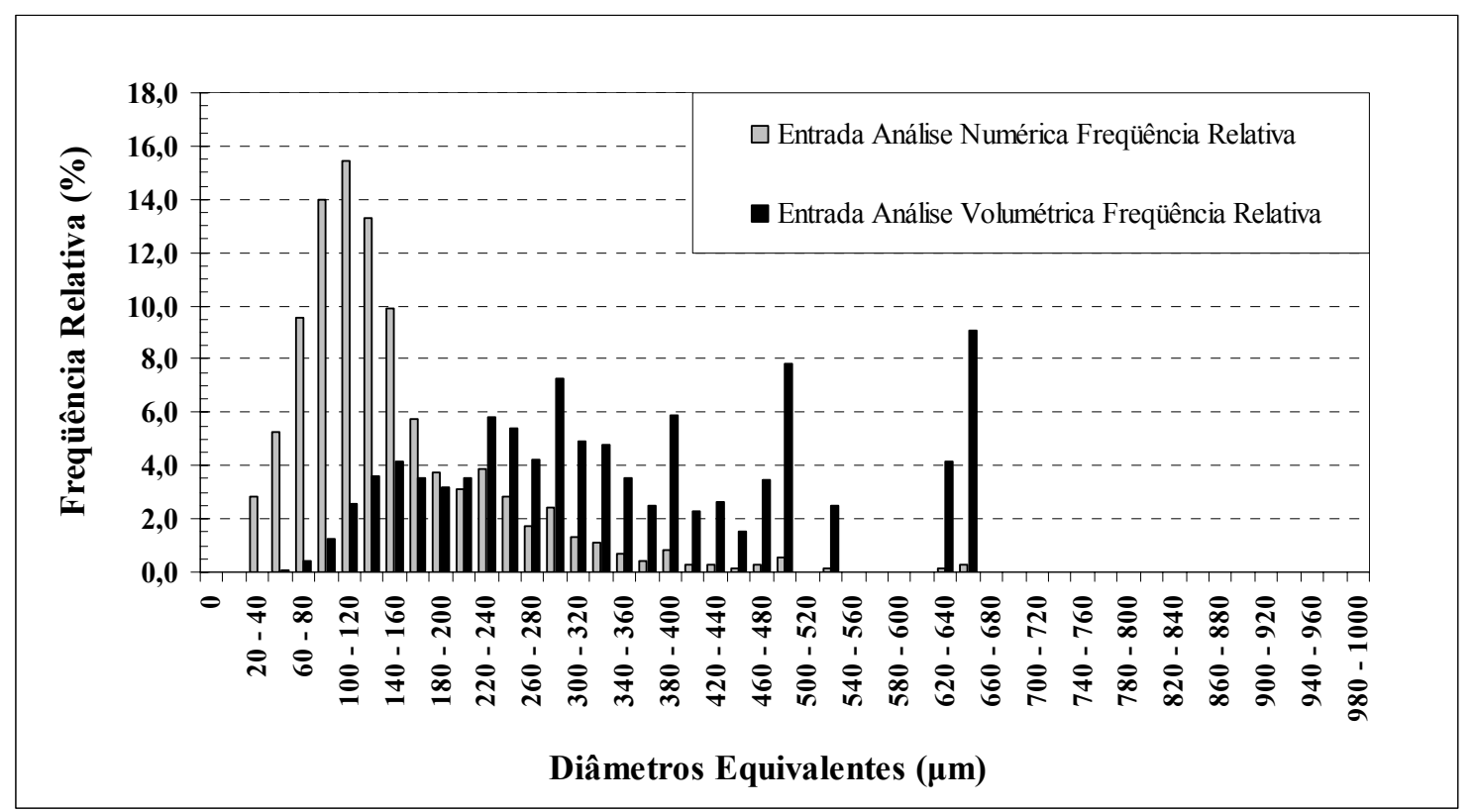

Figura 4.30 - Histograma das distribuições de freqüências relativas numéricas e volumétricas obtidas a partir das 745 partículas observadas na amostra coletada aos 06/11/2005, às $13 \mathrm{~h} 30 \mathrm{~min}$. Concentração de areia na amostra de $8,5 \mathrm{mg} / \mathrm{l}$.

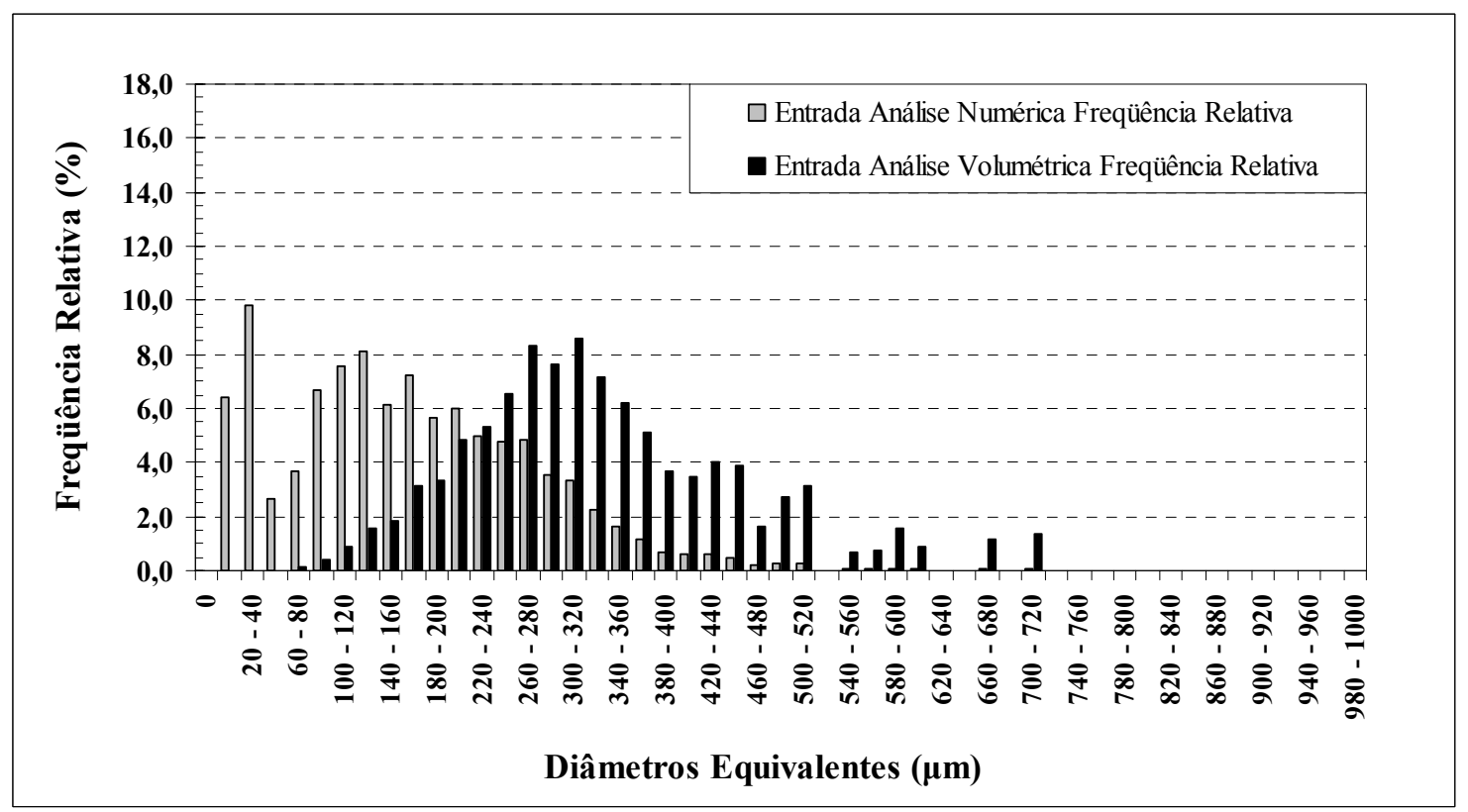

Figura 4.31 - Histograma das distribuições de freqüências relativas numéricas e volumétricas obtidas a partir das 2.237 partículas observadas na amostra coletada aos 09/11/2005, às 11h30min. Concentração de areia na amostra de 178,7 mg/l. 


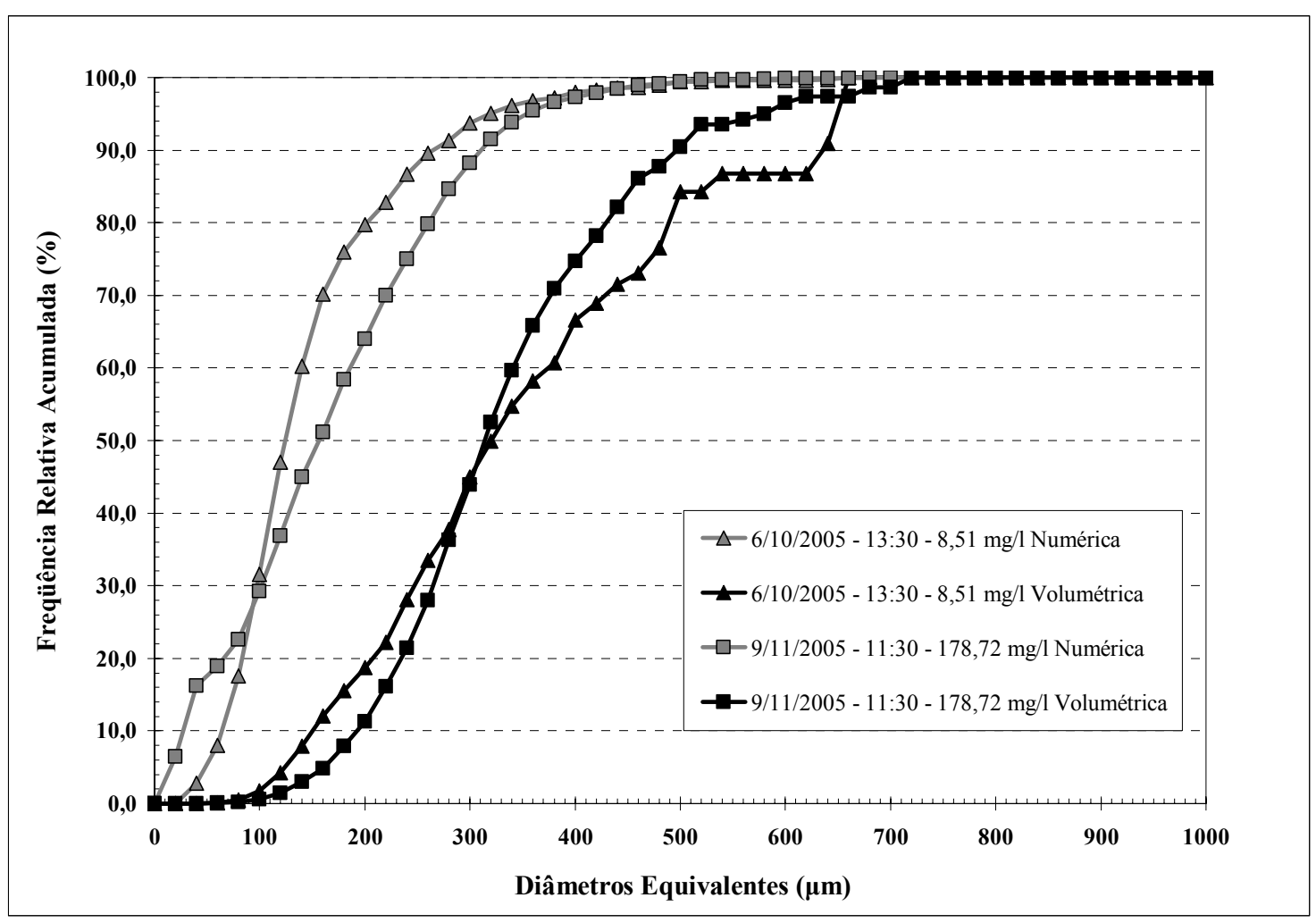

Figura 4.32 - Gráfico das distribuições de freqüências relativas acumuladas numéricas e volumétricas de duas amostras. Amostra coletada aos 06/10/2005, às $13 \mathrm{~h} 30 \mathrm{~min}$, com 745 partículas e concentração de areia de $8,51 \mathrm{mg} / \mathrm{l}$; e amostra coletada aos 09/11/2005, às $11 \mathrm{~h} 30 \mathrm{~min}$, com 2.237 partículas e concentração de areia de $178,7 \mathrm{mg} / 1$.

Tabela 4.11 - Diâmetros estatísticos obtidos a partir das 745 partículas observadas na amostra coletada aos 06/10/2005, às 13h30min. Concentração de areia de 8,5 mg/l.

\begin{tabular}{lr}
\hline \multicolumn{2}{c}{ Diâmetros Estatísticos } \\
\hline \multicolumn{2}{c}{ Diâmetro $(\boldsymbol{\mu m})$} \\
\hline Saulter $[3,2]$ & 271,97 \\
Aritmético $[1, \mathrm{~N}]$ & 147,67 \\
Mínimo & 20,4 \\
Máximo & 658,1 \\
\hline $\mathrm{N}^{\circ}$ de Partículas Contadas & 745 \\
\hline
\end{tabular}

Tabela 4.12 - Diâmetros estatísticos obtidos a partir das 2.237 partículas observadas na amostra coletada aos 09/11/2005, às 11h30min. Concentração de Areia de 178,7 mg/l.

\begin{tabular}{lr}
\hline \multicolumn{2}{c}{ Diâmetros Estatísticos } \\
\hline \multicolumn{2}{c}{ Diâmetro $(\boldsymbol{\mu m})$} \\
\hline Saulter [3,2] & 287,48 \\
Aritmético $[1, \mathrm{~N}]$ & 167,46 \\
Mínimo & 5,1 \\
Máximo & 702,6 \\
\hline $\mathrm{N}^{\circ}$ de Partículas Contadas & 2.237 \\
\hline
\end{tabular}


Nos histogramas da Figura 4.30, pode-se observar que a distribuição numérica de freqüências relativas é mais "regular" que a distribuição volumétrica. A "irregularidade" do histograma de freqüências relativas da distribuição volumétrica de tamanho de partículas pode ser explicada pelo "pequeno" número de partículas contadas na amostra coletada aos 06/10/2005, 745. Segundo Allen (1997) os resultados de determinação de tamanho de partículas que se baseiam em medidas como massa ou volume das partículas são mais suscetíveis a problemas amostrais pois, em termos volumétricos, ao se desconsiderar a presença de uma única partícula de $500 \mu \mathrm{m}$, comete-se o mesmo erro que deixar de contar 1000 partículas de $50 \mu \mathrm{m}$. Por isso, para que resultados apresentados em termos de massa ou volume apresentem o mesmo nível de erro dos resultados apresentados em termos numéricos é necessária a contagem de um número maior de partículas do limite superior de tamanhos. Nos histogramas da Figura 4.30 pode-se notar a ocorrência deste problema; as faixas de tamanho que vão de $620 \mu \mathrm{m}$ a $640 \mu \mathrm{m}$ e de $640 \mu \mathrm{m}$ a $660 \mu \mathrm{m}$ reúnem apenas $0,40 \%$ do número total de partículas, todavia, respondem por quase $15 \%$ do volume de partículas presentes na amostra. Os histogramas da Figura 4.31 corroboram toda essa argumentação, pois não são percebidas "anomalias" ou "irregularidades" em ambas as distribuições de freqüências, as quais foram construídas a partir de um número de partículas 3 vezes maior (2.237) que aquele utilizado na construção dos histogramas da Figura 4.30.

Nos gráficos da Figura 4.32 constata-se que a distribuição granulométrica da amostra coletada aos 09/11/2005 é mais uniforme que a da amostra coletada aos 06/10/2005. Tal fato pode ser comprovado ao se comparar o coeficiente de desuniformidade $(\mathrm{CD})$ das duas curvas. $\mathrm{O}$ coeficiente de desuniformidade é a relação entre $\mathrm{d}_{60}$ (tamanho do grão referente passagem de $60 \%$ do material em volume ou peso) e o tamanho efetivo $d_{10}$ da distribuição granulométrica (tamanho do grão referente passagem de $10 \%$ do material em volume ou peso). Para a amostra de 06/10/2005, $\mathrm{d}_{60}$ é $380 \mu \mathrm{m}, \mathrm{d}_{10}$ é $150 \mu \mathrm{m}$, resultando em CD de 2,53; para a amostra de 09/11/2005, $\mathrm{d}_{60}$ é $340 \mu \mathrm{m}, \mathrm{d}_{10}$ é $195 \mu \mathrm{m}$, resultando em um CD de 1,74.

Além de mais uniformemente distribuídos, de acordo com os valores dos diâmetros estatísticos mostrados nas Tabelas 4.11 e 4.12, os grão de areia encontrados na amostra de 09/11/2005 são mais "grossos" (de maior tamanho, em média) que aqueles encontrados na amostra de 06/11/2005. Em relação à forma dos grãos 
encontrados nas duas amostras, pode-se notar pelas Tabelas 4.13 e 4.14, que para ambas as amostras a circularidade média dos grãos é de aproximadamente 0,79 .

Tabela 4.13 - Resultados da análise estatística dos 745 valores de circularidade obtidos pela análise imagens para a amostra de esgoto de 06/10/2005, coletada às $13 \mathrm{~h} 30 \mathrm{~min}$. Intervalo de confiança com $98 \%$ de significância para a média populacional calculado assumindo amostras aleatórias distribuídas normalmente ao redor da média.

\begin{tabular}{lr}
\hline \multicolumn{2}{c}{ Circularidade } \\
\hline Média Aritmética & 0,786 \\
Erro padrão & 0,0031 \\
Mediana & 0,80 \\
Moda & 0,85 \\
Desvio padrão & 0,0851 \\
Variância da amostra & 0,0072 \\
Mínimo & 0,35 \\
Máximo & 1,00 \\
\hline $\mathrm{N}^{\circ}$ de partículas contadas & 745 \\
\hline \multicolumn{2}{c}{ Intervalo de Confiança } \\
\multicolumn{2}{c}{$\mathbf{I C}\left(\boldsymbol{\mu}_{\mathbf{a}} ; \mathbf{9 8 \%}\right)=[\mathbf{0 , 7 7 9 ;} \mathbf{0 , 7 9 3 ]}$} \\
\hline
\end{tabular}

Tabela 4.14 - Resultados da análise estatística dos 2.237 valores de circularidade obtidos pela análise imagens para a amostra de esgoto de 09/11/2005, coletada às $11 \mathrm{~h} 30 \mathrm{~min}$. Intervalo de confiança com $98 \%$ de significância para a média populacional calculado assumindo amostras aleatórias distribuídas normalmente ao redor da média.

\begin{tabular}{lr}
\hline \multicolumn{2}{c}{ Circularidade } \\
\hline Média Aritmética & 0,790 \\
Erro padrão & 0,0017 \\
Mediana & 0,79 \\
Moda & 0,786 \\
Desvio padrão & 0,0807 \\
Variância da amostra & 0,0065 \\
Mínimo & 0,39 \\
Máximo & 1,00 \\
\hline$N^{o}$ de partículas contadas & 2.237 \\
\hline \multicolumn{2}{c}{ Intervalo de Confiança } \\
\multicolumn{2}{c}{$\mathbf{I C}\left(\boldsymbol{\mu}_{\mathbf{a}} ; \mathbf{9 8 \%}\right)=[\mathbf{0 , 7 9 4 ; ~ 0 , 7 8 6 ]}$} \\
\hline \multicolumn{2}{c}{}
\end{tabular}




\subsection{Conclusões}

Os resultados apresentados nesse capítulo permitiram concluir que:

- $\quad$ O método desenvolvido para determinar concentração de areia no esgoto sanitário mostrou-se viável, pois além de fornecer resultados satisfatórios, o método é acessível à boa parte dos laboratórios de análise;

- A concentração média de areia no esgoto sanitário afluente da ETE Jardim das Flores, que foi utilizado para alimentar o separador hidrodinâmico por vórtice, tema dessa pesquisa, está entre $20 \mathrm{mg} / \mathrm{L}$ e $73 \mathrm{mg} / \mathrm{L}$, com $95 \%$ de confiança;

- A ocorrência de valores de concentração de areia de até $265 \mathrm{mg} / \mathrm{L}$, somada ao fato de que o intervalo de confiança obtido a partir da média aritmética de todos os valores amostrais de concentração de areia ter ficado, aproximadamente, entre $50 \mathrm{mg} / 1$ e $100 \mathrm{mg} / \mathrm{l} \mathrm{com}$ 95\% de confiança demonstra a necessidade de um olhar mais crítico por parte de projetistas de ETE, para as unidades de desarenação, pois o custo agregado à remoção, deságüe e disposição final desse material pode ser significativo no cálculo do custo operacional de uma ETE, e por outro lado, se esse material não for removido em desarenadores, os problemas nas unidades subseqüentes poderão ter conseqüências danosas à operação e à vida útil de equipamentos;

- A concentração de areia no esgoto afluente da ETE Jardim das Flores apresentou grande variabilidade, tanto horária quanto diária. Esta variabilidade não apresentou qualquer padrão significativo de ocorrência;

- A concentração média de areia no esgoto afluente da ETE Jardim das Flores, entre $09 \mathrm{~h} 30 \mathrm{~min}$ e $13 \mathrm{~h} 30 \mathrm{~min}$, não apresentou diferença significativa da concentração média de areia encontrada para o mesmo esgoto, entre $13 \mathrm{~h} 30 \mathrm{~min}$ e $17 \mathrm{~h} 30 \mathrm{~min}$; 
- $\quad$ As vazões de alimentação do SHV (10 1/s; 15 1/s e 20 1/s), empregadas durante as amostragens, não interferiram na determinação dos valores de concentração de areia no esgoto afluente da unidade;

- A utilização da análise de imagens como técnica de determinação de tamanho de partículas demonstrou-se uma ferramenta poderosa para o estudo da distribuição granulométrica da areia presente no esgoto, embora bastante laboriosa e demorada;

- A distribuição granulométrica dos grãos de areia presentes nas amostras de esgoto sanitário afluente da ETE Jardim das Flores apresentou grande variabilidade, tanto horária, quanto diária;

- Menos de $2 \%$ da massa total de areia encontrada no esgoto sanitário afluente da ETE Jardim das Flores é composta por grãos menores ou iguais a $100 \mu \mathrm{m}$, em termos numéricos esse porcentual é bem maior, cerca de 39\% do número total de grãos de areia tem diâmetro equivalente menor ou igual a $100 \mu \mathrm{m}$;

- Aproximadamente $16 \%$ da massa total de areia encontrada no esgoto sanitário afluente da ETE Jardim das Flores é constituída de grãos de areia menores ou iguais a $200 \mu \mathrm{m}$, em termos numéricos essas partículas respondem por $75 \%$ do número total de grãos de areia;

- A circularidade dos grãos de areia encontrados no esgoto afluente da ETE Jardim das Flores apresenta pouca variabilidade, pois com 98\% de confiança, ela está entre 0,794 e 0,796, aproximadamente 0,80 ; 


\section{Capítulo 5 - Análise do Desempenho do Separador Hidrodinâmico por Vórtice e da Grade Fina de Fluxo Tangencial}

Este capítulo apresenta a análise de desempenho da unidade de tratamento preliminar de esgoto sanitário desenvolvida na presente tese, a qual é constituída de separador hidrodinâmico por vórtice e de grade fina de fluxo tangencial. A grade fina de fluxo tangencial foi avaliada por meio da observação de seu funcionamento, durante o período em que a unidade de tratamento preliminar foi operada, recebendo esgoto sanitário bombeado do poço de sucção da estação elevatória da estação de tratamento de esgoto Jardim das Flores no município de Rio Claro, SP. Constatou-se não ter sido confirmada a hipótese de o escoamento circulatório ao redor de uma grade cilíndrica e que o padrão de escoamento nas adjacências da grade assemelha-se ao vórtice de ralo (vórtice livre). Tal padrão de escoamento fez com que os sólidos grosseiros fossem "lançados" de encontro à face externa da grade obstruindo-a em poucos minutos. O separador hidrodinâmico por vórtice foi avaliado por meio de análises estatísticas de valores de eficiência de remoção de sólidos suspensos voláteis, eficiência de remoção de areia e eficiência de remoção parcial de areia. Durante a avaliação de desempenho da unidade, verificou-se que o separador hidrodinâmico por vórtice, além de não remover matéria orgânica particulada (medida em termos de sólidos suspensos voláteis), apresentou elevadas eficiências de remoção de areia e produziu efluentes com baixíssima quantidade de grãos de areia de tamanho maior ou igual a $200 \mu \mathrm{m}$. 


\subsection{Introdução}

Os sistemas de gradeamento e peneiramento são empregados como unidades de tratamento preliminar em estações de tratamento de esgoto (ETE) há mais de um século, porém a literatura que reporta este assunto resume-se a alguns poucos livros, os quais fornecem, apenas, alguns parâmetros de projeto dessas unidades (WATER ENVIRONMENT FEDERATION, 1994, 1998; METCALF \& EDDY, 2003). Publicações especializadas que abordem a operação e o desempenho de sistemas de peneiramento e gradeamento, praticamente, inexistem.

No caso dos separadores hidrodinâmicos por vórtice (SHV), o cenário é menos crítico, graças a trabalhos pontuais de alguns grupos de pesquisa dos Estados Unidos, Inglaterra e Alemanha. Todavia, tais grupos estudam os SHVs no âmbito do tratamento de águas residuárias provenientes de sistemas de drenagem urbana ou de sistemas do tipo coletor unitário (esgoto sanitário mais água de drenagem urbana); conseqüentemente, são escassos trabalhos científicos referentes ao desempenho dos SHVs como unidades de desarenação de ETEs.

Sullivan et al. (1974) apresentaram um dos primeiros trabalhos científicos acerca do emprego de SHVs como unidades de desarenação de ETEs. Segundo estes investigadores, no início da década de 1970, um programa de pesquisa americano, fomentado pela Environmental Protection Agency (EPA) e pela Americam Public Works Association (APWA), resultou no desenvolvimento de um SHV, designado por seus inventores Swirl Concentrator. Esta unidade atingia eficiências de remoção de areia similares àquelas observadas nos desarenadores convencionais, se operada com taxas de aplicação superficial (TAS) de até $1.927 \mathrm{~m}^{3} / \mathrm{m}^{2} \mathrm{~d}$.

Consoante Sullivan et al. (1982) ${ }^{1}$ apud Field e O'Connor (1996), em testes realizados durante o desenvolvimento do Swirl Concentrator, nos quais foram utilizados sólidos sintéticos (velocidade de sedimentação maior ou igual a 2,6 cm/s) para simular

${ }^{1}$ SULliVAN, R. H.; URE, J. E.; PARKINSON, F.; ZIELINSKI, P. (1982). Design manual - Swirl and helical bend pollution control devices. Edison, N.J., USA, American Public Woks Association/ National Environmental Research Center, Office of Research and Development, Environmental Protection Agency. Report n. EPA 600/8-82/013.

PRADO, G. S. (2006) 
grãos de areia e sólidos orgânicos densos, a unidade atingiu eficiência de remoção de areia que variou entre $70 \%$ e $100 \%$.

Le Cornu et al. (2000) também estudaram o emprego do SHV como unidade de desarenação. Para tanto, os pesquisadores operaram um SHV de 1,2 m de diâmetro com TAS de $535 \mathrm{~m}^{3} / \mathrm{m}^{2} \mathrm{~d}$ a $1.920 \mathrm{~m}^{3} / \mathrm{m}^{2} \mathrm{~d}$, usando como afluente uma suspensão bastante diluída de água e areia - 91\% da massa total de areia era composta por grãos com tamanhos compreendidos entre $75 \mu \mathrm{m}$ e $425 \mu \mathrm{m}$. As eficiências de remoção de areia obtidas variaram de $73 \%$, para TAS de $1.920 \mathrm{~m}^{3} / \mathrm{m}^{2} \mathrm{~d}$, a aproximadamente $100 \%$, para a TAS de $535 \mathrm{~m}^{3} / \mathrm{m}^{2} \mathrm{~d}$.

De forma geral, os SHVs são unidades que apresentam variável eficiência de remoção de sólidos, contudo, isso não significa que o desempenho desse tipo de unidade seja variável também. Consoante Andoh e Saul (2003), para uma mesma TAS a eficiência de remoção de sólidos de um SHV varia de acordo com a concentração de sólidos sedimentáveis presentes em seu afluente. Os mesmos autores asseveram que os SHVs produzem efluentes com concentrações de sólidos relativamente constantes, apesar de apresentarem variáveis eficiências de remoção de sólidos. Faram et al. (2004) atestaram esta afirmação e acrescentaram que os SHVs são unidades de desempenho bastante estável, extremamente tolerantes a cargas de choque e variações de vazão. A razão disso é que a concentração de sólidos no efluente de uma unidade de sedimentação eficaz - como um SHV propriamente projetado - reflete o limiar de sólidos não sedimentáveis presentes em seu afluente (ANDOH e SAUL, 2003; FARAM et al., 2004).

Um raciocínio análogo ao que foi exposto no parágrafo anterior pode ser aplicado para avaliar o desempenho dos SHVs como unidades de desarenação, porquanto a eficiência de remoção de areia de um SHV, para uma mesma taxa de aplicação superficial (TAS), variará de acordo com a concentração e a distribuição granulométrica dos grãos de areia presentes no esgoto sanitário afluente da unidade; enquanto seu efluente, possivelmente, apresentará concentrações de areia relativamente constantes. Como as unidades de desarenação são projetadas para remover grãos de areia de tamanho superior ou igual a $150 \mu \mathrm{m}$ ou $200 \mu \mathrm{m}$ (tamanhos comumente adotados no Brasil), quanto maior a quantidade de grãos com essas dimensões no afluente de um SHV, maior a eficiência de remoção de areia atingida pela unidade. 


\subsection{Materiais e Métodos}

\subsubsection{Considerações iniciais}

Ao se estudar o desempenho de unidades de processo ou operação unitária de estações de tratamento de esgoto (ETEs) ou de estações de tratamento de água (ETAs), geralmente, o que se pretende determinar é a eficiência dessas unidade na remoção de um determinado contaminante. No caso dos desarenadores, o "contaminante" em questão é a areia; por conseguinte, uma forma de avaliar o desempenho do separador hidrodinâmico por vórtice (SHV), desenvolvido na presente pesquisa, é averiguar quais sãos as eficiências de remoção de areia que a unidade pode atingir, quando operada com vazões de 10 1/s, 15 1/s e 20 1/s, as quais correspondem às taxas de aplicação superficial (TAS) de $764 \mathrm{~m}^{3} / \mathrm{m}^{2} \mathrm{~d} ; 1.146 \mathrm{~m}^{3} / \mathrm{m}^{2} \mathrm{~d}$ e $1.528 \mathrm{~m}^{3} / \mathrm{m}^{2} \mathrm{~d}$.

Há três tipos diferentes de apresentação de eficiência de remoção de areia que podem ser utilizadas para avaliar o desempenho de um SHV como unidade de desarenação: a eficiência de remoção total ${ }^{1}$, a eficiência de remoção parcial e a eficiência de remoção granulométrica. A eficiência de remoção total pode ser definida como a fração da massa de areia presente no esgoto sanitário que foi removida pelo SHV; a eficiência de remoção parcial expressa a fração dos grãos de areia pertencentes a determinada faixa de tamanho (grãos de areia maiores ou iguais a $200 \mu \mathrm{m}$ ), que se encontrava no esgoto sanitário e foi removida pelo SHV; e a eficiência de remoção granulométrica representa a fração dos grãos de areia de determinado tamanho (e.g. 200 $\mu \mathrm{m}$ ), que estava presente no esgoto sanitário e foi removida pelo SHV (GARDNER e DEAMER, 1996).

Como para estimar qualquer um dos três tipos de eficiência de remoção apresentados no parágrafo anterior é imprescindível conhecer a concentração e a distribuição granulométrica da areia presente no afluente e no efluente dos SHVs, os poucos trabalhos de pesquisa que tratam do desempenho dessas unidades como desarenadores baseiam-se em resultados obtidos de experimentos controlados, nos quais os afluentes empregados para alimentar os SHVs eram previamente preparados, isto é, a

\footnotetext{
${ }^{1}$ O termo eficiência de remoção total de areia será substituído por apenas eficiência de remoção de areia no restante deste capítulo.
} 
concentração e a distribuição granulometria da areia presente nesses afluentes foram estipuladas pelos pesquisadores e mantidas constantes durante a execução dos ensaios.

Porém, na presente pesquisa, a utilização de afluentes "sintéticos" não era recomendada devido à impossibilidade de simular, de forma relativamente fiel, os sólidos grosseiros presentes no esgoto sanitário bruto, uma vez que o $\mathrm{SHV}$, tema central desta tese, acumulava as funções de desarenador e de sistema de gradeamento fino, as quais deveriam ser avaliadas concomitantemente.

A alternativa encontrada foi avaliar o desempenho do SHV usando esgoto sanitário bruto (após gradeamento grosseiro) para alimentá-lo, pois este afluente - por carrear certa quantidade de areia em suspensão e transportar materiais sólidos flutuantes, como: restos de comida, pontas de cigarro, preservativo masculino, materiais fibrosos, entre outros - permitiria, simultaneamente, verificar a efetividade do SHV como desarenador e avaliar o desempenho da grade fina de fluxo tangencial da unidade.

Decidiu-se, então, transportar o protótipo do SHV para o município de Rio Claro SP, e instalar a unidade junto ao poço de sucção da estação elevatória da ETE Jardim das Flores, onde o SHV permaneceu por aproximadamente quatro meses, de agosto de 2005 até novembro de 2005. Durante esse período, foram avaliados: a efetividade do SHV como unidade de desarenação e o funcionamento de dois modelos diferentes de grade fina de fluxo tangencial.

Nas seções seguintes são apresentados: os principais materiais e equipamentos utilizados na montagem da instalação experimental, uma breve descrição da instalação experimental e as metodologias empregadas para avaliar o SHV como unidade de desarenação e como sistema de gradeamento fino de fluxo tangencial.

\subsubsection{Materiais e equipamentos necessários para a montagem da instalação experimental}

Os principais materiais e equipamentos utilizados para a montagem da instalação experimental empregada para avaliar o desempenho do separador hidrodinâmico por vórtice (SHV) foram: 
- $\quad$ Separador hidrodinâmico por vórtice (SHV) mostrado nas Figuras 2.18, 2.19 e 2.22 na seção 2.4.5 (Histórico do desenvolvimento do protótipo do separador hidrodinâmico por vórtice tema da presente tese) do Capítulo 2 (O Tratamento Preliminar de Esgoto Sanitário e os Separadores Hidrodinâmicos por Vórtice: Conceitos e Aplicações) desta tese;

- Câmara do vertedor triangular usada para controlar o nível de água dentro da unidade e para medir a vazão, a qual é mostrada na Figura 2.19 na seção 2.4.5 (Histórico do desenvolvimento do protótipo do separador hidrodinâmico por vórtice tema da presente tese) do Capítulo 2 (O Tratamento Preliminar de Esgoto Sanitário e os Separadores Hidrodinâmicos por Vórtice: Conceitos e Aplicações) dessa tese;

- $\quad$ Bomba submersível de $5 \mathrm{CV}$;

- $\quad$ Quinze metros de mangueira siraflex 65 PSI de diâmetro igual a quatro polegadas (4");

- “T" de quatro polegadas (4");

- Válvula de esfera de quatro polegadas (4”);

- Garrafas plásticas de um litro para coleta e armazenamento das amostras.

\subsubsection{A instalação experimental}

Na seção 4.2.2.2 (Amostragem e conservação das amostras) do Capítulo 4 (A Problemática da Determinação da Quantidade de Areia no Esgoto Sanitário) desta tese, foram discutidos alguns aspectos da instalação experimental montada na estação elevatória da ETE Jardim das Flores, a qual foi utilizada na avaliação do desempenho do SHV. Naquela seção, foi descrito o posicionamento da bomba submersível de $5 \mathrm{CV}$, a qual foi empregada para bombear parte do esgoto sanitário bruto, que adentrava o poço de sucção da estação elevatória, para dentro do SHV; assim, tal assunto não será abordado novamente neste capítulo. 
As Figuras 5.1; 5.2 e 5.3 mostram, respectivamente: esquema da instalação experimental com seus constituintes principais e pontos de amostragem; foto da instalação experimental, na qual são apontados alguns de seus constituintes principais e uma foto mostrando um panorama lateral da instalação experimental.

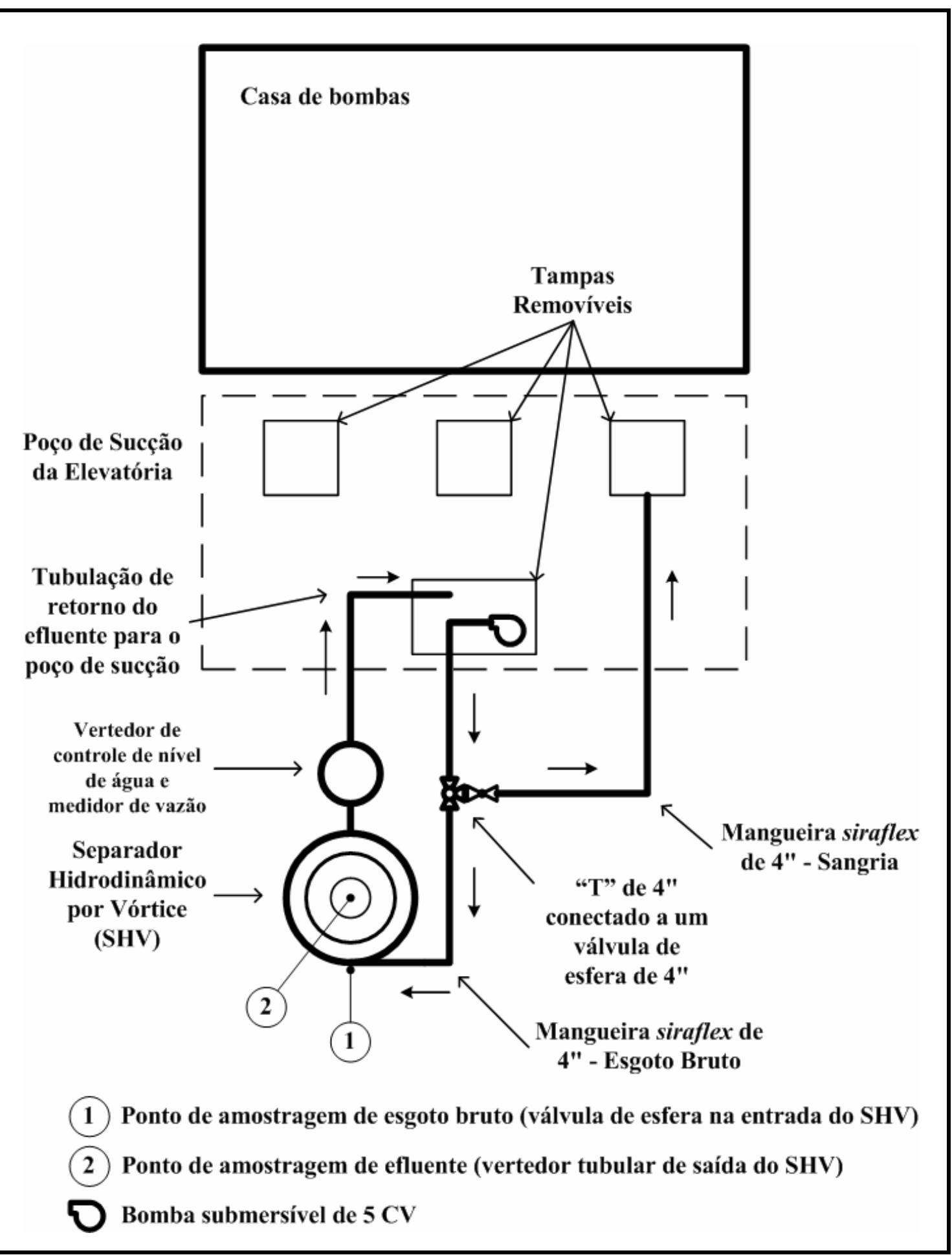

Figura 5.1 - Esquema da instalação experimental montada na estação elevatória da ETE Jardim das Flores do município de Rio Claro, SP, utilizada na avaliação do desempenho do SHV. 


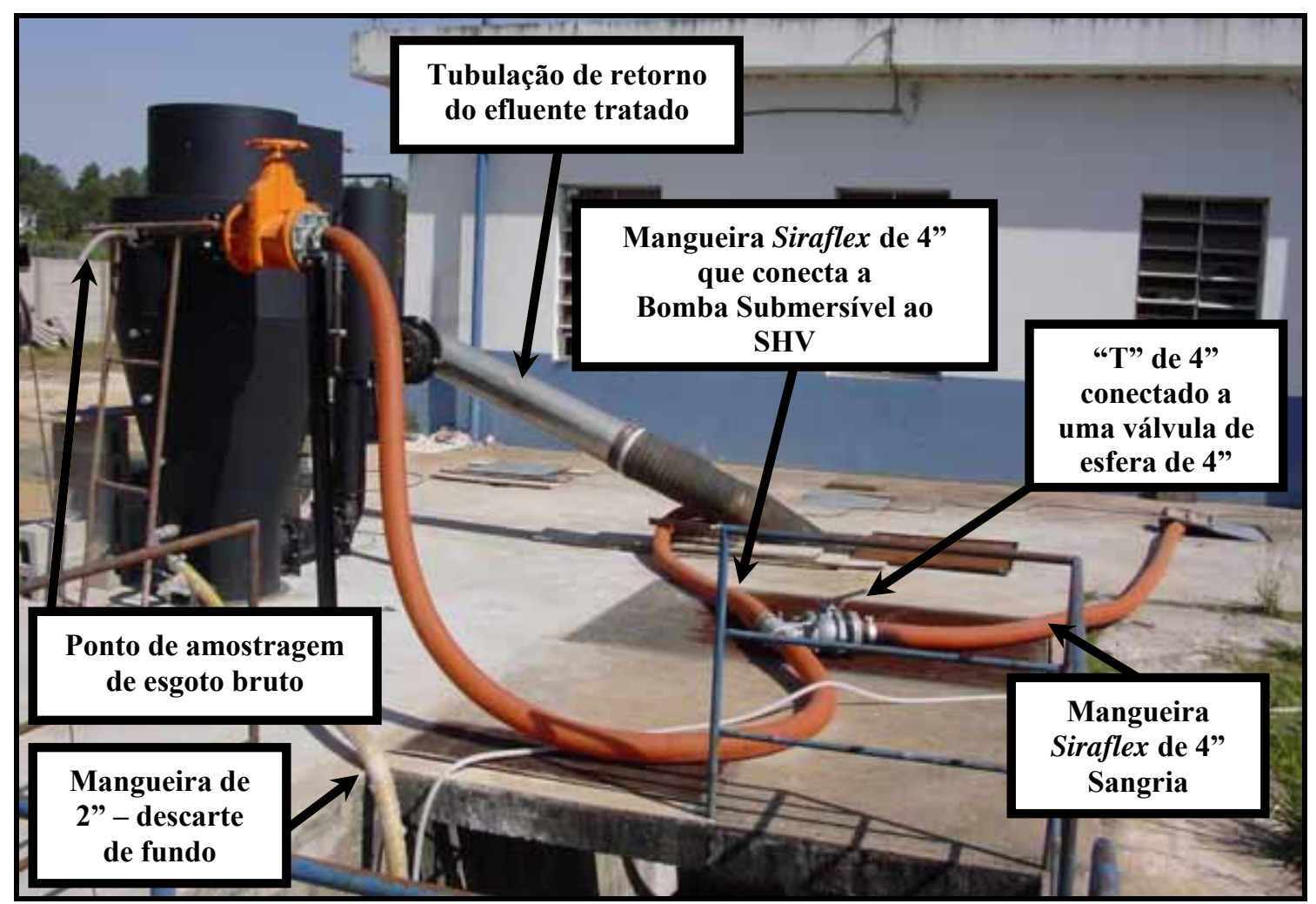

Figura 5.2 - Foto da instalação experimental montada na estação elevatória da ETE Jardim das Flores do município de Rio Claro, SP, utilizada para avaliar o desempenho do SHV como desarenador e sistema de gradeamento fino.

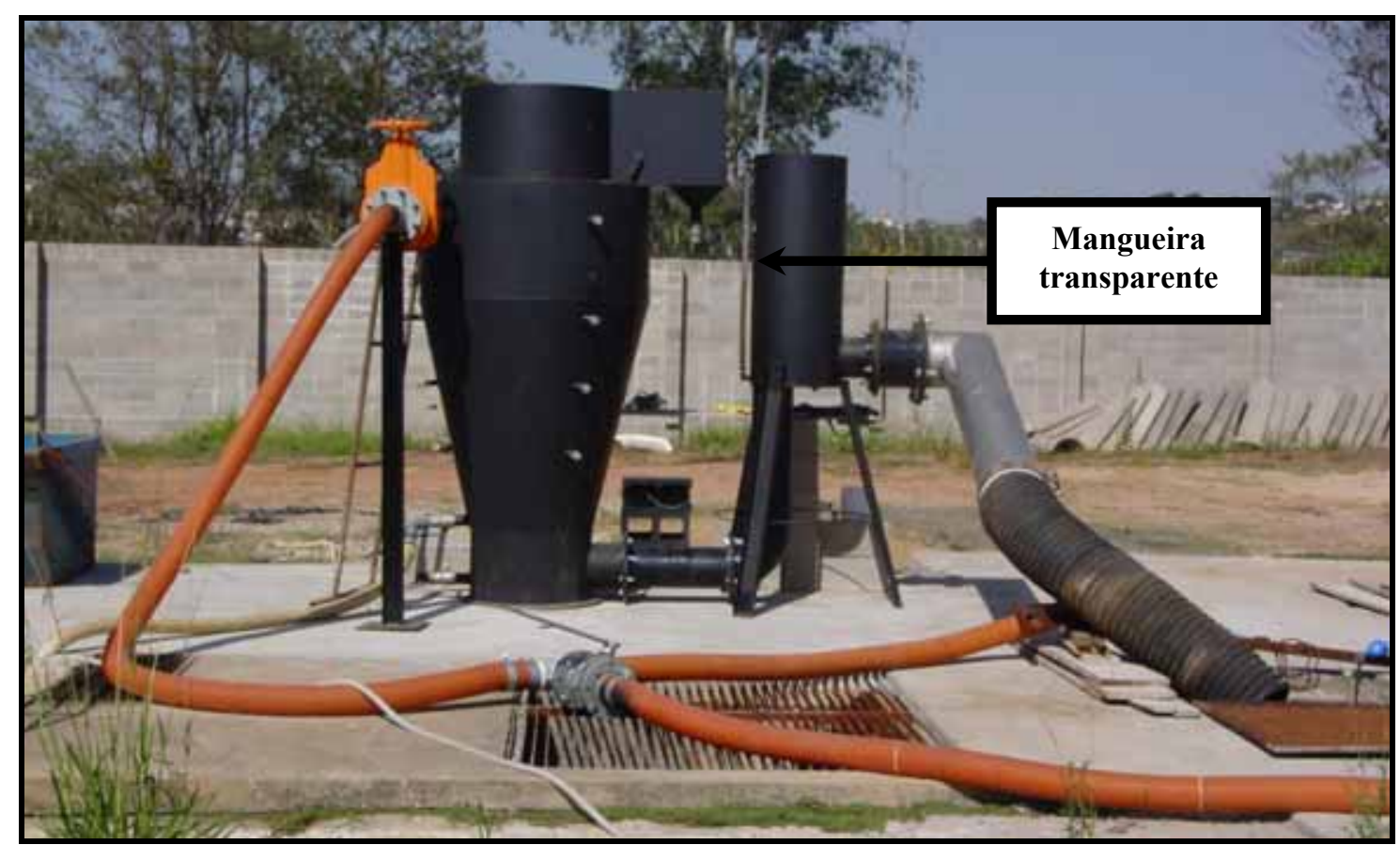

Figura 5.3 - Foto mostrando panorama lateral da instalação experimental montada na estação elevatória da ETE Jardim das Flores do município de Rio Claro, SP, utilizada para avaliar o desempenho do SHV como desarenador e sistema de gradeamento fino. 
Como pode ser observado na Figura 5.1, a bomba submersível de $5 \mathrm{CV}$ era usada para bombear esgoto sanitário bruto (após gradeamento - espaçamento entre barras de 20,0 mm) do poço de sucção da estação elevatória através de mangueira siraflex 65 PSI de quatro polegadas (4”) até o SHV. Entre a bomba submersível e o SHV foi instalada uma derivação em "T" e nela uma válvula de esfera de quatro polegadas (4"), conectada a outro pedaço de mangueira, utilizado para conduzir parte do esgoto bombeado pela bomba submersível de volta ao poço de sucção da estação elevatória (Figuras 5.1 e 5.2). Esta derivação foi utilizada como "sangria" da linha principal que ligava a bomba submersível ao SHV e era empregada para controlar a vazão alimentação da unidade.

A medição da vazão de alimentação do SHV era realizada por meio de vertedor triangular (Figura 2.19) instalado na câmara de controle de nível, mostrada logo à frente do SHV na Figura 5.3. Nota-se na mesma figura, que foi instalada uma mangueira transparente na parte posterior da câmara de controle de nível, cuja função era permitir a visualização do nível d'água dentro da mesma. Com isso foi possível estimar a carga hidráulica $(\mathrm{H})$ no vertedor triangular e calcular a vazão de alimentação do SHV pela Equação 5.1.

$$
\mathrm{Q}=\mathrm{C} \cdot \frac{8}{15} \cdot \operatorname{tg}\left(\frac{\alpha}{2}\right) \cdot \mathrm{H}^{\frac{5}{2}} \cdot \sqrt{2 \cdot \mathrm{g}}
$$

Em que:

Q: vazão $\left(\mathrm{L}^{3} \cdot \mathrm{T}^{-1}\right)$;

C: coeficiente de descarga $\left(\alpha=60^{\circ} \rightarrow C=0,578\right.$, TSUTIYA e SOBRINHO, 1999);

$\alpha$ : ângulo do vertedor triangular $\left(60^{\circ}\right)$;

H: carga hidráulica no vertedor $(\mathrm{L})$;

g: aceleração da gravidade $\left(L \cdot T^{-2}\right)$.

Sabe-se que a carga hidráulica $(\mathrm{H})$ de vertedores triangulares deve ser medida a uma distância maior ou igual a cinco vezes o valor de $H$; porém, as dimensões da câmara de controle de nível, que abrigava o vertedor triangular usado para medir a 
vazão de alimentação do SHV, impossibilitaram o cumprimento de tal regra. Com o intuito de superar esse obstáculo, foram realizados alguns ensaios de calibração do vertedor triangular, na bancada de testes da PROMINAS. Nestes ensaios, foram comparadas as vazões calculadas com a Equação 5.1 a partir de valores de $\mathrm{H}$ observados na mangueira localizada na lateral da câmara do vertedor triangular com as vazões fornecidas por um medidor de vazão. Verificou-se que os valores de vazão calculados com a Equação 5.1 ficaram muito próximos àqueles fornecidos pelo medidor de vazão e por isso, não seria necessário aplicar qualquer fator de correção.

\subsubsection{Metodologia empregada na avaliação do desempenho da grade fina de fluxo tangencial}

Durante os quatro meses em que o separador hidrodinâmico por vórtice (SHV) permaneceu instalado na estação elevatória da ETE Jardim das Flores, foi avaliado o desempenho de dois modelos diferentes de grade fina de fluxo tangencial, ambos cilíndricos e posicionados no topo do vertedor tubular de saída da unidade.

O primeiro modelo testado possuía diâmetro igual a $320 \mathrm{~mm}$, espaçamento entre barras de 3,0 mm, e não contava com qualquer sistema mecanizado de limpeza, ficando a cargo do escoamento circulatório do líquido ao redor da grade a limpeza da sua face externa (Figura 5.4).

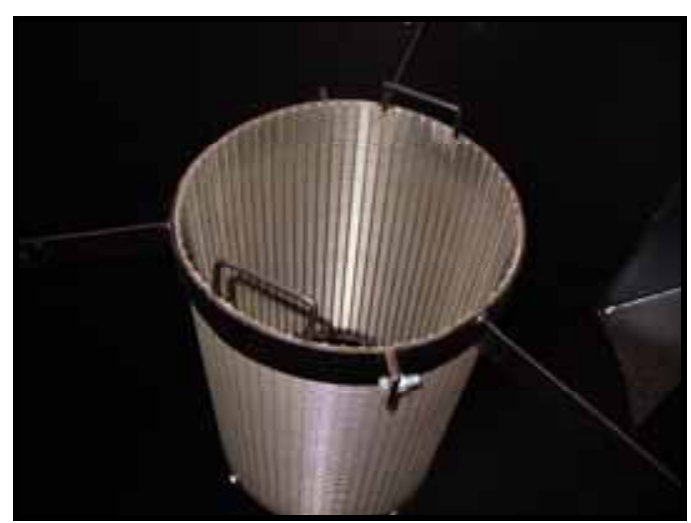

(a)

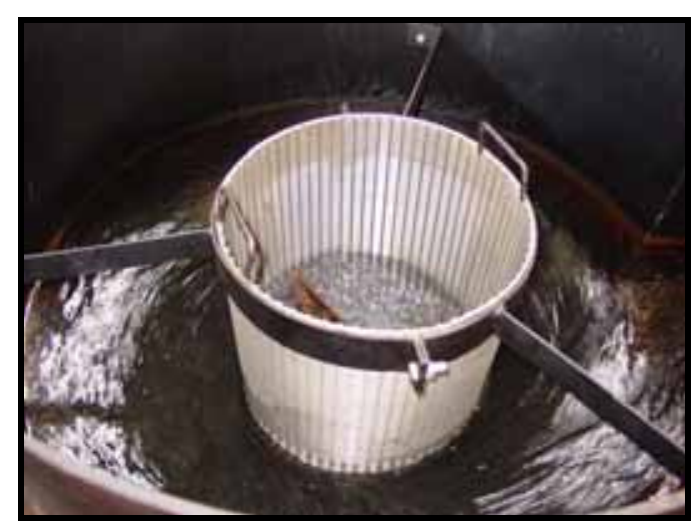

(b)

Figura 5.4 - Primeira configuração da grade fina de fluxo tangencial instalada no topo do vertedor tubular de saída do SHV, a qual possuía diâmetro de $320 \mathrm{~mm}$ e espaçamento entre barras de $3,0 \mathrm{~mm}$. (a) Foto da grade fina instalada no topo do vertedor tubular de saída do SHV. (b) Foto da grade fina instalada no topo do vertedor tubular de saída do SHV durante o período de pré-operação com água. 
O segundo modelo de grade fina possuía diâmetro igual a $600 \mathrm{~mm}$, espaçamento entre barras de 4,0 $\mathrm{mm}$, além de contar com sistema mecanizado de limpeza, responsável pela remoção dos sólidos grosseiros que se aderiam à superfície da grade (Figura 5.5 e 5.6).

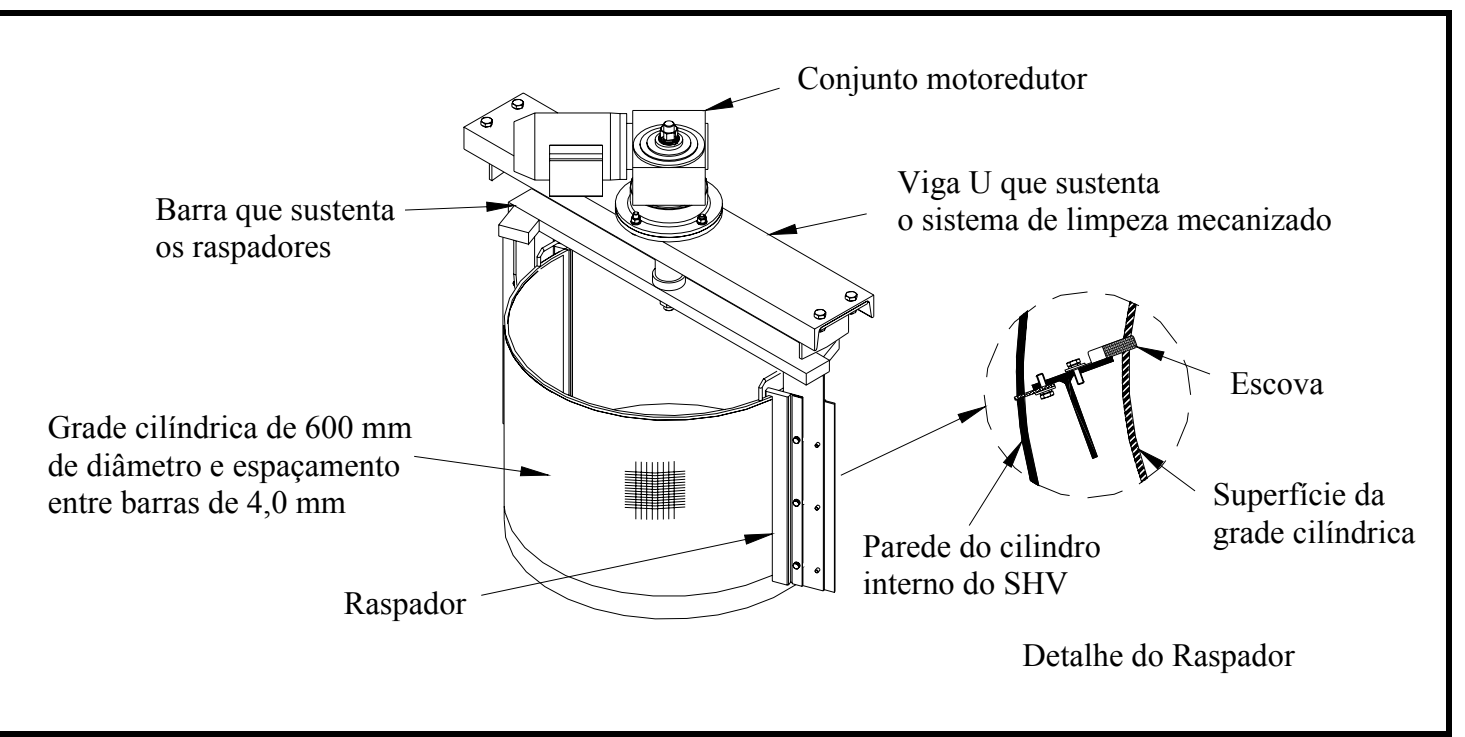

Figura 5.5 - Segunda configuração da grade fina de fluxo tangencial instalada no topo do vertedor tubular de saída do SHV, com diâmetro de $600 \mathrm{~mm}$, espaçamento entre barras de 4,0 mm, e com sistema mecanizado de limpeza.

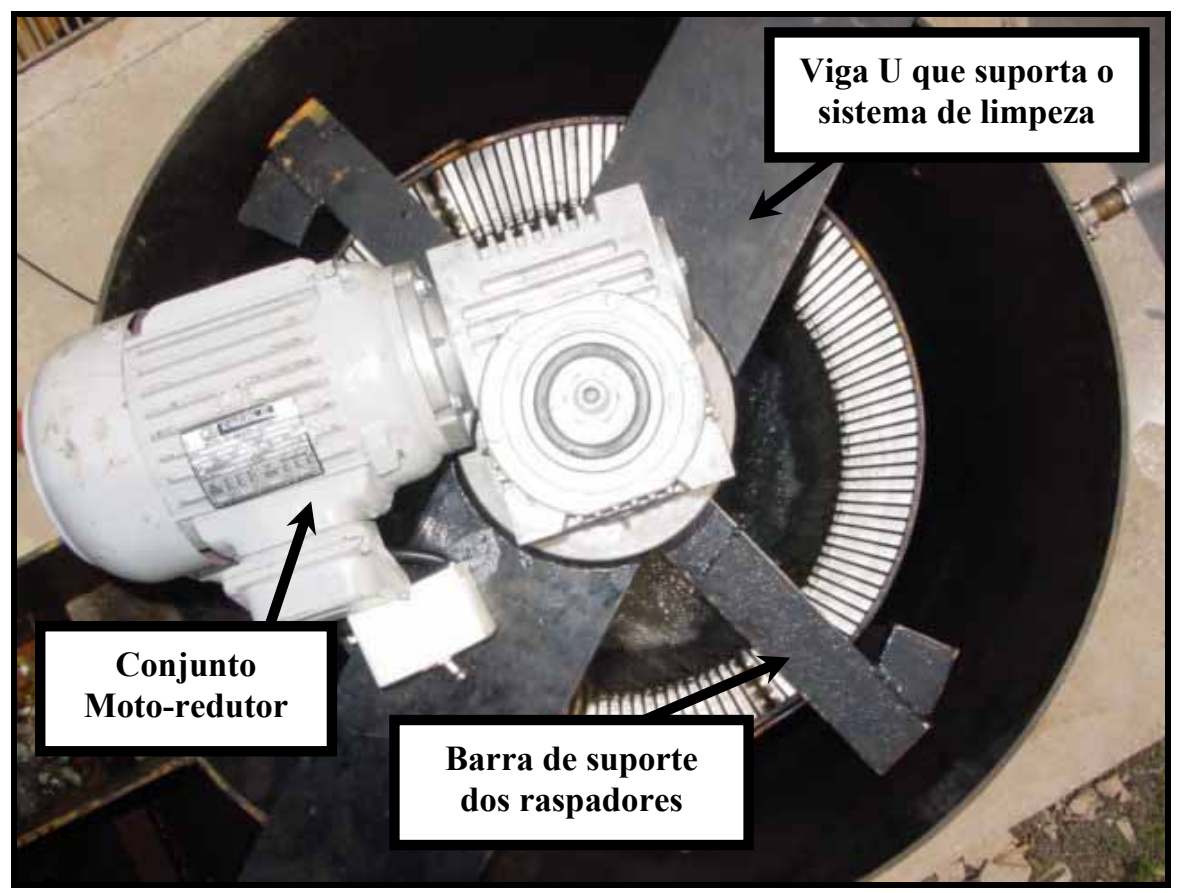

Figura 5.6 - Foto que mostra o sistema de limpeza mecanizado da segunda configuração da grade fina de fluxo tangencial, instalado no topo do SHV. 
A avaliação do desempenho dos dois modelos de grade fina de fluxo tangencial fundamentou-se na observação do funcionamento das grades, durante os meses em que o SHV foi operado, isto é, de agosto a novembro de 2005. O primeiro modelo de grade fina foi testado ao longo do mês de agosto de 2005, já o segundo modelo de grade fina foi projetado e construído em setembro de 2005 para depois ser testado durante os meses de outubro e novembro de 2005.

Neste texto serão apresentadas fotografias para corroborar as constatações feitas acerca dos dois modelos de grade fina de fluxo tangencial testados. Vale ressaltar que não foi realizada caracterização alguma do peneirado retido nas grades estudadas, portanto nenhuma amostra deste material foi coletada e analisada.

\subsubsection{Metodologia empregada na avaliação do desempenho do separador hidrodinâmico por vórtice como unidade de desarenação}

\subsubsection{Considerações iniciais}

A avaliação do desempenho do separador hidrodinâmico por vórtice (SHV) como unidade de desarenação balizou-se no questionamento de três quesitos:

- O SHV permite que os sólidos orgânicos presentes em seu afluente passem pela a unidade sem serem removidos, ao ser operado com taxas de aplicação superficial (TAS) de $764 \mathrm{~m}^{3} / \mathrm{m}^{2} \mathrm{~d} ; 1.146 \mathrm{~m}^{3} / \mathrm{m}^{2} \mathrm{~d}$ e 1.528 $\mathrm{m}^{3} / \mathrm{m}^{2} \mathrm{~d}$ ?

- $\quad$ O SHV remove areia presente em seu afluente, ao ser operado com taxas de aplicação superficial (TAS) de $764 \mathrm{~m}^{3} / \mathrm{m}^{2} \mathrm{~d} ; 1.146 \mathrm{~m}^{3} / \mathrm{m}^{2} \mathrm{~d}$ e 1.528 $\mathrm{m}^{3} / \mathrm{m}^{2} \mathrm{~d}$ ?

- $\quad$ O SHV produz efluentes livres de grãos de areia de tamanho maior ou igual a $200 \mu \mathrm{m}$, ao ser operado com taxas de aplicação superficial (TAS) de $764 \mathrm{~m}^{3} / \mathrm{m}^{2} \mathrm{~d} ; 1.146 \mathrm{~m}^{3} / \mathrm{m}^{2} \mathrm{~d}$ e $1.528 \mathrm{~m}^{3} / \mathrm{m}^{2} \mathrm{~d}$ ? 
Para responder ao primeiro e ao segundo quesito, foram feitas análises estatísticas dos valores de eficiência de remoção de sólidos suspensos voláteis (SSV) e de eficiência de remoção de areia, os quais foram calculados com as Equações 5.2 e 5.3. O terceiro quesito foi respondido de duas formas: pela análise estatística das eficiências de remoção parcial de areia, isto é, das eficiências do SHV na remoção de grãos de areia de tamanho maior ou igual a $200 \mu \mathrm{m}$, as quais foram calculadas com as Equações 5.4; 5.5 e 5.6; e pela comparação das curvas de distribuição numérica de tamanho de grãos de areia (curvas de distribuição granulométrica dos grãos de areia) que foram obtidas para o afluente e para o efluente do SHV.

$$
\begin{gathered}
\operatorname{Ef}(\%)=100 \cdot \frac{\left(\mathrm{SSV}_{0}-\mathrm{SSV}\right)}{\mathrm{SSV}_{0}} \\
\mathrm{Ef}(\%)=100 \cdot \frac{\left(\mathrm{C}_{0 \text { areia }}-\mathrm{C}_{\text {areia }}\right)}{\mathrm{C}_{0 \text { areia }}} \\
\mathrm{Ef}_{\mathrm{p}}(\%)=100 \cdot \frac{\left(\mathrm{C}_{\mathrm{g} \geq 200 \mathrm{i}}-\mathrm{C}_{\mathrm{g} \geq 200 \mathrm{f}}\right)}{\mathrm{C}_{\mathrm{g} \geq 200 \mathrm{i}}} \\
\mathrm{C}_{\mathrm{g} \geq 200 \mathrm{i}}=\mathrm{C}_{0 \text { areia }} \cdot \mathrm{P}_{\mathrm{g} \geq 200} \\
\mathrm{C}_{\mathrm{g} \geq 200 \mathrm{f}}=\mathrm{C}_{\text {areia }} \cdot \mathrm{P}_{\mathrm{g} \geq 200}
\end{gathered}
$$

Em que:

$\mathrm{SSV}_{0}$ : concentração de SSV presente no afluente do SHV (mg/l);

SSV : concentração de SSV presente no afluente do SHV (mg/l);

$\mathrm{C}_{0 \text { areia }}$ : concentração de areia presente no afluente do SHV (mg/l);

$\mathrm{C}_{\text {areia }}$ : concentração de areia ou presente no efluente do SHV (mg/l);

Ef(\%) : eficiência de remoção de areia ou de SSV (\%);

$\mathrm{Ef}_{\mathrm{p}}(\%)$ : eficiência de remoção parcial (\%); 
$\mathrm{C}_{\mathrm{g} \geq 200 \mathrm{i}}$ :concentração de areia com grãos maiores ou iguais a $200 \mu \mathrm{m}$ no afluente do SHV (mg/l);

$\mathrm{C}_{\mathrm{g} \geq 200 \mathrm{i}}$ :concentração de areia com grãos maiores ou iguais a $200 \mu \mathrm{m}$ no efluente do SHV (mg/l);

$\mathrm{P}_{\mathrm{g} \geq 200}$ : porcentual de grãos de areia de tamanho maior ou igual a $200 \mu \mathrm{m}$, obtido na curva de distribuição volumétrica de tamanho de partícula.

\subsubsection{Amostragem e conservação das amostras}

A avaliação do desempenho do separador hidrodinâmico por vórtice (SHV) como unidade de desarenação pode ser dividida em duas partes. Primeiro, verificou-se a capacidade do SHV em permitir que a matéria orgânica particulada passasse pela unidade sem ser removida, depois avaliou-se a eficiência do SHV na remoção de areia.

Para a execução da primeira parte da avaliação de desempenho do SHV foram realizadas doze amostragens, quatro para cada taxa de aplicação superficial (TAS). Cada amostragem consistia na coleta de duas amostras de um litro, uma de esgoto sanitário afluente do SHV e outra de esgoto sanitário efluente do SHV. As coletas foram executadas em sete dias diferentes, entre 04/08/2005 e 06/09/2005, das 09h00min às $15 \mathrm{~h} 40 \mathrm{~min}$.

Para a execução da segunda parte da avaliação de desempenho do SHV foram realizadas vinte e quatro amostragens horárias, oito por TAS. Cada amostragem consistia na coleta de duas amostras de um litro, uma de esgoto sanitário afluente do SHV e outra de esgoto sanitário efluente do SHV. As coletas foram executadas em seis dias diferentes, entre 06/10/2005 e 21/11/2005, das 10h30min às $13 \mathrm{~h} 30 \mathrm{~min}$ ou das 14h30min às $17 \mathrm{~h} 30 \mathrm{~min}$. Na Tabela 5.1 podem ser observados: a data e os períodos de operação do SHV em que foram feitas as coletas, o número de amostras coletadas por período e a vazão de alimentação usada no momento de cada coleta.

Todas as coletas de amostras de esgoto sanitário afluente do SHV seguiram o mesmo protocolo apresentado na seção 4.2.2.2 (Amostragem e conservação das amostras) do Capítulo 4 (A Problemática da Determinação da Quantidade de Areia no 
Esgoto Sanitário) desta tese. As amostras de esgoto sanitário efluente do SHV foram coletadas no interior do vertedor tubular de saída da unidade (Figura 5.1).

Tabela 5.1 - Data, período, número de amostras coletadas e vazão de alimentação do SHV no momento das coletas realizadas para a avaliação do desempenho do SHV na remoção de areia do esgoto sanitário.

\begin{tabular}{|c|c|c|c|c|}
\hline Data & Período & $\begin{array}{c}n^{0} \text { de amostras } \\
\text { Afluente }\end{array}$ & $\begin{array}{c}\mathrm{n}^{0} \text { de amostras } \\
\text { Efluente }\end{array}$ & $\begin{array}{c}\text { Vazão } \\
(1 / \mathbf{s})\end{array}$ \\
\hline $6 / 10 / 2005$ & $10 \mathrm{~h} 30 \mathrm{~min} \rightarrow 14 \mathrm{~h} 30 \mathrm{~min}$ & 4 (horárias) & 4 (horárias) & \multirow{2}{*}{10,0} \\
\hline $11 / 10 / 2005$ & $14 \mathrm{~h} 30 \mathrm{~min} \rightarrow 17 \mathrm{~h} 30 \mathrm{~min}$ & 4 (horárias) & 4 (horárias) & \\
\hline $4 / 11 / 2005$ & $10 \mathrm{~h} 30 \mathrm{~min} \rightarrow 14 \mathrm{~h} 30 \mathrm{~min}$ & 4 (horárias) & 4 (horárias) & \multirow{2}{*}{15,0} \\
\hline $17 / 11 / 2005$ & $14 \mathrm{~h} 30 \mathrm{~min} \rightarrow 17 \mathrm{~h} 30 \mathrm{~min}$ & 4 (horárias) & 4 (horárias) & \\
\hline $9 / 11 / 2005$ & $10 \mathrm{~h} 30 \mathrm{~min} \rightarrow 14 \mathrm{~h} 30 \mathrm{~min}$ & 4 (horárias) & 4 (horárias) & \multirow{2}{*}{20,0} \\
\hline $21 / 11 / 2005$ & $14 \mathrm{~h} 30 \mathrm{~min} \rightarrow 17 \mathrm{~h} 30 \mathrm{~min}$ & 4 (horárias) & 4 (horárias) & \\
\hline & Total de amostras & 24 & 24 & \\
\hline
\end{tabular}

Após a amostragem do esgoto bruto, esperava-se tempo igual ao tempo de detenção hidráulica teórico $\left(\mathrm{TDH}_{\mathrm{t}}\right)$ do $\mathrm{SHV}$ (150 segundos para a vazão de 10 1/s; 100 segundos para vazão de 15 l/s e 75 segundos para a vazão de 20 l/s) e então efetuava-se a coleta do efluente do SHV, mergulhando uma garrafa plástica de um litro no interior do vertedor tubular de saída da unidade.

Todas as amostras coletadas eram conservadas em refrigerador, na ETE Jardim das Flores, onde permaneciam até serem transportadas para o Laboratório de Tratamento Avançado e Reuso de Água (LATAR) da Escola de Engenharia de São Carlos (EESC) da Universidade de São Paulo (USP), onde foram conduzidas as determinações de concentração de sólidos suspensos voláteis (SSV); de concentração e distribuição granulométrica da areia presente nas amostras.

5.2.5.3. Determinação da concentração de sólidos suspensos voláteis e da concentração e distribuição granulométrica da areia presente nas amostras de esgoto sanitário afluente e efluente do separador hidrodinâmico por vórtice

As amostras de esgoto sanitário afluente e efluente do separador hidrodinâmico por vórtice (SHV) foram submetidas a três tipos de determinação: concentração de 
sólidos suspensos voláteis (SSV), concentração de areia presente nas amostras e distribuição granulométrica dos grãos dessa areia.

As determinações de sólidos suspensos voláteis nas amostras de esgoto sanitário afluente e efluente do SHV foram realizadas em quadruplicata e seguiram os procedimentos descritos no Standard Methods for Examination of Water and Wastewater (APHA, 1999).

A determinação da concentração de areia em amostras de esgoto sanitário baseia-se em procedimentos simples, como: concentrar os sólidos de uma amostra de esgoto em cones Imhoff, centrifugar os sólidos concentrados, separar a areia da matéria orgânica por oxidação com peróxido de hidrogênio seguida de enxágües sucessivos com água destilada e, finalmente, calcinar e pesar a areia separada.

A determinação da distribuição granulométrica da areia presente nas amostras de esgoto foi realizada por meio de adaptação de uma técnica de determinação de tamanho de partículas chamada análise de imagens. Tal adaptação consiste em coletar, com fita adesiva transparente, os grãos de areia provenientes dos procedimentos de determinação da concentração de areia no esgoto, colá-los em lamínulas de vidro, fotografá-los por meio de câmera acoplada a um microscópio óptico, tratar as imagens adquiridas e proceder a contagem e determinação de tamanho dos grãos em um software de análise de imagens.

Ambas as técnicas empregadas foram desenvolvidas durante este pesquisa e são pormenorizadamente apresentadas no Capítulo 4 (A Problemática da Determinação da Quantidade de Areia no Esgoto Sanitário) desta tese.

Vale ressaltar que apenas oito das dezesseis amostras coletadas para cada vazão estudada (4 de esgoto sanitário afluente e 4 de esgoto sanitário efluente do SHV) foram submetidas à determinação da distribuição granulométrica dos grãos de areia, pois a técnica de análise de imagem é extremamente laboriosa e demorada, o que impossibilitou a determinação da distribuição granulométrica da areia de todas as amostras. 


\subsection{Resultados e Discussão}

\subsubsection{Avaliação do desempenho do sistema de gradeamento fino de fluxo tangencial do separador hidrodinâmico por vórtice}

Desde a primeira metade de 2002 quando foi iniciado o presente trabalho de pesquisa, um dos objetivos almejados sempre foi o desenvolvimento de um sistema de gradeamento fino que não necessitasse de equipamento mecânico de limpeza. Uma alternativa ao uso de sistemas mecanizados de limpeza seria tentar usar o próprio padrão de escoamento da unidade para realizar tal função, para tanto pensou-se em fazer com que o afluente do sistema de gradeamento escoasse tangencialmente em relação a uma grade fina.

Como pode ser observado na seção 2.4 .5 (Histórico do desenvolvimento do protótipo do separador hidrodinâmico por vórtice tema da presente tese) do Capítulo 2 (O Tratamento Preliminar de Esgoto Sanitário e os Separadores Hidrodinâmicos por Vórtice: Conceitos e Aplicações) desta tese, foram idealizadas várias configurações diferentes para o sistema de gradeamento fino de fluxo tangencial (Figuras 2.16; 2.17; 2.18); no entanto, optou-se pela configuração mostrada nas Figuras 2.18 e 5.4, isto é, uma grade cilíndrica de $320 \mathrm{~mm}$ de diâmetro e espaçamento entre barras de 3,0 $\mathrm{mm}$, posicionada no topo do vertedor tubular de saída, localizado no centro do separador hidrodinâmico por vórtice (SHV). Porém, ao se tomar tal decisão, não foram considerados todos os aspectos do padrão de escoamento daquela região da unidade; imaginou-se, apenas, que a velocidade do líquido circulando a grade cilíndrica seria suficientemente alta e não permitiria a aderência de sólidos à sua superfície e que devido ao padrão de escoamento circulatório, a inércia das partículas suspensas no esgoto sanitário bruto afastaria os sólidos grosseiros da superfície da grade.

Constatou-se depois - durante o período de pré-operação do SHV, quando foram realizados os ensaios de estímulo-resposta e as medições de pressão total, que são apresentados no Capítulo 3 (Estudo da Hidrodinâmica do Separador Hidrodinâmico por Vórtice) desta tese - que o padrão de escoamento que se desenvolve nas adjacências do vertedor tubular de saída do SHV assemelha-se a um "vórtice de ralo" ou vórtice livre. Este tipo de escoamento circulatório pode ser observado quando água é drenada através 
de um orifício no fundo de um tanque e tem, como característica, linhas de corrente que se dirigem ao centro do orifício de saída, como mostra a Figura 5.7. Além disso, de acordo com Knauss (1987), nos vórtices livres, quanto mais próximo do orifício de saída maior a velocidade do fluido. Este aumento da velocidade do fluido ocasiona o aumento dos atritos viscosos que, por sua vez acarreta o rebaixamento da superfície livre nas proximidades do orifício de saída (Figura 5.8) (CASAMASSA NETO, 1991).

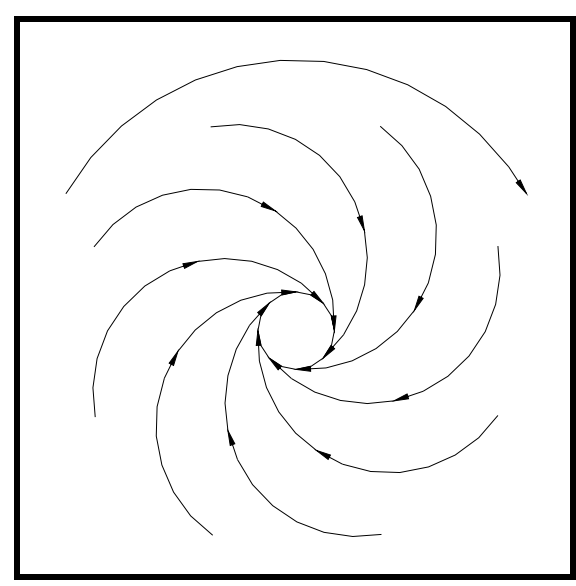

Figura 5.7 - Padrão de linhas de corrente de um "vórtice de ralo" ou vórtice livre. Adaptado de White (1999).

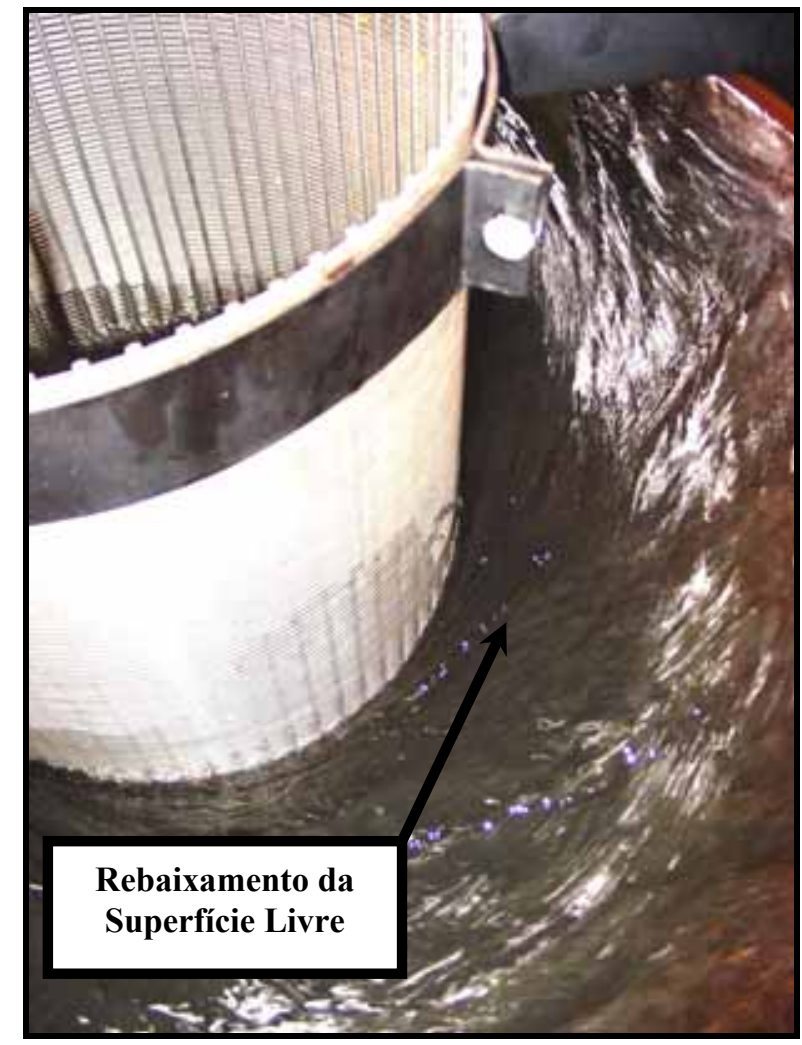

Figura 5.8 - Foto que mostra a superfície livre que se forma no topo do SHV nas adjacências da grade cilíndrica. 
Verificou-se - com a execução de experimento simples realizado na bancada de testes da PROMINAS, no qual foram utilizados pequenos pedaços de poliestireno (isopor) para simular sólidos grosseiros flutuantes presentes no esgoto sanitário - ter sido um erro considerar alguns aspectos do padrão de escoamento que se desenvolve nas proximidades da grade cilíndrica, porquanto, conforme pôde ser observado, o efeito combinado do sentido das linhas de corrente e da inclinação da superfície livre fez com que o poliestireno lançado na superfície livre junto à parede do cilindro interno do SHV fosse carreado diretamente para a superfície da grade cilíndrica, como mostra a Figura 5.9(a) e (b).

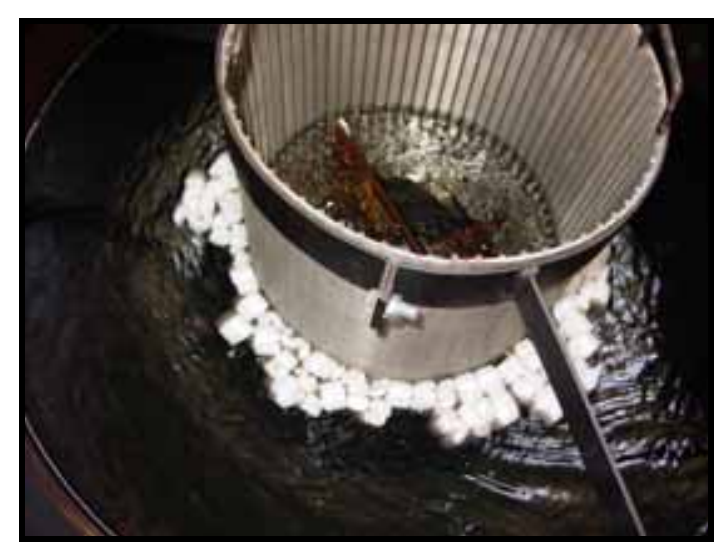

(a)

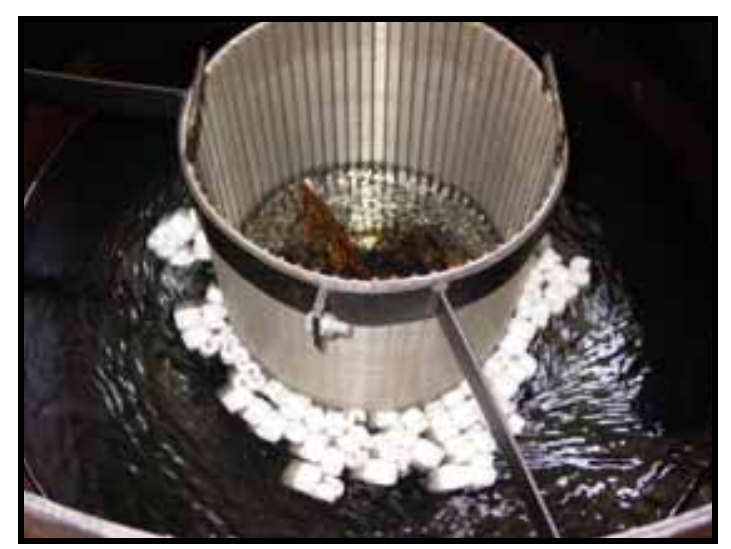

(b)

Figura 5.9 - Foto que mostra o acúmulo de pedaços de poliestireno junto à grade cilíndrica posicionada no topo do vertedor tubular de saída do SHV.

Constatou-se, também, no mesmo experimento, que aumentando a vazão de alimentação do SHV, aumentava-se a velocidade do escoamento ao redor da grade cilíndrica e, conseqüentemente, acentuava-se o rebaixamento da superfície livre, fazendo com que os pedaços de poliestireno fossem mais rapidamente carreados para junto da superfície da grade cilíndrica. No entanto, como os pedaços de poliestireno possuíam características diferentes dos sólidos grosseiros presentes no esgoto sanitário, as altas velocidades do escoamento junto à grade cilíndrica impediram sua aderência à superfície da grade.

Todavia, quando o SHV foi alimentado com esgoto sanitário bruto (após gradeamento grosseiro - espaçamento entre barras de 20,0 $\mathrm{mm}$ ) bombeado do poço de sucção da estação elevatória da ETE Jardim das Flores, durante a avaliação do seu desempenho como unidade de desarenação e sistema de gradeamento fino, os sólidos grosseiros presentes no afluente do SHV obstruíram a grade cilíndrica em poucos 
minutos, independentemente, da vazão de alimentação empregada (10 1/s; 15 1/s; 20 1/s) (Figuras 5.10 e 5.11). Acredita-se que isso tenha ocorrido devido a algumas características dos sólidos grosseiros presentes no esgoto sanitário bruto, por exemplo: a presença de grande quantidade de materiais fibrosos, como: fios de cabelo, linhas e, principalmente, estopa, os quais, por estarem impregnados de matéria orgânica do esgoto sanitário, tornaram-se extremamente pegajosos, o que facilitou, ainda mais, sua aderência à superfície da grade (Figura 5.11).

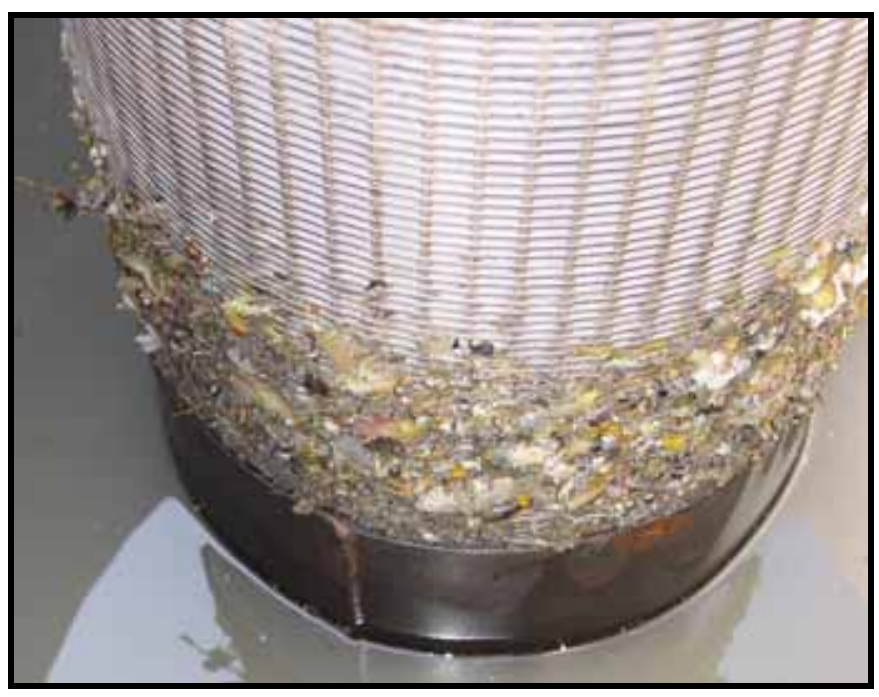

Figura 5.10 - Foto que mostra a grade cilíndrica posicionada no topo do vertedor tubular de saída do SHV obstruída por sólidos grosseiros após 5 minutos de operação com vazão de alimentação de $20 \mathrm{l} / \mathrm{s}$ (TAS de $1.528 \mathrm{~m}^{3} / \mathrm{m}^{2} \mathrm{~d}$ ).

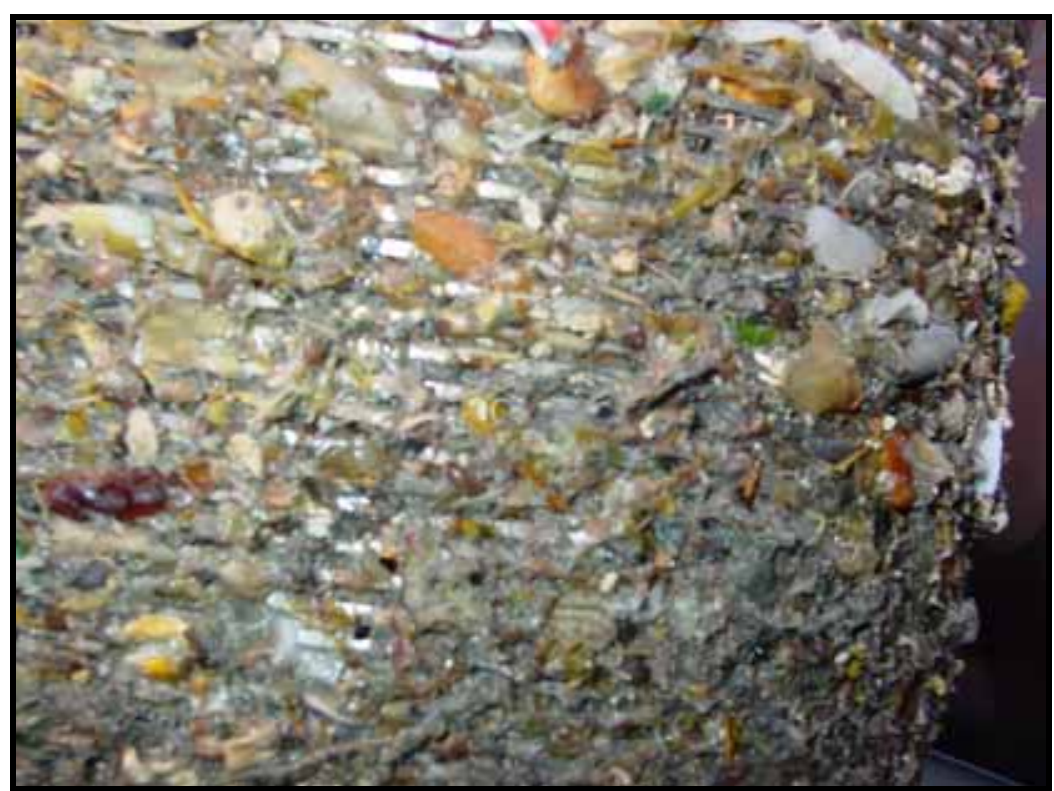

Figura 5.11 - Foto que mostra em detalhe os sólidos grosseiros que obstruíram a grade cilíndrica posicionada no topo do vertedor tubular de saída do SHV, após 5 minutos de operação com vazão de alimentação de $201 / \mathrm{s}$ (TAS de $1.528 \mathrm{~m}^{3} / \mathrm{m}^{2} \mathrm{~d}$ ). 
Dada a impossibilidade de operar o SHV sem a utilização de algum tipo de mecanismo de limpeza, decidiu-se aumentar o diâmetro da grade cilíndrica de $320 \mathrm{~mm}$ para $600 \mathrm{~mm}$, alargar o espaçamento entre barras de 3,0 $\mathrm{mm}$ para $4,0 \mathrm{~mm}$, e mais, foi desenvolvido e instalado um sistema mecanizado de limpeza que impedia a aderência de sólidos grosseiros à superfície da grade (Figura 5.5; 5.6; 5.12 e 5.13). Vale ressaltar que tais alterações na grade fina de fluxo tangencial do SHV, tinham como único objetivo permitir que a unidade fosse operada ininterruptamente por várias horas, para ser possível testar a efetividade do SHV como unidade de desarenação.

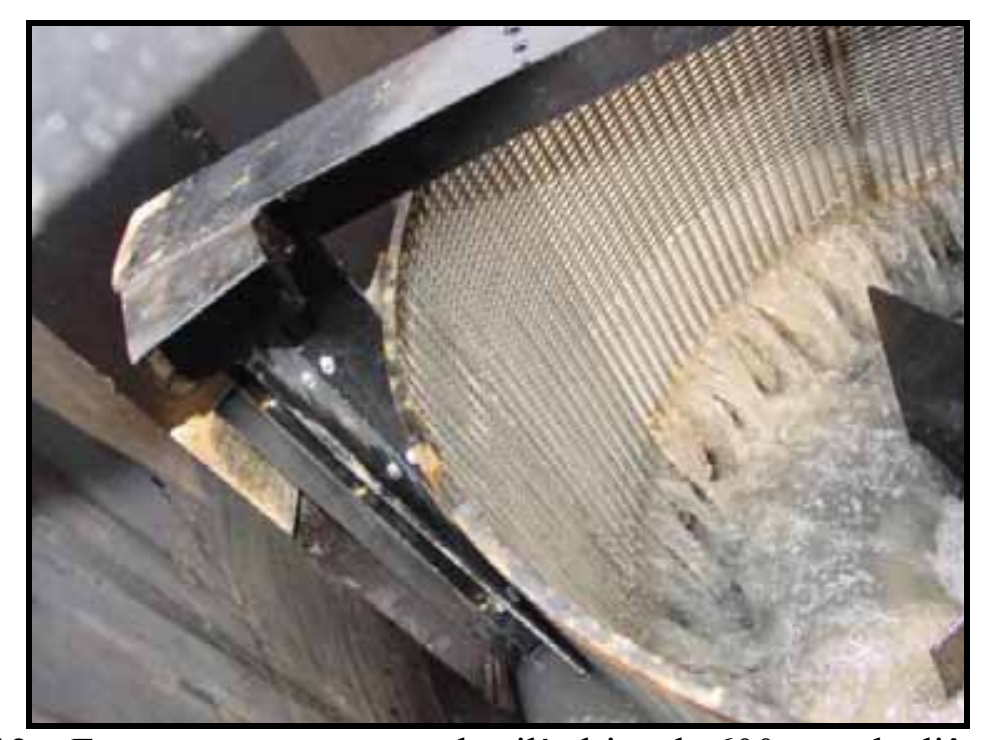

Figura 5.12 - Foto que mostra: a grade cilíndrica de $600 \mathrm{~mm}$ de diâmetro e com espaçamento entre barras de 4,0 mm, instalada no topo do vertedor tubular de saída do SHV; e o sistema mecanizado de limpeza da mesma em operação.

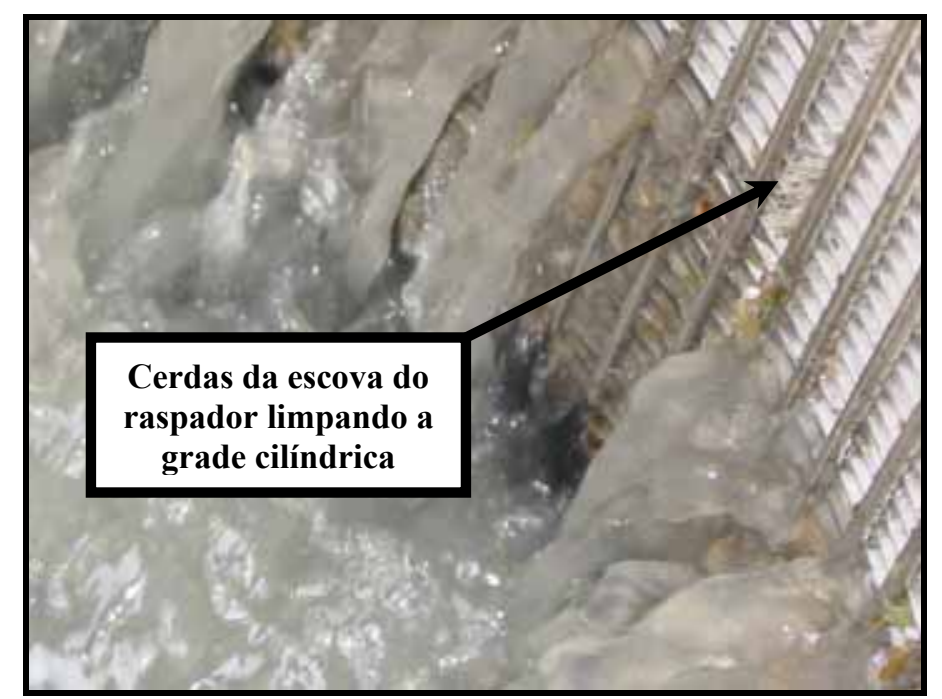

Figura 5.13 - Foto que mostra: detalhe da face interna da grade cilíndrica de $600 \mathrm{~mm}$ de diâmetro e com espaçamento entre barras de $4,0 \mathrm{~mm}$, instalada no topo do vertedor tubular de saída do SHV; e as cerdas da escova do raspador do sistema mecanizado de limpeza da mesma em operação. 
Após a instalação do segundo modelo da grade cilíndrica de fluxo tangencial, o qual contava com sistema de limpeza mecanizado, foi possível operar o SHV por até quatro horas, sem ser necessária nenhuma interrupção para promover a limpeza de sua superfície. Porém, apesar de manter a superfície da grade cilíndrica livre de sólidos, o sistema de limpeza mecanizado não possuía qualquer tipo de dispositivo que removesse os sólidos grosseiros de dentro do SHV, assim, era necessário parar os raspadores a cada trinta minutos para remover manualmente os sólidos presos a eles.

Constatou-se, ainda, outro problema com a grade cilíndrica de fluxo tangencial da unidade de tratamento preliminar, tema da presente tese. Como a grade cilíndrica foi posicionada no topo do vertedor tubular de saída do SHV, os sólidos grosseiros que adentravam a unidade, necessariamente passavam pela região de separação (RSe) da mesma, conseqüentemente, aqueles sólidos grosseiros que possuíam boa sedimentabilidade eram removidos juntamente com os grãos de areia e acumulavam-se na região de acúmulo (RA) do SHV. Tal fato ocasionou, várias vezes, a obstrução da tubulação de descarte da região de acúmulo da unidade (Figura 5.2), e mais, a presença de matéria orgânica na areia removida pelo SHV faz com que seja necessária a "lavagem" dessa areia antes de sua disposição final.

Após aproximadamente três meses de operação da grade fina de fluxo tangencial do SHV, e concomitante observação do esgoto sanitário afluente da estação elevatória da ETE Jardim das Flores, é possível afirmar, com muita segurança, que o maior obstáculo para o desenvolvimento de sistemas de gradeamento ou peneiramento autolimpantes é a presença de grande quantidade de materiais fibrosos no esgoto sanitário, principalmente, fiapos, fios de roupa e estopa. Estes materiais entrelaçam-se nas barras das grades e, por estarem impregnados de matéria orgânica proveniente do esgoto sanitário, tornam-se pegajosos e aderem-se à superfície das mesmas, o que dificulta, ainda mais, sua remoção. Por conseguinte, julga-se ser muito difícil a concepção de sistemas de gradeamento ou peneiramento fino de fluxo tangencial para estações de tratamento de esgoto sanitário que sejam totalmente auto-limpantes; e que sempre será necessária a utilização de algum tipo de equipamento de limpeza, preferencialmente, automatizado. Uma sugestão seria o uso de raspadores e jatos de água ligados à temporizadores ou a dispositivos de detecção de nível de água que acionassem o sistema de limpeza, sempre que fosse atingido um determinado nível de água. 


\subsubsection{Avaliação do desempenho do separador hidrodinâmico por vórtice como unidade de desarenação}

Como mencionado na seção 5.2.5 (Metodologia empregada na avaliação do desempenho do separador hidrodinâmico por vórtice como unidade de desarenação) deste capítulo, a avaliação do desempenho do separador hidrodinâmico por vórtice (SHV) como unidade de desarenação balizou-se na verificação de três quesitos:

- O SHV permite que os sólidos orgânicos (medidos em termos de concentração de sólidos suspensos voláteis) presentes no esgoto sanitário afluente da estação de tratamento de esgoto (ETE) Jardim das Flores passem pela a unidade sem serem removidos, ao ser operado com taxas de aplicação superficial (TAS) de $764 \mathrm{~m}^{3} / \mathrm{m}^{2} \mathrm{~d} ; 1.146 \mathrm{~m}^{3} / \mathrm{m}^{2} \mathrm{~d}$ e 1.528 $\mathrm{m}^{3} / \mathrm{m}^{2} \mathrm{~d}$ ?

- $\quad$ O SHV remove areia presente no esgoto sanitário afluente da ETE Jardim das Flores, ao ser operado com taxas de aplicação superficial (TAS) de $764 \mathrm{~m}^{3} / \mathrm{m}^{2} \mathrm{~d} ; 1.146 \mathrm{~m}^{3} / \mathrm{m}^{2} \mathrm{~d}$ e $1.528 \mathrm{~m}^{3} / \mathrm{m}^{2} \mathrm{~d}$ ?

- $\quad$ O SHV produz efluentes livres de grãos de areia de tamanho maior ou igual a $200 \mu \mathrm{m}$, ao ser operado com taxas de aplicação superficial (TAS) de $764 \mathrm{~m}^{3} / \mathrm{m}^{2} \mathrm{~d} ; 1.146 \mathrm{~m}^{3} / \mathrm{m}^{2} \mathrm{~d}$ e $1.528 \mathrm{~m}^{3} / \mathrm{m}^{2} \mathrm{~d}$ ?

Desses três quesitos, optou-se por discutir, inicialmente, o primeiro. Para tanto, foram realizadas análises estatísticas dos valores de eficiência de remoção de sólidos suspensos voláteis (SSV) obtidos a partir de concentrações de SSV encontradas em amostras coletadas em doze amostragens, quatro por TAS, sendo que, cada amostragem consistia na coleta de duas amostras de um litro, uma de esgoto sanitário afluente e outra de esgoto sanitário efluente do SHV.

Para cada amostra foram feitas determinações de concentração de SSV, em quadruplicata, e os valores médios obtidos são mostrados na Tabela 5.2, juntamente com seus respectivos valores de eficiência de remoção de SSV, com as médias aritméticas destes valores de eficiência (uma para cada TAS estudada) e com os desvios padrões destas médias. 
Tabela 5.2 - Concentrações de sólidos suspensos voláteis do esgoto sanitário afluente e efluente do SHV, respectivos valores de eficiência de remoção e as eficiências médias de remoção e seus desvios padrões para as TAS de $764 \mathrm{~m}^{3} / \mathrm{m}^{2} \mathrm{~d} ; 1.146 \mathrm{~m}^{3} / \mathrm{m}^{2} \mathrm{~d}$ e 1.528 $\mathrm{m}^{3} / \mathrm{m}^{2} \mathrm{~d}$.

\begin{tabular}{|c|c|c|}
\hline \multicolumn{3}{|c|}{$Q=10 \mathrm{l} / \mathrm{s}\left(\mathrm{TAS}=764 \mathrm{~m}^{3} / \mathrm{m}^{2} \mathrm{~d}\right)$} \\
\hline $\mathrm{SSV}_{\text {afluente }}(\mathrm{mg} / \mathrm{l})$ & $\mathrm{SSV}_{\text {efluente }}(\mathrm{mg} / \mathbf{l})$ & $\begin{array}{c}\text { Eficiência de } \\
\text { Remoção (\%) }\end{array}$ \\
\hline 256 & 247 & 3,5 \\
\hline 252 & 247 & 2,1 \\
\hline 358 & 344 & 4,0 \\
\hline 260 & 262 & $-0,6$ \\
\hline \multicolumn{2}{|c|}{ Média das Eficiências de Remoção } & 2,27 \\
\hline \multicolumn{2}{|r|}{ Desvio Padrão } & 2,08 \\
\hline \multicolumn{3}{|c|}{$Q=15 \mathrm{l} / \mathrm{s}\left(\mathrm{TAS}=1.146 \mathrm{~m}^{3} / \mathrm{m}^{2} \mathrm{~d}\right)$} \\
\hline $\mathrm{SSV}_{\text {afluente }}(\mathrm{mg} / \mathrm{l})$ & $\mathrm{SSV}_{\text {efluente }}(\mathrm{mg} / \mathrm{l})$ & $\begin{array}{l}\text { Eficiência de } \\
\text { Remoção (\%) }\end{array}$ \\
\hline 329 & 329 & $-0,2$ \\
\hline 645 & 601 & 6,9 \\
\hline 319 & 316 & 0,4 \\
\hline 326 & 351 & $-7,5$ \\
\hline \multicolumn{2}{|c|}{ Média das Eficiências de Remoção } & $-0,11$ \\
\hline & Desvio Padrão & 5,89 \\
\hline \multicolumn{3}{|c|}{$Q=20 \mathrm{l} / \mathrm{s}\left(\mathrm{TAS}=1.528 \mathrm{~m}^{3} / \mathrm{m}^{2} \mathrm{~d}\right)$} \\
\hline $\mathrm{SSV}_{\text {afluente }}(\mathrm{mg} / \mathrm{l})$ & $\operatorname{SSV}_{\text {efluente }}(\mathrm{mg} / \mathrm{l})$ & $\begin{array}{l}\text { Eficiência de } \\
\text { Remoção (\%) }\end{array}$ \\
\hline 352 & 339 & 3,5 \\
\hline 330 & 314 & 4,7 \\
\hline 421 & 398 & 5,6 \\
\hline 310 & 330 & $-6,5$ \\
\hline \multicolumn{2}{|c|}{ Média das Eficiências de Remoção } & 1,80 \\
\hline & Desvio Padrão & $\mathbf{5 , 5 9}$ \\
\hline
\end{tabular}

Nota-se, na Tabela 5.2, que o SHV apresentou eficiências médias de remoção de SSV bastante baixas $\left(2,3 \%\right.$ para TAS de $764 \mathrm{~m}^{3} / \mathrm{m}^{2} \mathrm{~d} ;-0,1 \%$ para TAS de $1.146 \mathrm{~m}^{3} / \mathrm{m}^{2} \mathrm{~d}$ e $1,8 \%$ para TAS de $1.528 \mathrm{~m}^{3} / \mathrm{m}^{2} \mathrm{~d}$ ) e que confrontação destes valores médios com seus desvios padrões sugere que o SHV, praticamente, não removeu SSV quando operado com TAS de $764 \mathrm{~m}^{3} / \mathrm{m}^{2} \mathrm{~d} ; 1.146 \mathrm{~m}^{3} / \mathrm{m}^{2} \mathrm{~d}$ e $1.528 \mathrm{~m}^{3} / \mathrm{m}^{2} \mathrm{~d}$. Porém, para comprovar estatisticamente esta afirmação, foram realizados testes de hipóteses (Teste-t) das 
médias populacionais das eficiências de remoção de SSV. Para tanto, foram testadas as hipóteses das eficiências de remoção de SSV para as TAS de $764 \mathrm{~m}^{3} / \mathrm{m}^{2} \mathrm{~d} ; 1.146 \mathrm{~m}^{3} / \mathrm{m}^{2} \mathrm{~d}$ e $1.528 \mathrm{~m}^{3} / \mathrm{m}^{2} \mathrm{~d}$ serem nulas. Tais testes foram montados de acordo com as Equações 5.7 e 5.8 e seus resultados são mostrados na Tabela 5.3 .

$$
\begin{aligned}
& \mathrm{H}_{0}: \mu_{\text {ef. }}=0 \\
& \mathrm{H}_{\mathrm{a}}: \mu_{\text {ef. }} \neq 0 \\
& \mathrm{RC}=\left\{\mathrm{t} \in \mathfrak{R}: \mathrm{t}_{\text {obs }}<-\mathrm{t}_{\text {crítico }} \text { ou } \mathrm{t}_{\text {obs }}>\mathrm{t}_{\text {crítico }}\right\}
\end{aligned}
$$

Em que:

$\mathrm{H}_{0}$ : hipótese nula;

$\mathrm{H}_{\mathrm{a}}$ : hipótese alternativa;

$\mu_{\text {ef.: }}$ média populacional das eficiências de remoção;

RC: região crítica de não aceitação da hipótese nula;

tobs: parâmetro estatístico padronizado do Teste-t calculado a partir das médias amostrais e de seus desvios padrões;

$\mathrm{t}_{\text {crítico: }}$ : parâmetro estatístico limite da região crítica, obtido da distribuição $\mathrm{t}$ Student com $n$-1 graus de liberdade e nível de significância $\alpha$.

Como pode ser observado na Tabela 5.3, nenhum dos valores de $\mathrm{t}_{\mathrm{obs}}$ pertence à região crítica de não aceitação da hipótese nula, isto é, eficiência de remoção de SSV igual a zero. Por conseguinte, pode-se concluir que o SHV não removeu, significativamente, matéria orgânica particulada "finamente dividida" (medida em termos de concentração de SSV) presente no esgoto sanitário afluente da ETE Jardim das Flores, ao ser operado com TAS de $764 \mathrm{~m}^{3} / \mathrm{m}^{2} \mathrm{~d} ; 1.146 \mathrm{~m}^{3} / \mathrm{m}^{2} \mathrm{~d}$ e $1.528 \mathrm{~m}^{3} / \mathrm{m}^{2} \mathrm{~d}$. 
Tabela 5.3 - Parâmetros estatísticos usados para a realização dos testes de hipóteses para a eficiência de remoção de sólidos suspensos voláteis.

\begin{tabular}{|c|c|}
\hline \multicolumn{2}{|c|}{$\begin{array}{l}\text { Teste-t: Teste da hipótese das eficiências médias de remoção de } \\
\text { SSV serem iguais a zero; com nível de significância } \alpha=0,05\end{array}$} \\
\hline Parâmetros Estatísticos & $764 \mathrm{~m}^{3} / \mathrm{m}^{2} d$ \\
\hline Eficiência média de remoção de SSV (\%) & 2,27 \\
\hline Desvio padrão & 2,08 \\
\hline Observações $(n)$ & 4 \\
\hline Graus de liberdade & 3 \\
\hline Stat $t\left(t_{\text {obs }}\right)$ & 2,1827 \\
\hline $\mathrm{t}_{\text {crítico }}$ bi-caudal & 3,1820 \\
\hline \multicolumn{2}{|c|}{$\mathrm{RC}=\left\{\mathrm{t} \in \mathfrak{R}: \mathrm{t}_{\mathrm{obs}}<-3,1820\right.$ ou $\left.\mathrm{t}_{\mathrm{obs}}>3,1820\right\}$} \\
\hline Parâmetros Estatísticos & $1.146 \mathrm{~m}^{3} / \mathrm{m}^{2} d$ \\
\hline Eficiência média de remoção de SSV (\%) & $-0,11$ \\
\hline Desvio padrão & 5,89 \\
\hline Observações $(n)$ & 4 \\
\hline Graus de liberdade & 3 \\
\hline Stat $\mathrm{t}\left(\mathrm{t}_{\mathrm{obs}}\right)$ & 0,0374 \\
\hline$t_{\text {crítico }}$ bi-caudal & 3,1820 \\
\hline \multicolumn{2}{|c|}{$\mathrm{RC}=\left\{\mathrm{t} \in \mathfrak{R}: \mathrm{t}_{\mathrm{obs}}<-3,1820\right.$ ou $\left.\mathrm{t}_{\mathrm{obs}}>3,1820\right\}$} \\
\hline Parâmetros Estatísticos & $1.528 \mathrm{~m}^{3} / \mathrm{m}^{2} d$ \\
\hline Eficiência média de remoção de SSV (\%) & 1,80 \\
\hline Desvio padrão & 5,59 \\
\hline Observações $(n)$ & 4 \\
\hline Graus de liberdade & 3 \\
\hline Stat $t\left(t_{\text {obs }}\right)$ & 0,6440 \\
\hline$t_{\text {crítico }}$ bi-caudal & 3,1820 \\
\hline $\mathrm{RC}=\left\{\mathrm{t} \in \mathfrak{R}: \mathrm{t}_{\mathrm{obs}}<-3,1820 \mathrm{ou}\right.$ & $820\}$ \\
\hline
\end{tabular}

Nos parágrafos anteriores foram apresentadas evidências que atestam ineficácia do SHV na remoção de matéria orgânica particulada medida em termos de SSV. Porém, um desarenador eficaz, além de não separar os sólidos orgânicos do esgoto sanitário, deve ser capaz de remover areia presente no afluente líquido usado para alimentá-lo, por esta ser sua principal função. Para verificar a eficiência do SHV desenvolvido na presente pesquisa no cumprimento de tal tarefa, foram analisados valores de eficiência de remoção de areia calculados a partir das concentrações de areia encontradas em 
amostras coletadas em vinte e quatro amostragens, oito por TAS estudada $\left(764 \mathrm{~m}^{3} / \mathrm{m}^{2} \mathrm{~d}\right.$; $1.146 \mathrm{~m}^{3} / \mathrm{m}^{2} \mathrm{~d} ; 1.528 \mathrm{~m}^{3} / \mathrm{m}^{2} \mathrm{~d}$ ), sendo que, cada amostragem consistia na coleta de duas amostras de um litro, uma de esgoto sanitário afluente e outra de esgoto sanitário efluente do SHV.

As concentrações de areia encontradas em cada amostra e as eficiências de remoção de areia calculadas com a Equação 5.3, assim como as médias geométricas e os desvios padrões de todos esses valores foram agrupados em tabelas de acordo com a TAS. Na Tabela 5.4 foram tabulados os dados referente à TAS de $764 \mathrm{~m}^{3} / \mathrm{m}^{2} \mathrm{~d}$, na Tabela 5.5 os dados referente à TAS de $1.146 \mathrm{~m}^{3} / \mathrm{m}^{2} \mathrm{~d}$ e na Tabela 5.6 os dados referente à TAS de $1.528 \mathrm{~m}^{3} / \mathrm{m}^{2} \mathrm{~d}$.

Contudo, os dados mostrados nas Tabelas 5.4; 5.5 e 5.6 são valores amostrais e como tal não devem ser generalizados. Por essa razão, foram estimados valores médios populacionais que representam, significativamente, todo o universo amostral, isto é, foram calculados os intervalos de confiança (IC): das concentrações de areia no esgoto sanitário afluente e efluente do SHV e dos valores de eficiência de remoção de areia, para as TAS de $764 \mathrm{~m}^{3} / \mathrm{m}^{2} \mathrm{~d} ; 1.146 \mathrm{~m}^{3} / \mathrm{m}^{2} \mathrm{~d}$ e $1.528 \mathrm{~m}^{3} / \mathrm{m}^{2} \mathrm{~d}$ Todos estes valores são mostrados na Tabela 5.7.

Tabela 5.4 - Valores de concentração de areia presente em cada uma das amostras de esgoto sanitário afluente e efluente do SHV, valores de eficiência de remoção de areia calculados com a Equação 5.3, assim como as médias geométricas e os desvios padrões de todos esses valores. Condições operacionais: TAS de $764 \mathrm{~m}^{3} / \mathrm{m}^{2} \mathrm{~d}(10 \mathrm{l} / \mathrm{s})$.

\begin{tabular}{|c|c|c|c|c|}
\hline \multirow{2}{*}{ Data } & \multirow{2}{*}{ Horário } & \multicolumn{2}{|c|}{ Concentração (mg/L) } & \multirow{2}{*}{$\begin{array}{l}\text { Eficiência de } \\
\text { Remoção (\%) }\end{array}$} \\
\hline & & Esgoto Bruto & Efluente & \\
\hline $6 / 10 / 2005$ & $10 \mathrm{~h} 30 \mathrm{~min}$ & 32 & 5 & 86 \\
\hline $6 / 10 / 2005$ & $11 \mathrm{~h} 30 \mathrm{~min}$ & 16 & 3 & 81 \\
\hline $6 / 10 / 2005$ & $12 \mathrm{~h} 30 \mathrm{~min}$ & 5 & 2 & 53 \\
\hline $6 / 10 / 2005$ & 13h30min & 8 & 2 & 72 \\
\hline $11 / 10 / 2005$ & 14h30min & 55 & 6 & 89 \\
\hline $11 / 10 / 2005$ & $15 \mathrm{~h} 30 \mathrm{~min}$ & 10 & 8 & 18 \\
\hline $11 / 10 / 2005$ & $16 \mathrm{~h} 30 \mathrm{~min}$ & 14 & 5 & 65 \\
\hline $11 / 10 / 2005$ & $17 \mathrm{~h} 30 \mathrm{~min}$ & 21 & 4 & 79 \\
\hline \multicolumn{2}{|c|}{ Médias Geométrica } & 15,5 & 4,1 & 61,9 \\
\hline \multicolumn{2}{|c|}{ Desvio Padrão } & 17,05 & 2,12 & 24,13 \\
\hline
\end{tabular}

Os dados em negrito marcam as amostras para as quais foram determinadas as distribuições granulométricas dos grãos de areia. 
Tabela 5.5 - Valores de concentração de areia presente em cada uma das amostras de esgoto sanitário afluente e efluente do SHV, valores de eficiência de remoção de areia calculados com a Equação 5.3, assim como as médias geométricas e os desvios padrões de todos esses valores. Condições operacionais: TAS de1146 m³ $/ \mathrm{m}^{2} \mathrm{~d}(15 \mathrm{l} / \mathrm{s})$.

\begin{tabular}{|c|c|c|c|c|}
\hline \multirow{2}{*}{ Data } & \multirow{2}{*}{$\begin{array}{c}\text { Tempo } \\
\text { (h) }\end{array}$} & \multicolumn{2}{|c|}{ Concentração (mg/L) } & \multirow{2}{*}{$\begin{array}{c}\text { Eficiência } \\
\text { Remoção (\%) }\end{array}$} \\
\hline & & Esgoto Bruto & Efluente & \\
\hline $4 / 11 / 2005$ & $10 \mathrm{h30min}$ & 45 & 14 & 69 \\
\hline $4 / 11 / 2005$ & $11 \mathrm{~h} 30 \mathrm{~min}$ & 37 & 13 & 67 \\
\hline $4 / 11 / 2005$ & $12 \mathrm{~h} 30 \mathrm{~min}$ & 37 & 9 & 77 \\
\hline $4 / 11 / 2005$ & 13h30min & 27 & 12 & 57 \\
\hline $17 / 11 / 2005$ & $14 \mathrm{~h} 30 \mathrm{~min}$ & 28 & 8 & 70 \\
\hline $17 / 11 / 2005$ & $15 \mathrm{~h} 30 \mathrm{~min}$ & 21 & 6 & 74 \\
\hline $17 / 11 / 2005$ & $16 \mathrm{~h} 30 \mathrm{~min}$ & 20 & 6 & 67 \\
\hline $17 / 11 / 2005$ & 17h30min & 14 & 1 & 91 \\
\hline \multicolumn{2}{|c|}{ Média Geométrica } & 26,9 & 7,1 & 70,9 \\
\hline \multicolumn{2}{|c|}{ Desvio Padrão } & 10,62 & 4,38 & 9,78 \\
\hline
\end{tabular}

Os dados em negrito marcam as amostras para as quais foram determinadas as distribuições granulométricas dos grãos de areia.

Tabela 5.6 - Valores de concentração de areia presente em cada uma das amostras de esgoto sanitário afluente e efluente do SHV, valores de eficiência de remoção de areia calculados com a Equação 5.3, assim como as médias geométricas e os desvios padrões de todos esses valores. Condições operacionais: TAS de $1528 \mathrm{~m}^{3} / \mathrm{m}^{2} \mathrm{~d}(201 / \mathrm{s})$.

\begin{tabular}{|c|c|c|c|c|}
\hline \multirow{2}{*}{ Data } & \multirow{2}{*}{$\begin{array}{c}\text { Tempo } \\
\text { (h) }\end{array}$} & \multicolumn{2}{|c|}{ Concentração (mg/L) } & \multirow{2}{*}{$\begin{array}{c}\text { Eficiência } \\
\text { Remoção (\%) }\end{array}$} \\
\hline & & Esgoto Bruto & Efluente & \\
\hline $9 / 11 / 2005$ & $10 \mathrm{~h} 30 \mathrm{~min}$ & 78 & 9 & 88 \\
\hline 9/11/2005 & $11 \mathrm{~h} 30 \mathrm{~min}$ & 179 & 10 & 95 \\
\hline $9 / 11 / 2005$ & $12 \mathrm{~h} 30 \mathrm{~min}$ & 45 & 6 & 87 \\
\hline $9 / 11 / 2005$ & $13 \mathrm{~h} 30 \mathrm{~min}$ & 43 & 3 & 93 \\
\hline $21 / 11 / 2005$ & $14 \mathrm{h30min}$ & 112 & 16 & 85 \\
\hline $21 / 11 / 2005$ & $15 \mathrm{~h} 30 \mathrm{~min}$ & 89 & 10 & 89 \\
\hline $21 / 11 / 2005$ & $16 \mathrm{~h} 30 \mathrm{~min}$ & 207 & 10 & 95 \\
\hline $21 / 11 / 2005$ & 17h30min & 38 & 6 & 83 \\
\hline \multicolumn{2}{|c|}{ Média Geométrica } & 82,1 & 8,0 & 89,2 \\
\hline \multicolumn{2}{|c|}{ Desvio Padrão } & 66,27 & 4,01 & 4,46 \\
\hline
\end{tabular}

Os dados em negrito marcam as amostras para as quais foram determinadas as distribuições granulométricas dos grãos de areia. 
Observando os intervalos de confiança da Tabela 5.7, nota-se que o SHV apresentou altas eficiências de remoção de areia para todas as TAS estudadas (de $42 \%$ a $82 \%$ para a TAS de $764 \mathrm{~m}^{3} / \mathrm{m}^{2}$ d; de $63 \%$ a $79 \%$ para TAS de $1.146 \mathrm{~m}^{3} / \mathrm{m}^{2}$ d; de $85 \%$ e $93 \%$ para a TAS de $1.528 \mathrm{~m}^{3} / \mathrm{m}^{2} \mathrm{~d}$ ). Porém, dada a amplitude dos intervalos de confiança, tanto da concentração de areia no esgoto sanitário afluente da unidade como da eficiência de remoção de areia, não é possível identificar para qual TAS o SHV apresentou melhores eficiências de remoção de areia.

Tabela 5.7 - Intervalos de confiança (ICs) com nível de significância de 95\% das médias populacionais das concentrações de areia das amostras de esgoto sanitário afluente e efluente do SHV, e das eficiências de remoção de areia observadas para as TAS de $764 \mathrm{~m}^{3} / \mathrm{m}^{2} \mathrm{~d} ; 1146 \mathrm{~m}^{3} / \mathrm{m}^{2} \mathrm{~d}$ e $1528 \mathrm{~m}^{3} / \mathrm{m}^{2} \mathrm{~d}$.

\begin{tabular}{|c|c|}
\hline TAS & Concentração de Areia no Afluente do SHV \\
\hline $764 \mathrm{~m}^{3} / \mathrm{m}^{2} \mathrm{~d}$ & $\mathrm{IC}\left(\mu_{\mathrm{a}} ; 95 \%\right)=[1,2 \mathrm{mg} / \mathrm{l} ; 29,7 \mathrm{mg} / \mathrm{l}]$ \\
\hline $1.146 \mathrm{~m}^{3} / \mathrm{m}^{2}$ & $\mathrm{IC}\left(\mu_{\mathrm{a}} ; 95 \%\right)=[18,0 \mathrm{mg} / 1 ; 35,8 \mathrm{mg} / 1]$ \\
\hline $1.528 \mathrm{~m}^{3} / \mathrm{m}^{2} \mathrm{~d}$ & $\mathrm{IC}\left(\mu_{\mathrm{a}} ; 95 \%\right)=[26,6 \mathrm{mg} / 1 ; 137,4 \mathrm{mg} / \mathrm{l}]$ \\
\hline TAS & Concentração de Areia no Efluente do SHV \\
\hline $764 \mathrm{~m}^{3} / \mathrm{m}^{2} \mathrm{~d}$ & $\mathrm{IC}\left(\mu_{\mathrm{a}} ; 95 \%\right)=[2,3 \mathrm{mg} / 1 ; 5,9 \mathrm{mg} / \mathrm{l}]$ \\
\hline $1.146 \mathrm{~m}^{3} / \mathrm{m}^{2}$ & $\mathrm{IC}\left(\mu_{\mathrm{a}} ; 95 \%\right)=[3,4 \mathrm{mg} / 1 ; 10,8 \mathrm{mg} / \mathrm{l}]$ \\
\hline $1.528 \mathrm{~m}^{3} / \mathrm{m}^{2} \mathrm{~d}$ & $\mathrm{IC}\left(\mu_{\mathrm{a}} ; 95 \%\right)=[4,6 \mathrm{mg} / 1 ; 11,3 \mathrm{mg} / 1]$ \\
\hline TAS & Eficiência de Remoção de Areia \\
\hline $764 \mathrm{~m}^{3} / \mathrm{m}^{2} \mathrm{~d}$ & $\mathrm{IC}\left(\mu_{\mathrm{ef}} ; 95 \%\right)=[41,7 \% ; 82,1 \%]$ \\
\hline $1.146 \mathrm{~m}^{3} / \mathrm{m}^{2}$ & $\operatorname{IC}\left(\mu_{\mathrm{ef}} ; 95 \%\right)=[62,8 \% ; 79,1 \%]$ \\
\hline $1.528 \mathrm{~m}^{3} / \mathrm{m}^{2} \mathrm{~d}$ & $\operatorname{IC}\left(\mu_{\mathrm{ef}} ; 95 \%\right)=[85,5 \% ; 93,0 \%]$ \\
\hline intervalos de & $\begin{array}{l}\text { foram calculados com base na distribuição de } \\
\text { on nível de significância de } 95 \% \text { e com } 7 \text { graus de } \\
\text { media populacional de areia no esgoto sanitário afluente } \\
\text { iência média populacional de remoção de areia. }\end{array}$ \\
\hline
\end{tabular}

Até este ponto, foram respondidos dois dos três quesitos apresentados no início dessa seção; por conseguinte já se sabe que o SHV foi capaz de remover areia do esgoto sanitário com alta eficiência, sem remover matéria orgânica particulada (medida em termos de concentração SSV) presente em seu afluente; porém, para que se comprove a eficácia da unidade ainda falta responder uma última questão: o SHV produz efluentes 
livres de grãos de areia de tamanho maior ou igual a $200 \mu \mathrm{m}$, ao ser operado com taxas de aplicação superficial (TAS) de $764 \mathrm{~m}^{3} / \mathrm{m}^{2} \mathrm{~d} ; 1.146 \mathrm{~m}^{3} / \mathrm{m}^{2} \mathrm{~d}$ e $1.528 \mathrm{~m}^{3} / \mathrm{m}^{2} \mathrm{~d}$ ?

Para responder essa última pergunta foram determinadas as distribuições numéricas e volumétricas de tamanho de grãos de areia presentes em 24 amostras de esgoto sanitário, as quais estão marcadas em negrito nas Tabelas 5.4, 5.5 e 5.6. A escolha de quais amostras seriam submetidas à determinação da distribuição granulométrica de grãos de areia baseou-se no seguinte critério: primeiro foram selecionadas as amostras que apresentaram a maior e a menor eficiência de remoção de areia para cada uma TAS e depois foram aleatoriamente selecionadas outras duas amostras por TAS. Deste modo, acredita-se que as amostras escolhidas representam adequadamente cada um dos conjuntos de dados mostrados nas Tabelas 5.4, 5.5 e 5.6.

Para cada TAS estudada foram plotados oito gráficos de distribuição de tamanho de grãos de areia; destes, quatro são gráficos de distribuição numérica de tamanho de grãos de areia e quatro são gráficos de distribuição volumétrica de tamanho de grãos de areia. Por razões meramente organizacionais, os gráficos de distribuição volumétrica de tamanho de grãos de areia foram dispostos no Apêndice A desta tese, enquanto os gráficos de distribuição numérica de tamanho de grãos de areia são apresentados neste capítulo e podem ser vistos nas Figuras $5.14 ; 5.15 ; 5.16 ; 5.17 ; 5.18 ; 5.19 ; 5.20 ; 5.21$; $5.22 ; 5.23 ; 5.24$ e 5.25 .

Analisando os gráficos mostrados nas Figuras 5.14, 5.15, 5.16, 5.17, 5.18, 5.19, 5.20, 5.21, 5.22, 5.23, 5.24 e 5.25, nota-se que, quando o SHV foi operado com TAS de $764 \mathrm{~m}^{3} / \mathrm{m}^{2} \mathrm{~d}$, de $0,8 \%$ a $2,7 \%$ do número total de grãos de areia presentes no seu efluente possuíam tamanho maior ou igual a $200 \mu \mathrm{m}$; enquanto que, ao se operar o SHV com as TAS de $1.146 \mathrm{~m}^{3} / \mathrm{m}^{2} \mathrm{~d}$ e $1.528 \mathrm{~m}^{3} / \mathrm{m}^{2} \mathrm{~d}$, este porcentual ficou, aproximadamente, entre $2,0 \%$ e $12,0 \%$. Em média, apenas $5,3 \%$ do número total de grãos de areia presentes no efluente do SHV possuíam tamanho maior ou igual a $200 \mu \mathrm{m}$. Logo, pode-se concluir que SHV desenvolvido na presente pesquisa produziu efluentes com baixa quantidade de grãos de areia de tamanho igual ou superior a $200 \mu \mathrm{m}$, independentemente da TAS empregada para operá-lo.

Dos doze gráficos de distribuição numérica de tamanho de grãos de areia apresentados nesse capítulo, dois (os gráficos mostrados nas Figuras 5.16 e 5.19) 
chamam a atenção por demonstrarem que um desarenador não deve ser avaliado unicamente pela eficiência de remoção de areia que este tipo de unidade pode atingir.

A Figura 5.16 mostra o gráfico de distribuição numérica de tamanho de grãos de areia presentes nas amostras de esgoto sanitário afluente e efluente do SHV, as quais foram coletadas aos 11/10/2005, às $15 \mathrm{~h} 30 \mathrm{~min}$. De acordo com este gráfico, 1,2\% do número total de grãos de areia presentes no efluente do SHV possuíam tamanho maior ou igual a $200 \mu \mathrm{m}$. No entanto, ao se observar a Tabela 5.4, verifica-se que a eficiência de remoção de areia, calculada a partir da concentração de areia dessas amostras, foi de apenas 18\% (menor eficiência de remoção de areia obtida).

O mesmo ocorre com as amostras de esgoto sanitário afluente e efluente do SHV, que foram coletadas aos 04/11/2005, às 13h30min. Como pode ser visto na Tabela 5.5, a eficiência de remoção de areia alcançada pelo SHV para essas amostras foi de $57 \%$ (menor eficiência obtida para a TAS de $1.146 \mathrm{~m}^{3} / \mathrm{m}^{2} \mathrm{~d}$ ); todavia, o gráfico da Figura 5.19 mostra que apenas $2,1 \%$ do número total de grãos de areia presentes no efluente do SHV possuíam tamanho maior ou igual a $200 \mu \mathrm{m}$.

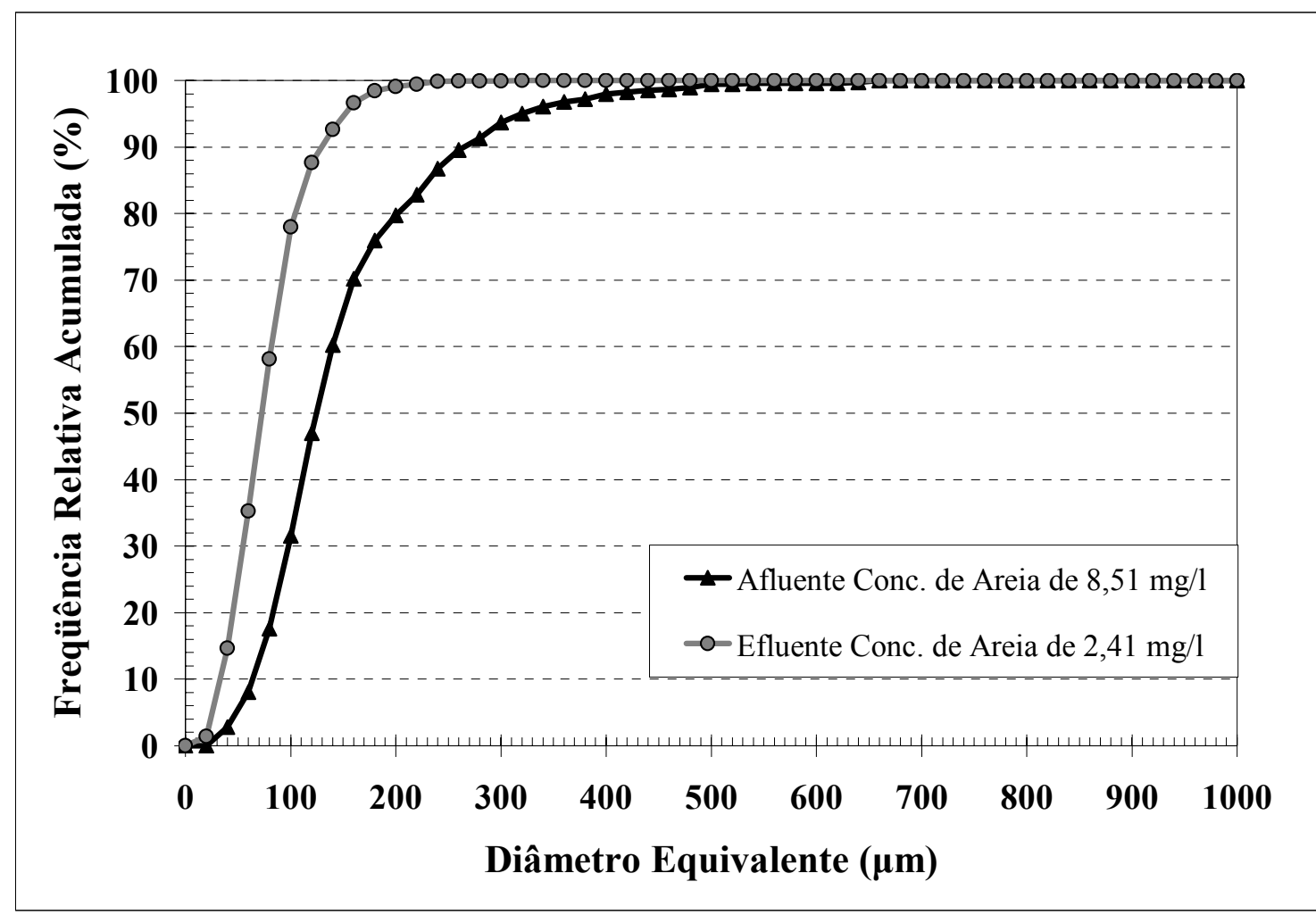

Figura 5.14 - Gráfico de distribuição numérica de tamanho de grãos de areia presentes na amostra coletada aos 06/10/2005 às $13 \mathrm{~h} 30 \mathrm{~min}$. TAS de $764 \mathrm{~m}^{3} / \mathrm{m}^{2} \mathrm{~d}$. 


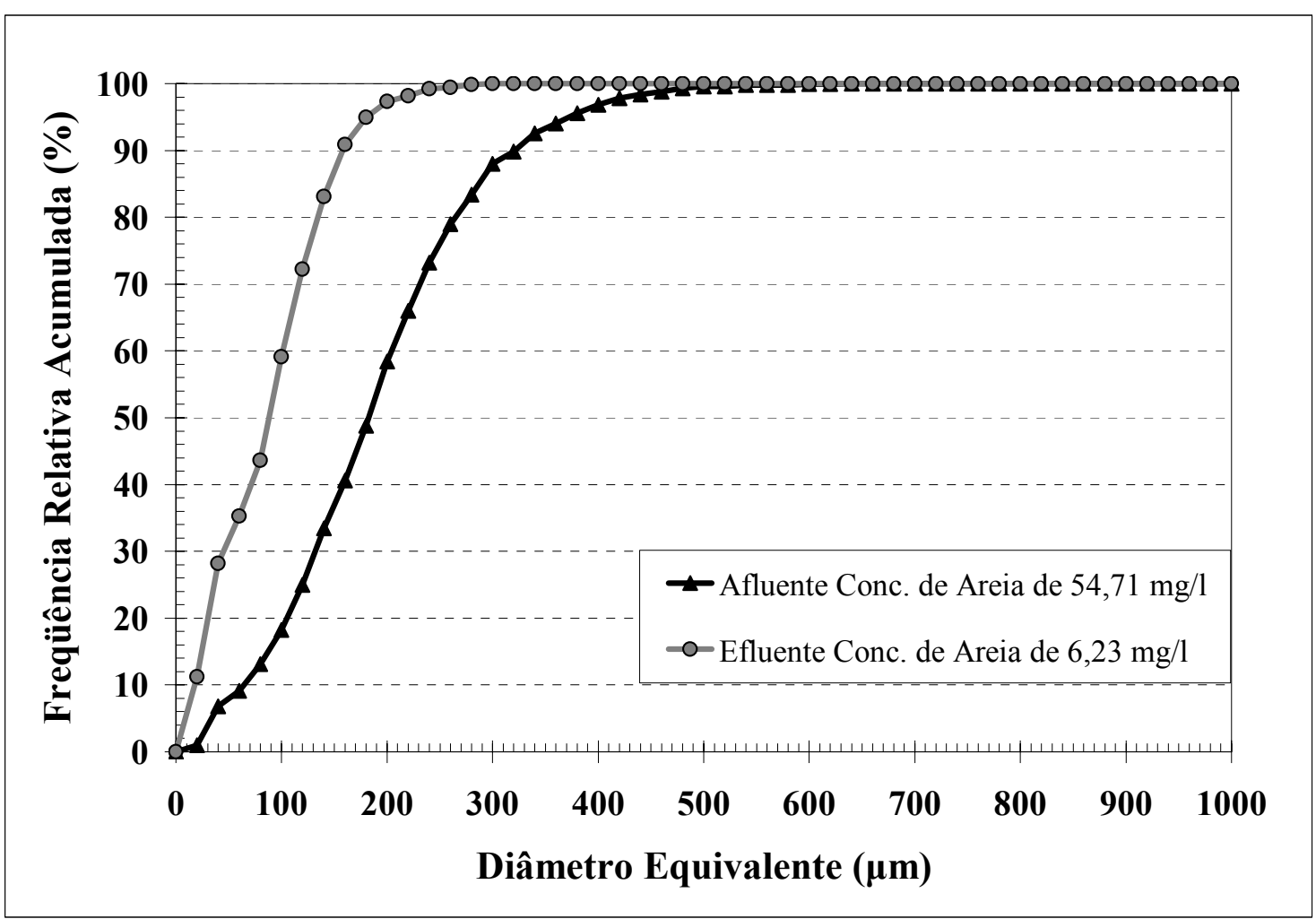

Figura 5.15 - Gráfico de distribuição numérica de tamanho de grãos de areia presentes na amostra coletada aos 11/10/2005 às $14 \mathrm{~h} 30 \mathrm{~min}$. TAS de $764 \mathrm{~m}^{3} / \mathrm{m}^{2} \mathrm{~d}$.

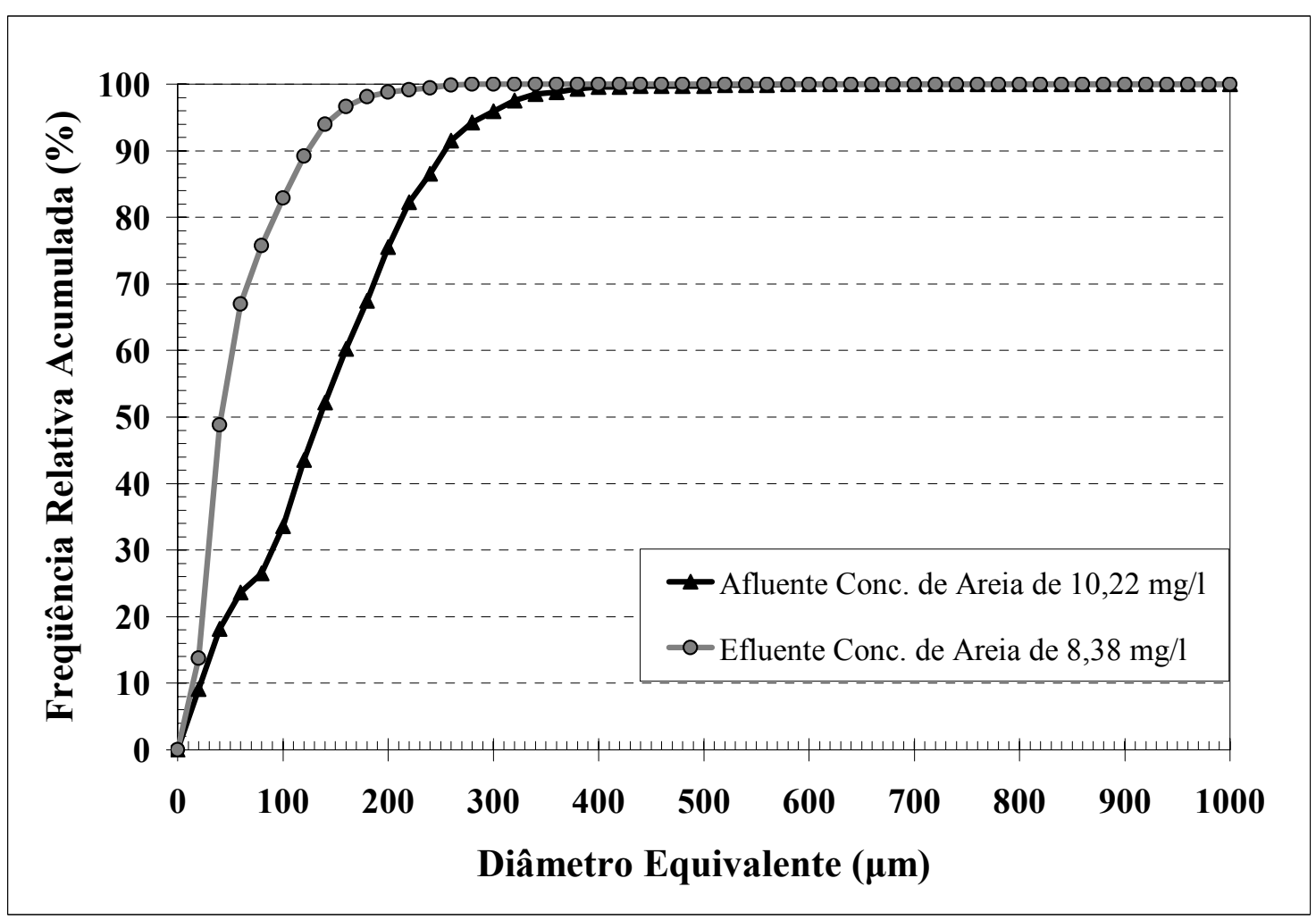

Figura 5.16 - Gráfico de distribuição numérica de tamanho de grãos de areia presentes na amostra coletada aos $11 / 10 / 2005$ às $15 \mathrm{~h} 30 \mathrm{~min}$. TAS de $764 \mathrm{~m}^{3} / \mathrm{m}^{2} \mathrm{~d}$. 


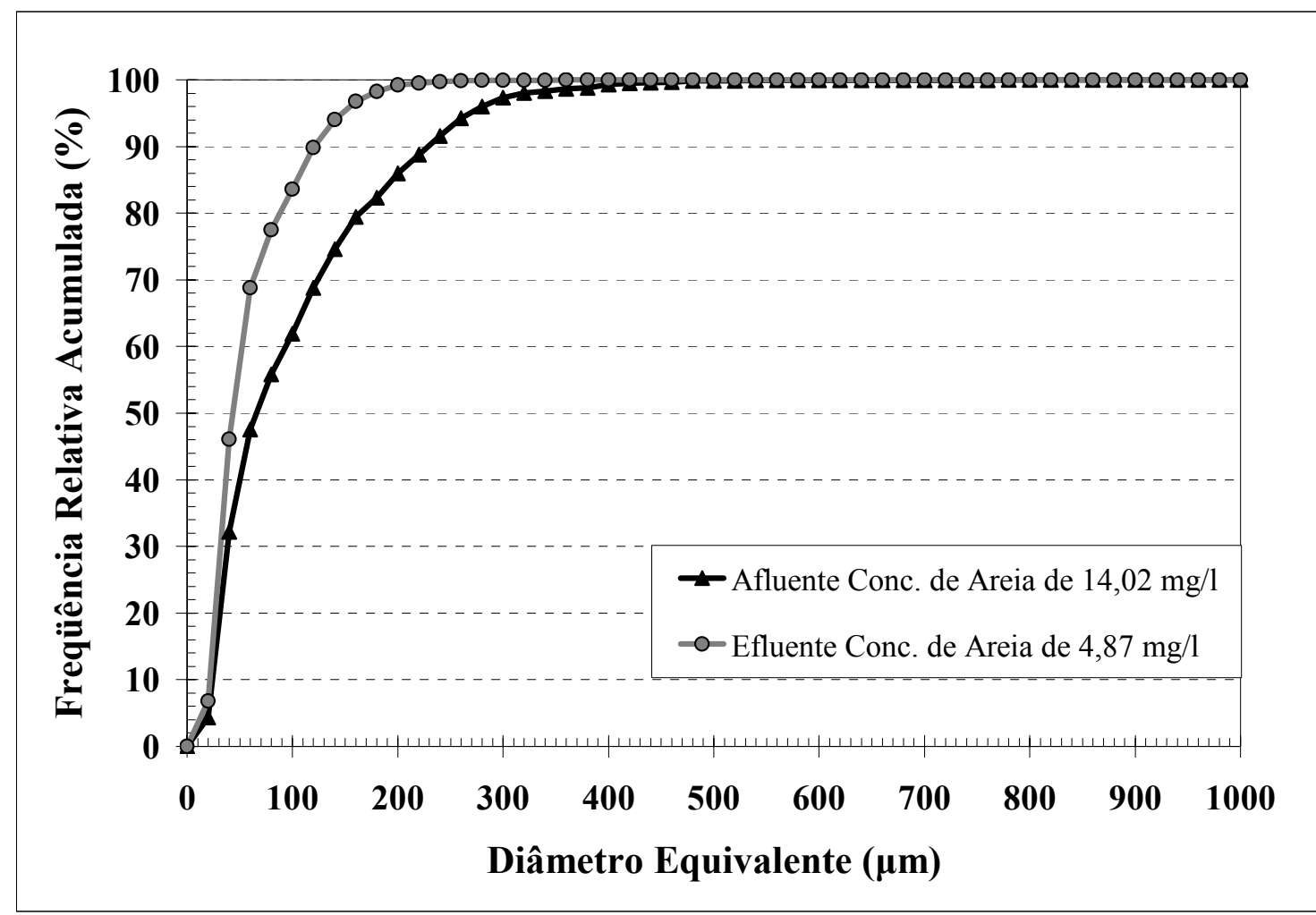

Figura 5.17 - Gráfico de distribuição numérica de tamanho de grãos de areia presentes na amostra coletada aos 11/10/2005 às $16 \mathrm{~h} 30 \mathrm{~min}$. TAS de $764 \mathrm{~m}^{3} / \mathrm{m}^{2} \mathrm{~d}$.

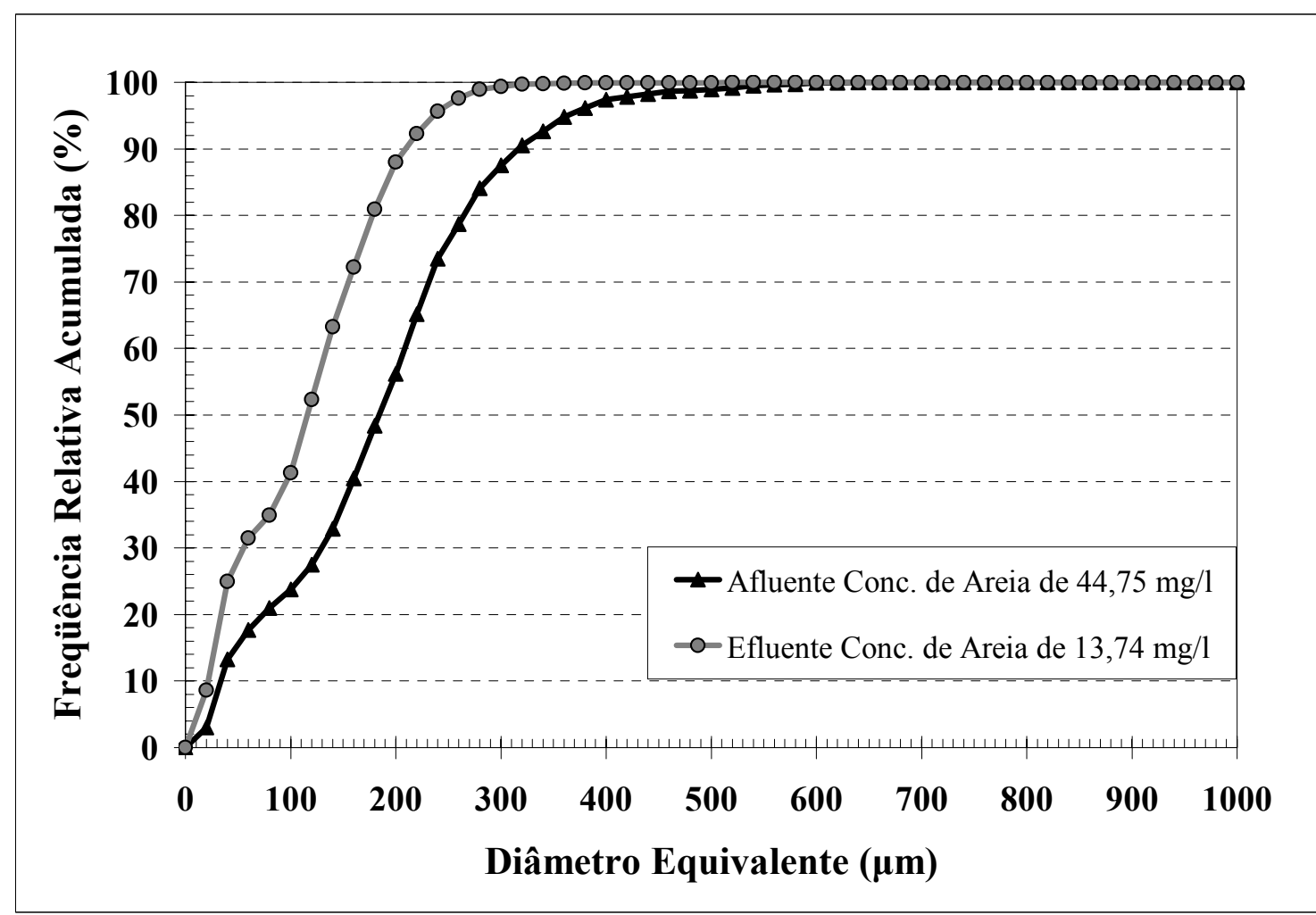

Figura 5.18 - Gráfico de distribuição numérica de tamanho de grãos de areia presentes na amostra coletada aos 04/11/2005 às $10 \mathrm{~h} 30 \mathrm{~min}$. TAS de $1.146 \mathrm{~m}^{3} / \mathrm{m}^{2} \mathrm{~d}$. 


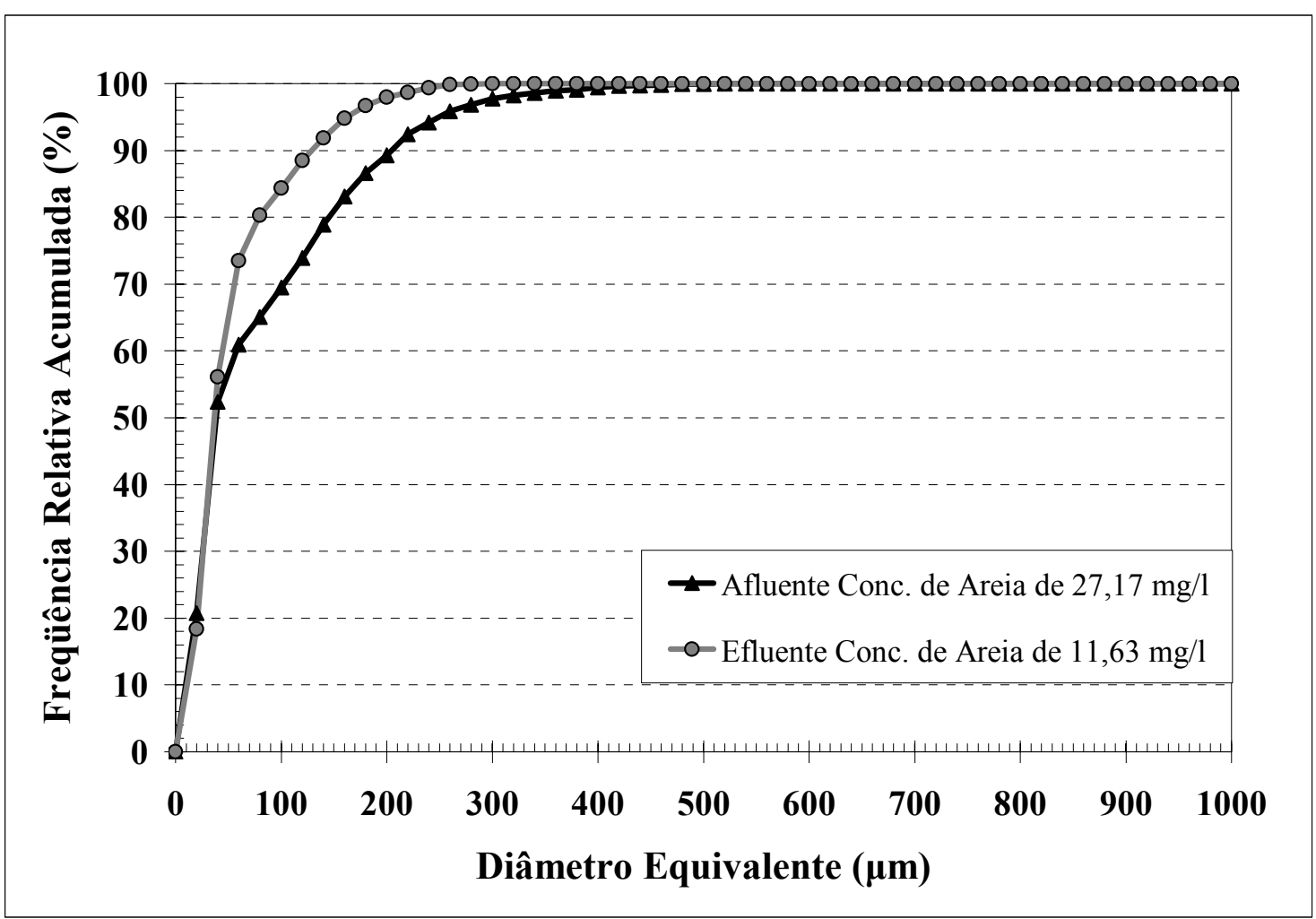

Figura 5.19 - Gráfico de distribuição numérica de tamanho de grãos de areia presentes na amostra coletada aos 04/11/2005 às $13 \mathrm{~h} 30 \mathrm{~min}$. TAS de $1.146 \mathrm{~m}^{3} / \mathrm{m}^{2} \mathrm{~d}$.

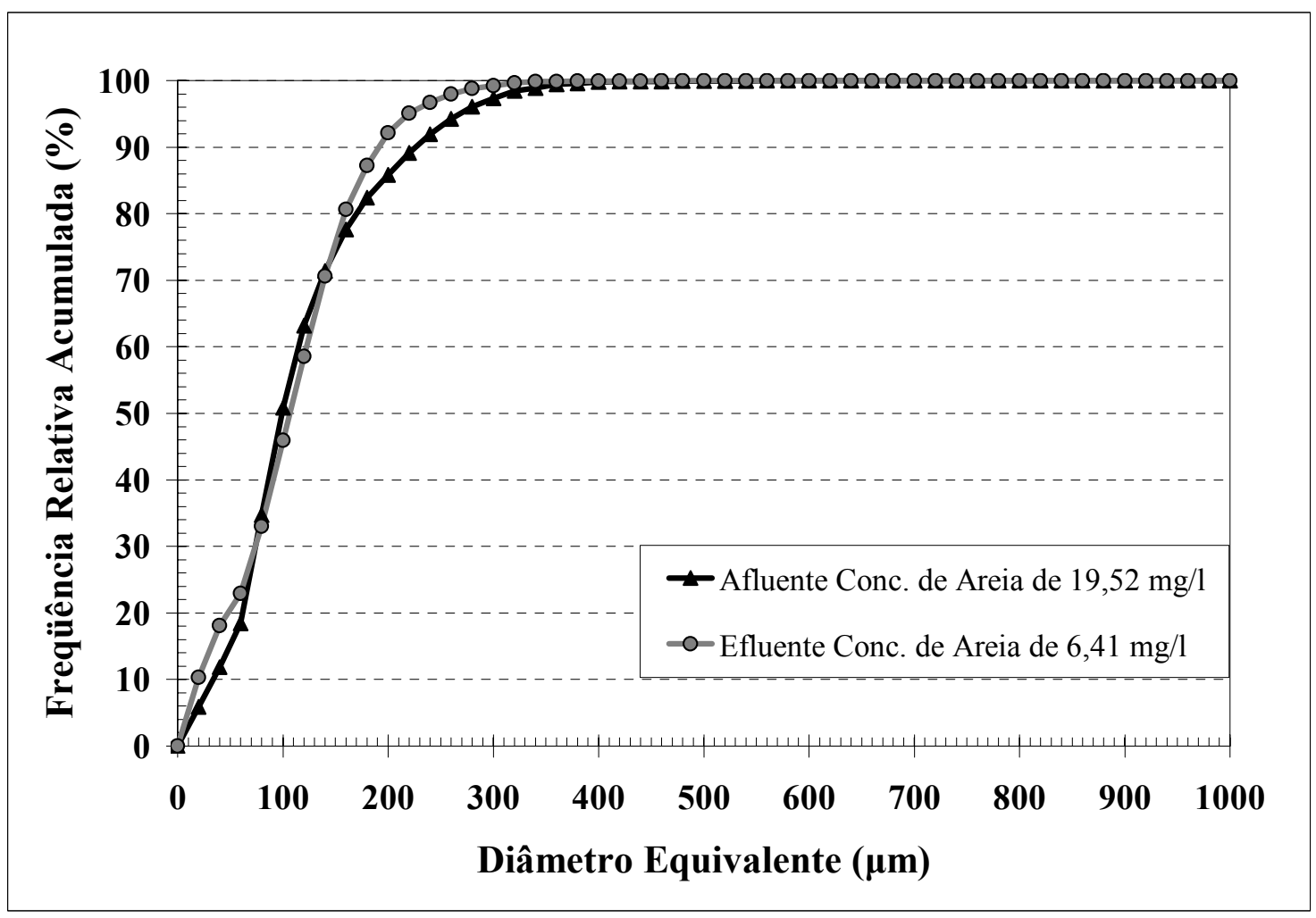

Figura 5.20 - Gráfico de distribuição numérica de tamanho de grãos de areia presentes na amostra coletada aos $17 / 11 / 2005$ às $16 \mathrm{~h} 30 \mathrm{~min}$. TAS de $1.146 \mathrm{~m}^{3} / \mathrm{m}^{2} \mathrm{~d}$. 


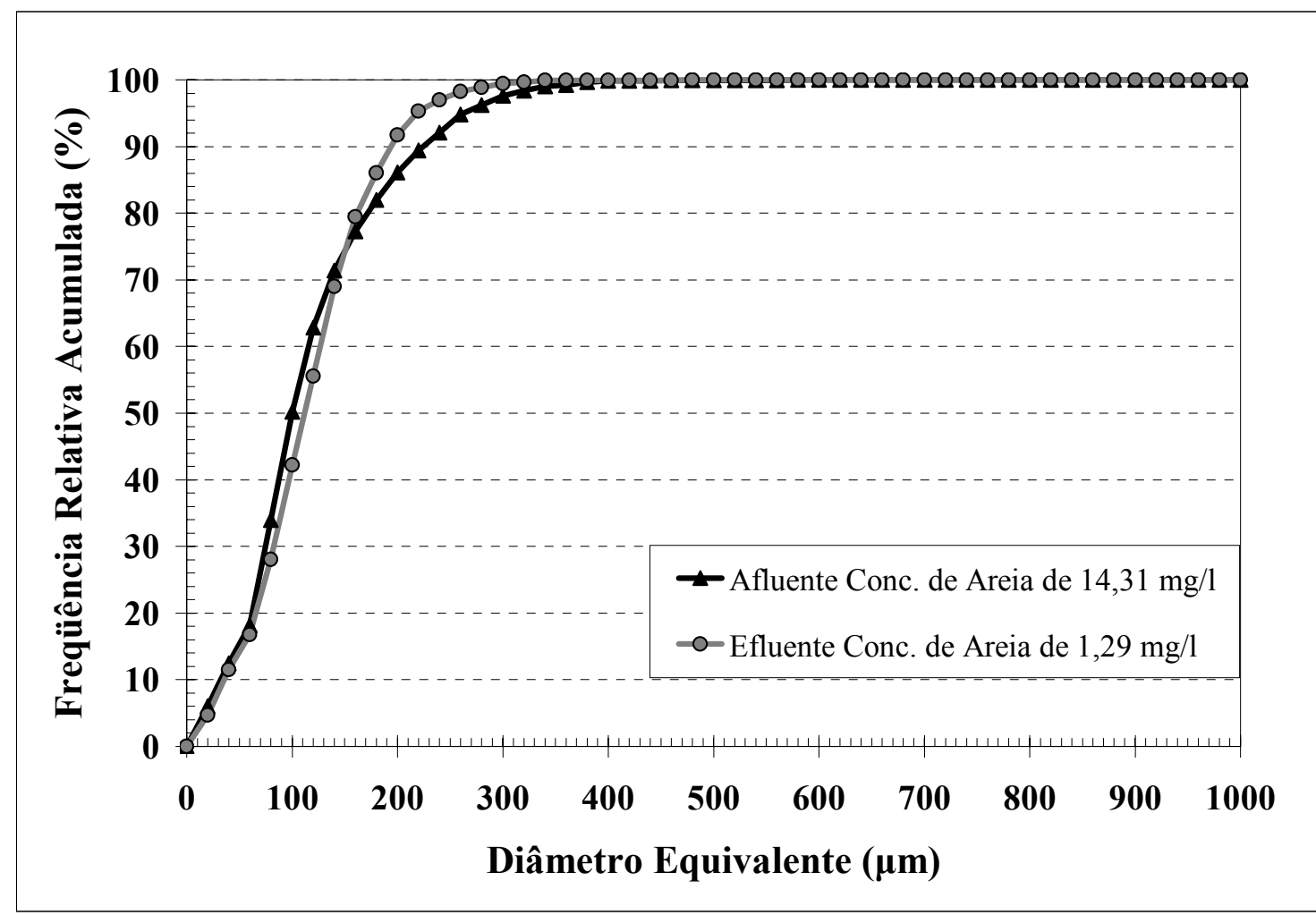

Figura 5.21 - Gráfico de distribuição numérica de tamanho de grãos de areia presentes na amostra coletada aos 17/11/2005 às $17 \mathrm{~h} 30 \mathrm{~min}$. TAS de $1.146 \mathrm{~m}^{3} / \mathrm{m}^{2} \mathrm{~d}$.

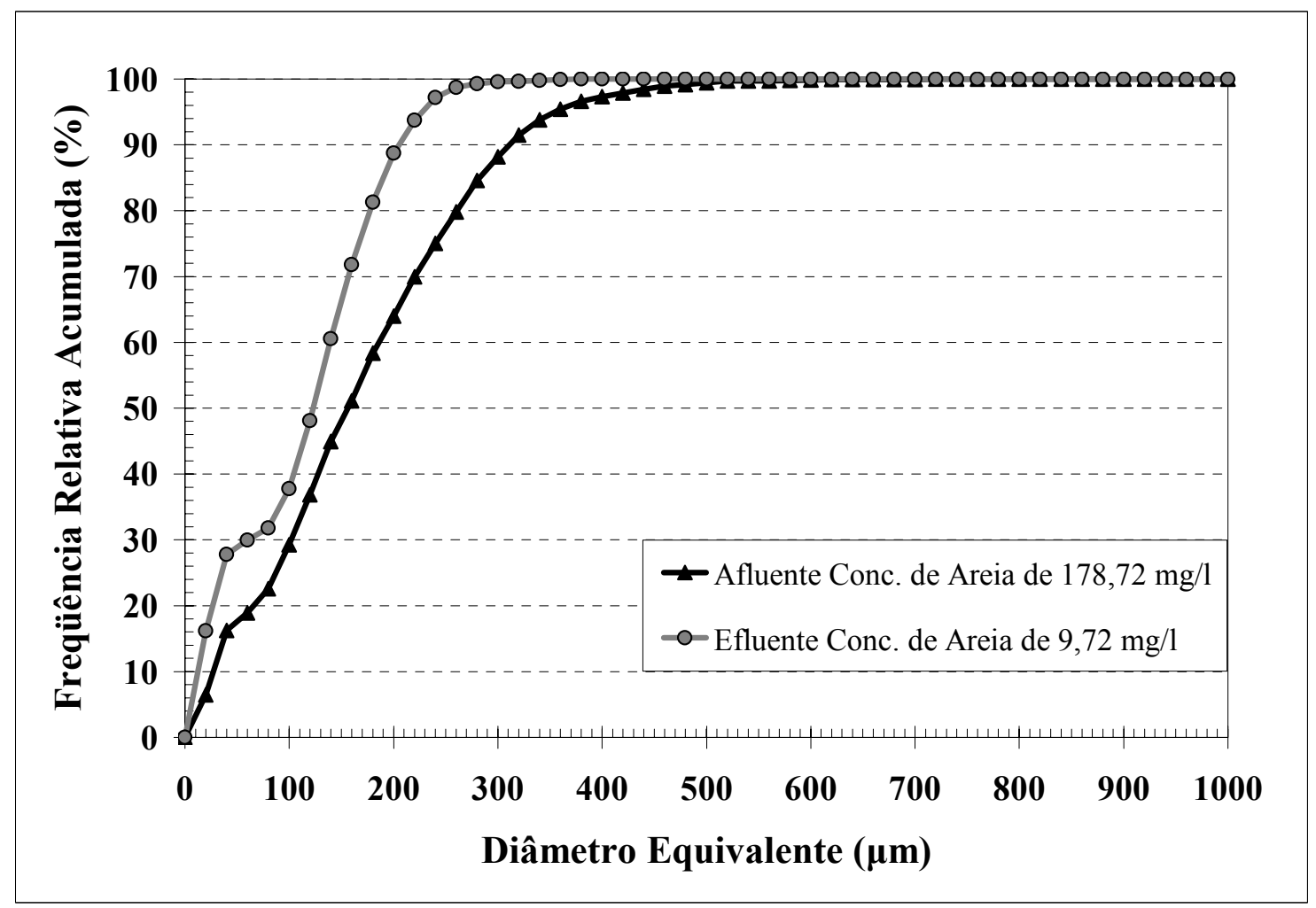

Figura 5.22 - Gráfico de distribuição numérica de tamanho de grãos de areia presentes na amostra coletada aos 09/11/2005 às $11 \mathrm{~h} 30 \mathrm{~min}$. TAS de $1.528 \mathrm{~m}^{3} / \mathrm{m}^{2} \mathrm{~d}$. 


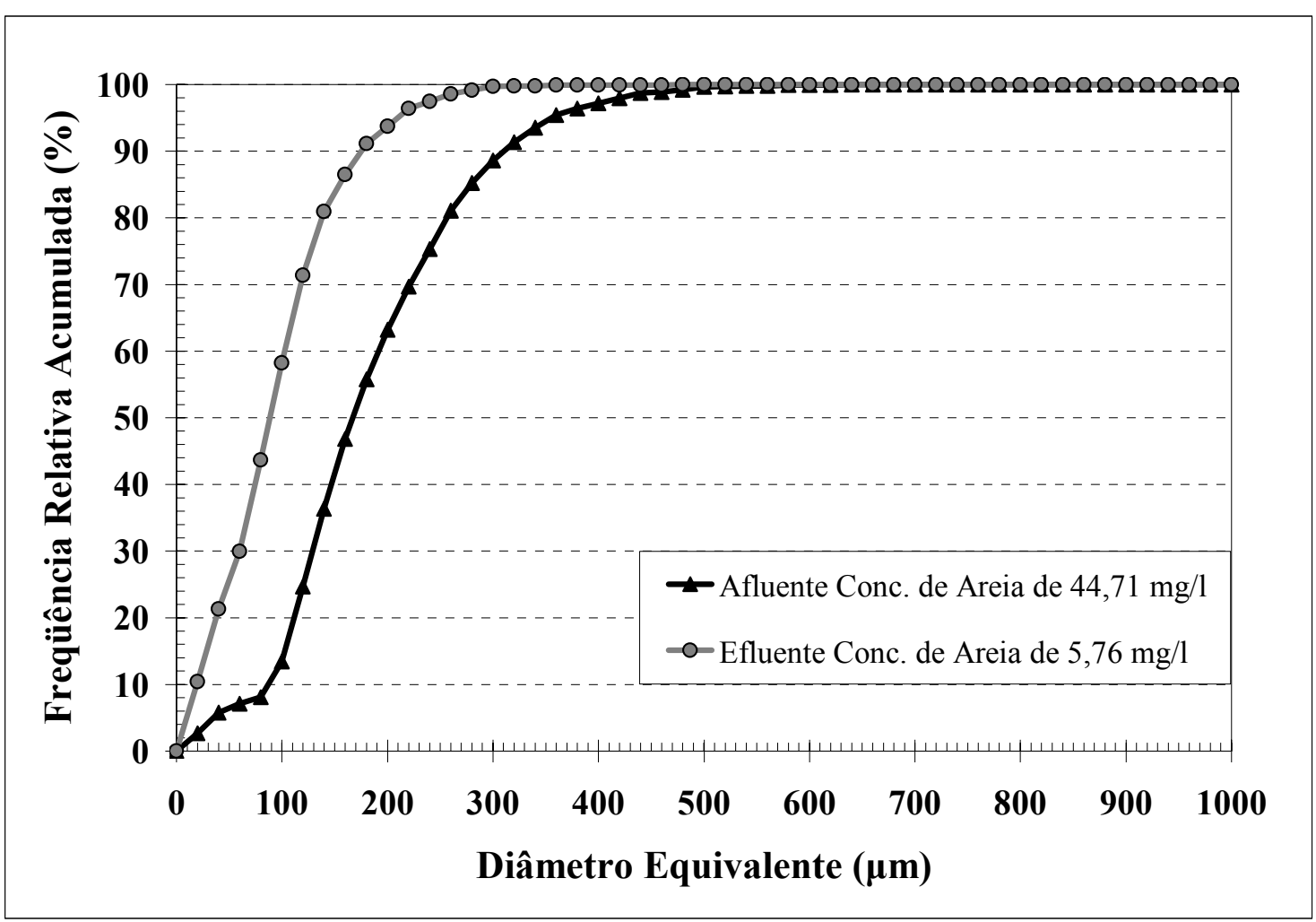

Figura 5.23 - Gráfico de distribuição numérica de tamanho de grãos de areia presentes na amostra coletada aos 09/11/2005 às $12 \mathrm{~h} 30 \mathrm{~min}$. TAS de $1.528 \mathrm{~m}^{3} / \mathrm{m}^{2} \mathrm{~d}$.

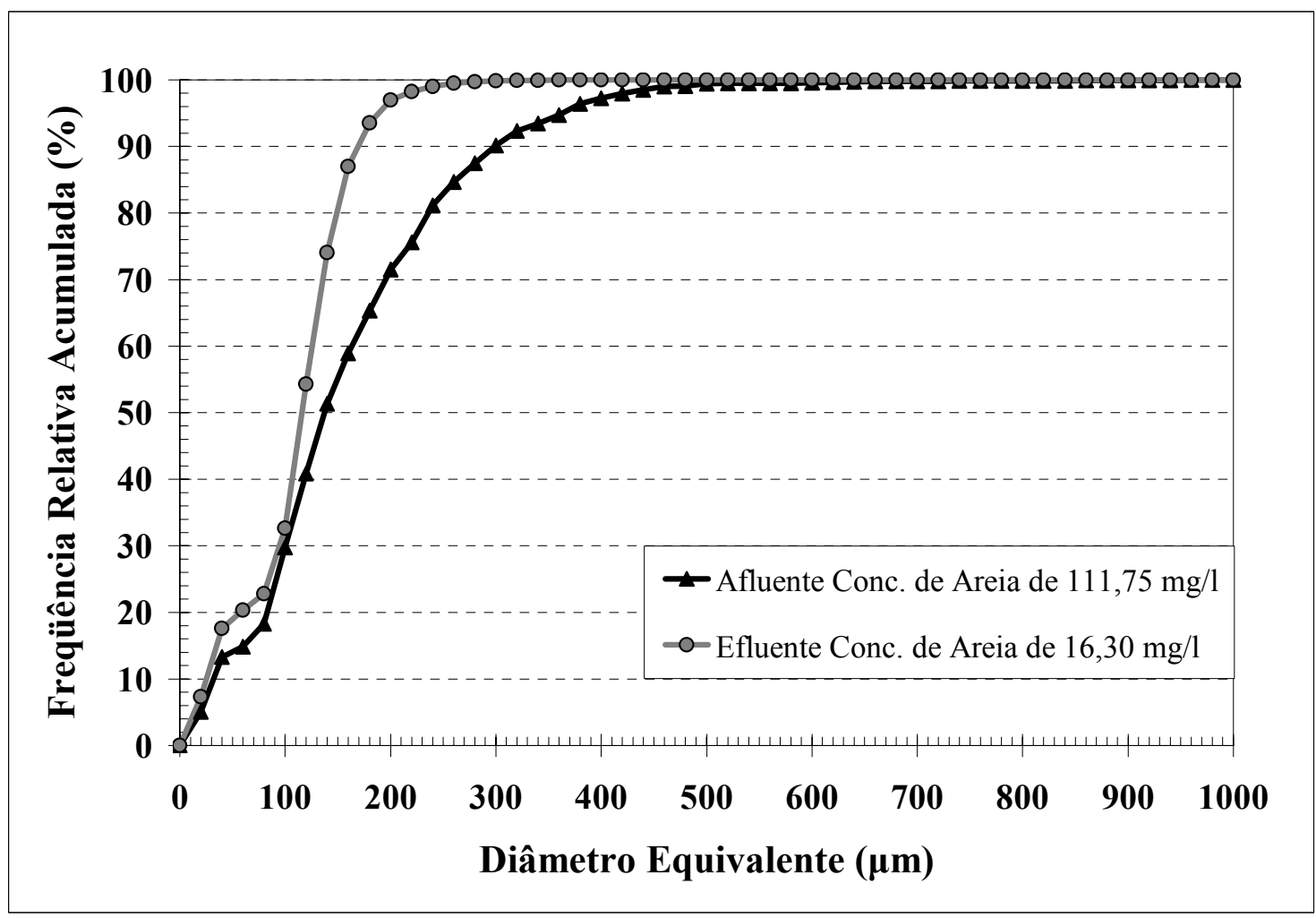

Figura 5.24 - Gráfico de distribuição numérica de tamanho de grãos de areia presentes na amostra coletada aos $21 / 11 / 2005$ às $14 \mathrm{~h} 30 \mathrm{~min}$. TAS de $1.528 \mathrm{~m}^{3} / \mathrm{m}^{2} \mathrm{~d}$. 


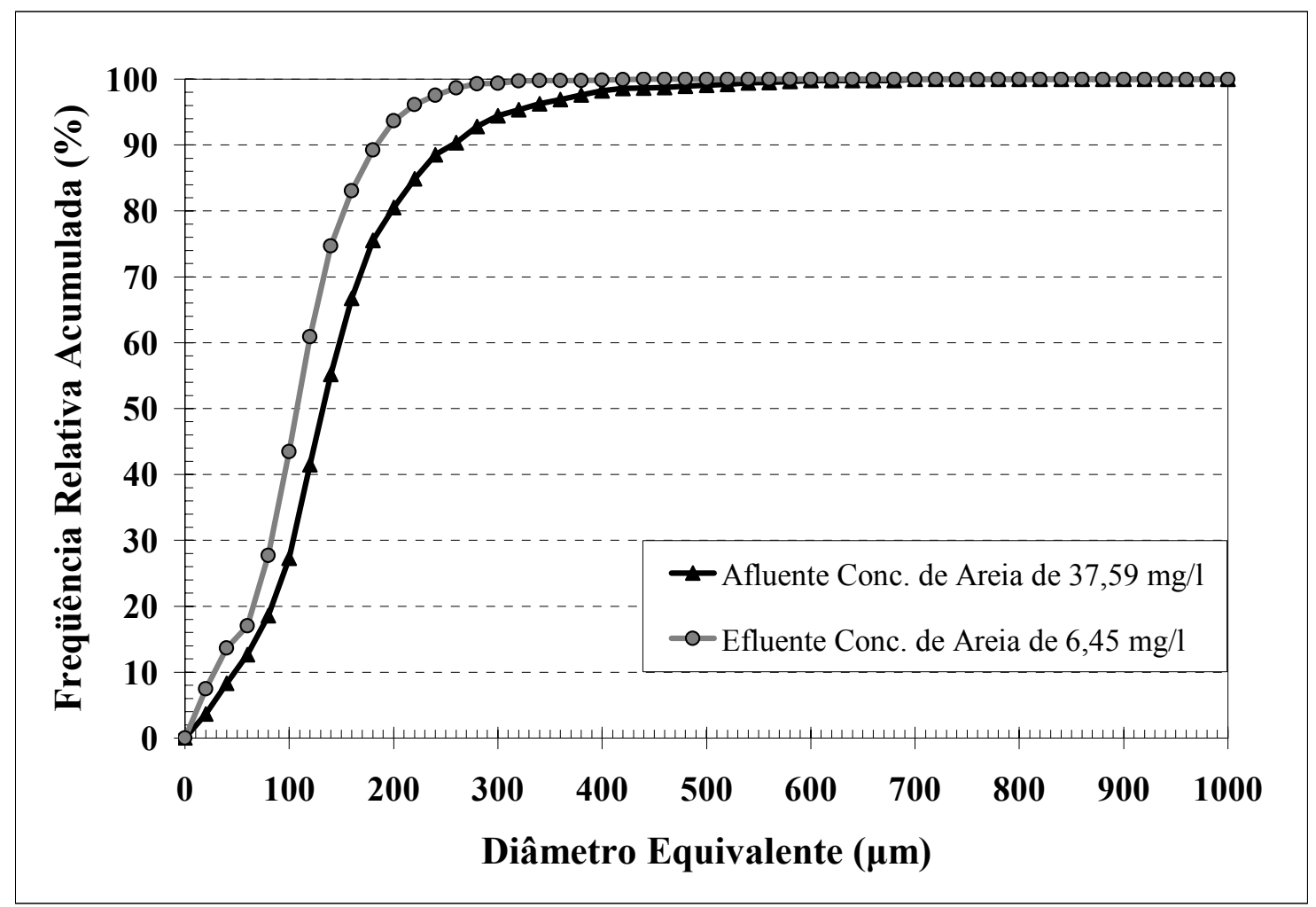

Figura 5.25 - Gráfico de distribuição numérica de tamanho de grãos de areia presentes na amostra coletada aos $21 / 11 / 2005$ às $17 \mathrm{~h} 30 \mathrm{~min}$. TAS de $1.528 \mathrm{~m}^{3} / \mathrm{m}^{2} \mathrm{~d}$.

A partir dos gráficos de distribuição volumétrica de tamanho de grãos de areia mostrados no Apêndice A desta tese, e das concentrações ${ }^{1}$ de areia presentes no esgoto sanitário afluente e efluente do SHV, apresentadas nas Tabelas 5.4, 5.5 e 5.6, foram calculadas, com as Equações 5.4, 5.5 e 5.6, as eficiências de remoção parcial de areia ${ }^{2}$, as quais foram agrupadas de acordo com a TAS e dispostas nas Tabelas 5.8, 5.9 e 5.10. Nas mesmas tabelas foram dispostos, também, os percentuais mássicos de grãos de areia de tamanho maior ou igual a $200 \mu \mathrm{m}$ presentes no afluente do SHV (obtidos nos gráficos de distribuição volumétrica de tamanho de grãos de areia mostrados no Apêndice A), assim como as médias geométricas e desvios padrões destes valores.

Como pode ser observado nas Tabelas 5.8; 5.9 e 5.10, o SHV alcançou eficiências de remoção parcial de areia que variaram entre 75\% (menor eficiência atingida) e 98\% (maior eficiência atingida). Desperta a atenção, nessas tabelas, o

\footnotetext{
1 Valores em negrito, para os quais foram determinadas as distribuições numéricas e volumétricas de tamanho de grão de areia.

2 Eficiência de remoção de grãos de areia de tamanho igual e superior a $200 \mu \mathrm{m}$.
} 
aumento da eficiência média de remoção parcial de areia com o aumento do percentual mássico médio de grãos de areia de tamanho maior ou igual a $200 \mu \mathrm{m}$. Tal fato, além de estar plenamente de acordo com o que preconiza Andoh (1998), pode explicar a diminuição da eficiência média de remoção de areia observada para a TAS de 1.146 $\mathrm{m}^{3} / \mathrm{m}^{2} \mathrm{~d}$, uma vez que o efluente do SHV carreava menor quantidade de grãos de areia com tamanho maior ou igual a $200 \mu \mathrm{m}$ (em termos percentuais) durante o período em que essa TAS foi testada.

Tabela 5.8 - Valores de percentual mássico de grãos de areia de tamanho maior ou igual a $200 \mu \mathrm{m}$ encontrados nas amostras de esgoto sanitário afluente do SHV, valores de eficiência de remoção parcial de areia, assim como, as médias geométricas e os desvios padrões de todos esses valores. TAS de $764 \mathrm{~m}^{3} / \mathrm{m}^{2} \mathrm{~d}(10 \mathrm{l} / \mathrm{s})$.

\begin{tabular}{cccc}
\hline Data & Horário & $\begin{array}{c}\text { Percentual Mássico de } \\
\text { Grãos de Areia } \geq \mathbf{2 0 0} \\
\boldsymbol{\mu m} \text { do Afluente do } \\
\text { SHV (\%) }\end{array}$ & $\begin{array}{c}\text { Eficiência de } \\
\text { Remoção } \\
\text { Parcial (\%) }\end{array}$ \\
\hline $6 / 10 / 2005$ & $13 \mathrm{~h} 30 \mathrm{~min}$ & 81 & 97 \\
$11 / 10 / 2005$ & $14 \mathrm{~h} 30 \mathrm{~min}$ & 87 & 97 \\
$11 / 10 / 2005$ & $15 \mathrm{~h} 30 \mathrm{~min}$ & 75 & 75 \\
$11 / 10 / 2005$ & $16 \mathrm{~h} 30 \mathrm{~min}$ & 80 & 92 \\
\hline \multicolumn{2}{c}{ Médias geométricas } & $\mathbf{8 0 , 6}$ & $\mathbf{8 9 , 8}$ \\
\multicolumn{2}{c}{ Desvios padrões } & $\mathbf{4 , 9 3}$ & $\mathbf{1 0 , 4 5}$ \\
\hline \multicolumn{5}{c}{}
\end{tabular}

Tabela 5.9 - Valores de percentual mássico de grãos de areia de tamanho maior ou igual a $200 \mu \mathrm{m}$ encontrados nas amostras de esgoto sanitário afluente do SHV, valores de eficiência de remoção parcial de areia, assim como, as médias geométricas e os desvios padrões de todos esses valores. TAS de $1.146 \mathrm{~m}^{3} / \mathrm{m}^{2} \mathrm{~d}(15 \mathrm{l} / \mathrm{s})$.

\begin{tabular}{cccc}
\hline Data & Horário & $\begin{array}{c}\text { Percentual Mássico de } \\
\text { Grãos de Areia } \geq \mathbf{2 0 0} \\
\boldsymbol{\mu m} \text { do Afluente do } \\
\text { SHV (\%) }\end{array}$ & $\begin{array}{c}\text { Eficiência de } \\
\text { Remoção } \\
\text { Parcial (\%) }\end{array}$ \\
\hline $4 / 11 / 2005$ & $10 \mathrm{~h} 30 \mathrm{~min}$ & 89 & 84 \\
$4 / 11 / 2005$ & $13 \mathrm{~h} 30 \mathrm{~min}$ & 77 & 82 \\
$17 / 11 / 2005$ & $16 \mathrm{~h} 30 \mathrm{~min}$ & 70 & 81 \\
$17 / 11 / 2005$ & $17 \mathrm{~h} 30 \mathrm{~min}$ & 69 & 95 \\
\hline \multicolumn{2}{c}{ Média geométrica } & $\mathbf{7 5 , 8}$ & $\mathbf{8 5 , 3}$ \\
\multicolumn{2}{c}{ Desvio padrão } & $\mathbf{9 , 2 3}$ & $\mathbf{6 , 4 6}$ \\
\hline \multicolumn{4}{c}{}
\end{tabular}


Tabela 5.10 - Valores de percentual mássico de grãos de areia de tamanho maior ou igual a $200 \mu \mathrm{m}$ encontrados nas amostras de esgoto sanitário afluente do SHV, valores de eficiência de remoção parcial de areia, assim como, as médias geométricas e os desvios padrões de todos esses valores. TAS de $1.528 \mathrm{~m}^{3} / \mathrm{m}^{2} \mathrm{~d}(20 \mathrm{l} / \mathrm{s})$.

\begin{tabular}{cccc}
\hline Data & Horário & $\begin{array}{c}\text { Percentual Mássico de } \\
\text { Grãos de Areia } \geq \mathbf{2 0 0} \\
\boldsymbol{\mu m} \text { do Afluente do } \\
\text { SHV (\%) }\end{array}$ & $\begin{array}{c}\text { Eficiência de } \\
\text { Remoção } \\
\text { Parcial (\%) }\end{array}$ \\
\hline $9 / 11 / 2005$ & $11 \mathrm{~h} 30 \mathrm{~min}$ & 89 & 98 \\
$9 / 11 / 2005$ & $12 \mathrm{~h} 30 \mathrm{~min}$ & 85 & 94 \\
$21 / 11 / 2005$ & $14 \mathrm{~h} 30 \mathrm{~min}$ & 87 & 97 \\
$21 / 11 / 2005$ & $17 \mathrm{~h} 30 \mathrm{~min}$ & 78 & 93 \\
\hline \multicolumn{2}{c}{ Média geométrica } & $\mathbf{8 4 , 6}$ & $\mathbf{9 5 , 5}$ \\
\multicolumn{2}{c}{ Desvio padrão } & $\mathbf{4 , 7 9}$ & $\mathbf{2 , 3 8}$ \\
\hline \multicolumn{4}{c}{}
\end{tabular}

Porém, vale ressaltar que as eficiências médias de remoção parcial de areia mostradas nas Tabelas 5.8, 5.9 e 5.10 são valores médios amostrais e, por essa razão, não devem ser generalizados. No intuito de obterem-se valores globais que permitam algum tipo de generalização, foram calculados os intervalos de confiança das eficiências de remoção parcial de areia para cada uma das TAS estudadas, os quais podem ser vistos na Tabela 5.11 .

Tabela 5.11 - Intervalos de confiança (ICs) com nível de significância de 95\% das médias populacionais das eficiências de remoção parcial de areia observadas para as TAS de $764 \mathrm{~m}^{3} / \mathrm{m}^{2} \mathrm{~d} ; 1146 \mathrm{~m}^{3} / \mathrm{m}^{2} \mathrm{~d}$ e $1528 \mathrm{~m}^{3} / \mathrm{m}^{2} \mathrm{~d}$.

\begin{tabular}{cc}
\hline TAS & Eficiência de Remoção Parcial de Areia \\
\hline $764 \mathrm{~m}^{3} / \mathrm{m}^{2} \mathrm{~d}$ & $\mathrm{IC}\left(\mu_{\mathrm{ef}} ; 95 \%\right)=[74 \% ; 100 \%]$ \\
$1.146 \mathrm{~m}^{3} / \mathrm{m}^{2}$ & $\mathrm{IC}\left(\mu_{\mathrm{ef}} ; 95 \%\right)=[72 \% ; 98 \%]$ \\
$1.528 \mathrm{~m}^{3} / \mathrm{m}^{2} \mathrm{~d}$ & $\mathrm{IC}\left(\mu_{\mathrm{ef}} ; 95 \%\right)=[91 \% ; 99 \%]$ \\
\hline Para todas as TAS & $\mathrm{IC}(\mu \mathrm{ef} ; 95 \%)=[85 \% ; 95 \%]$ \\
\hline
\end{tabular}

Com base nos intervalos de confiança das eficiências de remoção parcial de areia e nos gráficos de distribuição numérica de tamanho de grãos de areia, mostrados nas Figuras 5.14, 5.16 e 5.18, pode-se concluir que o SHV foi eficiente na remoção de grãos de areia de tamanho igual e superior a $200 \mu \mathrm{m}$. Por conseguinte, pode-se concluir, 
também, que o desempenho do SHV desenvolvido na presente pesquisa como unidade de desarenação foi bastante satisfatório, porquanto, além de não remover sólidos orgânicos (medidos em termos de concentração de SSV) presente no seu afluente, o SHV apresentou elevadas eficiências de remoção parcial de areia para as três TAS estudadas $\left(74 \%\right.$ a $100 \%$ para TAS de $764 \mathrm{~m}^{3} / \mathrm{m}^{2} \mathrm{~d} ; 72 \%$ a $98 \%$ para TAS de 1.146 $\mathrm{m}^{3} / \mathrm{m}^{2} \mathrm{~d} ; 85 \%$ a $95 \%$ para TAS de $1.528 \mathrm{~m}^{3} / \mathrm{m}^{2} \mathrm{~d}$ ) e, conseqüentemente, produziu efluentes com baixa quantidade de grãos de areia de tamanho maior ou igual a $200 \mu \mathrm{m}$ (em média, 5,3\% do número total de grãos de areia presentes no efluente do SHV eram compostos por grãos de tamanho maior ou igual a $200 \mu \mathrm{m}$ ).

\subsection{Conclusões}

Os resultados apresentados neste capítulo permitem concluir que:

- O maior obstáculo para o desenvolvimento de sistemas de gradeamento ou peneiramento autolimpantes é a presença de grande quantidade de materiais fibrosos no esgoto sanitário, principalmente, fiapos, fios e estopa, pois estes materiais entrelaçam-se nas barras das grades e, por estarem impregnados de matéria orgânica proveniente do esgoto sanitário, aderem-se à superfície das mesmas, fato que dificulta, ainda mais, a sua remoção;

- A grade cilíndrica de fluxo tangencial, sem sistema mecanizado de limpeza, desenvolvida na presente pesquisa, demonstrou não ser adequada. Devido às características dos sólidos grosseiros presentes no esgoto sanitário, acredita-se que seja muito difícil a concepção de sistemas de gradeamento ou peneiramento fino de fluxo tangencial autolimpantes; acredita-se também que será sempre necessária a utilização de algum tipo de equipamento de limpeza, preferencialmente automatizado;

- As unidades de desarenação devem ser instaladas à jusante dos sistemas de gradeamento ou peneiramento fino, pois estes removem do esgoto sanitário, sólidos grosseiros (e.g.: pequenos pedaços de comida, grãos diversos etc.) que sedimentariam junto com a areia nos desarenadores; 
- O separador hidrodinâmico por vórtice (SHV) não removeu, significativamente, matéria orgânica particulada (medida em termos de concentração de SSV) presente no esgoto sanitário afluente da ETE Jardim das Flores, ao ser operado com taxas de aplicação superficial (TAS) de $764 \mathrm{~m}^{3} / \mathrm{m}^{2} \mathrm{~d} ; 1.146 \mathrm{~m}^{3} / \mathrm{m}^{2} \mathrm{~d}$ e $1.528 \mathrm{~m}^{3} / \mathrm{m}^{2} \mathrm{~d}$;

- O separador hidrodinâmico por vórtice (SHV) removeu areia do esgoto sanitário afluente da ETE Jardim das Flores com eficiências elevadas: de $42 \%$ a $82 \%$ e para TAS de $764 \mathrm{~m}^{3} / \mathrm{m}^{2} \mathrm{~d}$; de $63 \%$ a $79 \%$ para a TAS de $1.146 \mathrm{~m}^{3} / \mathrm{m}^{2} \mathrm{~d}$; e de $86 \%$ e $93 \%$ para a TAS de $1.528 \mathrm{~m}^{3} / \mathrm{m}^{2} \mathrm{~d}$;

- $\quad$ O separador hidrodinâmico por vórtice (SHV) produziu efluentes com baixa quantidade de grãos de areia de tamanho maior ou igual a $200 \mu \mathrm{m}$, ao ser operado com TAS de $764 \mathrm{~m}^{3} / \mathrm{m}^{2} \mathrm{~d} ; 1.146 \mathrm{~m}^{3} / \mathrm{m}^{2} \mathrm{~d}$ e $1.528 \mathrm{~m}^{3} / \mathrm{m}^{2} \mathrm{~d}$, em média apenas $5,3 \%$ do número total de grãos de areia encontrados no efluente da unidade possuíam essas dimensões;

- Não se deve avaliar o desempenho de desarenadores, unicamente pela remoção de areia que essas unidades podem atingir, pois, em certos casos, um desarenador pode apresentar baixa eficiência de remoção de areia e, mesmo assim, produzir efluentes com baixíssima quantidade de grãos de areia de tamanho maior ou igual a $200 \mu \mathrm{m}$;

- $\quad$ O SHV apresentou bons níveis de eficiências de remoção parcial de areia, isto é, remoção de grãos de areia de tamanho maior ou igual a $200 \mu \mathrm{m}$ : de $74 \%$ a $100 \%$ e para TAS de $764 \mathrm{~m}^{3} / \mathrm{m}^{2} \mathrm{~d}$; de $72 \%$ a $98 \%$ para a TAS de $1.146 \mathrm{~m}^{3} / \mathrm{m}^{2} \mathrm{~d}$; e de $85 \%$ e $99 \%$ para a TAS de $1.528 \mathrm{~m}^{3} / \mathrm{m}^{2} \mathrm{~d}$; 


\section{Capítulo 6 - Considerações Finais e Conclusões} da Tese

Este capítulo apresenta as considerações finais e as conclusões da presente pesquisa. Primeiramente, são apresentadas as considerações finais da tese, destacando o seqüenciamento lógico adotado para verificação das três hipóteses assumidas e demonstrando a interdependência entre tais hipóteses e os objetivos específicos traçados para a realização deste doutorado. Em seguida, são listadas as principais conclusões desta tese e algumas sugestões para futuras pesquisas. 


\subsection{Considerações Finais}

A presente pesquisa teve como principal objetivo a concepção, desenvolvimento e avaliação do desempenho de uma unidade de tratamento preliminar em escala plena, constituída de separador hidrodinâmico por vórtice e grade fina cilíndrica de fluxo tangencial, cujas funções eram, respectivamente, remover areia e reter sólidos grosseiros presentes no esgoto sanitário. Para tanto, firmou-se acordo com uma empresa local - a PROMINAS do Brasil - especializada na produção de sistemas de gradeamento e peneiramento para estações de tratamento de água e esgoto como, também, para diversos segmentos industriais. O resultado de tal parceria foi a construção de um protótipo de separador hidrodinâmico por vórtice (SHV), em escala plena, o qual é apresentado no Capítulo 2 (O Tratamento Preliminar de Esgoto Sanitário e os Separadores Hidrodinâmicos por Vórtice: Conceitos e Aplicações) desta tese.

Foram admitidas três hipóteses para a realização desta pesquisa, duas relacionadas ao SHV e uma relacionada à grade fina cilíndrica de fluxo tangencial. Admitiu-se que a geometria do separador hidrodinâmico por vórtice e de seus componentes internos propiciaria condições para desenvolvimento de padrão circulatório de escoamento, caracterizado pelo movimento helicoidal e descendente do fluido junto à parede externa da unidade e pelo movimento helicoidal e ascendente do fluido próximo ao eixo central da mesma; e que tal padrão de escoamento faria com que partículas em suspensão no afluente do SHV experimentassem a ação do campo de aceleração “centrífuga” (efeito da inércia das partículas), a qual suplementaria a ação do campo de aceleração gravitacional na separação de partículas discretas, como grãos de areia. Em relação à grade fina cilíndrica de fluxo tangencial posicionada no topo do vertedor de saída do SHV, foi admitida a hipótese de que o padrão circulatório de escoamento ao redor de sua face externa impediria a aderência de sólidos grosseiros à grade ou, pelo menos, minimizaria a freqüência de limpezas. A validade de tais hipóteses foi verificada à medida que foram cumpridos os objetivos específicos listados na seção 1.3 do Capítulo 1 (Introdução) desta tese.

O Capítulo 3 (Estudo da Hidrodinâmica do Separador Hidrodinâmico por Vórtice) relata os resultados de um estudo a respeito da hidrodinâmica do SHV, que se fundamenta em resultados de ensaios de estímulo-resposta com traçador não reativo, medições de pressão total e simulações computacionais, em software de dinâmica dos 
fluidos computacional, do padrão de escoamento que se desenvolve no SHV. Os resultados dos ensaios de estímulo resposta mostraram que o regime de macro-mistura do escoamento que se desenvolve no SHV aproxima-se do plug-flow, porém com certo grau de mistura que diminui com o aumento da taxa de aplicação superficial empregada. Por sua vez, os resultados das simulações computacionais, validados com valores de pressão total medidos no protótipo do $\mathrm{SHV}$, permitiram verificar a validade da primeira hipótese assumida nesta tese, ou seja, a existência de duas regiões com escoamento helicoidal em sentido oposto - junto à parede externa do SHV o deslocamento do fluido é descendente e na região interna do SHV, próximo ao eixo central da unidade, o movimento do fluido é ascensional.

Comparando os resultados dos ensaios de estímulo-resposta com aqueles obtidos nas simulações computacionais foi possível identificar, no interior do SHV, quatro regiões que apresentam escoamento com características distintas: região de entrada (RE), região de saída (RS), região de separação (RSe) e região de acúmulo (RA). Na RE, o escoamento é fortemente influenciado pelo jato de fluido que adentra o SHV pelo bocal de entrada da unidade, gerando turbulência e, consequentemente, elevado grau de mistura na região. Na RSe, onde provavelmente ocorre a separação sólido-líquido, o escoamento é caracterizado pela presença de duas regiões com movimento vertical do fluido em sentidos opostos: junto à parede externa do SHV o movimento do fluido é helicoidal e descendente e na região central da unidade o movimento do fluido é helicoidal e ascendente; acredita-se que, nessa região, o regime de macro-mistura do escoamento seja altamente pistonado. Na RA o escoamento apresenta velocidades muito mais baixas que as encontradas no restante do SHV. Por fim, na RS localiza-se o vertedor tubular de saída do SHV. Tal fato faz com que o escoamento na região apresente certo grau de “desordem”, ocasionado pela formação de vórtice de ralo (vórtice livre) no topo da unidade.

O estudo da hidrodinâmica do SHV também possibilitou constatar a necessidade de alterar a geometria da unidade. Devido à presença de movimentos ascensionais de fluido na entrada da RA, faz-se necessário mudar a posição dos anteparos que a “protegem”, como também, aumentar o volume da mesma para que as velocidades em seu interior decresçam, porquanto os valores velocidade encontrados são suficientemente altos para promover ressuspensão de grãos de areia previamente retidos. 
O Capítulo 4 (A Problemática de Determinação de Areia Presente no Esgoto Sanitário) desta tese apresenta dois métodos desenvolvidos, um para determinação da concentração de areia no esgoto sanitário e outro para determinação da distribuição granulométrica dos grãos dessa areia. O método de determinação de areia presente no esgoto sanitário é totalmente original e consiste em concentrar os sólidos sedimentáveis presentes no esgoto por meio de sedimentação em cone Imhoff e centrifugação, separar a matéria orgânica da areia presentes nas amostras concentradas por meio de oxidação com peróxido de hidrogênio seguida de sucessivos enxágües com água destilada, calcinar a areia separada para eliminar qualquer resíduo que ainda persista na amostra e, por fim, pesar a areia seca. O método de determinação da distribuição granulométrica da areia presente no esgoto é uma adaptação da técnica determinação de tamanho de partículas denominada análise de imagens e consiste em coletar grãos de areia com fita adesiva transparente, colá-los em lamínulas de vidro, fotografá-los por meio de câmera CCD (Charge Coupled Device) acoplada a um microscópio óptico, tratar as imagens adquiridas e proceder a contagem e determinação de tamanho de partículas em software de análise imagens.

O método de determinação da concentração de areia no esgoto sanitário demonstrou ser extremamente viável, porquanto sua realização demanda equipamentos e materiais comuns à boa parte dos laboratórios de análise. Por sua vez, o método de determinação da distribuição granulométrica da areia presente no esgoto, apesar de fornecer resultados assaz úteis, trata-se de técnica laboriosa e, conseqüentemente, muitíssimo demorada; deste modo, provavelmente, sua aplicação não ultrapasse as fronteiras do meio acadêmico.

No Capítulo 5 (Análise do Desempenho do Separador Hidrodinâmico por Vórtice e da Grade Fina de Fluxo Tangencial) desta tese, são expostos os resultados da avaliação do desempenho da unidade de tratamento preliminar desenvolvida. Durante esta fase da pesquisa, o separador hidrodinâmico por vórtice foi alimentado com esgoto sanitário afluente da estação de tratamento de esgoto Jardim das Flores do município de Rio Claro, SP, permitindo, assim, constatar a nulidade da terceira hipótese assumida para realização desta tese, ou seja, o padrão circulatório de escoamento ao redor da grade fina cilíndrica de fluxo tangencial não impediu os sólidos grosseiros, presentes no esgoto sanitário afluente da unidade, de acumularem-se na superfície da mesma, e mais, tal padrão de escoamento fez com que os sólidos 
grosseiros fossem carreados diretamente à superfície externa da grade, obstruindo-a em poucos minutos.

Todavia a aplicação dos métodos de determinação da concentração de areia e da granulometria dessa areia, apresentados no Capítulo 4 (A Problemática de Determinação de Areia Presente no Esgoto Sanitário) desta tese, possibilitaram verificar a efetividade do separador hidrodinâmico por vórtice na remoção de grãos de areia de tamanho maior ou igual a $200 \mu \mathrm{m}$, presentes no esgoto sanitário usado para alimentá-lo. Tal fato somado à ineficácia da unidade na remoção de sólidos orgânicos (medidos em termos de concentração de sólidos suspensos voláteis), demonstrada no Capítulo 5 (Análise do Desempenho do Separador Hidrodinâmico por Vórtice e da Grade Fina de Fluxo Tangencial) desta tese, permite inferir a validade da segunda hipótese admitida para a realização da presente pesquisa, isto é, o movimento helicoidal e descendente do fluido junto à parede externa do separador hidrodinâmico por vórtice fez com que partículas em suspensão no seu afluente experimentassem a ação de um campo de aceleração “centrífuga” (efeito da inércia das partículas), a qual suplementou a ação do campo de aceleração gravitacional na separação de partículas discretas, como grãos de areia. Esta afirmação pode ser corroborada por Andoh e Smisson (1993); Field e O’Connor (1996) e Andoh (1998), porquanto os autores asseveram que o padrão de escoamento dos separadores hidrodinâmicos por vórtice propicia condições para que ocorra remoção de partículas discretas e densas como grão de areia sem que haja remoção dos sólidos orgânicos de menor densidade presentes no esgoto sanitário.

Como descrito nos parágrafos anteriores, a presente pesquisa seguiu seqüência lógica, na qual as três hipóteses assumidas na concepção desta tese foram, uma a uma, verificadas à medida que os objetivos específicos da tese foram cumpridos; no entanto até este ponto nada foi mencionado acerca do cumprimento do objetivo principal desta pesquisa, isto é, a concepção de uma unidade de tratamento preliminar de esgoto sanitário. Sobre este tema, pode-se afirmar que o emprego do separador hidrodinâmico por vórtice como unidade de desarenação mostrou-se promissor, mas o conceito de grade fina cilíndrica de fluxo tangencial auto-limpante posicionada no topo do vertedor de saída do SHV simplesmente é inviável. Na seqüência serão apresentadas as principais conclusões desta tese e algumas sugestões para futuras pesquisas.

PRADO, G. S. (2006) 


\subsection{Conclusões da Tese}

A partir dos resultados apresentados no Capítulo 3 (Estudo da Hidrodinâmica do Separador Hidrodinâmico por Vórtice), no Capítulo 4 (A Problemática da Determinação da Quantidade de Areia no Esgoto Sanitário) e no Capítulo 5 (Análise do Desempenho do Separador Hidrodinâmico por Vórtice e da Grade Fina de Fluxo Tangencial) desta tese pode concluir-se que:

O separador hidrodinâmico por vórtice, desenvolvido na presente pesquisa, demonstrou enorme potencialidade na remoção de areia presente no esgoto sanitário quando operado com taxas de aplicação superficial de $764 \mathrm{~m}^{3} / \mathrm{m}^{2} \mathrm{~d} ; 1.146 \mathrm{~m}^{3} / \mathrm{m}^{2} \mathrm{~d}$ e $1.528 \mathrm{~m}^{3} / \mathrm{m}^{2} \mathrm{~d}$, porquanto a unidade, além de não remover, significativamente, matéria orgânica particulada (medida em termos de sólidos suspensos voláteis), atingiu bons níveis de remoção mássica de areia e elevada eficiência de remoção mássica de grãos de areia maiores ou iguais a $200 \mu \mathrm{m}$. Porém, a grade fina cilíndrica de fluxo tangencial (auto-limpante) posicionada no topo do vertedor de saída do separador hidrodinâmico por vórtice revelou-se inviável pois, devido ao padrão de escoamento nas suas adjacências (vórtice livre), os sólidos grosseiros presentes no esgoto sanitário foram carreados diretamente à sua superfície, colmatando-a em poucos minutos.

- O maior obstáculo para desenvolvimento de sistemas de gradeamento ou peneiramento autolimpantes é a presença de grande quantidade de materiais fibrosos no esgoto sanitário, principalmente, fiapos, fios e estopa, pois estes materiais entrelaçam-se nas barras das grades e, por estarem impregnados de matéria orgânica proveniente do esgoto sanitário, tornam-se pegajosos e aderem à superfície das mesmas, fato que dificulta, ainda mais, sua remoção;

- As unidades de desarenação devem ser instaladas à jusante dos sistemas de gradeamento ou peneiramento fino, pois tais sistemas removem do esgoto sanitário, sólidos grosseiros (e.g.: pequenos 
pedaços de comida, grãos diversos etc.) que sedimentar-se-iam com a areia nos desarenadores;

- Não se deve avaliar o desempenho de desarenadores, unicamente pela remoção de areia que essas unidades podem atingir pois, em certos casos, um desarenador pode apresentar baixa eficiência de remoção de areia e, mesmo assim, produzir efluentes com pequena quantidade de grãos de areia de tamanho maior ou igual a $200 \mu \mathrm{m}$;

- O separador hidrodinâmico por vórtice removeu areia do esgoto sanitário afluente da estação de tratamento de esgoto Jardim das Flores com as seguintes eficiências: de $42 \%$ a $82 \%$ e para taxa de aplicação superficial de $764 \mathrm{~m}^{3} / \mathrm{m}^{2} \mathrm{~d}$; de $63 \%$ a $79 \%$ para taxa de aplicação superficial de $1.146 \mathrm{~m}^{3} / \mathrm{m}^{2} \mathrm{~d}$; e de $86 \%$ e $93 \%$ para a taxa de aplicação superficial de $1.528 \mathrm{~m}^{3} / \mathrm{m}^{2} \mathrm{~d}$;

- O separador hidrodinâmico por vórtice produziu efluentes com baixa quantidade de grãos de areia de tamanho maior ou igual a $200 \mu \mathrm{m}$, ao ser operado com taxa de aplicação superficial de $764 \mathrm{~m}^{3} / \mathrm{m}^{2} \mathrm{~d}$; $1.146 \mathrm{~m}^{3} / \mathrm{m}^{2} \mathrm{~d}$ e $1.528 \mathrm{~m}^{3} / \mathrm{m}^{2} \mathrm{~d}$; em média apenas $5,3 \%$ do número total de grãos de areia encontrados no efluente da unidade possuíam tais dimensões;

- O separador hidrodinâmico por vórtice apresentou bom desempenho na remoção de grãos de areia de tamanho maior ou igual a $200 \mu \mathrm{m}$, uma vez que foram alcançadas eficiências de remoção parcial de areia: de $74 \%$ a $100 \%$ e para taxa de aplicação superficial de 764 $\mathrm{m}^{3} / \mathrm{m}^{2} \mathrm{~d}$; de $72 \%$ a $98 \%$ para taxa de aplicação superficial de 1.146 $\mathrm{m}^{3} / \mathrm{m}^{2} \mathrm{~d}$; e de $85 \%$ e $99 \%$ para taxa de aplicação superficial de 1.528 $\mathrm{m}^{3} / \mathrm{m}^{2} \mathrm{~d}$;

A análise combinada de resultados de ensaios de estímulo-resposta e de simulações computacionais em softwares de dinâmica dos fluidos computacional (CFD - Computational Fluid dynamics) revelou-se uma ferramenta poderosa para estudos acerca da hidrodinâmica do 
separador hidrodinâmico por vórtice, porquanto permitiu não somente verificar a ocorrência de recirculações do fluido, regiões de estagnação e curtos-circuitos hidráulicos como, também, identificar a localização de tais fenômenos fornecendo, assim, subsídios para otimização do padrão de escoamento da unidade por meio de “ajustes” pontuais na geometria do separador hidrodinâmico por vórtice, isto é, alterações nos componentes que realmente apresentam problemas;

- O regime de macro-mistura do escoamento que se desenvolve no separador hidrodinâmico por vórtice, para as taxas de aplicação superficial de $764 \mathrm{~m}^{3} / \mathrm{m}^{2} \mathrm{~d} ; 1.146 \mathrm{~m}^{3} / \mathrm{m}^{2} \mathrm{~d}$ e $1.528 \mathrm{~m}^{3} / \mathrm{m}^{2} \mathrm{~d}$, aproximase do plug-flow, porém com certo grau de mistura, o qual diminui com o aumento da taxa de aplicação superficial empregada;

- Podem ser identificadas quatro regiões no interior do separador hidrodinâmico por vórtice as quais apresentam padrões de escoamento com características distintas, são elas: região de entrada (RE), região de saída (RS), região de separação (RSe) e região de acúmulo (RA);

- Na região de entrada o escoamento apresenta forte influência do jato de fluido que adentra pelo bocal de entrada do separador hidrodinâmico por vórtice com altas velocidades, consequentemente, nesta região a alta turbulência do escoamento faz surgir escoamentos secundários. Pode-se deduzir que o regime de macro-mistura do escoamento na região de entrada aproxima-se da mistura perfeita;

- Na região de acúmulo o escoamento apresenta velocidades mais baixas que as encontradas no restante do separador hidrodinâmico por vórtice e, por isso, pode ser considerada como região de estagnação de fluido;

- $\quad$ Na região de separação, onde provavelmente ocorre a separação sólido-líquido, o escoamento é caracterizado pela presença de duas regiões com movimento vertical do fluido em sentidos opostos: junto 
à parede externa do separador hidrodinâmico por vórtice o movimento do fluido é helicoidal e descendente e na região central da unidade o movimento do fluido é helicoidal e ascendente. Esta característica do escoamento na região de separação acarreta a formação de um plano de cisalhamento com velocidade vertical zero o LZVV. Análises das velocidades radiais na região de separação forneceram indícios da existência de um LZRV (plano de cisalhamento com velocidade radial zero) que, praticamente, coincide com o LZVV. Pode-se inferir que o regime de macro-mistura do escoamento na região de separação aproxima-se do plug-flow;

- Na região de saída, localiza-se o vertedor tubular de saída do separador hidrodinâmico por vórtice, o que faz com que, nesta região, o escoamento apresente certo grau de “desordem”, ou seja, elevada turbulência e escoamentos secundários (recirculações internas). Pode-se deduzir que o regime de macro-mistura do escoamento na região de saída aproxima-se da mistura perfeita;

- Deve-se alterar a posição dos anteparos que “protegem” a região de acúmulo do separador hidrodinâmico por vórtice pois, para as três vazões de alimentação estudadas, foram detectados movimentos ascensionais do fluido na entrada da mesma;

- Deve-se aumentar o volume da região de acúmulo do separador hidrodinâmico por vórtice, com intuito de diminuir as velocidades em seu interior, pois foram observadas velocidades suficientemente altas para promoverem ressuspensão de grãos de areia previamente retidos na região de acúmulo;

\section{O método desenvolvido para determinar concentração de areia no} esgoto sanitário mostrou-se viável, pois além de fornecer resultados satisfatórios, o método é acessível à boa parte dos laboratórios de análise;

- A concentração média de areia no esgoto sanitário afluente da estação de tratamento de esgoto Jardim das Flores, utilizado para 
alimentar o separador hidrodinâmico por vórtice, tema desta pesquisa, fica entre $20 \mathrm{mg} / \mathrm{l}$ e $73 \mathrm{mg} / \mathrm{l}$;

- A ocorrência de valores de concentração de areia de até 265 mg/l, somada ao fato de que o intervalo de confiança obtido a partir da média aritmética de todos os valores amostrais de concentração de areia ter ficado, aproximadamente, entre $50 \mathrm{mg} / \mathrm{l}$ e $100 \mathrm{mg} / \mathrm{l}$ demonstra a necessidade de óptica mais crítica por parte de projetistas de estação de tratamento de esgoto, para as unidades de desarenação - pois o custo agregado à remoção, deságüe e disposição final desse material pode ser significativo no cálculo do custo operacional de uma estação de tratamento de esgoto e, por outro lado, se esse material não for removido em desarenadores, os problemas causados nas unidades subseqüentes poderão ter conseqüências danosas à operação e à vida útil de equipamentos;

\section{A utilização da análise de imagens como técnica de determinação de tamanho de partículas demonstrou ser ferramenta poderosa para estudo da distribuição granulométrica da areia presente no esgoto, embora seja, também, uma técnica bastante laboriosa e, conseqüentemente, extremamente demorada;}

- Menos de 2\% da massa total de areia encontrada no esgoto sanitário afluente da estação de tratamento de esgoto Jardim das Flores é composta por grãos menores ou iguais a $100 \mu \mathrm{m}$; em termos numéricos esse porcentual é bem maior, cerca de 39\% do número total de grãos de areia tem diâmetro equivalente menor ou igual a $100 \mu \mathrm{m}$;

- Aproximadamente $16 \%$ da massa total de areia encontrada no esgoto sanitário afluente da estação de tratamento de esgoto Jardim das Flores é constituída por grãos de areia menores ou iguais a $200 \mu \mathrm{m}$; em termos numéricos essas partículas respondem por 75\% do número total de grãos de areia 


\subsection{Sugestões para Futuras Pesquisas}

Tendo em vista o que foi apresentado e discutido nesta tese sugere-se:

Empregar os métodos de determinação da concentração e distribuição granulométrica da areia presente no esgoto sanitário para avaliar o desempenho de outros tipos de desarenadores;

Empregar o método de determinação da concentração da areia presente no esgoto sanitário de forma sistêmica com o intuito de buscar correlações entre concentração de areia e vazão afluente de estações de tratamento de esgoto;

Otimizar a geometria do separador hidrodinâmico por vórtice e de seus componentes internos por meio de simulações do padrão de escoamento que se desenvolve na unidade em software de dinâmica dos fluidos computacional.

> Construir protótipos de diferentes tamanhos e avaliar a interferência da mudança de dimensão sobre a eficiência de remoção de areia da unidade; 


\section{Referências Bibliográficas}

ALKHADDAR, R.; CHEONG, C. H.; PHIPPS, D. A; ANDOH, R. Y. G.; JAMES, A.;HIGGINS, P. (2001b). The development of a mathematical model for the prediction o the residence time distribution of a hydrodynamic vortex separator. In: NOVATECH, 2001, v.2, p. 835-842.

ALKHADDAR, R.; EVANS, J.; HIGGINS, P.; PHIPPS, D. A. (2000). Characterisation for in situ disinfection using a hydrodynamic vortex separator (HDVS). In: CONGRESS OF THE INTERNATIONAL WATER ASSOCIATION, 1., 2000, 3-7 July, Paris, France.

ALKHADDAR, R.; EVANS, J.; HIGGINS, P.; PHIPPS, D. A.; ANDOH, R. Y. G. (2001a). Residence time distribution of a model hydrodynamic vortex separator. Urban Water, v.3, p.17-24.

ALLEN, T. (1997). Particle size measurement. 5.ed. London: Chapman \& Hall. Powder sampling and particle size measurement, v.1.

ANDOH, R. Y. G.; HIDES, S. P.; SAUL, A. J. (2002). Improving water quality using hydrodynamic vortex separator and screening systems. In: INTERNATIONAL CONFERENCE ON URBAN DRAINAGE, 9., 2002, 8-13 September, Portland, Oregon, USA.

ANDOH, R. Y. G.; SAUL, A. J. (2003). The use of hydrodynamic vortex separators and screening systems to improve water quality. Water Science and Technology, v.47, n.4, p.175-183.

ANDOH, R. Y.G.; SMISSON, R. P. M. (1993). High rate sedimentation in hydrodynamic separators. In: INTERNATIONAL CONFERENCE ON HYDRAULIC 
MODELLING DEVELOPMENT AND APPLICATION OF PHYSICAL AND MATHEMATICAL MODELS, 2., 1993, 14-16 June, Stratford, UK.

ANDOH, R.Y.G. (1998). Improving environmental quality using hydrodynamic vortex separators. WQI, p.47-51, Jan-Feb.

APHA (1999). Standard methods for examination of water and wastewater. 20.ed. Washington, D.C., USA.

ASSOCIAÇÃO BRASILEIRA DE NORMAS TÉCNICAS (1992). NBR - 12.209 Elaboração de projetos hidráulicos sanitários de sistemas de esgoto sanitário. Rio de Janeiro.

BARROS NETO, B.; SCARMINIO, I. S.; BRUNS, R. E. (2002). Como fazer experimentos: pesquisa e desenvolvimento na ciência e na indústria. 2.ed. Campinas, SP: Editora da Unicamp.

BIGGS, C. A.; PRALL, C.; TAIT, S.; ASHLEY, R. (2005). Investigating the effect of storm events on the particle size distribution in a combined sewer simulator. Water Science and Technology, v.52, n.3, p.129-136.

BONER, M. C.; GHOSH, D. R.; HARPER, S. R.; TURNER, B. G. (1995). Modified vortex separator and UV disinfection for combined sewer overflow treatment. Water Science and Technology, v.31, n.3-4, p.263-274.

BRETCHER, U.; KREBS, P.; HAGER, W. H. (1992). Improvement of flow in final settling tanks. Journal of Environmental Engineering ASCE, v.118, n.3, p.307-321.

BROUCKAERT, C. J.; BUCKLEY, C. A. (1999). The use of computational fluid dynamics for improving the design and operation of water and wastewater treatment plant. Water Science and Technology, v.40, n.4-5, p.81-89.

CAMP, T. R. (1942). Grit chamber design. Sewage Work Journal, v.14, n.2, p.368-381, March. 
CASAMASSA NETO, J. (1991). Vórtices. 89p. Tese (Mestrado) - Escola Politécnica, Universidade de São Paulo, São Paulo. 1991.

CFX (2004). CFX 5.5 software user’s guide and tutorials. ANSYS.

EGARR, D. A.; FARAM, M. G.; O’DOHERTY, T.; SYRED, N. (2004). An investigation into the factors that determine the efficiency of a hydrodynamic vortex separator. In: NOVATECH, 2004, p.1-8.

FARAM, M. G.; ANDOH, R. Y. G. (2000). Application of simulation and predictive techniques for the evaluation of hydrodynamic separator. In: CIWEM/AETT MILLENNIUM CONFERENCE; 'WASTEWATER TREATMENT: STANDARDS AND TECHNOLOGIES TO MEET THE CHALLENGES OF THE $21^{\text {st }}$ CENTURY', 2000, 4-6 April, Leeds, UK, p.223-230.

FARAM, M. G.; HARDWOOD, R. (2000). CFD for the water industry; the role of CFD as a tool for the development of wastewater treatment systems. In: FLUENT USERS' SEMINAR, 2000, 21-22 September, Sheffield, UK.

FARAM, M. G.; HARDWOOD, R. (2002). Assessment of the effectiveness of stormwater treatment chambers using computational fluid dynamics. In: INTERNATIONAL CONFERENCE ON URBAN WATER DRAINAGE, 9., 2002, 913 September, Portland, Oregon, USA.

FARAM, M. G.; HARDWOOD, R. (2003). a method for the numerical assessment of sediment interceptors. Water Science and Technology, v.74, n.4, p.167-174.

FARAM, M. G.; JAMES, M. D.; WILLIAMS, C. A. (2004). Wastewater treatment using hydrodynamics vortex separators. In: CIWEM NATIONAL CONFERENCE, 2., 2004, 13-15 September, Wakefield, UK, p.79-87.

FEITZ, A. J.; GUAN, J.; WAITE, T. D. (2001). Size and structure effects on centrifugal dewatering of digested sewage sludge. Water Science and Technology, v.44, n.2, p.427435. 
FIELD, R.; O’CONNOR, T. (1996). Swirl Technology: enhancement of design, evaluation, and application. Journal of Environmental Engineering ASCE, v.122, n.8, p.741-748, Aug.

GARDNER, P.; DEAMER, A. (1996). An evaluation of methods for assessing the removal efficiency of a grit separation device. Water Science and Technology, v.33, n.9, p.269-275.

GELDER, A. M. V.; CHOWDHURY, Z. K.; LAWLER, D. (1999). Conscientious particle counting. Journal of American Water Works Association, v.91, n.12, p.64-76, Dec.

GIERGER, H. (1942). Snadfange fur Abwasserklanranlagen. Archivfur Wasserwirtschaft des Reichsuerbandes des Deutschen Wasserwirtschaft E.V., Arbeitskreis, Wasserwirtschaft. In: NSBDT, n.58. (Translated to English for the American Public Works Association by Patricia Ure Petersen)

GONZALES, R. C.; WOODS, R. (1993). Digital image processing. Addison - Wesley.

HIDRO INTERNATIONAL (sem data). Print Screen de uma apresentação em Flash, obtida do website da Hydro International: http://www.hydrointernational.biz/europe/ind_wastewater.html. Acesso em 10 jan.

HORVÁTH, I. (1994). Hydraulics in water and waste-water treatment technology. Chicherster, England, John Wiley \& Sons.

HYNDS ENVIRONMENTAL (sem data). Downstream Defender Catalogue. HYNDS Environmental, Greenlane, Auckland, New Zealand.

IVES, J. K. (1995). The inside story of water-treatment processes. Journal of Environmental Engineering, ASCE. v. 121, n. 12, p. 846-849., 1995.

JOHN MEUNIER, INC. (sem data). Fluidsep Catalogue. John Meunier, Inc. 
KNAUSS, J. (1987). Hydraulic structures design manual: Swirling flow problems at intakes. Rotterdam, Netherlands: A.A.BALKEMA.

KREBS, P. (1991). The hydraulics of final settling tanks. Water Science and Technology, v.23, n.3-4, p.1037-1046.

LAWLER, D. F; CHUNG, Y. J.; HWANG, S. J.; HULL, B. A. (1986). Anaerobic digestion: effects on particle size and dewaterability. Journal of Water Pollution Control Federation, v.58, n.12.

LE CORNU, P.; FARAM, M. G.; ANDOH, R. Y. G. (2000). A novel device for the removal of grits and oils from stormwater run-off. In: CIWEM/AETT MILLENNIUM CONFERENCE; 'WASTEWATER TREATMENT: STANDARDS AND TECHNOLOGIES TO MEET THE CHALLENGES OF THE $21^{\text {st }}$ CENTURY', 2000, 4-6 April, Leeds, UK, p.727-738.

LEVENSPIEL, O. (2000). Engenharia das reações químicas. 3.ed. São Paulo: Edgard Blücher Ltda.

LEWIS, C. M.; HARGESHEIMER, E. E.; YENTSCH, C. M. (1992). Selecting particle counters for process monitoring. Journal of American Water Works Association, Dec.

MAGALHÃES, M. N.; LIMA, A. C. P. (2002). Noções de probabilidade e estatística. 5.ed. São Paulo: Editora da Universidade de São Paulo.

MENEZES, F. M.; AMAL, R.; LUKETINA, D. (1996). Removal of particle using coagulation and flocculation in a dynamic separator. Powder Technology, v.88, p.27-31.

METCALF \& EDDY (2003). Wastewater engineering: treatment and reuse. 4.ed. New York: McGraw-Hill, Inc.

MOILLERON, R.; PEREZ, J.; GARNAUD, S. (2005). Grain size distribution of metals and polycyclic aromatic hydrocarbons in silt trap sediments from the combined sewer network of Paris (France). Water Science and Technology, v.52, n.3, p.111-118. 
MORUZZI, R. B. (2005). Avaliação da influência da distribuição de tamanho de partículas e do binômio velocidade/tempo de detenção na zona de reação no desempenho da flotação com utilização de sonda ultrasônica e técnica de análise por imagem. 240p. Tese (Doutorado) - Escola de Engenharia de São Carlos, Universidade de São Paulo, São Carlos, 2005.

O’SHAUGHNESSY, P. T.; BARSOTTI, M. G.; FAY, J. W.; TIGHE, S.W. (1997). Evaluating particle counters. Journal of American Water Works Association, v.89, n.12, p.64-76, Dec.

OKAMOTO, Y.; KUNUGI, M.; TSUCHIYA, H. (2002). Numerical simulation of the performance of a hydrodynamic separator. In: INTERNATIONAL CONFERECE ON URBAN DRAINAGE, 9., 8-13 September, Portland, Oregon, USA, 10p. (Proceedings).

PAUL, T. C.; SAYAL, S. K.; SAKHUJA, V. S.; DHILLON, G. S. (1989). Vortexsettling basin design considerations. Journal of Hydraulic Engineering, v.117, n.2, p.172-189, Feb.

RUSHTON, A.; WARD, A. S.; HOLDICH, R. G. (1996). Solid-liquid filtration and separation technology. New York: VCH.

RUSS, J. C. (1994). Computer-Assisted Microscopy: the measurement and analysis of images. New York: Plenum Press \& sons.

RUSS, J. C. (1994). The image processing handbook. 2.ed. CRC Press Inc.

SANTOS, H. R.; PRADO, G. S.; VIDAL, C. M. S.; MORUZZI, R. B.; CAMPOS, J. R. (2004). Aplicabilidade das técnicas de determinação de tamanho de partículas em sistemas de tratamento de água e esgoto. Engenharia Sanitária e Ambiental ABES, Rio de Janeiro, v.9, n.4, p.291-300, Out-Dez.

SIMM, D. H. (1983). Secondary flow and their significance in the design and operation of hydraulic structures. Journal of the Institute of Water Engineers and Scientists, v.37, n.3, p.251-256. 
SMISSOM, B. (1967). Design, construction and performance of vortex overflows. In: SYMPOSIUM ON STORM SEWAGE OVERFLOWS, Institute of Civil Engineers, London, p.81-91.

SULlIVAN, R. H.; COHN, M. M.; URE, J. E.; PARKINSON, F. (1974). The swirl concentrator as a grit separator device. Cincinnati, Ohio, USA, American Public Woks Association/ National Environmental Research Center, Office of Research and Development, Environmental Protection Agency. Report n. EPA 670/2-74-026.

SVAROVSKY, L. (1984). Hydrocyclones. London: TECNOMIC Publishing Co., Inc.

USFILTER (2003). Link-belt catenary bar screen data sheet. Chalfont, USFilter Envirex Products. Bulletin n.325-03-5.

VEERAPEN, J. P.; LOWRY, B. J.; COUTURIER, M, F. (2005). Design methodology for the swirl separator. Aquacultural Engineering, v.33, p.21-45.

WATER ENVIRONMENT FEDERETION (1998). Design of municipal wastewater treatment plants. Water Environment Federation manual of practice n.8. 4.ed. v.2. Alexandria, USA: Water Environment Federation and American Society of Civil Engineers.

WATER ENVIRONMENTAL FEDERATION. Operations and Maintenance Subcommittee of the Technical Practice Committee (1994). Preliminary treatment for wastewater facilities. Alexandria, USA: Water Environment Federation. (Manual of Practice; OM-2).

WHITE, F. M. (1999). Mecânica dos Fluidos. 4.ed. Rio de Janeiro: McGraw-Hill do Brasil.

WILSON, G. E. (1985). Is There Grit in Your Sludge? Civil Engineering Magazine, v.55, n.4, p.61-63, Apr. 


\section{APÊNDICE A - Gráficos de Distribuição \\ Volumétrica de Tamanho dos Grãos de Areia \\ Presentes no Esgoto Sanitário Afluente e Efluente do Separador Hidrodinâmico por Vórtice}




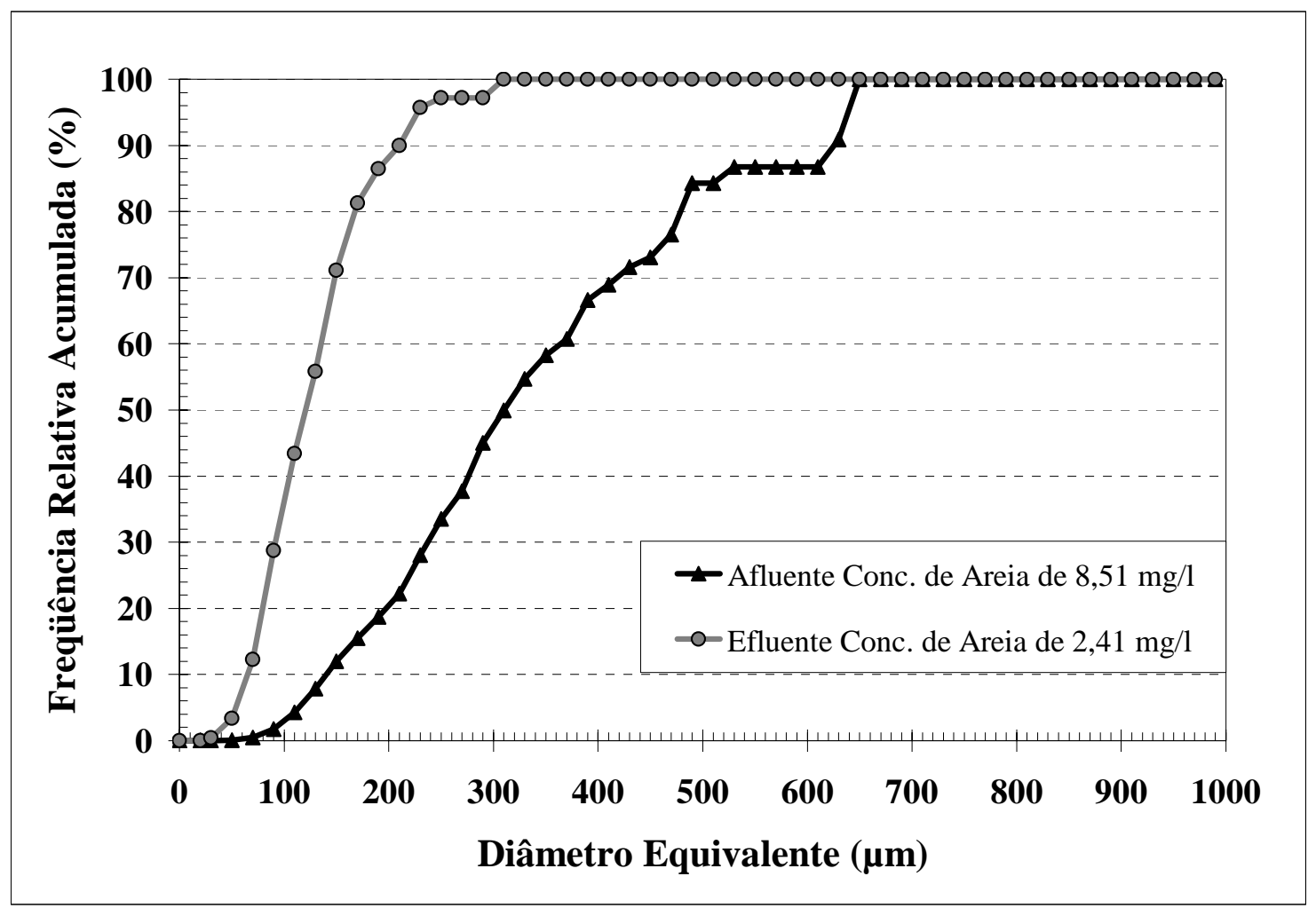

Figura A1 - Gráfico de distribuição volumétrica de tamanho de grãos de areia presentes na amostra coletada aos 06/10/2005 às 13h30min. TAS de $764 \mathrm{~m}^{3} / \mathrm{m}^{2} \mathrm{~d}$.

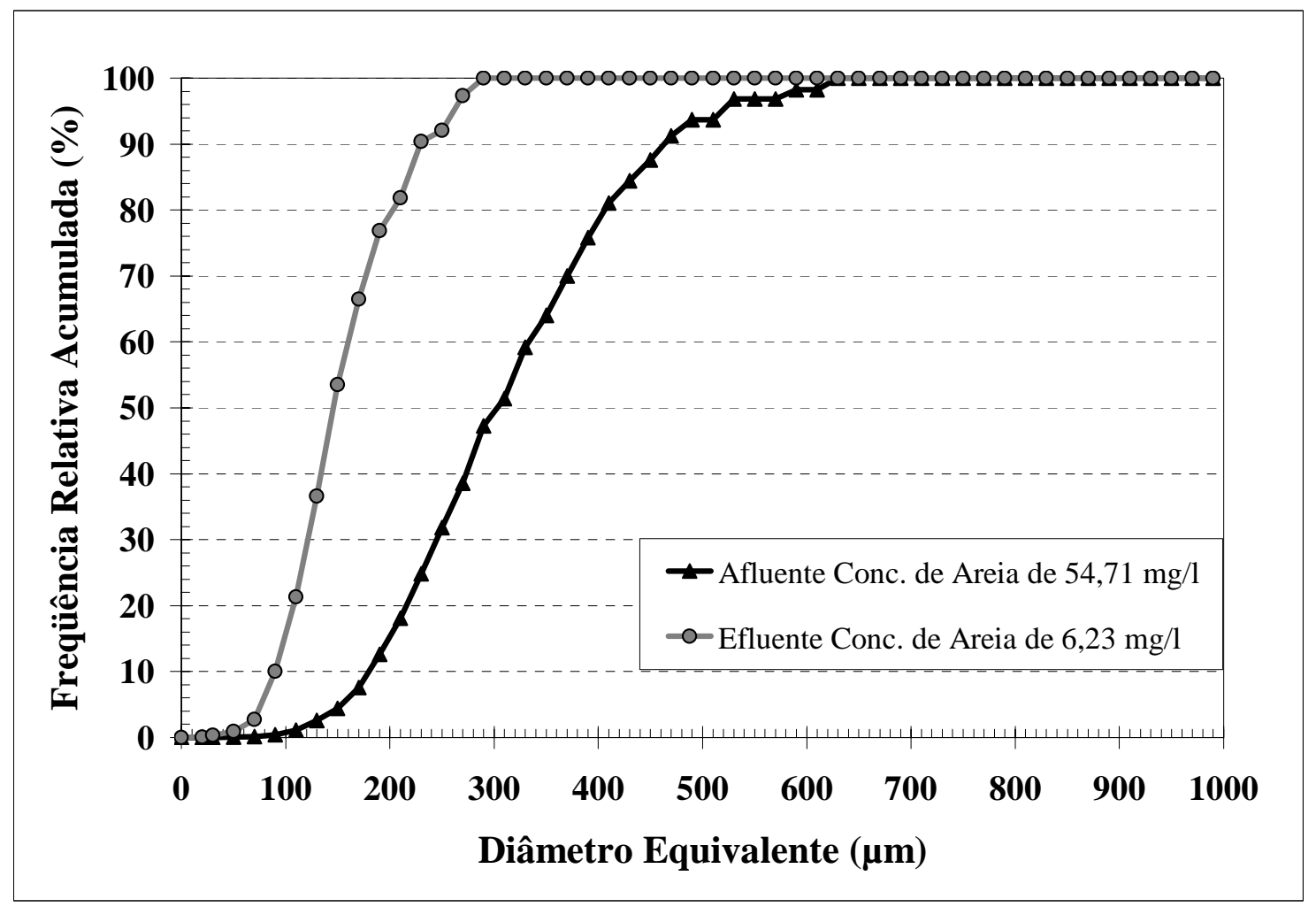

Figura A2 - Gráfico de distribuição volumétrica de tamanho de grãos de areia presentes na amostra coletada aos $11 / 10 / 2005$ às $14 \mathrm{~h} 30 \mathrm{~min}$. TAS de $764 \mathrm{~m}^{3} / \mathrm{m}^{2} \mathrm{~d}$. 


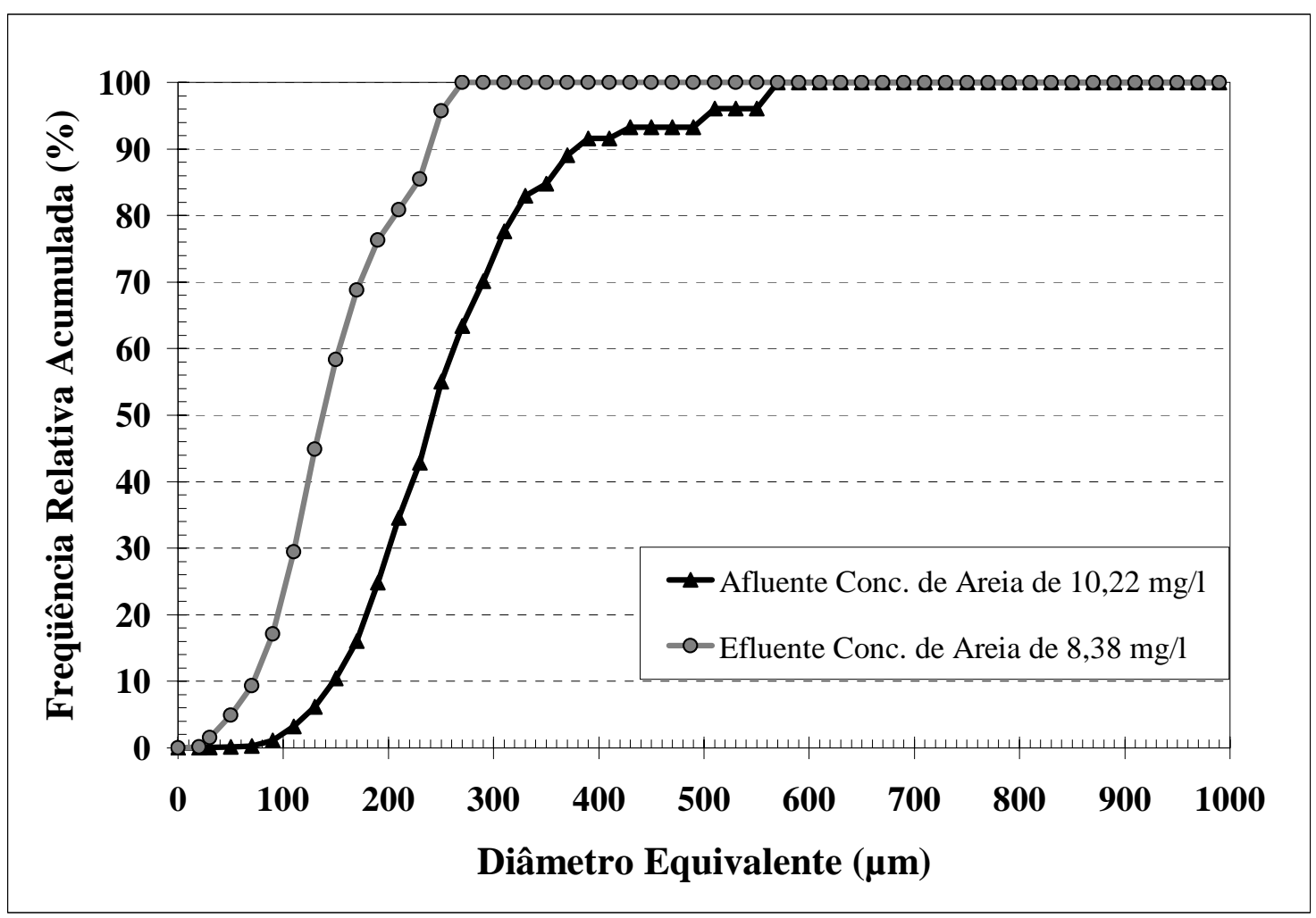

Figura A3 - Gráfico de distribuição volumétrica de tamanho de grãos de areia presentes na amostra coletada aos 11/10/2005 às 15h30min. TAS de $764 \mathrm{~m}^{3} / \mathrm{m}^{2} \mathrm{~d}$.

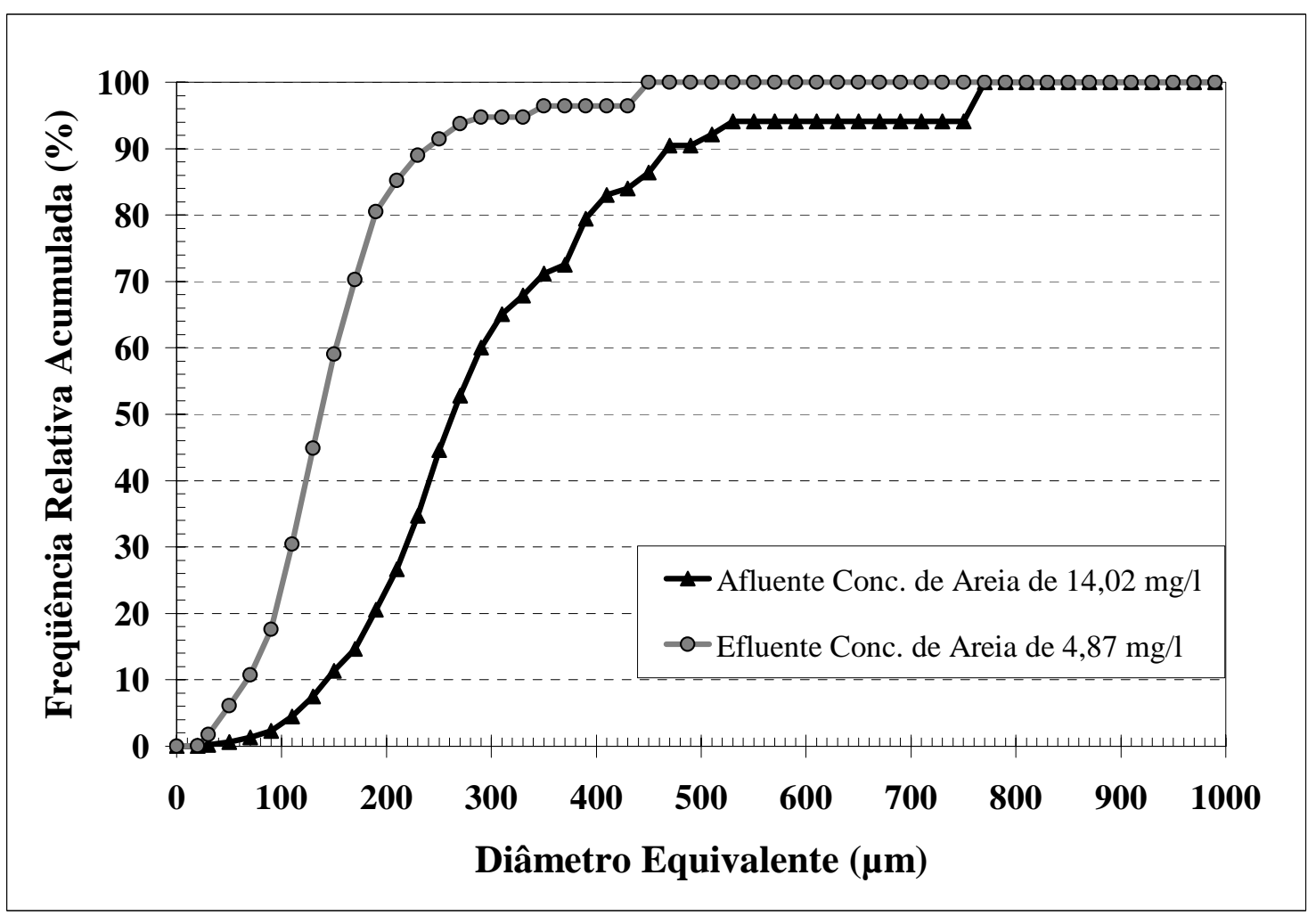

Figura A4 - Gráfico de distribuição volumétrica de tamanho de grãos de areia presentes na amostra coletada aos 11/10/2005 às 16h30min. TAS de $764 \mathrm{~m}^{3} / \mathrm{m}^{2} \mathrm{~d}$. 


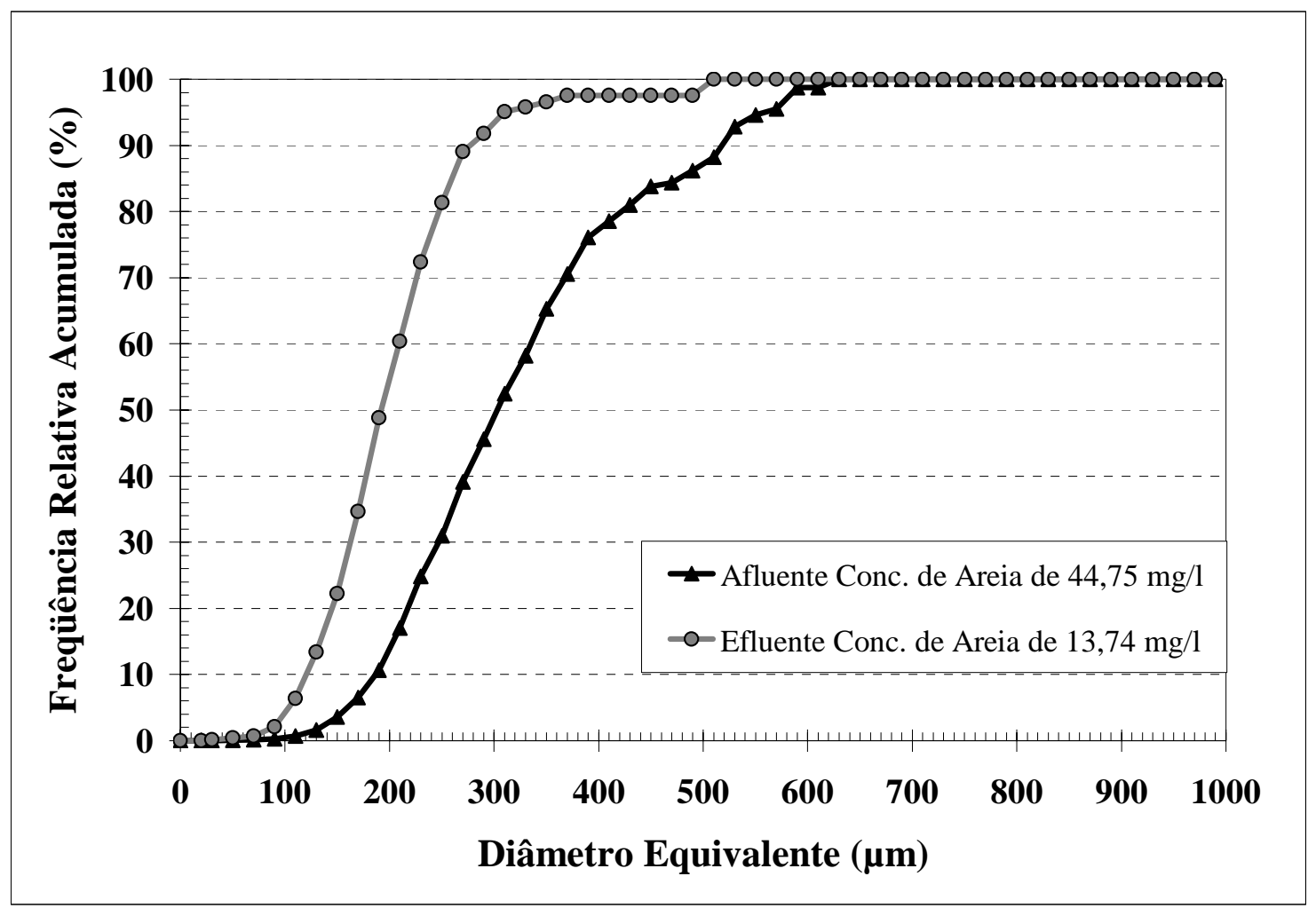

Figura A5 - Gráfico de distribuição volumétrica de tamanho de grãos de areia presentes na amostra coletada aos 04/11/2005 às 10h30min. TAS de $1.146 \mathrm{~m}^{3} / \mathrm{m}^{2} \mathrm{~d}$.

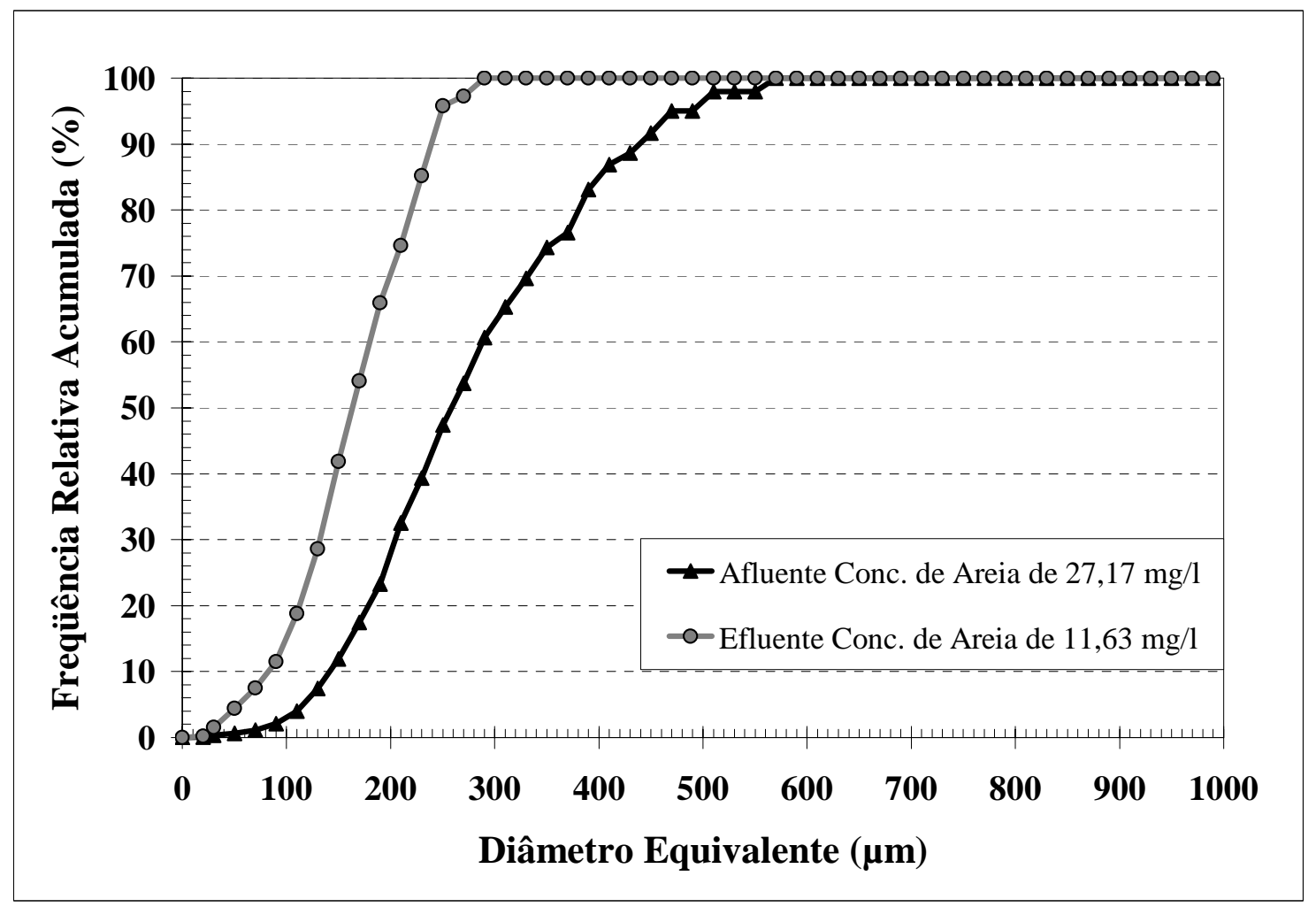

Figura A6 - Gráfico de distribuição volumétrica de tamanho de grãos de areia presentes na amostra coletada aos 04/11/2005 às 13h30min. TAS de $1.146 \mathrm{~m}^{3} / \mathrm{m}^{2} \mathrm{~d}$. 


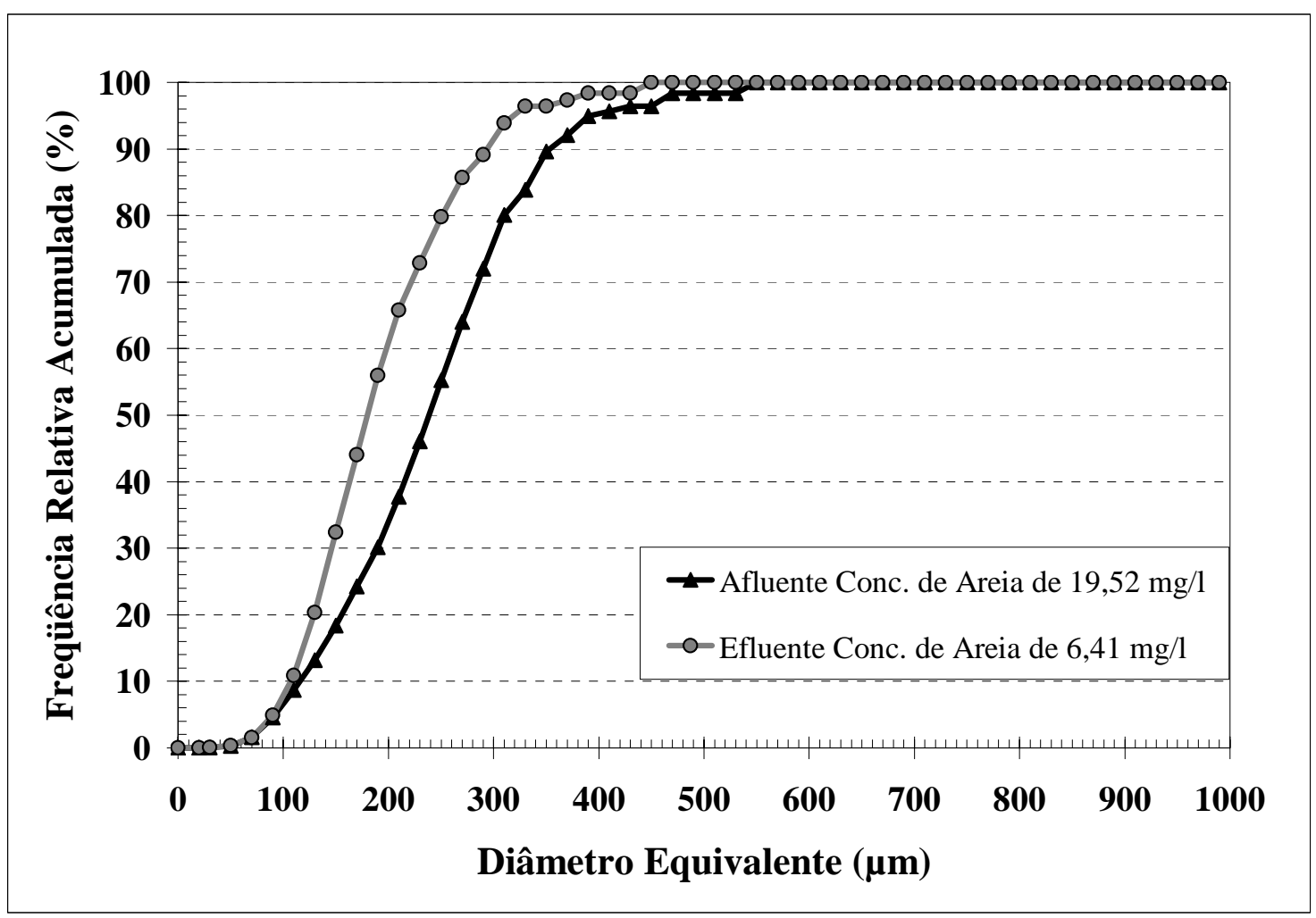

Figura A7 - Gráfico de distribuição volumétrica de tamanho de grãos de areia presentes na amostra coletada aos 17/11/2005 às $16 \mathrm{~h} 30 \mathrm{~min}$. TAS de $1.146 \mathrm{~m}^{3} / \mathrm{m}^{2} \mathrm{~d}$.

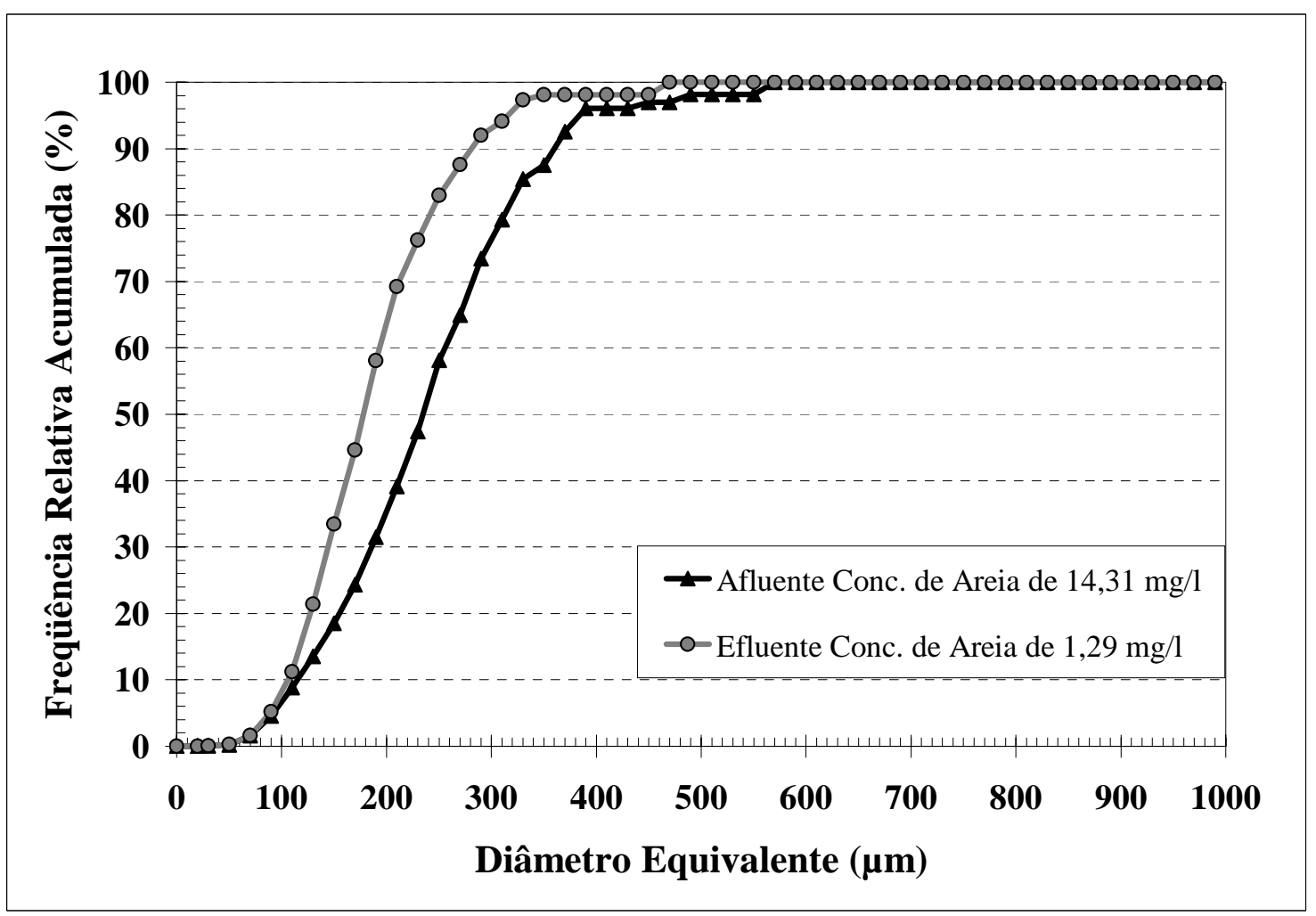

Figura A8 - Gráfico de distribuição volumétrica de tamanho de grãos de areia presentes na amostra coletada aos 17/11/2005 às $17 \mathrm{~h} 30 \mathrm{~min}$. TAS de $1.146 \mathrm{~m}^{3} / \mathrm{m}^{2} \mathrm{~d}$. 


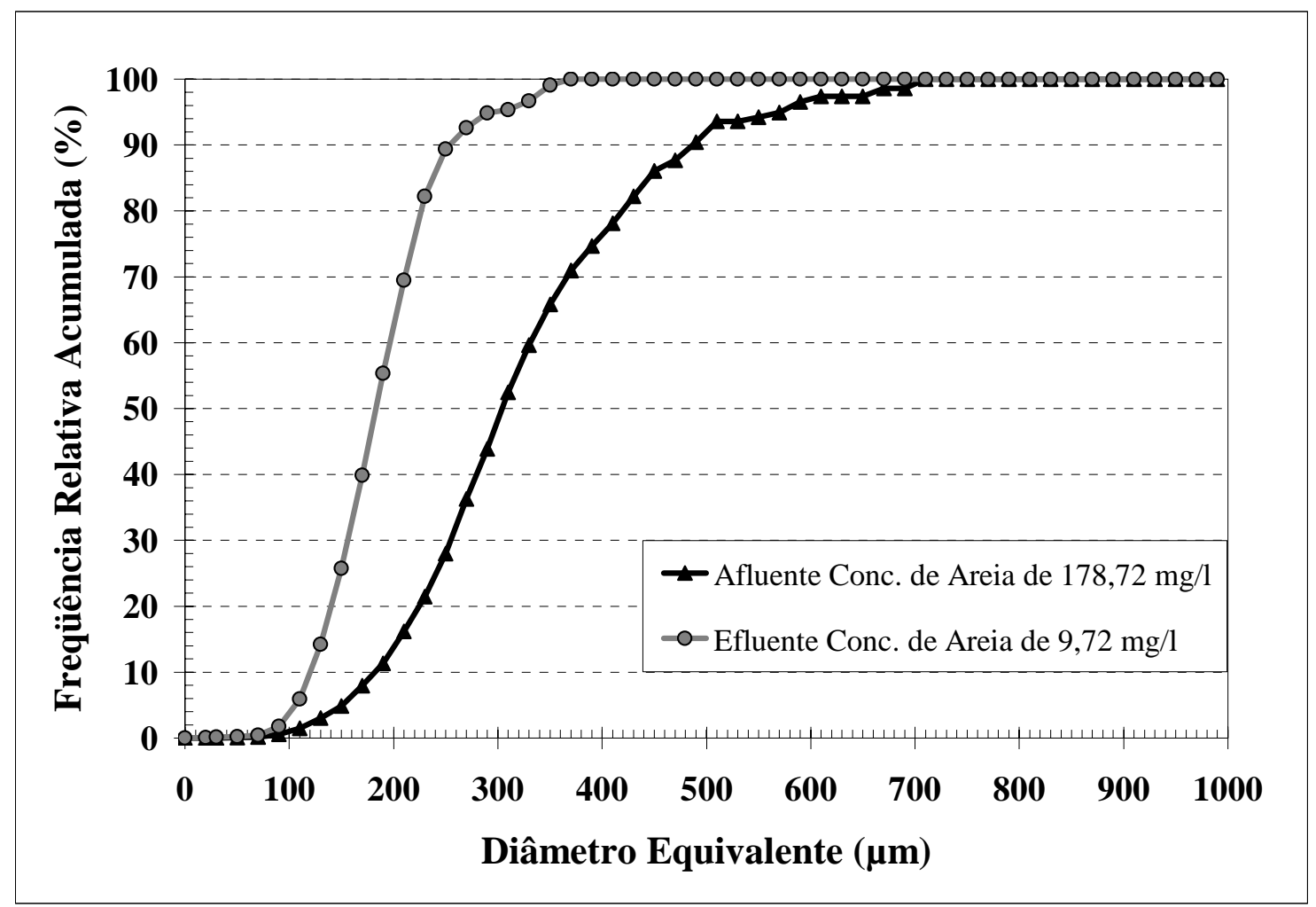

Figura A9 - Gráfico de distribuição volumétrica de tamanho de grãos de areia presentes na amostra coletada aos 09/11/2005 às 11h30min. TAS de $1.528 \mathrm{~m}^{3} / \mathrm{m}^{2} \mathrm{~d}$.

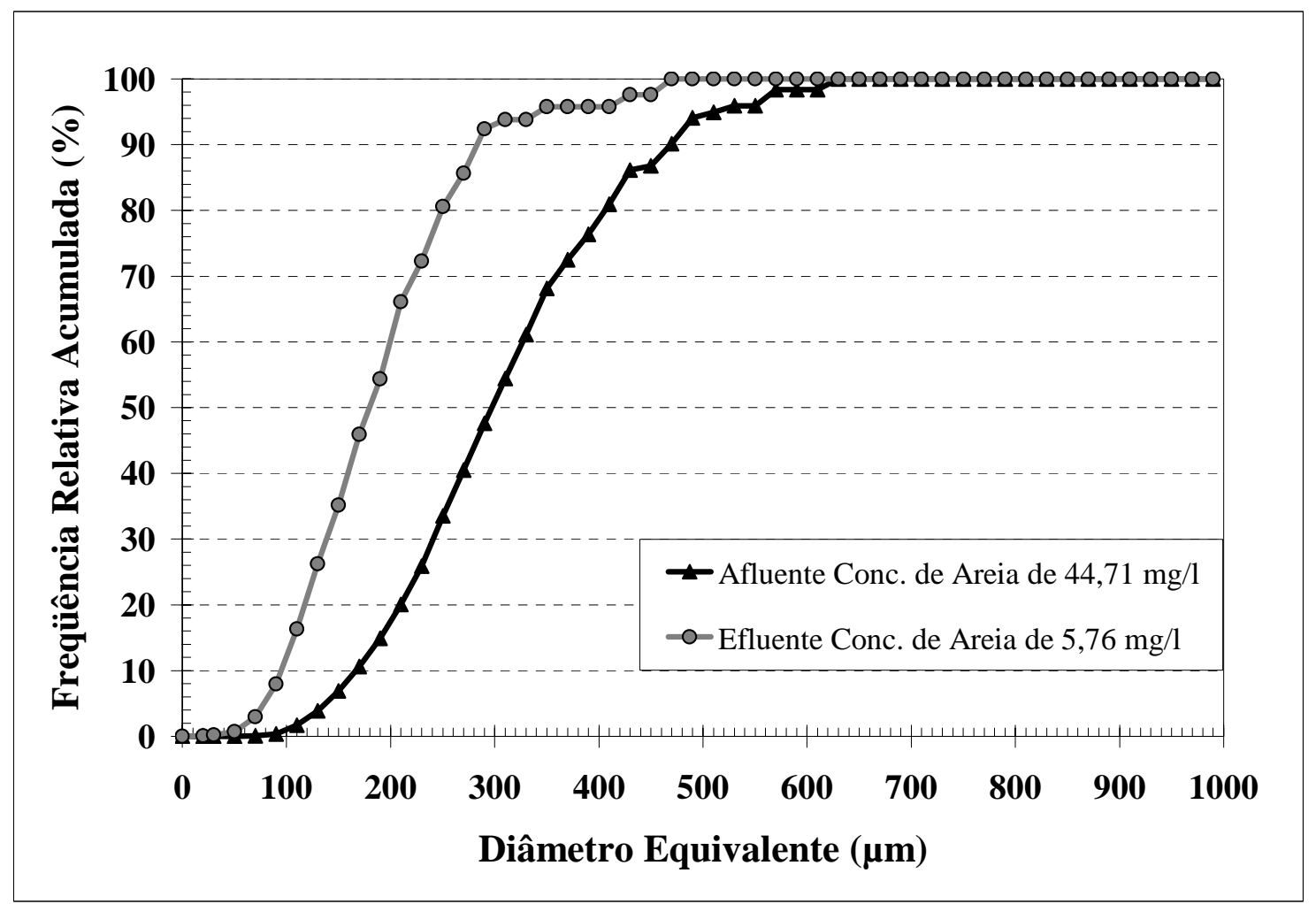

Figura A10 - Gráfico de distribuição volumétrica de tamanho de grãos de areia presentes na amostra coletada aos 09/11/2005 às $12 \mathrm{~h} 30 \mathrm{~min}$. TAS de $1.528 \mathrm{~m}^{3} / \mathrm{m}^{2} \mathrm{~d}$. 


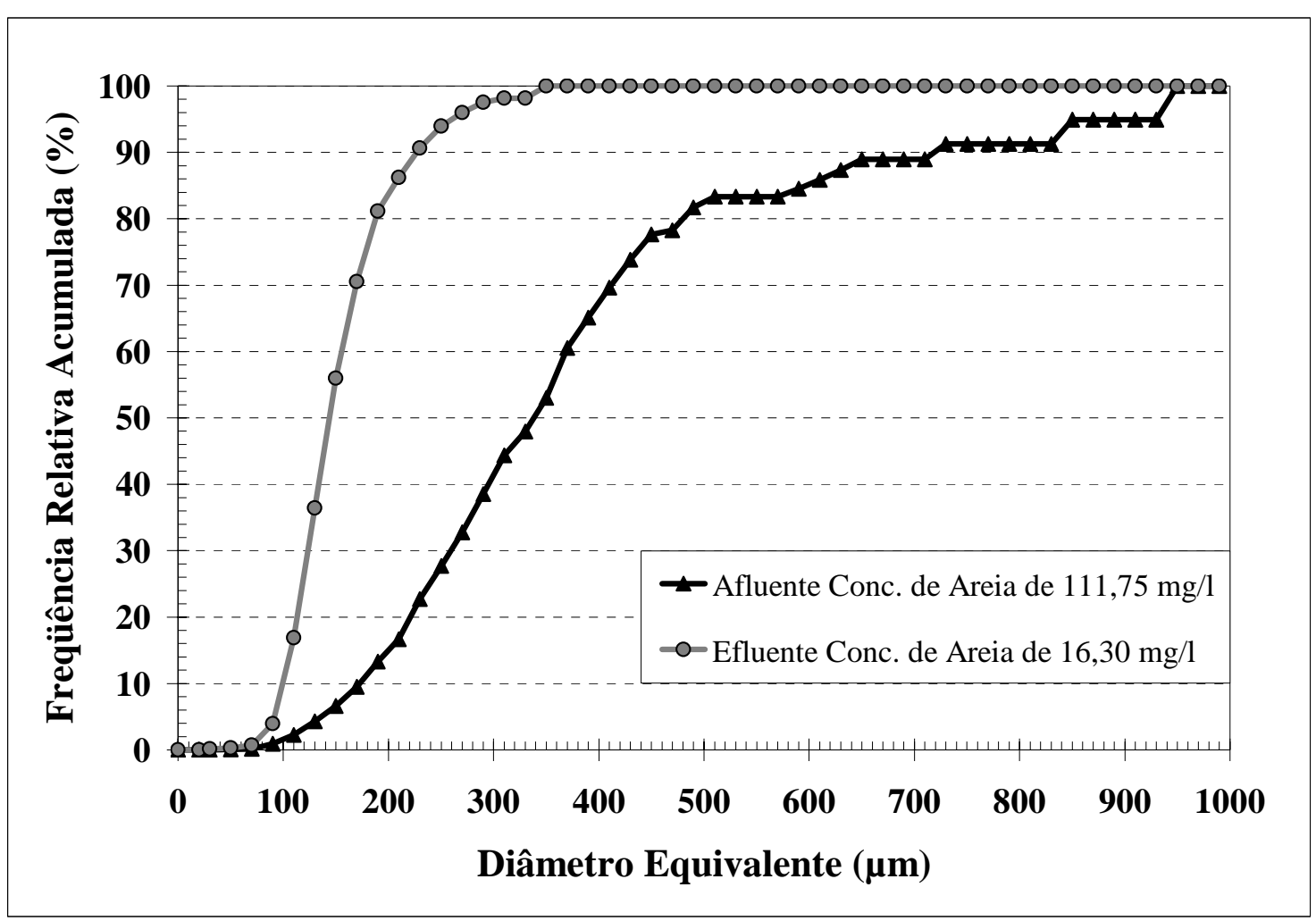

Figura A11 - Gráfico de distribuição volumétrica de tamanho de grãos de areia presentes na amostra coletada aos 21/11/2005 às $14 \mathrm{~h} 30 \mathrm{~min}$. TAS de $1.528 \mathrm{~m}^{3} / \mathrm{m}^{2} \mathrm{~d}$.

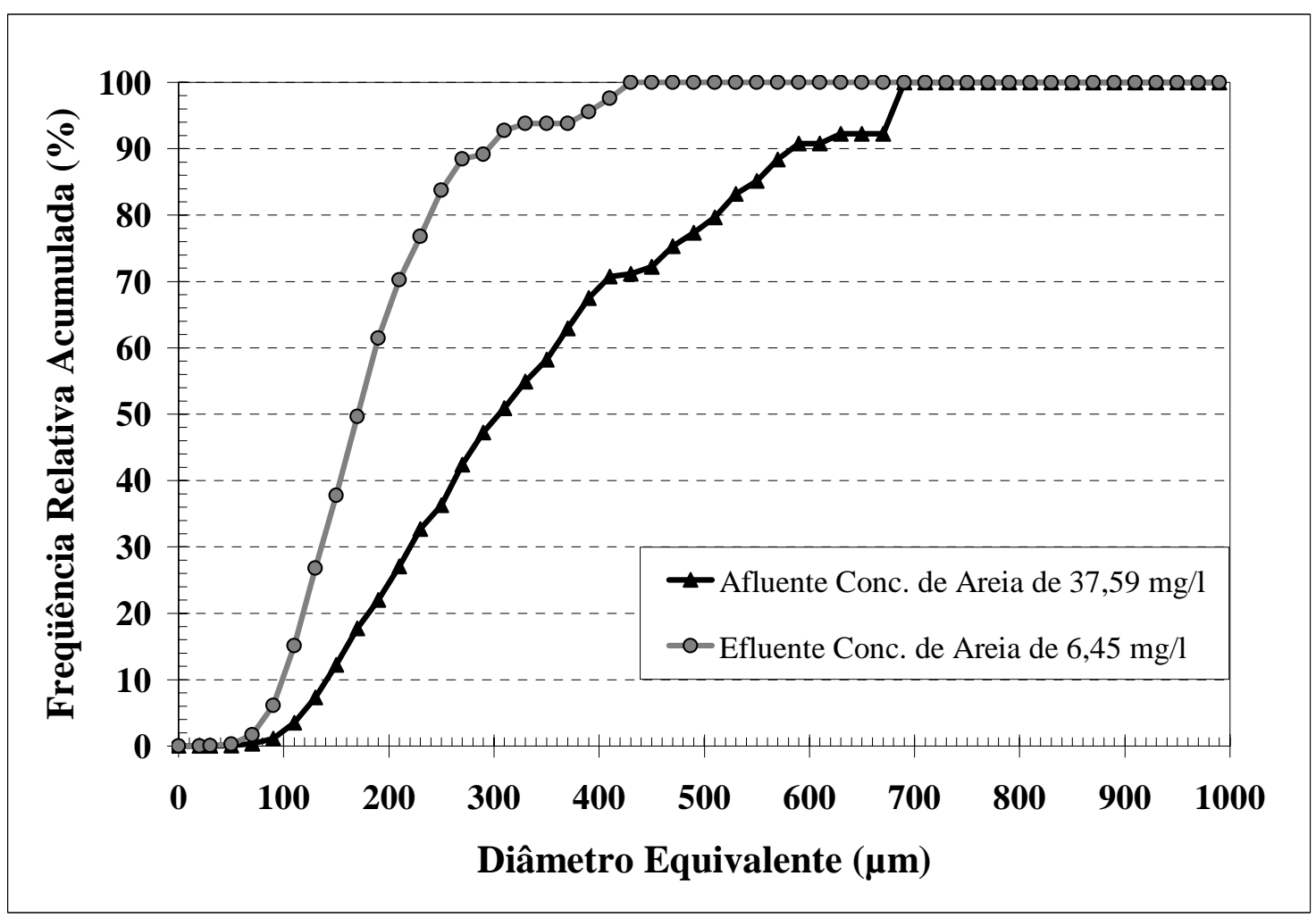

Figura A12 - Gráfico de distribuição volumétrica de tamanho de grãos de areia presentes na amostra coletada aos 21/11/2005 às $17 \mathrm{~h} 30 \mathrm{~min}$. TAS de $1.528 \mathrm{~m}^{3} / \mathrm{m}^{2} \mathrm{~d}$. 